\title{
Persistent pulmonary hypertension of the newborn : a point of view from vascular pharmacology
}

Citation for published version (APA):

Villamor, E. (2001). Persistent pulmonary hypertension of the newborn : a point of view from vascular pharmacology. [Doctoral Thesis, Maastricht University]. Universiteit Maastricht. https://doi.org/10.26481/dis.20010518ev

Document status and date:

Published: 01/01/2001

DOI:

$10.26481 /$ dis.20010518ev

Document Version:

Publisher's PDF, also known as Version of record

\section{Please check the document version of this publication:}

- A submitted manuscript is the version of the article upon submission and before peer-review. There can be important differences between the submitted version and the official published version of record.

People interested in the research are advised to contact the author for the final version of the publication, or visit the DOI to the publisher's website.

- The final author version and the galley proof are versions of the publication after peer review.

- The final published version features the final layout of the paper including the volume, issue and page numbers.

Link to publication

\footnotetext{
General rights rights.

- You may freely distribute the URL identifying the publication in the public portal. please follow below link for the End User Agreement:

www.umlib.nl/taverne-license

Take down policy

If you believe that this document breaches copyright please contact us at:

repository@maastrichtuniversity.nl

providing details and we will investigate your claim.
}

Copyright and moral rights for the publications made accessible in the public portal are retained by the authors and/or other copyright owners and it is a condition of accessing publications that users recognise and abide by the legal requirements associated with these

- Users may download and print one copy of any publication from the public portal for the purpose of private study or research.

- You may not further distribute the material or use it for any profit-making activity or commercial gain

If the publication is distributed under the terms of Article $25 \mathrm{fa}$ of the Dutch Copyright Act, indicated by the "Taverne" license above, 
Persistent Pulmonary Hypertension of the Newborn. A Point of View from Vascular Pharmacology 
Cover: portrait of Miguel Servet by Eduardo Villamor Martinez

Back-cover: portrait of Miguel Servet thinking of a baby by Isabel Villamor Martinez

ISBN $90-5681-107-X$ 


\section{Persistent Pulmonary Hypertension of the Newborn. A point of view from Vascular Pharmacology}

\section{PROEFSCHRIFT}

ter verkrijging van de graad van doctor aan de Universiteit Maastricht, op gezag van de Rector magnificus, Prof.dr. A.C. Nieuwenhuijzen Kruseman, volgens het besluit van het College van Decanen, in het openbaar te verdedigen op vrijdag 18 mei 2001 om 12.00 uur

door

Eduardo Villamor Zambrano 


\section{Promotores:}

Prof. dr. C.E. Blanco

Prof. dr. J. Tamargo Menéndez (Universidad Complutense de Madrid)

Co-promotor:

Dr. F. Pérez Vizcaíno (Universidad Complutense de Madrid)

Beoordelingcommissie:

Prof.dr. J.G.R. de Mey (voorzitter)

Prof.dr. F. van Bel (Universiteit Utrecht)

Prof.dr. R.A.M.G. Donckerwolcke

Prof.dr. L. Poston (King's College London)

Prof.dr. J.F. Smits

Prof.dr. D. Tibboel (Erasmus Universiteit Rotterdam) 
aan Ana

aan Eduardo, Isabel, Lola en María 



\section{Abbreviations}

$\mathrm{ACh}$, acetylcholine

ANP, atrial natriuretic peptide

AP-1, activator protein-1

$\mathrm{BH}_{4}$, tetrahydrobiopterin

BPD, broncopulmonary displasia.

cAMP, cyclic adenosine-3', 5'-monophosphate cfu, colonies forming units

cGK, cGMP-dependent kinase

cGMP, cyclic guanosine-3', 5'-monophosphate

$\mathrm{CI}$, confidence interval

CLD, chronic lung disease

CO, carbon monoxide

COX, cyclooxygenase

DA, ductus arteriosus

ECE, endothelin converting enzyme

ECMO, extracorporeal membrane oxygenation

EDNO, endothelium-derived nitric oxide

EDRF, endothelium-derived relaxing factor

eNOS, endothelial nitric oxide synthase

ET, endothelin

GBS, group B Streptococcus

GTP, guanosine-5' -triphosphate 
HFOV, high-frequency oscillatory ventilation

HIF, hypoxia inducible factor

HO, heme oxygenase

HPV, hypoxic pulmonary vasoconstriction

iNOS, inducible nitric oxide synthase

IL-1, interleukin-1

$\mathrm{IP}_{3}$, inositol 1,4,5-triphosphate

L-NAME, $\mathrm{N}^{\omega}$-Nitro-L-arginine methyl ester (NOS inhibitor)

LPS, lipopolysaccharide

$\mathrm{MgSO}_{4}$, magnesium sulfate

NA, noradrenaline

nNOS, neuronal nitric oxide synthase

NO, nitric oxide

$\mathrm{NO}_{2}$, nitrogen dioxide

NOS, nitric oxide synthase

ODQ, 1H-[1,2,4]oxadiazolo[4,3-a]quinoxalin-1-one (sGC inhibitor)

OI, oxygenation index

$\mathrm{ONOO}^{\circ}$, peroxynitrite

PAF, platelet-activating factor

PAP, pulmonary artery pressure

PDE, phosphodiesterase

PG prostaglandin

PGHS, prostaglandin endoperoxide $\mathrm{H}$ synthase 
$\mathrm{PGI}_{2}$, prostacyclin

PPHN, persistent pulmonary hypertension of the newborn

PVR, pulmonary vascular resistance

SAP, systemic arterial pressure

sGC, soluble guanylate cyclase

SNP, sodium nitroprusside

SOD, superoxide dismutase

SVR, systemic vascular resistance

TNF, tumor necrosis factor

TX, thromboxane

U46619, 9,11-dideoxy-11 $\alpha, 9 \alpha$-epoxymethano-prostaglandin $\mathrm{F}_{2 \alpha}$ (TXA $\mathrm{TX}_{2}$ analog)

VEGF, vascular endothelial growth factor

VSM, vascular smooth muscle

$[\mathrm{X}] \mathrm{i}, \mathrm{X}$ intracellular concentration

[X]o, X extracellular concentration 


\section{PART I}

Chapter I. General introduction.

I.1 Persistent pulmonary hypertension of the newborn (PPHN): failure of lung circulation to undergo postnatal adaptation. 8

I.2 Outline of the thesis. 12

Chapter II. Factors involved in the prenatal-postnatal pulmonary circulatory transition and in the pathophysiology of PPHN. 15

II.1 Nitric oxide 15

Mechanisms of Action of NO $\quad 16$

Nitric oxide and the perinatal lung 21

Nitric oxide and PPHN 23

II.2 Endothelin-1 28

Endothelin-1 and the perinatal lung 30

Endothelin-I and PPHN

II. 3 Eicosanoids 33

Eicosanoids and the perinatal lung 34

Eicosanoids and PPHN 36

II.4 carbon monoxide $\quad 37$

II.5 Oxygen 39

Oxygen and the perinatal lung $\quad 42$ 
Chapter III. Sepsis and PPHN. 47

III.1 Early phase sepsis-induced pulmonary hypertension.

III.2 Late phase sepsis-induced pulmonary hypertension.

III.3 NO and Sepsis-induced changes in vascular contractility. 48

III.4 Coexistence during sepsis of elevated pulmonary vascular NO production and pulmonary hypertension.

Chapter IV. Treatment of PPHN. In search of a selective pulmonary vasodilator.

IV.1 Intravenous pulmonary vasodilators.

IV.2 Selective pulmonary vasodilation through inhalation of NO. From the laboratory to the clinical experience.

Toxicity of inhaled NO $\quad 59$

Lack of response to inhaled NO 63

Adjuvant therapies to augment

the response to inhaled $N O$

65

Inhaled NO in the premature infant 66

References 


\section{PART II}

Chapter V. Chronic intrauterine pulmonary hypertension impairs endothelial nitric oxide synthase in the ovine fetus. (Am J Physiol. 1997; 272:L1013-20).

Chapter VI. Endothelium-derived nitric oxide-dependent response to hypoxia in piglet intrapulmonary arteries. (Biol Neonate. 1997; 72:62-70).

Chapter VII. Group B Streptococcus and E. coli LPS-induced NO-dependent hyporesponsiveness to noradrenaline in isolated intrapulmonary arteries of neonatal piglets. (Br J Pharmacol. 1995; 115:261-6).

Chapter VIII. Lack of endotoxin-induced hyporesponsiveness to U46619 in isolated neonatal porcine pulmonary but not mesenteric arteries.

(J Vasc Res. 1996; 33:249-57).

Chapter IX. Effects of group B Streptococcus on the responses to U46619, endothelin-1, and noradrenaline in isolated pulmonary and mesenteric arteries of piglets.

(Pediatr Res. 1996; 40:827-33).

Chapter $\mathbf{X}$. Involvement of protein kinase $\mathbf{C}$ in reduced relaxant responses to the NO/cyclic GMP pathway in piglet pulmonary arteries contracted by the thromboxane $A_{2}$-mimetic $\mathbf{U} 46619$. (Br J Pharmacol. 1997; 121:1323-33). 
Chapter XI. Pulmonary versus systemic effects of vasodilator drugs: an in vitro study in isolated intrapulmonary and mesenteric arteries of neonatal piglets.

(Eur J Pharmacol. 1996; 314:91-8).

Chapter XII. In vitro effects of magnesium sulfate in isolated intrapulmonary and mesenteric arteries of piglets. (Pediatr Res. 1996; 39:1107-12).

Chapter XIII. Relaxant effects of carbon monoxide compared with nitric oxide in pulmonary and systemic vessels of newborn piglets. (Pediatr Res. 2000; 48:546-553).

\section{PART III}

Chapter XIV. General discussion, summary, and future perspectives.

Samenvatting

Acknowledgements

Curriculum vitae 


\section{Chapter I. General introduction}

\section{I.1 Persistent pulmonary hypertension of the newborn (PPHN): failure of lung circulation to undergo postnatal adaptation.}

During prenatal life the lungs do not participate in gas exchange and the fetus is dependent on the placenta to supply oxygen and nutrients. At this stage, the lungs receive a small proportion of venous return, to ensure pulmonary growth and development, and the rest is diverted through the foramen ovale and the ductus arteriosus to the systemic circulation. Thus, the fetal pulmonary circulation exists as a high-resistance, low-flow circuit accepting less than $10 \%$ of the combined ventricular output (Rudolph \& Heymann 1968;Fineman et al., 1991; Walker, 1993; Ziegler et al., 1995a; Abman 1999; Heymann, 1999). At birth, when the lung assumes the respiratory function, the pulmonary circulation undergoes a striking transition characterized by a fall in pulmonary vascular resistance (PVR), as blood flow rapidly increases 8to 10-fold, followed by a more gradual decline in pulmonary arterial pressure (Cassin et al., 1964; Walker, 1993; Ziegler et al., 1995a; Abman 1999; Lakshminrusimha \& Steinhorn, 1999). Therefore, successful adaptation of the newborn to postnatal conditions requires a dramatic transition of the pulmonary circulation from a high resistance state in utero to a low-resistance state within minutes after birth.

Several mechanisms contribute to the normal fall in PVR at birth, including the establishment of a gas-liquid interface in the lung, increased oxygen tension, rhythmic distension of the lung and shear stress (Cassin et al., 1964; Dawes \& Mott, 1962; Enhorning et al., 1966; Blanco et al., 1984; Tiktinsky \& Morin, 1993; Cornfield et al., 1992; Abman, 1999). These physical stimuli act, at least partially, through the production of vasoactive products, especially the release of potent vasodilator substances, such as nitric oxide (NO) and prostacyclin (PGI $)$ (Ziegler et al., 1995a; Abman 1999; Heymann, 1999). 


PHYSICAL FACTORS
Drainage of fetal lung liquid
Establishment of an air-liquid interface
Rhythmic distension
Increased $\mathrm{PO}_{2}$
Shear stress
Cessation of umbilical flow

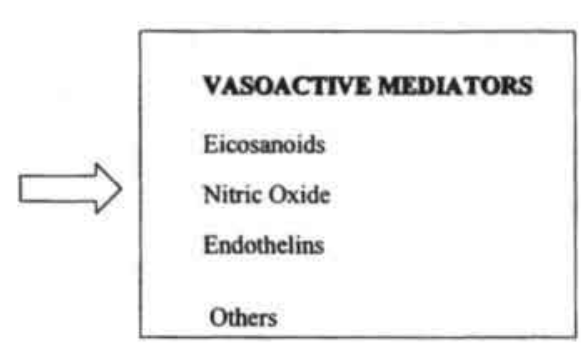

Figure 1. Factors involved in the transition between the fetal and the neonatal circulation

Failure of the pulmonary circulation to undergo a normal transition results in persistent pulmonary hypertension of the newborn (PPHN), a clinical syndrome of various neonatal cardiopulmonary disorders which are characterized by sustained elevation of PVR after birth, leading to right-to-left shunting of blood across the ductus arteriosus or foramen ovale and severe hypoxemia (Levin et al., 1976). PPHN is a pathophysiological phenomenon occurring in a heterogeneous group of diseases with a wide diversity of etiologies (Table 1). These range from transient reversible pulmonary hypertension attributable to perinatal insults to irreversible fixed structural malformations of the lung (Kinsella \& Abman, 1995). Diseases associated with the syndrome of PPHN can be classified in three categories (Abman, 1999): 1) Maladaptation, in which vessels are presumably of normal structure but have abnormal vasoreactivity; 2) Excessive muscularization, in which smooth muscle cell thickness is increased and muscle extends distally to vessels that usually are nonmuscular; and 3) Underdevelopment, in which lung hypoplasia is associated with decreased number of pulmonary arteries. These categories are not watertight compartments and, in fact, the inability to effectively lower PVR during the 
first moments of life in a 'maladaptative' disorder may rapidly cause aggressive hypertensive changes, leading to fixed pulmonary hypertension due to smooth muscle cell proliferation and remodeling (Roberts et al., 1997a). Altered vascular reactivity and structural remodeling appear to represent a continuum, in which, vasoconstriction induces hypertensive structural changes that further alters vascular responsiveness (Roberts et al., 1997a). Either as a primary condition or secondary to other pulmonary or extra-pulmonary diseases, PPHN is an important cause of cardiorespiratory failure and responsible for a relevant percentage of morbidity in the neonatal intensive care units (Davidson et al., 1999).

Current therapies for PPHN are aimed at lowering pulmonary vascular resistance with the use of hyperoxia, hypocarbic or metabolic alkalosis and theoretical selective vasodilators; increasing pulmonary compliance with surfactant; using lung recruitment strategies such as high frequency ventilation; and optimizing systemic tension with inotropes and volume expanders (Kennaugh et al., 1997; Goldman et al., 1996; Mok et al., 1999; Kinsella \& Abman, 1999). Current therapies are often limited by adverse effects or incomplete responsiveness (Roberts et al., 1997a). Patients who fail conventional therapy often require treatment with extracorporeal membrane oxygenation (ECMO). Although ECMO has improved survival in refractory PPHN, it remains labor-intensive, is costly, has multiple side effects, and may be associated with long-term neurological sequelae (Kennaugh et al., 1997; Roberts et al., 1997a). Safer, more effective therapies for PPHN will be possible only when they can be directed toward the specific defects producing this condition. In this sense, the remarkable basic scientific discovery that the simple gas molecule NO was endogenously released by endothelial cells, producing paracrine vasodilatory effects in the adjacent vascular smooth muscle, enormously boosted the search for a specific treatment for PPHN. Administered by inhalation, characterized by a short half-life and the absence of measurable systemic effects, the use of inhaled NO as an adjunct to conventional PPHN therapy is, presently, widespread (Davidson et al., 1999; Kinsella, 1999; Mok et al., 1999). 
Table 1. Factors associated with PPHN (modified from Roberts et al., 1997a)

Pulmonary

Meconium aspiration

Amniotic fluid aspiration

Blood aspiration

Hyaline membrane disease

Surfactant deficiency

Transient tachypnea

Diaphragmatic hernia

Cystic adenomatoid malformation

Pulmonary hypoplasia

Pneumonia

Thromboemboli

Peripheral pulmonary vascular occlusion

Alveolar capillary dysplasia

Pulmonary hemorrhage

Phrenic nerve agenesis

\section{Sepsis}

Group B Streptococcus

Escherichia coli

Listeria monocytogenes

Haemophilus influenzae

Others

Metabolic

Hypoglycemia

Hypocalcemia

Acidosis

Hypoxia
Hematological

Polycythemia

Thrombocytopenia

Thrombotic endocarditis

Acute hemorrhage

Gastrointestinal

Omphalocele

Gut perforation

Gastroschisis

Intrauterine insults

Chronic hypoxia

Postmaturity

Premature ductal closure

Maternal hypoxia, hemorrhage, hypotension

Drug-induced

Aspirin

Indomethacin

Naproxen

Hydantoin

Parenteral lipids

Amitriptyline

Lithium

Terbutaline

Tobacco smoke

Others

Idiopathic

Systemic hypertension

Shock

Pulmonary artery distension 


\section{I.2 Outline of the thesis}

Because PPHN represents the failure of postnatal adaptation of the lung circulation at birth, understanding the basic mechanisms of normal functional and structural development of the pulmonary circulation in utero, and the mechanisms that contribute to transitional pulmonary vasodilation, may provide insights into the syndrome of PPHN and its treatment (Abman, 1999). From this perspective, the present thesis focuses on some aspects of the pathophysiology and treatment of PPHN. In chapters II, III, and IV the state of the art of the problem is reviewed and in chapters V to XII some original contributions are presented.

Specifically, we review, in chapter II, some of the mediators (NO, eicosanoids, endothelin-1, CO) most widely involved in the control of pulmonary vascular tone, as well as in the circulatory transition and, consequently, in PPHN, the failure of this process. The role of oxygen in the above-mentioned processes is also analyzed.

Chapter III review sepsis-induced changes in vascular reactivity and its role in the pathophysiology of both pulmonary hypertension, and systemic hypotension that accompany neonatal generalized infection.

Chapter IV is focused on the treatment of PPHN, describing the difficulties for finding a selective pulmonary vasodilator and use of inhaled NO in this respect.

In Chapter V (Am J Physiol. 1997; 272:L1013-20) we analyze the alterations that chronic intrauterine pulmonary hypertension produces on lung endothelial NO synthase (eNOS). The model of chronic intrauterine pulmonary hypertension caused by ductus arteriosus compression in the fetal lamb, closely mimics the hemodynamic and pathological changes observed in fatal clinical PPHN. We measured eNOS content and activity in this experimental model, to determine the possible involvement of an impairment of the NO relaxant pathway in PPHN. 
Chapter VI (Biol Neonate 1997; 72:62-70) is focused on the pulmonary vascular response to hypoxia. We investigated the response to hypoxia in isolated intrapulmonary arteries and veins from newborn piglets, evaluating the role of NO and eicosanoids on this response. Furthermore, we compared the effects of hypoxia in pulmonary vessels with systemic (coronary and mesenteric) arteries.

Chapters VII (Br J Pharmacol. 1995; 115:261-6), VIII (J Vasc Res. 1996; 33:249-57), and IX (Pediatr Res. 1996; 40:827-33) include experimental evidences of sepsis-induced changes in pulmonary and systemic vascular contractility. We analyzed the effects of incubation of piglet pulmonary, and mesenteric arteries with heat inactivated group B Streptococcus, and Escherichia coli lipopolysaccharide, on the vascular responses to several vasoconstrictor agonists, including those involved in the pathophysiology of sepsis-induced PPHN.

In chapter X (Br J Pharmacol. 1997; 121:1323-33) we studied the interactions between vasoconstrictor and vasodilator agents that are released during sepsis, playing a role in PPHN, and systemic vascular disturbances. Specifically, we analyzed the interactions of noradrenaline, the TXA ${ }_{2}$-mimetic U46619 and ET-1 with the relaxation induced via cyclic GMP. In addition, we studied the mechanisms involved in NO/cyclic GMP-induced relaxation in isolated intrapulmonary arteries.

Since lowering pulmonary artery pressure while maintaining systemic vascular resistance and good cardiac output is crucial for newborns with PPHN, the ideal drug for their treatment should be a vasodilator with selectivity for pulmonary over systemic vessels. In chapters XI (Eur J Pharmacol. 1996; 314:91-8), and XII (Pediatr Res. 1996; 39:1107-12) we compared the relaxant effects of some of the proposed, and even clinically used, selective

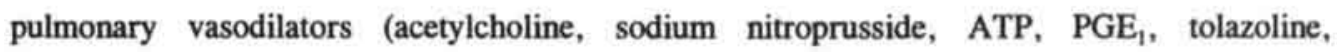
nifedipine, and magnesium sulfate) in isolated piglet pulmonary and mesenteric arteries.

Finally, in chapter XIII (Pediatr Res. 2000; 48:546-553) the pulmonary vascular 
Chapter II. Factors involved in the prenatal-postnatal pulmonary circulatory transition and in the pathophysiology of PPHN.

\section{II.1 Nitric oxide}

The discovery that the biological actions of endothelium-derived relaxing factor (Furchgott and Zawadzki, 1980) are due to the endogenous release of NO (Palmer et al., 1987; Ignarro et al., 1987; Khan \& Furchgott, 1987) revealed the existence of an ubiquitous biochemical pathway (Moncada et al., 1989; Moncada et al., 1997). NO is a unique messenger molecule involved in the regulation of diverse physiological processes including smooth muscle contractility, platelet reactivity, central and peripheral neurotransmission, and the cytotoxic actions of immune cells (Moncada et al., 1997). Therefore, NO is crucial for many physiological functions, and inappropriate release of this mediator has been linked to a number of pathologies (Hibbs \& Moncada, 1999).

NO is formed endogenously by a family of enzymes known as NO synthases (NOS). Three distinct isoforms of NOS have been identified (Moncada et al., 1997). Molecular cloning has shown these to share $50-60 \%$ homology. There is a constitutive form, neuronal (nNOS or NOS I), whose activity is regulated by $\mathrm{Ca}^{2+}$ and calmodulin, and which is found in neural tissue, both centrally and peripherally. A second, $\mathrm{Ca}^{2+} /$ calmodulin-requiring, constitutive enzyme is present in vascular endothelial cells (eNOS or NOS III). A third, $\mathrm{Ca}^{2+}$-independent inducible isoform (iNOS or NOS II) can be isolated from a variety of cells following induction with inflammatory mediators and bacterial products. The association of the three NOS isoenzymes with the endothelium (eNOS), neurons (nNOS) and inducibility (iNOS) is an oversimplification (Moncada et al., 1997). For example, eNOS is located not only in the vascular endothelial cells but also in platelets (Radomski et al., 1990) and in certain neuronal populations in the brain (Dinerman et al., 1994), whereas nNOS has been found in the epithelium of the bronchi and trachea (Kobzik et al., 1993), as well as in skeletal muscle (Kobzik et al., 1994). In addition, the constitutive eNOS can be induced in certain situations such as during chronic exercise (Sessa et al., 1994) or during pregnancy, when both eNOS and iNOS are induced (Weiner et al., 1994). In 
contrast iNOS appears to be present constitutively in some tissues, including human bronchial epithelium (Kobzik et al., 1993), rat kidney (Mohaupt et al., 1994) and ovine pulmonary fetal tissues (Rairigh et al., 1998

NO is generated by NOS via a five-electron oxidation of a terminal guanidinium nitrogen on L-arginine (Palmer \& Moncada, 1989). The reaction is both oxygen- and NADPHdependent and yields L-citrulline in addition to NO, in a 1:1 stoichiometry (Bush et al., 1992). This process occurs in at least two distinct steps. The initial reaction involves $\mathrm{N}$-hydroxylation of the guanidinium nitrogen to form $\mathrm{N}$-hydroxy-L-arginine, which is the only intermediate that has been identified (Wallace \& Fukuto, 1991; Pufahl et al., 1992). In spite of extensive research, the precise mechanism by which NOS catalyzes the oxidation of L-arginine to NO remains unclear (Hibbs \& Moncada, 1999). It appears that many aspects of NOS biochemistry relate directly to the actions of cytochrome P-450. NADPH acts as the source of electrons for oxygen activation and substrate oxidation, and flavin adenine dinucleotide and flavin mononucleotide shuttle electrons from NADPH to the iron heme (Hibbs \& Moncada, 1999). The heme moiety of NOS resembles cytochrome P-450, supporting the thesis that the heme component of NOS represents the catalytic center, responsible for binding and reducing molecular oxygen and subsequent oxidation of substrate. In contrast to cytochrome P-450, NOS also requires tetrahydrobiopterin $\left(\mathrm{BH}_{4}\right)$ for maximal activity (Kwon et al., 1989). NOS isoforms are subject to a negative feedback control loop mediated by NO (Rogers \& Ignarro, 1992; Assreuy et al., 1993), presumably via NO ligation to the heme moiety. Moreover, $\mathrm{BH}_{4}$ is capable of preventing and reversing this feedback pathway, and although the explanation for this is unclear, this may be one role for $\mathrm{BH}_{4}$ as a cofactor (Griscavage et al., 1994).

\section{Mechanisms of Action of NO}

Most of the physiological actions of NO are brought about by its activation of the soluble guanylate cyclase (sGC) (Murad et al., 1990; Ignarro, 1997; Hobbs 1997). Binding of NO to the heme moiety of this enzyme causes a conformational change that increases the enzyme activity approximately 400 -fold and results in the enzymatic conversion of guanosine- 
5'-triphosphate (GTP) to the intracellular second messenger cyclic guanosine-3',5'monophosphate (cGMP). The activation of sGC by NO appears to be a complex process. First, NO binds to the iron in the haem group of the enzyme forming a hexacoordinate complex which then converts to a pentacoordinate nitrosyl-haem complex by one of two routes (Fig 2). For approximately $25 \%$ of the haem, this conversion occurs rapidly, whereas for the remaining hexacoordinate nitrosyl complex this process is considerably slower, and appears dependent upon the interaction of NO with an unidentified, non-haem site on the protein (Stone \& Marletta, 1994; Deinum et al., 1996; Hobbs, 1997). The relevance of the formation of the pentacoordinate complex for the activation of sGC is illustrated by carbon monoxide (CO). $\mathrm{CO}$ also forms a complex with the haem moiety of sGC, but unlike NO, only the six-coordinate complex is formed (Stone \& Marletta, 1995), resulting in a low activation of purified sGC when compared with that attained by NO (Hobbs, 1997).
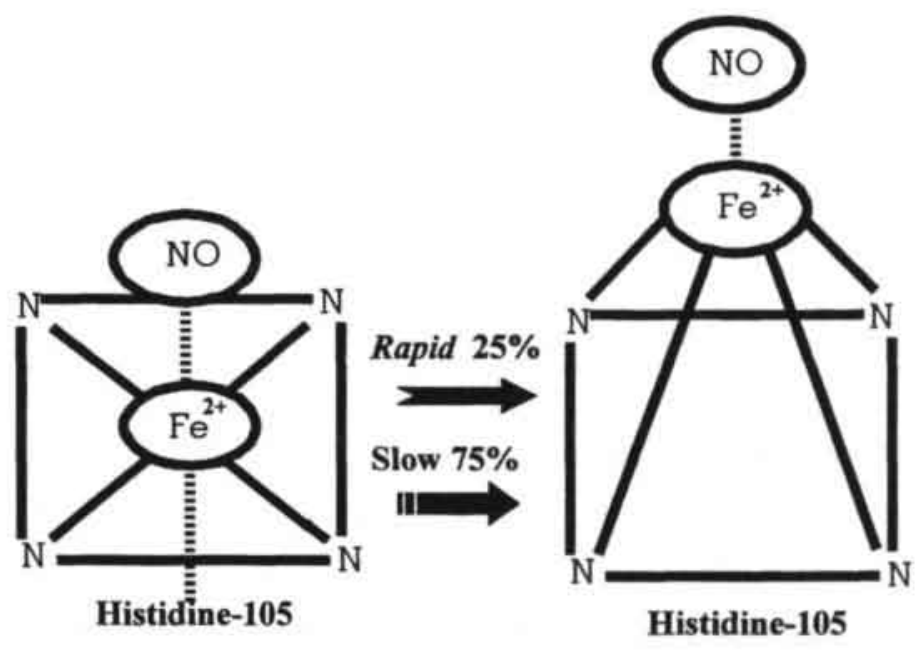

Figure 2. Activation of soluble guanylate cyclase by $\mathrm{NO}$ 
Agents such as NO, nitrovasodilators, and ANP which raise intracellular levels of cGMP via activation of either the soluble or particulate isoform of GC, are well established to cause relaxation of vascular smooth muscle (Hobbs \& Ignarro, 1997). Formation of cGMP by particulate and soluble GC is a common signal transduction pathway utilized by a diverse family of biological messengers. Consequently, to fulfill this role cGMP is capable of modulating a number of cellular functions. In contrast to the cAMP second-messenger system where the activation of a specific protein kinase is responsible for a predominant number, if not all, of the physiological effects, cGMP regulates a variety of enzymes and proteins, including cGMP-gated ion channels, cGMP regulated PDEs and cGMP-dependent protein kinases (Beavo \& Reifsnyder, 1990; Kaupp, 1991; Lincoln et al, 1988; Hobbs \& Ignarro, 1997). Two major isoforms of vertebrate cGMP-dependent kinase have been recognized, the cytosolic type I (cGKI) and the membrane bound type II (cGKII) (Hobbs \& Ignarro, 1997).

Despite extensive research into the cyclic nucleotide receptors mediating this effect, the precise mechanisms by which cGMP induces vascular smooth muscle relaxation remain still unclear. However, there is general agreement that an important part of the process involves interaction and modulation of $\mathrm{Ca}^{2+}$ homeostasis by several mechanisms (Hobbs \& Ignarro, 1997). First, cGMP may stimulate $\mathrm{Ca}^{2+}$ extrusion by activation of the $\mathrm{Ca}^{2+} \mathrm{ATPase}$ on the plasma membrane (Popescu et al., 1985a, 1985b). It is though that cGK regulates this $\mathrm{Ca}^{2+}$ pump by phosphorylation of an intermediate protein, possibly a phosphatidylinositol kinase (Vrolix et al., 1988). A second mechanism by which cGMP may lower $\left[\mathrm{Ca}^{2+}\right]_{i}$ is to enhance uptake into the endoplasmic reticulum, via regulation of a $\mathrm{Ca}^{2+} \mathrm{ATPase}$ similar to that found on the plasma membrane (Twort \& Van Breemen, 1988). Third, $\mathrm{Na}^{+}-\mathrm{Ca}^{2+}$ exchange through the plasma membrane may also represent a site of cGK-mediated modulation of $\mathrm{Ca}^{2+}$ homeostasis (Hobbs \& Ignarro, 1997). Fourth, cGMP may have a dual effect on $\mathrm{Ca}^{2+}$ channel activity. In addition to directly suppressing the movement of ions through L-type $\mathrm{Ca}^{2+}$ channels, cGMP also opposes the inward movement of $\mathrm{Ca}^{2+}$ via enhancement of the delayed outward $\mathrm{K}^{+}$current (Bkaily et al, 1988). Additionally, an inhibitory effect of cGMP on receptor operated $\mathrm{Ca}^{2+}$ channels has also been reported (Hobbs \& Ignarro, 1997). Finally, the stimulation of phospholipase $\mathrm{C}$ by a variety of hormones and neurotransmitters to yield the second messenger 


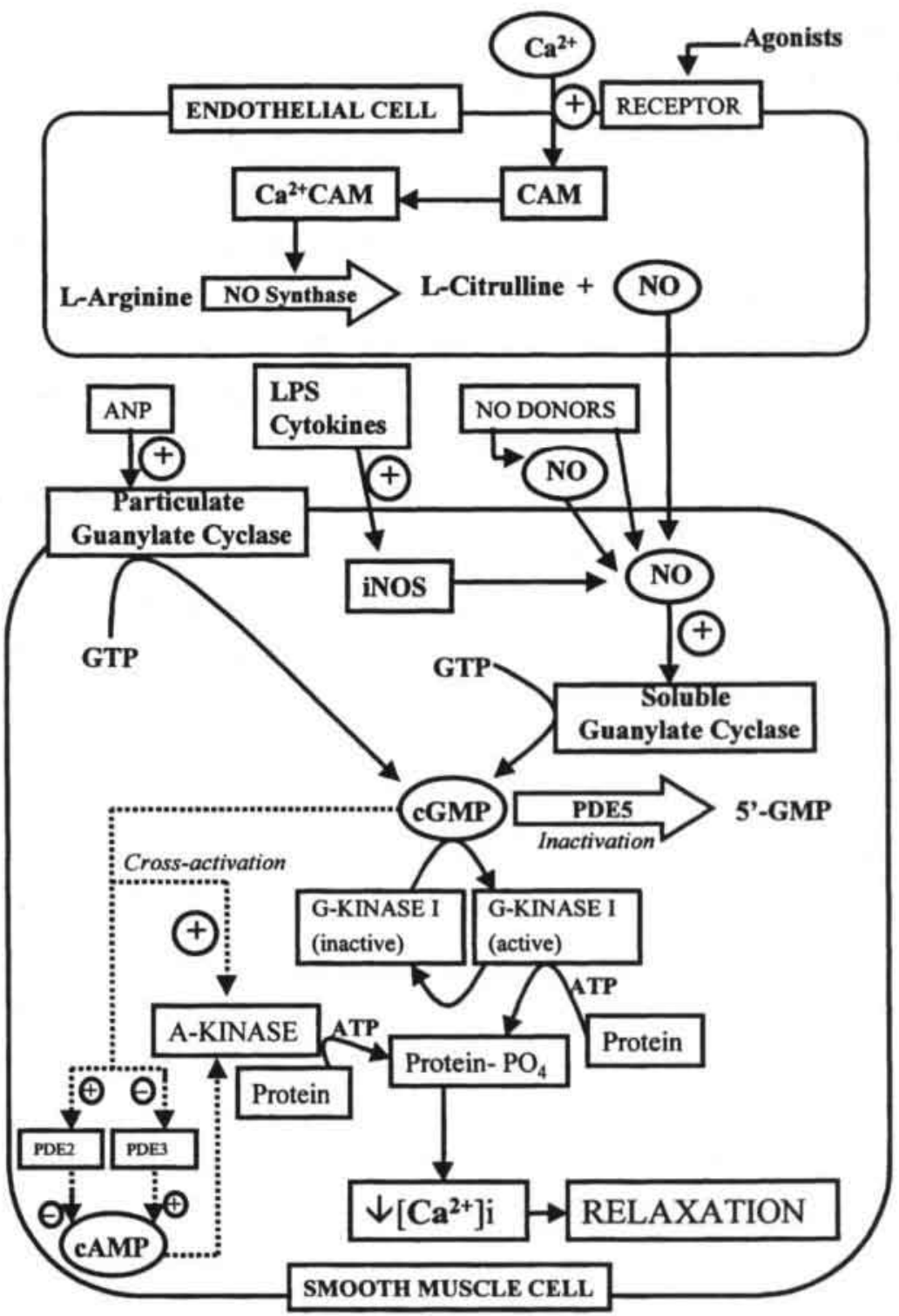

Figure 3. Mechanisms of action of NO 
inositol 1,4,5-triphosphate $\left(\mathrm{IP}_{3}\right)$ and diacylglycerol is a well-established mechanism triggering vascular smooth muscle contraction (Hobbs \& Ignarro, 1997). Modification of this pathway and prevention of $\mathrm{Ca}^{2+}$ release from the endoplasmic reticulum appears yet another method by which cGMP can regulate $\mathrm{Ca}^{2+}$ homeostasis (Hobbs \& Ignarro, 1997).

Physiological responses to both cGMP and cAMP are governed, at least in part, by cyclic nucleotide phosphodiesterases (PDEs) that specifically hydrolyze them to biologically inert 5'-nucleotides, and thereby turn off the signal they are conveying (Beavo 1995, Polson \& Strada, 1996). Seven PDE families have been described based on different kinetic properties, cyclic nucleotide preferences, regulatory mechanisms, and sensitivities to pharmacological inhibitors (Beavo, 1995; Polson \& Strada, 1996). Recently, it was determined that within each major gene family, there were multiple PDE isoforms and splice variants, each exhibiting different characteristics and tissue distribution (Beavo, 1995; Polson \& Strada, 1996). PDE1 (calcium/calmodulin-dependent PDE), PDE2 (cGMP-stimulated PDE), PDE3 (cGMP-inhibited PDE), PDE4 (cAMP-specific PDE), and PDE5 (cGMP-specific PDE) were identified in vascular smooth muscle (Lugnier et al, 1986; Miyahara et al, 1995; Saeki \& Saito, 1993). PDE5 has a strong preference for cGMP as substrate, a high affinity noncatalityc binding site for cGMP, and accounts for the majority of cGMP hydrolysis in vascular smooth muscle. Therefore, PDE5 plays a major role in vasoregulation by lowering cGMP levels in VSM. Dipyridamole, zaprinast, and sildenafil are potent inhibitors of PDE5 (Rosman et al., 1997; Ziegler et al., 1995b; Hanson et al., 1998). On the other hand, PDE2 and PDE3 are both cAMP-selective, but they have significant relevance to the NO/cGMP transduction system since the rate of cAMP hydrolysis by $\mathrm{PDE}_{2}$ and $\mathrm{PDE}_{3}$ is stimulated and inhibited, respectively, by cGMP (Lindgren et al., 1991; Hobbs \& Ignarro, 1997). As such, these PDEs represent a mechanism by which cGMP can mediate part of its effects (Fig 3).

Independently of its activation of sGC, exposure to NO inhibits the activity of a number of enzymes, such as aconitase and complexes I, II and IV (Nathan \& Hibbs, 1991; Clementi et al., 1998). In addition, DNA synthesis can be impaired by the inhibitory action of NO on ribonucleotide reductase. Such actions render NO cytotoxic or cytostatic for invading 
microorganisms and sometimes for the NO-generating cells. These actions explain, at least in part, the pathophysiological actions of NO. At this point, it is not clear to what extent these actions are due to NO itself or result from the combination of NO and other molecules, predominantly superoxide. Indeed the interaction between NO and superoxide leads to the generation of peroxynitrite (ONOO-), which is a powerful oxidant (Beckman et al., 1990; Rodi et al., 1991). Peroxynitrite induces toxicity through nitrosation and/or nitration of amino acids such as tyrosine and cysteine on various proteins. Such modifications alter protein function and consequently disrupt cellular activity. The measurement of 3-nitrotyrosine formation is being widely used as an indicator of ONOO- generation in tissues (Hibbs \& Moncada, 1999).

\section{NO and the perinatal lung}

The NO/cGMP pathway has been identified as playing a critical role in the control of pulmonary fetal vascular tone and during the normal postnatal circulatory transition (Abman et al., 1990; 1991; Cornfield et al., 1992; Shaul et al., 1992; Tiktinsky \& Morin, 1993; McQueston et al., 1993). In fact, despite its high PVR, the normal fetal pulmonary circulation continuously releases NO under basal conditions, as demonstrated by the hypertensive effects of intrapulmonary infusions of NOS blockers (Abman et al., 1990; Moore et al., 1992). This was originally revealed in studies using nonspecific NOS antagonists. In more recent experiments the unique contributions of iNOS and nNOS to vascular regulation was addressed. In fetal lambs, the intrapulmonary infusion of three selective iNOS inhibitors caused $69-82 \%$ increases in pulmonary vascular resistance (Rairigh et al., 1998). Similarly, it has recently been reported that the infusion of a nNOS-specific inhibitor increased pulmonary vascular resistance in the fetal lamb (Rairigh et al., 2000). These observations suggest that both iNOS and $\mathrm{nNOS}$ contribute to the modulation of vascular tone in the developing fetal lung. Therefore, the three isoforms of NOS are present in the developing lung and seem to play a role in the control of fetal pulmonary circulation. eNOS is predominantly present in vascular endothelial cells early in gestation in sheep, rat, and human lung, and appears to be developmentally regulated (Abman et al., 1991; Halbower et al., 1994; North et al., 1994; Parker et al., 2000). Estrogen upregulated eNOS gene expression in fetal pulmonary artery 
endothelial cells through the activation of estrogen receptor (MacRitchie et al., 1997). nNOS has been identified in lung neuronal, epithelial, and endothelial cells, and its expression increases with advancing fetal age in the rat (North et al., 1994; Xue et al., 1996; Kobzik et al., 1993). iNOS has been identified in the endothelium, epithelium, and macrophages in human and fetal rat lung by immunostaining (Xue et al., 1996; Kobzik et al., 1993).

The NO/cGMP cascade plays several important physiological roles in regulation of the fetal pulmonary circulation. These include: 1) the above-mentioned modulation of basal PVR in the fetus; 2) mediation of the vasodilator response to specific physiological and pharmacological stimuli; and 3) Reduction of the strong myogenic tone in the normal fetal lung (Abman, 1999). Thus, NOS inhibition selectively blocks pulmonary vasodilation to stimuli such as acetylcholine, oxygen, and shear stress in the normal fetus (McQueston et al., 1993). However, in comparison with newborn and adult pulmonary arterial rings, rings from fetal lambs showed little relaxation to endothelium-dependent agonists, including acetylcholine, adenosine diphosphate and the calcium ionophore A23187 (Abman et al., 1991). No age-differences were observed in the response to the NO-donor sodium nitroprusside (Abman et al., 1991), suggesting that fetal pulmonary arteries display a limited capacity to release NO but are fully capable to respond to it. Additional studies have demonstrated that the response of the ovine fetal lung to acethylcoline and oxygen are absent or decreased prior to $78 \%$ of gestation, and increases toward term (Morin et al., 1988a; Lewis et al., 1976). In contrast, inhaled NO is a potent fetal pulmonary vasodilator as early as 0.75 gestation (Kinsella et al., 1994a). Thus, it appears that the ability of developing pulmonary vascular smooth muscle to respond to exogenous NO precedes maturation of the endothelium's ability to release NO. More recent studies suggested that NO release plays a role in modulating high intrinsic or myogenic tone in the fetal pulmonary circulation. The vascular myogenic response refers to the acute reaction of a blood vessel to a change in transmural pressure (Davis \& Hill, 1999). This response is critically important for the development of resting vascular tone, upon which other control mechanisms exert vasodilator and vasoconstrictor influences. In vitro studies demonstrated the presence of a myogenic response in sheep pulmonary arteries (Belik et al., 1995) and greater myogenic activity in fetal pulmonary arteries than neonatal or adult arteries (Belik et al., 1994). More 
recent studies of intact fetal lambs have demonstrated that high myogenic tone operates normally in the fetus and contributes to maintaining high PVR in utero (Storme et al., 1999). NOS inhibition further unmasks this potent myogenic response (Storme et al., 1999).

In late gestation lambs, the immediate and dramatic fall in PVR produced by cesarean section and ventilation with $100 \%$ oxygen is markedly attenuated if delivery and ventilation take place following the infusion of NOS inhibitors (Abman et al., 1990). Studies have also been performed to define which birth-related stimuli stimulate NO at birth. Vasodilation during hypoxic ventilation was attenuated by NOS inhibition, as was the fall in pulmonary artery pressure during administration of $100 \%$ oxygen (Cornfield et al., 1992; Tiktinsky et al., 1993). Similarly, NOS inhibition blocked the marked decrease in PVR during acute mechanical increases in flow or shear stress related to brief compression of the ductus arteriosus (Cornfield et al., 1992). These finding suggest that ventilation, increased oxygenation, and shear stress are independently capable of stimulating NOS activity at birth. Moreover, rhythmic distension of the lung and increased oxygenation, both concomitantly and independently, produced induction of eNOS gene expression in lung vessels (Black et al., 1997).

\section{NO and PPHN}

Altered NOS activity during pulmonary or systemic hypertension has been reported in several vascular beds. In spite of the unique responses of the developing lung, many lessons from the alterations of vascular reactivity and structure in chronic pulmonary hypertension carry over into the perinatal lung. Loss of EDNO-dependent vasodilation has been demonstrated in isolated lungs from chronically hypoxic rats (Adnot et al., 1991) and in human conduit pulmonary arteries obtained at lung transplant from patients with chronic hypoxic pulmonary hypertension (Dinh Xuan et al., 1991). In contrast, other authors demonstrate that EDNO is upregulated in experimental chronic hypoxic pulmonary hypertension, as a possible compensatory mechanism (Hampl et al., 1993; Isaacson et al., 1994). Steudel et al. (1997) investigated the pulmonary vascular phenotype of mice with targeted disruption of the eNOS gene, finding increased pulmonary vascular resistance, but only minimal hypoxic pulmonary 
hypertension, and no evidence of pulmonary vascular remodeling. Yet, this group later found enhanced chronic hypoxic pulmonary hypertension in eNOS-null mice (Steudel et al., 1998). Using the same model, Fagan et al (1999) demonstrated that in the pulmonary circulation, the loss of endothelium-derived NO led to reversible vasoconstriction, with evidence of distal extension of pulmonary artery. However, information from knockout models should be cautiously interpreted, in view of possible upregulation of compensatory pathways (Mashimo \& Goyal, 1999; Steudel et al., 2000). Whether eNOS is ever deficient in the pulmonary circulation of adult patients with pulmonary hypertension remains controversial. Giaid and Saleh (1995), using histochemical and immunohistochemical assays, in situ hybridization, and Northen blot analyses, demonstrated that patients with primary or secondary pulmonary hypertension have reduced eNOS mRNA and immunoreactivity. Furthermore, they showed a significant inverse correlation between the expression of eNOS and the severity of vascular morphological changes, and the increase in PVR.

Intrauterine events appear to be related to the development of PPHN (Abman \& Stevens, 1997). Exposure to pulmonary hypertension or hypoxia in utero may initially alter vasoreactivity prior to the development of hypertensive vascular remodeling (Allen et al., 1986; Abman et al., 1989; Abman \& Stevens, 1997). Thus, the duration and severity of exposure to a prenatal adverse stimulus may determine the initial severity of pulmonary vascular disease in the early postnatal period. The possible effect of hypoxia is extensively commented upon another part of this introduction (see II.4). The following information is focused on the role of chronic intrauterine pulmonary hypertension as pathogenic factor for the development of PPHN. Levin et al. (1978), demonstrated that intrauterine artery ligation of the ovine fetus caused systemic hypertension, which in the setting of a patent ductus arteriosus, transmitted high pressure directly to the pulmonary circulation and produced increased wall thickness of small pulmonary arteries. Pharmacological closure of the ductus arteriosus by indomethacin produced similar effects in fetal lambs (Levin et al., 1979). Based on these facts, Abman et al. (1989), characterized an animal model of perinatal pulmonary hypertension due to partial compression of the ductus. They observed that ductus compression, through the placement of an inflatable vascular occluder, elevated pulmonary artery pressure without altering $\mathrm{PO}_{2}$. The pulmonary blood flow was only 
transiently increased (Abman \& Accurso, 1989) but fetal PVR progressively increased over several days, resulting in a situation of high pressure without high flow. After cesarean-section delivery, PVR remained markedly elevated despite ventilation with $100 \% \mathrm{O}_{2}$, leading to right-toleft shunting across the ductus arteriosus and foramen ovale and marked hypoxia. Additionally, they described, at autopsy, striking thickening of small pulmonary arteries and right ventricular hypertrophy (Abman et al., 1989). Concomitant studies from Morin (1989) and Wild et al (1989) also demonstrated that ligation of the ductus led to similar structural changes and sustained elevation of PVR. Therefore, the model of chronic compression or ligation of the ductus arteriosus mimics the hemodynamic and pathological features of PPHN and has become an useful tool for the study of the pathophysiology and the treatment of this clinical entity (Abman \& Stevens 1997; Steinhorn et al., 1997a; Abman, 1999).

Alterations in every step of the NO/cGMP cascade have been described in the experimental model of PPHN produced by chronic intrauterine ductus compression (Fig 4). Initially, it was observed that there was an impaired response to pharmacological and physiological stimuli acting through the activation of eNOS such as acetylcholine (McQueston et al., 1995), the calcium ionophore A23187 (Steinhorn et al., 1995a), oxygen (Abman et al., 1989, Zayek et al., 1995) and shear stress (Abman et al., 1989), but relative sparing of responses to endothelium -independent agonists, like atrial natriuretic peptide (McQueston et al., 1995) and inhaled NO (Zayek et al., 1995). These findings led to the hypothesis of an impairment of eNOS, and later research demonstrated a decrease in eNOS enzymatic activity, protein content, and mRNA (Shaul et al., 1997; present thesis). Additionally, a dysregulation of the normal content of the $\alpha_{1}, \alpha_{2}$ and $\beta_{1}$ subunits of soluble guanylate cyclase (Tzao et al., 1998; 1999) as well as an increase in PDE5 activity (Hanson et al., 1998) have been described in this experimental model. Therefore, after chronic intrauterine pulmonary hypertension there is a reduced production of NO in response to pharmacological or physiological stimuli, due to a reduction in eNOS. This NO is acting over an impaired sGC and, as a consequence of that, less cGMP is produced. This cGMP is more rapidly degraded to inactive 5'GMP due to an increased PDE5 activity (Figure 4). It is difficult, however, to determine whether the impairment of the NO/cGMP pathway is the cause or the consequence of the pulmonary hypertension. If deficient basal EDNO synthesis or activity 
was a cause of pulmonary hypertension in DA-compressed animals, then chronic pharmacological depletion of EDNO should reproduce the hemodynamic effects of DA compression. Infusion of low doses of a NOS blocker for 10 days before delivery does not increase basal PVR, but it markedly blunts its decrease and the increase in flow at birth (Fineman et al., 1994). This effect is not different from the one of acute infusion of NOS blockers (Abman et al., 1990) and suggests that impairment in NOS activity could not be responsible for the increase in PVR during chronic intrauterine pulmonary hypertension, but could play a determinant role in the failure in postnatal adaptation and the lack of response to the vasodilatory birth-related stimuli observed in these animals.

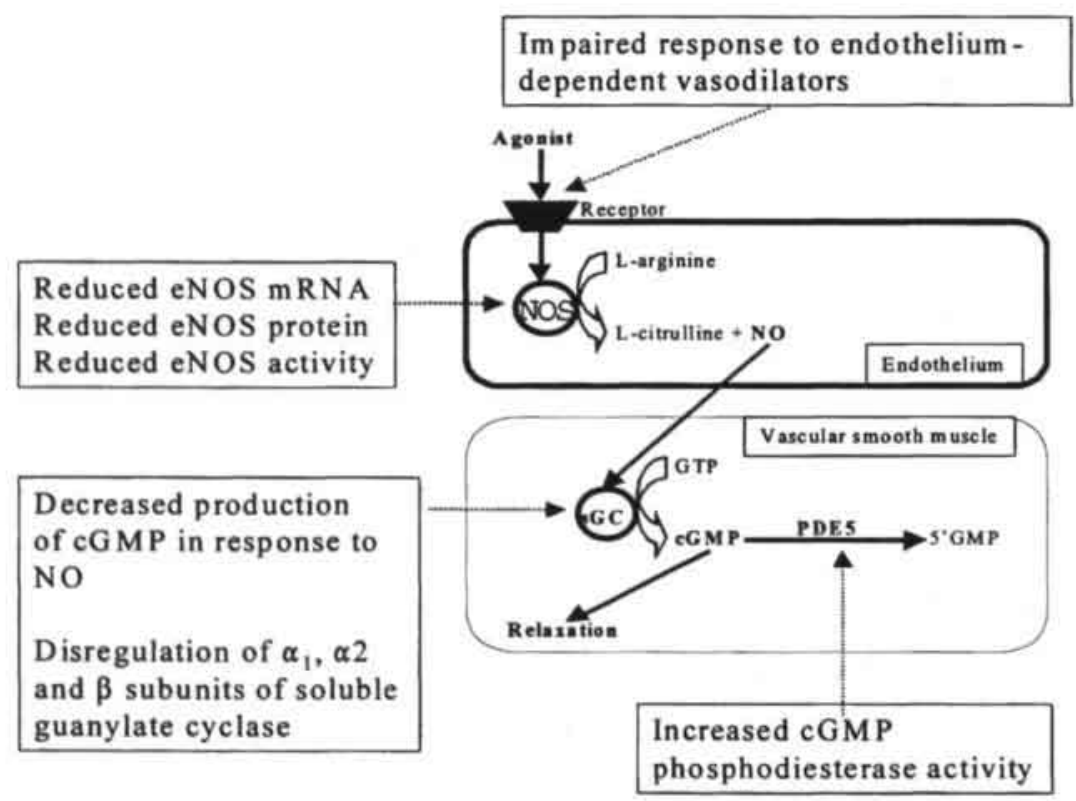

Figure 5. Alterations of the NO/cGMP pathway described in the experimental model of $P$ PHN produced by chronic intrauterine ductus compression. 
Direct evidences of an impairment of the NO/cGMP pathway in patients with PPHN are difficult to obtain. However, Dollberg et al. (1995) have shown that the urinary metabolites of NO, i.e. nitrite and nitrate, were reduced in PPHN patients and Christou et al. (1997) that the plasma concentrations of cGMP were significantly lower compared to healthy newborns. Castillo et al. (1995), demonstrated a reduced nitrate urinary excretion and plasma arginine utilization during the acute vasoconstrictive state of PPHN compared to the convalescence period. Evidence based on measurement of urinary metabolites of NO is often confounded by variations in dietary intake of nitrate (Wang et al., 1997), but the newborns included in the above mentioned studies received a homogeneous diet. Finally, umbilical vein endothelial cells cultured from infants with PPHN showed a decrease in eNOS gene expression (Villanueva et al., 1998). However, this occurred only in newborns who suffered intrapartum stress and not in PPHN without a history of perinatal asphyxia. 


\section{II.2 Endothelin-1}

Endothelin-1 (ET-1), a 21-amino acid peptide, was identified in 1988, as a potent vasoconstrictor and pressor substance, in the supernatant of cultured porcine aortic endothelial cells (Yanagisawa et al., 1988). ET-1 is present in many mammalian species, including humans. Two additional human ET isopeptides, ET-2 and ET-3 (Inoue et al., 1989) are encoded by separate genes. These isoforms of ET show a high degree of amino acid sequence identity. ET-1 is initially synthesized as a prepropeptide. Human preproET-1 is a 212-amino acid protein proteolytically cleaved to form a 38-amino acid residue intermediate peptide, termed big ET-1 (Kido et al., 1997). Big ET-1 is subsequently cleaved to ET-1 by another endopeptidase, termed ET converting enzyme (ECE), which appears to be specific for ET (Yanagisawa et al., 1988). The conversion of big ET-1 to ET-1 is essential for biological activity, because the pressor action of big ET-1 is almost completely abolished by inhibition of ECE (Matsumura et al., 1990; Gardiner et al., 1991). ECE expressed on endothelial cells may differ to ECE expressed on vascular smooth muscle cells. Whilst endothelial ECE has been found to have specificity for big ET-1 (Plumptom et al., 1996; Davenport et al., 1998), smooth muscle ECE is capable of processing big ET-2 and big ET-3 (Tsukahara et al., 1993; Maguire et al., 1997; Davenport et al., 1998). The physiological role of this and other novel putative converting enzymes on regulation of ET remains to be determined (Russell \& Davenport, 1999).

Although vascular endothelial cells are the major source of ET-1, the genes that encode the three ET isopeptides are expressed in a wide variety of cell types, including cardiac myocytes, vascular smooth muscle, renal tubular epithelium, glomerular mesangium, glia, the pituitary, macrophages, mast cells, etc, which suggests that the peptides may participate in complex regulatory mechanisms in various organs (Inoue et al., 1989; Sakurai et al., 1991). In blood vessels, ETs act by at least three different receptor subtypes, the ETA receptor, which is localized on vascular smooth muscle cells and mediates vasoconstriction, and two different ETB receptor subtypes. The ETB1 receptor subtype is present in vascular endothelial cells and mediates endothelium-dependent vasodilation. The ETB2 receptor subtype is present on smooth muscle cells causing vasoconstriction (Zimmermann \& Seifert, 1998). ET-1 and -2 are 
more potent agonists of the ETA receptor than ET-3. For the ETB receptors the three isopeptides have almost equal potency (Miyauchi \& Masaki, 1999)

Despite numerous studies of ET function, the physiological significance of ET in the cardiovascular system is unclear (Miyauchi \& Masaki, 1999). Because the plasma concentration is very low, ET is not a circulating hormone, but it may be a paracrine/autocrine mediator. The ET-1 that is released from vascular beds presumably acts on the underlying smooth muscle to increase peripheral vascular resistance (Haynes et al., 1996). In vivo and in vitro studies have demonstrated that infusions of ET-1 cause progressive and sustained vasoconstriction in most vascular beds, often following a transient dilator response (Miyauchi \& Masaki, 1999). The initial depressor response is due to a relaxing factor released from endothelium (NO or $\mathrm{PGI}_{2}$ ) and the subsequent vasoconstriction is due to the direct action of ET-1 on smooth muscle. In isolated cardiac muscle, ET-1 exerts a potent positive inotropic action. ET-1 is also reported to induce a positive chronotropic action via ETB receptors and a negative chronotropic action via ETA receptors. In addition to controlling vascular tone and contraction of myocytes, ET-1 also participates in the modulation of growth properties of the underlying vascular smooth muscle and the hypertrophy of cardiac myocyte (Miyauchi \& Masaki, 1999).

Expression of ET-1 mRNA is increased after treatment of endothelial cells with growth factors and cytokines such as thrombin (Emori et al., 1992), transforming growth factor B (Kurihara et al., 1989), tumor necrosis factor (Marsden et al., 1992), immunoglobulin 1 (Maemura et al., 1992), and insulin, or with vasoactive substances (Marsden et al., 1991; Imai et al., 1992) such as norepinephrine, angiotensin II, vasopressin, and bradykinin. Furthermore, high shear stress decreases ET-1 mRNA expression, whereas low shear stress increases it (Shaefki et al., 1991; Malek et al., 1992; Yosizumi et al., 1989). In contrast, the expression of ET-1 mRNA is inhibited by endothelium-derived NO, $\mathrm{PGI}_{2}$, and $\mathrm{ANP}$, presumably via cGMPmediated inhibition of phosphatidylinositide metabolism (Emori et al., 1993). 


\section{Endothelin-1 and the perinatal lung}

The physiological role of ET-1 in the normal fetal lung is controversial. ET-1 is present in the perinatal lung (MacCumber et al., 1989), and is vasoactive in the fetus (Ivy et al., 1994, 1996; Chatfield et al., 1991; Jones \& Abman, 1994; Tod \& Cassin, 1992). Brief infusion of ET-1 causes acute pulmonary vasodilation (Lippton et al., 1991; Cassin et al., 1991). However, with prolonged infusion, pulmonary hypertension prevails (Chatfield et al., 1991; Liben et al., 1993). Some studies of exogenous infusion of ET-1 have emphasized that the major effect of ET-1 in the normal late gestation fetal lung is vasodilation, and that the majority of ET-1 receptors active in the ovine fetal lung are the ETB1 receptors (Cassin et al., 1991; Wong et al., 1993) which mediate only vasodilation (Ivy et al., 1994). In contrast, several studies suggest that the ETA receptors play an important role in mediating vasoconstriction in the late gestation ovine fetus (Wang \& Coceani, 1992; Ivy et al., 1994, 1996). Infusion of exogenous ET-1, on the other hand, may not accurately describe the hemodynamic effects of endogenous production of ET-1 in the fetal lung (Ivy et al., 1997). As mentioned above, evidence suggests that ET-1 acts as a local autocrine and paracrine factor rather than a circulating hormone, since secretion of ET-1 by endothelial cells is polar and directed abluminally toward the interstitial region (Wagner et al., 1992). Intrapulmonary infusion of big-ET-1, the precursor to ET-1, causes progressive and sustained pulmonary hypertension without even transient vasodilation (Ivy et al., 1994; Jones \& Abman, 1994), suggesting that stimulation of endogenous ET-1 may have very different effects than brief exogenous infusions of ET-1. Blockade of the ETA receptors causes vasodilation (Ivy et al., 1994; Wong et al., 1994), whereas selective blockade of the ETB receptors does not change basal pulmonary tone in the ovine fetus (Ivy et al., 1996a). Brief and prolonged stimulation of the ETB receptors with sarafotoxin S6c, however, causes only vasodilation in the ovine fetal

lung, suggesting the presence of only ETB1 receptors (Ivy et al., 1994). In contrast, studies in newborn piglets suggest the presence of both ETB1 and ETB2 receptors in the neonatal lung (Perreault \& Baribeau, 1995). Therefore, it appears that the primary role of ET-1 in the normal late-gestation fetal lung is vasoconstriction. On the other hand it has been shown that combined ETA and ETB receptor blockade with Ro 47-0203 did not change the decrease in 
PVR with in utero oxygen ventilation, suggesting that endogenous ET-1 activity does not play a major role in the pulmonary vascular changes during the normal transitional circulation at birth (Winters et al., 1996).

\section{Endothelin-1 and PPHN}

Circulating ET-1 levels in patients with PPHN are markedly elevated, correlate with disease severity, and decline with resolution of PPHN (Rosenberg et al., 1993). In general, ET-1 levels are increased in several forms of pulmonary hypertension including primary pulmonary hypertension (Cacoub et al, 1993), the Eisenmenger syndrome (Cacoub et al., 1993), and children with pulmonary hypertension associated with congenital heart disease (Vincent et al., 1993) and bronchopulmonary dysplasia (Allen et al., 1993). In adult patients with primary pulmonary hypertension, increased expression of ET-1-like immunoreactivity and ET-1 mRNA in vascular endothelial cells have been reported suggesting that the local production of ET-1 may contribute to the altered vascular reactivity and structural changes seen in this clinical entity (Giaid et al., 1993).

High ET-1 concentrations, ET-1 mRNA expression, and ET receptor mRNA expression have been described in adult animal models of pulmonary hypertension, such as the monocrotaline (Miyauchi et al., 1993; Yorikane et al., 1993) or the chronic hypoxia models ( $\mathrm{Li}$ et al., 1994). In the experimental model of PPHN due to chronic compression of the ductus, Ivy et al. (1996b) demonstrated a marked increase in ET-1 levels with a progressive loss of the vasodilator activity of ET-1, mediated through ETB receptors, but a persistence of the vasoconstrictor activity, mediated through ETA receptors. Moreover, they observed, in the same model, increased steady-state preproET-1 mRNA and decreased ETB-receptor mRNA without changes in ECE-1 mRNA or ETA-receptor mRNA expression, suggesting that the combination of increased ET-1 production and decreased ETB-receptor-induced vasodilation may contribute to increased vasoconstrictor tone (Ivy et al., 1998a). On the other hand, chronic intrauterine blockade of the ETA receptor with BQ 123 decreased distal muscularization of small pulmonary arteries, and right ventricular hypertrophy, and partially attenuated the failure in 
circulatory transition observed at delivery in lambs subjected to chronic intrauterine ductus compression. Selective ETA receptor blockade acutely lowered PVR, in this model, after ventilation with $100 \% \mathrm{O}_{2}$ and inhaled $\mathrm{NO}$, demonstrating that ETA-mediated vasoconstriction is responsible for maintaining a residual high tone, that is not reversed by potent vasodilatory stimuli (Ivy et al., 1997).

Giaid \& Saleh (1995), showed, in adult patients with pulmonary hypertension, a significant inverse correlation between the decreased expression of NOS and the increased expression of ET-1, leading to the hypothesis that down-regulation of the endothelium-derived relaxing and antiproliferative factors (e.g. NO) and up-regulation of the endothelium-derived vasoconstrictor and mitogenic factors (e.g. ET-1) contribute to chronic pulmonary hypertension. Interestingly, a similar coordinated reduction of genes of the NO pathway and up-regulation of genes of the ET-1 pathway has been described in the ovine model of PPHN by ligation of the ductus (Black et al., 1998), In addition, concomitantly increased ET-1 and decreased cGMP plasma concentrations have been found in patients with PPHN (Christou et al., 1997). Interestingly, treatment with inhaled NO decreased ET-1 levels in these patients.

Finally, the ET system is highly activated during septic shock and ET-1 together with TXA 2 (see chapter III) seems to play a role in sepsis-induced pulmonary hypertension in adult animal models (Weitzberg et al., 1996; Wanecek et al., 1997). The plasma concentrations of ET-1 and the expression of ET-1 mRNA in pulmonary artery and aorta were significantly increased in rats after LPS injection. In isolated pulmonary arteries from septic rats, ET-1 induced vasoconstriction, mediated through ETA receptors, was maintained, but ET-1-induced vasodilatation, mediated through ETB receptors was impaired (Curzen et al., 1996). Very recently, Fujii et al. (2000) demonstrated that activation of ETA receptors, by rising ET-1 concentration, enhanced NO production and iNOS expression in pulmonary and systemic vessels of septic rats, suggesting an interaction between the NO and the ET-1 pathways in both sepsis-induced systemic hypotension and lung injury. In fact, in patients with septic shock the response to NOS inhibitors depends on the plasma level of ET-1, suggesting that NOS induction may mask a tonic pressor response of ET-1 in septic shock (Avontuur et al., 1999). 
Introduction: Eicosanoids

\section{II.3 Eicosanoids}

Eicosanoids are arachidonic acid metabolites that are generated by several cellular types including vascular endothelial cells (Coceani \& Olley, 1988). Arachidonic acid may be metabolized via two main pathways. Cyclooxygenase (COX), also referred as prostaglandin endoperoxide $\mathrm{H}$ synthase (PGHS), leads to the formation of prostaglandins (PGs) and thromboxanes (TXs). The lipoxygenase pathway produces hydroxyeicosatetranoic acids and leukotrienes. A third pathway, involving a cytochrome P450-linked monooxygenase, may generate several epoxides, hydroxy acids and other products whose physiological importance remains to be clarified (Murphy, 1989; Smith \& DeWitt 1996). Also of interest are the isoprostanes, i.e. PG-like compounds that are produced independent of the COX pathway by a non-enzymatic free-radical-induced peroxidation of arachidonic acid (Roberts \& Morrow, 1997; Morrow et al., 1999). The isoprostanes can provide an exclusive and selective index for the oxidant component of several inflammatory and degenerative diseases (Roberts \& Morrow, 1997). Moreover, because isoprostanes are isomeric to COX derived PG, which exert potent biological activity, they may not be simply markers of lipid peroxidation but also posses a specific activity (Roberts \& Morrow, 1997). In fact 8-iso-PGF ${ }_{2 a}$, one of the more abundant isoprostanes that is produced in vivo (Morrow et al., 1994), has been found to be a potent pulmonary, renal, and coronary vasoconstrictor (Kang et al., 1993; Roberts \& Morrow, 1997; John \& Valentin, 1997; Wilson et al., 1999).

PGs and TXs are synthesized from arachidonic acid by COX-1 and COX-2. Both enzymes catalyze the formation of $\mathrm{PGH}_{2}$ from arachidonic acid, and both are inhibited by nonsteroidal anti-inflammatory drugs such as aspirin. COX-1 is generally constitutively active, whereas COX-2 is induced by growth factors, cytokines, and tumor promoters (Smith \& DeWitt 1996). Both COX-1 and -2 have been localized immunocytochemically to the lumen of the endoplasmic reticulum and the outer nuclear envelope (Morita et al., 1995), which implies that the site of PG synthesis is intracellular. PGs and TXs play fundamental roles in health and disease and, increasingly, as therapeutic agents. Examples of these broad roles include gastric protection and peptic ulcer formation; pregnancy, labor, delivery, abortion, luteolysis, and 
menstruation; glaucoma; blood pressure control and vascular tone; intestinal fluid secretion; liver protection and damage; airway resistance and asthma; fever; and modulation of inflammatory cells (Schuster, 1999). Additionally, eicosanoids have been implicated in the regulation of pulmonary vascular tone under physiological and pathological conditions (Barnes \& Liu, 1995).

\section{Eicosanoids and the perinatal lung}

It appears that the COX pathway is the predominant for arachidonic acid metabolism in the fetal and transitional circulation, with prostacyclin $\left(\mathrm{PGI}_{2}\right)$, the most influential prostanoid mediator formed (Coceani \& Olley, 1988; Ziegler et al., 1995a). Several pioneering studies revealed the critical importance of $\mathrm{PGI}_{2}$ in the developing pulmonary circulation. It has been shown that $\mathrm{PGI}_{2}$ is produced by fetal pulmonary blood vessels in vitro (Terragno \& Terragno, 1979), and that it causes very potent vasodilation when infused into the fetal lung in vivo (Cassin et al., 1981). However, in vivo COX inhibition has minimal effect on basal PVR and does not increase myogenic tone in the fetal lamb (Abman, 1999). Throughout gestation, a maturational increase in $\mathrm{PGI}_{2}$ parallels the decrease in PVR in the fetal third trimester (Shaul et al., 1993a). The developmental upregulation of $\mathrm{PGI}_{2}$ synthesis is related to a maturational increase in COX-1 gene expression (Shaul et al., 1999). Physiologic concentrations of estrogen cause direct upregulation of COX-1 gene expression in fetal pulmonary artery endothelial cells, and this is mediated by estrogen receptor activation (Brannon et al., 1998). Moreover, $\mathrm{PGI}_{2}$ synthesis in fetal intrapulmonary arteries is acutely modulated by changes in $\mathrm{O}_{2}$, with decreasing $\mathrm{O}_{2}$ causing attenuated synthesis and increasing $\mathrm{O}_{2}$ causing enhanced synthesis (Shaul et al., 1992). This process is due to an effect on COX activity, it causes marked parallel changes in the production of the second messenger cAMP, and it is specific to the pulmonary circulation (Shaul et al., 1992; 1999). In contrast, in the newborn it has been shown that lung $\mathrm{PGI}_{2}$ production is stimulated by hypoxia and that inhibition of $\mathrm{PGI}_{2}$ production augments hypoxic pulmonary vasoconstriction (Green \& Leffler, 1984; Tyler et al., 1975).

It has been suggested that $\mathrm{PGI}_{2}$ plays a major role in the transition of the pulmonary 
circulation at birth since inhibition of PG synthesis attenuates the birth-related decline in pulmonary vascular resistance. (Davidson, 1988; Leffler, 1978; Velvis, 1991). In the late gestation fetus, $\mathrm{PGI}_{2}$ production increases acutely with ventilation and acute oxygenation (Leffler et al., 1980; 1984a; 1984b). However, Velvis et al. (1991) demonstrated that COX inhibition abolished the drop in PVR associated with rhythmic distension of the lungs (with a hypoxic gas), but had no effect on PVR during static distension or during ventilation with oxygenation. Therefore, under normal circumstances (i.e. ventilation with oxygenation), $\mathrm{PGI}_{2}$ production is not essential for a smooth postnatal transition (Velvis et al., 1991; Ziegler et al., 1995a).

Prostaglandins of the D and E series manifest vasodilatory activity when infused into the fetal lung (Coceani \& Olley, 1988). Prostaglandins of the F series induce vasoconstriction in the fetal pulmonary vasculature (Coceani \& Olley, 1988), but these PGs probably are not important, given the predominantly vasoconstrictive effect of COX inhibition in the fetus at birth (Ziegler et al., 1995a). Moreover, the effects of exogenous and endogenous PGF $_{2 \alpha}$ on perinatal circulation are difficult to assess because the circulatory responses involve a complex interaction of uterine, umbilical, and ductal blood flow, and fetoplacental metabolism of PGF $_{2 \alpha}$ (Leffler et al., 1979).

Lipoxygenase activity has been demonstrated in human fetal lungs as early as 12 to 18 weeks of gestation (Saeed \& Mitchell 1982). Leukotriene inhibition decreases PVR in fetal lambs (Soifer et al., 1985; Heymann et al., 1988; Lebiodois et al., 1987). It was further suggested that reduced leukotriene production, at birth, contributes to the drop in PVR during postnatal transition (Ziegler et al., 1995a). However, the nonspecificity of the leukotriene antagonists used in these studies made speculations regarding leukotriene importance in the fetal circulation questionable (Ziegler et al., 1995a). In fact, it has been found that leukotriene content in fetal lamb lung tissues and fetal lamb tracheal fluid was very low (Cassin et al.,1990; Abman \& Stenmark, 1992), and that no significant changes in lung leukotrienes levels during the transition in normal or hypertensive ovine fetuses were produced (Abman \& Stenmark, 1992). Therefore, the specific role of leukotrienes in maintaining high PVR in the 
fetus and in the transitional circulation is still unclear.

\section{Eicosanoids and PPHN}

There is evidence from experimental animal studies and human patients that alterations in eicosanoid homeostasis may be involved in the pathogenesis of PPHN (Stenmark et al., 1983; Shaul, 1999). It has been demonstrated that $\mathrm{PGI}_{2}$ synthesis is markedly reduced in intrapulmonary arteries isolated from newborn calves with pulmonary hypertension (Badesch et al., 1989). However, increased levels of 6-keto-PGF ${ }_{1 \alpha}$ and $\mathrm{TXB}_{2}$ and, stable metabolites of $\mathrm{PGI}_{2}$ and $\mathrm{TXA}_{2}$ respectively, have been observed in an experimental model of meconium aspiration-induced pulmonary hypertension (Soukka et al., 1998). Moreover, the levels of $\mathrm{TXB}_{2}$ were significantly correlated with pulmonary artery pressures in individual infants with a primary diagnosis of meconium aspiration (Bui et al., 1992). Concentrations of $\mathrm{TXB}_{2}, 6$-keto$\mathrm{PGF}_{1 \alpha}, \mathrm{PGD}_{2}, \mathrm{PGE}_{2}, \mathrm{LTB}_{4}$, and $\mathrm{LTE}_{4}$ were elevated in infants with PPHN that required ECMO treatment. Eicosanoid concentrations decreased in all infants with a good clinical outcome after ECMO, but they remained elevated in those with a poor outcome (Dobyns et al., 1994).

PPHN has been reported in newborns of mothers who received COX inhibitors, such as indomethacin or aspirin, during pregnancy (Csaba et al., 1978; Levin et al., 1978b; Van Marter et al., 1996). However, this effect seems to be more related to the premature closure of the ductus arteriosus, and consequently with the presence of intrauterine pulmonary hypertension, than to a direct effect of COX inhibition in the pulmonary vessels (Steinhorn et al., 1995b; Abman \& Stevens, 1997). Nevertheless, $\mathrm{PGI}_{2}$ is an important modulator of vascular cell growth in the pulmonary circulation (Huttner et al., 1977) and chronic inhibition of its synthesis induces pulmonary hypertension and alterations of lung vessel morphology in adult sheep (Meyrick et al., 1985).

Finally, there is a great body of evidence about the relevant role of $\mathrm{TXA}_{2}$ in sepsis-induced PPHN. This aspect, together with other vasoactive mediators involved in sepsis-induced altered pulmonary vasoreactivity, is extensively discussed in chapter III. 


\section{II.4 Carbon monoxide}

Over the last years, there is increasing interest in the potential role of $\mathrm{CO}$ as a regulator of vascular tone. $\mathrm{CO}$ has been traditionally considered as a toxic pollutant that poisons by binding to the iron containing heme group found in hemoglobin and some enzymes, but evidence is accumulating that $\mathrm{CO}$ can be an endogenous regulator of various physiologic processes (Marks et al., 1991). CO appears to mimic many of the function of NO, including smooth muscle relaxation and inhibition of platelet aggregation (Brunne \& Ullrich 1987), which are mainly mediated through the activation of sGC (Kharitonov et al., 1995).

CO is produced endogenously by two sources, i.e. enzymatic peroxidation of microsomal lipids and heme destruction catalyzed by heme oxygenase (HO) (Marks et al., 1991; Maines, 1997). HO is a ubiquitous protein that exists in two isoforms: HO-1, an inducible form, and HO-2, a constitutive form (Maines, 1997). HO-2 is the predominant isoform present in endothelial cells, smooth muscle cells, connective tissue, and epithelial cells (Zakhary et al., 1996). HO-1 is also present in endothelial cells (Coceani et al., 1997) and is upregulated by many stimuli including shear stress, hypoxia, hyperoxia, metals, and heat shock (Cantoni et al., 1991; Okinaga et al., 1996). In addition, putative inhibitors of HO, including zinc protoporphyrin IX and tin protoporphyrin IX, are capable of producing a pressor effect in vivo, causing a rise in systemic blood pressure and peripheral vascular resistance (Johnson et al., 1995; Caudill et al., 1998)

The ability of exogenous $\mathrm{CO}$ to induce vasorelaxation has long been known (Duke \& Killick, 1952). CO-induced vasorelaxation has been described in many vascular beds from several species (Furchgott \& Jothianandan; 1991; Brian et al., 1994; Wang et al., 1997). However it is not a universal finding and the sensitivity of the different vessels to $\mathrm{CO}$ is variable. A vasoregulatory role for endogenous $\mathrm{CO}$ produced by constitutive $\mathrm{HO}-2$ has been postulated in the maintenance of sinusoidal tone in the perfused rat liver (Suematsu et al., 1995), and the vascular tone of porcine distal pulmonary arteries (Zakhary et al., 1996). Alternatively, endogenously released $\mathrm{CO}$, as a consequence of $\mathrm{HO}-1$ induction, participated in the regulation of vascular contractility in rat aorta (Sammut et al., 1998) and fetal lamb ductus 
arteriosus (Coceani et al., 1997). An interaction between CO and nitric oxide may also significantly contribute to the fine-tuning of vascular tone (Maines, 1997; Wang, 1998). Recently, Grover et al (2000) studied the effects of inhaled CO on late-gestation fetal lambs. Inhaled $\mathrm{CO}$ did not alter pulmonary vascular resistance at any of the study doses ranging from 5 to $2500 \mathrm{ppm}$, and combined treatment with inhaled $\mathrm{CO}$ did not enhance the vasodilator response to inhaled NO. Moreover, they also report that zinc protoporphyrin IX had no effect on basal pulmonary vascular or DA tone, suggesting that endogenous $\mathrm{CO}$ production does not modulate basal pulmonary hemodynamics in the fetal lung (Grover et al., 2000). 


\section{II.5 Oxygen}

Vascular tone is under the active influence of respiratory gases. One feature that distinguishes the pulmonary circulation from other vascular beds is its response to hypoxia. In the systemic circulation, hypoxia causes vasodilation or, less often, no change in vascular tone. In contrast, the pulmonary circulation responds to hypoxia with vigorous vasoconstriction. Hypoxic pulmonary vasoconstriction (HPV) is a physiological response whereby circulating blood is diverted away from hypoxic alveoli, thus matching perfusion and ventilation and optimizing arterial oxygenation (Barnes \& Liu, 1995).

Despite extensive investigation, the mechanisms producing HPV are incompletely characterized (Barnes \& Liu, 1995). It has been proposed that pulmonary vascular tone increases by alveolar hypoxia because of reduced release or activity of a vasodilator, increased release or activity of a vasoconstrictor, and/or because hypoxia directly stimulates contraction of vascular smooth muscle cells (Barnes \& Liu, 1995). In the search for chemical mediators of HPV many vasoactive substances have been considered as candidates including catecholamines (Fishman 1976), histamine (Hauge 1968), angiotensin-II (Berkov 1974), prostaglandins (Weir et al 1976; Shaul et al., 1991), leukotrienes (Morganroth et al., 1984; McDonnell et al., 1990), 5-HT (Fishman, 1976), PAF (McCormack 1989a), or ATP (McCormack 1989b). However, none of these substances has proved to be essential for HPV (Barnes \& Liu, 1995), although they may have a modulatory role, or might play a role in setting up the background that is necessary for HPV to occur. Endothelial factors are important modulators of vascular tone but the role of endothelium in mediating or modulating HPV has not been clearly defined. Hypoxia causes an immediate, transient contraction of isolated pulmonary and systemic arteries that is endothelium dependent and mediated by inhibition of the basal activity of endotheliumderived NO (De Mey \& Vanhoutte 1983; Holden \& McCall, 1984; Rubanyi et al., 1985; Johns et al., 1989; Graser \& Vanhoutte, 1991; Kovitz et al., 1993;). In contrast, hypoxic constriction in the intact pulmonary circulation does not involve this mechanism (Archer et al., 1989; Brashers et al., 1988), which might suggest that the constriction is endothelium independent. In fact, hypoxia-induced contraction of cultured pulmonary vascular smooth muscle cells has been 
demonstrated (Murray et al., 1990; Madden et al., 1992), suggesting that a reduction in $\mathrm{pO}_{2}$ can exert a direct effect on vascular smooth muscle.

Several possible mechanisms have been proposed to explain how the direct action of hypoxia on vascular smooth muscle cells causes pulmonary vasoconstriction: (1) inhibition by hypoxia of several metabolic pathways including glycolisis, tricarboxylic acid cycle or oxidative phosphorylation (Rounds \& McMurtry, 1981; Stanbrook \& McMurtry, 1983); (2) Existence of a heme protein, such as the cytochrome P450 system, which acts as oxygen sensor (Sylvester and McGowan, 1978); (3) regulation by oxygen tension of the production of reactive oxygen species, which control transmembrane $\mathrm{Ca}^{2+}$ flux (Archer, 1993); or (4) inhibition by hypoxia of an oxygen-sensitive $\mathrm{K}^{+}$channel causing membrane depolarization and calcium entry through the voltage-dependent calcium channels (Post et al., 1992; Weir \& Archer, 1995). In addition, it has been suggested that the responses of specific vessels at different stages of development (fetal, neonatal and adult) to changes in oxygen tension may be determined by the distribution of a variety of ion channels in the smooth muscle cells (Weir et al., 1997). Moreover, there are morphological and electrophysiological differences between individual pulmonary artery smooth muscle cells. For example, in some cells the hypoxia-sensitive $\mathrm{K}^{+}$current is predominantly carried by delayed rectifier channels and in others by calcium-sensitive $\mathrm{K}^{+}$ channels cells (Archer et al., 1996). Delayed rectifier channels are more common in the resistance pulmonary arteries and calcium-sensitive potassium channels in the conduit arteries (Archer et al., 1996). This diversity explains, in part, the segmental differences in the response of the pulmonary circulation to hypoxia (Archer et al., 1996). In addition, age dependent differences in the ionic channels that may control HPV have been described. In adult pulmonary arterial smooth muscle cells the oxygen-sensitive $\mathrm{K}^{+}$channel appears to be a 4aminopyridine-sensitive delayed rectifier channel (Reeve et al., 1998). In contrast, in fetal pulmonary arterial smooth muscle cells hypoxia produces inhibition of a calcium-sensitive $\mathrm{K}^{+}$ channel (Reeve et al., 1998).

Although decreased production of endothelium-derived dilators or increased production of endothelium-derived constrictors does not primarily mediate HPV, they may play an important 
role in initiating or amplifying smooth muscle constriction in response to hypoxia. Gaine et al. (1998) demonstrated that hypoxic pulmonary endothelial cells release a diffusible, cyclooxygenase-independent and distinct from endothelin, contractile factor that mediates hypoxic constriction in isolated pulmonary arteries. The nature of this factor and the mechanisms controlling its activity remain to be determined. On the other hand, studies in pulmonary endothelial cells, isolated pulmonary vascular rings, isolated perfused lungs, and whole animals support an important role for NO in modulating the pulmonary vascular response to oxygen (Voelkel, 1986; Nelin et al., 1996; Phelan \& Faller, 1996; Johns et al., 1989; McQueston et al., 1993; Cornfield et al., 1996; Blitzer et al., 1996). Hypoxia interferes several steps of NO synthesis, release or activity. Hypoxia inhibits: (1) L-arginine uptake by pulmonary artery endothelial cells (Block et al., 1995); (2) the conversion of L-citrulline to Larginine in pulmonary artery endothelial cells (Su \& Block, 1995); (3) NOS activity by limiting the availability of oxygen, a substrate for NOS that is a dioxygenase which catalyses the reaction between molecular oxygen and L-arginine (Rengasamy \& Johns, 1991); (4) endothelial ATP content (Rounds \& McMurtry, 1981) which is necessary for agonist-induced production of EDNO; (5) eNOS by reducing the endothelial intracellular $\mathrm{Ca}^{2+}$ concentration which primarily regulates eNOS activity (Mathew et al., 1991; Stevens et al., 1994); (6) the supply of NADPH and 6-methyltetrahydropterine both essential cofactors for NOS activity (Rubanyi \& Vanhoutte, 1986). Finally, (7) hypoxia could induce the production of superoxide anions by the endothelial cells that would inactivate EDNO (Rubanyi \& Vanhoutte, 1986). In contrast, experimental data are compatible with the hypothesis that, unlike severe hypoxia, moderate hypoxia does not reduce (Warren et al, 1989) and may actually increase (Hampl et al., 1995) NO synthesis in pulmonary endothelial cells.

Extravascular produced NO has also been proposed to modulate HPV. The free diffusion of NO and the close apposition of airways to medium-sized pulmonary vessels, which modulate pulmonary vascular tone (Sobol et al., 1963), suggest that NO, produced in airways proximal to the alveoli, may mediate pulmonary vasodilatation. Furthermore, hemoglobin in blood vessels may serve as a natural biological sink for NO, creating a continuous concentration gradient for NO to move toward perivascular myocytes and thus regulate blood 
flow (Dweik et al., 1998). According to this hypothesis, Dweik et al. (1998) showed that oxygen regulates NO levels through effects on iNOS enzyme kinetics in proportion to the inspired oxygen concentration throughout the physiological range.

\section{Oxygen and the perinatal lung}

Oxygen tension plays a critical role in the regulation of pulmonary vascular tone in utero and during transition at birth through direct and indirect effects on vascular function. The fetal pulmonary circulation can sense small changes in $\mathrm{pO}_{2}$, which is at least partly responsible for maintaining high PVR in utero and decreasing PVR at birth (Abman et al., 1987; Blanco et al., 1988). The vessel wall responds to a continuum of $\mathrm{pO}_{2}$ whereas normal fetal $\mathrm{pO}_{2}$ is approximately $20 \mathrm{mmHg}$ and changes of $5-10 \mathrm{mmHg}$ markedly alters PVR (Abman et al., 1987). Mechanisms of fetal $\mathrm{O}_{2}$ sensing may be, therefore, critical to enhance our understanding of vascular function with normal development and with vascular injury in diseases such as PPHN.

The acute response to hypoxia in the normal fetus is vigorous and is characterized by increased pulmonary and systemic arterial pressures with a fall in pulmonary blood flow (Campbell et al., 1967a; 1967b). The fetal hypoxic response is present before 0.7 term in the fetal lamb, and increases with gestational age (Lewis et al., 1976). Carotid chemoreceptors mediate the cardiovascular response to hypoxia in the fetal lamb (Blanco et al., 1984; Bartelds et al., 1993). However, acute elevation of fetal PVR is likely to be due to direct effects of lowered $\mathrm{pO}_{2}$ on smooth muscle (Cornfield et al., 1994), and modulated by various neural and humoral mediators. Changes in oxygen tension influence the release of endothelium-derived products, such as NO, ET, prostaglandins and others, which provide short term modulation of fetal pulmonary vascular tone (Ziegler et al., 1995a). Acute fetal HPV is not blocked by alphaadrenergic antagonists (Lewis et al., 1976). However, with severe of prolonged intrauterine hypoxia neurohumoral stimulation contributes to altered pulmonary vascular tone and reactivity (Parer et al., 1980; Abman et al., 1987). 
The change in oxygen tension is one of the central stimuli of the cascade of events that regulate the transition between the prenatal and postnatal circulation (Walker, 1993). At birth, arterial $\mathrm{pO}_{2}$ increases from fetal levels of 20 to over $50 \mathrm{mmHg}$ within minutes (Abman \& Stevens, 1997). Increased oxygen tension in the absence of other birth related stimuli, such as rhythmic distension of the lung or umbilical cord occlusion, produced a marked increase in fetal lung blood flow (Blanco et al., 1988; Morin et al., 1988a; Tittinsky \& Morin, 1993). Reactivity of the human fetal pulmonary circulation to hyperoxygenation increases with gestational age but is absent before 26 weeks of gestation (Rasanen et al., 1998). In the ovine fetus, oxygen-induced increase in pulmonary blood flow was unaffected by COX inhibition (Morin et al., 1988b), or endothelin receptor blockade (Winters et al., 1996), but markedly reduced by NOS inhibition (Moore et al., 1992; Tittinsky \& Morin, 1993; McQueston et al., 1994). Experimental studies, in which rhythmic distension of the lungs with hypoxic gases and oxygenation without ventilation have been studied sequentially, have not completely succeeded in determining which of these changes at the onset of air breathing is the more important (Walker, 1993). Dawes (1966) attributed one third of the total vasodilation to each of ventilation, oxygenation, and decreasing $\mathrm{CO}_{2}$ levels. Other studies have attributed almost the entire response to oxygenation alone (Morin et al., 1988a) or ventilation alone (Teitel et al., 1990). Individual responses within a group of animals can vary between these two extremes (Teitel et al., 1990) and it is possible that differences in lung liquid clearance and lung compliance produce varying responses in the pulmonary circulation at birth (Walker, 1993).

\section{Hypoxia and PPHN}

Hypoxia is considered a major cause of PPHN (Haworth, 1997). In newborns who die soon after birth with PPHN precipitated by severe intrauterine or intrapartum hypoxia, without significant parenchymal lung damage, post-morten examination shows thick-walled undilated pulmonary arteries (Haworth \& Reid, 1976; Haworth, 1997). However, whether chronic hypoxia alone can cause PPHN is controversial (Abman, 1999). Initial studies demonstrated that newborn rats exposed in utero to chronic hypoxia showed smooth muscle thickening in 
small pulmonary arteries (Goldeberg et al., 1971). Other studies have failed to consistently find morphological evidences of hypertensive changes in fetal or neonatal pulmonary arteries after chronic intrauterine hypoxia (Murphy et al., 1986; Geggel et al., 1986). In adult rats, chronic hypoxia induced pulmonary hypertension but only slightly increased the medial area and did not alter the lumen area of pulmonary arteries with an external diameter between 30 $200 \mu \mathrm{m}$ (van Suylen et al., 1998). Physiological studies of sheep have suggested that hypoxia caused by placental embolization (Drummond \& Bissonnette, 1978), maternal hypotension (Gersony et al., 1976) or partial cord compression (Soifer et al., 1987) may alter pulmonary vascular reactivity. Additionally, immediate postnatal exposure to hypoxia also produced in piglet pulmonary arteries medial hypertrophy and a marked increase in connective tissue (Allen \& Haworth, 1986), as well as an altered reactivity (Tulloh et al., 1997).

The role of NO production in chronic hypoxia-induced pulmonary hypertension in adults and newborns remains unclear. In the adult rat lung, gene expression for endothelial eNOS is upregulated in the alveolar arteries after three weeks of normobaric hypoxic exposure (Shaul et al., 1995; Le Cras et al., 1996). Upregulation by hypoxia of iNOS and nNOS expression has also been reported (Xue et al., 1994; Shaul et al., 1995; Le Cras et al., 1996), but it is not an universal finding (Tyler et al., 1999). Chronic hypoxia in adult rats enhanced the vasoconstrictor response to the NOS inhibitor L-NAME, implying increased NO release (Isaacson et al., 1996). Concentrations of nitrites and nitrates, the stable metabolic products of NO, were higher in lung perfusate of chronically hypoxic rats than in control rats (Isaacson et al., 1994; Muramatsu et al., 1996; Tyler et al., 1999). In contrast, other investigators report impaired acetylcholine-induced relaxation following chronic hypoxic exposure in the adult and neonatal lung (Adnot et al., 1991; Crawley et al., 1992; Shaul et al., 1993b; Eddahibi et al., 1992; Fike \& Kaplowitz, 1996; Tulloh et al., 1997). This observation is not incompatible with normal or even upregulated endothelial NOS. The excessive contraction of pulmonary arterial smooth muscle cells in a hypoxic environment may stimulate NO release (Wanstall et al., 1995). Shear stress will increase in contracted vessels and an increase in shear stress also increases NO production (Ohno et al., 1993). The balance of evidence suggests that NO production is at least normal during chronic hypoxia, but that endothelium-dependent 
relaxation is impaired. This suggests that other parts of the NO effector system may be altered (Hislop et al., 1997). However, not only NO production but also eNOS content was reduced in lungs from neonatal piglets subjected to postnatal hypoxia (Fike et al., 1998). Hislop et al. (1997) showed an interesting pattern of up- down-regulation in neonatal piglets depending on the time of exposure to hypoxia. In animals made hypoxic from birth, the lung vessel eNOS immunoreactivity was decreased, but in those animals made hypoxic after 3 to 6 days, was increased. In contrast, Berkenbosch et al. (2000) showed that exposure of newborn piglets to 3 days of hypoxia did not affect eNOS activity, but exposure to 14 days reduced it. Interestingly, they observed that exposure to hypoxia also reduced the response to endothelium-independent stimulators of the NO/cGMP pathway, such as NO donors or the cGMP analog 8-bromocGMP, suggesting hypoxia-induced impairment of cGMP-mediated vasodilation.

Changes in the environmental oxygen tension to which cells are exposed in vivo result in physiological and sometimes pathological consequences that are associated with differential expression of specific genes (Faller, 1999). Hypoxia affects endothelial cellular physiology in vivo and in vitro in a number of ways, including the transcriptionally regulated expression of vasoactive substances, and matrix proteins involved in modulation of vascular tone and structure. While much of the mechanisms coupling $\mathrm{pO}_{2}$ to changes in gene expression are still unknown, a part of this pathway is emerging. Several transcription factors have been found to be regulated by hypoxia including hypoxia inducible factor 1 (HIF-1), activator protein-1 (AP1), the tumor suppressor $\mathrm{p} 53$, nuclear factor $\mathrm{kB}$ and the heat shock transcription factor HSF (Faller, 1999). Therefore, hypoxia results in the transcriptional induction of genes encoding vasoconstrictors and smooth muscle mitogens such as platelet derived growth factor-B, ET-1 (Kourembanas et al., 1991), vascular endothelial growth factor (VEGF) (Namiki et al., 1995) or thrombospondin-1 (Phelan et al., 1998); genes encoding matrix or remodelling molecules such as collagenase IV (Bandyopadhyay et al., 1995), and reciprocal transcriptional inhibition of vasodilatory or anti-mitogenic effectors such as NOS (Phelan et al., 1996; Faller, 1999). Short-term exposure of endothelial cells to low oxygen tension results in the synthesis of predominantly vasoconstricting effectors, while longer-term and more severe hypoxic exposure generates factors that can induce smooth muscle proliferation and remodelling (Faller, 1999). 
Thus, the endothelial cell response to hypoxic stress can result in two different consequences in the surrounding tissues, depending on the duration of the exposure: short-term exposure causes physiological and reversible modulation of vascular tone and blood flow; chronic hypoxic stress results in irreversible remodelling of the vasculature and surrounding tissues, with smooth muscle proliferation and fibrosis. This dichotomy of responses to hypoxia may explain, in part, both the acute and chronic pathophysiological sequelae of diseases characterized by regional hypoxia, including pulmonary hypertension (Faller, 1999). 


\section{Chapter III. Sepsis and PPHN}

The lung is a major target organ in neonatal sepsis (Ablow et al 1976). In general, the lung plays a determinant role in the sepsis in some animal species that exhibit a pulmonary bacterial clearance (e.g. sheep, pig) but not in species (e.g. dog, rat, rabbit) in which bacteria localize predominantly in the liver and spleen (Winkler, 1988). The uptake of bacteria by pulmonary intravascular macrophages and the subsequent release of inflammatory mediators are central to the pathological changes produced in animal models of sepsis-induced adult respiratory distress syndrome and sepsis-induced PPHN (Warner et al., 1987; Bowdy et al., 1990). Moreover, pulmonary hypertension is the single most reliable circulatory disturbance noted in every laboratory model of neonatal sepsis (Gibson et al., 1987; Runkle et al., 1984; Truog et al., 1986; Goldberg et al., 1986; 1988; Hammerman et al., 1988; Meadow et al., 1986; Philips et al., 1988; Schreiber et al., 1992; Covert \& Schreiber, 1993; Meadow \& Rudinsky, 1995). In these models sepsis produces a complex pulmonary response in which two different phases (i.e. early and late sepsis-induced pulmonary hypertension) have been delimited.

\section{III.1 Early phase sepsis-induced pulmonary hypertension.}

In most animal models, pulmonary arterial pressure begins to rise within the first 5 minutes of the sepsis protocol, eventually reaching two to three times its baseline value (Meadow \& Rudinsky, 1995; Gibson et al., 1987; Runkle et al., 1984). This rise in pulmonary arterial pressure occurs despite a concurrent fall in cardiac output. As a result, PVR increases by as much as 5 times (Meadow \& Rudinsky, 1995).

At least in laboratory animals, the mediator of this early phase pulmonary hypertension in newborn experimental sepsis is well known. $\mathrm{TXA}_{2}$ has been shown to be responsible for sepsis-induced pulmonary hypertension in both piglets and lambs (Meadow \& Rudinsky, 1995). Within minutes of infusion of live GBS organisms (Hammerman et al., 1988; Runkle et al., 1984; Truog et al., 1986) or heat-killed GBS organisms (Barefield et al., 1994) both plasma levels of $\mathrm{TXA}_{2}$ and PAP rise in concert. This parallel rise in TXA $\mathrm{T}_{2}$ and PAP is blocked 
by either the cyclooxygenase inhibitor indomethacin (Runkle et al., 1984), the TX synthase inhibitor dazmagrel (Truog et al., 1986, Hammerman et al, 1988), or after TX receptor blockade (Sandberg et al., 1994). Moreover, TXA ${ }_{2}$ mimetics (e.g.U46619) induce changes in the pulmonary circulation indistinguishable from the early changes induced by GBS (Crowley et al., 1991). Finally, newborn human infants infected with GBS who demonstrate elevated PVR have been shown to have elevated levels of circulating TX metabolites (Hammerman et al., 1987). Therefore, $\mathrm{TXA}_{2}$ appears to be both necessary and sufficient to account for the early phase pulmonary hypertension noted in models of neonatal sepsis (Meadow \& Rudinsky, 1995).

\section{III.2 Late phase sepsis-induced pulmonary hypertension.}

A second TXA ${ }_{2}$-independent rise in PVR is described to occur by about 4 hours in most animal neonatal sepsis protocols (Runkle et al., 1984; Truog et al., 1986; Meadow \& Rudinsky, 1995). This phase is associated with pulmonary vascular injury (Hellerqvist et al., 1981) and generalized pulmonary edema, with consequent abnormalities of ventilation/perfusion matching and lung compliance (Truog et al., 1986; Meadow \& Rudinsky, 1995). The mediators of this late phase of pulmonary insult have not been well established. A large amount of vasoactive substances is stimulated by, and contributes to, pulmonary tissue damage during sepsis (Suffredini, 1994). Attempts to inhibit some of them (e.g. TNF, IL-1) in the course of experimental sepsis have met with only partial effect on the cardiopulmonary events (Meadow \& Rudinsky, 1995). The complex interrelationships between the inflammatory and vasoactive factors involved in the late onset sepsis-induced pulmonary hypertension are likely to explain the partial effect of therapeutics based on the inhibition of one isolated factor.

\section{III.3 NO and sepsis-induced changes in vascular contractility.}

NO is generated in large quantities during host defense and immunological reactions (Nathan \& Hibbs, 1991;Nussler \& Billiar, 1993). Such generation of NO was first observed in activated macrophages (Hibbs et al., 1988; Marletta et al., 1988; Stuehr et al., 1989), where it 
contributes to their cytotoxicity against tumor cells, bacteria, viruses and other invading microorganisms. The cytostatic/cytotoxic actions of NO result from its inhibitory actions on key enzymes in the respiratory chain and in the synthesis of DNA in the target cells (Hibbs et al., 1990; Nguyen et al., 1992). NO may also interact with oxygen-derived radicals to produce other toxic substances (Hibbs, 1992) such as peroxynitrite (Beckman et al., 1990). Thus, NO plays a role in immunological host defense and is also involved in the pathogenesis of conditions such as septic shock and inflammation.

During sepsis, pathological overproduction of NO due to cytokine- or endotoxin-related induction of iNOS can lead to inappropriate vasodilation, loss of systemic vascular resistance and hypotension (Hobbs et al., 1999). The role of increased NO generation in the hypotension associated with septic shock has been demonstrated in numerous animal studies (Thiemermann \& Vane 1990, Rees et al., 1990, Killbourn et al., 1990; Thiemermann, 1994). Moreover, urinary nitrate is significantly elevated in patients with infectious disease, which suggests a systemic increase in NO production (Wagner et al., 1984; Goede et al., 1995; Wong et al., 1995). An early phase of NO-induced hypotension and vascular hyporeactivity, independent of iNOS induction, has been described in experimental sepsis (Szabo et al., 1993), but a later involvement of iNOS in this process has been clearly established. Thus, in a rodent model of shock, dexamethasone and aminoguanidine prevent the drop in mean arterial blood pressure and $\mathrm{pO}_{2}$ and the increase in plasma glutamate-pyruvate transaminase (a marker of hepatocellular injury), urea/creatinine (markers of renal dysfunction), and nitrate (a degradation product of NO) (Kengatharan et al., 1996). Nonselective inhibition of NOS also attenuates the microvascular injury associated with the pathophysiological changes that follow Escherichia coli LPS administration in rodents (Laszlo et al., 1995). Other inhibitors of iNOS, including 1-amino-2-hydroxy-guanidine and aminoethyl-isothiourea, increase survival of animals exposed to LPS (Wu et al., 1995; Rueten et al., 1996). Mice lacking the iNOS gene are significantly more resistant to administration of LPS than are wild-type control mice; they exhibit little or no hypotensive response and their survival rate is greater (MacMicking et al., 1995; Wei et al., 1995).

Isolated vascular rings either incubated with LPS or obtained from animals subjected to 
prolonged periods of endotoxemia show a reduced contractile response to several vasoconstrictor stimuli including noradrenaline, vasopressin, angiotensin II, serotonin, histamin, and $\mathrm{KCl}$ (Parratt, 1973; Schaller et al., 1985; Fink et al., 1985; Wakabayashi et al., 1987; McKenna, 1990; Thiemermann, 1994). There is a great body of evidence to support that an excessive formation of NO due to induction of iNOS in vascular smooth muscle accounts for this vascular hyporeactivity (Fleming et al., 1990; Gray et al., 1990; Julou-Schaeffer et al., 1990; Rees et al., 1990; Thiemermann, 1994). Endotoxemia, incubation with LPS or with cytokines -such as TNF or IL-1 induce de novo biosynthesis of iNOS in vascular smooth muscle (Busse \& Mulsch, 1990; Rees et al., 1990; Thiemermann, 1994). This effect is prevented by inhibition of protein biosynthesis with cycloheximide or by the presence of dexamethasone (Busse \& Mulsch, 1990; Rees et al., 1990; Thiemermann, 1994). Expression of iNOS mRNA have been demonstrated in vascular tissues from endotoxemic rats but was absent in control animals (Weigert et al., 1995; Taguchi et al., 1996). NOS inhibitors -both nonselective and selective for iNOS- reversed the vascular hyporeactivity associated with sepsis or vascular incubation with LPS or cytokines (Fleming et al., 1990; Busse \& Mulsch, 1990; Griffiths et al., 1995a; Joly et al., 1994; 1995).

As stated above, the hemodynamic findings of sepsis in adult patients or experimental models in adult animals can be at least partially explained by iNOS induction. However the extrapolation of these findings to septic newborns or experimental models of neonatal sepsis is controversial. Sepsis in adults is characterized by two distinct hemodynamic constellations: "warm" and "cold" shock (Meadow \& Rudinsky, 1995). Warm, or hyperdynamic, shock describes a condition of increased cardiac output, reduced blood pressure, and reduced systemic vascular resistance (Breslow et al., 1987). Cold, or hypodynamic, shock describes a condition in which cardiac output is reduced, blood pressure falls and SVR is elevated markedly (Tracey et al., 1987). Because the hemodynamic disturbances noted in the warm shock phase of sepsis are consistent with excessive vasodilation, a pathological augmentation of NO production seems to be a plausible explanation (Meadow \& Rudinsky, 1995). However, in contrast to descriptions of sepsis in adults, clinical descriptions of septic newborns are uniformly characterized by cold shock (Meadow \& Rudinsky, 1995). Moreover, detailed descriptions of hemodynamic changes 
during sepsis in neonatal animal models consistently describe reduced cardiac output and elevated systemic and PVR (Meadow \& Meus, 1986; Runkle et al., 1984; Truog et al., 1986; Philips et al, 1988). This constellation of hemodynamic findings does not square with an overproduction of vasodilators. However, it has been demonstrated increased nitrite and nitrate levels in the urine of septic newborns, supporting $\mathrm{NO}$ as a potential mediator of the cardiovascular responses observed in these neonates (Shi et al, 1993). Moreover, methylene blue, a sGC inhibitor, has been shown to increase blood pressure in neonates with hypotension, presumably secondary to infection, unresponsive to colloids, inotropic agents and corticosteroids (Driscoll et al., 1996). In fact, in neonates with early-onset GBS sepsis, the development of hypotension is one of the most sensitive predictors of mortality (Cabal et al., 1990; Hocker et al., 1992).

\section{III.4 Coexistence during sepsis of elevated pulmonary vascular NO production and pulmonary hypertension.}

Investigators have long recognized that sepsis is characterized by maldistribution of blood flow that is different between different vascular beds (Lang et al., 1984). The most obvious changes are pulmonary hypertension coupled with systemic hypotension. This dichotomous response may be due to a different sensitivity of the pulmonary and systemic vessels to the vasoactive factors released in sepsis. These factors include, among others, the vasoconstrictors TXA $\mathrm{T}_{2}$ and ET-1 (see above), and the vasodilator NO that are produced in large amounts during systemic inflammatory response.

Exhaled NO concentration increases significantly in humans and animals with sepsis, but neither the source nor NOS isoforms responsible for this rise in pulmonary NO production are clear (Stewart et al., 1995; Hussain et al., 1996; Stitt et al., 1997; Fujii et al.,1998; Fischer et al., 1999). Fujii et al. (1998) demonstrated in pigs, a rise in exhaled NO concentration in the extrathoracic compartment (i.e. upper airways, nasal and paranasal) after 45 minutes of LPS injection. Exhaled NO in the intrathoracic compartment (i.e. bronchi, 
bronchioles and alveoli) also rose significantly but after 90 minutes of endotoxin infusion. However, this rise in exhaled NO was accompanied by an increase in $\mathrm{Ca}^{2+}$-dependent but not in $\mathrm{Ca}^{2+}$-independent NOS activity in the lung. Moreover, LPS injection elicited no significant alterations in the pulmonary expression of iNOS in dogs (Hussain et al., 1996) and pigs (Fuji et al., 1998; Mehta et al., 1999). In contrast, protein and mRNA expression of iNOS was significantly enhanced in rat pulmonary artery (Griffiths et al., 1995b) and rat lung after LPS injection (Kobzik et al., 1993; Carraway et al., 1998; Wang et al., 1999). Moreover, increased expression of iNOS has been described in alveolar macrophages of septic patients (Kobayashi et al., 1998).

In vitro studies demonstrated that iNOS mRNA is induced in rat pulmonary artery smooth muscle and endothelium when cultured cells are stimulated by a combination of cytokines and LPS (Nakayama et al., 1992; Geiger et al., 1997). Induction of iNOS and decreased responses to pressor agents have been reported after in vitro incubation of pulmonary arteries from piglets (present thesis) or adult rats (Griffiths et al., 1993; Zelenkov et al., 1993) with LPS or GBS. Griffiths et al. (1995b) reported the presence of iNOS mRNA in the pulmonary artery after in vivo LPS, which was associated with hypocontractility to $\mathrm{KCl}$ and phenylephrine. Li \& McKenna (1996) showed that vascular reactivity was significantly depressed in lungs from septic rats in comparison to sham-operated controls, and that pretreatment with the NOS inhibitor L-NAME restored the depressed vasoreactivity. In contrast, other investigators found no effect of LPS on pulmonary vascular contractility in rats (Pulido et al., 2000) sheep (Nelson et al., 1991) or pigs (Suba et al., 1992). The explanation for these differences remains unknown, but it has been pointed out the vasomotor effects of iNOS-produced NO may vary, depending on the local NO tissue concentration, the specific mechanisms producing vasoconstriction, and the type of vessel (conductance or resistance) (Stoclet et al., 1998; Pulido et al., 2000). In the pulmonary circulation, the contractile and pharmacological response of large and small arteries are not identical and the vascular reactivity depends on the agonist employed (Zellers Vanhoutte 1989; Leach et al., 1992; Kemp et al., 1997; Gao et al., 1998). Similar differences are present in the systemic circulation. Although the LPS-induced increase in vascular iNOS and subsequent marked hyporeactivity 
has been well characterized in large systemic elastic arteries, other investigators (Mitchell et al., 1993; Schneider et al., 1994) failed to find significant vascular dysfunction in smaller resistance arteries, despite a measured increase in iNOS activity. Kleschyov et al. (1998) implicated the adventitia as an important source of NO, and the relatively greater amounts of adventitial cells in the large conductance vessels, versus the smaller resistance arteries, may explain these divergent findings (Pulido et al., 2000). However, iNOS protein was expressed in lung tissues from septic rats mainly in the resistance vessels ( $\mathrm{Li} \&$ McKenna, 1996). The possible role of these factors in the vascular responsiveness of pulmonary vessels from septic animals requires further investigations.

The coexistence of pulmonary hypertension and systemic hypotension in septic shock presents particular problems in elation to potential therapeutic approaches. The evidence that excessive NO synthesis within the vasculature is one of the primary mechanisms causing the hemodynamic manifestations of septic shock, including the pathological systemic vasodilation and diminished response to vasoconstrictors (see above), led to the use of NOS inhibitors to treat this condition. Studies using adult animal models of septic shock reported restoration in the balance of systemic vasomotor tone and reduction in mortality for animals treated, after the onset of shock, with NOS inhibitors (Kilbourn et al., 1990a; 1990b; Meyer et al., 1994; Rees et al., 1995). However, NOS inhibitors have been also reported to produce serious and even lethal side effects in some animal models, presumably as a result of blocking the adaptive consequences of increased NO synthesis during inflammation (Cobb, 1999). These adaptive consequences may include maintenance of microvascular blood flow, inhibition of platelet agglutination and leukocyte adhesion, nonspecific immunity, and inhibition of stress-induced endothelial cell apoptosis (Cobb \& Danner, 1996; DeMeester et al., 1998; Cobb, 1999; Galley et al., 1999).

In fact, trials of NOS inhibitors in adult sepsis were stopped recently following safety reports, which demonstrated increased mortality rates in patients who received these drugs (Kilbourn, 1999). The seemingly positive effects reported, such as increased systemic vascular resistance and decreased requirements of vasoactive drugs, appeared to be offset by the 
negative effects, such as decreased cardiac output, increased pulmonary hypertension and potential myocardial ischemia (Avontuur et al., 1998a; 1998b; Cobb, 1999). The cause of the progressive cardiac dysfunction produced by NO inhibition during sepsis may be multifactorial, including 1) coronary artery vasoconstriction with myocardial ischemia and reduced contractility; 2) reduced endocardial cell production of NO with potential decreased myocardial performance, and 3) increased cardiac afterload with the acute increase in PVR and SVR (Gibson et al; 1994; Cohen et al., 1998). The decrease in cardiac output, after NOS inhibition, due to increased right ventricular afterload related to a worsening in pulmonary hypertension seems to be particularly relevant in animal models of neonatal sepsis. Piglets treated with a NOS inhibitor before GBS infusion demonstrated a more rapid and profound pulmonary hypertensive response to the bacteria (Barrington et al., 2000). This suggests that GBS-induced pulmonary hypertension is usually diminished by endogenous NO production. Thus, pulmonary hypertension resulting from GBS infusion is much worse if endogenous NO production is completely inhibited (Gibson et al., 1994; Meadow et al., 1995; Barrington et al., 2000). In addition, when inhaled NO is used to reverse pulmonary hypertension in experimental sepsis, fall in cardiac output was significantly delayed and survival was improved (Klemm et al., 1995; Barrington et al., 2000).

Therefore,whether lung iNOS induction exerts a positive or a detrimental effect during sepsis is controversial. Mice deficient in the iNOS gene are more resistant to LPS induced acute lung injury than corresponding wild-type mice (Kristof et al., 1998). In contrast, Aikio et al (2000), demonstrated a diminished pulmonary iNOS expression in fulminant early-onset neonatal pneumonia, suggesting that delayed production rather than excess of pulmonary inflammatory NO was associated with severe symptoms. 
Chapter IV. Treatment of PPHN. In search of a selective pulmonary vasodilator.

\section{IV.1 Intravenous pulmonary vasodilators.}

Part of the challenge in finding an effective strategy for the treatment of PPHN is that vasodilators that decrease pulmonary vascular resistance also decrease the vascular resistance of the systemic bed. Since the magnitude of the shunt depends on the difference between pulmonary artery and aortic pressure, systemic vasodilation would increase the flow across the ductus reducing the blood supply to the lung and worsening the pulmonary gas exchange. Therefore, the ideal drug for the treatment of PPHN should be a vasodilator with selectivity for pulmonary over systemic vessels (Drummond and Lock 1984; Roberts and Shaul 1993). The term selective applied to a vasodilator from the pulmonary vasculature has two meanings, each with a different pathophysiological and therapeutical implication. The term macroselectivity has been used to distinguish the effects of a vasodilator drug on the pulmonary vasculature as opposed to the systemic vasculature, as measured by the pulmonary/systemic pressure or resistance ratio (Nelin \& Hoffman, 1998). The term microselective has been used to distinguish the effects of a vasodilator drug on the distribution of perfusion within the lung. Most intravenous vasodilator drugs have resulted in worsening of ventilation/perfusion matching by disruption of HPV. Thus, the property of microselectivity is important to maintain or enhance intrapulmonary gas exchange (Nelin \& Hoffman, 1998).

As Truog pointed out (1998), from the original description of Gersony et al. (1969) of the syndrome of "persistent fetal circulation" -now PPHN- investigators have sought the "Holy Grail" of an agent capable of selective reduction of PVR without affecting systemic vascular resistance. Various intravenous vasodilators including the $\alpha$-adrenoceptor blocker tolazoline (Stevenson et al., 1979; Ward, 1984; Gouyon and Francoise, 1992; Bos et al., 1993), PGI 2 (Bos et al., 1993), PGE 1 (Gouyon \& Francoise, 1992), the calcium channel blocker nifedipine (Simonneau et al., 1981), $\mathrm{MgSO}_{4}$ (Abu-Osba et al., 1992; Tolsa et al., 1995), acetylcholine (Tripp et al., 1980), the NO donor sodium nitroprusside (Benitz et al., 1985) and ATP (Fineman 
et al., 1990; Konduri \& Woodard, 1991) have been used to reduce the increased pulmonary vascular resistance in experimental models or in patients with PPHN (Drummond \&Lock, 1984; Kulik \& Lock, 1984; Gouyon \& Francoise; 1992; Roberts \& Shaul, 1993). However, until now there is no clinically evaluated intravenous selective pulmonary vasodilator (Finer \& Barrington, 2000).

IV.2 Selective pulmonary vasodilation through inhalation of NO. From the laboratory to the clinical experience

The discovery of EDRF, and its subsequent identification as NO, a volatile gas susceptible to be administered by inhalation, dramatically changed the search of a specific pulmonary vasodilator and has led to novel therapeutic approaches in the management of PPHN. The first laboratory reports about the pulmonary selectivity of inhaled NO (Frostell et al., 1991; Fratacci et al., 1991) were confirmed in fetal and neonatal animals and in experimental models of PPHN (Kinsella et al., 1992a; Roberts et al., 1993; Zayek et al., 1993). In aduit patients with pulmonary hypertension, Pepke-Zaba et al (1991) showed that inhaled NO at $40 \mathrm{ppm}$ had a beneficial effect in reducing PVR with no change SVR. Two clinical reports in newborn patients appeared in 1992. One demonstrated that inhaled NO improved saturation in patients with PPHN (Roberts et al., 1992), and the other demonstrated that the clinical improvement seen with inhaled NO in patients with PPHN was sustained (Kinsella et al., 1992b). After the publication of these and others pilot studies several randomized, controlled trials were conducted to evaluate the efficacy of inhaled NO in PPHN (table 2).

The systematic review from Finner and Barrington (2000) for the Cochrane Collaboration include, until the present moment, the following trials: Barefield et al., 1996; Day et al., 1996; Neonatal Inhaled Nitric Oxide Study Group, 1997a; 1997b; Roberts et al., 1997b; Wessel et al., 1997; Kinsella et al., 1997a; and Davidson et al. 1998. This meta-analysis provides evidence about $\mathrm{PaO}_{2}$ improvement in the inhaled $\mathrm{NO}$ treated infants by $46.4 \mathrm{mmHg}$ (weighted mean difference) compared with controls (95\% CI, 34.2, 58.5), and a significant decrease in the 
oxygenation index by 10.7 ( $95 \% \mathrm{CI},-14.1,-7.4)$. The use of inhaled NO reduced the requirement for ECMO, overall, by $15 \%$ (Risk Difference $-14.8 \%, 95 \%$ CI $-23.0 \%,-6.6 \%$ ). Thus, the number of infants needed to be treated with inhaled NO in order to expect to prevent one infant requiring ECMO would be 6.8 (95\% CI 4.3, 15.2). Mortality was not reduced, relative risk for death was 1.03 ( $95 \% \mathrm{CI} 0.62,1.72)$. The combined incidence of death or need for ECMO was significantly reduced by treatment with inhaled NO, relative risk 0.72 compared to control $(95 \% \mathrm{CI}, 0.6,0.87)$ with the majority of the improvement seen in the reduction in the need for ECMO. Therefore, according to this meta-analysis, inhaled NO appears to improve outcome in hypoxemic term and near term infants by reducing the incidence of ECMO and of the combined endpoint of death or need for ECMO. This reduction seems to be entirely a reduction in need for ECMO. The outcome of infants with diaphragmatic hernia was not improved and even, there is a suggestion that was slightly worsened. They conclude that "on the evidence presently available, it appears reasonable to use inhaled nitric oxide in a concentration of $20 \mathrm{ppm}$ for term and near term infants with hypoxic respiratory failure who do not have a diaphragmatic hernia" (Finer \& Barrington, 2000).

Little information is available about long-term neurodevelopmental and pulmonary follow-up of infants treated with inhaled NO. In a 1- to 2-yr follow-up study of children who received inhaled NO treatment for PPHN, neurodevelopment scores, growth rates (growth percentiles for weight, length, and occipitofrontal circumference), the frequency of airway disease, and the need for supplemental oxygen were comparable to conventionally ventilated or ECMO-treated patients (Rosenberg et al., 1997). More recently, the results of the neurodevelopmental follow-up of infants enrolled in the NINOS trial have been reported, showing that inhaled NO was not associated with an increase in neurodevelopmental, behavioral, or medical abnormalities at two years of age (Neonatal Inhaled Nitric Oxide Study Group, 2000). 
Table 2. Randomized controlled trials of inhaled NO in term and near term (>34 weeks) newborns with PPHN or hypoxic respiratory failure.

\begin{tabular}{|c|c|c|c|c|}
\hline Reference & $\begin{array}{l}\text { No. } \\
\text { Pat. }\end{array}$ & $\begin{array}{l}\text { Inclusion } \\
\text { Criteria }\end{array}$ & $\begin{array}{l}\text { Treatment } \\
\text { Protocol }\end{array}$ & Outcome \\
\hline $\begin{array}{l}\text { Day et al., } \\
1996\end{array}$ & 22 & $\begin{array}{l}25<\mathrm{OI}<40 \\
\text { Echocardiographic } \\
\text { evidence of PPHN }\end{array}$ & $\begin{array}{l}20 \text { ppm NO vs. } \\
\text { control. If control } \\
\text { deteriorated } \\
(\mathrm{OI}>40) \text { use of } \\
\text { NO allowed. }\end{array}$ & $\begin{array}{l}\text { After } 30-60 \text { minutes of therapy OI } \\
\text { was } 17.5 \text { (SD 10.6) in the NO group } \\
\text { and } 32.6 \text { (SD 13.3) in controls, } \\
\text { Weighted Mean Difference }-15.1 \\
(95 \% \text { CI }-25.14,-5.06)\end{array}$ \\
\hline $\begin{array}{l}\text { Barefield et } \\
\text { al., } 1996\end{array}$ & 17 & $\begin{array}{l}\mathrm{PaO}_{2}<100 \text { mmHg on } \\
\mathrm{FIO}_{2}=1 \text { on ventilator } \\
(16 \text { patients had } \\
\text { echocardiographic } \\
\text { evidence of PPHN) }\end{array}$ & $\begin{array}{l}\mathrm{NO} \text { at } 20 \text { to } 40 \\
\text { ppm increased to } \\
80 \text { if } \mathrm{PaO}_{2} \text { stayed } \\
<100 \text {. Backup use } \\
\text { of inhaled NO } \\
\text { allowed in case of } \\
\text { failure of control } \\
\text { treatment. }\end{array}$ & $\begin{array}{l}\text { No differences between groups in } \\
\text { primary outcome variables (treatment } \\
\text { failure and meeting of ECMO } \\
\text { criteria). } \\
\text { After } 30-60 \text { minutes of therapy OI } \\
\text { was } 23 \text { (SD 18.2) in the NO group and } \\
38 \text { (SD 15.6) in controls. Weighted } \\
\text { Mean Difference - } 15.0 \text { ( } 95 \% \text { CI - } \\
32.76,2.76 \text { ) }\end{array}$ \\
\hline $\begin{array}{l}\text { Roberts et al., } \\
1997 \mathrm{~b}\end{array}$ & 58 & $\begin{array}{l}\text { PPHN (by echo) } \\
\mathrm{PaO}_{2}<55 \text { mmHg on } 2 \\
\text { consecutive } \\
\text { Measurements }\end{array}$ & $\begin{array}{l}80 \text { ppm } \mathrm{NO} \text { at } \mathrm{FlO}_{2} \\
0.9 \text { vs. } \mathrm{FIO}_{2}=0.9 \\
\text { (control) }\end{array}$ & $\begin{array}{l}\text { Responders: } 53 \% \text { in NO } \\
\text { group; } 7 \% \text { in control group. } \\
\text { Need for ECMO: } 40 \% \text { NO group; } \\
70 \% \text { control group }(P=0.02) \text {. } \\
\text { Survival: similar in NO and control } \\
\text { groups. }\end{array}$ \\
\hline $\begin{array}{l}\text { Neonatal } \\
\text { Inhaled NO } \\
\text { Study Group } \\
\text { (NINOS), } \\
1997 \text { a }\end{array}$ & 235 & $\begin{array}{l}\text { Hypoxic respiratory } \\
\text { failure or PPHN } \\
\text { requiring mechanical } \\
\text { ventilation; OI }>25 \text { ( } 2 \\
\text { consecutive) }\end{array}$ & $\begin{array}{l}20 \mathrm{ppm} \mathrm{NO} \text {, trial at } \\
80 \mathrm{ppm} \text { if no } \\
\text { response to } 20 \text {, vs. } \\
\text { control }\left(\mathrm{FIO}_{2}=1\right)\end{array}$ & $\begin{array}{l}\text { Responders: } 51 \% 20 \text { ppm NO; } 15 \% \\
\text { control. } \\
\text { Need for ECMO: } 39 \% \text { NO group: } \\
55 \% \text { control group (P=0.014). } \\
\text { Survival: } 86 \% \text { NO group; } 84 \% \text { control }\end{array}$ \\
\hline $\begin{array}{l}\text { Neonatal } \\
\text { Inhaled NO } \\
\text { Study Group } \\
\text { (NINOS). } \\
1997 \mathrm{~b}\end{array}$ & 53 & $\begin{array}{l}\text { Congenital } \\
\text { diaphragmatic hernia } \\
\text { (PPHN in } 51 \text { of } 53 \\
\text { patients) } \\
\text { OI }>25 \text { ( } 2 \text { consecutive) }\end{array}$ & $\begin{array}{l}20 \mathrm{ppm} \mathrm{NO} \text {, trial at } \\
80 \mathrm{ppm} \text { if no } \\
\text { response to } 20 \mathrm{vs} \text {. } \\
\text { control }\left(\mathrm{FIO}_{2}=1\right) .\end{array}$ & $\begin{array}{l}\text { Responders: } 48 \% 20 \text { ppm NO; } 19 \% \\
\text { control. } \\
\text { Need for ECMO: } 80 \% \text { NO group; } \\
54 \% \text { control group (P=0.043). } \\
\text { Survival: } 52 \% \text { NO group; } 57 \% \\
\text { control. }\end{array}$ \\
\hline $\begin{array}{l}\text { Wessel et al., } \\
1997\end{array}$ & 49 & $\begin{array}{l}\mathrm{PaO}_{2}<100 \mathrm{~mm} \mathrm{Hg} \\
\text { during mechanical } \\
\text { ventilation on } \mathrm{FIO}_{2}=1 \\
\text { Echocardiographic } \\
\text { evidence of PPHN }\end{array}$ & $\begin{array}{l}80 \mathrm{ppm} \text { NO, } \\
\text { reduced to } 40 \mathrm{ppm} \\
\text { after } 1 \mathrm{~h} \\
\text { vs. control }\end{array}$ & $\begin{array}{l}\text { Responders: } 57 \% \mathrm{NO} \text { group. } \\
\text { Improvement in } \mathrm{PaO}_{2}, \mathrm{O}_{2} \text { saturation, } \\
\text { and } \mathrm{OI} \text { in the } \mathrm{NO} \text { group at } 15 \text { min. } \\
\text { and } 12 \mathrm{~h} \text {. } \\
\text { No differences in mortality ( } 8 \%) \text {, use } \\
\text { of ECMO ( } 33 \%) \text {, days on mechanical } \\
\text { ventilation or supplemental } \mathrm{O}_{2} \text {. }\end{array}$ \\
\hline $\begin{array}{l}\text { Kinsella et } \\
\text { al., 1997a }\end{array}$ & 205 & $\begin{array}{l}\text { PPHN (by echo) } \\
\mathrm{PaO}_{2}<80 \mathrm{mmHg} \text { at } \\
\mathrm{FIO}_{2}=1\end{array}$ & $\begin{array}{l}\text { NO }(20,40 \mathrm{ppm}) \\
\text { vs. } \\
\text { HFOV,crossover } \\
\text { and combination }\end{array}$ & $\begin{array}{l}\text { Overall response rate } 60 \% \text {. } \\
\text { All responders survived. } \\
72 \% \text { of non responders treated with } \\
\text { ECMO survived. Overall survival } \\
86 \%\end{array}$ \\
\hline
\end{tabular}




\begin{tabular}{|c|c|c|c|c|}
\hline Reference & $\begin{array}{l}\text { No. } \\
\text { Pat. }\end{array}$ & $\begin{array}{l}\text { Inclusion } \\
\text { Criteria }\end{array}$ & $\begin{array}{l}\text { Treatment } \\
\text { Protocol }\end{array}$ & Outcome \\
\hline $\begin{array}{l}\text { Davidson et } \\
\text { al., } 1998\end{array}$ & 155 & $\begin{array}{l}\mathrm{FIO}_{2}=1 \text { and } \mathrm{MAP} \geq 10 \\
\mathrm{~cm} \mathrm{H} 2 \mathrm{O}, \mathrm{PaO}_{2} \\
\text { between } 40 \text { and } 100 \\
\text { mmHg } \\
\text { PPHN (by echo) or } \\
\text { preductal-postductal } \\
\text { saturation }>10 \%\end{array}$ & $\begin{array}{l}\text { NO at doses of } 0 \text {, } \\
5,20 \text { or } 80 \mathrm{ppm} \\
\text { Sequential } 20 \% \\
\text { decrements. }\end{array}$ & $\begin{array}{l}\text { Survival: } 92 \% \text { NO group; } 98 \% \text { control } \\
(P=0.22) \text {. } \\
\text { Need for ECMO: } 22 \% \text { NO group; } \\
34 \% \text { control ( } P=0.12) \text {. } \\
\text { BPD: } 13 \% \text { NO group; } 15 \% \text { control. }\end{array}$ \\
\hline $\begin{array}{l}\text { Cornfield et } \\
\text { al., } 1999\end{array}$ & 38 & $\begin{array}{l}\text { OI } \geq 25 \text { on } 2 \\
\text { consecutive blood } \\
\text { gases } 60 \text { minutes apart } \\
\text { Echocardiographic } \\
\text { evidence of PPHN }\end{array}$ & $\begin{array}{l}\text { NO } 2 \text { ppm vs. } \\
\text { control } \\
\text { Patients (from both } \\
\text { groups) with an OI } \\
\geq 35 \text { for }>1 \text { hour } \\
\text { treated with NO at } \\
20 \text { ppm }\end{array}$ & $\begin{array}{l}\text { Treatment with } \mathrm{NO} \text { at } 2 \mathrm{ppm} \text { did not } \\
\text { induce any detectable acute effect in } \\
\text { oxygenation } \\
\text { NO at } 20 \mathrm{ppm} \text { acutely improves } \\
\text { oxygenation in infants initially treated } \\
\text { with } 0 \mathrm{ppm} \text {, but not in infants } \\
\text { previously treated with } 2 \mathrm{ppm}\end{array}$ \\
\hline $\begin{array}{l}\text { Clark et al, } \\
2000\end{array}$ & 248 & $\begin{array}{l}\text { Clinical or } \\
\text { echocardiografic } \\
\text { evidence of PPHN } \\
\mathrm{OI}>25 \text {. In addition, } \\
\mathrm{pH}>7.55 \text { to maintain } \\
\mathrm{PaO}_{2}>60 \mathrm{mmHg}^{2}\end{array}$ & $\begin{array}{l}20 \mathrm{ppm} \text { NO for } \\
\text { max. } 24 \mathrm{~h} \text { followed } \\
\text { by } 5 \mathrm{ppm} \text { for max. } \\
96 \mathrm{~h} \text {. } \\
\text { Control group } \\
\text { received nitrogen }\end{array}$ & $\begin{array}{l}\text { Need for ECMO: } 38 \% \text { NO group; } \\
64 \% \text { control }(P=0.001) \\
\text { Survival: similar } \\
\text { Chronic lung disease: } \\
7 \% \text { in NO group; } 20 \% \text { control group } \\
(P=0.02)\end{array}$ \\
\hline $\begin{array}{l}\text { Christou et } \\
\text { al., } 2000\end{array}$ & 41 & $\begin{array}{l}\text { Clinical or } \\
\text { echocardiografic } \\
\text { evidence of } \mathrm{PPHN} \text { and } \\
\text { hypoxemia }\left(\mathrm{PaO}_{2} \leq 100\right. \\
\left.\text { mm } \mathrm{Hg} \text { on } \mathrm{FIO}_{2}=1\right)\end{array}$ & $\begin{array}{l}\text { NO initiated at } 40 \\
\text { ppm. Decreased to } \\
20 \mathrm{ppm} \text { after } 1 \mathrm{~h} \text {. } \\
\text { Dose response test } \\
\text { daily to determine } \\
\text { the lowest } \\
\text { acceptable dose of } \\
\text { NO }\end{array}$ & $\begin{array}{l}\text { Need for ECMO: } 14 \% \text { NO group; } \\
55 \% \text { control }(P=0.007) \\
\text { Survival: similar }\end{array}$ \\
\hline
\end{tabular}

\section{Toxicity of inhaled NO}

The primary observed toxic effect of NO is formation of methemoglobin (Toothill, 1967; Kinsella et al., 1993; Young \& Dyar, 1996; Phillips et al., 1999). Methemoglobin is formed when NO, which has an affinity for hemoglobin nearly 1000000 times that of oxygen, combines with the heme group of hemoglobin. Methemoglobin formation prevents oxygen from being transported to the tissues of the body (Phillips et al., 1999). It has been reported that among adult patients receiving NO therapy, the fraction of hemoglobin converted to methemoglobin typically does not exceed 5\% (Young \& Dyar, 1996). Moreover, in the 
neonatal multicenter study of Davidson et al. (1998) methemoglobinemia, defined as $>7 \%$ methemoglobin, was seen in 13 of 37 patients administered NO at the 80-ppm level, but was not seen in the groups of 41 and 36 patients administered 5-ppm NO and 20-ppm NO, respectively.

A second potential hazard of $\mathrm{NO}$ is its conversion, in the presence of oxygen, to nitrogen dioxide $\left(\mathrm{NO}_{2}\right)$, a brownish gas that is a potent pulmonary irritant (Young \& Dyar, 1996; Mercier et al., 1993). Because $\mathrm{NO}$ always exists in equilibrium with $\mathrm{NO}_{2}$ in air, mixed $\mathrm{NO}$ and $\mathrm{NO}_{2}$ are often referred to collectively as nitrogen oxides or NOx. The conversion of NO to $\mathrm{NO}_{2}$ can be quite slow (Bouchet et al., 1993; Phillips et al., 1999): in a 20-ppm mixture of $\mathrm{NO}$ in air, only approximately 1- to 3-ppm $\mathrm{NO}_{2}$ would be generated in 10 minutes. However, because the rate of $\mathrm{NO}_{2}$ formation is proportional to the oxygen concentration and to the square of the $\mathrm{NO}$ concentration, $\mathrm{NO}_{2}$ is formed more rapidly in oxygen enriched atmospheres, such as those found in a patient ventilation circuit, or at higher concentrations of NO. It may take less than one minute for 1-ppm $\mathrm{NO}_{2}$ to be generated from a 20 -ppm mixture of $\mathrm{NO}$ in $95 \%$ oxygen at $100 \%$ relative humidity (Bouchet et al., 1993). Effects of human exposure to various levels of $\mathrm{NO}_{2}$ have been reported; these include increased flow resistance of the airway after 10-minute exposure at 0.7 to $2 \mathrm{ppm}$, mild irritation of the eyes, nose, and upper respiratory tract at 10 to $20 \mathrm{ppm}$, respiratory irritation and chest pain after 60 -minute exposure at $25 \mathrm{ppm}$, and pulmonary edema and death after 60-minute accidental exposure at 100 ppm (Phillips et al., 1999). In neonatal patients, Davidson et al. (1998) observed $\mathrm{NO}_{2}$ concentrations higher than 3 ppm only after treatment with 80 -ppm but not with 5-ppm or 20 ppm NO.

Additionally, several concerns have been made about the exposure to NO in the caregivers of the intensive care units (Markhorst et al., 1996; Mourgeon et al., 1997). During earlier clinical NO trials, the expiratory gas was vacuum scavenged to prevent release of NO into the room air (Roberts et al., 1993). However, this practice had been discontinued and currently the expiratory limb of the ventilator is vented to the room. In spite of this fact, Phillips et al. (1999) have demonstrated that exposure of the caregivers to detectable levels of 
$\mathrm{NO}$ and $\mathrm{NO}_{2}$ in room air was brief, infrequent, and well below established limits.

Part of the concerns about NO toxicity relates to it being a free radical. The biological chemistry of $\mathrm{NO}$ as a free radical can be simplified to three main reactions (Figure 5) (Beckman \& Koppenol, 1996): (1) its activation of sGC responsible for signal transduction; (2) its elimination by oxyhemoglobin to form nitrate and methemoglobin; and (3) its reaction with superoxide to form the binary peroxynitrite. NO and superoxide readily react to form peroxynitrite at nearly a diffusion-limited rate (Beckman \& Koppenol, 1996). Under physiological conditions, this reaction is limited by the intracellular micromolar concentrations of superoxide dismutase (SOD) that scavenge endogenous superoxide. However, when the concentration of NO is increased (i.e. by the use of inhaled NO or by pathological conditions as sepsis) and approaches that of SOD, or in the presence of increased superoxide concentrations, or after superoxide scavengers are exhausted, significant concentrations of peroxynitrite may be produced (Beckman \& Koppenol, 1996). Peroxynitrite directly causes oxidation, peroxidation, and nitration of lipids, proteins, or DNA (Szabo, 1996a; 1996b; Steudel et al., 1999). Peroxynitrite can cause cell apoptosis by DNA strand breakage, activation of poly-adenosine-diphosphate-ribosyltransferase and by inhibition of mitochondrial respiratory enzymes (Steudel et al., 1999). An important example of a reaction caused by peroxynitrite is the nitration of tyrosine. Tyrosine nitration inhibits tyrosine phosphorylation, alters the dynamics of assembly and disassembly of cytoskeletal proteins, and inhibits tyrosine hydroxylase, thereby reducing dopamine production by neurons and inhibiting cytoskeletal movements of endothelial cells (Szabo, 1996a; Steudel et al., 1999). Nitrotyrosine has been detected in lung tissue sections from adult patients with lung injury (Haddad et al., 1994a; Kooy et al., 1995). Plasma 3-nitrotyrosine content is increased during the first month of life in infants who develop bronchopulmonary dysplasia, a chronic lung disease of infancy that appears to be caused in part by oxidative stress from hyperoxia (Banks et al., 1998). This suggests that peroxynitrite-mediated oxidant stress may contribute to the development of lung injury in premature infants. In contrast, in newborns treated with inhaled NO, no evidence was found of either nitrotyrosine production or of increase in lipid peroxidation, suggesting lack of toxicity produced by peroxynitrite (Hallman et al., 1998). Additionally, no evidence was found 
in these patients of NO-related increased concentration of proinflamatory or anti-inflammatory cytokines (Hallman et al., 1998). Moreover, in preterm lambs delivered at $78 \%$ of term, 5 ppm NO increased pulmonary blood flow and improved gas exchange without increasing pulmonary edema and decreased accumulation of lung neutrophils (Kinsella et al., 1997b). Lambs delivered at $90 \%$ of gestation and mechanically ventilated for 5 hours with $20 \mathrm{ppm}$ NO showed no evidence of lung oxidative stress injury (Storme et al., 1998) and newborn lambs subjected to GBS sepsis and up to $60 \mathrm{ppm}$ NO showed no changes in pulmonary antioxidative capacity or lipid peroxidation (Lopes-Cardozo et al., 1996). It has been demonstrated, in animal models, that inhaled NO, when administered in combination with hyperoxic gas mixtures, protected against the injurious consequences of prolonged hyperoxia, such as inflammation and apoptosis (Gutierrez et al., 1996; McElroy et al., 1997; Nelin et al., 1998; Howlett et al., 1999). However this point remains controversial. Ekekezie et al. (2000) have found, in young piglets, that the combination of NO and oxygen exposure produced an increase in lung apoptosis and that NO may prevent upregulation of SOD and catalase activity during hyperoxia, potentially increasing oxidative injury. In addition, recombinant human SOD mitigated the inflammatory changes, oxidative damage, and acute lung injury from exposure to 100 ppm NO and 90\% O2 in newborn piglets (Robbins et al., 1997). Finally, hyperoxic exposure of rat pups up-regulated both iNOS and eNOS, suggesting that increased generation of endogenous NO may contribute to the pathogenesis of hyperoxia-induced lung damage (Radomski et al., 1998; Potter et al., 1999).

Another point of concern about the NO/peroxynitrite toxicity is its possible effect on the surfactant system (Robbins et al., 1995; Steudel et al., 1999). Peroxynitrite exposure impaired pulmonary surfactant function, because of peroxidation of surfactant lipids, and decreased the ability of the major hydrophilic surfactant, protein $\mathrm{A}$, to aggregate lipids and act synergistically with other surfactant proteins to reduce the minimum surface tension (Haddad et al., 1994b; Hallman \& Bry, 1996). These changes of surfactant protein A were associated with nitrotyrosine formation (Haddad et al., 1993). Besides peroxynitrite, methemoglobin and $\mathrm{NO}_{2}$ deteriorate surfactant activity in vitro (Haddad et al., 1993; Hallman et al., 1996a; 1996b) Recombinant human SOD did not appear to reduce the impairment in surfactant function 
produced by the combination of high doses of NO $(100 \mathrm{ppm})$ and hyperoxia in newborn piglets (Robbins et al., 1995). However, no decrease in surfactant activity have been observed in PPHN patients treated with NO (Hallman et al., 1998) and even 14-ppm of inhaled NO prevented the hyperoxia-induced detrimental effects on alveolar surfactant (Issa et al., 1999).

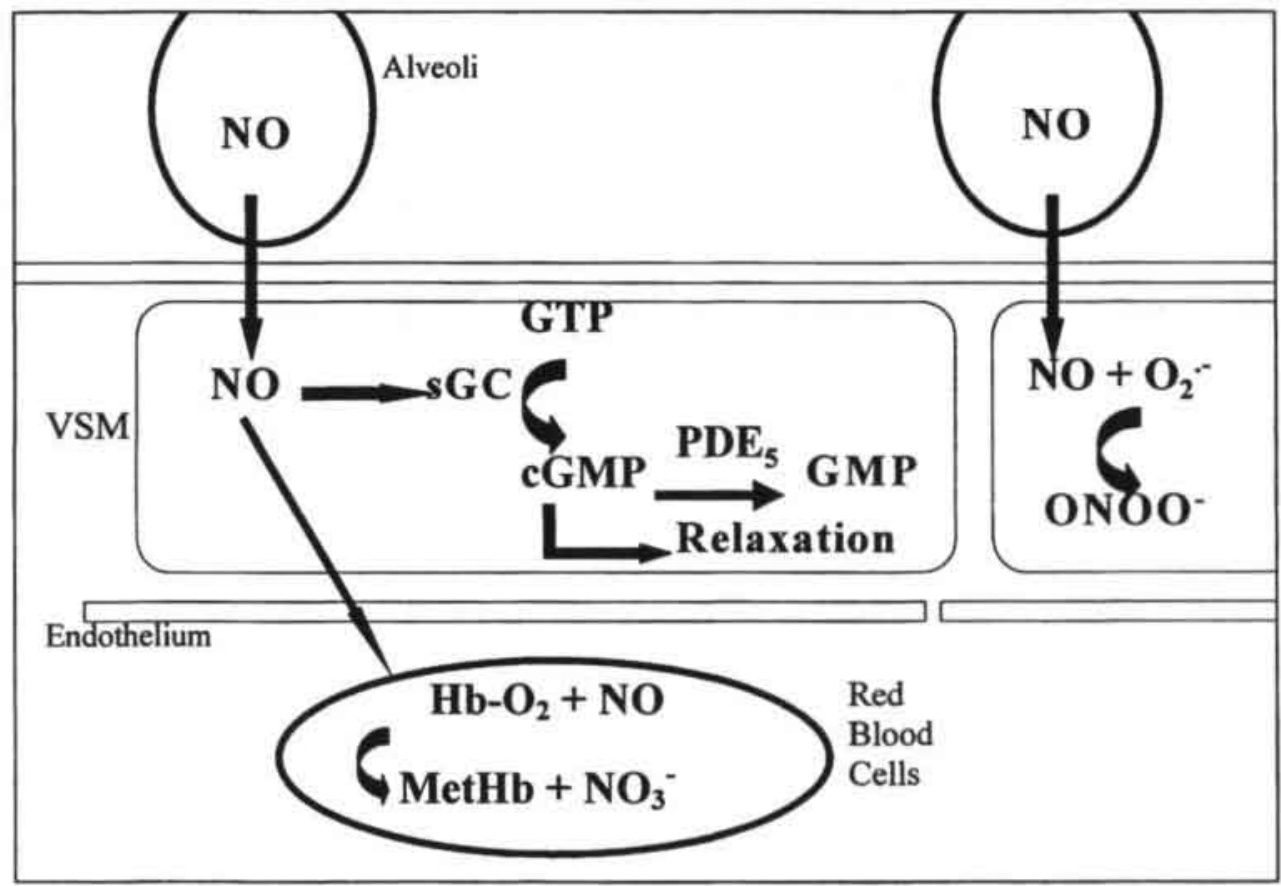

Figure 5. NO as a free radical

\section{Lack of response to inhaled $N O$}

Approximately $40-50 \%$ of the infants assigned to NO in randomized controlled trials failed to respond (Finer \& Barrington, 2000). This is particularly notable because response was defined as a relatively modest increase in arterial oxygen tension (Truog, 1998). Several 
mechanisms may explain clinical variability in responsiveness to inhaled NO therapy including: (i) the inability to deliver NO to the pulmonary circulation due to poor lung inflation that may cause intrapulmonary shunting and hypoxemia that is not reversed by vasodilators (Kinsella \& Abman, 1995; Roberts et al., 1997b); (ii) the presence of myocardial dysfunction or systemic hypotension that increase the right-left shunt and elevate pulmonary wedge pressures (Kinsella \& Abman, 1995; Roberts et al., 1997a); (iii) the presence of missed anatomical cardiovascular or pulmonary lesions such as total anomalous venous return, coarctation of the aorta, lung hypoplasia or alveolar capillary dysplasia (Roberts et al., 1997a; Steinhorn et al., 1997b); (iv) the inflammation of the airways due to pneumonia or aspiration of meconium that may reduce the diffusion of NO (Roberts et al., 1997b; (v) the excess of vasoconstrictive agents, such as $\mathrm{TXA}_{2}$ or ET-1, that might limit the vasodilatory action of inhaled NO (Cristhou et al., 1997; Truog et al., 1998) ; (vi) the use of an inadequate dose. The first published experience of inhaled NO treatment in term newborns reported initial doses that ranged from 6-20 ppm (Kinsella et al., 1992b) to $80 \mathrm{ppm}$ (Roberts et al., 1992). These doses were based on concentrations that had previously been found to be effective in animal experimentation (Kinsella et al., 1992a; Roberts et al., 1993). Afterwards, it has been demonstrated that acute (Finer et al., 1994, Davidson et al., 1998) as well as sustained (Davidson et al., 1998) improvement in oxygenation during treatment with inhaled NO was not different with doses ranging from 5 to $80 \mathrm{ppm}$. Moreover, the $80 \mathrm{ppm}$ dose did not seem to have any advantages over the 20 and 5 ppm doses and resulted in elevated methemoglobin and $\mathrm{NO}_{2}$ levels (Davidson et al., 1998). High doses of NO that can paradoxically worsen oxygenation due to the loss of selective pulmonary vasodilatation, producing an increased ventilation-perfusion mismatch (Kinsella \& Abman, 1995). On the other hand, the use of NO at doses too low may not achieve maximal lowering of PVR. Moreover, Cornfield et al. (1999) have demonstrated that initial treatment with low dose of inhaled NO (2 ppm) may diminish the clinical response to $20 \mathrm{ppm}$ and have adverse clinical sequelae.

Finally (vii), the presence of an abnormal pulmonary vascular structure and/or altered smooth muscle cell responsiveness or sensitivity can also explain the lack of action of inhaled NO. It is possible that the thickened pulmonary arteries of some infants reduce the diffusion of 
$\mathrm{NO}$ and even continue to restrict the blood flow in spite of NO-induced relaxation (Roberts et al., 1997b; Shehata et al., 2000). Additionally, as described in animal models of PPHN, decreased SGC or increased PDE5 activities may limit the vasodilator response to NO (Steinhorn et al., 1995a; Hanson et al., 1998; Abman, 1999). Furthermore, sGC activity may be regulated via the action of an endogenous inhibitor, which has been partially purified from bovine lung and exerts an allosteric inhibition (Kim \& Burstyn, 1994). It has been also suggested that genetic factors can contribute to the response of some patients to inhaled NO. Weimann et al. (1998) demonstrated, in adult patients with acute respiratory distress syndrome, a relation between the oxygenation response to inhaled NO and the ABO blood group system. Thus, the response to inhaled NO was significantly decreased in patients with genotype $\mathrm{B}$ who express blood group $\mathrm{B}$ or $\mathrm{AB}$. They speculate with a possible genetic linkage between the $\mathrm{ABO}$ gene locus and another, as yet unknown, gene locus that might be involved in the pulmonary vascular response to NO. In contrast, in a group of newborns and children median age 1.6 months- McFadzean et al. (1988) found no differences in the percentage of non responders to inhaled $\mathrm{NO}$ between patients with blood group $\mathrm{B} / \mathrm{AB}$ and patients with $\mathrm{O} / \mathrm{A}$. However, they observed a trend to a earlier response in the O/A patients.

\section{Adjuvant therapies to augment the response to inhaled NO}

Based on some of the facts described above, several treatment strategies have been proposed to increase the response to inhaled NO. Considering the important role of parenchymal lung disease in many cases of PPHN, the combined use of high-frequency HFOV, with a strategy designed to recruit and sustain lung volume, plus inhaled NO was more successful than treatment with HFOV or inhaled NO alone (Kinsella et al., 1997a). Additionally, pharmacological augmentation of the response to inhaled NO with the use of PDEs inhibitors has been tested in animal models (Thusu et al., 1995; Dukarn et al., 1998; Steinhorn et al., 2000), PPHN patients (Kinsella et al., 1995; al-Alaiyan et al., 1996, Thebaud et al., 1999), and infants with pulmonary hypertension (Ziegler et al., 1998; Ivy et al., 1998b). However, the use of PDE inhibitors not selective for the pulmonary circulation raises the problem of their systemic effects similar to that described for intravenous vasodilators. Further 
studies with more selective PDE5 inhibitors -such as E4021, DMPPO, and zaprinast- (Kinsella \& Abman, 1998) or using these drugs by inhalation (Ichinose et al., 1998) may lead to novel clinical strategies to enhance the treatment of PPHN with inhaled NO.

On the other hand, strategies based on the augmentation of cofactors for enzymatic activity of sGC, such as the divalent cations $\mathrm{Mg}^{2+}$ and $\mathrm{Mn}^{2+}$, might also improve the response to inhaled NO. In the presence of $\mathrm{Mg}^{2+}$, stimulation of the sGC by NO is dramatically enhanced and the affinity of substrate (GTP) binding to the enzyme increased (Hobbs, 1997). Additionally, the fact that NO is a free radical and that it forms peroxynitrite with superoxide has led to the suggestion of the use of antioxidant enzymes, mainly SOD, not only as a way to reduce toxicity, but also as a method to ameliorate the response to inhaled NO. It is well known that SOD significantly increased in vitro relaxant activity of NO, and that SOD induces endothelium dependent vasodilatation by protecting basal NO from the destructive action of endogenously produced superoxide anions (Ohsltein \& Nichols, 1989; MacKenzie et al., 1999) . The role of exogenous SOD on the relaxation induced in vivo by exogenous NO remains unknown, but promising preliminary results show that the use of human recombinant SOD improved the response to NO in the experimental ovine model of PPHN induced by ductus compression (Albert et al., 1999).

\section{Inhaled $N O$ in the premature infant}

Research in human preterm infants has demonstrated that pulmonary hypertension with extracardiac right-to-left shunt can complicate the course of hyaline membrane disease and is associated with mortality, despite surfactant therapy (Walther \& Benders 1992; Seppanen et al., 1993). Premature lambs with hyaline membrane disease do have elevated PVR and seem to respond to inhaled NO with an improvement in gas exchange and reduction in PVR (Kinsella et al., 1994b; Skimming et al., 1995). This improvement was not accompanied by an increase in lung edema and, in fact, inhaled NO reduced lung neutrophil accumulation, suggesting a reduction of the inflammatory process (Kinsella et al., 1994b; 1997b). Preliminary case reports 
and uncontrolled studies in human premature neonates with severe hypoxemic respiratory failure supported the potential role of low-dose inhaled NO as an adjuvant therapy (Abman et al., 1993; Peliowski et al., 1995; Skimming et al., 1997). In terms of the premature infant, one of the potential risks of most concern is the prolongation in bleeding time associated with inhaled NO (Hogman et al. 1993; Samana et al., 1995). This could exacerbate intraventricular hemorrhage complications. Preliminary data from small, nonrandomized noncontrolled studies showed frequent grade 3 and 4 intraventricular bleeds and poor neurodevelopmental outcome in premature infants with severe hypoxemia treated with inhaled NO (Cheung et al., 1998). However, other factors not related to the use of inhaled NO, but related to the illness severity in these infants might be involved in the evolution of the intracraneal bleeds. On the other hand, premature children treated with inhaled NO might have a higher risk for the development of chronic lung disease because of the possible toxicity caused by $\mathrm{NO}_{2}$ and peroxynitrite over lungs with a reduced development of antioxidant defenses (Frank, 1998; Saugstad, 1999). The findings and concerns previously described showed the need for controlled randomized trials, and three of them have been published until the present moment (Table 3)

Two of this studies (Subhedar et al., 1997; Kinsella et al., 1999) demonstrated an improvement in oxygenation with inhaled NO. Neither study, however, showed any significantly increased survival in the treatment groups. The frequency of likely adverse effects, such as intracraneal haemorrhage or chronic lung disease, was not increased in the NO group in any of these trials. The meta-analysis of Barrington and Finer (2000) only includes, until now, the study of Subhedar et al. Based on that data they conclude that there is no published information to support the use of inhaled NO in preterm infants. The inclusion in this systematic review of the results of the studies of Kinsella et al., and The Franco-Belgium group might not seem to extend the benefits of inhaled NO to outcomes other than acute improvement of oxygenation. Therefore, NO therapy for premature infants should be considered as an experimental drug and its use confined to clinical studies in which adverse effects can be monitored (Saugstad, 1999). 
failure.

Table 3. Randomized controlled trials of inhaled NO in newborns $<34$ weeks with respiratory

\begin{tabular}{|c|c|c|c|c|}
\hline Reference & $\begin{array}{l}\text { No. } \\
\text { Pat. }\end{array}$ & $\begin{array}{l}\text { Inclusion } \\
\text { Criteria }\end{array}$ & $\begin{array}{l}\text { Treatment } \\
\text { Protocol }\end{array}$ & Outcome \\
\hline $\begin{array}{l}\text { Subhedar et } \\
\text { al., } 1997\end{array}$ & 42 & $\begin{array}{l}\text { Gestational age < } 32 \\
\text { weeks; mechanical } \\
\text { ventilation since } \\
\text { birth; surfactant } \\
\text { therapy; and high } \\
\text { risk of developing } \\
\text { CLD (defined by a } \\
\text { prediction score) }\end{array}$ & $\begin{array}{l}20 \mathrm{ppm} \text { NO. If } \\
\text { response, weaning } \\
\text { after } 2 \text { hours in steps } \\
\text { of } 5 \mathrm{ppm} \text {. } \\
\text { Four groups: NO, } \\
\text { dexamethasone, } \\
\text { NO+dexamethasone, } \\
\text { and control }\end{array}$ & $\begin{array}{l}\text { Greater percentage decrease in OI in } \\
\text { NO group }(16,9 \% \text { ) than in control (no } \\
\text { change) } \\
\text { However, oxygenation was not well } \\
\text { matched at baseline between the } \\
\text { groups. } \\
\text { No differences in the combined } \\
\text { incidence of CLD and/or death } \\
\text { between infants treated with NO and } \\
\text { controls (RR } 1.05,95 \% \mathrm{CI} 0.84-1.25 \text { ) }\end{array}$ \\
\hline $\begin{array}{l}\text { Kinsella et } \\
\text { al., } 1999\end{array}$ & 80 & $\begin{array}{l}\text { Gestational age }<34 \\
\text { weeks; age }<7 \text { days; } \\
\text { severe hypoxemia } \\
\text { (arterial/alveolar } \mathrm{O}_{2} \\
\text { ratio }<0.1 \text { on } 2 \\
\text { sequential blood } \\
\text { gases) despite } \\
\text { mechanical } \\
\text { ventilation and } \\
\text { surfactant (predicted } \\
\text { mortality rate } 50 \% \text { ) }\end{array}$ & $\begin{array}{l}5 \text { ppm NO vs. } \\
\text { control }\end{array}$ & $\begin{array}{l}\text { NO improved oxygenation after } 60 \\
\text { min }(p=0.03) \text {. } \\
\text { Survival: NO group } 52 \% \text {, control } \\
47 \% \text {. } \\
\text { NO and control groups did not differ } \\
\text { for adverse events or outcomes } \\
\text { (intracranial haemorrhage grade } 2-4 \text { : } \\
\text { NO } 28 \% \text { control } 33 \% \text {; pulmonary } \\
\text { haemorrhage: } 13 \% \text { and } 9 \% \text {; CLD: } \\
60 \% \text { and } 80 \%)\end{array}$ \\
\hline $\begin{array}{l}\text { The Franco- } \\
\text { Belgium } \\
\text { Collaborative } \\
\text { NO Trial } \\
\text { Group, } 1999\end{array}$ & 85 & $\begin{array}{l}\text { Gestational age }<33 \\
\text { weeks: } \\
12.5<\text { OI }<30 \text { on } 2 \\
\text { consecutive } \\
\text { measurements. }\end{array}$ & $\begin{array}{l}10 \text { ppm NO vs. } \\
\text { control. } \\
\text { When successful NO } \\
\text { decreased to } 5 \text { ppm } \\
\text { and slowly tapered }\end{array}$ & $\begin{array}{l}\text { No significant improvement in } \\
\text { oxygenation with NO. } \\
\text { Survival: NO group } 73 \% \text {, control } 65 \% \\
\text { NO and control groups did not differ } \\
\text { for adverse events or outcomes } \\
\text { (intracranial haemorrhage grade } 2-4 \\
\text { and cystic leucomalacia: NO } 32 \% \text {, } \\
\text { control } 27 \% ; \mathrm{O}_{2} \text { therapy at } 28 \text { days: } \\
45 \% \text { and } 48 \% ; \mathrm{O}_{2} \text { therapy at } 36 \\
\text { postconcepcional weeks: } 24 \% \text { and } \\
29 \% \text { ) }\end{array}$ \\
\hline
\end{tabular}




\section{References}

Abman SH, Accurso FJ, Wilkening RB, Meschia G. Persistent fetal pulmonary hypoperfusion after acute hypoxia. Am J Physiol. 1987; 253:H941-8

Abman SH, Accurso FJ. Acute effects of partial compression of ductus arteriosus on fetal pulmonary circulation. Am J Physiol. 1989; 257:H626-34.

Abman SH, Shanley PF, Accurso FJ. Failure of postnatal adaptation of the pulmonary circulation after chronic intrauterine pulmonary hypertension in fetal lambs. J. Clin. Invest. 1989; 83:1849-1858.

Abman SH, Chatfield BA, Hall SL, McMurtry IF. Role of endothelium-derived relaxing factor during transition of pulmonary circulation at birth. Am. J. Physiol. 1990; 259:H1921-1927.

Abman SH, Chatfield BA, Rodman DM, Hall SL, McMurtry IF. Maturational changes in endothelium-derived relaxing factor activity of ovine pulmonary arteries in vitro. Am. J. Physiol. 1991; 260: L280-L285.

Abman SH, Stenmark KR. Changes in lung eicosanoid content during normal and abnormal transition in perinatal lambs. Am J Physiol. 1992; 262:L214-22.

Abman SH, Kinsella JP, Schaffer MS, Wilkening RB. Inhaled nitric oxide in the management of a premature newborn with severe respiratory distress and pulmonary hypertension. Pediatrics. 1993; 92:606-9.

Abman SH, Stevens T. Perinatal pulmonary vasoregulation: implications for the pathophysiology and treatment of neonatal pulmonary hypertension. In: Haddad G, Lister G, eds. Tissue Oxygen Deprivation: Developmental, Molecular and Integrative Function. Marcel Dekker, New York, 1996, pp 367-432.

Abman SH. Abnormal vasoreactivity in the pathophysiology of persistent pulmonary hypertension of the newborn. Pediatr Rev (Online). 1999; 20:e103-9.

Abu-Osba,Y.K, Galal O, Manasra K, Rejjal A. Treatment of severe persistent pulmonary hypertension of the newborn with magnesium sulfate. Arch. Dis. Child. 1992; 67:31-35.

Adnot S, Raffestin B, Eddahibi S, Braquet P, Chabrier P-E. Loss of endothelium dependent relaxant activity in the pulmonary circulation of rats exposed to chronic hypoxia. J Clin Invest 1991; 87:155-162.

al-Alaiyan S, al-Omran A, Dyer D. The use of phosphodiesterase inhibitor (dipyridamole) to wean from inhaled nitric oxide. Intensive Care Med. 1996; 22:1093-5.

Aikio O, Vuopala K, Pokela ML, Hallman M. Diminished inducible nitric oxide synthase expression in fulminant early-onset neonatal pneumonia. Pediatrics. 2000; 105:1013-9.

Albert GP, Davis JM, Robbins CG, Steinhom RH. Recombinant human CuZn superoxide dismutase (rhSOD) as an adjucnctive therapy for inhaled nitric oxide. Pediatr Res 1999 45:293A

Allen KM, Haworth SG. Impaired adaptation of pulmonary circulation to extrauterine life in newborn pigs exposed to hypoxia: an ultrastructural study. J Pathol. 1986; 150:205-12.

Allen SW, Chatfield BA, Koppenhafer SA, Schaffer MS, Wolfe RR, Abman SH. Circulating immunoreactive endothelin-1 in children with pulmonary hypertension. Association with acute hypoxic pulmonary vasoreactivity. Am. Rev. Respir. Dis. 1993; 148: 519-522. 
Arai H, Hori S, Aramori I, Aramori I, Ohkub H, Nakanishi S. Cloning and expression of a cDNA encoding an endothelin receptor. Nature $1990 ; 348: 730-32$.

Archer SL, Tolins JP, Raij L, Weir EK. Hypoxic pulmonary vasoconstriction is enhanced by inhibition of the synthesis of an endothelium derived relaxing factor. Biochem. Biophys. Res. Commun. 1989; 164:1198-1205.

Archer SL, Huang J, Henry T, Peterson D, Weir EK. A redox-based $\mathrm{O} 2$ sensor in rat pulmonary vasculature. Circ Res. 1993; 73:1100-12.

Archer SL, Huang JM, Reeve HL, Hampl V, Tolarova S, Michelakis E, Weir EK. Differential distribution of electrophysiologically distinct myocytes in conduit and resistance arteries determines their response to nitric oxide and hypoxia. Circ Res. 1996; 78:431-42.

Assreuy J, Cunha FQ, Liew FY, Moncada S. Feedback inhibition of nitric oxide synthase activity by nitric oxide. Br. J. Pharmacol. 1993; 108:833-37

Avontuur JA, Biewenga M, Buijk SL, Kanhai KJ, Bruining HA. Pulmonary hypertension and reduced cardiac output during inhibition of nitric oxide synthesis in human septic shock. Shock. 1998a; 9:451-4

Avontuur JA, Tutein Nolthenius RP, van Bodegom JW, Bruining HA Prolonged inhibition of nitric oxide synthesis in severe septic shock: a clinical study. Crit Care Med. 1998b; 26:660-7.

Avontuur JA, Boomsma F, van den Meiracker AH, de Jong FH, Bruining HA. Endothelin- 1 and blood pressure after inhibition of nitric oxide synthesis in human septic shock. Circulation. 1999; 99:271-5.

Badesch DB, Orton EC, Zapp LM, Westcott JY, Hester J, Voelkel NF, Stenmark KR. Decreased arterial wall prostaglandin production in neonatal calves with severe chronic pulmonary hypertension. Am J Respir Cell Mol Biol. 1989; 1:489-98.

Bandyopadhyay RS, Phelan M, Faller DV. Hypoxia induces AP-1-regulated genes and AP-1 transcription factor binding in human endothelial and other cell types. Biochim Biophys Acta. 1995; 1264:72-8.

Banks BA, Ischiropoulos H, McClelland M, Ballard PL, Ballard RA. Plasma 3-nitrotyrosine is elevated in premature infants who develop bronchopulmonary dysplasia. Pediatrics. 1998; 101:870-4.

Barefield ES, Hicks TP, Philips JB 3rd. Thromboxane and pulmonary morphometry in the development of the pulmonary hypertensive response to group B streptococcus. Crit Care Med. 1994; 22:506-14.

Barefield ES, Karle VA, Phillips JB 3rd, Carlo WA.Inhaled nitric oxide in term infants with hypoxemic respiratory failure. J Pediatr. 1996; 129:279-86.

Barnes PJ, Liu SF. Regulation of pulmonary vascular tone. Pharmacol Rev 1995; 47:87-131.

Barrington KJ, Finer NN. Inhaled nitric oxide for respiratory failure in preterm infants (Cochrane Review). In: The Cochrane Library, Issue 1, 2000. Oxford: Update Software.

Barrington KJ, Etches PC, Schulz R, Talbot JA, Graham AJ, Pearson RJ, Cheung PY. The hemodynamic effects of inhaled nitric oxide and endogenous nitric oxide synthesis blockade in newborn piglets during infusion of heatkilled group B streptococci. Crit Care Med. 2000; 28:800-8.

Bartelds B, van Bel F, Teitel DF, Rudolph AM. Carotid, not aortic, chemoreceptors mediate the fetal 
cardiovascular response to acute hypoxemia in lambs. Pediatr Res. 1993; 34:51-5.

Beavo JA, Reifsnyder DH. Primary sequenc e of cyclic nucleotide phosphodiesterase isozymes and the design of selective inhibitors. Trends Pharmacol Sci. 1990; 11:150-5

Beavo JA. Cyclic nucleotide phosphodiesterases: functional implications of multiple isoforms. Physiol. Rev. 1995; 75:725-748.

Beckman JS, Beckman TW, Chen J, Marshall P A, Freeman B A. Apparent hydroxyl radical production by peroxynitrite: implications for endothelial injury from nitric oxide and superoxide. Proc. Natl. Acad. Sci. USA 1990; 87:1620-1624.

Beckman JS, Koppenol WH. Nitric oxide, superoxide, and peroxynitrite The good, the bad, and the ugly. Am J Physiol 1996; 271: 1424-37

Belik J. Myogenic response in large pulmonary arteries and its ontogenesis. Pediatr Res. 1994; 36:34-40.

Belik J. The myogenic response of arterial vessels is increased in fetal pulmonary hypertension. Pediatr Res. 1995; 37:196-201.

Benitz, WE, Malachowski N, Cohen RS, Stevenson DK, Ariagno RL, Sunshine P. Use of sodium nitroprusside in neonates: efficacy and safety. J. Pediatr. 1985; 106:102-110.

Berkenbosch JW, Baribeau J, Perreault T. Decreased synthesis and vasodilation to nitric oxide in piglets with hypoxia-induced pulmonary hypertension. Am J Physiol Lung Cell Mol Physiol. 2000; 278:L276-83.

Berkov S. Hypoxic pulmonary vasoconstriction in the rat. The necessary role of angiotensin II. Circ Res 1974; $35: 256-261$.

Bkaily G, Peyrow M, Yamamoto T, Sculptoreanu A, Jacques D, Sperelakis N. Macroscopic Ca2+ - Na+ and K+ currents in single heart and aortic cells. Mol Cell Biochem. 1988; 80:59-72.

Black SM, Johengen MJ, Ma ZD, Bristow J, Soifer SJ. Ventilation and oxygenation induce endothelial nitric oxide synthase gene expression in the lungs of fetal lambs. J Clin Invest. 1997; 100:1448-58.

Black SM, Johengen MJ, Soifer SJ. Coordinated regulation of genes of the nitric oxide and endothelin pathways during the development of pulmonary hypertension in fetal lambs. Pediatr Res 1998; 44:821-30.

Blanco CE, Dawes GS, Hanson MA, McCooke HB. The response to hypoxia of arterial chemoreceptors in fetal sheep and new-born lambs. J Physiol (Lond). 1984; 351:25-37.

Blanco CE, Martin CB, Rankin J, Landauer M, Phernetton T. Changes in fetal organ flow during intrauterine mechanical ventilation with or without oxygen. J Dev Physiol. 1988; 10:53-62.

Blitzer ML, Loh E, Roddy MA, Stamler JS, Creager MA. Endothelium-derived nitric oxide regulates systemic and pulmonary vascular resistance during acute hypoxia in humans. J. Am. Coll. Cardiol. 1996; 28:591-596

Block ER, Herrera H, Couch M. Hypoxia inhibits L-arginine uptake by pulmonary artery endothelial cells. Am J Physiol 1995; 269:L574-L580.

Brannon TS, MacRitchie AN, Jaramillo MA, Sherman TS, Yuhanna IS, Margraf LR, Shaul PW. Ontogeny of cyclooxygenase-1 and cyclooxygenase-2 gene expression in ovine lung. Am J Physiol. 1998; 274:L66-71. 
Brashers VL, Peach MJ, Rose CE. Augmentation of hypoxic pulmonary vasoconstriction in the isolated perfused rat lung by in vitro antagonists of endothelium-dependent relaxation. J. Clin. Invest. 1988; 82:1495-1502.

Breslow MJ, Miller CF, Parker SD, Waiman AT, Traystman RJ. Effect of vasopressors on organ blood flow during endotoxin shock in pigs. Am J Physiol. 1987; 252:H291-300.

Bos AP, Tibboel D, Koot VC, Hazebroek FW, Molenaar JC. Persistent pulmonary hypertension in high-risk congenital diaphragmatic hernia patients: incidence and vasodilator therapy. J Pediatr Surg. 1993; 28:1463-5.

Bouchet M, Renaudin MH, Raveau C, Mercier JC, Dehan M, Zupan V. Safety requirement for use of inhaled nitric oxide in neonates. Lancet. 1993; 341:968-9.

Brian JE Jr, Heistad DD, Faraci FM. Effect of carbon monoxide on rabbit cerebral arteries. Stroke1994; 25:639-643

Brune B, Ullrich V. Inhibition of platelet aggregation by carbon monoxide is mediated by activation of guanylate cyclase. Mol Pharmacol 1987: 32:497-504

Bui KC, Martin G, Kammerman LA, Hammerman C, Hill V, Short BL. Plasma thromboxane and pulmonary artery pressure in neonates treated with extracorporeal membrane oxygenation. J Thorac Cardiovasc Surg. 1992; 104:1249.

Bush PA, Gonzalez NE, Griscavage JM, Ignarro LJ. Nitric oxide synthase from cerebellum catalyzes the formation of equimolar quantities of nitric oxide and citrulline from L-arginine. Biochem. Biophys. Res. Commun. 1992; 185:960-66

Busse R, Mulsch A. Induction of nitric oxide synthase by cytokines in vascular smooth muscle cells. FEBS Lett. $1990 ; 275: 87-90$.

Bustamante, SA, Pang Y, RomeroS, Pierce M, Voelker CA, Thompson JH, Sandoval M, Liu X, Miller MJS. Inducible nitric oxide synthase and the regulation of central vessel caliber in the fetal rat. Circulation. 1996; 94 : 1948-1953.

Butler RR Jr, Wise WC, Halushka PV, Cook JA. Thromboxane and prostacyclin production during septic shock. Adv Shock Res. 1982; 7:133-45.

Cabal LA, Siassi B, Cristofani C, Cabal C, Hodgman JE. Cardiovascular changes in infants with B-hemolytic streptococcus sepsis. Crit Care Med 1990; 18:715-718

Cacoub P, Dorent R, Maistre G, Nataf P, Carayon A, Piette C, Godeau P, Cabrol C, Gandjbakhch 1. Endothelin-1 in primary pulmonary hypertension and the Eisenmenger syndrome. Am. J. Cardiol. 1993; 71:448-450

Campbell AG, Dawes GS, Fishman AP, Hyman AI. Pulmonary vasoconstriction and changes in heart rate during asphyxia in immature foetal lambs. J Physiol (Lond). 1967a; 192:93-110.

Campbell AG, Cockburn F, Dawes GS, Milligan JE. Pulmonary vasoconstriction in asphyxia during cross-circulation between twin foetal lambs. J Physiol (Lond), 1967b; 192:111-21

Cantoni L, Rossi C, Rizzardini M, Gardina M, Ghezzi P. Interleukin-1 and tumor necrosis factor induce hepatic haeme oxygenase. Biochem J 1991; 279:891-894.

Carraway MS, Piantadosi CA, Jenkinson CP, Huang YC. Differential expression of arginase and iNOS in the 
lung in sepsis. Exp Lung Res. 1998; 24:253-68.

Cassin S, Dawes GS, Mott JC, Ross BB, Strang LB. Vascular resistance of the foetal and newly ventilated lung of the lamb. J. Physiol. 1964; 171:61-79.

Cassin S, Winikor I, Tod M, Philips J, Frisinger J, Jordan J, Gibbs C. Effects of prostacyclin on the fetal pulmonary circulation. Pediatr Pharmacol (New York). 1981; 1:197-207.

Cassin S, Stenmark KR, Gause G, Zapp LM, Kuck H, Westcott JY. Leukotrienes and prostaglandins in fetal lung liquid. J Appl Physiol. 1990; 68:2214-22.

Cassin S, Kristova V, Davis T, Kadowit P, Gause G. Tone-dependent responses to endothelin in the isolated perfused fetal sheep pulmonary circulation in situ. J. Appl. Physiol. 1991; 70: 1228-1234.

Castillo L, DeRojas-Walker T, Yu YM, Sanchez M, Chapman TE, Shannon D, Tannenbaum S, Burke JF, Young VR. Whole body arginine metabolism and nitric oxide synthesis in newborns with persistent pulmonary hypertension. Pediatr Res. 1995; 38:17-24.

Caudill TK, Resta TC, Kanagy NL, Walker BR. Role of endothelial carbon monoxide in attenuated vasoreactivity following chronic hypoxia. Am J Physiol Regulatory Integrative Comp Physiol 1998; 275:R1025-R1030

Chatfield BA, McMurtry IF, Hall SL, Abman SH. Hemodynamic effects of endothelin-1 on ovine fetal pulmonary circulation. Am. J. Physiol. 1991; 261: 182-187

Cheung PY, Peliowski A, Robertson CM. The outcome of very low birth weight neonates $(</=1500 \mathrm{~g})$ rescued by inhaled nitric oxide: neurodevelopment in early childhood. J Pediatr 1998; 133:735-9.

Christou H, Adatia I, Van Marter LJ, Kane JW, Thompson JE, Stark AR, Wessel DL, Kourembanas S. Effect of inhaled nitric oxide on endothelin-1 and cyclic guanosine 5'-monophosphate plasma concentrations in newborn infants with persistent pulmonary hypertension. J Pediatr. 1997; 130:603-11.

Christou H, Van Marter LJ, Wessel DL, Allred EN, Kane JW, Thompson JE, Stark AR, Kourembanas S. Inhaled nitric oxide reduces the need for extracorporeal membrane oxygenation in infants with persistent pulmonary hypertension of the newborn. Crit Care Med. 2000; 28:3722-7.

Clark RH, Kueser TJ, Walker MW, Southgate WM, Huckaby Л, Perez JA, Roy BJ, Keszler, M, Kinsella JP. Lowdose nitric oxide therapy for persistent pulmonary hypertension of the newborn. Clinical Inhaled Nitric Oxide Research Group. N Engl J Med. 2000; 342:469-74.

Clementi E, Brown GC, Feelisch M, Moncada S. Persistent inhibition of cell respiration by nitric oxide: crucial role of S-nitrosylation of mitochondrial complex I and protective action of glutathione. Proc. Natl. Acad. Sci. USA 1998; 95:7631-36

Cobb JP, Danner RL Nitric oxide and septic shock. JAMA. 1996; 275:1192-6

Cobb JP. Use of nitric oxide synthase inhibitors to treat septic shock: the light has changed from yellow to red. Crit Care Med. 1999; 27:855-6

Coceani F, Olley PM: Eicosanoids in the fetal and transitional pulmonary circulation. Chest 1988; 93:112S-117S.

Coceani F, Kelsey L, Seidlitz E, Marks GS, McLaughlin BE, Vreman HJ, Stevenson DK, Rabinovitch M, Ackerley C. Carbon monoxide formation in the ductus arteriosus in the lamb: implications for the regulation of muscle tone. 
Br J Pharmacol 1997; 120:599-608

Cohen RI, Shapir Y. Chen L, Scharf SM. Right ventricular overload causes the decrease in cardiac output after nitric oxide synthesis inhibition in endotoxemia. Crit Care Med. 1998; 26:738-47.

Cornfield DN, Chatfield BA, McQueston JA, McMurtry IF, Abman SH. Effects of birth-related stimuli on L-arginine -dependent pulmonary vasodilation in the ovine fetus. Am J Physiol 1992; 262:H1474-H1481.

Cornfield DN, Stevens T, McMurtry IF, Abman SH, Rodman DM. Acute hypoxia causes membrane depolarization and calcium influx in fetal pulmonary artery smooth muscle cells. Am J Physiol 1994; 266:L469-75

Comfield DN, Reeve HL, Tolarova S, Weir EK, Archer S. Oxygen causes fetal pulmonary vasodilation through activation of a calcium-dependent potassium channel. Proc. Natl. Acad. Sci. USA. 1996; 93:8089-8094

Cornfield DN, Maynard RC, deRegnier RA, Guiang SF 3rd, Barbato JE, Milla CE. Randomized, controlled trial of lowdose inhaled nitric oxide in the treatment of term and near-term infants with respiratory failure and pulmonary hypertension. Pediatrics 1999; 104:1089-94.

Covert RF, Schreiber MD. Three different strains of heat-killed group B beta-hemolytic streptococcus cause different pulmonary and systemic hemodynamic responses in conscious neonatal lambs. Pediatr Res 1993; 33:3739.

Crawley DE, Zhao L, Giembycz MA, Liu S, Barnes P, Winter RJD. Chronic hypoxia impairs soluble guanylyl cyclase-mediated pulmonary arterial relaxation in the rat. Am J Physiol 1992; 263:L325-L332.

Crowley MR, Fineman JR, Soifer SJ. Effects of vasoactive drugs on thromboxane A2 mimetic-induced pulmonary hypertension in newborn lambs. Pediatr Res 1991; 29:167-72.

Csaba IF, Sulyok E, Ertl T. Relationship of maternal treatment with indomethacin to persistence of fetal circulation syndrome. J Pediatr. 1978; 92:484.

Cucchiaro G, Tatum AH, Brown MC, Camporesi EM, Daucher JW, Hakim TS. Inducible nitric oxide synthase in the lung and exhaled nitric oxide after hyperoxia. Am J Physiol 1999; 277:L636-44.

Cummings JJ. Pulmonary vasodilator drugs decrease lung liquid production in fetal sheep. J Appl Physiol 1995; 79:1212-1218.

Cummings JJ. Nitric oxide decreases lung liquid production in fetal lambs. J Appl.Physiol 1997; 83:1538-1544.

Curzen NP, Mitchell JA, Jourdan KB, Griffiths MJ, Evans TW. Endothelin-1-induced contraction of pulmonary arteries from endotoxemic rats is attenuated by the endothelin-A receptor antagonist, BQ123. Crit Care Med. 1996; 24:2007-13.

Curzen NP, Kaddoura S, Griffiths MJ, Evans TW. Endothelin-1 in rat endotoxemia: mRNA expression and vasoreactivity in pulmonary and systemic circulations. Am J Physiol. 1997; 272:H2353-60.

Davenport AP, Kuc RE, Mockridge JW. Endothelin-converting enzyme in the human vasculature: evidence for differential conversion of big endothelin-3 by endothelial and smooth-muscle cells. J Cardiovasc Pharmacol. 1998; 31 Suppl 1:S1-3

Davidson D. Pulmonary hemodynamics at birth: effect of acute cyclooxygenase inhibition in lambs. J Appl Physiol. 1988; 64:1676-82. 
Davidson D, Barefield ES, Kattwinkel J, Dudell G, Damask M, Straube R, Rhines J, Chang CT. Inhaled nitric oxide for the early treatment of persistent pulmonary hypertension of the term newborn: a randomized, double-masked, placebo-controlled, dose-response, multicenter study. The I-NO/PPHN Study Group. Pediatrics 1998; 101:325-34.

Davidson D, Barefield ES, Kattwinkel J, Dudell G, Damask M, Straube R, Rhines J, Chang CT. Safety of withdrawing inhaled nitric oxide therapy in persistent pulmonary hypertension of the newborn. Pediatrics 1999; 104:231-6.

Davis MJ, Hill MA. Signaling mechanisms underlying the vascular myogenic response. Physiol Rev 1999; 79:387-42

Dawes GS, Mott JC. The vascular tone of the foetal lung. J. Physiol 1962; 164:465-477.

Dawes GS. Pulmonary circulation in the foetus and new-born. Br Med Bull. 1966; 22:61-5.

Day RW, Lynch JM, White KS, Ward RM. Acute response to inhaled nitric oxide in newborns with respiratory failure and pulmonary hypertension. Pediatrics 1996; 98:698-705.

De Mey JG, Vanhoutte PM. Anoxia and endothelium-dependent reactivity of the canine femoral artery. J Physiol. 1983; 335:65-74.

Deinum G, Stone JR, Babcock GT, Marletta MA. Binding of nitric oxide and carbon monoxide to soluble guanylate cyclase as observed with Resonance raman spectroscopy. Biochemistry 1996; 35:1540-1547

DeMeester SL, Qiu Y, Buchman TG, Hotchkiss RS, Dunnigan K, Karl IE, Cobb JP. Nitric oxide inhibits stressinduced endothelial cell apoptosis. Crit Care Med. 1998; 26:1500-9.

Dickstein, PJ,Trintade O, Goldberg RN, Bancalari E. The effect of calcium antagonists on hypoxic pulmonary hypertension in the piglet. Pediatr. Res 1984; 18:1262-1267.

Dinerman JL, Dawson TM, Schell MJ, Snowman A, Snyder SH. Endothelial nitric oxide synthase localized to hippocampal pyramidal cells: implications for synaptic plasticity. Proc. Natl. Acad. Sci. USA 1994; 91:4214-4218.

Dinh Xuan AT, Higginbottam TW, Clelland C, Pepke-Zaba J, Cremona G, Butt AY, Large SR, Wells FC, Wallwork $\mathrm{J}$. Impairment of endothelium-dependent pulmonary artery relaxation in chronic obstructive lung disease. $\mathrm{N}$. Engl J. Med. 1991; 324:1539-1547.

Dollberg S, Warner BW, Myatt L. Urinary nitrite and nitrate concentrations in patients with idiopathic persistent pulmonary hypertension of the newborn and effect of extracorporeal membrane oxygenation. Pediatr Res 1995; 37:314.

Driscoll W, Thurin S, Carrion V, Steinhorn RH, Morin FC 3rd. Effect of methylene blue on refractory neonatal hypotension. J Pediatr. 1996; 129:904-8.

Drummond WE, Lock J. Neonatal "pulmonary vasodilator" drugs. Dev. Pharmacol. Ther. 1984; 7:1-20.

Drummond WH, Bissonnette JM. Persistent pulmonary hypertension in the neonate: development of an animal model. Am J Obstet Gynecol. 1978; 131:761-3.

Dubin D, Pratt RE, Cooke JP, Dzau VJ. Endothelin, a potent vasoconstrictor, is a vascular smooth muscle mitogen. J. Vasc. Med. Biol. 1989; 1: 150-4.

Dukarm RC, Morin FC 3rd, Russell JA, Steinhorm RH. Pulmonary and systemic effects of the phosphodiesterase 
inhibitor dipyridamole in newborn lambs with persistent pulmonary hypertension. Pediatr Res. 1998; 44:831-7.

Duke HN, Killick EM. Pulmonary vasomotor responses of isolated perfused cat lungs to anoxia. J Physiol 1952; 117:303-316

Dweik RA, Laskowski D, Abu-Soud HM, Kaneko F, Hutte R, Stuehr DJ, Erzurum SC. Nitric oxide synthesis in the lung. Regulation by oxygen through a kinetic mechanism. J Clin Invest. 1998; 101:660-6.

Eddahibi S, Adnot S, Carville C, Blouquit Y, Raffestin B. L-arginine restores endothelium-dependent relaxation in pulmonary circulation of chronically hypoxic rats. Am J Physiol 1992; 263:L194-L200.

Ekekezie II, Thibeault DW, Zwick DL, Rezaiekhaligh MH, Mabry SM, Morgan RE, Norberg M, Truog WE. Independent and combined effects of prolonged inhaled nitric oxide and oxygen on lung inflammation in newborn piglets. Biol Neonate. 2000; 77:37-44.

Emori T, Hirata Y, Imai T, Ohta K, Kanno K, Eguchi S, Marumo F. Cellular mechanisms of thrombin on endothelin-1 biosynthesis and release in bovine endothelial cell. Biochem. Pharmacol. 1992; 44:2409-11.

Emori T, Hirata Y, Imai T, Eguchi S, Kanno K, Marumo F. Cellular mechanism of natriuretic peptides-induced inhibition of endothelin-1 biosynthesis in rat endothelial cells. Endocrinology 1993; 133:2474-80.

Enhorning G, Adams FH, Norman A. Effect of lung expansion of the fetal lamb circulation. Acta Paediatr. Scand. 1966; $55: 441-451$.

Fagan KA, Fouty BW, Tyler RC, Morris KG Jr, Hepler LK, Sato K, LeCras TD, Abman SH, Weinberger HD, Huang PL, McMurtry IF, Rodman DM. The pulmonary circulation of homozygous or heterozygous eNOS-null mice is hyperresponsive to mild hypoxia. J Clin Invest 1999; 103:291-299.

Faller DV. Endothelial cell responses to hypoxic stress. Clin Exp Pharmacol Physiol. 1999; 26:74-84.

Fike CD, Kaplowitz MR. Chronic hypoxia alters nitric oxide-dependent pulmonary vascular responses in lungs of newborn pigs. J Appl Physiol. 1996; 81:2078-87.

Fike CD, Kaplowitz MR, Thomas CJ, Nelin LD. Chronic hypoxia decreases nitric oxide production and endothelial nitric oxide synthase in newborn pig lungs. Am J Physiol. 1998; 274:L517-26.

Fineman JR, Crowley MR, Soifer SJ. Selective pulmonary vasodilation with ATP- $\mathrm{MgCl}_{2}$ during pulmonary hypertension in lambs. J. Appl. Physiol 1990; 69:1836-1841.

Fineman JR, Soifer SJ, Heymann MA. The role of pulmonary vascular endothelium in perinatal pulmonary circulatory regulation. Semin Perinatol. 1991; 15:58-62.

Fineman JR, Wong J, Morin III FC, Wild LM, Soifer SJ. Chronic nitric oxide inhibition in utero produces persistent pulmonary hypertension in newborn lambs. J. Clin. Invest. 1994; 93:2675-2683.

Finer NN, Barrington KJ. Nitric oxide for respiratory failure in infants born at or near term (Cochrane Review). In: The Cochrane Library, Issue 1, 2000. Oxford: Update Software.

Fink MP, Homer LD, Fletcher JR. Diminished pressor response to exogenous norepinephrine and angiotensin II in septic, unanesthetized rats: evidence for a prostaglandin-mediated effect. J Surg Res. 1985; 38:335-42.

Fischer LG, Horstman DJ, Hahnenkamp K, Kechner NE, Rich GF. Selective iNOS inhibition attenuates acetylcholine- and bradykinin-induced vasoconstriction in lipopolysaccharide-exposed rat lungs. Anesthesiology. 
1999; 91:1724-32.

Fishman AP. Hypoxia on the pulmonary circulation. How and where it acts. Circ Res. 1976; 38:221-3

Fleming I, Gray GA, Julou-Schaeffer G, Parratt JR, Stoclet JC. Incubation with endotoxin activates the L-arginine pathway in vascular tissue. Biochem Biophys Res Commun. 1990; 171:562-8.

Frank L. Development of the antioxidant defenses in fetal life. Semin Neonatol 1998; 3:173-182.

Fratacci MD, Frostell CG, Chen TY, Wain JC Jr, Robinson DR, Zapol WM. Inhaled nitric oxide. A selective pulmonary vasodilator of heparin-protamine vasoconstriction in sheep. Anesthesiology. 1991; 75:990-9.

Frostell C, Fratacci MD, Wain JC, Jones R, Zapol WM. Inhaled nitric oxide. A selective pulmonary vasodilator reversing hypoxic pulmonary vasoconstriction. Circulation. 1991; 83:2038-47.

Fujii Y, Goldberg P, Hussain SN. Intrathoracic and extrathoracic sources of exhaled nitric oxide in porcine endotoxemic shock. Chest. 1998; 114:569-76.

Fujii Y, Magder S, Cernacek P, Goldberg P, Guo Y, Hussain SN. Endothelin Receptor blockade Attenuates Lipopolysaccharide-induced Pulmonary Nitric Oxide Production. Am J Respir Crit Care Med. 2000; 161:982-989.

Furchgott RF, Zawadzki JV. The obligatory role of endothelial cells in the relaxation of arterial smooth muscle by acetylcholine. Nature (Lond.) 1980; 288:373-376.

Furchgott RF, Jothianandan D. Endothelium-dependent and -independent vasodilation involving cyclic GMP: relaxation induced by nitric oxide, carbon monoxide and light. Blood Vessels 1991; 28:52-61

Gaine SP, Hales MA, Flavahan NA. Hypoxic pulmonary endothelial cells release a diffusible contractile factor distinct from endothelin. Am J Physiol. 1998; 274:L657-64.

Galley HF, Nelson SJ, Dhillon J, Dubbels AM, Webster NR. Effect of the nitric oxide inhibitor, L-N(G)monomethylarginine, on accumulation of interleukin-6 and interleukin-8, and nuclear factor-kappaB activity in a human endothelial cell line. Crit Care Med. 1999; 27:908-12.

Gao Y, Tolsa JF, Raj JU. Heterogeneity in endothelium-derived nitric oxide-mediated relaxation of different sized pulmonary arteries of newborn lambs. Pediatr Res. 1998; 44:723-9.

Gardiner SM, Compton AM, Kemp PA, Bennett T. The effects of phosphoramidon on the regional haemodynamic responses to human proendothelin (1-38) in conscious rats. Br. J. Pharmacol. 1991; 103:2009-15

Geggel RL, Aronovitz MJ, Reid LM. Effects of chronic in utero hypoxemia on rat neonatal pulmonary arterial structure. J Pediatr. 1986; 108:756-9.

Geiger M, Stone A, Mason SN, Oldham KT, Guice KS. Differential nitric oxide production by microvascular and macrovascular endothelial cells. Am J Physiol. 1997; 273:L275-81.

Gersony WM, Duc GV, Sinclair JC. 'P.F.C.' syndrome (persistence of the fetal circulation. Circulation 1969; 40 (suppl 3):87

Gersony WM, Morishima HO, Daniel SS, Kohl S, Cohen H, Brown W, James LS. The hemodynamic effects of intrauterine hypoxia: an experimental model in newborn lambs. J Pediatr. 1976; 89:631-5. 
Giaid A, Yanagisawa M, Langleben D, Michel RP, Levy R, Shennib H, Kimura S, Masaki T, Duguid WP, Stewart DJ.Expression of endothelin-1 in the lungs of patients with pulmonary hypertension. N. Engl. J. Med. 1993; 328:1732-1739

Giaid A, Saleh D. Reduced expression of endothelial nitric oxide synthase in the lungs of patients with pulmonary hypertension. New Engl. J. Med. 1995; 333:214-221.

Gibson RL, Truog WE, Redding GJ. Thromboxane-associated pulmonary hypertension during three types of grampositive bacteriemia in piglets. Pediatr Res 1987; 23:553-556

Gibson RL, Berger J, Redding GJ, Standaert TA, Mayock DE, Truog WE. Effect of nitric oxide synthase inhibition during group B streptococcal sepsis in neonatal piglets. Pediatr Res. 1994; 36:776-83.

Goldberg RN, Suguihara C, Streitfeld MM, Bancalari A, Clark MR, Bancalari E. Effects of a leukotriene antagonist on the early hemodynamic manifestations of group B streptococcal sepsis in piglets. Pediatr Res. 1986; 20:1004-8.

Goldberg RN, Suguihara C, Martinez O, Bancalari A, Clark MR, Bancalari E. The role of leukotrienes in the late hemodynamic manifestations of group B streptococcal sepsis in piglets. Prostaglandins Leukot Essent Fatty Acids. 1988; 33:191-8.

Goldberg SJ, Levy RA, Siassi B, Betten J. The effects of maternal hypoxia and hyperoxia upon the neonatal pulmonary vasculature. Pediatrics. 1971; 48:528-33.

Goldman AP, Tasker RC, Haworth SG, Sigston PE, Macrae DJ. Four patterns of response to inhaled nitric oxide for persistent pulmonary hypertension of the newborn. Pediatrics 1996; 98:706-13.

Goode HF, Howdle PD, Walker BE, Webster NR. Nitric oxide synthase activity is increased in patients with sepsis syndrome. Clin. Sci 1995; 88:131-33.

Gouyon JB, Francoise M. Vasodilators in persistent pulmonary hypertension of the newborn: A need for optimal appraisal of efficacy. Dev. Pharmacol. Ther 1992; 19:62-68.

Graser T, Vanhoutte PM. Hypoxic contraction of canine coronary arteries: role of endothelium and cGMP. Am. J. Physiol 1991; 261: H1769-H1777.

Gray GA, Julou-Schaeffer G, Oury K, Fleming I, Parratt JR, Stoclet JC. An L-arginine-derived factor mediates endotoxin-induced vascular hyposensitivity to calcium. Eur J Pharmacol. 1990; 191:89-92.

Green RS, Leffler CW. Hypoxia stimulates prostacyclin synthesis by neonatal lungs. Pediatr Res. 1984; 18:832-5.

Griffiths MJ, Messent M, MacAllister RJ, Evans TW. Aminoguanidine selectively inhibits inducible nitric oxide synthase. Br J Pharmacol. 1993; 110:963-8.

Griffiths MJ, Messent M, Curzen NP, Evans TW. Aminoguanidine selectively decreases cyclic GMP levels produced by inducible nitric oxide synthase. Am J Respir Crit Care Med. 1995a; 152:1599-604.

Griffiths MJ, Liu S, Curzen NP, Messent M, Evans TW. In vivo treatment with endotoxin induces nitric oxide synthase in rat main pulmonary artery. Am J Physiol. 1995b; 268:L509-18.

Griscavage JM, Fukuto JM, Komori Y, Ignarro LJ. Nitric oxide inhibits neuronal nitric oxide synthase by interacting with the heme prosthetic group. Role of tetrahydrobiopterin in modulating the inhibitory action of nitric oxide. J.Biol. Chem. 1994; 269:21644-49 
Grover TR, Rairigh RL, Zenge JP, Abman SH, Kinsella JP. Inhaled carbon monoxide does not cause pulmonary vasodilation in the late-gestation fetal lamb. Am J Physiol Lung Cell Mol Physiol. 2000; 278:L779-84.

Gutierrez HH, Nieves B, Chumley P, Rivera A, Freeman BA. Nitric oxide regulation of superoxide-dependent lung injury: oxidant-protective actions of endogenously produced and exogenously administered nitric oxide. Free Radic Biol Med. 1996; 21:43-52.

Haddad IY, Ischiropoulos H, Holm BA, Beckman JS, Baker JR, Matalon S. Mechanisms of peroxynitrite-induced injury to pulmonary surfactants. Am J Physiol 1993; 265: L555-64

Haddad IY, Pataki G, Hu P, Galliani C, Beckman JS, Matalon S. Quantitation of nitrotyrosine levels in lung sections of patients and animals with acute lung injury. J Clin Invest 1994a; 94: 2407-13

Haddad IY, Crow JP, Hu P, Ye Y, Beckman J, Matalon S. Concurrent generation of nitric oxide and superoxide damages surfactant protein A. Am J Physiol 1994b; 267: L242-9

Halbower AC, Tuder RM, Franklin WA, Pollock JS, Forstermann U, Abman SH. Maturation-related changes in endothelial nitric oxide synthase immunolocalization in developing ovine lung. Am. J. Physiol. 1994; 267: L585-L591

Hallman M, Bry K. Nitric oxide and lung surfactant. Semin Perinatol 1996; 20: 173-85

Hallman M, Waffarn F, Bry K, Turbow R, Kleinman MT, Mautz WJ, Rasmussen RE, Bhalla DK, Phalen RF. Surfactant dysfunction after inhalation of nitric oxide. J Appl Physiol. 1996a; 80:2026-34.

Hallman M, Bry K, Lappalainen U. A mechanism of nitric oxide-induced surfactant dysfunction. J Appl Physiol. 1996 b; 80:2035-43.

Hallman M, Bry K, Turbow R, Waffarn F, Lappalainen U. Pulmonary toxicity associated with nitric oxide in term infants with severe respiratory failure. J Pediatr. 1998; 132:827-9.

Hammerman C, Lass N, Strates E, Komar K, Bui KC. Prostanoids in neonates with persistent pulmonary hypertension. J Pediatr. 1987; 110:470-2

Hammerman C, Komar K, Meadow W, Strates E. Selective inhibition of thromboxane synthetase reduces group-Bbeta-hemolytic-streptococci-induced pulmonary hypertension in piglets. Dev Pharmacol Ther. 1988; 11:306-12.

Hampl V, Archer SL, Nelson DP, Weir EK. Chronic EDRF inhibition and hypoxia: effects on pulmonary circulation and systemic blood pressure. J. Appl. Physiol. 1993; 75:1748-1757.

Hampl V, Comfield DN, Cowan NJ, Archer SL. Hypoxia potentiates nitric oxide synthesis and transiently increases cytosolic calcium levels in pulmonary artery endothelial cells. Eur Respir J 1995; 8:512-522.

Hanson KA, Ziegler JW, Rybalkin SD, Miller JW, Abman SH, Clarke WR. Chronic pulmonary hypertension increases fetal lung cGMP phosphodiesterase activity. Am J Physiol. 1998; 275:L931-41.

Hanson KA, Ziegler JW, Rybalkin SD, Miller JW, Abman SH, Clarke WR. Chronic pulmonary hypertension increases fetal lung cGMP phosphodiesterase activity. Am J Physiol. 1998; 275:L931-4I.

Hauge A. Role of histamine in hypoxic pulmonary hypertension in the rat. I. Blockade or potentiation of endogenous amines, kinins, and ATP. Circ Res. 1968; 22:371-83.

Haworth SG, Reid L. Persistent fetal circulation: Newly recognized structural features. J Pediatr. 1976; 88:614-20. 
Haworth SG. The pathophysiology of persistent pulmonary hypertension of the newborn. Semin Neonatol 1997; 2: 13-23

Haynes WG, Ferro CJ, O'Kane KP, Somerville D, Lomax CC, Webb DJ. Systemic endothelin receptor blockade decreases peripheral vascular resistance and blood pressure in humans. Circulation. 1996; 93(10):1860-70.

Heymann MA, LeBidois J, Soifer SJ, Clyman RI. Leukotriene synthesis inhibition increases pulmonary blood flow in fetal lambs. Chest. 1988; 93(3 Suppl):117S.

Hibbs, JB, Taintor RR, Vavrin Z, Rachlin EM. Nitric oxide: a cytotoxic activated macrophage effector molecule. Biochem. Biophys. Res. Commun 1988; 157: 87-94.

Hibbs JB, Taintor RR, Vavrin Z, Granger DL, Drapier J-C, Amber 1 J, Lancaster J R Jr. Synthesis of nitric oxide from a terminal guanidino nitrogen atom of $\mathrm{L}$-arginine: a molecular mechanism regulating cellular proliferation that targets intracellular iron. In: Moncada S, Higgs EA (eds.) Nitric Oxide from L-Arginine: A Bioregulatory System, Elsevier, Amsterdam, 1990, pp 189-223,

Hibbs J B. Overview of cytotoxic mechanisms and defence of the intracellular environment against microbes. In: Moncada S, Marletta MA, Hibbs JB, Higgs EA (eds.) The Biology of Nitric Oxide: Enzymology, Biochemistry and Immunology, Portland Press, London, 1992, Vol. 2., pp. 201-206

Hislop AA, Springall DR, Oliveira H, Pollock JS, Polak JM, Haworth SG. Endothelial nitric oxide synthase in hypoxic newborn porcine pulmonary vessels. Arch Dis Child Fetal Neonatal Ed. 1997; 77:F16-22.

Hobbs AJ, Ignarro LI. The nitric oxide-cyclic GMP signal transduction system. In: Zapol WM \& Bloch KD (eds.) Nitric oxide and the lung. Marcel Dekker, New York, 1997, pp 1-57

Hobbs AJ. Soluble guanylate cyclase: the forgotten sibling. Trends Pharmacol. Sci 1997; 18:484-91

Hobbs AJ, Higgs A, Moncada S. Inhibition of nitric oxide synthase as a potential therapeutic target. Annu Rev Pharmacol Toxicol. 1999; 39:191-220.

Hocker JR, Simpsom PM, Rabalais GP, Stewart DL, Cook LN. Extracorporeal membrane oxygenation and early-onset group B streptococcal sepsis. Pediatrics 1992; 89:1-4

Hogman M, Frostell C, Arnberg H, Hedenstierna G. Bleeding time prolongation and NO inhalation. Lancet. 1993; $341: 1664-5$.

Holden, W. E., McCall E. Hypoxia-induced contractions of porcine pulmonary artery strips depend on intact endothelium. Exp. Lung Res 1984; 7:101-112.

Honda K, Kobayashi H, Hataishi R, Hirano S, Fukuyama N, Nakazawa H, Tomita T. Inhaled nitric oxide reduces tyrosine nitration after lipopolysaccharide instillation into lungs of rats. Am J Respir Crit Care Med. 1999; 160:678-88.

Howlett CE, Hutchison JS, Veinot JP, Chiu A, Merchant P, Fliss H. Inhaled nitric oxide protects against hyperoxiainduced apoptosis in rat lungs. Am J Physiol. 1999; 277:L596-605.

Hu J, Discher DJ, Bishopric NH, Webster KA. Hypoxia regulates expression of the endothelin-1 gene through a proximal hypoxia-inducible factor-1 binding site on the antisense strand. Biochem Biophys Res Commun. 1998; 245:894-9. 
Hussain SN, Abdul-Hussain MN, el-Dwairi Q. Exhaled nitric oxide as a marker for serum nitric oxide concentration in acute endotoxemia. J Crit Care. 1996; 11:167-75

Huttner JJ, Gwebu ET, Panganamala RV, Milo GE, Cornwell DC, Sharma HM, Geer JC. Fatty acids and their prostaglandin derivatives: inhibitors of proliferation in aortic smooth muscle cells. Science 1977; 197:289-91.

Ichinose F, Adrie C, Hurford WE, Bloch KD, Zapol WM. Selective pulmonary vasodilation induced by aerosolized zaprinast. Anesthesiology 1998; 88:410-6.

Ignarro LJ, Buga GM, Wood KS, Byms RE, Chaudhuri G. Endothelium-derived relaxing factor produced and released from artery and vein is nitric oxide. Proc. Natl. Acad. Sci. USA 1987; 84: 9265-9269.

Ignarro LJ. Heme-dependent activation of guanylate cyclase by nitric oxide: a novel signal transduction mechanism. Blood Vessels 1991; 28:67-73

Imai T, Hirata Y, Emori T, Yanagisawa M, Masaki T, Marumo F. Induction of endothelin-1 gene by angiotensin and vasopressin in endothelial cells. Hypertension 1992; 19:753-57

Inoue A, Yanagisawa M, Kimura S, Kasuya Y, Miyauchi T, Goto K, Masaki T. The human endothelin family: three structurally and pharmacologically distinct isopeptides predicted by three separate genes. Proc. Natl. Acad. Sci. USA 1989; 86:2863-67

Isaacson TC, Hampl V, Weir EK, Nelson DP, Archer SL. Increased endothelium-derived NO in hypertensive pulmonary circulation of chronically hypoxic rats. J Appl Physiol 1994; 76:933-940.

Issa A, Lappalainen U, Kleinman M, Bry K, Hallman M. Inhaled nitric oxide decreases hyperoxia-induced surfactant abnormality in preterm rabbits. Pediatr Res. 1999; 45:247-54.

Ivy DD, Kinsella JP, Abman SH Physiologic characterization of endothelin A and B receptor activity in the ovine fetal pulmonary circulation. J. Clin. Invest. 1994; 93:2141-2148.

Ivy DD, Kinsella JP, Abman SH. Endothelin blockade augments pulmonary vasodilation in the ovine fetus. J. Appl. Physiol. 1996a; 81:2481-2487

Ivy DD, Ziegler JW, Dubus MF, Fox JJ, Kinsella JP, Abman SH. Chronic intrauterine pulmonary hypertension alters endothelin receptor activity in the ovine fetal lung. Pediatr Res 1996b; 39:435-42

Ivy DD, Parker TA, Ziegler JW, Galan HL, Kinsella JP, Tuder RM, Abman SH. Prolonged endothelin A receptor blockade attenuates chronic pulmonary hypertension in the ovine fetus. J Clin Invest. 1997; 99:1179-86.

Ivy DD, Le Cras TD, Horan MP, Abman SH. Increased lung preproET-1 and decreased ETB-receptor gene expression in fetal pulmonary hypertension. Am J Physiol 1998a; 274:L535-41

Ivy DD, Kinsella JP, Ziegler JW, Abman SH Dipyridamole attenuates rebound pulmonary hypertension after inhaled nitric oxide withdrawal in postoperative congenital heart disease. J Thorac Cardiovasc Surg. 1998b; 115:875-82.

Jakupaj M, Martin RJ, Dreshaj LA, Potter CF, Haxhiu MA, Ernsberger P. Role of endogenous NO in modulating airway contraction mediated by muscarinic receptors during development. Am. J. Physiol. 1997; 273: L531-L536.

Johns RA, Linden JM, Peach MJ. Endothelium-dependent relaxation and cyclic GMP accumulation in rabbit 
pulmonary artery are selectively impaired by moderate hypoxia. Circ. Res.1989; 65:1508-1515.

Joly GA, Ayres M, Chelly F, Kilbourn RG. Effects of NG-methyl-L-arginine, NG-nitro-L-arginine, and aminoguanidine on constitutive and inducible nitric oxide synthase in rat aorta. Biochem Biophys Res Commun. $199428 ; 199: 147-54$.

Joly GA, Narayanan K, Griffith OW, Kilbourn RG. Characterization of the effects of two new arginine/citrulline analogues on constitutive and inducible nitric oxide synthases in rat aorta. $\mathrm{Br}$ J Pharmacol. 1995; 115:491-7.

Jones OW, Abman SH. Systemic and pulmonary hemodynamic effects of big endothelin-1 and phosphoramidon in the ovine fetus. Am. J. Physiol 1994; 266:R929-R955.

John GW, Valentin JP. Analysis of the pulmonary hypertensive effects of the isoprostane derivative, 8-isoPGF2alpha, in the rat. Br J Pharmacol. 1997; 122:899-905.

Johnson RA, Lavesa M, Askari B, Abraham NG, Nasjletti A. A heme oxygenase product, presumably carbon monoxide, mediates a vasodepressor function in rats. Hypertension 1995; 25:166-169, 1995

Julou-Schaeffer G, Gray GA, Fleming I, Schott C, Parratt JR, Stoclet JC. Loss of vascular responsiveness induced by endotoxin involves L-arginine pathway. Am J Physiol. 1990; 259:H1038-43.

Kang KH, Morrow JD, Roberts LJ 2d, Newman JH, Banerjee M. Airway and vascular effects of 8-epi-prostaglandin F2 alpha in isolated perfused rat lung. J Appl Physiol. 1993; 74:460-5.

Kaupp UB. The cyclic nucleotide-gated channels of vertebrate photoreceptors and olfactory epithelium. Trends Neurosci. 1991; 14:150-7.

Kemp BK, Smolich JJ, Cocks TM. Evidence for specific regional patterns of responses to different vasoconstrictors and vasodilators in sheep isolated pulmonary arteries and veins. Br J Pharmacol. 1997; 121:44150.

Kennaugh JM, Kinsella JP, Abman SH, Hemandez JA, Moreland SG, Rosenberg AA. Impact of new treatments for neonatal pulmonary hypertension on extracorporeal membrane oxygenation use and outcome. J Perinatol. 1997; 17:366-9.

Khan M.T, Furchgott RF. Additional evidence that endothelium-derived relaxing factor is nitric oxide. In: Rand MJ, Raper C (eds.) Pharmacology, Elsevier, Amsterdam, 1987, pp 341-344

Kharitonov VG, Sharma VS, Pilz RB, Magde D, Koesling D. Basis of guanylate cyclase activation by carbon monoxide. Proc Natl Acad Sci USA 1995; 92:2568-2571

Kido T, Sawamura T, Hoshikawa H, D'Orleans-Juste P, Denault JB, Leduc R, Kimura J, Masaki T. Processing of proendothelin-1 at the C-terminus of big endothelin-1 is essential for proteolysis by endothelin-converting enzyme1 in vivo. Eur. J. Biochem 1997; 244:520-26.

Kilbourn RG, Gross SS, Jubran A, Adams J, Griffith OW, Levi R, Lodato RF. NG-methyl-L-arginine inhibits tumor necrosis factor-induced hypotension: implications for the involvement of nitric oxide. Proc. Natl. Acad. Sci. USA 1990a; 87:3629-32

Kilbourn RG, Jubran A, Gross SS, Griffith OW, Levi R, Adams J, Lodato RF. Reversal of endotoxin-mediated shock by NG-methyl-L-arginine, an inhibitor of nitric oxide synthesis. Biochem Biophys Res Commun. 1990b; 172:1132-8. 
Kilbourn RG. Nitric oxide synthase inhibitors--a mechanism-based treatment of septic shock. Crit Care Med. 1999;27:857-8.

Kim TD, Burstyn JN. Identification and partial purification of an endogenous inhibitor of soluble guanylyl cyclase from bovine lung. J Biol Chem. 1994; 269:15540-5.

Kinsella JP, McQueston JA, Rosenberg AA, Abman SH. Hemodynamic effects of exogenous nitric oxide in ovine transitional pulmonary circulation. Am J Physiol. 1992a; 263:H875-80.

Kinsella JP, Neish SR, Shaffer E, Abman SH. Low-dose inhalational nitric oxide in persistent pulmonary hypertension of the newborn. Lancet 1992b. 340:819-820.

Kinsella JP, lvy DD, Abman SH. Ontogeny of NO activity and response to inhaled NO in the developing ovine pulmonary circulation. Am. J. Physiol. 1994a; 267:H1955-H1961.

Kinsella JP, Ivy DD, Abman SH. Inhaled nitric oxide improves gas exchange and lowers pulmonary vascular resistance in severe experimental hyaline membrane disease. Pediatr Res. 1994b; 36:402-8.

Kinsella JP, Abman SH. Recent developments in the pathophysiology and treatment of persistent pulmonary hypertension of the newborn. J Pediatr 1995; 126:853-64.

Kinsella JP, Torielli F, Ziegler JW, Ivy DD, Abman SH. Dipyridamole augmentation of response to nitric oxide. Lancet. 1995; 346:647-8.

Kinsella JP, Truog WE, Walsh WF, Goldberg RN, Bancalari E, Mayock DE, Redding GJ, deLemos RA, Sardesai S, McCurnin DC, Moreland SG, Cutter GR, Abman SH. Randomized, multicenter trial of inhaled nitric oxide and highfrequency oscillatory ventilation in severe, persistent pulmonary hypertension of the newborn. J Pediatr. 1997a; 131:55. 62.

Kinsella JP, Parker TA, Galan H, Sheridan BC, Halbower AC, Abman SH. Effects of inhaled nitric oxide on pulmonary edema and lung neutrophil accumulation in severe experimental hyaline membrane disease. Pediatr Res. 1997b; 41:457-63.

Kinsella JP. Clinical trials of inhaled nitric oxide therapy in the newborn. Pediatr Rev (Online). 1999; 20:e110-3.

Kinsella JP, Abman SH. Recent developments in inhaled nitric oxide therapy of the newborn. Curr Opin Pediatr. 1999; 11:121-5.

Kleschyov AL, Muller B, Schott C, Stoclet JC. Role of adventitial nitric oxide in vascular hyporeactivity induced by lipopolysaccharide in rat aorta. Br J Pharmacol. 1998; 124:623-6.

Kobayashi A, Hashimoto S, Kooguchi K, Kitamura Y, Onodera H, Urata Y, Ashihara T. Expression of inducible nitric oxide synthase and inflammatory cytokines in alveolar macrophages of ARDS following sepsis. Chest. 1998; 113:1632-9.

Kobzik L, Bredt DS, Lowenstein CJ, Drazen J, Gaston B, Sugarbaker D, Stamler J S. Nitric oxide synthase in human and rat lung: immunocytochemical and histochemical localization. Am. J. Respir. Cell Mol. Biol 1993; 9: 371-377.

Kobzik L, Reid MB, Bredt DS, Stamler JS. Nitric oxide in skeletal muscle. Nature (Lond.) 1994; 372: 546-548.

Komai H, Adatia IT, Elliott MJ, de Leval MR, Haworth SG. Increased plasma levels of endothelin-1 after 
cardiopulmonary bypass in patients with pulmonary hypertension and congenital heart disease. J. Thorac. Cardiovasc. Surg. 1993; 106: 473-478.

Konduri GG, Woodard LL. Selective pulmonary vasodilation by low-dose infusion of adenosine triphosphate in newborn lambs. J. Pediatr 1991; 119: 94-102.

Kooy NW, Royall JA, Ye YZ, Kelly DR, Beckman JS: Evidence for in vivo peroxynitrite production in human acute lung injury. Am J Respir Crit Care Med 1995; 151: 1250-4

Kourembanas S, Marsden PA, McQuillan LP, Faller DV. Hypoxia induces endothelin gene expression and secretion in cultured human endothelium. J Clin Invest. 1991; 88:1054-7.

Kovitz KL, Aleskowitch TD, Sylvester JT, Flavahan NA. Endothelium-derived contracting and relaxing factors contribute to hypoxic responses of pulmonary arteries. Am. J. Physiol. 1993; 265;H1139-H1148.

Kobzik L, Bredt DS, Lowenstein CJ, Drazen J, Gaston B, Sugarbaker D, Stamler JS. Nitric oxide synthase in human and rat lung: immunocytochemical and histochemical localization. Am J Respir Cell Mol Biol. 1993; 9:371-7.

Kristof AS, Goldberg P, Laubach V, Hussain SN. Role of inducible nitric oxide synthase in endotoxin-induced acute lung injury. Am J Respir Crit Care Med. 1998; 158:1883-9.

Kulik TJ, Lock JE. Pulmonary vasodilator therapy in persistent pulmonary hypertension of the newborn. Clin. Perinatol 1984; 11:693-701.

Kurihara H, Yoshizumi M, Sugiyama T, Takaku F, Yanagisawa M, Masaki T, Hamaoki M, Kato H, Yazaki Y. Transforming growth factor beta stimulates the expression of endothelin mRNA from vascular endothelial cells. Biochem. Biophys. Res. Commun. 1989;159:1435-40.

Kwon NS, Nathan CF, Stuehr DJ. Reduced biopterin as a cofactor in the generation of nitrogen oxides by murine macrophages. J. Biol. Chem. 1989;264:20496-501

Lakshminnusimha S, Steinhorn RH. Pulmonary vascular biology during neonatal transition. Clin Perinatol. 1999; 26:601-19.

Lang CH, Bagby GJ, Ferguson JL, Spitzer JJ. Cardiac output and redistribution of organ blood flow in hypermetabolic sepsis. Am J Physiol. 1984; 246:R331-7.

Laszlo F, Whittle BJ, Evans SM, Moncada S. Association of microvascular leakage with induction of nitric oxide synthase: effects of nitric oxide synthase inhibitors in various organs. Eur. J. Pharmacol.1995; 283:47-53.

Le Cras TD, Xue C, Rengasamy A, Johns RA. Chronic hypoxia upregulates endothelial and inducible NO synthase gene and protein expression in rat lung. Am J Physiol 1996; 270:L164-L170.

Leach RM, Twort CH, Cameron IR, Ward JP. A comparison of the pharmacological and mechanical properties in vitro of large and small pulmonary arteries of the rat. Clin Sci (Colch). 1992; 82:55-62.

Lebidois J, Soifer SJ, Clyman RI, Heymann MA.Piriprost: a putative leukotriene synthesis inhibitor increases pulmonary blood flow in fetal lambs. Pediatr Res. 1987; 22:350-4.

Leffler CW, Tyler TL, Cassin S. Effect of indomethacin on pulmonary vascular response to ventilation of fetal goats. Am J Physiol. 1978; 234:H346-51 
Leffler CW, Tyler TL, Cassin S. Responses of pulmonary and systemic circulations of perinatal goats to prostaglandin F2 alpha. Can J Physiol Pharmacol. 1979; 57:167-73.

Leffler CW, Hessler JR, Terragno NA. Ventilation-induced release of prostaglandinlike material from fetal lungs. Am J Physiol. 1980; 238:H282-6.

Leffler CW, Hessler JR, Green RS. Mechanism of stimulation of pulmonary prostacyclin synthesis at birth. Prostaglandins. 1984a; 28:877-87.

Leffler CW, Mitchell JA, Green RS. Cardiovascular effects of leukotrienes in neonatal piglets. Role in hypoxic pulmonary vasoconstriction? Circ Res. 1984b; 55:780-7.

Leffler CW, Hessler JR, Green RS. The onset of breathing at birth stimulates pulmonary vascular prostacyclin synthesis. Pediatr Res. 1984; 18:938-42.

Levin DL, Heymann MA, Kitterman JA, Gregory GA, Phibbs RH, Rudolph AM. Persistent pulmonary hypertension of the newborn. J. Pediatr 1976; 89:626-633.

Levin DL, Hyman AI, Heymann MA, Rudolph AM. Fetal hypertension and the development of increased pulmonary vascular smooth muscle: a possible mechanism for persistent pulmonary hypertension of the newborn. J Pediatr. 1978a; 92:265-9.

Levin DL, Fixler DE, Morriss FC, Tyson J. Morphologic analysis of the pulmonary vascular bed in infants exposed in utero to prostaglandin synthetase inhibitors. J Pediatr. 1978b; 92:478-83.

Levin DL, Mills LJ, Weinberg AG. Hemodynamic, pulmonary vascular, and myocardial abnormalities secondary to pharmacologic constriction of the fetal ductus arteriosus. A possible mechanism for persistent pulmonary hypertension and transient tricuspid insufficiency in the newborn infant. Circulation. 1979;60:360-4.

Lewis AB, Heymann MA, Rudolph AM. 1976. Gestational changes in pulmonary vascular responses in fetal lambs in utero. Circ. Res. 1976; 39:536-541.

Li H, Chen SJ, Chen YF, Meng QC, Durand J, Oparil S, Elton TS. Enhanced endothelin-1 and endothelin receptor gene expression in chronic hypoxia. J Appl Physiol. 1994; 77:1451-9.

Li S, Fan SX, McKenna TM. Role of nitric oxide in sepsis-induced hyporeactivity in isolated rat lungs. Shock. 1996; 5:122-9.

Liben S, Stewart DJ, De Marte J, Perreault T. Ontogeny of Big endothelin-1 effects in newborn piglet pulmonary vasculature. Am. J. Physiol. 1993; 265; 139-145

Lincoln TM, Thompson M, Cornwell TL. Purification and characterization of two forms of cyclic GMP-dependent protein kinase from bovine aorta. J Biol Chem. 1988; 263:17632-7.

Lindgren S, Rascon A, Andersson KE, Manganiello V, Degerman E. Selective inhibition of cGMP -inhibited and cGMP-noninhibited cyclic nucleotide phosphodiesterases and relaxation of rat aorta. Biochem Pharmacol. 1991; 42:54552.

Lippton, HL, Cohen GA, McMurtry IF, Hyman AL. Pulmonary vasodilation to endothelin isopeptides in vivo is mediated by potassium channel activation. J. Appl. Physiol. 1991; 70: 947-952 . 
Liu Y, Christou H, Morita T, Laughner E, Semenza GL, Kourembanas S. Carbon monoxide and nitric oxide suppress the hypoxic induction of vascular endothelial growth factor gene via the 5' enhancer. J Biol Chem. 1998; 273:15257-62.

Lock JE, Olley PM, Soldin S, Coceani F. Indomethacin-induced pulmonary vasoconstriction in the conscious newborn lamb. Am J Physiol. 1980; 238:H639-51.

Lopes Cardozo RH, de Beaufort AJ, Gesink BJ, Moison RM, van de Bor M, Berger HM, van Bel F. Inhalation of nitric oxide: effect on cerebral hemodynamics and activity, and antioxidant status in the newborn lamb. Biol Neonate. 1996; 69:284-92.

Lugnier C, Schoeffter P, Le Bec A, Strouthou E, Stoclet JC. Selective inhibition of cyclic nucleotide phosphodiesterases of human, bovine and rat aorta. Biochem. Pharmacol. 1986; 35: 1743-1751.

MacCumber MW, Ross CA, Glaser BM, Snyder SH. Endothelin: visualization of mRNAs by in situ hybridization provides evidence for local action. Proc. Natl. Acad. Sci. USA. 1989; 86:7285-7289.

MacKenzie A, Filippini S, Martin W. Effects of superoxide dismutase mimetics on the activity of nitric oxide in rat aorta. Br J Pharmacol 199; 127:1159-1164.

MacMicking JD, Nathan C, Hom G, Chartrain N, Fletcher DS, Trumbauer M, Stevens K, XieQW, Sokol K, Hutchinson $\mathrm{N}$. Altered responses to bacterial infection and endotoxic shock in mice lacking inducible nitric oxide synthase. Cell 1995; 81:641-50; Erratum. 1995. Cell 81:1171

MacRitchie AN, Jun SS, Chen Z, German Z, Yuhanna IS, Sherman TS, Shaul PW. Estrogen upregulates endothelial nitric oxide synthase gene expression in fetal pulmonary artery endothelium. Circ Res. 1997; 81:355-62.

Madden JA, Vadula MS, Kurup VP. Effects of hypoxia and other vasoactive agents on pulmonary and cerebral artery smooth muscle cells. Am J Physiol. 1992; 263:L384-93.

Maemura K, Kurihara H, Morita T, Hayashi Y, Yazaki Y. Production of endothelin-1 in vascular endothelial cells is regulated by factors associated with vascular injury. Gerontology 1992; 38(Suppl. 1):29-35

Maguire JJ, Johnson CM, Mockridge JW, Davenport AP. Endothelin converting enzyme (ECE) activity in human vascular smooth muscle. Br J Pharmacol. 1997; 122:1647-1654.

Maines MD. The heme oxygenase system: a regulator of second messenger gases. Annu Rev Pharmacol Toxicol 1997; 37:517-554

Malek A, Izumo S. Physiological fluid shear stress causes downregulation of endothelin-1 mRNA in bovine aortic endothelium. Am. J. Physiol 1992; 263:C389-96

Markhorst DG, Leenhoven T, Uiterwijk JW, Meulenbelt J, van Vught AJ. Occupational exposure during nitric oxide inhalational therapy in a pediatric intensive care setting. Intensive Care Med 1996; 22:954-8

Marks GS, Brien JF, Nakatsu K, McLaughlin BE. Does carbon monoxide have a physiological function?

Trends Pharmacol Sci 1991; 12:185-188

Marletta MA, Yoon PS, lyengar R., Leaf CD, Wishnok JS. Macrophage oxidation of L-arginine to nitrite and nitrate: nitric oxide is an intermediate. Biochemistry 1988; 27: 8706-8711.

Marsden PA, Dorfman DM, Collins T, Brenner BM, Orkin SH, Ballermann BJ. Regulated expression of endothelin1 in glomerular capillary endothelial cells. Am. J. Physiol. 1991; 261:F117-25 
Marsden PA, Brenner BM. Transcriptional regulation of the endothelin gene by TNF alpha. Am. J. Physiol. 1992; 262:C854-61

Masaki T, Vane JR, Vanhoutte PM. International union of pharmacology nomenclature of endothelin receptors. Pharmacol. Rev. 1994; 46:137-42.

Mashimo H, Goyal RK. Lessons from genetically engineered animal models. IV. Nitric oxide synthase gene knockout mice. Am J Physiol. 1999; 277:G745-50.

Mathew R, Burke-Wolin T, Gewitz MH, Wolin MS. $\mathrm{O}_{2}$ and rat pulmonary artery tone: effects of endothelium, $\mathrm{Ca}^{2+}$, cyanide, and monocrotaline. J Appl Physiol 1991; 71:30-36.

Mathew R. Development of the pulmonary circulation: metabolic aspects. In : Polin RA and Fox WW (eds.) Fetal and neonatal Physiology. WB Saunders Company, Philadelphia, 1998, pp 914-918.

Matsumura Y, Hisaki K, Takaoka M, Morimoto S. Phosphoramidon, a metalloprotase inhibitor, suppresses the hypertensive effect of big endothelin-1. Eur. J. Pharmacol. 1990; 185:103-6.

Meyer J, Lentz CW, Stothert JC Jr, Traber LD, Herndon DN, Traber DL. Effects of nitric oxide synthesis inhibition in hyperdynamic endotoxemia. Crit Care Med. 1994; 22:306-12.

McCormack DG, Barnes PJ, Evans TW. Purinoceptors in the pulmonary circulation of the rat and their role in hypoxic vasoconstriction. Br J Pharmacol 1989; 98:367-72.

McCormack DG, Barnes PJ, Evans TW. Evidence against a role for platelet-activating factor in hypoxic pulmonary vasoconstriction in the rat. Clin Sci 1989; 77:439-443.

McDonnell TJ, Wescott JY, Czartolomna J, Voelkel NF. Role of peptidoleukotrienes hypoxic pulmonary vasoconstriction in rats. Am J Physiol 1990; 259:H751-H758.

McElroy MC, Wiener-Kronish JP, Miyazaki H, Sawa T, Modelska K, Dobbs LG, Pittet JF. Nitric oxide attenuates lung endothelial injury caused by sublethal hyperoxia in rats. Am J Physiol. 1997; 272:L631-8.

McFadzean J, Tasker RC, Petros AJ. Nitric oxide ABO blood group difference in children. Lancet. 1999; $353: 1414$ 5.

McKenna TM. Prolonged exposure of rat aorta to low levels of endotoxin in vitro results in impaired contractility. Association with vascular cytokine release. J Clin invest. 1990; 86:160-8.

McQueston JA, Comfield DN, McMurtry IF, Abman SH. Effects of oxygen and exogenous L-arginine on EDRF activity in fetal pulmonary circulation. Am. J. Physiol. 1993; 264: H865-H871.

McQueston JA, Kinsella JP, Ivy DD, McMurtry IF, Abman SH. Chronic pulmonary hypertension in utero impairs endothelium-dependent vasodilation. Am. J. Physiol. 1995; 268:H288-H294.

Meadow W, Meus PJ. Early and late hemodynamic consequences of group B beta streptococcal sepsis in piglets: effects on systemic, pulmonary, and mesenteric circulations. Circ Shock. 1986; 19:347-56.

Meadow W, Rudinsky B. Inflammatory mediators and neonatal sepsis. Rarely has so little been known by so many about so much. Clin Perinatol. 1995; 22:519-36. 
Meadow W, Rudinsky B, Bell A, Hipps R. Effects of inhibition of endothelium-derived relaxation factor on hemodynamics and oxygen utilization during group B streptococcal sepsis in piglets. Crit Care Med. 1995; 23:705-14.

Mehta S, Javeshghani D, Datta P, Levy RD, Magder S. Porcine endotoxemic shock is associated with increased expired nitric oxide. Crit Care Med. 1999; 27:385-93.

Mercier JC, Zupan V, Dehan M, Renaudin MH, Bouchet M, Raveau C. Device to monitor concentration of inhaled nitric oxide. Lancet. 1993 Aug 14; 342:431-2.

Meyrick B, Niedermeyer ME, Ogletree ML, Brigham KL Pulmonary hypertension and increased vasoreactivity caused by repeated indomethacin in sheep. J Appl Physiol. 1985; 59:443-52.

Mitchell JA, Kohlhaas KL, Sorrentino R, Warner TD, Murad F, Vane JR. Induction by endotoxin of nitric oxide synthase in the rat mesentery: lack of effect on action of vasoconstrictors. Br J Pharmacol. 1993; 109:265-70.

Miyahara M., Ito M, Itoh H, Shiraishi T, Isaka N, Konishi T, Nakano T. Isoenzymes of cyclic nucleotide phosphodiesterase in the human aorta characterization and the effects of e4021. Eur. J. Pharmacol. 1995; 284:25-33.

Miyauchi T, Yorikane R, Sakai S, Sakurai T, Okada M, Nishikibe M, Yano M, Yamaguchi I, Sugishita Y, Goto K. Contribution of endogenous endothelin-1 to the progression of cardiopulmonary alterations in rats with monocrotalineinduced pulmonary hypertension. Circ Res. 1993; 73:887-97.

Miyauchi T, Masaki T. Pathophysiology of endothelin in the cardiovascular system. Annu Rev Physiol. 1999; 61:391415.

Mohaupt MG, Elzie JL, Ahn KY, Clapp WL, Wilcox CS, Kone BC. Differential expression and induction of mRNAs encoding two inducible nitric oxide synthases in rat kidney. Kidney Int 1994; 46: 653-665, 1994.

Mok Q, Yates R, Tasker RC. Persistent pulmonary hypertension of the term neonate: a strategy for management. Eur J Pediatr. 1999; 158:825-7.

Moncada S, Higgs EA. The L-arginine-nitric oxide pathway. N. Engl. J. Med. 1993; 329: 2002-2012.

Moncada S, Palmer RM, Higgs EA. Biosynthesis of nitric oxide from L-arginine: a pathway for the regulation of cell function and communication. Biochem. Pharmacol.1989; 38:1709-1715.

Moore P, Velvis H, Fineman JR, Soifer SJ, Heymann MA. EDRF inhibition attenuates the increase in pulmonary blood flow due to oxygen ventilation in fetal lambs. J Appl Physiol. 1992; 73:2151-7.

Morganroth ML, Reeves JT, Murphy CR, Voelkel NF. Leukotriene synthesis and receptor blockers block hypoxic pulmonary vasoconstriction. J Appl Physiol 1984; 56:1340-1346.

Morin FC 3d, Egan EA, Ferguson W, Lundgren CEC. Development of pulmonary vascular response to oxygen. Am. J. Physiol. 1988a. 254:H542-546.

Morin FC 3d, Egan EA, Norfleet WT. Indomethacin does not diminish the pulmonary vascular response of the fetus to increased oxygen tension. Pediatr Res. 1988b; 24:696-700.

Morin FC 3d. Ligating the ductus arteriosus before birth causes persistent pulmonary hypertension in the newborn lamb. Pediatr Res. 1989; 25:245-50. 
Morita I, Schindler M, Regier MK, Otto JC, Hori T, DeWitt DL, Smith WL. Different intracellular locations for prostaglandin endoperoxide $\mathrm{H}$ synthase-1 and -2 . J. Biol. Chem. 1995; 270:10902-8

Moro MA, Darley-Usmar VM, Goodwin DA, Read NG, Zamora-Pino R, Feelisch M, Radomski MW, Moncada S. Paradoxical fate and biological action of peroxynitrite on human platelets. Proc. Natl. Acad. Sci. USA 1994; 91 : 6702 6706.

Morrow JD, Minton TA, Badr KF, Roberts LJ 2nd. Evidence that the F2-isoprostane, 8-epi-prostaglandin F2 alpha, is formed in vivo. Biochim Biophys Acta. 1994; 1210:244-8.

Mourgeon E, Levesque E, Duveau C, Law-Koune JD, Charbit B, Ternissien E, Coriat P, Rouby J. Factors influencing indoor concentrations of nitric oxide in a Parisian intensive care unit. Am J Respir Crit Care Med 1997; 156:1692-5

Murad F, Ishii K, Forstermann U, Gorsky L, Kerwin JF Jr, Pollock J, Heller M. EDRF is an intracellular second messenger and autacoid to regulate cyclic GMP synthesis in many cells. Adv. Second Messenger Phosphoprotein Res. $1990 ; 24: 441-48$

Muramatsu M., Tyler RC, Rodman DM, McMurtry IF. Thapsigargin stimulates increased NO activity in hypoxic hypertensive rat lungs and pulmonary arteries. J. Appl. Physiol. 1996; 80: 1336-1344.

Murphy JD, Aronovitz MJ, Reid LM. Effects of chronic in utero hypoxia on the pulmonary vasculature of the newborn guinea pig. Pediatr Res. 1986; 20:292-5.

Murphy JD, Rabinovitch M, Goldstein JD, Reid. LM. The structural basis of persistent pulmonary hypertension of the newborn infant. J. Pediatr. 1981; 98:962-967.

Murphy RC. Cytochrome P-450 metabolism of arachidonic acid: formation and biological actions of epoxygenasederived eicosanoids. Pharmacol Rev 1989; 40:229-241.

Murray TR, Chen L, Marshall BE, Macarak EJ. Hypoxic contraction of cultured pulmonary vascular smooth muscle cells. Am J Respir Cell Mol Biol. 1990; 3:457-65.

Nakayama DK, Geller DA, Lowenstein CJ, Chern HD, Davies P, Pitt BR, Simmons RL, Billiar TR. Cytokines and lipopolysaccharide induce nitric oxide synthase in cultured rat pulmonary artery smooth muscle. Am J Respir Cell Mol Biol. 1992; 7:471-6.

Namiki A, Brogi E, Kearney M, Kim EA, Wu T, Couffinhal T, Varticovski L, Isner JM. Hypoxia induces vascular endothelial growth factor in cultured human endothelial cells. J Biol Chem. 1995; 270:31189-95.

Nathan CF, Hibbs JB Jr. Role of nitric oxide synthesis in macrophage antimicrobial activity. Curr. Opin. Immunol. $1991 ; 3: 65-70$

Nelin LD, Thomas CJ, Dawson CA. Effect of hypoxia on nitric oxide production in neonatal pig lung. Am. J. Physiol. 1996; 271: H8-H14.

Nelin LD, Welty SE, Morrisey JF, Gotuaco C, Dawson CA.Nitric oxide increases the survival of rats with a high oxygen exposure. Pediatr Res. 1998; 43:727-32.

Nelin LD, Hoffman GM. The use of inhaled nitric oxide in a wide variety of clinical problems. Pediatr Clin North Am. 1998; 45:531-48.

Nelson S, Steward RH, Traber L, Traber D. Endotoxin-induced alterations in contractility of isolated blood 
vessels from sheep. Am J Physiol. 199; 260:H1790-4.

Neonatal Inhaled Nitric Oxide Study Group. Inhaled nitric oxide in full-term and nearly full-term infants with hypoxic respiratory failure. N Engl J Med. 1997a; 336:597-604.

Neonatal Inhaled Nitric Oxide Study Group. Inhaled nitric oxide and hypoxic respiratory failure in infants with congenital diaphragmatic hernia. Pediatrics. 1997b; 99:838-45.

Neonatal Inhaled Nitric Oxide Study Group. Inhaled nitric oxide in term and near-term infants: neurodevelopmental follow-up of the neonatal inhaled nitric oxide study group (NINOS). J Pediatr. 2000;136:611-7.

Nguyen T, Brunson D, Crespi CL, Penman BW, Wishnok JS, Tannenbaum SR. DNA damage and mutation in human cells exposed to nitric oxide in vitro. Proc. Natl. Acad. Sci. USA 1992; 89: 3030-3034.

Novogrodsky A, Vanichkin A, Patya M, Gazit A, Osherov N, Levitzki A. Prevention of lipopolysaccharide-induced lethal toxicity by tyrosine kinase inhibitors. Science 1994; 264:1319-22

North A.J. Star RA, Brannon TS, Ujiie K, Wells LB, Lowenstein CJ, Snyder SH, Shaul PW. NO synthase type I and type III gene expression are developmentally regulated in rat lung. Am. J. Physiol. 1994; 266: L635-L641

NusslerAK, Billiar TR. Inflammation, immunoregulation and inducible nitric oxide synthase. J. Leukoc. Biol 1993; 54: $171-178$.

Ohistein EH, Nichols AJ. Rabbit polymorphonuclear neutrophils elicit endothelium-dependent contraction in vascular smooth muscle. Circ Res 1989; 65:917-24.

Ohno M, Gibbons GH, Dzau VJ, Cooke JP. Shear stress elevates endothelial cGMP. Role of a potassium channel and $G$ protein coupling. Circulation 1993; 88:193-197.

Okinaga S, Takahashi K, Takeda K, Yoshizawa M, Fujita H, Sasaki H, Shibahara S. Regulation of human heme oxygenase-1 gene expression under thermal stress. Blood 1996; 87:5074-5084

Palmer LA, Semenza GL, Stoler MH, Johns RA. Hypoxia induces type II NOS gene expression in pulmonary artery endothelial cells via HIF-1. Am J Physiol. 1998; 274:L212-9.

Palmer RM, FerrigeAG, Moncada S. Nitric oxide release accounts for the biological activity of endothelium-derived relaxing factor. Nature (Lond.) 1987; 327: 524-526.

Paimer RM, Moncada S. A novel citrulline-forming enzyme implicated in the formation of nitric oxide by vascular endothelial cells. Biochem. Biophys. Res. Commun. 1989; 158:348-52

Parer JT. The effect of acute maternal hypoxia on fetal oxygenation and the umbilical circulation in sheep. Eur J Obstet Gynecol Reprod Biol 1980; 10:125-36.

Parker TA, le Cras TD, Kinsella JP, Abman SH. Developmental changes in endothelial nitric oxide synthase expression and activity in ovine fetal lung. Am J Physiol Lung Cell Mol Physiol. 2000 ; 278:L202-L208.

Parratt JR. Myocardial and circulatory effects of $\mathrm{E}$. coli endotoxin; modification of responses to catecholamines $\mathrm{Br} \mathrm{J}$ Pharmacol. $1973 ; 47: 12-25$

Peliowski A, Finer NN, Etches PC, Tierney AJ, Ryan CA. Inhaled nitric oxide for premature infants after prolonged rupture of the membranes. J Pediatr. 1995; 126:450-3. 
Pepke-Zaba J, Higenbottam TW, Dinh-Xuan AT, Stone D, Wallwork J. Inhaled nitric oxide as a cause of selective pulmonary vasodilatation in pulmonary hypertension. Lancet. 1991; 338:1173-4.

Perreault T, Baribeau J. Characterization of endothelin receptors in newbom piglet lung. Am. J. Physiol. 1995; 268: 607614

Phelan MW, Forman LW, Perrine SP, Faller DV. Hypoxia increases thrombospondin-1 transcript and protein in cultured endothelial cells. J Lab Clin Med. 1998; 132:519-29.

Phelan MW, Faller DV. Hypoxia decreases constitutive nitric oxide synthase transcript and protein in cultured endothelial cells. J Cell Physiol. 1996; 167:469-76.

Philips JB 3d, Lyrene RK, Godoy G, Graybar G, Barefield E, Sams JE, Gray BM.Hemodynamic responses of chronically instrumented piglets to bolus injections of group B streptococci. Pediatr Res. 1988 ; 23:81-5.

Phillips ML, Hall TA, Sekar K, Tomey Л. Assessment of medical personnel exposure to nitrogen oxides during inhaled nitric oxide treatment of neonatal and pediatric patients. Pediatrics 1999; 104:1095-100

Plumpton C, Ashby MJ, Kuc RE, O'Reilly G, Davenport AP. Expression of endothelin peptides and mRNA in the human heart. Clin Sci (Colch). $1996 ; 90: 37-46$.

Polson JB, Strada SJ. Cyclic nucleotide phosphodiesterases and vascular smooth muscle. Annu Rev Pharmacol Toxicol 1996; 36:403-27

Popescu LM, Panoiu C, Hinescu M, Nutu O. The mechanism of cGMP-induced relaxation in vascular smooth muscle. Eur J Pharmacol. 1985a 8; 107:393-4.

Popescu LM, Foril CP, Hinescu M, Panoiu C, Cinteza M, Gherasim L. Nitroglycerin stimulates the sarcolemmal Ca++-extrusion ATPase of coronary smooth muscle cells. Biochem Pharmacol. 1985b May 15; 34:1857-60.

Post JM, Hume JR, Archer SL, Weir EK. Direct role for potassium channel inhibition in hypoxic pulmonary vasoconstriction. Am J Physiol. 1992; 262:C882-90.

Potter CF, Dreshaj IA, Haxhiu MA, Stork EK, Chatburn RL, Martin RJ. Effect of exogenous and endogenous nitric oxide on the airway and tissue components of lung resistance in the newborn piglet. Pediatr. Res. 1997; 41:886-891.

Potter CF, Kuo NT, Farver CF, McMahon JT, Chang CH, Agani FH, Haxhiu MA, Martin RJ. Effects of hyperoxia on nitric oxide synthase expression, nitric oxide activity, and lung injury in rat pups. Pediatr Res. 1999; 45:8-13.

Pufahl RA, Nanjappan PG, Woodard RW, Marletta MA. Mechanistic probes of N-hydroxylation of L-arginine by the inducible nitric oxide synthase from murine macrophages. Biochemistry 1992; 31:6822-28

Pulido EJ, Shames BD, Fullerton DA, Sheridan BC, Selzman CH, Gamboni-Robertson F, Bensard DD, McIntyre RC Jr. Differential inducible nitric oxide synthase expression in systemic and pulmonary vessels after endotoxin. Am J Physiol Regul Integr Comp Physiol. 2000; 278:R1232-9.

Radi R, Beckman JS, Bush KM, Freeman BA. Peroxynitrite-induced membrane lipid peroxidation: the cytotoxic potential of superoxide and nitric oxide. Arch. Biochem. Biophys. 1991; 288:481-87

Radomski A, Sawicki G, Olson DM, Radomski MW. The role of nitric oxide and metalloproteinases in the pathogenesis of hyperoxia-induced lung injury in newborn rats. Br J Pharmacol. 1998; 125:1455-62. 
Radomski MW, Paimer RMJ, Moncada S. An L-arginine/nitric oxide pathway present in human platelets regulates aggregation. Proc. Natl. Acad. Sci. USA 1990; 87: 5193-5197.

Rairigh RL, Le Cras TD, Ivy DD, Kinsella JP, Richter G, Horan MP, Fan ID, Abman SH. Role of inducible nitric oxide synthase in regulation of pulmonary vascular tone in the late gestation ovine fetus. J Clin Invest. 1998 ; 101:15-21.

Rairigh RL, Storme L, Parker TA, le Cras TD, Markham N, Jakkula M, Abman SH. Role of neuronal nitric oxide synthase in regulation of vascular and ductus arteriosus tone in the ovine fetus. Am J Physiol Lung Cell Mol Physiol. 2000; 278:L105-L110

Rasanen J, Wood DC, Debbs RH, Cohen J, Weiner S, Huhta JC. Reactivity of the human fetal pulmonary circulation to maternal hyperoxygenation increases during the second half of pregnancy: a randomized study. Circulation.1998; 27; 97:257-62.

Rees DD, Cellek S, Palmer RM, Moncada S. Dexamethasone prevents the induction by endotoxin of a nitric oxide synthase and the associated effects on vascular tone: an insight into endotoxin shock. Biochem. Biophys. Res. Commun. 1990; 173:541-47

Rees DD, Monkhouse JE, Moncada S. NG-monomethyl-L-arginine (L-NMMA: 546C88) improves survival in a conscious instrumented mouse model of endotoxic shock. Endothelium 1995; 3 (Suppl):S116.

Reeve HL, Weir EK, Archer SL, Cornfield DN. A maturational shift in pulmonary $\mathrm{K}+$ channels, from Ca2+ sensitive to voltage dependent. Am J Physiol. 1998; 275:L1019-25.

Rengasamy A, Johns RA: Characterization of endothelium-derived relaxing factor/nitric oxide synthase from bovine cerebellum and mechanism of modulation by high and low oxygen tensions. J Pharmacol Exp Ther 1991; 259:310-316.

Robbins CG, Davis JM, Merritt TA, Amirkhanian JD, Sahgal N, Morin FC, Horowitz S. Combined effects of nitric oxide and hyperoxia on surfactant function and pulmonary inflammation. Am J Physiol 1995; 269: L545-50

Robbins CG, Horowitz S, Merritt TA, Kheiter A, Tierney J, Narula P, Davis JM. Recombinant human superoxide dismutase reduces lung injury caused by inhaled nitric oxide and hyperoxia. Am J Physiol. 1997; 272:L903-7.

Roberts JD, Polaner DM, Lang P, Zapol WM. Inhaled nitric oxide in persistent pulmonary hypertension of the newborn. Lancet 1992; 340:818-819.

Roberts JD, Shaul PW. Advances in the treatment of persistent pulmonary hypertension, Pediatr. Clin. North Am. 1993; 40:983-995.

Roberts JD Jr, Chen TY, Kawai N, Wain J, Dupuy P, Shimouchi A, Bloch K, Polaner D, Zapol WM. Inhaled nitric oxide reverses pulmonary vasoconstriction in the hypoxic and acidotic newborn lamb. Circ Res. 1993; 72:246-54.

Roberts JD, Kinsella JP, Abman SH. Inhaled nitric oxide in neonatal pulmonary hypertension and severe respiratory distress syndrome: experimental and clinical studies. In: Zapol WM \& Bloch KD (eds.) Nitric oxide and the lung. Marcel Dekker, New York, 1997a, pp 333-363.

Roberts JD Jr, Fineman JR, Morin FC 3rd, Shaul PW, Rimar S, Schreiber MD, Polin RA, Zwass MS, Zayek MM, Gross I, Heymann MA, Zapol WM. Inhaled nitric oxide and persistent pulmonary hypertension of the newbom. The Inhaled Nitric Oxide Study Group. N Engl J Med. 1997b; 336:605-10. 
Roberts LJ 2nd, Morrow JD. The generation and actions of isoprostanes. Biochim Biophys Acta. 1997; 1345:12135.

Roberts LJ 2nd, Brame CJ, Chen Y, Morrow JD. Novel eicosanoids. Isoprostanes and related compounds. Methods Mol Biol. 1999;120:257-85.

Rogers NE, Ignarro LJ. Constitutive nitric oxide synthase from cerebellum is reversibly inhibited by nitric oxide formed from L-arginine. Biochem. Biophys. Res. Commun. 1992; 189:242-49

Rosenberg AA, Kennaugh J, Koppenhafer SL, Loomis M, Chatfield BA, Abman SH. Elevated immunorreactivity endothelin-1 levels in newborn infants with persistent pulmonary hyepertension. J. Pediatr. 1993; 14:109-114.

Rosman GJ, Martins TJ, Sonnenburg WK, Beavo JA, Ferguson K, Loughney K. Isolation and characterization of human cDNAs encoding a cGMP-stimulated 3'5'-cyclic nucleotide phoshodiesterase. Gene 1997; 191: 89-95.

Rounds S, McMurtry IF. Inhibitors of oxidative ATP production cause transient vasoconstriction and block subsequent pressor responses in rat lung. Circ Res 1981; 48:393-400.

Rubanyi GM, Vanhoutte PM. Hypoxia releases a vasoconstrictor substance from the canine vascular endothelium. J. Physiol. (Lond.) 1985; 364: 45-56.

Rubanyi GM, Vanhoutte PM. Superoxide anions and hyperoxia inactivate endothelium-derived relaxing factor. Am J Physiol 1986; 250:H822-H827.

Rudolph AM, Heymann MA. The fetal circulation. Annu Rev Med. 1968; 19:195-206.

Ruetten H, Southan GJ, Abate A, Thiemermann C. Attenuation of endotoxin-induced multiple organ dysfunction by 1-amino-2-hydroxy-guanidine, a potent inhibitor of inducible nitric oxide synthase. Br. J. Pharmacol. 1996; 118:261-70.

Runkle B, Goldberg RN, Streitfeld MM, Clark MR, Buron E, Setzer ES, Bancalari E. Cardiovascular changes in group B streptococcal sepsis in the piglet: response to indomethacin and the relationship to prostacyclin and thromboxane $\mathrm{A}_{2}$. Pediatr Res 1984; 18:874-878

Russell FD, Davenport AP. Secretory pathways in endothelin synthesis. Br J Pharmacol. 1999; 126:391-8.

Saeed SA, Mitchell MD. Arachidonate lipoxygenase activity in human fetal lung. Eur J Pharmacol. 1982; 78:38991.

Saeki, T., and I. Saito. Isolation of cyclic nucleotide phosphodiesterase isozymes from pig aorta. Biochem. Pharmacol. 1993; 46:833-839.

Sakurai T, Yanagisawa M, Takuwa Y, Miyazaki H, Kimura S, Goto K, Masaki T. Cloning of a cDNA encoding a non isopeptide selective subtype of the endothelin receptor. Nature 1990; 348:732-35.

Sakurai T, Yanagisawa M, Inoue A, Ryan US, Kimura S, Goto K, Masaki. cDNA cloning, sequence analysis and tissue distribution of rat preproendothelin-1 mRNA. Biochem. Biophys. Res. Commun. 1991; 175:44-47.

Samama CM, Diaby M, Fellahi J, Mdhafar A, Eyraud D, Arock M, Guillosson JJ, Coriat P, Rouby J. Inhibition of platelet aggregation by inhaled nitric oxide in patients with acute respiratory distress syndrome. Anesthesiology. 1995; 83:56-65. 
Sammut IA, Foresti R, Clark JE, Exon DJ, Vesely MJ, Sarathchandra P, Green CJ, Motterlini R. Carbon monoxide is a major contributor to the regulation of vascular tone in aortas expressing high levels of haeme oxygenase-1. $\mathrm{Br}$ J Pharmacol 1998; 125:1437-1444

Sandberg K, Edberg KE, Fish W, Parker RA, Hellerqvist C, Sundell H. Thromboxane receptor blockade (SQ 29,548 ) in group B streptococcal toxin challenge in young lambs. Pediatr Res. 1994; 35:571-9.

Saugstad OD. Inhaled nitric oxide for preterm infants--still an experimental therapy. Lancet. 1999; 354:1047-8.

Schaller MD, Waeber B, Nussberger J, Brunner HR. Angiotensin II, vasopressin, and sympathetic activity in conscious rats with endotoxemia. Am J Physiol. 1985; 249:H1086-92.

Schneider F, Bucher B, Schott C, Andre A, Julou-Schaeffer G, Stoclet JC. Related Effect of bacterial lipopolysaccharide on function of rat small femoral arteries. Am J Physiol. 1994; 266:H191-8.

Schreiber MD, Heymann MA, Soifer SJ. The differential effects of leukotriene C4 and D4 on the pulmonary and systemic circulations in newborn lambs. Pediatr Res. 1987; 21:176-82.

Schreiber MD, Covert RF, Torgerson LJ. Hemodynamic effects of heat-killed group B beta-hemolytic streptococcus in newborn lambs: role of leukotriene D4. Pediatr Res. 1992;31:121-6.

Seppanen MP, Kaapa PO, Kero PO, Saraste M. Doppler-derived systolic pulmonary artery pressure in acute neonatal respiratory distress syndrome. Pediatrics. 1994; 93:769-73.

Sessa WC, Pritchard K, Seyedi N, Wang J, Hintze TH. Chronic exercise in dogs increases coronary vascular nitric oxide production and endothelial cell nitric oxide synthase gene expression. Circ. Res. 1994; 74: 349-353.

Sharefki JB, Diamond SL, Eskin SG, Mclntire LV, Fenbach CW. Fluid flow decreases preproendothelin mRNA levels and suppresses endothelin-1 peptide release in cultured human endothelial cells. J. Vasc. Surg. 1991; 14:1-9.

Shaul PW, Kinane B, Farrar MA, Buja LM, Magness RR. Prostacyclin production and mediation of adenylate cyclase activity in the pulmonary artery. Alterations after prolonged hypoxia in the rat. J Clin Invest 1991; 88:447455.

Shaul PW, Farrer MA, Zellers TM. Oxygen modulates endothelium-derived relaxing factor production in fetal pulmonary arteries. Am. J. Physiol. 1992; 262:H355-H364.

Shaul PW, Farrar MA, Magness RR. Oxygen modulation of pulmonary arterial prostacyclin synthesis is developmentally regulated. Am J Physiol. 1993a; 265:H621-8.

Shaul PW, Wells LB, Horning KM. Acute and prolonged hypoxia attenuate endothelial nitric oxide production in rat pulmonary arteries by different mechanisms. J Cardiovasc Pharmacol 1993b; 22:819-827.

Shaul PW, North AJ, Brannon TS, Ujiie K, Wells LB, Nisen PA, Lowenstein CJ, Snyder SH, Star RA. Prolonged in vivo hypoxia enhances nitric oxide synthase type I and type III gene expression in adult rat lung. Am. J. Respir. Cell Mol. Biol. 1995; 13:167-174.

Shaul PW, Yuhanna IS, German Z, Chen Z, Steinhorn RH, Morin FC 3rd. Pulmonary endothelial NO synthase gene expression is decreased in fetal lambs with pulmonary hypertension. Am J Physiol. 1997; 272:L1005-12. Shaul PW. Regulation of vasodilator synthesis during lung development. Early Hum Dev. 1999; 54:271-9

Shaul PW, Pace MC, Chen Z, Brannon TS. Developmental changes in prostacyclin synthesis are conserved in 
cultured pulmonary endothelium and vascular smooth muscle. Am J Respir Cell Mol Biol. 1999; 20:113-21

Shi Y, Li HQ, Shen CK, Wang JH, Qin SW, Liu R, Pan J. Plasma nitric oxide levels in newborn infants with sepsis. J Pediatr. 1993; 123:435-8.

Simmoneau G, Escourrou P, Duroux P, Lockhart A. Inhibition of hypoxic pulmonary vasoconstriction by nifedipine. New Engl J Med 1981; 304:1582-5.

Skimming JW, DeMarco VG, Cassin S. The effects of nitric oxide inhalation on the pulmonary circulation of preterm lambs. Pediatr Res. 1995; 37:35-40.

Skimming JW, Bender KA, Hutchison AA, Drummond WH. Nitric oxide inhalation in infants with respiratory distress syndrome. J Pediatr. 1997; 130:225-30.

Smedegard G, Hedqvist P, Dahlen SE, Revenas B, Hammarstrom S, Samuelsson B. Leukotriene C4 affects pulmonary and cardiovascular dynamics in monkey. Nature. 1982; 295:327-9.

Smith WL, DeWitt DL. Prostaglandin endoperoxide H synthases-1 and -2. Adv. Immunol. 1996; 62:167-215

Sobol BJ, Bottex G, Emirgil C, Gissen H. Gaseous diffusion from alveoli to pulmonary vessels of considerable size. Circ. Res. 1963; 13:71-79

Soifer SJ, Loitz RD, Roman C, Heymann MA. Leukotriene end organ antagonists increase pulmonary blood flow in fetal lambs. Am J Physiol. 1985; 249:H570-6.

Soifer SJ, Kaslow D, Roman C, Heymann MA. Umbilical cord compression produces pulmonary hypertension in newborn lambs: a model to study the pathophysiology of persistent pulmonary hypertension in the newborn. J Dev Physiol. 1987; 9:239-52.

Soukka H, Viinikka L, Kaapa P. Involvement of thromboxane A2 and prostacyclin in the early pulmonary hypertension after porcine meconium aspiration. Pediatr Res. 1998; 44:838-42.

Stanbrook HS, McMurtry IF. Inhibition of glycolysis potentiates hypoxic vasoconstriction in rat lungs. J Appl Physiol. 1983; 55:1467-73.

Starling MB, Neutze JM, Elliott RL, Elliott RB. Comparative studies on the hemodynamic effects of prostaglandin $\mathrm{E}_{1}$, prostacyclin and tolazoline upon elevated pulmonary vascular resistance in neonatal swine. Prostaglandin Med 1981; 7:349-35.

Steinhom RH, Russell JA, Morin FC. Disruption of cGMP production in pulmonary arteries isolated from fetal lambs with pulmonary hypertension. Am. J. Physiol. 1995a; 268:H1483-H1489.

Steinhorn RH, Millard SL, Morin FC 3rd. Persistent pulmonary hypertension of the newborn. Role of nitric oxide and endothelin in pathophysiology and treatment. Clin Perinatol. 1995b; 22:405-28.

Steinhorn RH, Morin FC 3rd, Fineman JR. Models of persistent pulmonary hypertension of the newborn (PPHN) and the role of cyclic guanosine monophosphate (GMP) in pulmonary vasorelaxation. Semin Perinatol. 1997a; 21:393-408

Steinhorn RH, Cox PN, Fineman JR, Finer NN, Rosenberg EM, Silver MM, Tyebkhan J, Zwass MS, Morin FC 3rd. Inhaled nitric oxide enhances oxygenation but not survival in infants with alveolar capillary dysplasia. J Pediatr. 1997b; 130:417-22. 
Steinhorn RH, Gordon JB, Tod ML. Site-specific effect of guanosine 3',5'-cyclic monophosphate phosphodiesterase inhibition in isolated lamb lungs. Crit Care Med. 2000; 28:490-5.

Stenmark KR, James SL, Voelkel NF, Toews WH, Reeves JT, Murphy RC. Leukotriene C4 and D4 in neonates with hypoxemia and pulmonary hypertension. N Engl J Med. 1983; 309:77-80.

Steudel W, Ichinose F, Huang PL, Hurford WE, Jones RC, Bevan JA, Fishman MC, Zapol WM. Pulmonary vasoconstriction and hypertension in mice with targeted disruption of the endothelial nitric oxide synthase (NOS 3 ) gene. Circ. Res. 1997; 81:34-41.

Steudel W, Scherrer-Crosbie M, Bloch KD, Weimann J, Huang PL, Jones RC, Picard MH, Zapol WM. Sustained pulmonary hypertension and right ventricular hypertrophy after chronic hypoxia in mice with congenital deficiency of nitric oxide synthase 3 . J. Clin. Invest. 1998; 101:2468-2477

Steudel W, Hurford WE, Zapol WM. Inhaled nitric oxide: basic biology and clinical applications. Anesthesiology. 1999; 91:1090-121.

Steudel W, Kirmse M, Weimann J, Ultrich R, Hromi J, Zapol WM. Exhaled nitric oxide production by nitric oxide synthase-deficient mice. Am J Respir Crit Care Med. 2000;162:1262-7.

Stevens T, Cornfield DN, McMurtry IF, Rodman DM. Acute reductions in $\mathrm{pPO}_{2}$ depolarize pulmonary endothelial cells and decrease $\left[\mathrm{Ca}^{2+}\right]$. Am J Physiol 1994; 266:H1416-H1421.

Stevenson DK, Kasting DS, Darnall RA, Ariagno RL, Jonhson JD, Malachowski N, Beets CL, Sunshine P. Refractory hypoxemia associated with neonatal pulmonary disease: The use and limitations of tolazoline. J. Pediatr 1979; 95:595-9.

Stewart TE, Valenza F, Ribeiro SP, Wener AD, Volgyesi G, Mullen JB, Slutsky AS. Increased nitric oxide in exhaled gas as an early marker of lung inflammation in a model of sepsis. Am J Respir Crit Care Med. 1995; 151:713-8.

Stitt JT, Dubois AB, Douglas JS, Shimada SG. Exhalation of gaseous nitric oxide by rats in response to endotoxin and its absorption by the lungs. J Appl Physiol. 1997; 82:305-16.

Stoclet JC, Andriantsitohaina R, Klesschyov A, Muller B. Nitric oxide and cyclic GMP in regulation of arterial tone. Trends Cardiovasc Med 1998; 8:14-19.

Stone JR, Marietta MA Soluble guanylate cyclase from bovine lung: activation with nitric oxide and carbon monoxide and spectral characterization of the ferrous and ferric states. Biochemistry 1994; 33:5636-5640

Stone JR, Marletta MA. The ferrous heme of soluble guanylate cyclase: formation of hexacoordinate complexes with carbon monoxide and nitrosomethane. Biochemistry. 1995; 34(50):16397-403

Storme L, Zerimech F, Riou Y, Martin-Ponthieu A, Devisme L, Slomianny C, Klosowski S, Dewailly E, Cneude F, Zandecki M, Dupuis B, Lequien P. Inhaled nitric oxide neither alters oxidative stress parameters nor induces lung inflammation in premature lambs with moderate hyaline membrane disease. Biol Neonate. 1998; 73:172-81.

Storme L, Rairigh RL, Parker TA, Kinsella JP, Abman SH. In vivo evidence for a myogenic response in the fetal pulmonary circulation Pediatr Res. 1999; 45:425-31.

Stuehr D, Gross S, Sakuma I, Levi R, Nathan C. Activated murine macrophages secrete a metabolite of arginine 
with the bioactivity of endothelium-derived relaxing factor and the chemical reactivity of nitric oxide. J. Exp. Med. 1989; 169:1011-1020.

Su Y, Block ER: Hypoxia inhibits L-arginine synthesis from L-citrulline in porcine pulmonary artery endothelial cells. Am J Physiol 1995;L581-L587.

Suba EA, McKenna TM, Williams TJ. Differential contractile responses of mesenteric and pulmonary artery segments to norepinephrine and phorbol ester in the septic pig. Circ Shock. 1992; 37:164-8.

Suematsu M, Goda N, Sano T, Kashiwagi S, Egawa T, Shinoda Y, Ishimura Y. Carbon monoxide: an endogenous modulator of sinusoidal tone in the perfused rat liver. J Clin Invest 1995; 96:2431-2437

Sylvester JT, McGowan C The effects of agents that bind to cytochrome P-450 on hypoxic pulmonary vasoconstriction. Circ Res. 1978; 43:429-37.

Szabo C, Mitchell JA, Thiemermann C, Vane JR. Nitric oxide-mediated hyporeactivity to noradrenaline precedes the induction of nitric oxide synthase in endotoxin shock. Br J Pharmacol. 1993; 108:786-92.

Szabo C. The pathophysiological role of peroxynitrite in shock, inflammation, and ischemia-reperfusion injury. Shock 1996a; 6: 79-88.

Szabo C. DNA strand breakage and activation of poly-ADP ribosyltransferase A cytotoxic pathway triggered by peroxynitrite. Free Radic Biol Med 1996b; 21: 855-69.

Taguchi H, Heistad DD, Chu Y, Rios CD, Ooboshi H, Faraci FM. Vascular expression of inducible nitric oxide synthase is associated with activation of $\mathrm{Ca}(++)$-dependent $\mathrm{K}+$ channels. J Pharmacol Exp Ther. 1996; 279:1514-9.

Tarpey MN, Graybar GB, Lyrene RK, Godoy G, Oliver J, Gray BM, Philips JB 3d.

Thromboxane synthesis inhibition reverses group B Streptococcus-induced pulmonary hypertension. Crit Care Med. 1987; 15:644-7.

Teitel DF, Iwamoto HS, Rudolph AM. Changes in the pulmonary circulation during birth-related events. Pediatr Res. 1990; 27:372-8.

Terragno NA, Terragno A. Prostaglandin metabolism in the fetal and maternal vasculature. Fed Proc. 1979; $38: 75-$ 7.

Thebaud B, Saizou C, Farnoux C, Hartman JF, Mercier JC. Dypiridamole, a cGMP phosphodiesterase inhibitor, transiently improves the response to inhaled nitric oxide in two newborns with congenital diaphragmatic hernia. Intensive Care Med. 1999; 25:300-3.

Thiemermann C, Vane J. Inhibition of nitric oxide synthesis reduces the hypotension induced by bacterial lipopolysaccharides in the rat in vivo. Eur. J. Pharmacol. 1990; 182:591-95.

Thiemermann C. The role of the L-arginine: nitric oxide pathway in circulatory shock. Adv Pharmacol. 1994; 28:45-79.

Thusu KG, Morin FC 3rd, Russell JA, Steinhorn RH. The cGMP phosphodiesterase inhibitor zaprinast enhances the effect of nitric oxide. Am J Respir Crit Care Med. 1995; 152:1605-10.

Tiktinsky M.H., Morin FC. Increasing oxygen tension dilates fetal pulmonary circulation via endothelium-derived relaxing factor. Am. J. Physiol. 1993; 265:H376-H380. 
Tod ML, Cassin S. Endothelin-1-induced pulmonary arterial dilation is reduced by Nomega-nitro-L-arginine in fetal lambs. J. Appl. Physiol. 1992; 72:1730-1734 .

Tolsa JF, Cotting J, Sekarski N, Payot M, Micheli Л, Calame A. Magnesium sulphate as an alternative and safe treatment for severe persistent pulmonary hypertension of the newborn. Arch Dis Child Fetal Neonatal Ed. 1995; 72:F184-7.

Toothill $\mathrm{C}$ The chemistry of the in-vivo reaction between haemoglobin and various oxides of nitrogen. $\mathrm{Br} \mathrm{J}$ Anaesth. 1967; 39:405-412

Tracey KJ, Fong Y, Hesse DG, Manogue KR, Lee AT, Kuo GC, Lowry SF, Cerami A. Anti-cachectin/TNF monoclonal antibodies prevent septic shock during lethal bacteraemia. Nature 1987; 330:662-4.

Tripp ME, Drummond WH, Heymann MA, Rudolf AM. Hemodynamic effect of pulmonary arterial infusion of vasodilators in newborn lambs, Pediatr. Res. 1980; 14:1311-1315.

Tristani-Firouzi M, Reeve HL, Tolarova S, Weir EK, Archer SL. Oxygen-induced constriction of rabbit ductus arteriosus occurs via inhibition of a 4-aminopyridine-, voltage-sensitive potassium channel. J Clin Invest. 1996; 98:1959-65.

Truog WE, Sorensen GK, Standaert TA, Redding GJ. Effects of the thromboxane synthetase inhibitor, dazmegrel (UK 38,485), on pulmonary gas exchange and hemodynamics in neonatal sepsis. Pediatr Res. 1986; 20:481-6.

Truog WE. Inhaled nitric oxide: a tenth anniversary observation. Pediatrics. 1998; 101:696-7.

Tsukahara Y, Matsumura Y, Kuninobu K, Kojima T, Takaoka M, Morimoto S. Phosphoramidon-sensitive endothelin converting enzyme in cultured vascular smooth muscle cells converts big endothelin-3 to endothelin-3. Life Sci. 1993; 53:465-71.

Tulloh RM, Hislop AA, Boels PJ, Deutsch J, Haworth SG. Chronic hypoxia inhibits postnatal maturation of porcine intrapulmonary artery relaxation. Am J Physiol. 1997; 272:H2436-45.

Twort $\mathrm{CH}$, van Breemen C. Cyclic guanosine monophosphate-enhanced sequestration of $\mathrm{Ca} 2+$ by sarcoplasmic reticulum vascular smooth muscle. Circ Res. 1988; 62:961-4.

Tyler T, Wallis R, Leffler C, Cassin S. The effects of indomethacin on the pulmonary vascular response to hypoxia in the premature and mature newborn goat. Proc Soc Exp Biol Med. 1975; 150:695-8.

Tyler RC, Muramatsu M, Abman SH, Stelzner TJ, Rodman DM, Bloch KD, McMurtry IF. Variable expression of endothelial NO synthase in three forms of rat pulmonary hypertension. Am J Physiol. 1999; 276:L297-303.

Tzao C, Nickerson PA, Russell JA, Gugino SF, Steinhorn RH. Content of specific subunits of soluble guanylyl cyclase in pulmonary vessels from lambs with pulmonary hypertension. Pediatr Res 1998; 43:301A

Tzao C, Nickerson PA, Russell JA, Steinhorn RH. Localization of nitric oxide synthase I and III and the $\alpha$ I subunit of soluble guanylate cyclase in the pulmonary vasculature of normal and hypertensive fetal lambs. Pediatr Res $1999 ; 45: 323 \mathrm{~A}$

Van Marter LJ, Leviton A, Allred EN, Pagano M, Sullivan KF, Cohen A, Epstein MF. Persistent pulmonary hypertension of the newborn and smoking and aspirin and nonsteroidal antiinflammatory drug consumption during pregnancy. Pediatrics. 1996; 97:658-63. 
van Suylen RJ, Smits JF, Daemen MJ. Pulmonary artery remodeling differs in hypoxia- and monocrotaline-induced pulmonary hypertension. Am J Respir Crit Care Med. 1998; 157:1423-8.

Velvis H, Moore P, Heymann MA. Prostaglandin inhibition prevents the fall in pulmonary vascular resistance as a result of rhythmic distension of the lungs in fetal lambs. Pediatr Res. 1991; 30:62-8.

Villanueva ME, Zaher FM, Svinarich DM, Konduri GG. Decreased gene expression of endothelial nitric oxide synthase in newborns with persistent pulmonary hypertension. Pediatr Res. 1998; 44:338-43.

Vincent JA, Ross RD, Kassab J, Hsu JM, Pinsky WW. Relation of elevated plasma endothelin in congenital heart disease to increased pulmonary blood flow. Am. J. Cardiol. 1993; 71:1204-1207.

Voelkel, N.F. Mechanisms of hypoxic pulmonary vasoconstriction. Am. Rev. Respir. Dis.1986; 133:1186-1195

Vrolix M, Raeymaekers L, Wuytack F, Hofmann F, Casteels R. Cyclic GMP-dependent protein kinase stimulates the plasmalemmal Ca2+ pump of smooth muscle via phosphorylation of phosphatidylinositol. Biochem J. 1988; 255:855-63.

Wagner DA, Young VR, Tannenbaum SR, Schultz DS, Deen WM. Mammalian nitrate biochemistry: metabolism and endogenous synthesis. IARC Sci. Publ. 1984; 57:247-53.

Wagner OF, Christ G, Wojta J, Vierhapper H, Parzer S, Nowotny PJ, Schneider B, WaldhausI W, Binder BR. Polar secretion of endothelin-1 by cultured endothelial cells. J. Biol. Chem. 1992; 267: 16066-16068.

Wakabayashi I, Hatake K, Kakishita E, Nagai K. Diminution of contractile response of the aorta from endotoxininjected rats. Eur J Pharmacol. 1987 Sep 2; 141:117-22.

Walker AM. Circulatory transition at birth and the control of neonatal circulation. In Hanson MA, Spencer JAD, Rodeck CH (eds.): fetus and neonate physiology and clinical applications, Volume 1, The Circulation. Cambridge University Press 1993, pp 160-196.

Wallace GC, Fukuto JM. Synthesis and bioactivity of $\mathrm{N}$ omega-hydroxyarginine: a possible intermediate in the biosynthesis of nitric oxide from arginine. J. Med. Chem. 1991; 34:1746-48

Walther FJ, Benders MJ, Leighton JO. Persistent pulmonary hypertension in premature neonates with severe respiratory distress syndrome. Pediatrics. 1992; 90:899-904.

Wanecek M, Rudehill A, Hemsen A, Lundberg JM, Weitzberg E. The endothelin receptor antagonist, bosentan, in combination with the cyclooxygenase inhibitor, diclofenac, counteracts pulmonary hypertension in porcine endotoxin shock. Crit Care Med. 1997; 25:848-57.

Wang D, Wei J, Hsu K, Jau J, Lieu MW, Chao TJ, Chen HI. Effects of nitric oxide synthase inhibitors on systemic hypotension, cytokines and inducible nitric oxide synthase expression and lung injury following endotoxin administration in rats. J Biomed Sci. 1999; 6:28-35.

Wang J, Brown MA, Tam SH, Chan MC, Whitworth JA. Effects of diet on measurement of nitric oxide metabolites. Clin Exp Pharmacol Physiol. 1997; 24:418-20.

Wang Y, Coceani F. Isolated pulmonary resistance vessels from fetal lambs. Contractile behavior and responses to indomethacin and endothelin-1. Circ. Res.1992; 71:320-330 
Wang $\mathrm{R}$, Wang $\mathrm{Z}$, Wu $\mathrm{L}$. Carbon monoxide-induced vasorelaxation and the underlying mechanisms. $\mathrm{Br} \mathrm{J}$ Pharmacol 1997; 121:927-934

Wang R . Resurgence of carbon monoxide: an endogenous gaseous vasorelaxing factor. Can J Physiol Pharmacol 1998; 76:1-15

Wanstall JC, Hughes IE, O'Donnell SR. Evidence that nitric oxide from the endothelium attenuates inherent tone in isolated pulmonary arteries from rats with hypoxic pulmonary hypertension. $\mathrm{Br} \mathrm{J}$ Pharmacol 1995; 144:109-114.

Ward RM. Pharmacology of tolazoline. Clin. Perinatol. 1984; 11:703-711.

Warren JB, Maltby NH, MacCormack D, Barnes PJ. Pulmonary endothelium-derived relaxing factor is impaired in hypoxia. Clin Sci 1989; 77:671-6.

Wei XQ, Charles IG, Smith A, Ure J, Feng GJ, Huang FP, Xu D, Muller W, Moncada S, Liew FY. Altered immune responses in mice lacking inducible nitric oxide synthase. Nature 1995; 375:408-11.

Weigert AL, Higa EM, Niederberger M, McMurtry IF, Raynolds M, Schrier RW. Expression and preferential inhibition of inducible nitric oxide synthase in aortas of endotoxemic rats. J Am Soc Nephrol. 1995; 5:2067-72.

Weimann J, Bauer H, Bigatello L, Bloch KD, Martin E, Zapol WM. ABO blood group and inhaled nitric oxide in acute respiratory distress syndrome. Lancet. 1998; 351:1786-7.

Weiner, C. P., Lizasoain, I., Baylis, S. A., Knowles, R. G., Charles, 1. G Moncada, S. Induction of calciumdependent nitric oxide synthases by sex hormones. Proc. Natl. Acad. Sci. USA 1994; 91:5212-5216.

Weir EK, McMurtry IF, Tucker A, Reeves JT, Grover RF. Prostaglandin synthetase inhibitors do not decrease hypoxic pulmonary vasoconstriction. J Appl Physiol 1976; 41: 714-8

Weir EK, Archer SL. The mechanism of acute hypoxic pulmonary vasoconstriction: the tale of two channels. FASEB J. 1995; 9:183-9.

Weitzberg E, Hemsen A, Rudehill A, Modin A, Wanecek M, Lundberg JM. Bosentan-improved cardiopulmonary vascular performance and increased plasma levels of endothelin-1 in porcine endotoxin shock. Br J Pharmacol. $1996 ; 118: 617-26$.

Wenger RH, Gassmann M. Oxygen(es) and the hypoxia-inducible factor-1. Biol Chem. 1997; 378:609-16.

Wessel DL, Adatia I, Van Marter LJ, Thompson JE, Kane JW, Stark AR, Kourembanas S. Improved oxygenation in a randomized trial of inhaled nitric oxide for persistent pulmonary hypertension of the newborn. Pediatrics. 1997; 100:E7.

Wild LM, Nickerson PA, Morin FC 3d. Ligating the ductus arteriosus before birth remodels the pulmonary vasculature of the lamb. Pediatr Res. 1989; 25:251-7.

Willis D, Moore AR, Frederick R, Willoughby DA. Heme oxygenase: a novel target for the modulation of the inflammatory response. Nat Med 1996; 2:87-90.

Wilson SH, Best PJ, Lerman LO, Holmes DR Jr, Richardson DM, Lerman A. Enhanced coronary vasoconstriction to oxidative stress product, 8-epi-prostaglandinF2 alpha, in experimental hypercholesterolemia. Cardiovasc Res. $1999 ; 44: 601-7$. 
Winters JW, Wong J, Van Dyke D, Johengen M, Heymann MA, Fineman JR. Endothelin receptor blockade does not alter the increase in pulmonary blood flow due to oxygen ventilation in fetal lambs. Pediatr Res. 1996; 40:1527.

Wong J, Fineman JR, Heymann MA The role of endothelin and endothelin receptor subtypes in regulation of fetal pulmonary vascular tone. Pediatr. Res. 1994; 35:664-670.

Wong HR, Carcillo JA, Burckart G, Shah N, Janosky JE. Increased serum nitrite and nitrate concentrations in children with the sepsis syndrome. Crit. Care Med. 1995; 23:835-42.

Wu CC, Chen SJ, Szabo C, Thiemermann C, Vane JR. Aminoguanidine attenuates the delayed circulatory failure and improves survival in rodent models of endotoxic shock. Br. J. Pharmacol. 1995; 114:1666-72

Xue C, Rengasamy A, Le Cras TD, Koberna PA, Dailey GC, Johns RA. Distribution of NOS in normoxic vs. hypoxic rat lung: upregulation of NOS by chronic hypoxia. Am J Physiol. 1994; 267:L667-78.

Xue, C., P.R. Reynolds, and R.A. Johns. Developmental expression of NOS isoforms in fetal rat lung: implications for transitional circulation and pulmonary angiogenesis. Am. J. Physiol. 1996; 270: L88-L100.

Yanagisawa M, Kurihara H, Kimura S, Tomobe Y, Kobayashi M, Mitsui Y, Yazaki Y, Goto K, Masaki. A novel potent vasoconstrictor peptide produced by vascular endothelial cells. Nature 1988; 332:411-15.

Yorikane R, Miyauchi T, Sakai S, Sakurai T, Yamaguchi I, Sugishita Y, Goto K. Altered expression of ETBreceptor mRNA in the lung of rats with pulmonary hypertension. J Cardiovasc Pharmacol. 1993; 22 Suppl 8:S3368.

Yoshizumi M, Kurihara H, Sugiyama T, Takaku F, Yanagisawa M, Masaki T, Yazaki Y. Hemodynamic shear stress stimulates endothelin production by cultured endothelial cells. Biochem. Biophys. Res. Commun. 1989; 161:859-64.

Young JD, Dyar OJ. Delivery and monitoring of inhaled nitric oxide. Intensive Care Med. 1996; 22:77-86

Zakhary R, Gaine SP, Dinerman J, Ruat M, Flavahan NA, Snyder SH. Heme oxygenase 2: endothelial and neuronal localization and role in endothelium-dependent relaxation. Proc Natl Acad Sci USA 1996; 93:795-798

Zayek M, Cleveland D, Morin FC 3d. Treatment of persistent pulmonary hypertension in the newborn lamb by inhaled nitric oxide. J Pediatr. 1993; 122:743-50.

Zayek M, Cleveland D, Morin FC. Treatment of persistent pulmonary hypertension of the newborn lamb by inhaled NO. J. Pediatr. 1995; 122:743-750.

Zelenkov P, McLoughlin T, Johns RA. Endotoxin enhances hypoxic constriction of rat aorta and pulmonary artery through induction of EDRF/NO synthase. Am J Physiol. 1993; 265:L346-54.

Zellers TM, Vanhoutte PM. Heterogeneity of endothelium-dependent and independent responses among large and small porcine pulmonary arteries. Pulm Pharmacol. 1989; 2:201-8.

Ziegler JW, Ivy DD, Kinsella JP, Abman SH. The role of nitric oxide, endothelin, and prostaglandins in the transition of the pulmonary circulation. Clin Perinatol. 1995a; 22:387-403.

Ziegler JW, Ivy DD, Fox JJ, Kinsella JP, Clarke WR, Abman SH. Dipyridamole, a cGMP phosphodiesterase inhibitor, causes pulmonary vasodilation in the ovine fetus. Am J Physiol. 1995b; 269:H473-9 
Ziegler JW, Ivy DD, Wiggins JW, Kinsella JP, Clarke WR, Abman SH.Effects of dipyridamole and inhaled nitric oxide in pediatric patients with pulmonary hypertension. Am J Respir Crit Care Med. 1998; 158:1388-95.

Zimmermann M, Seifert V. Endothelin and subarachnoid hemorrhage: an overview. Neurosurgery. 1998; 43:863-75 
Chapter V. Chronic intrauterine pulmonary hypertension impairs endothelial nitric oxide synthase in the ovine fetus. (Am J Physiol. 1997; 272:L1013-20). 



\title{
Chronic intrauterine pulmonary hypertension impairs endothelial nitric oxide synthase in the ovine fetus
}

\author{
EDUARDO VILLAMOR, ${ }^{1}$ TIMOTHY D. LE CRAS, ${ }^{2}$ MARILEE P. HORAN, ${ }^{2}$ \\ ANN C. HALBOWER, ${ }^{2}$ RUBIN M. TUDER, ${ }^{3}$ AND STEVEN H. ABMAN ${ }^{2}$ \\ Pediatric Heart-Lung Center and Departments of ${ }^{2}$ Pediatrics and ${ }^{3}$ Pathology, University \\ of Colorado School of Medicine, Denver, Colorado 80218; and ${ }^{1}$ Servicio de Neonatologia, \\ Departmento de Pediatria, Hospital Universitario San Carlos, Madrid, Spain
}

Villamor, Eduardo, Timothy D. Le Cras, Marilee P. Horan, Ann C. Halbower, Rubin M. Tuder, and Steven H. Abman. Chronic intrauterine pulmonary hypertension impairs endothelial nitric oxide synthase in the ovine fetus. Am. J. Physiol. 272 (Lung Cell. Mol. Physiol. 16): L1013L1020, 1997. - Endothelial (e) nitric oxide synthase (NOS) activity modulates pulmonary vascular tone in the normal fetus and decreases pulmonary vascular resistance (PVR) at birth. Mechanisms contributing to sustained elevations of PVR and the failure of postnatal adaptation at birth are uncertain but may include decreased eNOS activity. To test this hypothesis, we studied the effects of chronic intrauterine pulmonary hypertension on lung eNOS content and NOS activity in an ovine model of perinatal pulmonary hypertension and in normal lambs. We measured eNOS mRNA and protein content by Northern and Western blot analyses, respectively. Calcium-dependent and total NOS activities were determined by assaying the conversion of $\mathrm{L}-\left[{ }^{14} \mathrm{C}\right]$ arginine to $\mathrm{L}-\left[{ }^{14} \mathrm{C}\right]$ citrulline from lung homogenates. To determine the effects of intrauterine hypertension on lung eNOS content, fetal lung tissue was harvested 8-12 days after intrauterine closure of the ductus arteriosus (DA) performed at 125128 days of gestation (term $=147$ days). Although positive immunostaining for $\mathrm{NOS}$ persisted in lung vascular endothelium, eNOS protein content was reduced by $48 \%$, as measured by Western analysis $(P<0.001)$. Chronic hypertension reduced lung eNOS mRNA content by $30 \%(P<0.05)$. Compared with age-matched controls, $\mathrm{Ca}^{2+}$-dependent NOS activity was decreased after DA ligation by $75 \%(P<0.01)$. We conclude that chronic intrauterine pulmonary hypertension decreases eNOS in the fetal lung. We speculate that decreased NO production contributes to failure of postnatal adaptation in this experimental model of persistent pulmonary hypertension of the newborn.

endothelium; pulmonary circulation; persistent pulmonary hypertension of the newborn

POSTNATAL SURVIVAL is dependent on successful transition of the pulmonary circulation at birth. Multiple birth-related mechanisms contribute to the normal decrease in pulmonary vascular resistance (PVR) during this transition from fetal to neonatal life $(2,9,14$, 26). These stimuli act in part by altering pulmonary vascular production of vasoactive mediators, including the endothelium-derived relaxing factor or nitric oxide (NO; see Refs. 2, 11, and 16). The endothelial cell releases NO during the conversion of L-arginine to L-citrulline by type III NO synthase (eNOS) under basal conditions and upon activation by physiological or pharmacological stimuli. NO has been shown to play a major role in control of pulmonary vascular tone in the normal fetus and newborn $(2,11,13,16)$. Despite high PVR in the fetus, endogenous NO activity modulates pulmonary vascular tone and reactivity at least as early as 0.75 term in the ovine fetus (29) and contributes to the fetal pulmonary vasodilator response to oxygen, shear stress, and other stimuli $(11,34,46)$. In vivo and in vitro studies have demonstrated maturational increases in endothelium-dependent vasodilation in the fetal lung $(3,42)$. Because inhibition of NO production attenuates the normal fall in PVR after delivery, NO contributes to the dramatic changes in pulmonary vascular tone at birth $(2,11)$. Whether sustained elevation of PVR and severe hypoxemia in the sick neonate are due to an inability to sustain NO production is unknown.

Persistent pulmonary hypertension of the newborn (PPHN) is a clinical syndrome characterized by sustained elevations of PVR after birth, leading to right to left shunting of blood across the ductus arteriosus (DA) or foramen ovale and severe hypoxemia (32). Although the pathogenesis of PPHN is uncertain, experimental and clinical studies suggest that intrauterine stimuli, such as chronic hypoxia or hypertension, contribute to its etiology $(4,18,19,22,33,37)$. For example, clinical studies demonstrated extensive hypertensive structural abnormalities even in neonates dying during the first days of life (19). Early experimental studies suggested that prolonged hypertension in utero alters pulmonary vascular structure in fetal lambs (33). These observations led to the development of an experimental model of perinatal pulmonary hypertension that closely mimics human PPHN $(4,35,37)$. In this model, chronic DA closure increases fetal PVR (4), alters pulmonary vasoreactivity $(4,35)$, and leads to sustained elevation of PVR after delivery (4, 37). Hypertensive structural remodeling of small pulmonary arteries and striking right ventricular hypertrophy further mimic changes observed in fatal clinical PPHN $(4,37)$.

Mechanisms underlying changes in the pulmonary circulation in this experimental model of perinatal 
pulmonary hypertension are uncertain. Past physiological studies have demonstrated preferential impairment of the pulmonary vasodilator response to endotheliumdependent stimuli, including acetylcholine (35), shear stress (4), and oxygen (4), but relative sparing of endothelum-independent vasodilators, including atrial natriuretic peptide (ANP) and inhaled NO $(35,48)$. Because responses to acetylcholine, oxygen, and shear stress are dependent on NO release $(2,11,46)$, we hypothesized that decreased eNOS activity contributes to failure of the pulmonary circulation to achieve and sustain low PVR after birth in experimental PPHN. To test this hypothesis, we measured eNOS content and activity in normal fetal lamb lungs and from lungs harvested from animals after chronic intrauterine pulmonary hypertension caused by DA ligation. We report that chronic intrauterine pulmonary hypertension decreases lung eNOS mRNA, protein, and activity and speculate that impaired NOS activity may contribute to failure of postnatal adaptation.

\section{MATERIALS AND METHODS}

Materials. Tri-Reagent was obtained from Molecular Research Center (Cincinnati, $\mathrm{OH}$ ). Oligo(dT) affinity columns were from 5 Prime-3 Prime (Boulder, CO). The following cDNA fragments were used as probes: 4,091-bp EcoR I eNOS cDNA fragment (the $\mathrm{NOS} \mathrm{cDNA}$ clone was a kind gift from Dr. W. C. Sessa) and 550-bp EcoR I/Hind III $\beta$-actin cDNA fragment (American Type Culture Collection, Rockville, MD). The anti-eNOS immunoglobulin (Ig) $\mathrm{G}_{1}$ monoclonal antibody was kindly provided as a gift from Dr. Jennifer Pollock. Factor VIII monoclonal antibody was obtained from BioGenex Laboratories (San Ramos, CA). L-[U- ${ }^{14} \mathrm{C}$ ]arginine for the conversion assay was obtained from Amersham (Arlington Heights, IL). 2,4-ADP-Sepharose was purchased from Pharmacia (Piscataway, NJ). Chemicals not specifically mentioned were obtained from Sigma Chemical (St. Louis, MO).

Animals. Procedures used in these studies were previously reviewed and approved by the Animal Care and Use Committee at the University of Colorado School of Medicine. Fetal, neonatal, and adult Columbia-Rambouillet sheep (Nebekar Ranch, Lancaster, CA) were used in this study. Fetal ages ranged from 75 to 145 days $(0.51-0.98$ term; term is 147 days). Lung tissue was also obtained from neonatal lambs (1-6 days postnatal age) and adult sheep (ewes at 1-14 days after delivery). Ewes with time-dated pregnancies were fasted for $24 \mathrm{~h}$ and were sedated with pentobarbital sodium $(10 \mathrm{~g}$, total dose). Fetal lambs were rapidly delivered through a uterine incision after injection of pentobarbital sodium in the umbilical artery to prevent spontaneous breathing. Adult sheep were killed with intrajugular injection of high doses of pentobarbital sodium. Immediately after death, a thoracotomy was rapidly performed, and the lungs were isolated, freeze clamped, removed, and stored at $-70^{\circ} \mathrm{C}$ until study. In some animals, the lungs were perfused with agarose (trachea) and paraformaldehyde (pulmonary artery) for immunostaining.

Experimental model of chronic intrauterine pulmonary hypertension. Surgical compression of the DA was performed using slight modifications of previously described techniques (4). Sixteen mixed-breed (Columbia-Rambouillet) pregnant ewes between 126 and 129 days gestation (term $=147$ days) were fasted for at least $24 \mathrm{~h}$ before surgery. Ewes were sedated with intravenous pentobarbital sodium and were anesthetized with $1 \%$ tetracaine hydrochloride by lumbar injection (3 mg). Under sterile conditions, the fetal left forelimb was delivered through a uterine incision. After infiltration of the fetal skin with lidocaine, a left thoractomy was performed to expose the heart and great vessels. After gentle dissection of adherent connective tissue from the DA with cotton-tipped swabs, a saline-soaked umbilical tape was placed around the ductus and was tightened progressively. In some animals, polyvinyl catheters were placed in the main pulmonary artery between the pulmonic valve and DA (10-12 $\mathrm{mm}$ ) through a purse string suture, using a 16-gauge intravenous placement unit (Angiocath; Travenol, Deerfield, IL). Catheters were also placed in the axillary artery and vein and were gently advanced into the aorta and superior vena cava, respectively. A catheter was placed in the amniotic cavity to measure pressure. The hysterotomy was closed, the uterus was returned to the maternal abdominal cavity, and the catheters were exteriorized via subcutaneous tunnels to an external flank pouch. The ewes recovered rapidly from surgery and were generally standing in their pens within $6 \mathrm{~h}$. Food and water were provided ad libitum. After 8-12 days, animals were killed rapidly after high-dose maternal and fetal infusions of pentobarbital sodium, and lung tissues were harvested for the studies described below.

Lung NOS activity. Lung NOS activity was determined by duplicate measurements of the conversion of $\mathrm{L}-\left[\mathrm{U}-{ }^{14} \mathrm{C}\right]$ arginine to $\mathrm{L}-\left[\mathrm{U}-{ }^{14} \mathrm{C}\right]$ citrulline based on minor modifications of the original protocol of Salter et al. (39). Peripheral lung tissue $(200 \mathrm{mg})$ was homogenized in $3 \mathrm{vol}$ buffer containing $320 \mathrm{mM}$ sucrose, $50 \mathrm{mM}$ tris(hydroxymethyl)aminomethane (Tris) $\cdot \mathrm{HCl}$, $1 \mathrm{mM}$ EDTA, $1 \mathrm{mM}$ dithiothreitol, $100 \mu \mathrm{g} / \mathrm{ml}$ phenylmethylsulfonyl fluoride, $10 \mu \mathrm{g} / \mathrm{ml}$ soybean trypsin inhibitor, and $2 \mu \mathrm{g} / \mathrm{ml}$ aprotinin. Lung homogenates were centrifuged at $4^{\circ} \mathrm{C}$ at $12,000 \mathrm{~g}$ for $20 \mathrm{~min}$. Pellets were discarded, and supernatants were placed on ice until assay. The incubation buffer consisted of $50 \mathrm{mM} \mathrm{KH}_{2} \mathrm{PO}_{4}, 120 \mu \mathrm{M}$ NADPH, $1.2 \mathrm{mM}$ L-citrulline, 2.25 $\mu \mathrm{M}$ L-arginine, $1.2 \mathrm{mM} \mathrm{MgCl} 2,1 \mathrm{mM} \mathrm{CaCl}, 3 \mu \mathrm{M} \mathrm{FAD}, 3 \mu \mathrm{M}$ flavin mononucleotide, $3 \mu \mathrm{M} \mathrm{BH}$, and $0.5 \mu \mathrm{Ci} / \mathrm{ml} L-[\mathrm{U}$ ${ }^{14} \mathrm{C}$ ]arginine. L-Valine $(60 \mathrm{mM})$ was also added to the buffer to minimize potential interference from arginase. Calciumdependent activity was calculated as the difference beween the $\mathrm{L}-\left[\mathrm{U}-{ }^{14} \mathrm{C}\right]$ citrulline produced from control samples containing incubation buffer and samples containing buffer plus 1 $\mathrm{mM}$ ethylene glycol-bis( $\beta$-aminoethyl ether)- $N, N, N^{\prime}, N^{\prime}$. tetraacetic acid (EGTA). Activity of the calcium-independent NOS (inducible or type II NOS) was determined as the difference between samples containing $1 \mathrm{mM}$ EGTA in the incubation buffer and samples containing $1 \mathrm{mM}$ EGTA plus 2 $m M N^{G}$-monomethyl-L-arginine (L-NMMA). NOS activity was linear over $1 \mathrm{~h}$ and was inhibited completely by L-NMMA. All samples were run in duplicate.

Northern blots for eNOS mRNA. Total RNA was purified from hypertensive and control fetal lungs using Tri-Reagent and the method of Chomcynzski (10). Poly (A) mRNA was purified by oligo(dT) affinity chromatography. Poly (A) ${ }^{+}$mRNA was quantified by measuring the absorbance at $260 \mathrm{~nm}$. Twenty micrograms of poly $(A)^{+}$mRNA per lung sample were analyzed using standard Northern blot and hybridization techniques with cDNA probes. cDNA probes were labeled with a [ ${ }^{22}$ P]dCTP using random primer labeling (RTS Random Primer DNA Labeling System; GIBCO-BRL, Gaithersburg, MD; see Ref. 31). High-stringency washing conditions were followed. Bands were quantitated using a Phosphorimager and Imagequant software (Molecular Dynamics, Sunnyvale, CA). Autoradiographs were also obtained by exposure to film (Hyperfilm; Amersham, Arlington Heights, IL). A bovine eNOS cDNA probe was used to detect sheep eNOS 
mRNA. Densitometric values were normalized to the signal for $\beta$-actin mRNA.

Western blots for eNOS protein. Frozen lung samples were homogenized in cold $50 \mathrm{mM}$ Tris $\cdot \mathrm{HCl}(\mathrm{pH} \mathrm{7.4)}$ containing 0.1 mM EDTA, $0.1 \mathrm{mM}$ EGTA, $1 \mathrm{mM} \mathrm{KCl}, 10 \%$ glycerol, $20 \mathrm{mM}$ 3-[(3-cholamidopropyl)dimethylammonio]-1-propanesulfonate, $0.1 \% 2$-mercaptoethanol (2-ME), $1 \mathrm{mM}$ phenylmethylsulfonyl fluoride, $2 \mu \mathrm{M}$ leupeptin, $1 \mu \mathrm{M}$ pepstatin $\mathrm{A}$, and $5 \mu \mathrm{g} / \mathrm{ml}$ aprotinin (homogenization buffer). Samples were centrifuged at $12,000 \mathrm{~g}$ for $25 \mathrm{~min}$ to remove cell debris and DNA. Soluble fractions were assayed for protein content by the Bradford ( 8 ) method, using bovine serum albumin as the standard. Protein $\left(35 \mathrm{mg}\right.$ ) was incubated with $70 \mathrm{mg}$ preswollen $2^{\prime}, 5^{\prime}$-ADPSepharose (Pharmacia) at $4^{\circ} \mathrm{C}$ for $1 \mathrm{~h}$ and was centrifuged at $3,500 \mathrm{~g}$ at $4^{\circ} \mathrm{C}$ for $5 \mathrm{~min}$. Soluble material was discarded, and the Sepharose was washed with the homogenization buffer with $0.5 \mathrm{M} \mathrm{NaCl}$ and then without $\mathrm{NaCl}$. Buffer $(300 \mu \mathrm{l})$ containing $60 \mathrm{mM}$ Tris $\cdot \mathrm{HCl}(\mathrm{pH} 6.8)$ with $5 \%$ glycerol, $2 \%$ sodium dodecyl sulfate (SDS), and 5\% 2-ME was added to the Sepharose. The mixure was boiled for $10 \mathrm{~min}$ and was subjected to SDS-polyacrylamide gel electrophoresis (PAGE). After electrophoresis, proteins in the gel were transferred to nitrocellulose membrane. Membranes were blocked overnight with $5 \%$ nonfat dry milk in $40 \mathrm{mM}$ Tris. $\mathrm{HCl}$, $\mathrm{pH} 7.6$, and $300 \mathrm{mM} \mathrm{NaCl}$ (TBS), washed, and incubated with the primary monoclonal antibody against $\mathrm{eNOS}$ at a dilution of $1: 1,000$ in $1 \%$ nonfat dry milk for $2 \mathrm{~h}$ at room temperature. The blot was washed three times and was incubated with a secondary antibody (horseradish peroxidase-conjugated donkey anti-mouse IgG). After washing, bands for eNOS were visualized by enhanced chemiluminescence (ECL kit; Amersham) and were quantitated by densitometry.

Western blot analysis for factor VIII. Western analysis to quantitate lung factor VIII content was performed in lung homogenates, with some modifications of the techniques described above. Briefly, $100 \mu \mathrm{g}$ protein/lane were subjected to SDS-PAGE and then proteins from the gel were transferred to a nitrocellulose membrane. The blots were blocked with $5 \%$ nonfat dry milk in TBS with $0.1 \%$ Tween 20 . Monoclonal factor VIII antibody (1:200 dilution) in blocking solution was applied overnight at $4^{\circ} \mathrm{C}$. Secondary antibody (donkey anti-mouse Ig; Jackson Immunochemicals, West Grove, PA) was diluted to $1: 10,000$ in blocking solution and was incubated for $90 \mathrm{~min}$ at room temperature. After washing, factor VIII bands were visualized by ECL and were quantitated by densitometry. Protein from cultured pulmonary artery endothelial cells was used for positive controls.

Immunostaining for eNOS and factor VIII. At autopsy, lungs are prepared for immunostaining after agarose inflation and paraformaldehyde infusion into the left pulmonary artery, as we have reported $(23,24)$. The trachea was cannulated with plastic tubing for infusion of low-melt agarose (1\%: SeaKem GTC; FMC Bioproducts, Rockland, ME) heated to $65^{\circ} \mathrm{C}$. Agarose is infused slowly into the airway by perfusion pump (Masterflex; Cole-Parmer) to allow even inflation of the lung. The left pulmonary artery was cannulated for simultaneous perfusion with buffered saline followed by $1 \%$ paraformaldehyde in $0.1 \mathrm{M}$ borate buffer ( $\mathrm{pH} 9.5$ ) at physiological pressure until the effluent from the left atrium was clear. After immersion overnight in $0.45 \mathrm{M}$ sucrose in phosphatebuffered saline (PBS: $0.01 \mathrm{M}$ phosphate, $0.15 \mathrm{M} \mathrm{NaCl} ; \mathrm{pH}$ $7.25-7.5)$ at $4^{\circ} \mathrm{C}$, tissues were frozen and sectioned $(10 \mu \mathrm{m}$ thickness) on poly-L-lysine-coated glass slides for immunostaining. Tissue sections were stained by the avidin-biotinperoxidase complex method. Endogenous peroxidase activity was blocked by immersing the slides in $0.03 \%$ hydrogen peroxide in methanol for 30 min followed by washing in PBS. After nonspecific binding was blocked by incubation with $3 \%$ normal horse serum in PBS, the sections were incubated overnight with anti-NOS ascitic fluid diluted in PBS containing $0.05 \%$ bovine serum albumin and $0.1 \%$ sodium azide. After three washings with PBS, sections were incubated with biotinylated horse anti-mouse IgG $(1: 100)$ and freshly prepared avidin-biotin complex (Vectastain) for 30 and $60 \mathrm{~min}$, respectively. Peroxidase activity was detected using glucose oxidase-3,3'-diaminobenzidine with nickel enhancement. Immunohistochemistry was performed with a specific monoclonal eNOS antibody. The specificity of immunostaining was demonstrated by using simultaneous negative and positive controls on serial sections under the same fixation conditions. Negative controls consisted of isotype-matched $\operatorname{lgG}_{2} \alpha$-antibody at the same dilution as the specific anti-eNOS antibody. Positive controls consisted of factor VIII polyclonal antibody (Boehringer Mannheim).

Data analysis. In all experiments, $n$ represents the number of animals from which lung tissue was studied. Data are expressed as means \pm SE. Statistical analysis was performed with the Statview SE software package (Abacus Concepts, Berkeley, CA). Statistical comparisons were performed by using Student's unpaired $t$-test. Significance was accepted at $P<0.05$.

\section{RESULTS}

Chronic DA ligation increases mean pulmonary artery pressure and total pulmonary resistance, without affecting mean aortic pressure (Table 1). Despite chronic hypertension, eNOS immunoreactivity persisted in vascular endothelium in both normal and hypertensive fetal lungs (Fig. 1). As reported in previous studies (4), small pulmonary arteries from animals with chronic intrauterine pulmonary hypertension consistently had increased wall thickness compared with vessels from age-matched control animals. Intrauterine DA ligation decreased lung eNOS mRNA by $30 \%$ compared with control animals, as determined by Northern blot analysis $(P<0.05$; Fig. 2). Chronic intrauterine pulmonary hypertension also reduced eNOS protein by $48 \pm 4 \%$ $(P<0.001$; Fig. 3). No differences in lung factor VIII content were found between control and hypertensive lungs (Fig. 4). Compared with age-matched controls, chronic pulmonary hypertension also decreased lung NOS activity $\left(244 \pm 72 \mathrm{vs} .623 \pm 88 \mathrm{pmol} \cdot \mathrm{min}^{-1} \cdot \mathrm{mg}^{-1}\right.$; $P<0.001$; Fig. 5). As illustrated, the reduction in NOS activity from hypertensive lungs was due entirely to decreased $\mathrm{Ca}^{2+}$-dependent activity [116 \pm 66 (hyper-

\section{Table 1. Hemodynamic effects of DA ligation} in late-gestation fetal lambs

\begin{tabular}{|c|c|c|c|c|}
\hline Group & $\begin{array}{l}\text { Pulmonary Artery } \\
\text { Pressure, mmHg }\end{array}$ & $\begin{array}{c}\text { Aortic } \\
\text { Pressure, } \\
\text { mmH }\end{array}$ & $\begin{array}{l}\text { LPA Blood } \\
\text { Flow, } \\
\text { mVmin }\end{array}$ & $\frac{\text { TPR, }}{\mathrm{mmHg}_{\mathrm{g}} \cdot \mathrm{ml}^{-3} \cdot \min }$ \\
\hline Control & $42 \pm 2$ & $41 \pm 1$ & $74 \pm 2$ & $0.57 \pm 0.026$ \\
\hline DA ligation & $77 \pm 5^{*}$ & $40 \pm 1$ & $54 \pm 9^{\circ}$ & $1.59 \pm 0.26^{\circ}$ \\
\hline
\end{tabular}

Values are expressed as means $\pm \mathrm{SE} ; n=5$ animals in each group. LPA, left pulmonary artery; TPR, total pulmonary resistance (mean pulmonary artery pressure/LPA blood flow); DA, ductus arteriosus. $* P<0.05$ between groups. 

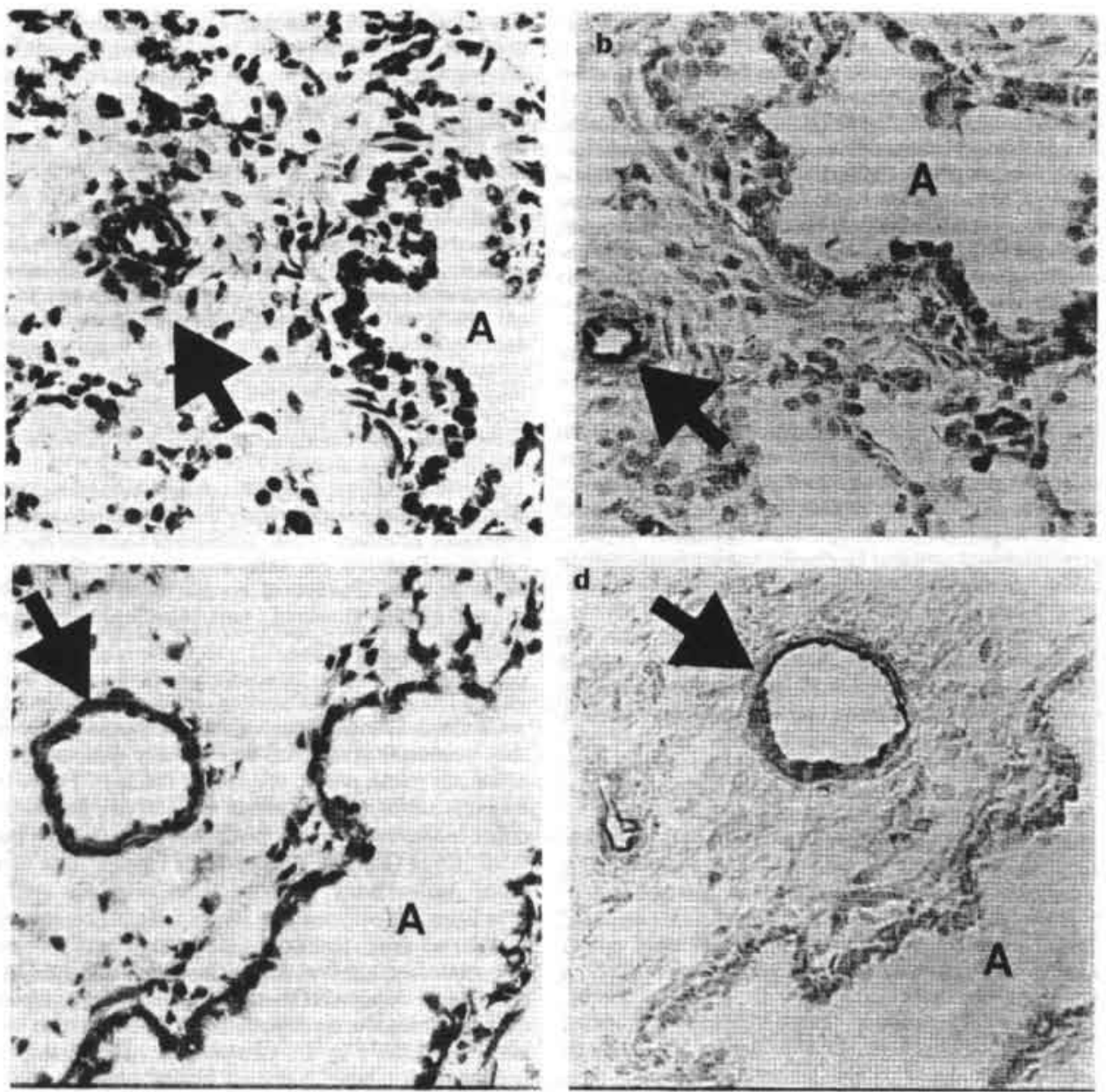

Fig. 1. Lung histology and endothelial (e) nitric oxide synthase (NOS) immunostaining in normal late-gestation lambs and after chronic intrauterine pulmonary hypertension. $a$ : Hypertensive structural changes in small pulmonary arteries from lambs after ligation of ductus arteriosus in utero; $c$ : example of lung histology from age-matched control; $b$ and $d$ : persistent immunoreactive eNOS protein in vascular endothelium of pulmonary arteries in lungs from hypertensive $(b)$ and control $(d)$ lambs. A, airway.

tensive) vs. $452 \pm 98$ (control) $\mathrm{pmol} \cdot \mathrm{min}^{-1} \cdot \mathrm{mg}^{-1} ; P<$ $0.001]$.

\section{Discussion}

On the basis of previous studies that demonstrated the role of endogenous NO activity in the fall in PVR during the normal transition at birth (2), we hypothesized that decreased NO production in the pulmonary circulation may contribute to persistent elevation of PVR after birth in neonatal pulmonary hypertension. To test this hypothesis, we measured eNOS mRNA and protein content and NOS activity in lungs from fetal lambs after normal gestation and in an experimental model of perinatal pulmonary hypertension caused by intrauterine DA closure $(4,35,37)$. Compared with age-matched fetal lambs, chronic pulmonary hypertension in utero decreased lung eNOS mRNA levels and protein content and decreased $\mathrm{Ca}^{2+}$-dependent NOS activity. These findings support previous physiological studies that demonstrated preferential impairment of endothelium-dependent pulmonary vasodilation in this experimental model of perinatal pulmonary hypertension (35). We conclude that intrauterine pulmonary hypertension impairs eNOS expression, which may lead to sustained pulmonary hypertension and impaired pulmonary vasodilation at birth.

Previous studies have demonstrated that eNOS is present early in fetal life $(24,38)$, increases with 

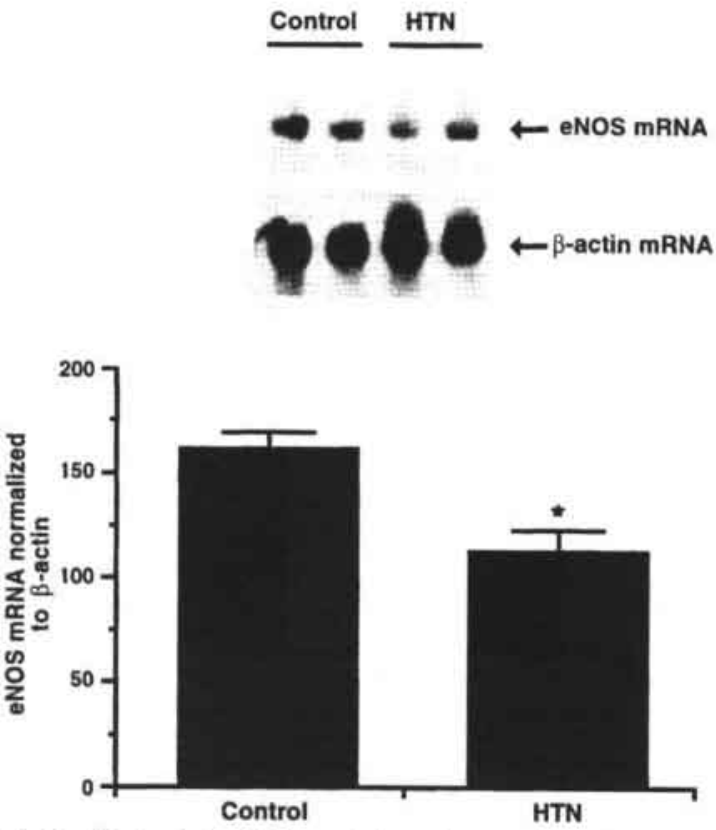

Fig. 2. Effects of chronic intrauterine pulmonary hypertension on lung eNOS mRNA expression. Representative Northern blot analyses for eNOS and $\beta$-actin mRNA from lung homogenates from control and hypertensive (HTN) lambs shown at top and is quantified by densitometry (bottom). As shown, lung eNOS mRNA as normalized to $\beta$-actin was reduced by chronic pulmonary hypertension $(n=4$ animals within each group: ${ }^{*} P<0.05$ ).

advancing gestational age $(29,38)$, modulates basal PVR in the normal pulmonary circulation during late fetal life (2), and contributes to the fall in PVR at delivery $(2,11,16)$. Lung eNOS mRNA and protein contents are apparently low in the early fetus and increase with advancing fetal age in the rat (38), but intense immunostaining for eNOS protein appears very early in the ovine fetus, at least as early as 0.29 gestation (24). Although eNOS is present in the early fetal lung, previous studies have demonstrated maturation-related changes in endothelium-dependent pulmonary vasodilator activity during the postnatal period (3). In contrast to conduit pulmonary artery rings from newborn and adult sheep, rings from fetal lambs showed little relaxation in response to endothelium-dependent agonists $(3,42)$. No age differences were observed in the response to the endothelium-indepependent agonist sodium nitroprusside, suggesting that fetal pulmonary arteries have diminished eNOS activity but are fully capable of responding to NO. Whole animal studies also suggest maturational changes in fetal pulmonary vasodilator responses to endothelium-dependent stimuli, including acetylcholine and increased fetal $\mathrm{PO}_{2}(26)$. In contrast, endothelium-independent agonists that directly increase guanosine $3^{\prime}, 5^{\prime}$-cyclic monophosphate (cGMP) content in vascular smooth muscle, including
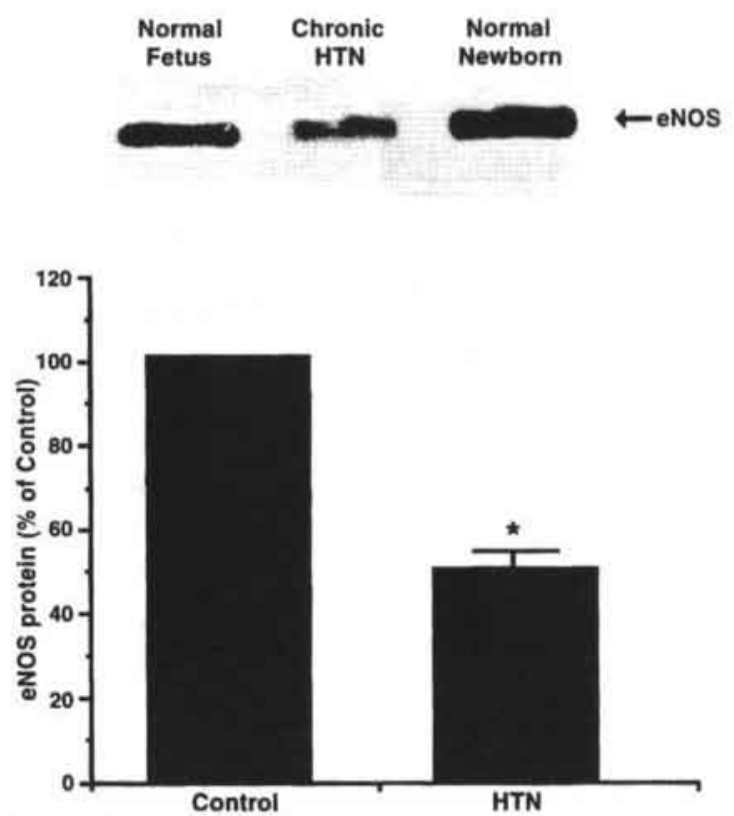

Fig. 3. Effects of chronic intrauterine pulmonary hypertension on lung $\mathrm{eNOS}$ protein content. Top: representative Western blot analy. sis of lung eNOS protein from normal late-gestation fetus, hypertensive fetus after chronic ductus ligation, and normal 1-day newborn. Bottom: summary data for quantitative densitometry shows decreased $\mathrm{eNOS}$ protein content after chronic ligation of ductus arteriosus $\left(n=8\right.$ animals within each group; $\left.{ }^{*} P<0.001\right)$.

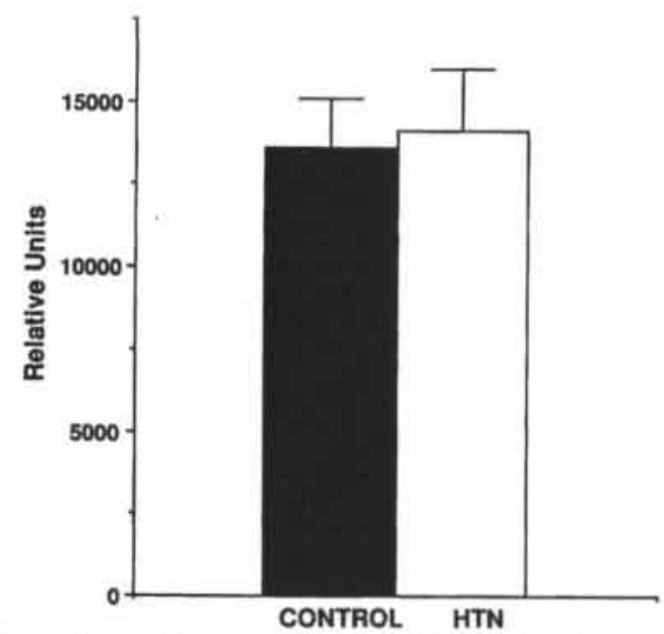

Fig. 4. Western blot analysis for factor VIII-associated antigen in lung homogenates from control and hypertensive lambs. As shown, there was no difference in factor VIII-associated antigen between groups ( $n=4$ animals within each group). 


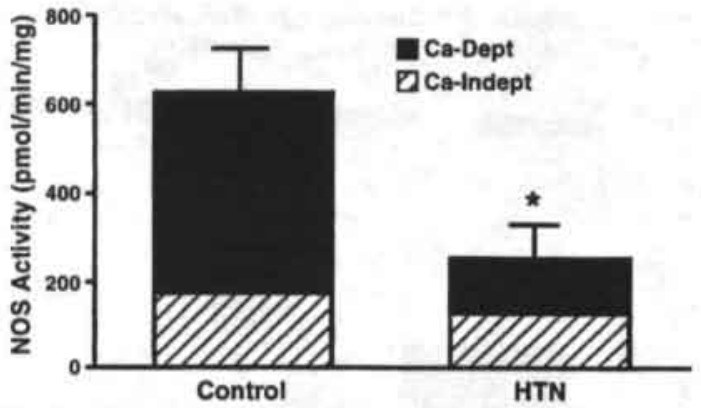

Fig. 5. Effects of chronic intrauterine pulmonary hypertension on NOS activity. As assessed by conversion of $\mathrm{L}-\mathrm{U}^{14} \mathrm{C}$ larginine to $\mathrm{L} / \mathrm{U} \cdot{ }^{14} \mathrm{C}$ leitrulline in lung homogenates, pulmonary hypertension markedly reduces calcium-dependent (Dept) NOS activity. Indept, independent. ${ }^{*} P<0.05$.

ANP, 8-bromoguanosine $3^{\prime}, 5^{\prime}$-cyclic monophosphate, and inhaled NO, cause greater and more sustained fetal pulmonary vasodilation than endothelium-dependent agonists $(1,29)$.

This model of perinatal pulmonary hypertension in the ovine fetus has been used by several investigators to examine mechanisms that lead to failure of postnatal adaptation in the early period after birth $(4,6,37)$. Clinical studies of neonates dying shortly after birth with severe PPHN demonstrate striking histological findings of hypertensive structural remodeling in small pulmonary arteries (19). These observations suggest that, in severe PPHN, chronic intrauterine stimuli contribute to its pathogenesis and pathophysiology. Early experimental studies showed that maternal hypoxia may cause smooth muscle thickening in small pulmonary arteries of late-gestation fetal rats, suggesting that chronic hypoxia in utero may contribute to PPHN (22). However, these observations have not been confirmed in recent studies of fetal hypoxia (18). Levin and co-workers (33) first suggested that intrauterine hypertension causes hypertensive structural lesions in the late-gestation ovine fetus. Based on these findings, investigators have demonstrated that chronic pulmonary hypertension, caused by partial or complete closure of the DA, markedly increases pulmonary artery pressure and PVR in utero (4), alters pulmonary vasoreactivity $(4,35)$, and causes right ventricular hypertrophy $(4,37)$ and hypertensive structural changes in small pulmonary arteries $(4,37)$. After delivery, these animals have persistent elevation of PVR despite mechanical ventilation with enriched $\mathrm{O}_{2}$. These physiological and pathological changes mimic the characteristic clinical and histological findings of human PPHN (32), providing a useful experimental model of severe PPHN for study.

Previous studies of this experimental model have demonstrated preferential impairment of pulmonary vasodilation to acetylcholine, $\mathrm{O}_{2}$, and shear stress but less attenuation of the dilator response to endothelium. independent agonists, including ANP (35) and inhaled
NO $(35,48)$. As acetylcholine, $\mathrm{O}_{2}$, and shear stressinduced pulmonary vasodilation are each partly mediated through NO release, we speculated that chronic pulmonary hypertension impairs NOS activity. This hypothesis is now supported by data from this study. After 8-12 days of intrauterine DA compression, $\mathrm{Ca}^{2+}$. dependent NOS activity and eNOS mRNA and protein expression were decreased when compared with normal fetuses of the same gestational age. Therefore, decreased physiological NOS activity is due at least partially to decreased eNOS protein, which contributes to high PVR and altered vasodilator responses to endothelium-dependent stimuli in this experimental model of PPHN. Because NO decreases smooth muscle cell growth in some experimental settings $(12,17)$, we speculate that decreased eNOS may also contribute to hypertensive remodeling of small pulmonary arteries in utero.

Altered NOS activity has been reported in other animal models of pulmonary hypertension. Loss of endothelium-dependent vasodilaton has been demonstrated in isolated lungs from chronically hypoxic rats (5), and decreased eNOS mRNA and protein were also demonstrated from lungs of patients with pulmonary hypertension (20). In contrast, eNOS is upregulated in adult rats with pulmonary hypertension due to chronic hypoxia $(27,31)$. Whether decreased eNOS in this model of pulmonary hypertension is due to the type or timing of the stimulus or to differences between species is uncertain. In experimental models of pulmonary hypertension due to chronic hypoxia in adult rats and chronic DA ligation in utero, alternate mechanisms, such as increased endothelin (ET)-1 production, may also contribute to high PVR and structural changes of pulmonary arteries $(21,28)$. Chronic intrauterine DA compression increases lung ET-1 levels and alters ET receptor activities, which contributes to high PVR in this model (28). This reduction of $\mathrm{eNOS}$ with concomitant increased lung ET-1 supports the hypothesis that downregulation of $\mathrm{NO}$, an endogenous vasodilator and antiproliferative factor, and upregulation of ET-1, an endogenous vasoconstrictor and mitogenic factor, contribute to chronic pulmonary hypertension $(7,30$, 36). An imbalance between NO and ET-1 production could play a key role in the development of hemody. namic and morphological alterations in PPHN. Altered vasodilation may also involve other components of the NO-cGMP cascade, such as decreased soluble guanylate cyclase (44) and increased or persistent type 5 phosphodiesterase activity (25).

In summary, chronic intrauterine pulmonary hypertension caused by DA closure decreases eNOS mRNA, protein, and activity in the late-gestation fetus. These findings support the hypothesis that adverse intrauterine stimuli, such as hypertension, can cause failure of postnatal adaptation of the pulmonary circulation at birth and may contribute to the pathophysiology of PPHN. 
This work was partly supported by National Heart, Lung, and Blood Institute Grant RO1 HL-41012 and Specialized Center for Research Grant HL-46481 and by an Established Investigator Award from the American Heart Association.

Address for reprint requests: S. H. Abman, Pulmonary Medicine, B395, The Children's Hospital, 1056 E. Nineteenth Ave., Denver, CO 80218-1088.

Received 9 October 1996; accepted in final form 29 January 1997.

\section{REFERENCES}

1. Abman, S. H., and F. J. Accurso. Sustained fetal pulmonary vasodilation during prolonged infusion of atrial natriuretic peptide and 8-bromo-GMP. Am. J. Physiol. 260 (Heart Circ. Physiol. 29): H183-H192, 1991.

2. Abman, S. H., B. A. Chatfield, S. L. Hall, and I. F. MeMurtry. Role of endothelium-derived relaxing factor during transition of pulmonary circulation at birth. Am. J. Physiol. 259 (Heart Circ. Physiol. 28): H1921-H1927, 1990.

3. Abman, S. H., B. A. Chatfield, D. M. Rodman, S. L. Hall, and I. F. MeMurtry. Maturation-related changes in endotheliumdependent relaxation of ovine pulmonary arteries. Am.J.Physiol. 260 (Lung Cell. Mol. Physiol. 4): L280-L.285, 1991.

4. Abman, S. H., P. F. Shanley, and F. J. Accurso. Failure of postnatal adaptation of the pulmonary circulation after chronic intrauterine pulmonary hypertension in fetal lambs. J. Clin. Invest. 83:1849-1858, 1989 .

5. Adnot, S., B. Raffestin, S. Eddahibi, P. Braquet, and P. Chabrier. Loss of endothelium-dependent relaxant activity in the pulmonary circulation of rats exposed to chronic hypoxia. $J$. Clin. Invest. 87: 155-162, 1991.

6. Belik, J., A. J. Halayko, K. Rao, and N. L. Stephens. Fetal ductus arteriosus ligation: pulmonary vascular smooth muscle biochemical and mechanical changes. Circ. Res. 72: 588-596, 1993.

7. Boulanger, C., and T. F. Luscher. Release of endothelin from the porcine aorta. Inhibition by endothelium-derived NO.J. Clin Invest. 85: 587-590, 1990 .

8. Bradford, M. A. A rapid and sensitive method for the quantitation of microgram quantities of protein utilizing the principle of protein-dye binding. Anal. Biochem. 72: 248-254, 1976.

9. Cassin, S., G. S. Dawes, and B. B. Ross. Pulmonary blood flow and vascular resistance in immature foetal lambs. $J$. Physiol. 171: 61-79, 1964

10. Chomczynski, P. A reagent for the single-step simultaneous isolation of mRNA. DNA, and proteins from cell and tissue samples. Biotechniques 15: 532-537, 1993.

11. Cornfield, D. N., B. A. Chatfield, J. A. McQueston, I. F. MeMurtry, and S. H.Abman. Effects of birth-related stimuli on $\mathrm{L}$-arginine dependent pulmonary vasodilation in the ovine fetus. Am. J. Physiol. 262 (Heart Circ. Physiol. 31): H1363-H1368, 1992

12. Cornwell, T. L., E. Arnold, N. J. Boerth, and T. M. Lincoln. Inhibition of smooth muscle cell growth by $\mathrm{NO}$ and activation of cAMP-dependent protein kinase by cGMP. Am. J. Physiol. 267 (Cell Physiol. 36): C1405-C1413, 1994.

13. Davidson, D., and A. Eldemerdash. Endothelium-derived relaxing factor: evidence that it regulates pulmonary vascular resistance in the isolated newborn guinea pig lung. Pediatr. Res. 29: 538-542, 1991.

14. Dawes, G. S. Foetal and Neonatal Physiology. Chicago, Il: Year Book, 1968 .

15. Feinberg, A. P., and B. Vogelstein. A technique for radiolabeling DNA restriction endonuclease fragments to high specific activity. Anal. Biochem. 132: 6-13, 1983. (Addendum. Anal. Biochem. 137: 266-267, 1984)

16. Fineman, J. R., J. Wong, F. C. Morin, L. M. Wild, and S. J. Soifer. Chronic nitric oxide inhibition in utero produces persis. tent pulmonary hypertension in newborn lambs. J. Clin. Invest. 93: 2675-2683, 1994.

17. Garg, U. C., and A. Hassid. NO-generating vasodilators and 8-bromo-cyclic guanosine monophosphate inhibit mitogenesis and proliferation of cultured rat vascular smooth muscle cells. $J$. Clin. Invest. 83: 1774-1777, 1989.
18. Geggel, R. L., M. J. Aronovitz, and L. M. Reid. Effects of chronic in utero hypoxemia on rat neonatal pulmonary arterial structure. J. Pediatr. 108: 756-759, 1986.

19. Geggel, R., and L. M. Reid. The structural basis for PPHN. Clin. Perinatol. 11: 525-549, 1984.

20. Giaid, A., and D. Saleh. Reduced expression of endothelial NO synthase in lungs of patients with pulmonary hypertension. $N$. Engl.J.Med. 333: 214-221, 1995.

21. Giaid, A., M. Yanagisawa, D. Langleben, R. P. Michel, R. Levy, H. Shennib, S. Kimura, T. Masaki, W. Duguid, and D. J. Stewart. Expression of ET-1 in the lungs of patients with pulmonary hypertension. $N$. Engl. J. Med. 328:1732-1739, 1993.

22. Goldberg, S. J., R. A. Levy, and B. Siassi. Effects of maternal hypoxia and hyperoxa upon the neonatal pulmonary vasculature (Abstract). Pediatrics 48: 528, 1971.

23. Halbower, A. C., R. J. Mason, S. H. Abman, and R. M. Tuder. Agarose inflation improves morphology of cryostat sections of lungs. Lab. Invest. 71: 149-153, 1994.

24. Halbower, A. C., R. M. Tuder, W. A. Franklin, J. S. Pollock, U. Forstermann, and S. H. Abman. Maturation-related changes in endothelial NOS immunolocalization in the developing ovine lung. Am. J. Physiol. 267 (Lung Cell. Mol. Physiol. 11) L585-L591, 1994.

25. Hanson, K. A., S. H. Abman, and W. R. Clarke. Elevation of pulmonary PDE5-specific activity in an experimental fetal pulmonary hypertension model (Abstract). Pediatr. Res. 39: 334A, 1996.

26. Heymann, M.A., and S. J. Soifer. Control of fetal and neonatal pulmonary circulation. In: Pulmonary Vascular Physiology and Pathophysiology, edited by E. K. Weir and J. T. Reeves. NY: Dekker, 1989, p. 33-50.

27. Isaacson, T. C., V. Hampl, E. K. Weir, D. P. Nelson, and S. L. Archer. Increased endothelium-derived NO in hypertensive pulmonary circulation of chronically hypoxic rats. J. Appl. Physiol. 76: 933-940, 1994.

28. Ivy, D. D., J. W. Ziegler, M. F. Dubus, J. J. Fox, J. P. Kinsella, and S. H. Abman. Chronic intrauterine pulmonary hypertension alters endothelin receptor activity in the ovine fetus. Pedi. atr. Res, 39: 335-342, 1995.

29. Kinsella, J. P., D. D. Ivy, and S. H. Abman. Ontogeny of NO activity and response to inhaled NO in the developing ovine pulmonary circulation. Am. J. Physiol. 267 (Heart Circ. Physiol. 36): H1955-H1961, 1994.

30. Kourembanas, S., L MeQuillan, G. Leung, and D. Faller. NO regulates the expression of vasoconstrictors and growth factors by vascular endothelium under normoxia and hypoxia. $J$. Clin. Invest. 92: 99-104, 1993.

31. Le Cras, T. D., C. Xue, A. Rengasamy, and R. A. Johns. Chronic hypoxia upregulates endothelial and inducible NOS gene and protein expression in rat lung. Am. J. Physiol. 270 (Lung Cell. Mol. Physiol. 14): L164-L170, 1996.

32. Levin, D. L., M. A. Heymann, J.A. Kitterman, G. A. Gregory, R. H. Phibbs, and A. M. Rudolph. Persistent pulmonary hypertension of the newborn. J. Pediatr. 89: 626-633, 1976.

33. Levin, D. L., A. I. Hyman, M. A. Heymann, and A. M. Rudolph. Fetal hypertension and the development of increased pulmonary vascular smooth muscle; a possible mechanism for PPHN infant. J. Pediatr. 92: 265-269, 1978.

34. MeQueston, J. A., D. N. Cornfield, I. F. MeMurtry, and S. H. Abman. Effects of oxygen and exogenous L-arginine on endothelium-derived relaxing factor activity in the fetal pulmonary circulation. Am. J. Physiol. 264 (Heart Circ. Physiol. 33): H865H871, 1993.

35. MeQueston, J. A., J. P. Kinsella, D. D. Ivy, I. F. MeMurtry, and S. H. Abman. Chronic pulmonary hypertension in utero impairs endothelium-dependent vasodilation. Am. J. Physiol. 268 (Heart Circ. Physiol. 37); H288-H294, 1995.

36. MeQuillan, L. P., G. K. Leung, P. A. Marsden, S. K. Kostyk, and $\mathrm{S}$. Kourembanas. Hypoxia inhibits expression of $\mathrm{eNOS}$ via transcriptional and posttranscriptional mechanisms. Am. J. Physiol. 267 (Heart Circ. Physiol, 36); H1921-H1927, 1994.

37. Morin, F. C. Ligating the ductus arteriosus before birth causes persistent pulmonary hypertension in the newborn lamb. Pediatr. Res, 25: 245-250, 1989. 
38. North, A. J., R. A. Star, T. S. Brannon, K. Ujile, L. B. Wells, C. J. Lowenstein, S. H. Snyder, and P. W. Shaul. NOS type I and type III gene expression are developmentally regulated in rat lung. Am. J. Physiol. 266 (Lung Cell. Mol. Physiol. 10); L635-L641, 1994.

39. Salter, M., R. G. Knowles, and S. Moncada. Widespread tissue distribution, species distribution and changes in activity of $\mathrm{Ca}^{2+}$ - dependent and $\mathrm{Ca}^{2+}$ - independent $\mathrm{NO}$ synthases, FEBS Lett. 291: 145-149, 1991.

40. Sambrook, J., E. F. Fritsch, and T. Maniatis. Molecular Cloning: A Laboratory Manual (2nd ed.). Cold Spring Harbor, NY: Cold Spring Harbor, 1989.

41. Sessa, W. C., J. K. Harrison, C. M. Barber, D. Zeng, M. E. Durieux, D. D. D'Angelo, K. R. Lynch, and M. J. Peach. Molecular cloning and expression of a cDNA encoding endothelial cell nitric oxide synthase. J. Biol. Chem. 267: 15274-15276, 1992.

42. Shaul, P. W., M. A. Farrar, and T. M. Zellers. Oxygen modulates endothelium-derived relaxing factor production in fetal pulmonary arteries. Am. J. Physiol. 262 (Heart Circ. Physiol. 31): H355-H364, 1992.
43. Shaul, P. W., A. J. North, T. S. Brannon, K. Ujiie, L. B. Wells, P. A. Nisen, C. J. Lowenstein, S. H. Snyder, and R. A. Star. Prolonged in vivo hypoxia enhances NOS type I and type III gene expression in adult rat lung. Am. J. Respir. Cell MoL. Biol. 13: $167-174,1995$.

44. Steinhorn, R. H., J.A. Russell, and F. C. Morin. Disruption of cGMP production in pulmonary arteries isolated from fetal lambs with pulmonary hypertension. Am. J. Physiol. 268 (Heart Circ. Physiol. 37): H1483-H1489, 1995.

45. Stenmark, K. R., S. H. Abman, and F. J. Accurso. Etiologic mechanisms of PPHN. In: Pulmonary Vascular Physiology and Pathophysiology, edited by E. K. Weir and J. T. Reeves, New York: Dekker, 1989, p. 335.

46. Tiktinsky, M. H., and F. C. Morin III. Increasing oxygen tension dilates fetal pulmonary circulation via EDRF. Am. $J$. Physiol. 265 (Heart Circ. Physiol. 34): H376-H380, 1993.

47. Wild, L. M., P.A. Nickerson, and F. C. Morin. Ligating the DA before birth remodels the pulmonary vasculature of the lamb. Pediatr. Res. 25: 251-257, 1989.

48. Zayek, M., D. Cleveland, and F. C. Morin. Treatment of persistent pulmonary hypertension of the newborn lamb by inhaled NO.J. Pediatr. 122: 743-750, 1993.

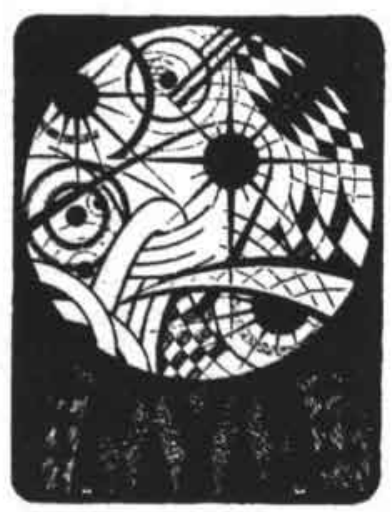


Chapter VI. Endothelium-derived nitric oxide-dependent response to hypoxia in piglet intrapulmonary arteries.

(Biol Neonate. 1997; 72:62-70). 

Biology of the Neonate

\section{Eduardo Villamor ${ }^{\mathrm{a}}$}

Teresa Ruiz ${ }^{\text {a }}$

Francisco Pérez-Vizcaino ${ }^{b}$

Juan Tamargo ${ }^{b}$

Manuel Moro ${ }^{\mathrm{a}}$

a Division of Neonatology,

Department of Pediatrics,

San Carlos University Hospital, and

b Department of Pharmacology, Institute of Pharmacology and Toxicology, School of Medicine, Complutense University, Madrid, Spain

\section{Key Words}

Hypoxia

Nitric oxide

Eicosanoids

Endothelium

Pulmonary artery, piglet

\section{Endothelium-Derived Nitric Oxide-Dependent Response to Hypoxia in Piglet Intrapulmonary Arteries}

\section{Abstract}

The purpose of this study was to determine the involvement of eicosanoids and nitric oxide (NO) in the response to hypoxia in isolated intrapulmonary (third branch) arteries from 10- to 17-day-old piglets. We also compared the response to hypoxia in pulmonary arteries to pulmonary veins, mesenteric arteries and coronary arteries. Hypoxia was generated in vascular rings (under resting force or precontracted with $30 \mathrm{mM} \mathrm{KCl}$ ) by switching the gas aerating the organ chambers from one composed of $21 \% \quad \mathrm{O}_{2}-5 \% \mathrm{CO}_{2}$-balance $\mathrm{N}_{2} \quad \mathrm{pO}_{2} 145 \pm$ $1.27 \mathrm{~mm} \mathrm{Hg})$ to a mixture of $5 \% \mathrm{CO}_{2}$-balance $\mathrm{N}_{2}\left(\mathrm{pO}_{2} 33.87\right.$ $\pm 0.24 \mathrm{~mm} \mathrm{Hg}$ ). In precontracted rings hypoxia produced a transient vasoconstriction $(26 \pm 8 \%$ of the precontraction value) reaching a peak in 3-4 min, followed by a relaxation. A similar pattern of response was observed in pulmonary veins, coronary arteries and mesenteric arteries. The contractile phase was not present in endothelium-denuded arteries or after incubation with the NO synthase inhibitor $L$-NAME $\left(10^{-4} M\right)$ or the guanylate cyclase inhibitor methylene blue $\left(10^{-5} M\right)$. No changes in the hypoxia-induced vasoconstriction were observed after preincubation with the NO precursor $L$-arginine $\left(10^{-5} \mathrm{M}\right)$, the cyclooxygenase inhibitor meclofenamate $\left(10^{-5} M\right)$, the lipoxygenase inhibitor AA 861 $\left(10^{-5} \mathrm{M}\right)$, or the cytochrome P450 oxidase inhibitor SKF $525 \mathrm{~A}\left(10^{-5} \mathrm{M}\right)$. These findings demonstrate that the contractile response to hypoxia in the isolated intrapulmonary porcine artery is caused by the loss of the inhibitory effects of endothelium-derived NO on the vascular tone. Eicosanoids do not appear to be involved in this response. Since the response to hypoxia in isolated rings is not specific to pulmonary vessels, any correlation between this response and hypoxic pulmonary vasoconstriction should be avoided.

\section{KARGER}

E-Mail karger@karger,ch

Fax +41613061234

http://www. karger.ch
Francisco Pérez-Vizcaino

Department of Pharmacology, Institute of Pharmacology and Toxicology School of Medicine, Universidad Complutense

E-28040 Madrid (Spain), Tel. (1) 3941472 , Fax (1) 3941470 E-Mail fperez@eucmax.sim.ucm.es 


\section{Introduction}

Hypoxic pulmonary vasoconstriction (HPV) is an adaptive mechanism by which circulating blood is diverted to better ventilated alveoli optimizing the ventilation/perfusion matching [1, 2]. HPV is a rather unique response specific for the pulmonary vascular bed [1,2]. During fetal life HPV is at least partially responsible for maintaining high pulmonary vascular resistance. Abolition of this $\mathrm{HPV}$ by elevation of arterial $\mathrm{pO}_{2}$ has been suggested as a mechanism to produce the pulmonary vasodilation that occurs at birth [35]. Afterwards, the neonate is at high risk for pulmonary vascular diseases that increase pulmonary vascular resistance and in which HPV plays a determinant role [6].

Despite extensive investigation, the mechanisms producing hypoxic vasoconstriction in the pulmonary circulation are not fully understood. It has been proposed that pulmonary vascular tone increases by alveolar hypoxia due to the reduced release or activity of a vasodilator, the increased release or activity of a vasoconstrictor, and/or because hypoxia directly stimulates contraction of vascular smooth muscle cells [1].

Modulation of vascular tone is one important function of the endothelium [7]. Endothelial cells have the capacity to produce and release several constrictor and dilator substances [8]. Moreover, many agonists influence pulmonary vascular tone via the release of a secondary endothelial mediator. The role of endothelium in the pulmonary vascular response to hypoxia in isolated vessels is unclear. Contradictory results showing abolishment [9-12], as well as enhancement [13, 14], of hypoxia-induced contraction in endothelium-denuded pulmonary arteries have been reported. In addition, it is also unclear whether the endothelium is the target organ which promotes the pulmonary re- sponse to hypoxia or acts as a modulator of a response generated on the pulmonary vascular smooth muscle.

Nitric oxide (NO) and eicosanoids are important endothelium-derived vasoactive mediators which actively participate in the control of pulmonary vascular tone [1]. Contradictory results have been reported on the implication of these mediators on the pulmonary vascular response to hypoxia [15-20]. Therefore, the aim of this work was to investigate the response to hypoxia in isolated intrapulmonary arteries and veins from 2-week-old piglets and to evaluate the role of $\mathrm{NO}$ and eicosanoids on this response. Furthermore, we also studied the effects of hypoxia in systemic (coronary and mesenteric) arteries and pulmonary veins.

\section{Materials and Methods}

\section{Tissue Preparation}

Male neonatal piglets (10-17 days of age, 4,106 \pm $242 \mathrm{~g}$ ) were killed by exsanguination and the lungs, hearts, and mesenteric beds were rapidly immersed in cold $\left(4^{\circ} \mathrm{C}\right)$ Krebs solution (composition in $\mathrm{mM}: \mathrm{NaCl}$ $118, \mathrm{KCl} 4.75, \mathrm{NaHCO}_{3} 25, \mathrm{MgSO}_{4} 1.2, \mathrm{CaCl}_{2} 2.0$, $\mathrm{KH}_{2} \mathrm{PO}_{4} 1.2$ and glucose 11$)$ and transported immediately to the laboratory. Pulmonary arteries and veins (third branch, internal diameter 1-2 mm), mesenteric arteries (internal diameter 1-2 mm) and coronary arteries (left anterior descending, internal diameter 0.5 $1 \mathrm{~mm}$ ) were carefully dissected free of surrounding tissue and cut into rings of $2-3 \mathrm{~mm}$ in length under a dissection microscope. In some experiments the endothelium was removed by gently rubbing the intimal surface of the rings with a metal rod. Two L-shaped stainless-steel wires were inserted into the arterial lumen and the rings were placed in Allhin organ chambers filled with Krebs solution at $37^{\circ} \mathrm{C}$, gassed with $21 \%$ $\mathrm{O}_{2}-5 \% \mathrm{CO}_{2}-74 \% \mathrm{~N}_{2}\left(\mathrm{pO}_{2} 145 \pm 1.27 \mathrm{~mm} \mathrm{Hg}\right.$ in the organ chamber as measured by a blood gas analyzer; BGA electrolyte, Instrumentation Laboratory Inc., USA). One wire was attached to the chamber and the other to an isometric force-displacement transducer (Grass FT07) and connected to a polygraph (Grass, Model 7) as previously described [21]. The rings were initially stretched to a resting tension of $1 \mathrm{~g}$ (pulmo- 
nary arteries, pulmonary veins, and coronary arteries) or $2 \mathrm{~g}$ (mesenteric arteries) and allowed to equilibrate for $60-90 \mathrm{~min}$. During this period tissues were restretched and washed every $30 \mathrm{~min}$ with warm Krebs solution. After equilibration the removal of endothelium was tested by the absence of a relaxant effect of $10^{-6} \mathrm{M}$ acetylcholine in rings precontracted with $10^{-6} M$ noradrenaline.

\section{Experimental Protocols}

In vascular rings under resting force or submaximally contracted with $30 \mathrm{mM} \mathrm{KCl}$, hypoxia was induced by changing from $21 \% \mathrm{O}_{2}-5 \% \mathrm{CO}_{2}-74 \% \mathrm{~N}_{2}$ to $95 \% \mathrm{~N}_{2}-5 \% \mathrm{CO}_{2}$ gas mixture $\left(\mathrm{pO}_{2} 33.87 \pm 0.24 \mathrm{~mm}\right.$ $\mathrm{Hg}$ ). $\mathrm{pH}$ and $\mathrm{pCO}_{2}$ of the experimental solution were the same with either gas mixture $(7.39 \pm 0.01$ vs. 7.40 \pm 0.01 and $29.9 \pm 0.2$ vs. $29.2 \pm 0.2 \mathrm{~mm} \mathrm{Hg}$, respectively). Hypoxia was maintained for $1 \mathrm{~h}$ and then the rings were reoxygenated with the original gas mixture for $15 \mathrm{~min}$.

To test whether NO, eicosanoids or ATP-dependent $\mathrm{K}^{+}$channels were involved in the hypoxic response in pulmonary artery rings, $10^{-4} M \mathrm{~N}^{\mathrm{\omega}}$-nitro- $L$ arginine methyl ester ( $L$-NAME, a NO synthase, NOS, inhibitor), $10^{-5} \mathrm{M}$ methylene blue (a guanylate cyclase inhibitor), $10^{-5} M L$-arginine (the NO precursor), $10^{-5} M$ meclofenamate (a cyclooxygenase inhibitor), $10^{-5} M$ 2,3,5-trimethyl-6-(12-hydroxy-5,10-dodecadynyl)-1,4-benzoquinone (AA 861, a lipoxygenase inhibitor), $10^{-5} \mathrm{M} \mathrm{N}, \mathrm{N}$-diethylaminoethyl-2,2-diphenylvalerate hydrochloride (SKF 525A, a cytochrome P450 oxidase inhibitor) or $10^{-5} \mathrm{M}$ glybenclamide (an ATPdependent $\mathrm{K}^{+}$channel antagonist) were added to the bath $30 \mathrm{~min}$ before the contraction induced by $30 \mathrm{mM}$ $\mathrm{KCl}$.

\section{Drugs}

The following drugs were used: (-)-noradrenaline bitartrate, acetylcholine chloride, $L$-NAME, $L$-arginine, methylene blue, glibenclamide (Sigma Chemical Co., London, UK); meclofenamate (Wamer Lambert Co., USA); AA 861 (Takeda Co., Japan), or SKF 525A (Research Biochemicals Inc., USA). Drugs were dissolved in deionized distilled water, meclofenamate was dissolved in ethanol and AA 861 was dissolved in dimethylsulfoxide. Further dilutions were carried out in Krebs solution. The concentrations are expressed as the final molar concentration in the tissue chamber.

\section{Statistical Analysis}

Results are expressed as means \pm SEM of measurements in the number of arteries. The contractile responses are expressed as absolute values (in milli- grams) and the relaxant responses as a percentage of the precontractile tone. Statistically significant differences were calculated by means of an unpaired Student's t test. $\mathrm{p}<0.05$ was considered statistically significant.

\section{Results}

Isolated intrapulmonary arteries from piglets did not respond to hypoxia while at passive resting tension (fig. 1). Because a submaximal level of active tension was required for the hypoxic response to occur, muscles were precontracted with $30 \mathrm{mM} \mathrm{KCl}(832 \pm$ $76 \mathrm{mg}, \mathrm{n}=21$ ). Under these conditions, hypoxia produced a rapid and transient increase in tension $(151.4 \pm 17.32 \mathrm{mg}, \mathrm{n}=21)$. This contraction reached its maximal value in about 3-4 min, and was followed by a relaxation which was initially fast (first 5-15 min) and slow but sustained afterwards (fig. 1). At the end of the $1 \mathrm{~h}$ of hypoxia the mean tension was $225 \pm 55 \mathrm{mg}$ below the precontraction level induced by $30 \mathrm{mM} \mathrm{KCl}$. Reoxygenation initially produced a small relaxation which was followed by a vigorous and sustained contraction reaching values close to non-hypoxic parallel controls (fig. 1,2). A similar pattern of response to hypoxia was observed in pulmonary veins, coronary arteries and mesenteric arteries. Representative tracings of the response of the different vessels are shown in figure 2.

The contractile responses to hypoxia of pulmonary artery rings with or without endothelium precontracted with $30 \mathrm{mM} \mathrm{KCl}$ are compared in figure 3 . In endothelium-denuded pulmonary arteries hypoxia-induced contraction was significantly reduced when compared to endothelium-intact arteries (44 \pm 7 vs. $151 \pm 17 \mathrm{mg}$, respectively, $\mathrm{p}<0.01$ ). Incubation of pulmonary artery rings with L-NAME $\left(10^{-4} M\right)$, a specific inhibitor 


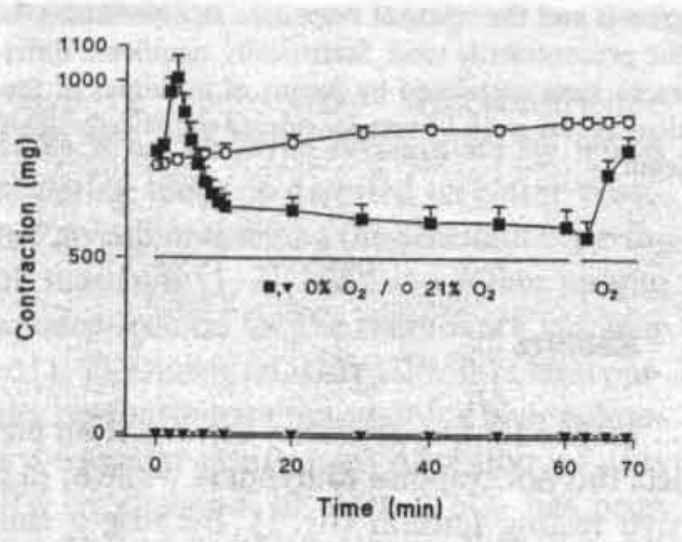

Fig. 1. Time course of the contractile response to hypoxia on piglet pulmonary artery rings at passive resting tension $(\boldsymbol{\nabla})$ and after preconstriction with $30 \mathrm{mM} \mathrm{KCl}(\mathbf{E})$. Muscles were precontracted submaximally with $30 \mathrm{mM} \mathrm{KCl}$ and, after the plateau of the contractile response was reached, hypoxia was generated by switching the gas bubbling the organ chambers from one composed of $21 \% \mathrm{O}_{2}-5 \% \mathrm{CO}_{2}$-balance $\mathrm{N}_{2}$ $\left(\mathrm{pO}_{2} 145 \pm 1.27 \mathrm{~mm} \mathrm{Hg}\right)$ to a mixture of $5 \% \mathrm{CO}_{2}$ balance $\mathrm{N}_{2}\left(\mathrm{pO}_{2} 33.87 \pm 0.24 \mathrm{~mm} \mathrm{Hg}\right)$. After $1 \mathrm{~h}$ of hypoxia the rings were bubbled for $15 \mathrm{~min}$ with the original gas mixture. Rings constricted with $30 \mathrm{mM}$ $\mathrm{KCl}$ but not subjected to hypoxia are also shown (O). Each symbol represents the mean \pm SEM of 5-8 experiments.

of NOS activity, or with methylene blue $\left(10^{-5} M\right)$, a guanylate cyclase activity inhibitor, produced a contractile response of $263 \pm$ 86 and $357 \pm 74 \mathrm{mg}$, respectively. When $30 \mathrm{~m} M \mathrm{KCl}$ was added, the arteries developed a final tension of $1,087 \pm 96 \mathrm{mg}(\mathrm{L}$ $\mathrm{NAME}+30 \mathrm{mM} \mathrm{KCl}$ ) and $1,105 \pm 146 \mathrm{mg}$ (methylene blue $+30 \mathrm{mM} \mathrm{KCl}$ ). This response was not significantly different from the peak level of contraction that developed in response to hypoxia in the control group ( 984 $\pm 82 \mathrm{mg}$ ). As shown in figure 4 , both $L$ NAME and methylene blue markedly reduced $(\mathrm{p}<0.01)$ the hypoxic vasoconstriction. To exclude the possibility that the in-
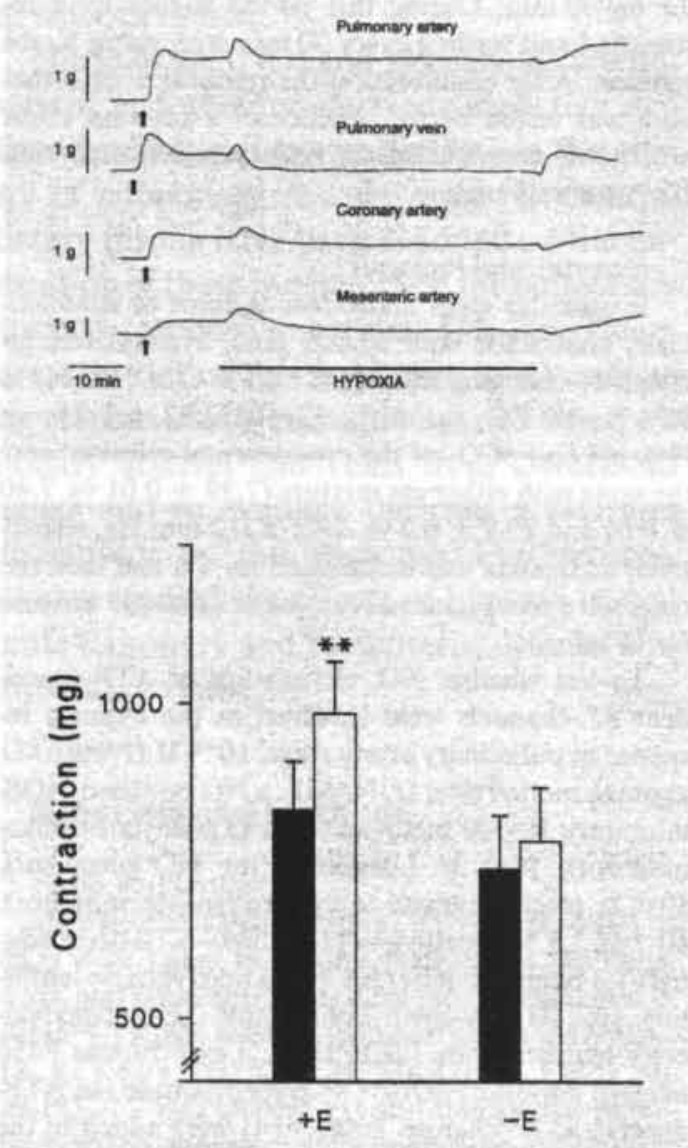

Fig. 2. Typical tracings of the response to hypoxia in isolated rings of piglet pulmonary artery, pulmonary vein, coronary artery and mesenteric artery. The vessels were initially preconstricted with $30 \mathrm{mM} \mathrm{KCl}$ as indicated by the arrows and hypoxia was generated when this preconstriction reached steady state (see legend to figure 1).

Fig. 3. Role of endothelium in the contractile response to hypoxia in isolated rings of piglet intrapulmonary arteries. Contractile tension induced by $30 \mathrm{mM} \mathrm{KCl}$ under normoxia ( $\mathrm{W}$ ) and peak value of hypoxic constriction $(\square)$ in endothelium-intact $(+E$, $\mathrm{n}=24)$ or endothelium-denuded $(-\mathrm{E}, \mathrm{n}=10)$ arteries. Each bar represents the mean \pm SEM. ${ }^{* *} p<0.01$ normoxia vs. hypoxia. 


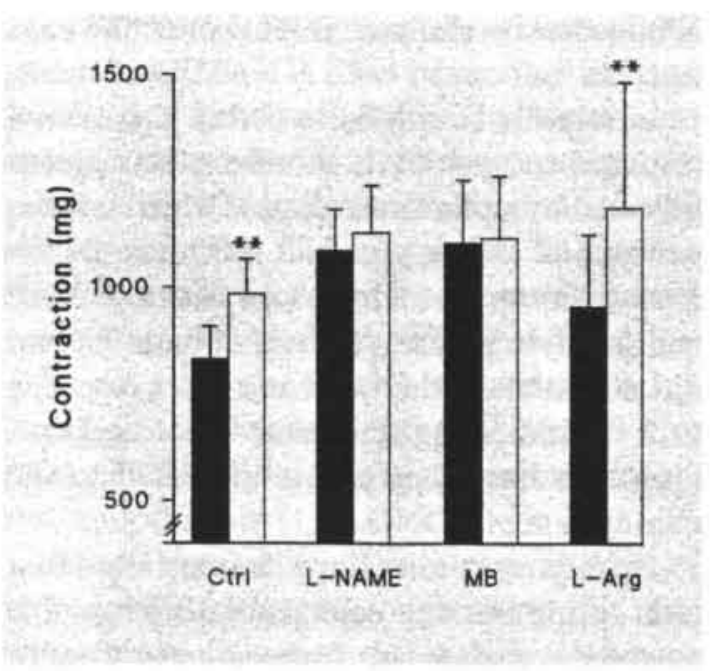

Fig. 4. Effects of $L-N A M E\left(10^{-4} M\right)$, methylene blue (MB, $10^{-5} \mathrm{M}$ ) and $L$-arginine (L-Arg, $10^{-5} \mathrm{M}$ ) on the contractile response to hypoxia in isolated endothelium intact rings of piglet intrapulmonary arteries. Drugs were added to the bath $30 \mathrm{~min}$ before preconstriction with $30 \mathrm{mM} \mathrm{KCl}$. Contractile tension induced by $30 \mathrm{mM} \mathrm{KCl}$ under normoxia (回) and peak value of hypoxic constriction ( $\square$ ). Each bar represents the mean \pm SEM of $14-24$ experiments. ${ }^{* *} p<0.01$ normoxia vs. hypoxia.

crease in the precontraction level seen with $L$ NAME or methylene blue may have limited hypoxic vasoconstriction, the hypoxic vasoconstriction was analyzed in rings in which the precontraction value was raised by the addition of $10^{-5} \mathrm{M}$ noradrenaline plus $30 \mathrm{mM}$ $\mathrm{KCl}$. Although this combination produced a similar increase in tone $(1,059 \pm 98 \mathrm{mg}, \mathrm{n}=$ $8, \mathrm{p}<0.05$ ) to that observed with $30 \mathrm{mM} \mathrm{KCl}$ plus $L$-NAME or $30 \mathrm{mM} \mathrm{KCl}$ plus methylene blue, hypoxia produced in these rings a contractile response similar to that obtained in parallel control arteries contracted by $30 \mathrm{mM}$ $\mathrm{KCl}$ alone $(79 \pm 14$ vs. $95 \pm 18 \mathrm{mg}$, respectively, $\mathrm{n}=8, \mathrm{p}>0.05$ ).

The effects of the NO precursor $L$-arginine $\left(10^{-5} M\right)$, the cyclooxygenase inhibitor meclo-

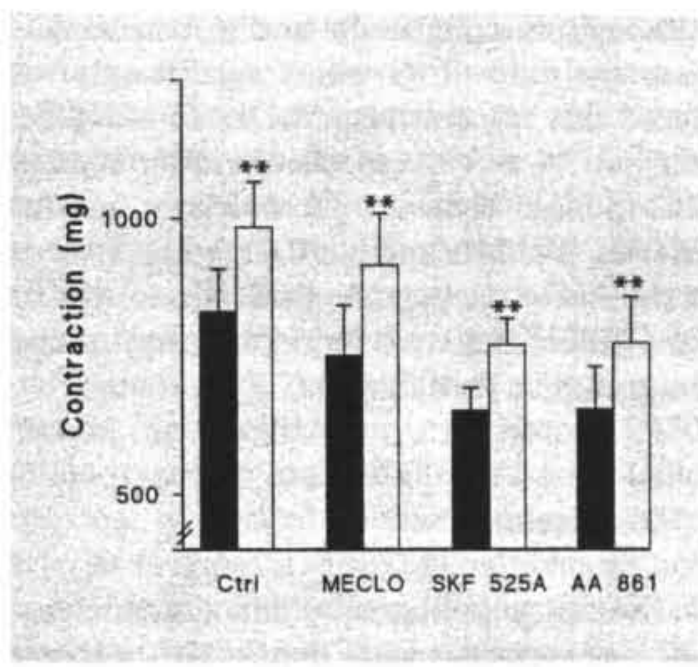

Fig. 5. Effects of meclofenamate (MECLO, 10-5 $M), \mathrm{AA} 861\left(10^{-5} \mathrm{M}\right)$, and SKF $525 \mathrm{~A}\left(10^{-5} \mathrm{M}\right)$ on the contractile response to hypoxia in isolated intact endothelium rings of piglet intrapulmonary arteries. Drugs were added to the bath $30 \mathrm{~min}$ before the muscles were precontracted with $30 \mathrm{mM} \mathrm{KCl}$. Contractile tension induced by $30 \mathrm{mM} \mathrm{KCl}$ under normoxia (菑) and peak value of hypoxic constriction ( $\square$ ). Each bar represents the mean \pm SEM of $11-24$ experiments. ${ }^{* *} p<0.01$ normoxia vs. hypoxia.

fenamate $\left(10^{-5} M\right)$, the lipoxygenase inhibitor AA $861\left(10^{-5} M\right)$ and the cytochrome P450 oxidase inhibitor SKF 525A $\left(10^{-5} \mathrm{M}\right)$ on the hypoxic response of pulmonary arteries precontracted with $30 \mathrm{mM} \mathrm{KCl}$ are shown in figures 4 and 5 . None of these agents significantly affected the contractile response to hypoxia in pulmonary arteries. Similarly, the ATP-dependent $\mathrm{K}^{+}$channel inhibitor glybenclamide $\left(10^{-5} M\right)$ had no effect on the contractile response to $\mathrm{KCl}(899 \pm 163 \mathrm{mg})$ or on the response to hypoxia $(128 \pm 35 \mathrm{mg}, \mathrm{n}=7$, $\mathrm{p}>0.05$ vs. control).

To evaluate the effects of the different pretreatments on the second vasodilator response, tension was measured at $15 \mathrm{~min}$ and at the end $(1 \mathrm{~h})$ of the exposure to hypoxia. 
Although meclofenamate and glybenclamide were the only drugs which significantly reduced this relaxant response at $15 \mathrm{~min}(106$ \pm 6 and $94 \pm 5 \%$, respectively, of the $30 \mathrm{mM}$ $\mathrm{KCl}$-induced tone vs. $83 \pm 3 \%$ in control arteries, $p<0.01$ and $p<0.05$, respectively), at the end of the hypoxic challenge no significant differences were found with any of the drugs studied (not shown).

\section{Discussion}

Isolated pig pulmonary and systemic vessels precontracted with $30 \mathrm{mM} \mathrm{KCl}$ respond to hypoxia by displaying an initial rapid increase in tension of short duration followed by a further relaxation. However, this contractile response was not observed in pulmonary arteries at resting tension. Even when the explanation for the requirement of some level of active tone is unknown, this result may indicate that hypoxic vasoconstriction is mediated by withdrawal of vasodilator tone rather than the activation of vasoconstrictor mechanisms. In addition, hypoxia-induced contraction was significantly reduced in endothelium-denuded pulmonary arteries, which suggested that hypoxia counteracts the activity of an endothelium-derived vasodilator. Moreover, the NOS inhibitor $L$-NAME or the guanylate cyclase inhibitor methylene blue raised basal tone in pulmonary arteries and markedly inhibited the hypoxic contractile response, whereas the NO precursor $L$-arginine had no effect. These results suggest that hypoxia produces an inhibition of the release and/or activity of endothelium-derived NO (EDNO). Therefore, $L-N A M E$ and methylene blue induced a contraction which mimics the initial contractile response to hypoxia (i.e. by removing endothelium-derived relaxing factor/NO, EDRF/NO) and further contraction cannot be achieved by hypoxia since EDRF/
NO is already eliminated. However, the contraction induced by both $L$-NAME and methylene blue is sustained, whereas the overall response to hypoxia is more complex and is followed by a relaxant response which is independent of changes in NO synthesis. Moreover, in constrast to the results with $L$-NAME and methylene blue, removal of endothelium did not enhance the vasoconstrictor response to $\mathrm{KCl}$, indicating that removal of endothelium also has other effects unrelated to the elimination of EDNO.

Numerous studies have demonstrated that NO, acting through activation of the soluble guanylate cyclase in smooth muscle cells, plays a major role in the regulation of pulmonary vascular tone both in fetal and postnatal life [1, 22]. NO is produced from $L$-arginine on conversion to $L$-citrulline by the enzyme NOS [23]. The formation of NO by vascular endothelial cells is catalyzed by the endothelial isoform of NOS (eNOS) [23]. Since the first classic report of the EDRF (afterwards identified as NO) [24], it is known that hypoxia inhibits agonist-induced release of NO. In pulmonary arteries from several species, including humans, it has been demonstrated that hypoxia reduced pulmonary endothelium-dependent vasodilation and diminished accumulation of cyclic GMP, suggesting a reduction in pulmonary NO activity $[25,26]$. This hypoxia-induced impairment of $\mathrm{NO}$ activity is independent of endothelial receptors because NOS activation by calcium ionophores (which act independent of these receptors) is also reduced by hypoxia [26]. However, hypoxia does not seem to impair the ability of NO to activate soluble guanylate cyclase because it did not affect the relaxation mediated by the NO donor sodium nitroprusside $[25,26]$. In agreement with the present results, other authors have demonstrated the suppression of the contractile response to hypoxia in isolated pulmonary artery rings 
after NOS or soluble guanylate cyclase inhibition $[11,12,26,27]$. These data may indicate a reduction in NO production by hypoxia. In contrast, Hampl et al. [15] demonstrated an increase in NO synthesis in pulmonary artery endothelial cells under hypoxia. To explain these contradictory data, it has been suggested that severe hypoxia $\left(\mathrm{pO}_{2} \quad 15-30 \mathrm{~mm} \mathrm{Hg}\right)$ impairs the release of EDNO, whereas a moderate degree of hypoxia $\left(\mathrm{pO}_{2} 40-45 \mathrm{~mm} \mathrm{Hg}\right)$ promotes NO synthesis in the pulmonary artery endothelium [15].

Hypoxia may interfere in several steps of NO synthesis, release or activity. In fact, it has been described that hypoxia inhibits: (1) $L$-arginine uptake by pulmonary artery endothelial cells [28]; (2) the conversion of $L$ citrulline to $L$-arginine in pulmonary artery endothelial cells [29]; (3) NOS activity by limiting the availability of oxygen, a substrate for NOS that is a dioxygenase which catalyses the reaction between molecular oxygen and $L$-arginine [30]; (4) endothelial ATP content [31] which is necessary for agonist-induced production of EDNO; (5) eNOS by reducing the endothelium intracellular $\mathrm{Ca}^{2+}$ concentration which primarily regulates eNOS activity $[32,33] ;(6)$ the supply of NADPH and 6methyltetrahydropterine, both essential cofactors for NOS activity [34], and finally, (7) hypoxia could induce the production of superoxide anions by the endothelial cells that would inactivate EDNO [34].

Eicosanoids are arachidonic acid metabolites which are generated by several cellular types including vascular endothelial cells [35]. Arachidonic acid may be metabolized via two main pathways: the cyclooxygenase pathway leads to the formation of prostaglandins and thromboxane $\mathrm{A}_{2}$, and the lipoxygenase pathway produces hydroxyeicosatetraenoic acids and leukotrienes. A third pathway, involving a cytochrome P450-linked monooxygenase, may generate several epoxides, hydroxy acids and other products whose physiological importance remains to be clarified [36]. Eicosanoids have been implicated in the regulation of pulmonary vascular tone under physiological and pathological conditions [1]. In the search for humoral mediators for HPV, leukotrienes $\left(\mathrm{C}_{4}, \mathrm{D}_{4}, \mathrm{E}_{4}\right)$ and prostaglandin $\mathrm{I}_{2}$ have been proposed by several authors [17-19]. In our experiments, the inhibition of cyclooxygenase, lipoxygenase or cytochrome P450 monooxygenase did not alter the contractile response of isolated porcine intrapulmonary arteries to hypoxia. Thus, eicosanoids do not appear to be involved in mediating this initial response. In contrast, meclofenamate inhibited the initial relaxant response to hypoxia indicating a role for cyclooxygenase-derived eicosanoids in this early vasodilatation, but it had no effect on the final tone after $1 \mathrm{~h}$ of hypoxia. Conflicting results regarding the release of prostacyclin by hypoxia (unchanged, increased or decreased levels) have been reported [37]. Other studies have shown that glybenclamide inhibits the relaxant response to hypoxia suggesting that an opening of ATPdependent $\mathrm{K}^{+}$channels is implicated in this vasorelaxation $[27,37]$. Thus, the vasodilator responses to hypoxia deserve further investigation.

Even when small arteries (outer diameter $<500 \mu \mathrm{m}$ ) have been identified as the location of contraction in response to alveolar hypoxia $[37,38]$, pulmonary artery rings of all sizes and from several species contract in response to hypoxia [2, 37]. However, it has been argued that these experiments in isolated vessels may not reflect the physiological mechanisms of HPV [1]. In fact, an in vitro hypoxic contraction has been demonstrated in several systemic arteries [12, 36, 39], whereas HPV is unique to pulmonary vessels. In the present work we demonstrate that a similar pattern of response to hypoxia is produced in pulmonary, coronary and mesenteric arteries and in 
pulmonary veins from the same animals. Thus, this is not a specific response for the pulmonary vessels and correlation of this, and other studies using pulmonary vascular rings, with HPV should be avoided.

In summary, the transient hypoxic contractile response observed in isolated piglet pulmonary arteries was due to inhibition of basal EDNO production. Eicosanoids were not involved in this contractile response. Studies with isolated vessels could be useful for the knowledge of some vascular effects of hypoxia but correlation between HPV and hypoxia-induced response on isolated pulmonary arteries is unclear. Both pulmonary and systemic vessels similarly responded to hypoxia whereas HPV is a physiological response specific for the pulmonary vascular bed.

\section{References}

1 Barnes PJ, Liu SF: Regulation of pulmonary vascular tone. Pharmacol Rev 1995;47:87-131.

2 Marshall BE, Marshall C, Frasch F. Hanson CW: Role of hypoxic pulmonary vasoconstriction in pulmonary gas exchange and blood flow distribution. 1. Physiologic concepts. Intensive Care Med 1994;20: 291-297.

3 McQueston JA, Cornfield DN, McMurtry IF, Abman SH: Effects of oxygen and exogenous $L$-arginine on EDRF activity in fetal pulmonary circulation. Am J Physiol 1993;264: H865-H871.

4 Tiktinsky MH, Morin FC: Increasing oxygen tension dilates fetal pulmonary circulation via endothelium-derived relaxing factor. Am J Physiol 1993;265:H376-H380.

5 Cornfield DN, Chatfield BA, McQueston JA, McMurtry IF, Abman SH: Effects of birth-related stimuli on $L$-arginine-dependent pulmonary vasodilation in the ovine fetus. Am J Physiol 1992;262: H1474-H1481.

6 Rabinovitch M: Vascular pathology of PPHNS; in Long WA (ed): Fetal and Neonatal Cardiology. Philadelphia, Saunders, 1990, pp 656-666.

7 Vanhoutte PM: Endothelium and control of vascular function. Hypertension 1989;13:658-667.

8 Inagami T, Naruse M, Hoover R: Endothelium as an endocrine organ. Annu Rev Physiol 1995;57:171189.
9 Holden WE, McCall E: Hypoxiainduced contractions of porcine pulmonary artery strips depend on intact endothelium. Exp Lung Res 1984;7:101-112.

10 Bennie RE, Packer CS, Powell DR, Jin N, Rhoades RA: Biphasic contractile response of pulmonary artery to hypoxia. Am J Physiol 1991; 261:L156-L163.

11 Omar HA, Wolin MS: Endothelium-dependent and independent cGMP mechansims appear to mediate $\mathrm{O}_{2}$ responses in calf pulmonary resistance arteries. Am J Physiol 1992;262:L560-L565.

12 Zelenkov P, McLoughlin T, Johns RA: Endotoxin enhances hypoxic constriction of rat aorta and pulmonary artery through induction of EDRF/NO synthase. Am J Physiol 1993;265:L346-L354.

13 Ogata M, Ohe M, Katayose D, Takishima T: Modulatory role of EDRF in hypoxic contraction of isolated porcine pulmonary arteries. Am J Physiol 1992;262:H691-H697.

14 Yuan XJ, Tod ML, Rubin LJ, Blaustein MP: Contrasting effects of hypoxia on tension in rat pulmonary and mesenteric arteries. Am J Physiol 1990;259:H281-H289.

15 Hampl V, Cornfield DN, Cowan NJ, Archer SL: Hypoxia potentiates nitric oxide synthesis and transiently increases cytosolic calcium levels in pulmonary artery endothelial cells. Eur Respir J 1995;8:512522.
16 Brashers VL, Peach MJ, Rose CE: Augmentation of hypoxic pulmonary vasoconstriction in the isolated perfused rat lung by in vitro antagonists of endothelium-dependent relaxation. J Clin Invest 1988;82: 1495-1502.

17 Morganroth ML, Reeves JT, Murphy CR, Voelkel NF: Leukotriene synthesis and receptor blockers block hypoxic pulmonary vasoconstriction. J Appl Physiol 1984;56: 1340-1346.

18 McDonnell TJ, Wescott JY, Czartolomna J, Voelkel NF: Role of peptidoleukotrienes hypoxic pulmonary vasoconstriction in rats. Am J Physiol 1990;259:H751-H758.

19 Shaul PW, Kinane B, Farrar MA, Buja LM, Magness RR: Prostacyclin production and mediation of adenylate cyclase activity in the pulmonary artery. Alterations after prolonged hypoxia in the rat. J Clin Invest 1991:88:447-455.

20 Shaul PW, Campbell WB, Farrar MA, Magness RR: Oxygen modulates prostacyclin synthesis in ovine fetal pulmonary arteries by an effect on cyclooxygenase. J Clin Invest 1992;90:2147-2155.

21 Villamor E, Pérez-Vizcaino F, Ruiz T, Leza JC, Moro M, Tamargo J: Group B Streptococcus and E. coli LPS-induced NO-dependent hyporesponsiveness to noradrenaline in isolated intrapulmonary arteries of neonatal piglets. $\mathrm{Br} \mathrm{J}$ Pharmacol 1995;115:261-266. 
22 Abman SH, Chatfield BA, Hall SL, McMurtry IF: Role of endotheliumderived relaxing factor during transition of pulmonary circulation at birth. Am J Physiol 1990;259: H1921-1927.

23 Moncada S, Palmer RMJ, Higgs EA: Nitric oxide: Physiology, pathophysiology, and pharmacology. Pharmacol Rev 1991;3:109-142.

24 Furchgott R, Zawadzki J: The obligatory role of endothelial cells in the relaxation of arterial smooth muscle by acetylcholine. Nature $1980 ; 288$ : 373-376.

25 Demiryurek AT, Wadsworth RM, Kane KA, Peacock AJ: The role of endothelium in hypoxic constriction of human pulmonary artery rings. Am Rev Respir Dis 1993;147:283290.

26 Johns RA, Linden JM, Peach MJ: Endothelium-dependent relaxation and cyclic GMP accumulation in rabbit pulmonary artery are selectively impaired by moderate hypoxia. Circ Res 1989;65:1508-1515.

27 Greenberg B, Kishiyama S: Endothelium-dependent and -independent responses to serve hypoxia in rat pulmonary artery. Am J Physiol 1993:265:H1712-H1720.
28 Block ER, Herrera H, Couch M: Hypoxia inhibits $L$-arginine uptake by pulmonary artery endothelial cells. Am J Physiol 1995;269:L574LS80.

29 Su Y, Block ER: Hypoxia inhibits $L$ arginine synthesis from $L$-citrulline in porcine pulmonary artery endothelial cells. Am J Physiol 1995;269: L581-L 587.

30 Rengasamy A, Johns RA: Characterization of endothelium-derived relaxing factor/nitric oxide synthase from bovine cerebellum and mechanism of modulation by high and low oxygen tensions. J Pharmacol Exp Ther 1991;259:310-316.

31 Rounds S, McMurtry IF: Inhibitors of oxidative ATP production cause transient vasoconstriction and block subsequent pressor responses in rat lung. Circ Res 1981;48:393-400.

32 Mathew R, Burke-Wolin T, Gewitz $\mathrm{MH}$, Wolin MS: $\mathrm{O}_{2}$ and rat pulmonary artery tone: effects of endothelium, $\mathrm{Ca}^{2+}$, cyanide, and monocrotaline. J Appl Physiol 1991;71:3036.
33 Stevens T, Cornfield DN, McMurtry IF, Rodman DM: Acute reductions in $\mathrm{pPO}_{2}$ depolarize pulmonary endothelial cells and decrease $\left[\mathrm{Ca}^{2+}\right]_{1}$. Am J Physiol 1994;266: H1416-H1421.

34 Rubanyi GM, Vanhoutte PM: Superoxide anions and hyperoxia inactivate endothelium-derived relaxing factor. Am J Physiol 1986;250: H822-H827.

35 Coceani F, Olley PM: Eicosanoids in the fetal and transitional pulmonary circulation. Chest 1988;93 (suppl):112-117.

36 Fitzpatrick FA, Murphy RC: Cytochrome P-450 metabolism of arachidonic acid: formation and biological actions of epoxygenase-derived eicosanoids. Pharmacol Rev 1989;40: 229-241.

37 Wadsworth RM: Vasoconstrictor and vasodilator effects of hypoxia. Trends Pharmacol Sci 1994;15:4753.

38 Bergofsky EH, Haas F, Porcelli R: Determination of the sensitive vascular sites from which hypoxia and hypercapnia elicit rises in pulmonary arterial pressure. Fed Proc 1968:27:1420-1425.

39 Pearson PJ, Lin PJ, Evora PRB, Schaff HV: Endothelium-dependent response of human internal mam. mary artery to hypoxia. Am J Physiol 1993:264:H376-H380. 

Chapter VII. Group B Streptococcus and E. coli LPS-induced NOdependent hyporesponsiveness to noradrenaline in isolated intrapulmonary arteries of neonatal piglets. (Br J Pharmacol. 1995; 115:261-6). 


\title{
Group B Streptococcus and E. coli LPS-induced NO-dependent hyporesponsiveness to noradrenaline in isolated intrapulmonary arteries of neonatal piglets
}

\author{
*Eduardo Villamor, 'Francisco Pérez-Vizcaino, *Teresa Ruiz, Juan C. Leza, \\ *Manuel Moro \& Juan Tamargo
}

\begin{abstract}
Department of Pharmacology, Institute of Pharmacology and Toxicology, School of Medicine, Universidad Complutense, 28040 Madrid and ${ }^{\circ}$ Division of Neonatology, Department of Pediatrics, Hospital Universitario 'S. Carlos', 28040 Madrid, Spain
\end{abstract} 1 The effects of endotoxin ( $E$. coli lipopolysaccharide, LPS) and heat inactivated group B Streptococcus
(GBS) were studied on the contractile responses to noradrenaline (NA) in isolated puimonary arteries
and on the activity of the constitutive and inducible nitric oxide synthase (NOS) in lung fragments of
neonatal piglets.

2 Short-term $(\leqslant 5 \mathrm{~h})$ incubation with LPS $\left(1 \mu \mathrm{g} \mathrm{ml}^{-1}\right)$ or GBS $\left(3 \times 10^{7}\right.$ colonies forming units $\left.\mathrm{ml}^{-1}\right)$ did not modify the vascular responsiveness to NA $\left(10^{-1} \mathrm{M}-10^{-4} \mathrm{M}\right)$ in isolated intrapulmonary arteries. However, long-term incubation $(20 \mathrm{~h})$ with LPS or GBS produced a significant reduction in the maximal contractile responses and shifted the concentration-response curve for NA downwards.

3 Endothelium removal or the cyclo-oxygenase inhibitor meclofenamate $\left(10^{-5} \mathrm{M}\right)$ did not affect the GBS- and LPS-induced hyporesponsiveness to NA.

4 The presence of the nitric oxide (NO) precursor, L-arginine $\left(10^{-3} \mathrm{M}\right), 30 \mathrm{~min}$ prior to the contractility challenge increased the LPS- and GBS-induced pulmonary vascular hyporesponsiveness to NA. In contrast, the addition, prior to the challenge with NA, of the NOS inhibitor $\mathrm{N}^{\mathrm{C}}$-nitro-L-arginine methyl ester ( $\left.\mathrm{L}-\mathrm{NAME}, 10^{-4} \mathrm{M}\right)$ or coincubation with dexamethasone $\left(3 \times 10^{-6} \mathrm{M}\right)$, a potent inhibitor of the induction of NOS, or with the protein synthesis inhibitor cycloheximide $\left(10^{-5} \mathrm{M}\right)$ completely restored the reactivity to NA in LPS- and GBS-treated pulmonary arteries.

5 The incubation for $20 \mathrm{~h}$ of lung fragments with LPS and GBS produced a significant increase in the $\mathrm{Ca}^{2+}$-independent (inducible) NOS activity determined by the conversion of radiolabelled $\mathrm{L}$-arginine to citrulline, but did not modify the constitutive NOS activity. This NOS induction was abolished by coincubation with dexamethasone $\left(3 \times 10^{-6} \mathrm{M}\right)$.

6 These results demonstrated that prolonged incubation with GBS and LPS causes an induction of NOS activity which results in a reduced vascular responsiveness to NA in pulmonary arteries of neonatal piglets. Thus, induction of NOS seems to be responsible for the delayed pulmonary vascular hyporesponsiveness induced by GBS (a Gram-positive) and E. coli (a Gram-negative), the most common causal agents of neonatal sepsis.

Keywords: Group B Streptococcus; lipopolysaccharide; nitric oxide synthase; pulmonary artery of piglet

\section{Introduction}

E. coli, a Gram-negative bacterium, and group B Streptococcus (GBS), a Gram-positive bacterium, are the most common causal agents of neonatal sepsis (Anthony, 1985: Guerina, 1991). In general, sepsis is characterized by systemic arterial hypotension, inadequate tissue perfusion and decreased responses of vascular smooth muscle to exogenous vasoconstrictors (Groeneveld et al., 1988). The pulmonary system also demonstrates important abnormalities that include changes in pulmonary haemodynamics and lung mechanics, increased vascular permeability and hypoxemia, and more subtle changes in responses of both airway and the pulmonary circulation to constrictor stimuli (Brigham \& Meyrick, 1986). Lipopolysaccharide (LPS), the major component of the outer membrane of Gram-negative bacteria, is the endotoxin presumed to cause injury to the lungs as well as to other organs (Thiemermann, 1994). Gram-positive bacteria do not contain LPS and a toxin common to all Gram-positive organisms has not been identified. However, intravenous infusions of GBS and other Gram-positive bacteria cause pulmonary haemodynamic and gas exchange abnormalities similar to those observed in LPS-injected animals (Rojas et

\footnotetext{
'Author for correspondence.
}

al., 1983; Schreiber et al., 1992) suggesting a common pathway leading to these abnormalities (Auguet et al., 1992).

There is evidence that enhanced release of NO plays an important role in the loss of systemic (McKenna, 1990; Julou-Schaffer et al., 1990; Moncada et al., 1991; for a review see Thiemermann, 1994) and pulmonary (Szabó et al., 1993; Zelenkov et al.. 1993) vascular responsiveness that occurs in sepsis. There are at least two distinct isoforms of NO synthase (NOS) which catalyzes the formation of NO from L-arginine (Moncada et al., 1991; Stuehr \& Griffith, 1992). A constitutive, $\mathrm{Ca}^{2+}$-dependent isoform (cNOS), is present in vascular endothelial cells. In addition, LPS and cytokines induce a $\mathrm{Ca}^{2+}$-independent, isoform (iNOS) in the lung (Knowles et al., 1990), macrophages (Marletta et al., 1988), endothelial cells (Radomski et al., 1990) and vascular smooth muscle (Busse \& Mũlsch, 1990). Induction of iNOS has been found in rat pulmonary arteries incubated with LPS (Zeienkov et al., 1993) and in rat lung after exposure to endotoxin (Salter et al., 1991; Szabó et al., 1993; Thiemermann, 1994). Unfortunately, the effects of GBS on vascular reactivity and on $\mathrm{cNOS}$ and iNOS are still unknown. Therefore, the aim of this work was: (1) to study and compare the effects of GBS with those of LPS on the contractile responses to noradrenaline (NA) in intact and endothelium-denuded pur- 
monary arteries of neonatal piglets, and (2) to determine whether GBS- and LPS-mediated pulmonary vascular hyporesponsiveness could be related to the activation of cNOS and/or iNOS.

\section{Methods}

\section{Tissue preparation and incubation}

Male neonatal piglets (10-17 days of age, $4277 \pm 343 \mathrm{~g}$ ) obtained from the local abattoir were used in this study. Piglets were killed by exsanguination and the lungs were rapidly immersed in cold $\left(4^{\circ} \mathrm{C}\right)$ Krebs solution containing ampicillin $\left(10 \mu \mathrm{g} \mathrm{ml}^{-1}\right)$ and gentamicin $\left(10 \mu \mathrm{g} \mathrm{ml}^{-1}\right)$ and transported immediately to the laboratory. The third branch of the pulmonary arteries (internal diameter 1-2 mm) was carefully dissected free of parenchyma and connective tissue and cut into rings of $2-3 \mathrm{~mm}$ of length. Pulmonary rings were then incubated in Krebs solution (composition in mM: $\mathrm{NaCl} 118, \mathrm{KCl} 4.75, \mathrm{NaHCO}_{3} 25, \mathrm{MgSO}_{4} 1.2, \mathrm{CaCl}_{2} 2.0$, $\mathrm{KH}_{2} \mathrm{PO}_{4} 1.2$ and glucose 11$)$ containing ampicillin $(10 \mu \mathrm{g}$ $\left.\mathrm{ml}^{-1}\right)$ and gentamicin $\left(10 \mu \mathrm{g} \mathrm{ml}^{-1}\right)$. The solution was gassed with $95 \% \mathrm{O}_{2}$ and $5 \% \mathrm{CO}_{2}$ and maintained at $37^{\circ} \mathrm{C}$.

The pulmonary artery rings were initially incubated in Krebs soltuion in the presence of vehicle, LPS $\left(1 \mu \mathrm{g} \mathrm{ml}^{-1}\right)$ or heat inactivated GBS $\left(3 \times 10^{7}\right.$ colony forming units, c.f.u. $\mathrm{ml}^{-1}$ ) for 1,5 or $20 \mathrm{~h}$. To confirm that LPS and GBS induced $\mathrm{iNOS}$, in some experiments pulmonary rings were coincubated for $20 \mathrm{~h}$ in Krebs solution containing dexamethasone $\left(3 \times 10^{-6} \mathrm{M}\right)$, an inhibitor of NOS induction, (Radomski et al., 1990) or cycloheximide $\left(10^{-5} \mathrm{M}\right.$, an inhibitor of protein synthesis). After incubation, two Lshaped stainless-steel wires were inserted into the arterial lumen and the rings were introduced in Allhin organ chambers filled with Krebs solution. One wire was attached to the chamber and the other to an isometric forcedisplacement transducer (Grass FT07) and connected to a polygraph (Grass, model 7) as previously described (PérezVizcaino et al., 1993). The rings were stretched to a resting tension of $0.5 \mathrm{~g}$ and allowed to equilibrate for $60-90 \mathrm{~min}$. During this period tissues were restretched and washed every $30 \mathrm{~min}$ with warm Krebs solution. In some experiments the endothelium was removed by gently rubbing the intimal surface of the rings with a metal rod. The presence of functional endothelium was verified by addition of acetylcholine ( $\mathrm{ACh}$. $10^{-6} \mathrm{M}$ ) in arteries precontracted with NA. The ability of $\mathrm{ACh}$ to induce relaxation of unrubbed rings was taken as an indicator of the presence of functional endothelium.

\section{Experimental protocol}

In pulmonary rings previously incubated with vehicle, LPS or GBS for 1,5 or $20 \mathrm{~h}$, concentration-response curves to NA $\left(10^{-1} \mathrm{M}\right.$ to $\left.10^{-4} \mathrm{M}\right)$ were constructed by increasing the organ chamber concentration by cumulative increments after a steady state response had been reached with each increment. In three groups of intact pulmonary arteries, following the incubation period of $20 \mathrm{~h}$, cumulative concentration-response curves to NA were performed in the presence of $\mathrm{N}^{\mathrm{O}}$-nitro-Larginine-methyl ester (L-NAME, $10^{-4} \mathrm{M}$, an inhibitor of both cNOS and iNOS, Sakuma et al., 1988), L-arginine $\left(10^{-3} \mathrm{M}\right.$, the precursor of NO. Palmer et al., 1988) or meclofenamate $\left(10^{-5} \mathrm{M}\right.$, an inhibitor of cyclo-oxygenase) which were added $30 \mathrm{~min}$ before the concentration-response curve to NA was obtained.

\section{Assay of NOS}

Lung fragments (weight $100-150 \mathrm{mg}$ ) were incubated in the same conditions as described for the arterial rings. After incubation, tissues were immediately stored at $-80^{\circ} \mathrm{C}$ until studied. The frozen tissues were homogenized at $0-4^{\circ} \mathrm{C}$ in 5 vols of a buffer containing $320 \mathrm{mM}$ sucrose, $50 \mathrm{~mm}$ Tris, $1 \mathrm{mM}$ EDTA, $1 \mathrm{~mm}$ DL-dithiothreitol, $100 \mu \mathrm{g} \mathrm{ml}^{-1}$ phenylmethylsulfonyl fluoride, $10 \mu \mathrm{g} \mathrm{ml}^{-1}$ leupeptin, $100 \mu \mathrm{g} \mathrm{ml}^{-1}$ soybean trypsin inhibitor and $2 \mu \mathrm{g} \mathrm{ml}^{-1}$ aprotinin brought to $\mathrm{pH} 7.0$ at $20^{\circ} \mathrm{C}$ with $\mathrm{HCl}$. The homogenates were then centrifuged at $4^{\circ} \mathrm{C}$ at $12000 \mathrm{~g}$ for $20 \mathrm{~min}$. The pellets were discarded and the supernatants were placed on ice until incubation the same day. NOS activity was determined by measuring in duplicate the conversion of $\mathrm{L}-\left[\mathrm{U}-{ }^{14} \mathrm{C}\right]$-arginine to $\mathrm{L}-\left[\mathrm{U} \cdot{ }^{14} \mathrm{C}\right]$-citrulline by $10 \mathrm{~min}$ incubation at $37^{\circ} \mathrm{C}$ as described in detail by Salter et al. (1991). The incubation buffer contained $50 \mathrm{mM}$ L-valine to minimize any interference from arginase. $\mathrm{Ca}^{2+}$-dependent NOS (cNOS) activity was calculated from the difference between the $\mathrm{L}-\left[\mathrm{U}-{ }^{14} \mathrm{C}\right\}$-citrulline produced from control samples containing incubation buffer and samples containing buffer plus $1 \mathrm{mM}$ EGTA. The activity of the $\mathrm{Ca}^{2+}$-independent NOS (iNOS) was determined from the difference between samples containing $1 \mathrm{mM}$ EGTA in the incubation buffer and samples containing $1 \mathrm{mM}$ EGTA plus $2 \mathrm{mM} \mathrm{N}^{6}$-monomethyl-L-arginine (a competitive inhibitor of NOS, Palmer et al., 1988).

\section{Drugs and heat-killed GBS preparation}

The following drugs were used: $(-)$-noradrenaline bitartrate, acetylcholine chloride, lipopolysaccharide from $E$. coli (serotype 055:B5), dexamethasone, cycloheximide, L-NAME L-arginine (Sigma Chemical Co., London) and meclofenamate (Warner Lambert Co., U.S.A.). Meclofenamate was dissolved in absolute ethanol. The concentrations are expressed as final molar concentration in the tissue chamber. L- $\left[\mathrm{U}-{ }^{14} \mathrm{C}\right\}$-arginine was obtained from Amersham International (U.K.).

GBS type III was isolated from the blood of a neonate who developed early-onset sepsis. Bacteria were grown in Todd-Hewitt broth for $18-36 \mathrm{~h}$ at $37^{\circ} \mathrm{C}$ to late log phase and harvested by centrifugation at 5000 r.p.m. for $15 \mathrm{~min}$. Bacteria were resuspended in sterile isotonic saline to a concentration determined by serial viable counts to be $1 \times 10^{\circ}$ c.f.u. $\mathrm{ml}^{-1}$. Heat-killed bacteria were obtained by heating bacteria to $60^{\circ} \mathrm{C}$ for $60 \mathrm{~min}$. GBS killing was confirmed by no growth on blood agar. Endotoxin levels in the heat-killed GBS preparation were undetectable as assayed by a standard Limulus assay kit (Sigma). Aliquots of heatkilled GBS were stored at $-80^{\circ} \mathrm{C}$ until the study day.

\section{Statistical analysis}

Results are expressed as means \pm s.e.mean of measurements in $n$ arteries. Individual cumulative concentration-response curves to NA were fitted to a logistic equation. In most of the experiments the point corresponding to $10^{-4} \mathrm{M}$ NA was below the maximal tension and was therefore excluded from the fitting. The drug concentration exhibiting $50 \%$ of the maximal contraction to NA was calculated for each ring and expressed as negative log molar $\left(\mathrm{pD}_{2}\right)$. The $\mathrm{E}_{\max }$ was defined as the maximal tension induced by NA in each ring. Statistically significant differences were calculated by means of an ANOVA analysis followed by a Newman Keuls means comparison testing. $P<0.05$ was considered statistically significant.

\section{Results}

\section{Effects of LPS and GBS in the presence or absence of endothelium}

Short-term incubation of intact pulmonary arteries with LPS $\left(1 \mu \mathrm{g} \mathrm{ml}^{-1}\right)$ or GBS $\left(3 \times 10^{7}\right.$ c.f.u. $\left.\mathrm{ml}^{-1}\right)$ for 1 or $5 \mathrm{~h}$ produced no significant effects on the concentration-response curve to NA (Table 1). However, as shown in Figure la, when the endothelium-intact arteries were incubated for a 
longer period $(20 \mathrm{~h})$ with LPS $\left(1 \mu \mathrm{g} \mathrm{ml}^{-1}\right)$ or GBS $\left(3 \times 10^{7}\right.$ c.f.u. $\mathrm{ml}^{-1}$ ) and then transferred to the organ bath in the absence of bacterial products, the maximal contractile response to NA was reduced and thus, a downward shift of the
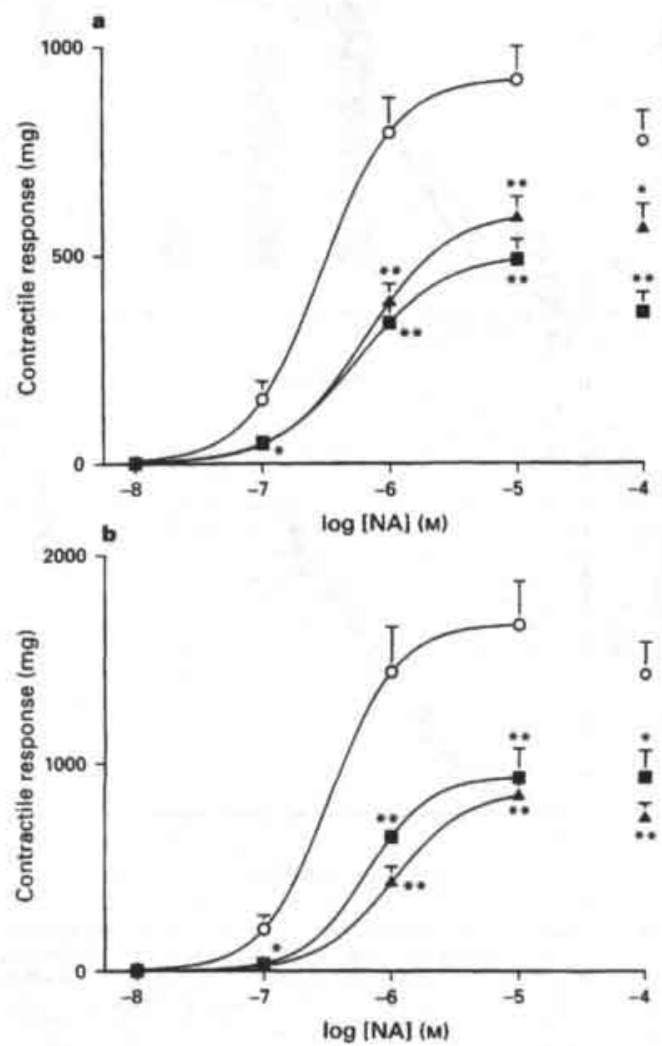

Figure 1 Concentration-response curve to noradrenaline (NA, $10^{-3}-10^{-4} \mathrm{M}$ ) in intrapulmonary arterial rings (a) with or (b) without endothelium, preincubated for $20 \mathrm{~h}$ in Krebs solution in the presence of vehicle (control, O), E coli lipopolysaccharide (LPS, $\left.1 \mu \mathrm{g} \mathrm{ml}^{-1}, \mathbf{D}\right)$ or heat inactivated group B Streptococcus (GBS, $3 \times 10^{7}$ c.f.u. $\left.\mathrm{ml}^{-1}, \mathbf{A}\right)$. The concentration-response curve to NA was carried out in the absence of bacterial products. Data are expressed as means \pm s.e.mean of $7-22$ observations. $* P<0.05$ and $* P<0.01$ represent significant differences with respect to control group. concentration-response curve to NA was observed. This was accompanied by a smail, but significant, decrease of the $\mathrm{pD}_{2}$ values (Table 1). These results indicate that pulmonary vascular hyporesponsiveness to NA is a delayed process and suggested the induction of a biological activity. Endotheliumdenuded arteries showed significantly greater maximal responses to NA as compared to endothelium-intact arteries $(P<0.01)$ incubated with vehicle, LPS or GBS (Table 1). Nevertheless, mechanical removal of endothelial cells did not affect the hyporeactivity to NA observed after long-term incubation $(20 \mathrm{~h})$ with LPS or GBS (Figure Ib).

\section{Effects of L-arginine, L-NAME and meclofenamate}

In order to assess the role of NO production in the hyporesponsiveness to NA, a concentration-response curve to NA was performed in control, LPS- and GBS-treated arteries acutely treated with either the NO-precursor, L-arginine $\left(10^{-5} \mathrm{M}\right)$, or the NOS inhibitor, L-NAME $\left(10^{-4} \mathrm{M}\right)$. As shown in Figure $2 \mathrm{a}$ and Table 1 , in control arteries treated with L-arginine the concentration-response curve to NA was not modified compared to that obtained in arteries in the absence of L-arginine. In contrast, in arteries incubated with LPS or GBS for $20 \mathrm{~h}$, the presence of L-arginine potentiated $(P<0.01)$ the hyporesponsiveness to NA. Addition of $10^{-4} \mathrm{M}$ L-NAME to resting arteries produced a small contractile effect averaging $45.7 \pm 6.6 \mathrm{mg} .44 .3 \pm 9.6 \mathrm{mg}$ and $43.1 \pm 5.9 \mathrm{mg}$, in untreated and in arteries treated with LPS and GBS, respectively. Thereafter, L-NAME induced an upward shift of the concentration-response curve to NA in the LPS- and GBS-treated arteries resulting in no differences between control, LPS- or GBS-treated arteries (Figure 2b). Therefore, L-NAME reversed the hyporesponsiveness to NA induced by LPS and GBS.

The possible role of vasodilator prostaglandins in the hyporeactivity to NA was assessed by acute treatment of the arteries with the cyclo-oxygenase inhibitor, meclofenamate. The presence of $10^{-5} \mathrm{M}$ meclofenamate did not affect the hyporesponsiveness to NA in LPS- and GBS-treated arteries (Table 1).

\section{Effect of dexamethasone and cycloheximide}

In order to assess the induction of NOS by LPS and GBS, intact pulmonary arteries were simultaneously incubated with LPS and GBS and $3 \times 10^{-6} \mathrm{M}$ dexamethasone or $10^{-6} \mathrm{M}$ cycloheximide for $20 \mathrm{~h}$. As shown in Figure 3, both dexamethasone and cycloheximide completely restored the reactivity to NA in LPS- and GBS-treated arteries. Moreover, dexamethasone (but not cycloheximide)-treated arteries showed greater $\mathrm{pD}_{2}$ values in control arteries (Table 1).

Table 1 Effects of E. coli lipopolysaccharide (LPS, $10 \mu \mathrm{g} \mathrm{ml}-1$ ) and group B Streptococcus (GBS, $3 \times 10^{7}$ c.f.u. $\mathrm{ml}^{-1}$ ) on the parameters $\left(\mathrm{E}_{\max }\right.$ and $\left.\mathrm{pD}_{2}\right)$ of the concentration-response curve to noradrenaline $(\mathrm{NA})$ in the absence and presence of various inhibitors

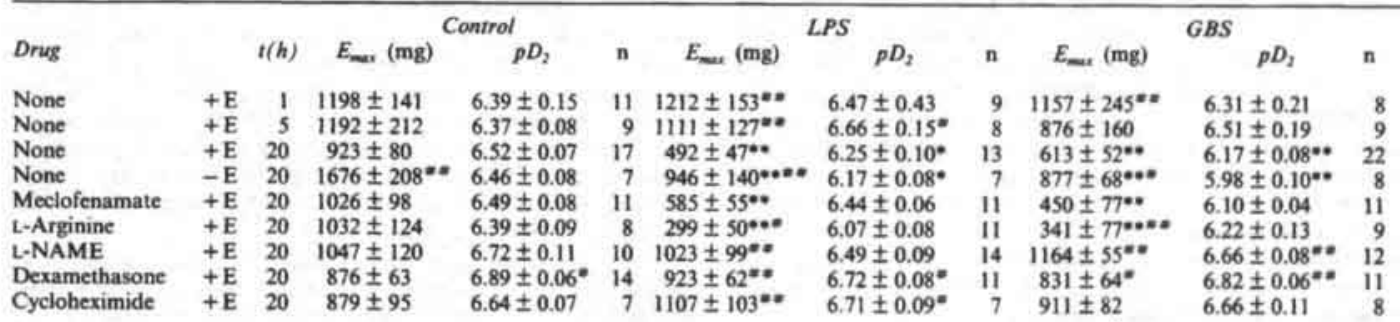

$t=$ incubation period. $+\mathrm{E}=$ endothelium intact, $-\mathrm{E}=$ endothelium denuded. Meclofenamate $\left(10^{-3} \mathrm{M}\right)$, $\mathrm{L}-\mathrm{arginine}\left(10^{-5} \mathrm{M}\right)$ or $\mathrm{N}^{0}$-nitro-t-arginine methyl ester (L-NAME, $10^{-4} \mathrm{M}$ ) were added to the organ bath solution 30 min before the addition of NA. Dexamethasone $\left(3 \times 10^{-6} \mathrm{M}\right)$ or cycloheximide $\left(10^{-3} \mathrm{M}\right)$ were included during the $20 \mathrm{~h}$ incubation period.

$\bullet P<0.05$ and $* P<0.01$ GBS- or LPS-treated vs control arteries. ${ }^{*} P<0.05$ and $* P<0.01$ vs arteries $+\mathrm{E}, 20 \mathrm{~h}$, no drug. The drug concentration exhibiting $50 \%$ of the maximal contraction to NA was calculated for each ring and expressed as negative log molar $\left(\mathrm{pD} \mathrm{D}_{2}\right.$. The $\mathrm{E}_{\text {max }}$ was defined as the maximal tension induced by $\mathrm{NA}$ in each ring. 

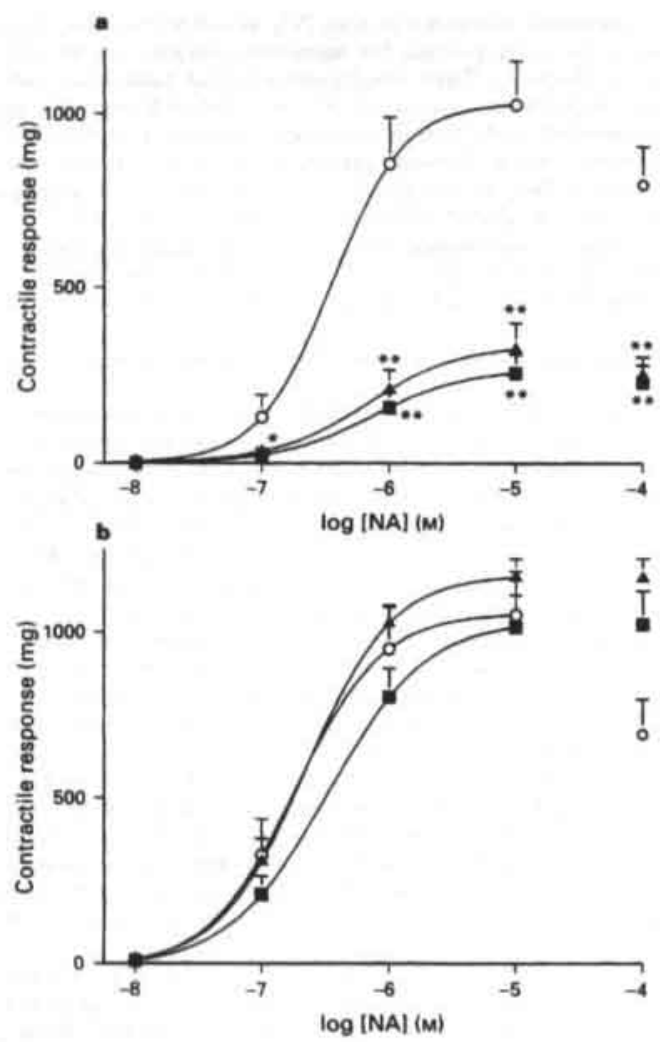

Figure 2 Effects of (a) L-arginine $\left(10^{-3} \mathrm{M}\right)$ or (b) $\mathrm{N}^{\mathrm{C}}$-nitro-Larginine methyl ester (L-NAME, $10^{-4} \mathrm{M}$ ) on $E$, colt lipopolysaccharide (LPS)- and group B Streptococcus (GBS)-induced hyporeactivity to noradrenaline (NA) in intrapulmonary artery rings. Concentration-response curves to noradrenaline (NA, $10^{-6}-10^{-4} \mathrm{M}$ ) were performed in intrapulmonary arterial rings previously incubated for $20 \mathrm{~h}$ in Krebs solution in the presence of vehicle (control, O), LPS $\left(1 \mu \mathrm{ml}^{-1}, \mathbf{n}\right)$ or heat-inactivated GBS $\left(3 \times 10^{7} \mathrm{c.f} . \mathrm{u} \cdot \mathrm{ml}^{-1}, \mathbf{A}\right)$. L-Arginine $\left(10^{-9} \mathrm{M}\right)$ or L-NAME $\left(10^{-4} \mathrm{M}\right)$ was added $30 \mathrm{~min}$ before addition of NA. The curve was obtained in the absence of bacterial products. Data are expressed as means \pm s.e.mean of 8-14 observa. tions. $* P<0.05$ and $* P<0.01$ represent significant differences with respect to control group.

\section{Effects of LPS and GBS on NOS activity}

NOS activity was measured by the conversion of radiolabelled L-arginine to citrulline (Salter et al., 1991). Using this method. NOS activity was almost undetectable in puimonary arteries. Therefore, the $\mathrm{cNOS}\left(\mathrm{Ca}^{2+}\right.$-dependent) and iNOS $\left(\mathrm{Ca}^{2+}\right.$-independent) activities were determined in lung fragments. Control values for cNOS and iNOS activities were $61.5 \pm 10.7$ and $36.0 \pm 6.4 \mathrm{pmol} \mathrm{min}^{-1} \mathrm{mg}^{-1}$ of tissue, respectively. As shown in Figure 4, no change in cNOS activity was detected after incubation with $1 \mu \mathrm{g} \mathrm{ml} \mathrm{m}^{-1}$ LPS or $3 \times 10^{7}$ c.f.u. $\mathrm{ml}^{-1}$ GBS for $20 \mathrm{~h}$. In contrast, LPS and GBS significantly increased the iNOS activity $(P<0.01)$. Dexamethasone $\left(3 \times 10^{-6} \mathrm{M}\right)$ produced no change in cNOS activity but completely abolished the LPS- and GBS-induced increase in iNOS activity (Figure 4).

\section{Discussion}

The present results demonstrated that only after prolonged $(>5 \mathrm{~h}$ ) incubation, did LPS and GBS reduce vascular res-
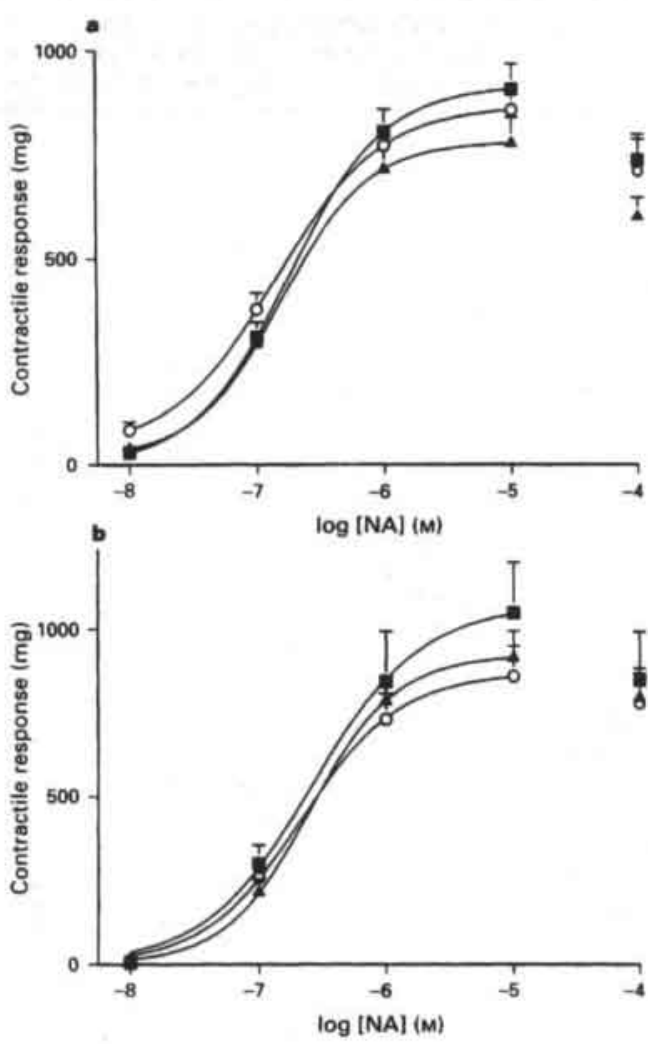

Figure 3 Effects of (a) dexamethasone $\left(3 \times 10^{-6} \mathrm{M}\right)$ or (b) cycioheximide $\left(10^{-3} \mathrm{M}\right)$ when coincubated with $E$, coli lipopolysaccharide (LPS) and group B Streptococcus (GBS), Concentration-response curves to noradrenaline (NA, $10^{-5}-10^{-4} \mathrm{M}$ ) were performed in intrapulmonary arterial rings previously incubated for $20 \mathrm{~h}$ in Krebs solution in the presence of vehicle (O), LPS $\left(1 \mu \mathrm{g} \mathrm{ml}^{-1}\right.$, E) or heat-inactivated GBS $\left(3 \times 10^{7}\right.$ c.f.u. $\left.\mathrm{ml}^{-1}, \mathbf{4}\right)$. The curve was obtained in the absence of bacterial products. Data are expressed as means \pm s.e mean of $7-14$ observations. $* P<0.05$ and $* P<0.01$ represent significant differences when compared to control group.

ponsiveness to NA in isolated pulmonary artery rings of neonatal pigs. After incubation, the experiments were performed in the absence of LPS or GBS which indicated that the hyporesponsiveness was a delayed process that was not due to a direct action of bacterial toxins but more likely to the induction of biological activity. The decreased response did not require the presence of an intact endothelium and was not mediated by products of cyclo-oxygenase activity since it was unaffected by endothelium removal or the cyclooxygenase inhibitor, meclofenamate, respectively. Our results strongly suggested that induction of iNOS is implicated in the GBS- and LPS-induced pulmonary vascular hyporesponsiveness to NA. To our knowledge this is the first paper showing that GBS produces hyporesponsiveness to NA and induction of iNOS activity.

There is a growing consensus that NO plays a major role in the control of pulmonary vascular smooth muscle tone (Moncada et al., 1991; Dinh-Xuan, 1992; Stamler et al., 1994). Thus, an impaired release of NO has been associated with an increased pulmonary vascular reactivity to constrictor stimuli and may contribute to the pathogenesis of pulmonary hypertension (Moncada et al., 1991; Dinh-Xuan, 1992). In the present experiments, L-arginine potentiated the reduced vascular reactivity to NA in pulmonary arteries of 


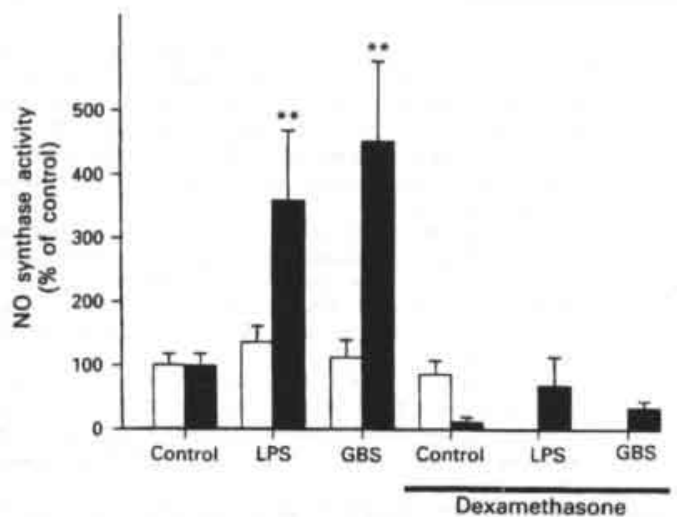

Figure $4 \mathrm{Ca}^{2+}$-dependent (constitutive, open columns) and $\mathrm{Ca}^{2+}$. independent (inducible, solid columns) nitric oxide synthase (NOS) activities in lung fragments incubated for $20 \mathrm{~h}$ in $37^{\circ} \mathrm{C}$ oxygenated Krebs solution in the presence of vehicle (control), $E$. coll lipopolysaccharide (LPS. $1 \mu \mathrm{g} \mathrm{ml} \mathrm{m}^{-1}$ ) or group B Streptococcus (GBS. $3 \times 10^{7}$ c.f.u. $\mathrm{ml}^{-1}$ ) and in the absence or presence of dexamethasone $\left(3 \times 10^{-6} \mathrm{M}\right)$. Data are expressed as percentage of the control $\mathrm{Ca}^{2+}$. dependent and $\mathrm{Ca}^{2+}$-independent activities, respectively (means \pm s.c.mean of 5-7 observations). Control values for eNOS and iNOS activities were $61.5 \pm 10.7$ and $36.0 \pm 6.4 \mathrm{pmol} \mathrm{min}^{-1} \mathrm{mg}^{-1}$ of tissue, respectively. $* P<0.01$ represent significant differences when compared to control group.

newborn piglets incubated with LPS and GBS, while LNAME completely reversed it. Moreover, dexamethasone, which inhibits the induction of NOS (Radomski et al., 1990) and cycloheximide, an inhibitor of protein synthesis when coincubated with LPS or GBS for $20 \mathrm{~h}$, completely reversed the reduced response to NA. All these results suggest that GBS- and LPS-induced pulmonary vascular hyporesponsiveness to NA is associated with enhanced formation of NO via the iNOS and requires the synthesis de novo of the enzyme in the pulmonary vasculature. However, in pulmonary arteries the NOS activity was below the limit of detection. This can be related to the fact that cNOS and iNOS activities in vascular smooth muscle are 5-50 times lower than in lung (Salter et al., 1991; Mitchell et al., 1993). Thus, we assessed the effects of LPS and GBS on both cNOS and $i N O S$ in lung fragments. LPS and GBS had no effect on cNOS but induced a marked increase in iNOS activity which was abolished when lung fragments were incubated with dexamethasone. GBS- and LPS-induction of iNOS in the lung supported the functional evidence of induction of iNOS in pulmonary arteries. As previously reported in rat and rabbit lung (Salter et al., 1991; Mitchell et al., 1993; Szabo et al., 1993), we found that iNOS activity was expressed basally in porcine lung tissue. Since basal iNOS activity was lowered by dexamethasone, it might indicate a certain endotoxin contamination of the incubation media.

GBS is able to produce sepsis only in the neonate and exceptionally in parturients and immunodepressive patients (Anthony, 1985). The mechanism of GBS-induced pulmonary injury in neonates is still a matter of controversy. Grampositive bacteria do not contain LPS and a common toxin to all Gram-positive organisms has not been identified. It has been shown recently that lipoteichoic acid (LTA), a component of the peptidoglycan layer of the cell wall in most Gram-positive bacteria, decreased the responses to pressor agents and induced iNOS in cultured vascular smooth muscle cells, rat aorta (Auguet et al., 1992) and in anaesthetized rats (De Kimpe et al., 1994). Killed whole $S$. aureus also induced
NOS in macrophages (Cunha et al., 1993). Clinical isolates of GSB, including type III. recovered from infants with sepsis, possessed significantly higher levels of LTA in their cell wall than those isolated from asymptomatic carriers (Nealon \& Mattingly, 1983). The molecular analysis of GBS LTA demonstrated a close similarity with the Group A Streptococcus LTA (Maurer \& Mattingly, 1991). Thus, the LTA component of GBS might be responsible for the effects on vascular reactivity and $\mathrm{INOS}$ induction described in the present paper. In addition, two different GBS polysaccharide toxins producing pathophysiological changes mimicking those of GBS infection in neonates have been identified, a non specific mannan polysaccharide (Hellerqvist et al., 1987) and the type III specific capsular polysaccharide (Hemming et al., 1984). However, the type III specific capsular polysaccharide does not seem to be required for the acute phase but it may play a role in the late phase $(>2 \mathrm{~h})$ of GBS-induced pulmonary haemodynamic alterations in piglets (Gibson et al., 1989). In the present experiments we used heat-inactivated GSB, i.e. an unfragmented capsule, isolated from the blood of a neonate who developed early-onset sepsis. Heat-inactivated GBS has been previously shown to cause similar haemodynamic effects as the live GBS (Schrieber et al., 1992). Further studies would be necessary to elucidate the specific component of GBS responsible for NOS induction.

The lung is a major target organ in neonatal sepsis (Ablow et al., 1976). In general, the lung plays a determinant role in the sepsis in some animal species that exhibit a pulmonary bacterial clearance (e.g. sheep, pig) but not in species (e.g. dog, rat, rabbit) in which bacteria localize predominantly in the liver and spleen (Winkler, 1988). The uptake of bacteria by pulmonary intravascular macrophages and the subsequent release of inflammatory mediators are central to the pathological changes produced in sepsis-induced adult respiratory distress syndrome in sheep (Warner et al., 1987) and in GBS-induced pulmonary hypertension in newborn pigiets (Bowdy et al., 1990). In these models, as in man, sepsis produces a complex pulmonary response in which two different phases have been delimited (Brigham \& Meyrick, 1986). Initially there is a marked increase in pulmonary artery pressure and hypoxemia, whereas the second phase is characterized by a returning of pulmonary pressure towards baseline and an increased lung vascular permeability. This latter phase is accompanied by marked increases in guanosine 3':5'-cyclic monophosphate (cyclic GMP. Snapper et al., 1983). NO-mediated vasorelaxation has been correlated with the activation of soluble guanylate cyclase which in turn increases the intracellular concentrations of cyclic GMP (Ignarro et al., 1987; Moncada et al., 1991). Thus, the increased production of NO following the induction of iNOS in pulmonary arteries described here could be responsible for the previously reported increased cyclic GMP production which is a main feature of the latter phase of the pulmonary response to sepsis.

In conclusion, the present results demonstrated that prolonged incubation with GBS, as previously reported with LPS, causes an induction of iNOS which results in a loss of vascular responsiveness to NA in intrapulmonary arteries of neonatal piglets. Thus, the induction of iNOS seems to be a key mediator in the delayed puimonary vascular hyporesponsiveness characteristic of the pulmonary injury induced by either Gram-positive or Gram-negative sepsis.

This work was supported by a CICYT (92/0157) and Fis $(95 / 0308)$ Grant. E.V. is a recipient of the Asociación Espanoola de Pediatria/ Arbora S.A. Grant for Pediatric Research. We would like to thank Dr Elorza, Dr Romero and Mrs Maria Gómez for providing the heat-killed Group B Streptococeus. 


\section{References}

ABLOW, R.C. DRISCOLL, S.G. EFFMANN, E.L., GROSS, 1., JOLLES, C.J., KAUY, R. \& WARSHAW, J.B. (1976). A comparison of earlyonset group B streptococcal neonatal infection and the respiratory-distress syndrome of the newborn. New Engl. J. Med., 294, 65-69.

ANTHONY, B.F. (1985). Epidemiology of GBS in man. Antibiot. Chemother., 35, 10-16.

AUGUET, M., LONCHAMPT, M.O., DELAFLOTTE, S., GOULINSCHULZ, J., CHABRIER, P.E. \& BRAQUET, P. (1992). Induction of nitric oxide synthase by lipoteichoic acid from Staphylococcus aureus in vascular smooth muscle cells. FEBS Len., 297, $183-185$.

BOWDY. B.D., MARPLE, S.L., PAULY, T.H., COONROD, J.D. \& GILLESPIE, M.N. (1990), Oxygen radical-dependent bacterial killing and pulmonary hypertension in piglets infected with group $B$ Streptococei. Am. Rev. Respir. Dis., 141, 648-653.

BRIGHAM, K.L. \& MEYRICK. B. (1986). Endotoxin and lung injury. Am. Rev. Respir. Dis., 133, 913-927.

BUSSE, R. \& MOLSCH. A. (1990). Induction of nitric oxide by cytokines in vascular smooth muscle cells. FEBS Lett., 275, 87-90.

CUNHA, F.Q. MOSS, D.W., LEAL, L.M., MONCADA, S. \& LIEW, F.Y. (1993). Induction of macrophage parasiticidal activity by Staphylococcus aureus and exotoxins through the nitric oxide synthase pathway. Immunology, 78, 563-567.

DE KIMPE, S.J. THIEMERMANN, C \& VANE, J.R. (1994). Lipoteichoic acid, a cell wall component of Gram-positive bacteria, causes hypotension 'and induction of nitric oxide synthase in anaesthetized rats. $\mathrm{Br}$. J. Pharmacol., 112, 442P.

DINH-XUAN, A.T. (1992). Endothelial modulation of pulmonary vascular tone. Eur. Respir. J., 5, 757-762.

GIBSON, R.L., REDDING, G.J., TRUOG, W.E., HENDERSON, W.R. \& RUBENS, C.E. (1989). Isogenic group B streptococei devoid of capsular polysaccharide or $\beta$-Hemolysin: pulmonary hemodynamic and gas exchange effects during bacteriemia in piglets. Pediatr. Res., 26, 241-245.

GROENEVELD. A.B.J. NAUTA, J.J.P. \& THIS., L.G. (1988). Peripheral vascular resistance in septic shock: its relation to outcome. Intensive Care Med., 14, 141-147.

GUERINA, N.G. (1991). Bacterial and fungal infections. In Manual of Neonatal Care. ed. Cloherty, J.P. \& Stark, A.R. pp. 146-148. Boston/Toronto/London: Little, Brown and Company.

HELLERQVIST, C.G., SUNDELL. H. \& GETTINS, P. (1987). Molecular basis of group B B-bacmolytic streptococcal disease. Proc. Natl. Acad. Sci. U.S.A., 84, 51-55.

HEMMING, V.G., O'BRIEN, W.F. FISCHER, G.W., GOLDEN, S.M. \& NOBEL. S.F. (1984). Studies of short-term puimonary and peripheral vascular responses induced in oophorectomized sheep by infusion of a group B streptococcal extract. Pediatr. Res., 18, 266-269.

IGNARRO, L., BYRNS, R.E., BUGA, G.M. \& WOOD, K.S. (1987). Endothelium-derived relaxing factor from pulmonary artery and vein possesses pharmacologic and chemical properties identical to those of nitric oxide radical. Circ. Res., 61, 866-879.

JULOU-SCHAEFFER. G., GRAY, G.A. FLEMING, I., SCHOTT, C, PARRATT, J.R. \& STOCLET, J.-C (1990). Loss of vascular responsiveness induced by endotoxin involves L-arginine pathway. $\mathrm{Am}$. J. Physiol., 259, H1038-H1043.

KNOWLES, R.G., MERRETT, M., SALTER, M. \& MONCADA, S. (1990). Differential induction of brain, lung and liver nitric oxide synthase by endotoxin in the rat. Biochem. $J_{.,}, 270,833-836$.

MARLETTA. M.A., YOON, P.A., IYENGAR, R., LEAF, C.D. \& WISHNOK, J.S. (1988). Macrophage oxidation of Larginine to nitrite and nitrate: nitric oxide is an intermediate. Biochemistry, 27, 8706-8711.

MAURER. J.J. \& MATTINGLY, SJ. (1991). Molecular analysis of lipoteichoic acid from Streptococcus agalactie. J. Bacteriol., 173, 487-494.

MCKENNA, T.M. (1990). Prolonged exposure of rat aorta to low levels of endotoxin in vitro results in impaired contractility. Association with vascular cytokine release. $J$. Clin. Invest., 86, $160-168$.
MITCHELL, J.A., KOHLHAAS, K.L., SORRENTINO, R., WARNER, T.D. MURAD, M. \& VANE, J. (1993). Induction by endotoxin of nitric oxide synthase in the rat mesentery: lack of effect on action of vasoconstrictors. Br. J. Pharmacol., 109, 265-270.

MONCADA, S. PALMER, R.M.J. \& HIGGS, E.A. (1991). Nitric oxide: physiology, pathophysiology, and pharmacology. Pharmacol. Rev., 43, $109-142$.

NEALON, T.J. \& MATTINGLY, S.J. (1983). Association of elevated levels of cellular lipoteichoic acids of group B Streptococei with human neonatal disease. Infect. Immun., 39, 1243-1251.

PALMER, R.M.J., ASHTON, D.S. \& MONCADA.S. (1988). Vascular endothelial cells synthesize nitric oxide from L-arginine. Nanure, 333, $664-666$.

PEREZ-VIZCAINO, F., CASIS, O., RODRIGUEZ, R., GOMEZ, L.A., GARCIA RAFANELL, J. \& TAMARGO, J. (1993). Effects of the novel potassium channel opener, UR-8225, on contractile response in rat isolated smooth muscle. Br. J. Pharmacol., 110, $1165-1171$.

RADOMSKI. M.W., PALMER, R.M.J. \& MONCADA. S. (1990). Glucocorticoids inhibit the expression of an inducible, but not the constitutive, nitric oxide synthase in vascular endothelial cells. Proc. Natl. Acad. Sci. U.S.A., 87, 10043-10047.

ROJAS, J., L.ARSON, LE., HELLERQVIST, C.G.; BRIGHAM, K.L., GRAY, M.E. \& STAHLMAN, M.T. (1983). Pulmonary hemodynamies and ultrastructural changes associated with group B streptococcal toxemia in adult sheep and newborn lambs. Pediatr. Res., 17, 1002-1008.

SAKUMA, I. STUEHR, D.J., GROSS, S.S., NATHAN, C. \& LEVI, R. (1988). Identification of arginine as a precursor of endothelium derived relaxing factor. Proc. Natl. Acad. Sci. U.S.A., 85, $8664-8667$.

SALTER, M., KNOWLES, R.G. \& MONCADA, S. (1991). Widespread tissue distribution, species distribution and changes in activity of $\mathrm{Ca}^{2+}$-dependent and $\mathrm{Ca}^{2+}$-independent nitric oxide synthases. FEBS Lett., 291, 145-149.

SCHREIBER. M.D. COVERT, R.F, \& TORGERSN, L. (1992). Hemodynamic effects of heat-killed group B $\beta$-hemolytic streptococcus in newborn lambs: role of leukotriene D4. Pediatr. Res., 31, $121-126$.

SNAPPER, J., BRIGHAM, K.L., HEFLIN, C., BOMBOY, J. \& GRABER, S. (1983). Effects of endotoxemia on cyclic nucleotides in the unanesthetized sheep. J. Lab. Clin. Med., 102, 240-249.

STAMLER, J.S., LOH, E., RODDY, M., CURRIE, K.E. \& CREAGER, M.A. (1994). Nitric oxide regulates basal systemic and pulmonary vascular resistance in healthy humans. Circulation, 89, 20352040.

STUEHR, D.J. \& GRIFFITH, D.W. (1992). Mammalian nitric oxide synthases. Adv. Enzymol. Mol. Biol., 65, 287-343.

SZABO, C. MTTCHELL, J.A., THIEMERMANN, C. \& VANE, J.R. (1993). Nitric oxide-mediated hyporeactivity to noradrenaline precedes the induction of nitric oxide synthase in endotoxin shock. Br. J. Pharmacol., 108, 786-792.

THIEMERMANN, C. (1994). The role of the L-arginine: nitric oxide pathway in circulatory shock. Adv. Pharmacol., 28, 45-79.

WARNER, A.E., MOLINA, R. \& BRAIN, J.D. (1987). Uptake of bloodborne bacteria by pulmonary intravascular macrophages and consequent inflammatory responses in sheep. Am. Rev. Respir. Dis., 136, 683-693.

WINKLER, G.G. (1988). Puimonary intravascular macrophages in domestic species: review of structural and functional properties. Am. J. Anat., 181, 217-234.

ZELENKOV, P., MCLOUGHLIN, T. \& JOHNS, R.A. (1993). Endotoxin enhances hypoxic constriction of rat aorta and pulmonary artery through induction of EDRF/NO synthase. Am. J. Physiol., 265, L.346-L.354.

(Received September 26, 1994 Revised January 5, 1995 Accepted February 6, 1995) 
Chapter VIII. Lack of endotoxin-induced hyporesponsiveness to U46619 in isolated neonatal porcine pulmonary but not mesenteric arteries. (J Vasc Res. 1996; 33:249-57). 



\section{Vascular Research}

\section{Francisco Pérez-Vizcaino ${ }^{2}$ Eduardo Villamor ${ }^{\mathrm{b}}$}

Buensuceso Fernandez del Pozo Manuel Moro ${ }^{\text {b }}$

Juan Tamargo ${ }^{2}$

a Department of Pharmacology, Institute of Pharmacology and Toxicology, School of Medicine, Universidad Complutense, and

${ }^{b}$ Division of Neonatology, Department of Pediatrics, Hospital Universitario S. Carlos, Madrid, Spain

\section{Key Words}

Endotoxin

U46619

Nitric oxide

Pulmonary artery

Piglet
J Vasc Res 1996:33:249-257

\begin{abstract}
The effects of endotoxin from Escherichia coli on the vasoconstrictor responses to noradrenaline $(10 \mathrm{n} M-100 \mu M)$ and the thromboxane $A_{2}$ analog U46619 (100 p M-1 $\mu M)$ were evaluated on isolated pulmonary and mesenteric arteries from neonatal pigiets. Incubation for $20 \mathrm{~h}$ with endotoxin $(1 \mu \mathrm{g}$ $\mathrm{ml}^{-1}$ ) induced a decrease in the contractile responses to noradrenaline in both arteries $\left(\mathrm{p}<0.05\right.$ ) which was inhibited by $N^{G}$-nitro- $L$-arginine-methyl ester $(L$-NAME, $100 \mu M)$. Endotoxin-treated mesenteric arteries also showed a reduction of the maximal contractions induced by U46619 (p<0.05) and this effect was inhibited by $L$-NAME. In contrast, the contractile responses to U46619 were similar in control and endotoxin-treated pulmonary arteries. In endothelium-denuded pulmonary rings, endotoxin was also unable to modify the contractile responses to $\mathrm{U} 46619$. In pulmonary rings, the contractions induced by $\mathrm{U} 46619(100 \mathrm{n} M)$ were much less sensitive to sodium nitroprusside, 8-bromo-cyclic GMP or dipyridamole than those induced by $10 \mu M$ noradrenaline. In conclusion, endotoxin-treated pulmonary arteries exhibited decreased responses to noradrenaline due to enhanced nitric oxide release but not to the thromboxane $A_{2}$ analog $U 46619$. This lack of hiyporesponsiveness to U46619 in pulmonary arteries may be attributed to a relative insensitivity to nitric oxide. The absence of pulmonary hyporesponsiveness to U46619 may explain why pulmonary hypertension occurs in septic shock despite $\mathrm{Ca}^{2+}$-independent nitric oxide synthase induction in the lung.
\end{abstract}

\section{Introduction}

Lipopolysaccharide is the endotoxin presumed to cause most, if not all, of the hemodynamic alterations following gram-negative sepsis $[1,2]$. In recent years, en- hanced formation of nitric oxide following endotoxinmediated induction of the $\mathrm{Ca}^{2+}$-independent nitric oxide synthase (iNOS) has been reported in several models of endotoxic shock [2]. iNOS is induced by endotoxin in a wide variety of tissues including the spleen, liver, mesen-

\section{KARGER}

E.Mat karzenokarger.ch

Fax +41613061234

http $/ /$ www. karger.ch
D I996 S. Karger AG. Basel

$1018-1172 / 96 / 0333-0249510.000$
Dr. Francisco Perez-Vuzcaino

Depurtment of Pharmacolog.

School of Medicine

Universidad Complutense

E-28040 Madrid (Spain)
Received:

September 13, 1995

Accepted after revition:

Decemiber is, 1995 
tery, lung, kidney, heart, and vascular smooth muscle [3, 4]. In systemic arteries, iNOS induction is responsible for the systemic hypotension in endotoxic shock [5]. In an attempt to counteract this severe hypotension, vasoconstrictors are endogenously released by reflex mechanisms [6] or are therapeutically administered [1]. However, sepsis is associated with a reduction in the pressor responses to vasoconstrictor agents ultimately resulting in therapyresistant hypotension [7-9].

The lung is the major target organ in neonatal sepsis [10]. In the adult, pulmonary complication, i.e. adult respiratory distress syndrome, continue to represent an important cause of mortality in patients with postsurgical septic complications [11]. As described in the systemic vasculature, both induction of iNOS and decreased responses to noradrenaline have been reported after in vitro incubation with endotoxin or group B streptococci in neonatal piglet [12] or adult rat pulmonary arteries [13, 14]. This is paradoxical since endotoxemia, both in the adult and in the neonate, is often associated with a marked increase in pulmonary artery pressure with little changes in cardiac output or left atrial pressure [15-18]. The early pulmonary hypertension in septic shock has been reported to be due to the enhanced production of thromboxane $A_{2}$, a potent pulmonary vasoconstrictor which reaches peak levels in lung lymph when pulmonary pressure is more marked $[15,19,20]$. In fact, specific inhibitors of thromboxane synthase reduce early pulmonary hypertension in sepsis [21]. Therefore, in contrast to the systemic hypotension occurring concomitantly with increased levels of circulating vasoconstrictors, the increased levels of pulmonary vasoconstrictors, particularly thromboxane $\mathrm{A}_{2}$, lead to pulmonary hypertension despite iNOS induction in the lung.

In an attempt to better understand the paradox of thromboxane- $\mathrm{A}_{2}$-induced pulmonary hypertension concurrent with iNOS induction in the lung during sepsis, we investigated the effects of endotoxin on the vasoconstrictor responses to noradrenaline and the stable thromboxane $A_{2}$ analog U46619 (9,11-dideoxy-11a,9a-epoxymethano-prostaglandin $\mathrm{F}_{2 \mathrm{a}}$ ) on isolated pulmonary and mesenteric arteries from neonatal piglets. Because anatomy and anatomical development of neonatal pig lung are similar to that of human lung, neonatal piglets have been widely used as an experimental model for sepsis-induced pulmonary hypertension of the newborn [22].

\section{Methods}

\section{Tissue Preparation and Incubation}

Male neonatal piglets (10-17 days of age, $4,277 \pm 343 \mathrm{~g}$ ) were used in this study. Piglets were killed by exsanguination and the lungs and mesenteric vascular beds were rapidly immersed in cold $\left(4^{\circ} \mathrm{C}\right)$ Krebs solution (composition in $\mathrm{mM}: \mathrm{NaCl} 118, \mathrm{KCl} 4.75, \mathrm{NaHCO}_{3}$ $25, \mathrm{MgSO}_{4} 1.2, \mathrm{CaCl}_{2} 2.0, \mathrm{KH}_{2} \mathrm{PO}_{4} 1.2$ and glucose 11 ). Krebs solution was supplemented with ampicillin $\left(10 \mu \mathrm{g} \mathrm{ml}^{-1}\right)$ and gentamicin $\left(10 \mu \mathrm{g} \mathrm{ml}^{-1}\right)$ to avoid bacterial growth during the dissection and incubation procedures. The pulmonary arteries (third branch) or mesenteric arteries (internal diameter 1-2 mm) were carefully dissected free of surrounding tissue and cut into rings of $2-3 \mathrm{~mm}$ of length. Some rings were incubated in Krebs solution (containing $10 \mu \mathrm{g} \mathrm{ml}^{-1}$ ampicillin and $10 \mu \mathrm{g} \mathrm{ml}^{-1}$ gentamicin and gassed with $95 \% \mathrm{O}_{2}$ and $5 \% \mathrm{CO}_{2}$ at $\left.37^{\circ} \mathrm{C}\right)$ in the presence of vehicle or endotoxin $\left(1 \mu \mathrm{g} \mathrm{ml}^{-1}\right)$ for $20 \mathrm{~h}$. Two L-shaped stainless-steel wires were inserted into the arterial lumen and the rings were introduced in Allhin organ chambers filled with $\mathrm{Krebs}$ solution (gassed with $95 \% \mathrm{O}_{2}$ and $5 \% \mathrm{CO}_{2}$ at $37^{\circ} \mathrm{C}$ ). One wire was attached to the chamber and the other to an isometric force-displacement transducer (Grass FT07) connected to a polygraph (Grass, Model 7) as previously described [12]. The rings were stretched to a resting tension of $0.5 \mathrm{~g}$ (pulmonary rings) or $2 \mathrm{~g}$ (mesenteric rings) and allowed to equilibrate for 60-90 min. During this period, tissues were restretched and washed every $30 \mathrm{~min}$ with warm Krebs solution. In some experiments, the endothelium was removed by gently rubbing the intimal surface of the rings with a metal rod. The presence of functional endothelium was verified by addition of acetylcholine $(1 \mu M)$ in arteries precontracted with $1 \mu M$ noradrenaline. The ability of acetylcholine to induce relaxation of unrubbed rings was taken as an indicator of the presence of functional endothelium.

\section{Experimental Protocol}

In pulmonary or mesenteric rings previously incubated with vehicle or endotoxin for $20 \mathrm{~h}$, concentration-response curves to noradrenaline $(10 \mathrm{n} M-100 \mu M)$ or $\mathrm{U} 46619(100 \mathrm{p} M-1 \mu M)$ were constructed by increasing the organ chamber concentration by cumulative additions after a steady-state response was reached after each increment. In some arteries the cumulative concentration-response curves to noradrenaline or $\mathrm{U} 46619$ were performed in the presence of $\mathrm{NG}^{\mathrm{S}}$. nitro- $L$-arginine-methyl ester ( $L-N A M E, 100 \mu M$, an inhibitor of nitric oxide synthesis) $[23,24]$, added $30 \mathrm{~min}$ before starting the concenctration-response curves.

In another set of experiments, after equilibration, fresh endothelium-denuded pulmonary rings were contracted with either $10 \mu \mathrm{M}$ noradrenaline or $100 \mathrm{nM}$ U46619. When the contractile response to each agonist reached a stable tension, cumulative concentrationresponse curves to sodium nitroprusside, 8-bromo-cyclic GMP or dipyridamole were carried out by cumulative increments of drug concentration after a steady state relaxant response was reached at each increment. Concentration-response curves to sodium nitroprusside were also carried out in fresh endothelium-denuded mesenteric arteries precontracted with $1 \mu M U 46619$ or $1 \mu M$ noradrenaline.

\section{Drugs}

The following drugs were used: (-)-noradrenaline bitartrate, acetylcholine chloride, endotoxin (lipopolysaccharide from $E$. coli, serotype 0.55:B5), L-NAME, L-arginine, sodium nitroprusside, 8-bromo-cyclic GMP and dipyridamole (Sigma Chemical Co., London). 


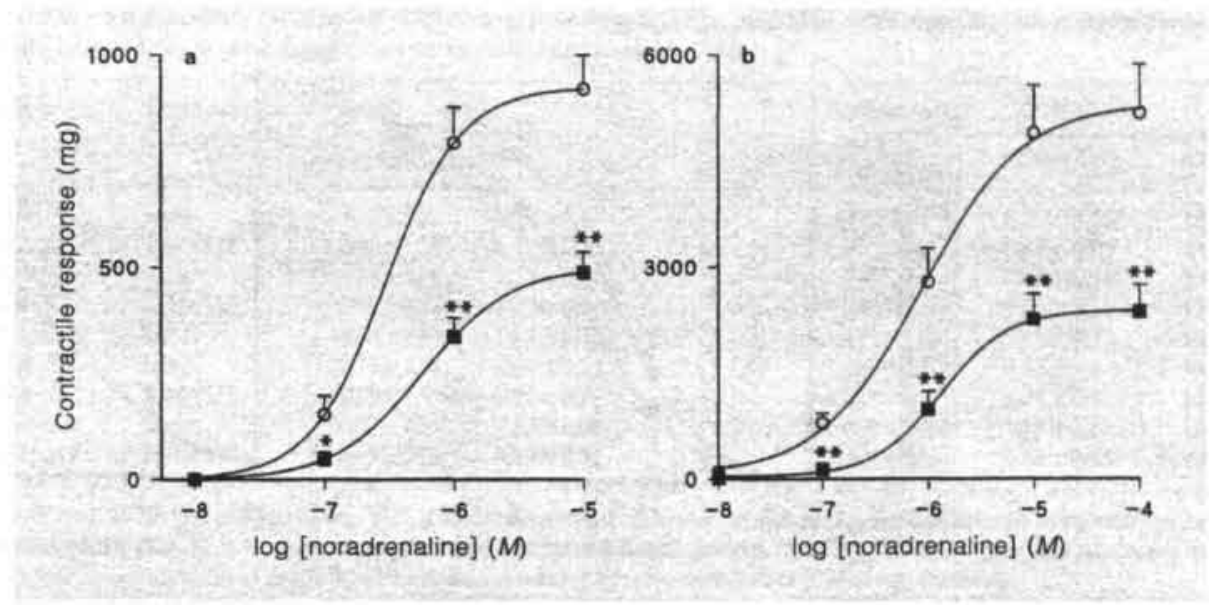

Fig. 1. Concentration-response curves to noradrenaline $(10 \mathrm{nM}-100 \mu M)$ in pulmonary artery (a) or mesenteric artery (b) rings preincubated for $20 \mathrm{~h}$ in Krebs solution in the presence of vehicle (control, O) or endotoxin ( $1 \mu \mathrm{g} \mathrm{ml} \mathrm{l}^{-1}$, E). The concentration-response curves to noradrenaline were carried out in the absence of endotoxin. Data are expressed as means \pm SEM of 8-17 observations. Ordinate: contractile response (mg). Abscissa: log noradrenaline concentration $(M) . * \mathrm{p}<0.05$ and $* \mathrm{p}<0.01$ compared to control group.

U46619 was a generous gift of Upjohn Co. (Mich., USA). All drugs were dissolved in distilled deionized water (except dipyridamole in dimethyl sulfoxide ) to prepare a 1 or $10 \mathrm{~m} M$ stock solution, further dilutions were made in PSS. The concentrations are expressed as final molar concentration in the tissue chamber.

\section{Statistical Analysis}

Results are expressed as means \pm SEM of measurements in $\mathbf{n}$ arteries. Individual cumulative concentration-response curves were fitted to a logistic equation. The drug concentration exhibiting $50 \%$ of the maximal effect $\left(\mathrm{E}_{\max }\right)$ was calculated from the fitted curve for each ring and expressed as negative $\log$ molar $\left(\mathrm{pD}_{2}\right)$. Statistically significant differences were calculated by means of an unpaired Student t test. $p<0.05$ was considered statistically significant.

\section{Results}

\section{Effects of Endotoxin on Noradrenaline-Induced Contractions}

As shown in figure 1, when pulmonary or mesenteric arteries were incubated for $20 \mathrm{~h}$ with endotoxin $(1 \mu \mathrm{g}$ $\mathrm{ml}^{-1}$ ) and then transferred to the organ bath in the absence of endotoxin, the maximal contractile response to noradrenaline $(10 \mathrm{n} M-100 \mu M)$ was significantly reduced $(p<0.01)$. This effect was accompanied by a weak rightward shift of the curve which reached statistical sig- nificance $(p<0.05)$ in the pulmonary but not in the mesenteric artery (table 1). In order to assess the role of nitric oxide production on the hyporesponsiveness to noradrenaline, the concentration-response curve to noradrenaline was performed in untreated and in endotoxin-treated arteries in the presence of $100 \mu M L$-NAME at a concentration which inhibits $>80 \%$ of nitric oxide synthesis by the constitutive and inducible isoforms of nitric oxide synthase [4]. Addition of $L-N A M E$ to resting arteries produced a contractile effect averaging $45.7 \pm 6.6 \mathrm{mg}$ and $44.3 \pm 9.6 \mathrm{mg}$ in untreated and endotoxin-treated pulmonary arteries $(p>0.05)$, respectively, and $2,281 \pm 485 \mathrm{mg}$ and $2,301 \pm 421 \mathrm{mg}$ in untreated and endotoxin-treated mesenteric arteries ( $p>0.05$ ), respectively. Since this contractile effect was unexpected, we further studied it in fresh mesenteric arteries in the absence or presence of $1 \mathrm{~m} M L$-arginine or in endothelium-denuded arteries $(\mathrm{n}=$ $9-10)$. Both $L$-arginine and endothelium removal greatly reduced $L$-NAME-induced contractions. Furthermore, $10 \mu M$ sodium nitroprusside fully relaxed endothelium intact arteries treated with $L$-NAME near to resting values whereas it relaxed endothelium-denuded arteries below baseline (not shown). These results suggest that when NO is released from the endothelium these arteries do not show tone and only when they are denuded of endothe- 


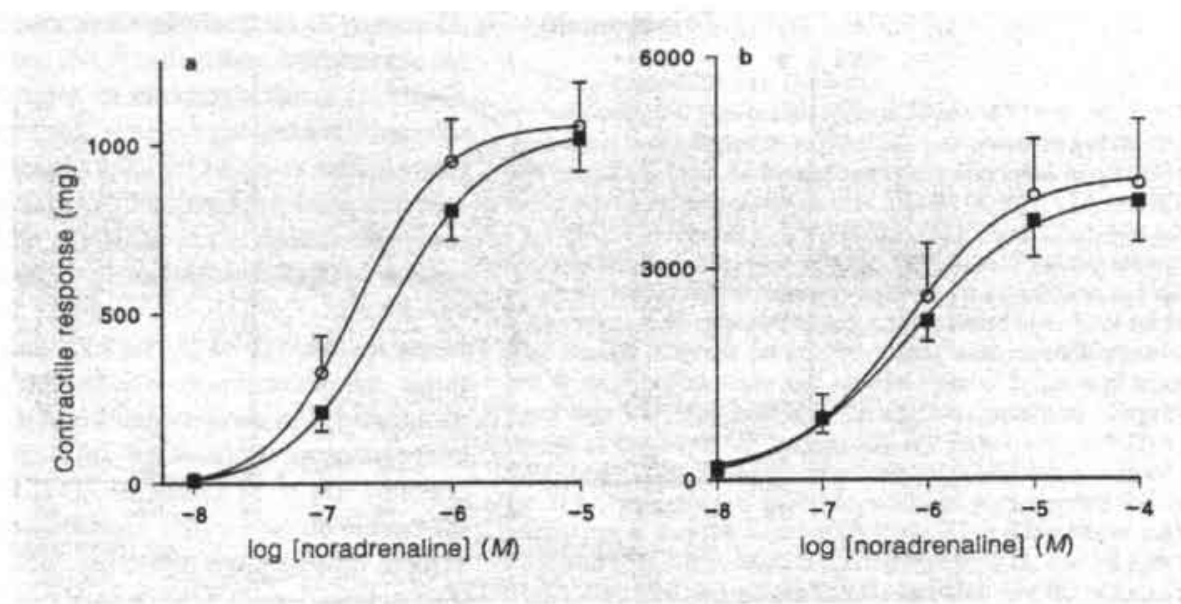

Fig. 2. Effects of L-NAME $(100 \mu M)$ on endotoxin-induced hyporeactivity to noradrenaline in pulmonary artery (a) or mesenteric artery (b) rings. Concentration-response curves to noradrenaline (10 $\mathrm{n} M-100 \mu M)$ were performed in rings previously incubated for $20 \mathrm{~h}$ in Krebs solution in the presence of vehicle (control, O) or endotoxin ( $1 \mu \mathrm{g} \mathrm{ml}^{-1}$, घ). L-NAME $(100 \mu \mathrm{M})$ was added $30 \mathrm{~min}$ before the addition of noradrenaline. The curves were carried out in the absence of endotoxin. Data are expressed as means \pm SEM of 8-14 observations. Ordinate: contractile reponse (mg). Abscissa: $\log$ noradrenaline concentration $(M)$.

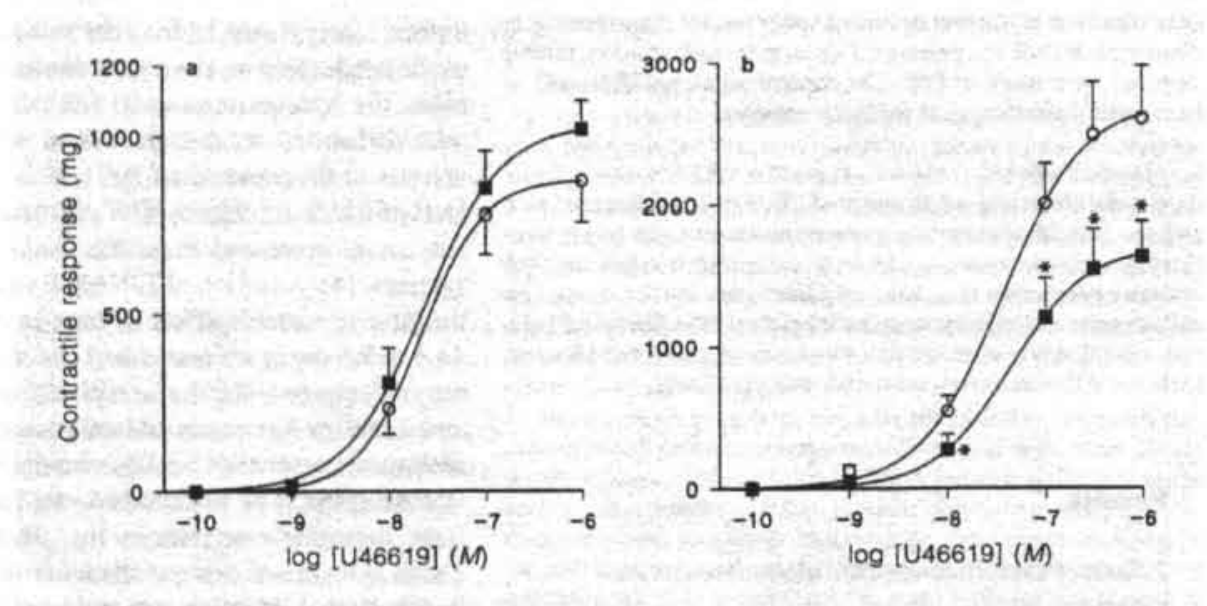

Fig. 3. Concentration-response curves to U $46619(100 \mathrm{p} M-1 \mu M)$ in pulmonary artery (a) or mesenteric artery (b) rings preincubated for $20 \mathrm{~h}$ in Krebs solution in the presence of vehicle (control, O) or endotoxin ( 1 g $\mathrm{ml}^{-1}$, E). The concentration-response curves to U46619 were carried out in the absence of endotoxin. Data are expressed as means \pm SEM of 10-13 observations. Ordinate: contractile response (mg). Abscissa: $\log U 46619$ concentration (M). * $\mathrm{p}<0.05$ represent significant differences with respect to the control group. 
Table 1. Effects of incubation with endotoxin $\left(10 \mu \mathrm{g} / \mathrm{ml}^{-1}\right)$ for $20 \mathrm{~h}$ on the parameters $\left(\mathrm{E}_{\max }\right.$ and $\left.\mathrm{pD}_{2}\right)$ of the concentration-response curves to noradrenaline and U46619 in pulmonary and mesenteric arteries (calculated from fig. 1-4)

\begin{tabular}{|c|c|c|c|c|c|c|c|c|}
\hline \multirow[t]{2}{*}{ Artery } & \multirow[t]{2}{*}{ Drug } & \multirow[t]{2}{*}{ Treatment } & \multicolumn{3}{|l|}{ Control } & \multicolumn{3}{|l|}{ Endotoxin } \\
\hline & & & $E_{\max }(m g)$ & $\mathrm{pD}_{2}$ & $\mathbf{n}$ & $E_{\max }(m g)$ & $\mathrm{pD}_{2}$ & n \\
\hline Pulmonary & NA & none & $923 \pm 80$ & $6.52 \pm 0.07$ & 17 & $492 \pm 47^{* t}$ & $6.25 \pm 0.10^{*}$ & 13 \\
\hline Pulmonary & NA & L-NAME & $1,047 \pm 120$ & $6.72 \pm 0.11$ & 10 & $1,023 \pm 98$ & $6.49 \pm 0.09$ & 14 \\
\hline Pulmonary & U46619 & none & $928 \pm 116$ & $7.51 \pm 0.06$ & 12 & $988 \pm 79$ & $7.60 \pm 0.26$ & 13 \\
\hline Pulmonary & U46619 & $L$-NAME & $971 \pm 82$ & $7.74 \pm 0.08$ & 14 & $1,142 \pm 86$ & $7.85 \pm 0.10$ & 19 \\
\hline Pulmonary & U46619 & $-\mathrm{E}$ & $844 \pm 133$ & $7.83 \pm 0.12$ & 14 & $1,119 \pm 171$ & $7.8 \pm 0.13$ & 13 \\
\hline Mesenteric & NA & none & $5,273 \pm 718$ & $6.07 \pm 0.11$ & 8 & $2,380 \pm 382^{* *}$ & $5.88 \pm 0.1$ & 12 \\
\hline Mesenteric & NA & $L$-NAME & $4,288 \pm 1,184$ & $6.22 \pm 0.06$ & 8 & $4,027 \pm 611$ & $6.23 \pm 0.1$ & 10 \\
\hline Mesenteric & U46619 & none & $3,007 \pm 463$ & $7.33 \pm 0.08$ & 11 & $1,650 \pm 240^{\circ}$ & $7.25 \pm 0.14$ & 10 \\
\hline Mesenteric & U46619 & L-NAME & $2,413 \pm 373$ & $7.43 \pm 0.12$ & 6 & $2,474 \pm 539$ & $7.37 \pm 0.16$ & 7 \\
\hline
\end{tabular}

-E = endothelium-denuded. $L$-NAME $(100 \mu M)$ was added to the organ bath solution 30 min before the addition of noradrenaline or U46619. The concentration exhibiting $50 \%$ of the maximal contraction to noradrenaline was calculated for each ring and expressed as negative $\log$ molar $\left(\mathrm{pD}_{2}\right)$. The $\mathrm{E}_{\max }$ was defined as the maximal tension induced by noradrenaline or $\mathrm{U} 46619$ in each ring.

${ }^{*} p<0.05$ and ${ }^{* *} p<0.01$ endotoxin vs. control.

lium or treated with $L$-NAME do they show an intrinsic contractile tone. Furthermore, $L$-NAME increased the maximal response to noradrenaline in endotoxin-treated but not in control arteries (fig. 2). Therefore, L-NAME reversed the hyporesponsiveness to noradrenaline induced by endotoxin in both pulmonary and systemic arteries.

\section{Effects of Endotoxin on U46619-Induced Contractions}

As shown in figure $3 \mathrm{a}$ and in contrast to the results obtained with noradrenaline, the maximal contractile responses to U46619 were similar in control and in endotoxin-treated pulmonary arteries and no change in the $\mathrm{pD}_{2}$ values was observed (table 1). The effect of $20 \mathrm{~h}$ incubation with endotoxin was also tested in rings in which the endothelium was removed after the incubation procedure and prior to the concentration-response curve to U46619. Under these experimental conditions, endotoxin did not modify the maximal contractile response to U46619 (table 1). In the presence of $100 \mu M$ L-NAME, the maximal contractile responses induced by $\mathrm{U} 46619$ were not significantly different in endotoxin-treated compared to control arteries (fig. 4a, table 1).

Figure $3 \mathrm{~b}$ shows that, in contrast to pulmonary arteries, endotoxin-treated mesenteric arteries showed a significant reduction of the maximal contractions induced by U46619 when compared to controls. Furthermore, pretreatment with $L$-NAME increased the maximal response

Endotoxin and U46619 on Pulmonary and

Mesenteric Arteries to U46619 in endotoxin-treated but not in untreated mesenteric arteries (fig. 4b). Therefore, $L$-NAME reversed the hyporesponsiveness to U46619 induced by endotoxin in mesenteric arteries (table 1).

\section{Effects of Sodium Nitroprusside, 8-Bromo-Cyclic GMP and Dipyridamole on the Contractions Induced by \\ Noradrenaline and U46619}

In endothelium-denuded pulmonary rings a single concentration of noradrenaline $(10 \mu M)$ or U46619 $(100 \mathrm{n} M)$ elicited contractile responses which averaged $691 \pm 87 \mathrm{mg}(\mathrm{n}=23)$ and $734 \pm 40 \mathrm{mg}(\mathrm{n}=27)$, respectively ( $p>0.05$ noradrenaline vs. U46619). Once the contraction had reached a maximum stable contraction, the addition of sodium nitroprusside $(10 \mathrm{n} M-100 \mu M)$ resulted in a concentration-dependent relaxation. However, there were marked differences in the relaxant potency of sodium nitroprusside depending on the agonist which precontracted the artery. In pulmonary arteries (figure 5a) U46619-induced contractions were much less sensitive to sodium nitroprusside than noradrenaline-induced contractions $\left(\mathrm{pD}_{2}=5.7 \pm 0.1\right.$ and $6.6 \pm 0.1$, respectively, $\mathrm{p}<$ 0.01 ). Furthermore, sodium nitroprusside was unable to fully relax the U46619-induced contractions, so that the highest concentration of sodium nitroprusside tested produced a maximal relaxation of $67 \pm 7 \%$. The effects of sodium nitroprusside were also tested in mesenteric arteries precontracted with concentrations of noradrenaline 


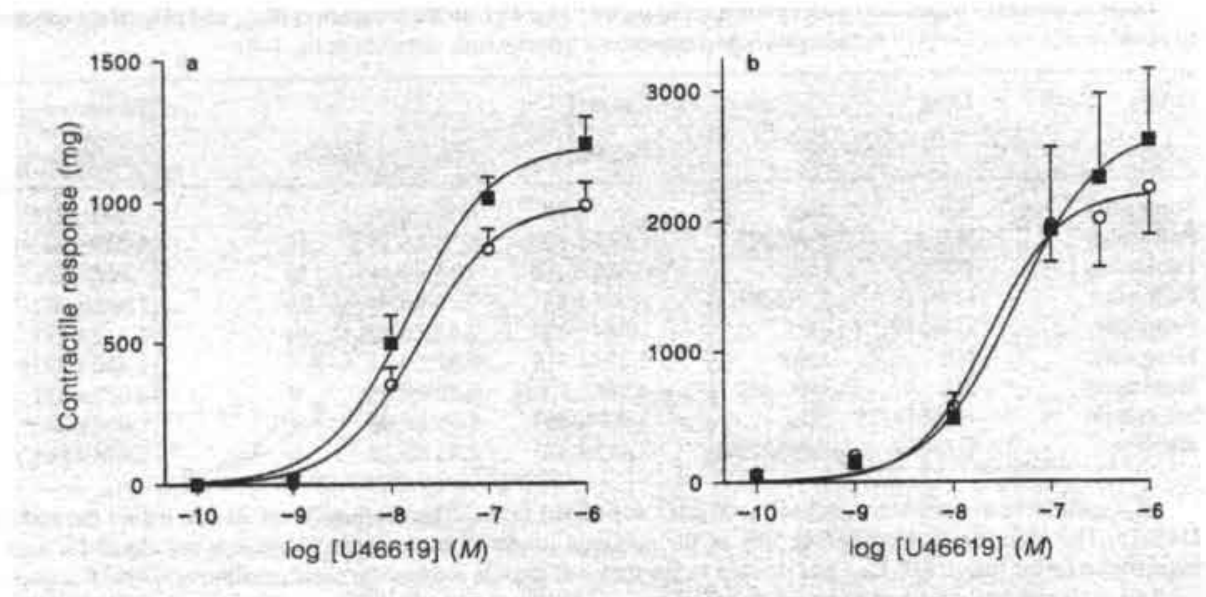

Fig. 4. Effects of $L$-NAME $(100 \mu M)$ on the concentration-response curves to U46619 in untreated and endotoxin-treated pulmonary artery (a) or mesenteric artery (b) rings. Concentration-reponse curves to U46619 (100 pM$1 \mu M$ ) were performed in rings previously incubated for $20 \mathrm{~h}$ in Krebs solution in the presence of vehicle $(\mathrm{control}, \mathrm{O})$ or endotoxin $\left(1 \mu \mathrm{g} \mathrm{ml}^{-1}, \mathrm{w}\right)$. NAME $(100 \mu \mathrm{M})$ was added $30 \mathrm{~min}$ before the addition of noradrenaline. The curves were carried out in the absence of endotoxin. Data are expressed as means \pm SEM of 6-19 observations. Ordinate: contractile response (mg). Abscissa: $\log \mathrm{U} 46619$ concentration $(M)$.
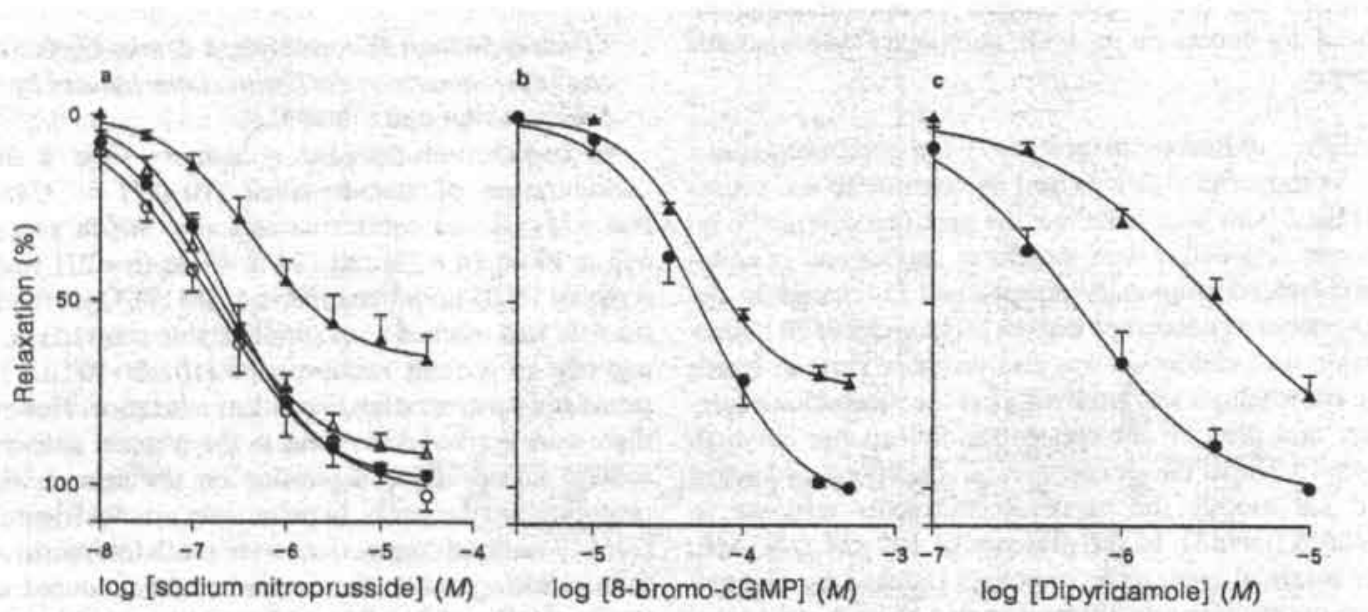

Fig. 5. Relaxant effects of sodium nitroprusside ( $10 \mathrm{n} M-30 \mu M)$ (a), 8-bromo-cyclic GMP (3-500 $\mu M$ ) (b) and

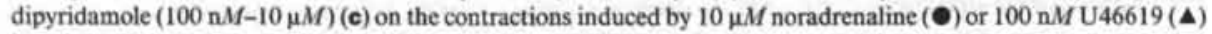
in pulmonary arteries and $1 \mu M$ noradrenaline $(O)$ or $1 \mu M U 46619(\Delta)$ in mesenteric arteries. Data are expressed as means \pm SEM of 5-10 observations. Ordinate: relaxant response (\%). Abscissa: log drug concentration $(M)$. 
$(1 \mu M)$ and U46619 $(1 \mu M)$ which induced similar contractile responses $(1,525 \pm 331$ and $1,640 \pm 352$, respectively; $\mathrm{p}>0.05$ ). Sodium nitroprusside also produced a concentration-dependent relaxation in mesenteric arteries (fig. 5a) which was not significantly different in noradrenaline- and U46619-contracted muscles $\left(\mathrm{pD}_{2}=6.7\right.$ \pm 0.2 and $6.7 \pm 0.1$, respectively, $p>0.05$ ) and similar to that produced in noradrenaline-precontracted pulmonary arteries. Therefore, the low sensitivity to sodium nitroprusside was specific of U46619-induced contractions in pulmonary arteries.

Furthermore, 8-bromo-cyclic GMP (fig. 5b) and dipyridamole (fig. 5c) also relaxed pulmonary arteries precontracted with noradrenaline $(10 \mu M)$ or $\mathrm{U} 46619(100 \mathrm{n} M)$ in a concentration-dependent manner. As reported above for sodium nitroprusside, U46619-induced contractions were also significantly less sensitive to the relaxant effects of 8-bromo-cyclic GMP and dipyridamole than noradrenaline-induced contractions.

\section{Discussion}

In the present study we have analyzed the effects of prolonged exposure to endotoxin on the contractile responses induced by noradrenaline and U46619, a stable thromboxane $A_{2}$ mimetic, on isolated pulmonary and systemic arteries from neonatal piglets. We have demonstrated that endotoxin reduced the maximum contractile responses to noradrenaline in both pulmonary and mesenteric arteries or to U46619 in mesenteric arteries. The nitric oxide synthase inhibitor $L$-NAME $[23,24]$, did not modify the vasoconstrictor responses in control arteries but increased the responses in endotoxin-treated arteries resulting in a reversal of the endotoxin-induced hyporesponsiveness. The contractions induced by U46619 in pulmonary arteries, however, appear to be an exception since they were not reduced by endotoxin treatment. Additionally, these contractions were much less sensitive to sodium nitroprusside, 8-bromo-cyclic GMP or dipyridamole when compared to U46619-induced contractions in mesenteric arteries or noradrenaline-induced contractions in pulmonary arteries.

The role of nitric oxide overproduction following iNOS induction in systemic hypotension and decreased responses to vasoconstrictors after endotoxin treatment has been reported by many authors in in vivo, ex vivo or in vitro studies [2]. In a previous study we have already reported that endotoxin or group B streptococcus reduced the contractile responses to noradrenaline in neonatal porcine pulmonary arteries [12]. This hyporesponsiveness was potentiated by $L$-arginine, while $L$-NAME completely reversed it, indicating that overproduction of nitric oxide was responsible for this effect. Dexamethasone, which inhibits the induction of iNOS [25, 26], and cycloheximide, an inhibitor of protein synthesis, when coincubated with endotoxin, completely reversed the reduced response to noradrenaline. Moreover, endotoxin had no effect on the constitutive nitric oxide synthase (cNOS) but induced a marked increase in iNOS activity which was abolished by dexamethasone. All these results indicate that endotoxin-induced pulmonary vascular hyporesponsiveness to noradrenaline is due to enhanced formation of nitric oxide via iNOS induction and requires the novo synthesis of the enzyme in the pulmonary vasculature [12]. In the present study, endotoxin-treated mesenteric arteries also showed decreased contractile responses to noradrenaline or U46619. The reversal by $L$-NAME of these reduced responses in mesenteric arteries strongly suggest that enhanced nitric oxide production was responsible for endotoxin-induced vascular hyporesponsiveness. Although we did not further analyze this possibility, it is likely that the increased nitric oxide production is largely related to the induction of $\mathrm{iNOS}$ and may contribute to the latter peripheral vascular failure and the hypotensive response associated with prolonged periods of sepsis caused by gram-negative bacteria.

More interestingly, not all vascular beds respond with depressed responses following endotoxin-mediated induction of iNOS. In the present study, the contractile responses to U46619 in pulmonary arteries were not diminished after prolonged incubation with endotoxin in spite of iNOS induction and decreased pulmonary responsiveness to noradrenaline. Likewise, isolated mesenteric beds from endotoxin-treated rats were not hyporesponsive to various vasoconstrictors, including U46619, despite significant iNOS induction [4]. However, the lack of effect of endotoxin on U46619-induced contractions is not a general finding since in pig mesenteric arteries (present study) or in rabbit [26] or rat [27] perfused hearts the vasoconstrictor responses to U46619 were attenuated by endotoxin. Decreased vasoconstrictor responses to U46619 (but not to angiotensin II) have also been reported in isolated perfused lungs from rats made septic by cecal ligation [28]. Therefore, endotoxin produces opposite effects on the contractions induced by $\mathrm{U} 46619$ in neonatal piglet and in adult rat arteries. These contradictory results therefore suggest that the effects of endotoxin on U46619-induced vascular responses may be tissue-, species- and/or age-dependent. 
In an attempt to explain the mechanism involved in the lack of hyporesponsiveness to U46619 in the pulmonary arteries we hypothesized that U46619-induced contractions might be insensitive to the relaxant action of nitric oxide, so that iNOS induction and the subsequent increase in nitric oxide release would not affect these contractile responses. In fact, pulmonary arteries precontracted with U46619 were relatively insensitive to the relaxant action of the nitric oxide donor sodium nitroprusside (e.g. $300 \mathrm{nM}$ sodium nitroprusside relaxed $61 \%$ of noradrenaline- but only $28 \%$ of U 46619 -induced contractions), suggesting an impairment of the signal transduction process leading to vasodilatation. Since nitric oxide is released from sodium nitroprusside independently of nitric oxide synthases [29], the reduced sensitivity to nitric oxide is unlikely to be due to an impairment of nitric oxide synthase activity. Nitric-oxide-induced vasodilatation is mediated through activation of smooth muscle soluble guanylate cyclase which in turn increases intracellular cyclic GMP levels [29]. In order to establish whether these reduced responses to nitric oxide were due to decreased activity of soluble guanylate cyclase, the effects of a stable analog of cyclic GMP, 8-bromo-cyclic GMP, were tested in pulmonary arteries precontracted with noradrenaline or U46619. The U46619-induced contractions were again less sensitive to the relaxant action of 8-bromo-cyclic GMP, which indicated that reduced nitric oxide sensitivity was not due to an interference of U46619 with guanylate cyclase. Furthermore, since these contractions were also less sensitive to the relaxant action of dipyridamole, a specific inhibitor of the cyclic-GMP-specific (type V) phosphodiesterase enzyme [30], the reduced sensitivity to nitric oxide could not be attributed to an enhancement of phosphodiesterase activity after exposure to U46619. Therefore, the low ability of nitric oxide to induce relaxation might be related to impaired activation of cyclic-GMP-dependent kinases or a mechanism located further in the cascade of events leading to vasodilatation. Reduced relaxant responses to sodium nitroprusside have also been reported on U46619-contracted pulmonary arteries from adult rats chronically exposed to hypoxia [31, 32]. Likewise, human umbilical arteries do not relax in response to sodium nitroprusside or phosphodiesterase inhibitors despite the increase of cyclic GMP concentrations [33].

The clinical relevance of the present experiments is unknown. However, the lung is the major target organ in neonatal sepsis [10]. The early pulmonary hypertension in septic shock has been associated with enhanced production of thromboxane $A_{2}$, a potent vasoconstrictor $[15,19$,
20]. Therefore, it is tempting to speculate that the increased levels of thromboxane $\mathrm{A}_{2}$ together with the lack of endotoxin-induced hyporesponsiveness to the thromboxane $A_{2}$ mimetic U46619 observed in this study may explain the pulmonary hypertension occurring in neonatal septic patients despite iNOS induction in the lung.

In conclusion, endotoxin-treated mesenteric arteries from neonatal piglets show decreased responses to noradrenaline and U46619 due to enhanced nitric oxide release, which may account for the systemic hypotension associated with septic shock. Endotoxin-treated pulmonary arteries exhibited a nitric oxide-mediated hyporesponsiveness to noradrenaline but not to the thromboxane $A_{2}$ mimetic U46619. This lack of endotoxin-induced hyporesponsiveness to U 46619 may be attributed to a relative insensitivity of these contractions to nitric oxide or cyclic GMP. The absence of pulmonary hyporesponsiveness to U46619 may explain why pulmonary hypertension occurs in septic shock despite iNOS induction in the lung.

\section{Acknowledgments}

This work was supported by a CICYT (92/0157) and a FIS (95/ 0308) grants. E.V. is a recipient of the Asociación Española de Pediatria/Arbora SA grant for pediatric research. We would like to thank Dr. Aguilera (Upjohn Farmoquimica) for kindly providing U46619. 


\section{References}

I Harris RL, Musher DM, Bloom K, Gathe J, Rice L, Sugarman B, Williams TW, Young EJ: Manifestations of sepsis. Arch Intern Med 1987; 147:1895-1906.

2 Thiemermann C: The role of the $L$-arginine: Nitric oxide pathway in circulatory shock. Adv Pharmacol 1994;28:45-79.

3 Salter M, Knowles RG, Moncada S: Wide spread tissuc distribution, species distribution and changes in activity of $\mathrm{Ca}^{2}$-dependent and $\mathrm{Ca}^{2}$-independent nitric oxide synthases. FEBS Lett 1991:291:145-149.

4 Mitchell JA, Kohlhas KL, Sorrentino R, Warner TD, Murad M, Vane J: Induction by endotoxin of nitric oxide synthase in the rat mesentery: Lack of effect on action of vasoconstrictors. Br J Pharmacol 1993:109:265-270.

5 Thiemermann C, Vane JR: Inhibition of nitric oxide synthesis reduces the hypotension induced by bacterial lipopolysaccharides in vivo. Eur J Pharmacol 1990;182:591-595.

6 Groves AC, Griffiths J, Leung F, Meek RN Plasma catecholamines in patients with serious postoperative infection. Ann Surg 1972:178: 102-107.

7 Groeneveld ABJ, Nauta JJP, Thijs LG: Peripheral vascular resistance in septic shock: Its relation to outcome. Intensive Care Med 1988:14: 141-147.

8 McKenna TM: Prolonged exposure of rat aora to low levels of endotoxin in vitro results in impaired contractility. Association with vascular cytokine release. J Clin Invest 1990:86:160168.

9 Julou-Schaeffer G, Gray GA, Fleming 1, Schott C. Parratt JR, Stoclet J-C: Loss of vascular responsiveness induced by endotoxin involves L-arginine pathway. Am J Physiol 1990;259: H1038-H1043.

10 Ablow RC, Driscoll SG, Effmann EL, Gross I, Jolles CJ. Kauy R, Warshaw JB: A comparison of early-onset group B streptococcal neonatal infection and the respiratory-distress syndrome of the newborn. N Engl J Med 1976;294;6569.

II Fein AM, Lippmann M, Holtzman A, Eliraz A. Goldberg SK: The risk factors, incidence, and prognosis of ARDS following septicemia. Chest 1983:83:40-42
12 Villamor E, Perez-Vizcaino F, Ruiz T, Leza JC. Moro M, Tamargo J: Group B streptococcus and E.coli L.PS produce nitric oxide-dependent hyporesponsiveness to noradrenaline in isolated intrapulmonary arteries of neonatal piglets. Br J Pharmacol 1995;115:261-266.

13 Zelenkov P, McLoughlin T, Johns RA: Endotoxin enhances hypoxic constriction of rat aorta and pulmonary artery through induction of EDRF/nitric oxide synthase. Am J Physiol 1993;265:L.346-L.354.

14 Griffiths MJD, Messent M, MacAllister RJ. Evans TW: Aminoguanidine selectively inhibitis inducible nitric oxide synthase. Br J Pharmacol 1993;110:963-968.

15 Brigham KI, Meyrick B: Endotoxin and lung injury. Am Rev Respir Dis 1986;133:913927.

16 Chen T.Y, Zapol WM, Greene E, Robinson DR, Rubin RH: Protective effects of ES, an antientotoxin monoclonal antibody, in the ovine pulmonary circulation. J Appl Physiol 1993:75:233-239.

17 Zapol WM, Snider MT: Pulmonary bypertension in severe acute respiratory failure. N Engl J Med 1977:296:476-480.

18 Demling RH, Smith M, Gunther G, Fynn JT, Gee MH: Pulmonary injury and prostacyclin production during endotoxacmia in conscious sheep. Am J Physiol 1981:240:H383-H386.

19 Hales CA, Sonne L, Peterson M, Miller M. Watkins WD: Role of thromboxane and prostacyclin in pulmonary vasomotor changes after endotoxin in dogs. J Clin Invest 1981:68:497506.

20 Slotman GJ, Quinn JV, Burchard KW, Gann DS: Thromboxane, prostacyclin, and the hacmodynamic effects of graded bacteriemic shock. Circ Shock 1985;16:395-404.

21 Fujioka K, Sugi K, Isago T, Flynn JT, Traber L. Herndon DN, Traber DL: Thromboxane synthase inhibition and cardiopulmonary function during endotoxemia in sheep. J Appl Physiol 1991:71:1376-1381.

22 Gibson RL. Truog WE, Redding GJ: Thromboxane-associated pulmonary hypertension during three types of gram-positive bacteriemia in pigiets. Pediatr Res 1987:23:553-556.

23 Sakuma I, Stuehr DJ, Gross SS, Nathan C, Levi R: Identification of arginine as a precursor of endothelium derived relaxing factor. Proc Natl Acad Sci USA 1988:85:8664-8667.
24 Palmer RMJ,Ashton DS, Moncada S: Vascular endothelial cells synthesize nitric oxide from $L$. arginine. Nature 1988;333:664-666.

25 Radomski MW, Palmer RMJ, Moncada S: Glucocorticoids inhibit the expression of an inducible, but not the constitutive, nitric oxide synthase in vascular endothelial cells. Proc Natl Acad Sci USA 1990;87:10043-10047.

26 Smith REA, Palmer RMJ, Moncada S: Coronary vasodilatation induced by endotoxin in the rabbit isolated perfused heart is nitric oxide-dependent and inhibited by dexamethasone. Br J Pharmacol 1991;104:5-6.

27 Baydoun AR, Foale RD, Mann GE: Bacterial endotoxin rapidly stimulates prolonged cndothelium-dependent vasodilatation in the rat isolated perfused beart. Br J Pharmacol 1993; 109:987-991

28 Schneidkraut MJ, Carlson RW: Bacterial sepsis-induced decrease in lung vascular reactivity to 9,11-dideoxy-11a,9a-epoxymethano-prostaglandin $F_{2 a}$ (U46619) in the rat. J Pharmacol Exp Ther 1990;253:1171-1176.

29 Ignarro L, Lippton H, Edwards JC, Baricos WH, Hyman AL, Kadowitz PJ, Gruetter CA: Mechanism of vascular smooth muscle relaxation by organic nitrates, nitrites, nitroprusside and nitric oxide: Evidence for the involvement of S-nitrosothiols as active intermediates. J Pharmacol Exp Ther 1981:218:739-749.

30 Beavo J, Reifsnyder DH: Primary sequence of cyclic nucleotide phosphodiesterase isozymes and the design of selective inhibitors. Trends Pharmacol Sci 1990;11:150-155.

31 Wanstall JC, Hughes IE, O'Donnell SR: Reduced relaxant potency of nitroprusside on pulmonary artery preparations taken from rats during the development of hypoxic pulmonary hypertension. Br J Pharmacol 1992;107:407413.

32 Maruyama J, Maruyama K: Impaired nitric oxide-dependent responses and their recovery in bypertensive pulmonary arteries of rats. Am J Physiol 1994:266:H2476-2488.

33 Bergh CM, Bropphy CM, Dransfield DT, Lincoln $T$, Goldenring JR, Rasmussen H: Impaired cyclic nucleotide vasorelaxation in human umbilical artery smooth muscle. Am J Physiol 1995;268:H202-H212 

Chapter IX. Effects of group B Streptococcus on the responses to U46619, endothelin-1, and noradrenaline in isolated pulmonary and mesenteric arteries of piglets. (Pediatr Res. 1996; 40:827-33). 



\title{
Effects of Group B Streptococcus on the Responses to U46619, Endothelin-1, and Noradrenaline in Isolated Pulmonary and Mesenteric Arteries of Piglets ${ }^{1}$
}

\author{
EDUARDO VILLAMOR, FRANCISCO PÉREZ-VIZCAÍNO, JUAN TAMARGO, AND \\ MANUEL MORO
}

\begin{abstract}
Division of Neonatology, Department of Pediatrics, Hospital Universitario San Carlos [E.V., M.M.], and Department of Pharmacology, Institute of Pharmacology and Toxicology. School of Medicine, Universidad Complutense [F.P.-V., J.T.], 28040 Madrid, Spain
\end{abstract}

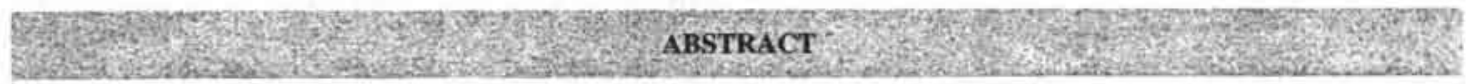

The release of endogenous vasoconstrictors together with changes in the vascular responses are central to the pathophysiology of sepsis. The effects of in vitro incubation for $20 \mathrm{~h}$ with heat-killed group B Streptococcus (GBS, $3 \times 10^{7}$ colonyforming units $\mathrm{mL}^{-1}$ ) on the vasoconstrictor responses to noradrenaline (NA, $10^{-8}$ to $10^{-4} \mathrm{M}$ ), the thromboxane $A_{2}$ analog 9,11-dideoxy-11 $\alpha, 9 \alpha$-epoxymethanoprostaglandin $\mathrm{F}_{2 \alpha}$ (U46619; $10^{-10} \mathrm{M}$ to $10^{-6} \mathrm{M}$ ) and endothelin-1 (ET-1, $10^{-11}$ to $3 \times 10^{-9}$ M) were evaluated on isolated intrapulmonary and mesenteric arteries from 10-17-d-old piglets. The incubation with GBS reduced the maximal contractile response to NA and ET-1 $(p<$ 0.01 ) in both arteries. The nitric oxide (NO) synthase (NOS) inhibitor $N^{N-}$-nitro-L-arginine methyl ester (L-NAME; $10^{-4} \mathrm{M}$ ) completely reversed this hyporesponsiveness. GBS-treated mesenteric arteries also showed a significant reduction of the maximal contractions induced by U46619 $(p<0.05)$ and this effect was inhibited by $10^{-4} \mathrm{M}_{\mathrm{L}}$-NAME. In contrast, the maximal contractile responses to U46619 were similar in control and in GBS-treated pulmonary arteries. Addition of L-NAME did not modify the contractile responses to U46619 in GBS-treated pulmonary arteries. In conclusion, GBS-treated systemic arteries from neonatal piglets showed decreased responses to NA.

GBS, a Gram-positive bacterium, is one of the most common causal agents of neonatal sepsis $(1,2)$. In the newborn, GBS produced acute pulmonary hypertension, respiratory failure, arterial hypoxemia, decreased cardiac output, and systemic

Received January 3, 1996; accepted June 5, 1996.

Correspondence and reprint requests: F. Pérez-Vizcaino, Department of Pharmacology. Institute of Pharmacology and Toxicology. School of Medicine, Universidad Complutense, 28040 Madrid, Spain.

Supported by a CICYT (SAF 96/0042) and FIS Grants (95/0308 and 95/0318) Grants. E. Villamor is a recipient of the Asociación Espatiola de Pediatria/Arbora S.A. Grant for Pectiatric Research.

'Presented at the 1st Buropean Congress of Pharmacology (EPHAR) and the 65th Annual Meeting of the Society for Pediatric Research. Washington. DC.
U46619, and ET-1 due to enhanced NO release. GBS-treated pulmonary arteries also exhibited decreased responses to NA and ET-1 but not to U46619. Induction of NOS in vascular smooth muscle may play a key role in the hypotension and loss of systemic vascular responsiveness that occurs in GBS sepsis. The absence of pulmonary hyporesponsiveness to U46619 may partially explain the coexistence during sepsis of pulmonary hypertension and lung NOS induction. (Pediatr Res 40: 827-833, 1996)

GBS, Group B Streptococcus

LPS, lipopolysaccharide

ET-1, endothelin-1

$\mathbf{T X A}_{2}$, thromboxane $\mathrm{A}_{2}$

NO, nitric oxide

iNOS, inducible nitric oxide synthase

NA, noradrenaline

U46619, 9,11-dideoxy-11 $\alpha, 9 \alpha$-epoxymethanoprostaglandin $\mathrm{F}_{2 \sigma}$ L-NAME, $N^{\omega}$-nitro-l-arginine methyl ester

cfu, colony-forming units hypotension, resulting in significant morbidity and mortality (2-4).

Endogenous production and release of several vasoactive agents play a determinant role in the pathophysiology of sepsis (5-16). Thus, sepsis-induced pulmonary hypertension has been divided into an early phase related to the arachidonic acidderived vasoconstrictor $\mathrm{TXA}_{2}$ and a late phase associated with development of pulmonary edema (5-7). Additionally, in an attempt to counteract systemic severe hypotension, circulating catecholamines are increased $(8,9)$. Moreover, elevated levels of the endothelium-derived vasoconstrictor ET-1 have been found in animal models of sepsis $(10)$ as well as in adult patients with septic shock (11). Unfortunately, to our knowl- 
edge, the levels of ET-I and catecholamines have not been evaluated in GBS sepsis. Together with these vasoconstrictors, endogenous vasodilators are also produced in sepsis (12-16). Currently, there is a great body of evidence that enhanced release of $\mathrm{NO}$ via induction of an inducible $\mathrm{Ca}^{2+}$-independent iNOS plays an important role in the loss of systemic (12-14) and pulmonary $(15,16)$ vascular responsiveness that occurs in Gram-negative sepsis. Gram-positive bacteria have been also recently demonstrated to induce iNOS in several tissues (17, 18). In fact, GBS induced iNOS in macrophages $(19,20)$ and in pulmonary arteries resulting in a reduced vasoconstrictor response to NA (21).

Therefore, the coexistence of pulmonary hypertension and systemic hypotension may be due to a different sensitivity of the pulmonary and systemic vessels to the vasoactive factors released in sepsis. The aim of the present work was to study the effects of in vitro incubation with heat-killed GBS on the vasoconstrictor responses to $\mathrm{NA}$, the stable $\mathrm{TXA}_{2}$ analog U46619, and ET-1 on isolated pulmonary and mesenteric arteries from piglets.

\section{METHODS}

\section{Tissue Preparation and Incubation}

Male neonatal piglets (32 animals, 10-17 d of age, $4162 \pm$ $297 \mathrm{~g}$ ) were used in this study. Piglets were killed by exsanguination, and the lungs and mesenteric vascular beds were rapidly immersed in cold $\left(4^{\circ} \mathrm{C}\right)$ Krebs solution of the following composition (mM): $\mathrm{NaCl} 118, \mathrm{KCl} 4.75, \mathrm{NaHCO}_{3} 25, \mathrm{MgSO}_{4}$ 1.2, $\mathrm{CaCl}_{2} 2.0, \mathrm{KH}_{2} \mathrm{PO}_{4} 1.2$, and glucose 11. The pulmonary (third branch, internal diameter 1-2 mm) and mesenteric arteries (internal diameter 1-2 mm) were carefully dissected free of surrounding tissue and cut into rings of 2-3-mm length (21). The arterial rings were incubated in Krebs solution gassed with $95 \% \mathrm{O}_{2}$ and $5 \% \mathrm{CO}_{2}$ at $37^{\circ} \mathrm{C}$ in the presence of vehicle or heat-inactivated GBS $\left(3 \times 10^{7} \mathrm{cfu} \mathrm{mL}^{-1}\right)$ for $20 \mathrm{~h}$. Krebs solution was supplemented with ampicillin $\left(10 \mu \mathrm{g} \mathrm{mL}^{-1}\right)$ and gentamicin $\left(10 \mu \mathrm{g} \mathrm{mL}^{-1}\right)$ to avoid bacterial growth during the dissection and incubation procedures. A maximal number of two rings per animal were used in each experimental group. Control and GBS-treated rings from the same animal were always run in parallel. After the incubation, two L-shaped stainless-steel wires were inserted into the arterial lumen, and the rings were introduced in Allhin organ chambers filled with Krebs solution gassed with $95 \% \mathrm{O}_{2}$ and $5 \% \mathrm{CO}_{2}$ and maintained at $37^{\circ} \mathrm{C}$. One wire was attached to the chamber and the other to an isometric force-displacement transducer (Grass FT07; Grass Instrument Co., Quincy, MA) connected to a polygraph (Grass model 7). The rings were stretched to a resting tension of $0.5 \mathrm{~g}$ (pulmonary rings) or $2 \mathrm{~g}$ (mesenteric rings) and allowed to equilibrate for $60-90 \mathrm{~min}$. During this period tissues were restretched and washed every $30 \mathrm{~min}$ with warm Krebs solution. In some experiments the endothelium was removed by gently nubbing the intimal surface of the rings with a metal rod. The presence or absence of functional endothelium was verified by testing the relaxant effect of acetylcholine $\left(10^{-6} \mathrm{M}\right)$ in arteries precontracted with NA $10^{-6} \mathrm{M}$.

\section{Experimental Protocol}

In puimonary and mesenteric rings previously incubated as described above, concentration-response curves to NA $\left(10^{-8}\right.$ to $\left.10^{-4} \mathrm{M}\right), \mathrm{U} 46619\left(10^{-10}\right.$ to $\left.10^{-6} \mathrm{M}\right)$, or ET-1 $\left(10^{-11}\right.$ to $3 \times$ $\left.10^{-9} \mathrm{M}\right)$, were constructed by increasing the organ chamber concentration by cumulative additions after a steady state response was reached after each increment. In some arteries the response to NA, U46619, or ET-1 were performed in the presence of L-NAME, $10^{-4} \mathrm{M}$, an inhibitor of NO synthesis), added $30 \mathrm{~min}$ before starting the concentration-response curves.

\section{Drugs and Heat-Killed GBS Preparation}

The following drugs were used: (-)-noradrenaline bitartrate, acetylcholine chloride, L-NAME, human ET-1, and U46619 (Sigma Chemical Co., London). All drugs were dissolved in distilled deionized water. The concentrations are expressed as a final molar concentration in the tissue chamber.

GBS type III was isolated from the blood of a neonate who developed early-onset sepsis. Bacteria were grown in ToddHewitt broth for $18-36 \mathrm{~h}$ at $37^{\circ} \mathrm{C}$ to late $\log$ phase and harvested by centrifugation at $5000 \mathrm{rpm}$ for $15 \mathrm{~min}$. Bacteria were resuspended in sterile isotonic saline to a concentration determined by serial viable counts to be $1 \times 10^{9} \mathrm{cfu} \mathrm{mL}^{-1}$. Heat-killed bacteria were obtained by heating bacteria to $60^{\circ} \mathrm{C}$ for $60 \mathrm{~min}$. GBS killing was confirmed by no growth on blood agar. Endotoxin levels in the heat-killed GBS preparation were undetectable as assayed using a standard Limulus assay kit (Sigma Chemical Co.). Aliquots of heat-killed GBS were stored at $-80^{\circ} \mathrm{C}$ until the study day.

\section{Statistical Analysis}

Results are expressed as means \pm SEM of measurements in $n$ arteries. Individual cumulative concentration-response curves were fitted to a logistic equation. The drug concentration exhibiting $50 \%$ of the maximal effect $\left(E_{\max }\right)$ was calculated from the fitted curve for each ring and expressed as negative $\log$ molar $\left(p D_{2}\right)$. Statistically significant differences were calculated by means of an unpaired $t$ test. $p<0.05$ was considered statistically significant.

\section{RESULTS}

\section{Effects of GBS on NA-Induced Contractions}

Both pulmonary and mesenteric arterial rings, incubated for $20 \mathrm{~h}$ with heat-killed GBS and then transferred to organ baths in the absence of GBS, showed a significant reduction $(p<$ $0.01)$ in the contractile response to NA $\left(10^{-8}\right.$ to $\left.10^{-4} \mathrm{M}\right)$ compared with controls (Fig. 1). The reduction of the maximal contraction $\left(E_{\max }\right)$ was more marked in mesenteric compared with pulmonary arteries (Table 1). However, a decrease of the $p D_{2}$ value was observed in pulmonary but not in mesenteric arteries. To determine whether NO production might have influenced the GBS-mediated hyporesponsiveness to NA, the concentration-response curve to NA was performed in the presence of L-NAME $\left(10^{-4} \mathrm{M}\right.$, a concentration which inhibits 

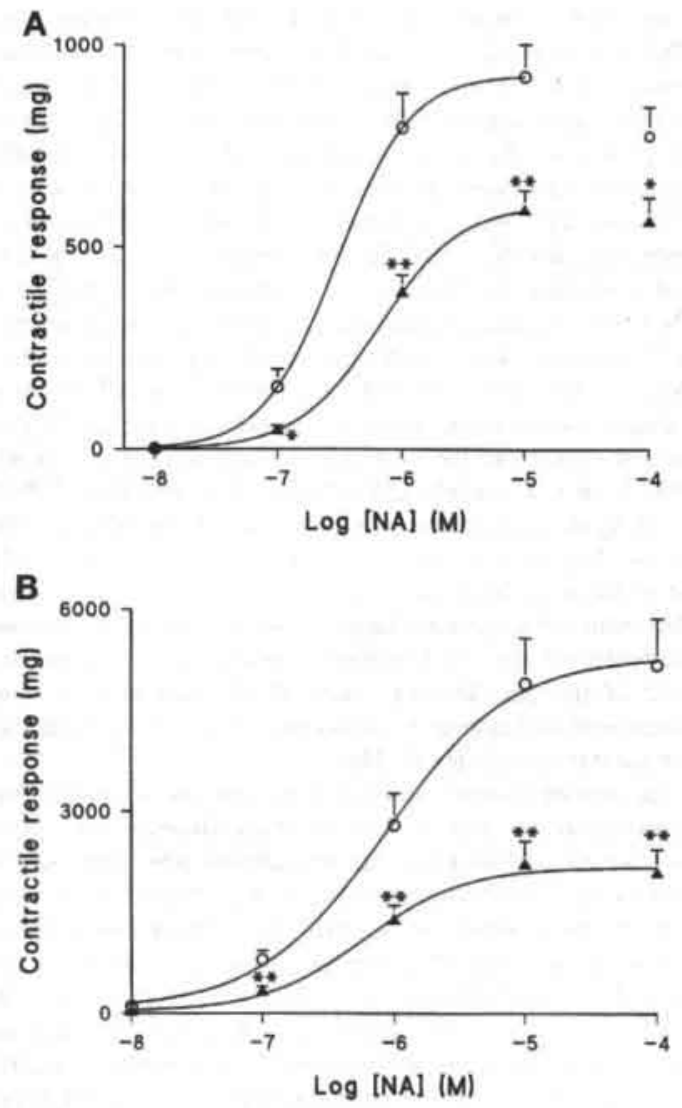

Figure 1. Concentration-response curves to $\mathrm{NA}\left(10^{-8}\right.$ to $\left.10^{-4} \mathrm{M}\right)$ in pulmonary $(A)$ or mesenteric $(B)$ artery rings preincubated for $20 \mathrm{~h}$ in Krebs solution in the presence of vehicle $(O)$ or GBS $\left(3 \times 10^{7} \mathrm{cfu} \mathrm{mL}^{-1}\right.$. A). The concentration-response curves to NA were carried out in the absence of GBS. Data are expressed as means \pm SEM of 8-21 observations. Ordinate, contractile re. sponse (mg); abscissa, $\log$ NA concentration (M). ${ }^{*} p<0.05$ and $* * p<0.01$ compared with control group.

$>80 \%$ of NO synthesis by the constitutive and inducible isoforms of NOS) (22). Fig. 2 shows that L-NAME induced an upward shift of the concentration-response to NA reversing the hyporesponsiveness to NA induced by GBS in both pulmonary and mesenteric arteries.

\section{Effects of GBS on U46619-Induced Contractions}

As shown in Fig. $3 A$, the maximal contractile responses to U46619 were similar in control and in GBS-treated pulmonary arteries and no change in the $p D_{2}$ values was observed (Table 1). In the absence of endothelium (Table 1) or in the presence of $10^{-4} \mathrm{M}$ L-NAME (Table 1, Fig. 4A), GBS was again unable to modify the contractile responses to U46619.

Fig. $3 B$ shows that, in contrast to pulmonary arteries, GBStreated mesenteric arteries showed a significant reduction $(p<$ 0.05 ) of the maximal contractions induced by U46619 compared with controls without affecting the $p D_{2}$ value. Pretreat-
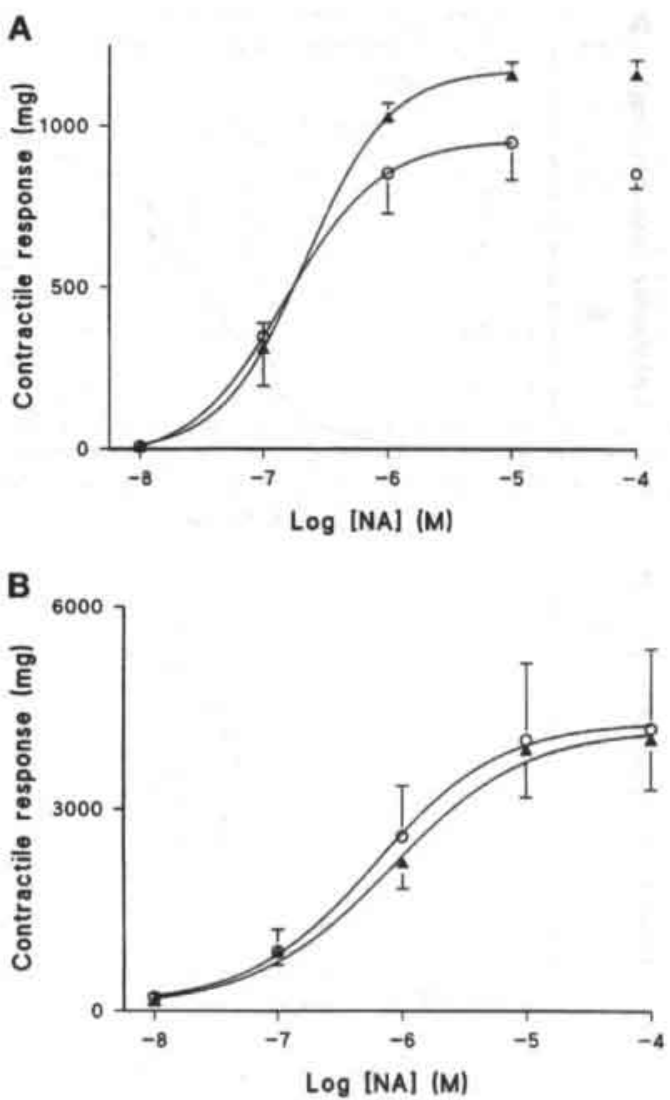

Figure 2. Effects of L-NAME $\left(10^{-4} \mathrm{M}\right)$ on GBS-induced hyporeactivity to NA in pulmonary $(A)$ or mesenteric $(B)$ artery rings. Concentration-response curves to NA $\left(10^{-8}\right.$ to $\left.10^{-4} \mathrm{M}\right)$ were performed in rings previously incubated for $20 \mathrm{~h}$ in Krebs solution in the presence of vehicle $(\mathrm{O})$ or GBS $3 \times 10^{7} \mathrm{cfu}$ $\left.\mathrm{mL}^{-1}, \mathbf{A}\right)$. L-NAME was added $30 \mathrm{~min}$ before the addition of NA. The curves were carried out in the absence of GBS. Data are expressed as means \pm SEM of seven to nine observations. Ordinate, contractile response $(\mathrm{mg})$; abscissa, $\log$ NA concentration (M).

ment with L-NAME induced an upward shift of the concentration-response to U46619 in the GBS-treated but not in untreated mesenteric arteries (Fig. 4B). Therefore, L-NAME reversed the hyporesponsiveness to U46619 induced by GBS in mesenteric arteries (Table 1).

\section{Effects of GBS on ET-1-Induced Contractions}

As shown in Fig. 5 the incubation for $20 \mathrm{~h}$ with GBS produced a marked decrease in the contractile response to ET-1 in both pulmonary and mesenteric arteries. Because the maximal concentration of ET-1 used $\left(3 \times 10^{-9} \mathrm{M}\right)$ did not reach maximal contractile effect, neither the $E_{\max }$ nor the $p D_{2}$ values could be calculated in these experiments. The GBS-induced reduction of the maximal contraction to ET-1 was more marked in mesenteric compared with pulmonary arteries ( $40 \pm$ $5 \%$ versus $60 \pm 4 . p<0.01$ ). Fig. 6 shows that GBS-induced 

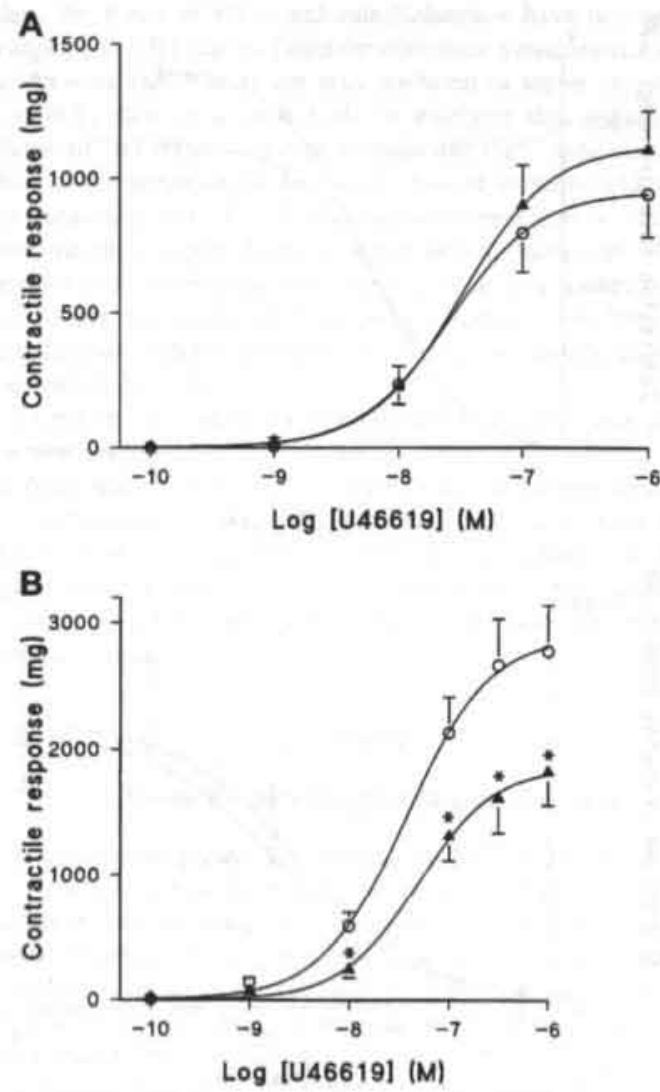

Figure 3. Concentration-response curves to U46619 $\left(10^{-10}\right.$ to $\left.10^{-6} \mathrm{M}\right)$ in pulmonary $(A)$ or mesenteric $(B)$ artery rings preincubated for $20 \mathrm{~h}$ in Krebs solution in the presence of vehicle $(0)$ or GBS $\left(3 \times 10^{7} \mathrm{cfu} \mathrm{mL}^{-1}, \mathbf{A}\right)$. The concentration-response curves to U 46619 were carried out in the absence of GBS. Data are expressed as means \pm SEM of 11-12 observations. Ordinate, contractile response (mg); abscissa, $\log U 46619$ concentration (M). " $p<0.05$ compared with control group.

hyporesponsiveness was completely reversed in the presence of L-NAME.

\section{DISCUSSION}

In the present report we have studied the effects of prolonged incubation with heat-killed GBS on the vascular contractile responses induced by NA, the TXA $\mathrm{T}_{2}$ mimetic U46619, and ET-1 on isolated pulmonary and systemic (mesenteric) arteries from piglets. The results demonstrate that GBS reduced the vascular responsiveness to NA, U46619, and ET-1 in mesenteric arteries and this effect was reversed by the presence of the NOS inhibitor L-NAME. In pulmonary arteries, GBS also reduced the response to NA and ET-1, and L-NAME reversed this hyporesponsiveness. In contrast, GBS did not affect the contractions induced by U46619 in pulmonary arteries both in presence or absence of L-NAME.

In a recent study we have reported that prolonged $(20 \mathrm{~h})$ incubation with GBS or Escherichia coli LPS, reduced the contractile responses to NA in piglet pulmonary arteries (21). This hyporesponsiveness was potentiated by the NO precursor L-arginine and reversed by L-NAME. Dexamethasone, which inhibits the induction of iNOS, and cycloheximide, an inhibitor of protein synthesis, when coincubated with GBS or LPS, completely reversed the reduced response to NA. Moreover, GBS and LPS induced a marked increase in iNOS activity, indicating that the vascular hyporesponsiveness was related to overproduction of $\mathrm{NO}$ as a consequence of the induction of iNOS. In the present study, incubation of mesenteric arteries with GBS also decreased the contractile responses induced by NA, U46619, and ET-1. The reversal by L-NAME of these reduced responses suggested that an enhanced NO production may be responsible for GBS-induced vascular hyporesponsiveness. It has been found that LPS leads to the induction of iNOS resulting in an overproduction of NO, which contributes to the severe hypotension seen in Gram-negative sepsis (12-14). More recently, iNOS induction in several tissues has also been demonstrated with some Gram-positive bacteria $(17,18)$ including GBS (19-21). Moreover, lipoteichoic acid, a component of the peptidoglycan layer of the cell wall in most Gram-positive bacteria, has been described as being responsible for this induction $(23,24)$.

In spite of the pulmonary hypertension that appears in the sepsis syndrome, induction of iNOS and decreased responses to pressor agents have been reported after in vitro incubation of pulmonary arteries from piglets $(21)$ or adult rats $(16,25)$ with LPS or GBS. Moreover, Curzen et al. (26) have described hyporesponsiveness to ET-1 in pulmonary arteries from LPStreated rats. Unfortunately, they did not evaluate the possible role of NO in this hyporesponsiveness. In the present study we have demonstrated that prolonged in vitro incubation with GBS reduces the pulmonary vascular response to NA and ET-1, but not to the TXA $\mathrm{T}_{2}$ mimetic U46619. Interestingly, in mesenteric arteries, the GBS-induced hyporesponsiveness to U46619 was less marked than that to NA or ET-1. The reason for this lack of hyporesponsiveness to U46619 in GBS-treated pulmonary arteries is unknown, but a reduced sensitivity to NO-mediated vasodilatation can be involved. In fact, we have previously reported that pulmonary arteries precontracted with U46619 were relatively insensitive to the relaxant action of the NO donor sodium nitroprusside or 8-bromo-cGMP, the stable analog of cGMP (27). In contrast, inhaled NO was able to reduce the pulmonary hypertension produced by U46619 infusions (28) or GBS-sepsis $(29,30)$. Interestingly, the response to U46619 after iNOS induction varies among species and vascular beds. Thus, isolated piglet pulmonary arteries incubated with endotoxin (27) or isolated mesenteric beds from endotoxin-treated rats were not hyporesponsive to U46619 despite significant iNOS induction (22), whereas in isolated rat lung (31), isolated piglet mesenteric arteries (27), and isolated perfused rat (32), or rabbit hearts (33), the vasoconstrictor responses to U 46619 were attenuated by endotoxin. In addition, increased responses to U46619 have been reported after treatment of isolated perfused guinea pig lungs with tumor necrosis factor- $\alpha$ (34) which is one of the most important cytokines released in septic shock or in experimental models of sepsis induced by Gram-negative and Gram-positive bacteria includ- 
Table 1. Effects of incubation with heat-killed GBS $\left(3 \times 10^{7} \mathrm{cfu} \mathrm{mL}^{-1}\right)$ for 20 h on the parameters $\left(E_{\max }\right.$ and $\left.p D_{2}\right)$ of the concentration-response curves to NA and U46619 in pulmonary and mesenteric arteries (calculated from Figs. 1-4)

\begin{tabular}{|c|c|c|c|c|c|c|c|c|}
\hline \multirow[b]{2}{*}{ Artery } & \multirow[b]{2}{*}{ Drug } & \multirow[b]{2}{*}{ Treatment } & \multicolumn{3}{|c|}{ Control } & \multicolumn{3}{|c|}{ GBS } \\
\hline & & & $E_{\max }(\mathrm{mg})$ & $p D_{2}$ & $n$ & $E_{\max }(\mathrm{mg}, \%$ of control) & $p D_{2}$ & $n$ \\
\hline Pulmonary & NA & None & $920 \pm 80$ & $6.52 \pm 0.07$ & 17 & $589 \pm 50^{* *} .64 \pm 5$ & $6.17 \pm 0.08 * *$ & 21 \\
\hline Pulmonary & NA & L-NAME & $947 \pm 115$ & $6.72 \pm 0.11$ & 8 & $1151 \pm 45,121 \pm 6$ & $6.66 \pm 0.08$ & 9 \\
\hline Pulmonary & U 46619 & None & $943 \pm 159$ & $7.51 \pm 0.06$ & 12 & $1108=142,117 \pm 15 \ddagger$ & $7.53 \pm 0.09$ & 11 \\
\hline Pulmonary & U46619 & L-NAME & $984 \pm 81$ & $7.61 \pm 0.08$ & 18 & $1081 \pm 88,109 \pm 9$ & $7.83 \pm 0.10$ & 18 \\
\hline Pulmonary E- & U46619 & None & $931 \pm 106$ & $7.65 \pm 0.1$ & 8 & $1027 \pm 139,110 \pm 15$ & $7.57 \pm 0.1$ & 9 \\
\hline Mesenteric & NA & None & $5175 \pm 693$ & $6.07 \pm 0.11$ & 8 & $2072 \pm 360^{* *}, 40 \pm 7 \dagger$ & $6.21 \pm 0.06$ & 10 \\
\hline Mesenteric & NA & L-NAME & $4193 \pm 1177$ & $6.22 \pm 0.06$ & 8 & $4010 \pm 722.97 \pm 15$ & $6.18 \pm 0.7$ & 7 \\
\hline Mesenteric & U46619 & None & $2777 \pm 364$ & $7.33 \pm 0.08$ & 11 & $1825 \pm 266^{\circ}, 66 \pm 9+. \ddagger$ & $7.18 \pm 0.07$ & 11 \\
\hline Mesenteric & U46619 & L-NAME & $2248 \pm 358$ & $7.43 \pm 0.12$ & 6 & $2591 \pm 623,115 \pm 21$ & $7.41 \pm 0.08$ & 7 \\
\hline
\end{tabular}

L-NAME $\left(10^{-4} \mathrm{M}\right)$ was added to the organ bath solution $30 \mathrm{~min}$ before the addition of NA or U46619. The concentration exhibiting $50 \%$ of the maximal contraction to NA was calculated for each ring and expressed as negative $\log$ molar $\left(p D_{2}\right)$. The $E_{\max }$ was defined as the maximal tension induced by NA or U46619 in each ring. E- indicates endothelium-denuded arteries. ${ }^{*} p<0.05$ and $* p<0.01$ GBS vs control. $+p<0.05$ pulmonary vs mesenteric arteries, $\ddagger p<0.05$ NA is U 46619 .

ing GBS $(20,35,36)$. Thus, a cytokine-mediated increase in pulmonary arterial sensitivity to TXA $\mathrm{T}_{2}$ has been also proposed as a mechanism for the persistence of pulmonary hypertension in sepsis (34). Because $\mathrm{TXA}_{2}$ is an important mediator in GBS sepsis-related pulmonary hypertension $(6,7)$, one could speculate that the lack of GBS-induced hyporesponsiveness to U46619 may explain the pulmonary hypertension despite iNOS induction in the lung. However, the relationship between these events is unclear, because $\mathrm{TXA}_{2}$-mediated pulmonary hypertension appears in the early phase of experimental sepsis (5-7), whereas iNOS induction seems to be a delayed process. In fact, we have observed iNOS induction in piglet pulmonary arteries after incubation for $20 \mathrm{~h}$ with GBS but not after 1 or $5 \mathrm{~h}$ (21). The uptake of bacteria by pulmonary intravascular macrophages and the subsequent release of inflammatory mediators are central to the pathophysiology of GBS-induced pulmonary hypertension (37). The absence of these cells in our model is another limitation of this study which may explain, at least in part, in vivo, in vitro, and organ- and species-differences. Moreover, due to its cytotoxic effects, NO may play a role in the edema and vascular injury that accompanies the late phases of sepsis-mediated pulmonary hypertension.

To the best of our knowledge this is the first report of NO-mediated vascular hyporesponsiveness induced by GBS in systemic arteries. Moreover, the percentage of reduction in the contractile response induced by GBS was greater in mesenteric compared with pulmonary arteries for any of the stimuli studied. These results may be relevant due to the association of GBS sepsis and hypotension. In fact, in neonates with earlyonset GBS sepsis, the development of hypotension is one of the most sensitive predictors of mortality $(4,38)$, and in newborns with Gram-positive or Gram-negative sepsis an association between plasma nitrite plus nitrate (metabolites of NO) and shock has been reported (39). Whether iNOS induction is beneficial in sepsis-induced shock or is an undesirable collateral effect remains controversial. Experiments using NO inhibitors have strongly implicated NO as a cytotoxic agent which plays a role in antimicrobial and inflammatory responses (40), whereas mortality related to experimental endotoxemia was abolished in mutant mice lacking the iNOS gene (41).
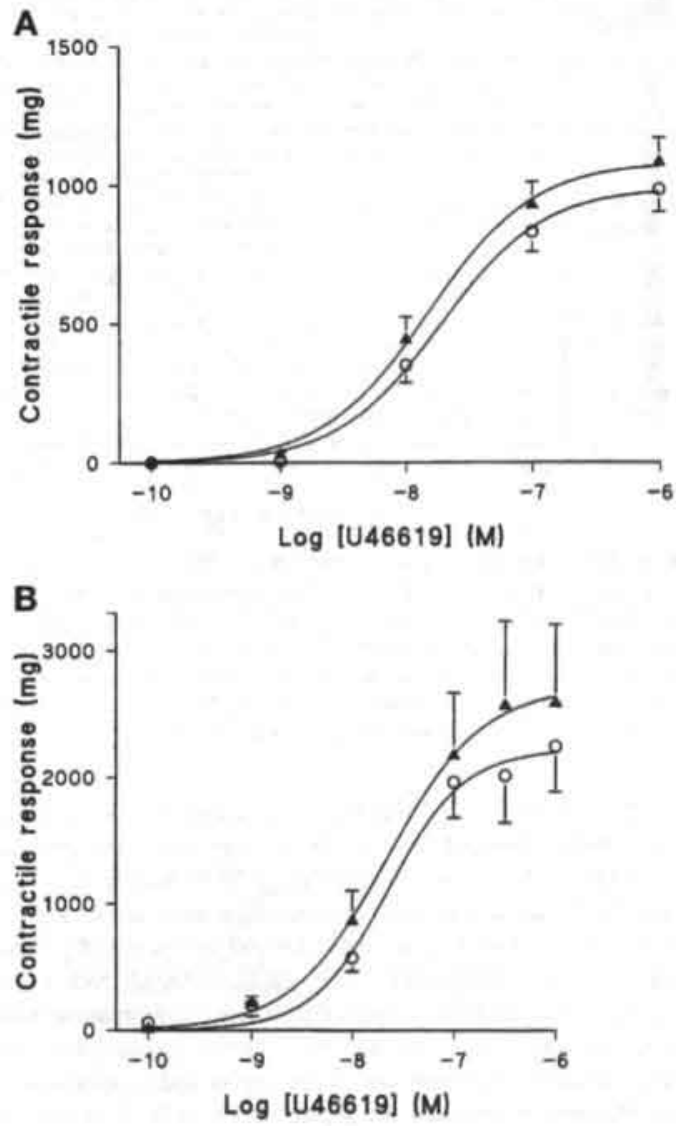

Figure 4. Effects of L-NAME $\left(10^{-4} \mathrm{M}\right)$ on the concentration-response curves to $U 46619$ in untreated and GBS-treated pulmonary $(A)$ or mesenteric $(B)$ artery rings. Concentration-response curves to U46619 $\left(10^{-10}\right.$ to $\left.10^{-6} \mathrm{M}\right)$ were performed in rings previously incubated for $20 \mathrm{~b}$ in Krebs solution in the presence of vehicle (control, O) or GBS $\left(3 \times 10^{7} \mathrm{cfu} \mathrm{mL}^{-1}, 4\right)$. L-NAME $\left(10^{-4} \mathrm{M}\right)$ was added $30 \mathrm{~min}$ before the addition of U46619. The curves were carried out in the absence of GBS. Data are expressed as means \pm SEM of 6-18 observations. Ordinate, contractile response (mg); abscissa, log U46619 concentration $(\mathrm{M})$. 

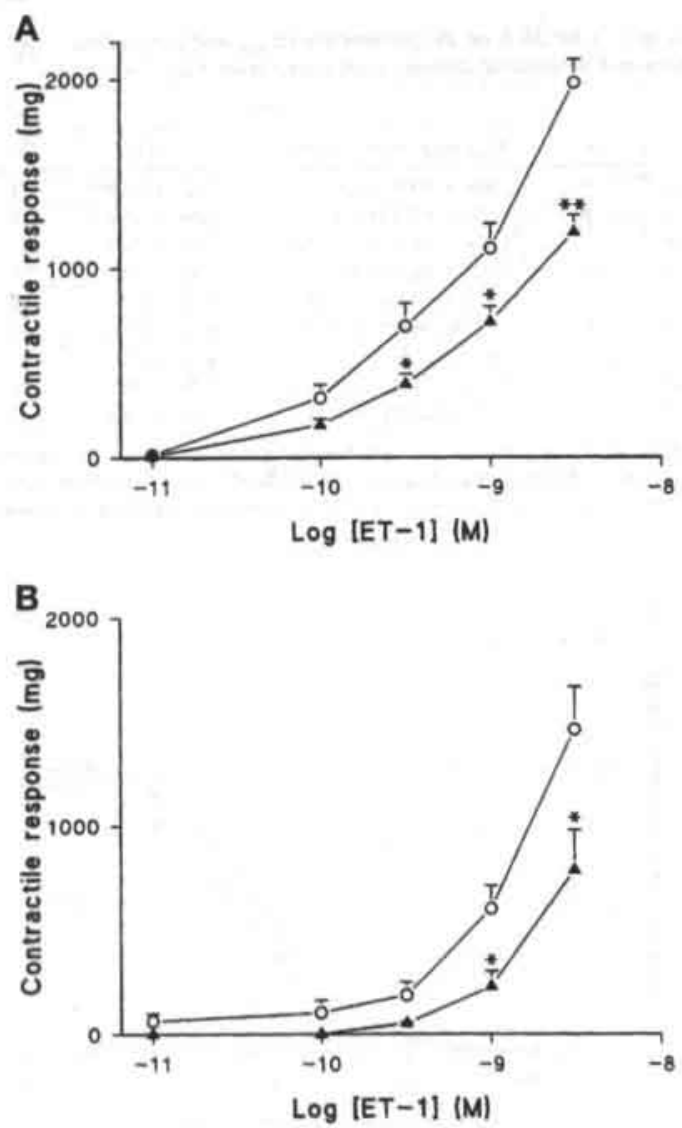

Figure 5. Concentration-response curves to ET-1 $\left(10^{-11}\right.$ to $\left.3 \times 10^{-9} \mathrm{M}\right)$ in pulmonary $(A)$ or mesenteric $(B)$ artery rings preincubated for $20 \mathrm{~b}$ in Krebs solution in the presence of vehicle $(O)$ or GBS $\left(3 \times 10^{7} \mathrm{cfu} \mathrm{mL}^{-1}\right.$. A ). The concentration-response curves to U46619 were carried out in the absence of GBS. Data are expressed as means \pm SEM of seven to nine observations. Ordinate, contractile response (mg); abscissa, $\log$ ET-1 concentration (M). ${ }^{*} p<0.05$ and $* * p<0.01$ compared with control group.

The coexistence of pulmonary hypertension and systemic hypotension in septic shock states important therapeutical problems. Systemic administration of NOS inhibitors to patients with sepsis reversed systemic hypotension but significantly enhanced mean pulmonary arterial pressure and pulmonary vascular resistances (42). Thus, inhaled NO (as a treatment for pulmonary hypertension) in combination with NOS inhibitors (as a treatment for systemic hypotension) has been studied in a porcine model of sepsis and proposed as a new therapeutic regimen for septic shock (43). However, in experimental models of GBS sepsis where systemic hypotension is not observed, probably due to the short duration of the GBS infusion, treatment with NOS inhibitors worsens the hemodynamic situation, increasing both pulmonary and systemic vascular resistances and decreasing cardiac output (44, 45). These data partially contradicts our findings, because L-NAME did not enhance the U46619-induced contractions in
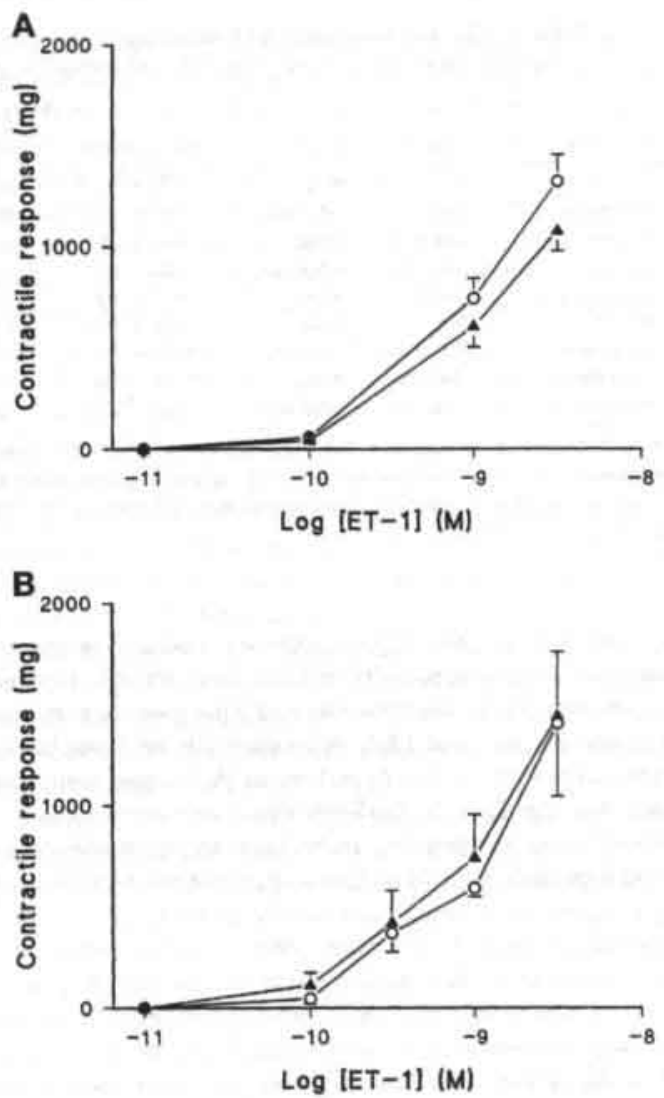

Figure 6. Effects of L-NAME $\left(10^{-4} \mathrm{M}\right)$ on the concentration-response curves to ET-1 $\left(10^{-11}\right.$ to $\left.3 \times 10^{-9} \mathrm{M}\right)$ in untreated and GBS-treated pulmonury $(A)$ or mesenteric $(B)$ artery rings. Concentration-response curves to ET-1 were performed in rings previously incubated for $20 \mathrm{~h}$ in Krebs solution in the presence of vehicle $(O)$ or GBS $\left(3 \times 10^{7} \mathrm{cfu} \mathrm{mL}^{-1}\right.$. A). L-NAME $\left(10^{-4} \mathrm{M}\right)$ was added $30 \mathrm{~min}$ before the addition of ET-1. The curves were carried out in the absence of GBS. Data are expressed as means \pm SEM of 7-10 observations. Ordinate, contractile response (mg); abscissa, $\log$ ET-1 concentration $(\mathrm{M})$.

GBS-incubated pulmonary arteries. Further studies, including the vascular responses of pulmonary and systemic vessels after prolonged in vivo GBS exposure, would be necessary to elucidate the pathophysiologic and therapeutical implications of sepsis-induced iNOS induction and the possible involvement of the changes in vascular tone which accompanies this process.

In conclusion, prolonged incubation of piglet mesenteric arteries with heat-killed GBS produced a marked hyporesponsiveness to NA, U46619, and ET-1 due to an enhanced NO release, suggesting a role for iNOS induction in the systemic hypotension associated with GBS sepsis. GBS-treated pulmonary arteries exhibited a NO-mediated hyporesponsiveness to NA and ET-1 but not to the TXA 2 mimetic U46619. This absence of pulmonary hyporesponsiveness to U46619 may 
contribute to the persistence of pulmonary hypertension in GBS sepsis despite iNOS induction in the lung.

Acknowledgments. The authors are grateful to Dr. Romero and Dr. Elorza for providing heat-killed GBS and to C. Rivas, R. Vara, and M. R. Gaítan for excellent technical assistance.

\section{REFERENCES}

1. Mayon-White RT 1985 The incidence of GBS disease in neonates in different countries. Antibiot Chemother 35:17-27

2. Baker CJ. Edwards MS 1991 Group B streptococcal infections. In Remington IS, Klein JO (eds) Infections Diseases of the Fetus and Newborn Infant. WB Saunders. Philadelphia, pp 820-881

3. Ferneri P 1985 GBS infections in the newborn infant: diagnosis and treatment Antibiot Chemother 35:211-224

4. Cabal LA, Siassi B, Cristofani C, Cabal C, Hodgman JE 1990 Cardiovascular changes in infants with $\beta$-hemolytic streptococcus sepsis. Crit Care Med 18:715-718

5. Brigham KL. Meyrick B 1986 Endotoxin and lung injury. Am Rev Respir Dis 133:913-927

6. Gibson RL. Truog WE, Redding GJ 1987 Thromboxanc-associated pulmonary hypertension during three rypes of Gram-positive bacteriemia in piglets. Pediatr Res 23:553-556

7. Runkle B, Goldberg RN, Sueitfeld MM, Clark MR, Buron E, Setzer ES, Bancalari E 1984 Cardiovascular changes in group B streptococcal sepsis in the piglet: response to indomethacin and the relationship to prostacyclin and thromboxane $A_{2}$. Pediatr Res 18:874-878

8. Groves AC, Griftiths J, Leung F. Meek RN 1972 Plasma catecholamines in patients with serious postoperative infection. Ann Surg 178:102-107

9. Groeneveld ABJ, Nauta JJP. Thijs LG 1988 Peripheral vascular resistance in septic shock: its relation to outcome. Intensive Care Med 14:141-147

10. Takakashi K. Silva A, Cohen J. Lam HC, Ghatei MA. Bloom SR 1990 Endotheli immunoreactivity in mice with Gram-negative bacteriemia: relation to tumor necrosis factor- $\alpha$. Clin Sei 79:619-62:

11. Pittet JF, Morel DR, Hemsen A, Gunning K, Lacroix JS, Suter PM. Landberg JM 1991 Elevated plasma endothelin-1 concentrations are associated with the severity of iliness in patients with sepsis. Ann Surg 213:261-264

12. McKenna TM 1990 Prolonged exposure of rat aorta to low levels of endotoxin in vitro results in impaired contractility. Association with vascular cytokine release 3 Clin Invest 86:160-168

13. Julou-Schaeffer G, Gray GA. Fleming 1, Schot C. Parratt JR, Stoclet J-C 1990 Los of vascular responsiveness induced by endotoxin involves L-arginine pathway. Am I Physiol 259:H1038-H1043

14. Thiemermann 1994 The role of the L-arginine: nitric oxide pathway in circulatory shock. Adv Pharmacol 28:45.79

15. Szabo C, Mitchell JA. Thiemermann C, Vane JR 1993 Nitric oxide-mediated hyporeactivity to notadrenaline precedes the induction of nitric oxide synthase in endotoxin shock. Br J Pharmacol 108:786-792

16. Zelenkov P, McL_oughlin T, Johns RA 1993 Endotoxin enhances hypoxic constriction of rat acra and pulmonary artery through induction of EDRFANO synthase. Am J Physiol 265:L.346-L.354

17. Rees DD, Cunha FQ. Assreuy J, Herman AG, Moncada S 1995 Sequential induction of nitric oxide synthase by Connebacterium parvam in different organs of the mouse. Br I Pharmacol 114-689-693

18. Cunha FQ. Moss DW, Leal LM, Moncada S. Liew FY 1993 Induction of macrophage purasiticidal activity by Staphylococcus aureus and exotoxins through the nitric oxide synthase pathway, Immunology 78:563-567

19. Goodrum KJ. McCormick L. Schneider B 1994 Group B Streptococcus-induced nitric oxide production is murine macrophages is CR3 (CDIIb/CDI8) dependent. Infect Imunun 62:3102-3107

20. Goodrum KJ, Dierksheide J, Yoder BJ 1995 Tumor necrosis factor alpha acts as a autocrine second signal with $\gamma$ interferon to induce nitric oxide in group B. Streptococcus-treated macrophages. Infect Immun 63:3715-3717

21. Villamor E, Pérez-Vizeaino F, Ruiz T, Leza JC, Moro M, Tamargo J 1995 Group B Streptococcus and $E$. coli LPS produce nitric oxide-dependent hyporesponsiveness to ooradrenaline in isolated intrapuimonary arteries of neonatal piglets. Be I Pharmacol $115: 261-266$
22. Mitchell JA, Kohlhas KI. Sorrentino R, Warner TD, Murad M. Vane J 1993 Induction by endotoxin of nitric oxide synthase in the rat mesentery: lack of effect on action of vasoconstrictors. Br $\mathrm{f}$ Pharmacol 109:265-270

23. Auguet M, Lonchampt MO, Delaflotte S, Goulin-Schulx J, Chabrier PE, Braquet P 1992 Induction of nitric oxide synthase by lipoteichoic acid from Slaphvlocorcu. aureus in vascular smooth muscle cells. FEBS Letr 297:183-185

24. De Kimpe SJ, Thiemermann C, Vane JR 1994 Lipoteichoic acid, a cell wall component of Gram-positive bacteria, causes bypotension and induction of nitric oxide synthase in anaesthetized rats. Br J Ptarmacol 112:442P

25. Griffiths MJD, Messent M. McAllister RJ. Evans TW 1993 Aminoguanidine selectively inhibits inducible nitric oxide synthase. Br J Pharmacol 110-963-968

26. Curzen NP, Griftiths MDD, Evans TW 1995 Contraction to endothelin- 1 in pulmonary arteries from endotoxin-treated rats is modulated by endothelium. Am I Physiol 268:HM260-H2266

27. Ptrez-Vizcaino F, Villamot E, Ruiz T. Femández del Pozo B, Moro M. Tamargo J $1995 \mathrm{E}$. coll and group B Streptococcus reduce puimonary antery responses to noradrenaline but not to U46619. Pharmacol Res 35:238

28. Tod ML. O'Donell DC, Gordon JB 1995 Sites of inhaled NO-induced vasodilation during hypoxia and U46619 infusion in isolated lamb lungs. Am J Physiol 268: H1422-H1427

29. Berger Jl, Gibson RL, Redding GJ. Standaert TA, Clarke WR, Truog WE 1993 Effect of inhaled nitric oxide during group B streptococcal sepsis in piglets. Am Rev Respir Dis 147:1080-1086

30. Abman SH, Kinsella JP, Schaffer MS, Wilkening RB 1993 Inhaled nitric oxide in the management of a premature newbom with severe respiratory distress and pulmonary bypertension. Pediatries $92-606-609$

31. Schneidkraut M. Carlson RW 1990 Bacterial sepsis-induced decrease in lung vascular reactivity to 9,11 -dideoxy-1/a,9a-epoxymethanoprostaglandin $F_{2}$ (U46619) in the rat. I Pharmacol Exp Ther 253:1171-1176

32. Baydoun AR, Foale RD, Mann GE 1993 Bacterial endotoxin rapidly stimulates prolonged endothelium-dependent vasodilatation in the rat isolated perfused bean. Br J Pharmacol 109:987.991

33. Smith REA, Palmer RMI, Moncada S 1991 Coronary vasodilatation induced by endotoxin in the rabbit isolated perfused heart is nitric oxide-dependent and inhibited by dexamethasone. Br J Pharmacol 104:5-6

34. Ferro TJ, Hocking DC, Johnson A 1993 Tumor necrosis factor-a alters pulmonary vasoreactivity via neutrophil-derived oxidants. Am J Physiol 265:L_462-L.471

35. Williams PA, Bohnsack JF, Auguntine NH. Drummond WK. Rubens CE. Hill HR 1993 Production of turnor necrosis factor by human cells in vitro and in vivo, induced by group B streptococci. J Pediatr 123:292.300

36. Mancuso G, Tomasello F, Hunelstoin C, Orefici G, Teti G 1994 Induction of tumor necrosis factor $\alpha$ by the group-and type-specific polysaccharides from type III group B streptococi. Infect Immun 62:2748-2753

37. Bowdy BD, Schewan MA, Marple SI. Yoneda K, Panh TH, Coonrod JD, Gillespie MN 1990 Organ-specific disposition of group B streptococci in piglets; evidence for a direct interaction with target cells in pulmonary circulation. Pediatr Res 27:344-348

38. Hocker JR, Simpsom PM, Rabalais GP, Stewant DL. Cook LN 1992 Extracorporeal membrane oxygenation and early-onset group B streptococcal sepais. Pediatrics $89: 1-4$

39. Shi Y, L H-Q. Shen C-K, Wang J-H, Qin S-W, Liu R, Pan J 1993 Plasma nitric oxide levels in newborn infants with sepsis. J Pediatr 123:435-438

40. Moocada S, Paimer RMU, Higgs EA 1991 Nitric oxide: physiology, pathophysiology. and pharmacology. Pharmacol Rev 43:109-142

41. Wei X, Charles IC, Smith A, Ure J. Feng G, Huang F, Xu D. Muller W, Moncada S. Liew FY 1995 Altered immune responses in mice lacking inducible nitric oxide synthase. Nature 375:408-41!

42. Petros A, Lamb G, Leone A, Mancada S, Bennet D, Vallance P 1994 Effects of a nitric oxide inhibitor in humans with septic shock. Cardiovase Res 28:34-39

43. Klemun P. Thiemermana C, Winklınaier G, Martorana PA, Henning R 1995 Eflects of nitric oxide synthase inhibition combined with nitric oxide inhalation in a porcine model of endotoxin shock. Br J Pharmacol 114:363-368

44. Gibson RL, Berger ת, Redding GI, Sundaen TA, Mayock DE, Truog WE 1994 Effect of nitric oxide synthase inhibition during group B streptococcal sepsis in neonatal piglets. Pediatr Res 36:776-783

45. Meadow W, Rudinsky B, Bell A, Hipps R 1995 Effects of inhibition of endotheliumderived relaxation factor on hemodynamics and oxygen utilization during group B streptococcal sepais in piglets. Crit Care Med 23:705-714 

Chapter X. Involvement of protein kinase $\mathbf{C}$ in reduced relaxant responses to the NO/cyclic GMP pathway in piglet pulmonary arteries contracted by the thromboxane $A_{2}$-mimetic U46619.

(Br J Pharmacol. 1997; 121:1323-33). 


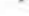




\title{
Involvement of protein kinase $\mathrm{C}$ in reduced relaxant responses to the $\mathrm{NO} /$ cyclic GMP pathway in piglet pulmonary arteries contracted by the thromboxane $\mathrm{A}_{2}$-mimetic U46619
}

\author{
'Francisco Pérez-Vizcaino, *Eduardo Villamor, ‡Juan Duarte \& Juan Tamargo
}

Department of Pharmacology, Institute of Pharmacology and Toxicology, School of Medicine, Universidad Complutense, 28040 Madrid; *Division of Neonatology, Department of Pediatrics, Hospital Universitario San Carlos, 28040 Madrid and $\ddagger$ Department of Pharmacology, School of Pharmacy, University of Granada, 18071 Granada, Spain

1 Impairment of nitric oxide (NO)/cyclic GMP production and/or increased activities of thromboxane $\mathrm{A}_{2}\left(\mathrm{TXA}_{2}\right)$ and endothelin-1 (ET-1) have been associated with pulmonary hypertension. We have

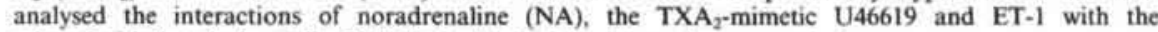
relaxation induced via cyclic GMP in isolated piglet intrapulmonary arteries.

2 The contractions induced by NA were augmented by endothelium removal or by methylene blue and pre-contracted rings were fully relaxed by acetylcholine, sodium nitroprusside (SNP), atrial natriuretic peptide and 8-bromo-cyclic GMP. In contrast, U46619- and ET-1 induced contractions were endothelium-independent and only partially relaxed by the latter vasodilators. Whereas the reduced responses to SNP in arteries contracted by U 46619 were independent of the U46619-induced tone, a higher concentration of ET-1 (tone higher than that induced by NA) was required to reduce the vasodilator responses to SNP. NA, U46619 and ET-1 had no effect on the SNP-induced increases in cyclic GMP.

3 The reduced relaxant responses to SNP in arteries pre-contracted by U46619 were specific for piglet pulmonary arteries since they were not observed in piglet mesenteric or coronary arteries or in rat pulmonary arteries. Furthermore, there were no differences in the relaxant response to the adenylate cyclase activator forskolin in piglet pulmonary arteries pre-contracted by either NA, U46619 or ET-1. 4 SNP-induced relaxation was inhibited by thapsigargin (but not by inhibition of the membrane $\mathrm{Na}^{+}$) $\mathrm{K}$ - ATPase nor $\mathrm{K}^{*}$ channels) indicating a role for $\mathrm{Ca}^{2+}$ sequestration by the $\mathrm{Ca}^{2+}$ ATPase in the effects of SNP.

5 The phorbol ester 12-myristate, 13-acetate inhibited the relaxant response to SNP. The inhibitory effect of U46619 on SNP-induced relaxation was abolished by the protein kinase C inhibitor (PKC) staurosporine suggesting that PKC may be a part of the signal transduction mechanism.

6 In summary, piglet pulmonary arteries when activated by a $\mathrm{TXA}_{2}$-mimetic show abnormally reduced relaxant responses to the NO/cyclicGMP pathway. This effect appears to be mediated by activation of PKC.

Keywords: Thromboxane $A_{2}$; endothelin-1; nitric oxide; cyclic GMP; pulmonary artery

\section{Introduction}

The nitric oxide (guanosine 3:5'-cyclic monophosphate) (NO/ cyclic GMP) pathway plays a key role in the maintenance of vasodilator tone in the vascular bed (Moncada et al., 1991; Warner et al., 1994). Under physiological conditions, the endothelium is the main source of NO for vascular smooth muscle relaxation whereas in several pathological states the induction of the inducible NO synthase (iNOS) in smooth muscle cells and macrophages may account for a large production of NO (Moncada et al., 1991). NO acting as an autocrine or paracrine mediator, activates the soluble guanylate cyclase and increases intracellular levels of cyclic GMP in vascular smooth muscle cells (Warner et al., 1994; Barnes \& Liu, 1995). Alterations of this pathway, at the level of NO and cyclic GMP synthesis or action in vascular smooth muscle have been associated with a number of vascular diseases. In the pulmonary system, NO is crucial for maintaining low vascular resistances and arterial pressure (Cremona et at., 1991; Barnes \& Liu, 1995). Reduced NO or cyclic GMP activities have been related to the maintenance of high pulmonary pressure during foetal life (Abman et al., 1990), experimental persistent pulmonary hypertension of the newborn

\footnotetext{
'Author for correspondence at: Department of Pharmacology, Institute of Pharmacology and Toxicology, School of Medicine, Universidad Complutense, 28040 Madrid, Spain.
}

(McQueston et al., 1995), hypoxia-induced pulmonary vasoconstriction as well as primary and secondary pulmonary hypertension (Dinh-Xuan et al., 1991; Giaid \& Saleh, 1995). In addition, in both adults and neonates, inhalation of NO has recently been introduced as a life-saving therapeutic approach with beneficial results in many subjects (Abman \& Kinsella, 1995; Roberts et al., 1997; Neonatal Inhaled Nitric Oxide Study Group, 1997).

On the other hand, increased activity of the pulmonary vasoconstrictors thromboxane $A_{2}\left(T X A_{2}\right)$ and endothelin-1 (ET-1) has also been implicated in several forms of pulmonary hypertension. TXA 2 has been shown to be responsible for the early phase of sepsis-induced pulmonary hypertension (Weitzberg et al., 1995). It has also been implicated in other experimental models of pulmonary hypertension induced by heparin/ protamine (Montalescot et al., 1990), leukotriene $\mathrm{D}_{4}$ (Noonan \& Malik, 1986), microembolism (Garcia-Szabo et al., 1988) and ischaemia-reperfusion (Zamora et al., 1993). Furthermore. elevated levels of thromboxane $\mathrm{B}_{2}$, the metabolite of TXA have been found in neonatal pulmonary hypertension (Dobyns et al., 1994). Augmented levels of ET-1 have also been shown to be associated with several forms of experimental and clinical pulmonary hypertension, including that induced by sepsis. hypoxia and monocrotaline (Weitzberg et al., 1996), persistent pulmonary hypertension of the newborn (Rosenberg et al., 1993), primary pulmonary hypertension (Giaid et al., 1993) and 
pulmonary hypertension associated with congenital heart disease (Yoshibayashi et al., 1991) or congestive heart failure (Cody et al., 1992).

In physiological situations, pulmonary vascular tone results from the balance of vasoconstrictors and vasodilators. Whether the imbalance which oceurs in pulmonary hypertension is due to alteration of a single factor or multiple vasoactive agents remains unclear. Therefore, the aim of the present investigation was to study the interactions of the vasoconstrictors noradrenaline (NA), the TXA ${ }_{2}$ mimetic, U46619, and ET. I with the NO/cyclic GMP pathway as well as the mechanisms involved in NO/cyclic GMP-induced relaxation in piglet isolated intrapulmonary arteries. The specificity of these interactions was analysed by comparing these results with those mediated through: (a) the cyclic AMP pathway in piglet pulmonary arteries, and (b) the NO/cyclic GMP pathway in piglet mesenteric and coronary arteries and in rat pulmonary arteries.

\section{Methods}

\section{Tissue preparation}

Two week old male piglets ( $10-17$ days, $3-5 \mathrm{~kg}$ ) were used in this study. Some experiments were also carried out on adult Wistar rats $(250-300 \mathrm{~g})$ and on $2-3$ month old piglets (15$25 \mathrm{~kg}$ ). Piglets were killed in the local abattoir by exsanguination and the lungs, hearts and mesenteric vascular beds were rapidly immersed in cold $\left(4^{\circ} \mathrm{C}\right) \mathrm{Krebs}$ solution (composition in mM: $\mathrm{NaCl} 118 . \mathrm{KCl} 4.75, \quad \mathrm{NaHCO}, 25, \quad \mathrm{MgSO}_{4} 1.2$, $\mathrm{CaCl}_{2} 2.0, \mathrm{KH}_{2} \mathrm{PO}, 1.2$ and glucose 11 ) and transported to the laboratory. Rats were killed in the laboratory by a sharp blow on the head followed by exsanguination. The intrapulmonary arteries (third branch), mesenteric and left descending coronary arteries from piglets (all with an internal diameter 1$2 \mathrm{~mm}$ ) and the right and left branches of the main rat pulmonary artery were carefully dissected free of surrounding tissue and cut into rings of $2-3 \mathrm{~mm}$ length (Pérez-Vizcaino et al., 1996; Villamor et al., 1996a,b). Except where stated otherwise, the endothelium was removed by gently rubbing the intimal surface of the rings with a metal rod. The endothelium removal procedure was verified by the inability of acetylcholine $\left(\mathrm{ACh}, 10^{-6} \mathrm{M}\right)$ to relax arteries precontracted with $10^{-6}$ M NA. Two L-shaped stainless-steel wires were inserted into the arterial lumen and the rings were introduced into Allhin organ chambers filled with Krebs solution (gassed with $95 \% \mathrm{O}_{2}$ and $5 \% \mathrm{CO}_{2}$ at $37^{\circ} \mathrm{C}$ ). One wire was attached to the chamber and the other to an isometric force-displacement transducer coupled to a signal amplifier (Model PRE 206-4. Cibertec, Madrid) and connected to a Hewlett Packard computer via an $\mathrm{A} / \mathrm{D}$ interface. Contractile tension was recorded by a REGXPC computer program (Cibertec, Madrid). The preparations were stretched to a resting tension of $0.5 \mathrm{~g}$ (pulmonary rings). $1 \mathrm{~g}$ (coronary rings) or $2 \mathrm{~g}$ (mesenteric rings) and allowed to equilibrate for $60-90 \mathrm{~min}$. During this period tissues were re-stretched and washed every $30 \mathrm{~min}$ with warm Krebs solution.

\section{Experimental protocols}

After equilibration, rings were contracted with either NA, U 46619 or ET-1. When the contractile response to each agonist reached a stable tension, cumulative concentration-response curves to methylene blue, ACh, sodium nitroprusside (SNP), atrial natriuretic peptide (ANP), 8-bromo-guanosine-3'-5'-cyclic monophosphate (8-Br-cyclic GMP), dipyridamole or forskolin, were carried out by cumulative addition of drugs after a steady-state response was reached after each increment. In some experiments the relaxant effect of SNP was tested in arteries precontracted with $3 \times 10^{-7} \mathrm{M}$ phorbol 12-myristate, 13-acetate (PMA). The relaxant effect of SNP was also analysed in arteries treated with thapsigargin $\left(2 \times 10^{-6} \mathrm{M}\right)$, staurosporine $\left(10^{-5} \mathrm{M}\right.$ and $\left.10^{-7} \mathrm{M}\right)$, PMA $\left(3 \times 10^{-\mathrm{k}} \mathrm{M}\right)$, meclofenamate $\left(10^{-5} \mathrm{M}\right)$ or $\mathrm{K}^{+}$-free solution (without $\mathrm{KCl}$ and $\mathrm{KH}_{2} \mathrm{PO}_{4}$ replaced with $\mathrm{NaH}_{2} \mathrm{PO}_{4}$ ) for 45 min before a contraction was induced with NA, U46619 or ET-1. Some arteries were contracted with $80 \mathrm{mM} \mathrm{KCl}$ (replacing $\mathrm{NaCl}$ isotonically), then relaxed with $10^{-5} \mathrm{M}$ nifedipine and, thereafter, NA or U46619 were added before the concentration-response curve to SNP was carried out. In other experiments, after a contraction had been induced with NA or U46619, arteries were treated with $10^{-6} \mathrm{M} \mathrm{IH}$ $[1,2,4]$ oxadiazolo[4,3-a]quinoxalin-1-one (ODQ). $3 \times 10^{-7} \mathrm{M}$ dipyridamole or $10^{-7} \mathrm{M}$ charybdotoxin for 20-30 min before concentration-response curves were constructed to SNP.

\section{Cyclic GMP assay}

Pulmonary rings were mounted in the organ chambers and tension was recorded as described above. After equilibration, they were exposed to vehicle, $10^{-5} \mathrm{M}$ NA, $10^{-6} \mathrm{M}$ U46619 or $3 \times 10^{-9} \mathrm{M}$ ET-1 for $40 \mathrm{~min}$ and finally, were either untreated or treated with $10^{-5} \mathrm{M}$ SNP for $3 \mathrm{~min}$. At the end of the $3 \mathrm{~min}$. rings were rapidly removed from the organ chamber and quickly frozen on dry ice and stored at $-80^{\circ} \mathrm{C}$. The rings were then homogenized in $600 \mu \mathrm{l}$ of $10 \%$ trichloroacetic acid, centrifuged at $10,000 \mathrm{~g}$ for $10 \mathrm{~min}$ at $4^{\circ} \mathrm{C}$ and the supernatant extracted 4 times in 3 volumes of water-saturated diethylether. The cyclic GMP concentrations were determined by radioimmunoassay by use of an acetylated Amersham $\left[{ }^{125} \mathrm{I}\right]$-cyclic GMP assay kit (Amersham International, Buckinghamshire, UK). The cyclic GMP was expressed as pmol g ${ }^{-1}$ wet tissue.

\section{Drugs}

The following drugs were used: (-)-noradrenaline bitartrate, acetylcholine chloride, sodium nitroprusside (SNP), human atrial natriuretic peptide (ANP), 8-bromo-cyclic GMP, 5-hydroxytryptamine (5-HT) creatine phosphate complex, adenosine $5^{\prime}$-trisphosphate magnesium salt (ATP). [Arg"]-vasopressin, U46619 (9,11-dideoxy-11 $\alpha, 9 \alpha$-epoxymethano-prostaglandin $\mathrm{F}_{2}$ methyl acetate solution), thapsigargin, endothelin-1 (ET-1), methylene blue, methoxamine hydrochloride, forskolin, staurosporine, phorbol 12-myristate, 13acetate and dipyridamole (Sigma Chemical Co.. London), charybdotoxin (RBI, Natick, MA), meclofenamate (Warner Lambert Co., U.S.A.), nifedipine (Bayer, Leverkussen, Germany) and $\mathrm{ODQ}(1 \mathrm{H}-[1,2,4]$ oxadiazolo[4,3-a]quinoxalin-1-one (Tocris Cookson Ltd, Bristol, U.K.). All drugs were dissolved initially in distilled deionized water (except for dipyridamole, staurosporine, thapsigargin, PMA and forskolin which were dissolved in dimethyl sulphoxide and nifedipine in ethanol) to prepare a $10^{-2} \mathrm{M}, 10^{-3} \mathrm{M}$ or $10^{-4} \mathrm{M}$ stock solution and further dilutions were made in PSS. The concentrations expressed are final molar concentrations in the tissue chamber.

\section{Statistical analysis}

Results are expressed as means \pm s.e.mean of measurements in $n$ arteries. Individual cumulative concentration-response curves were fitted to a logistic equation. The drug concentration exhibiting $50 \%$ of the maximal effect $\left(\mathrm{E}_{\text {max }}\right)$ was calculated from the fitted concentration-response curves for each ring and expressed as negative log molar concentration $\left(\mathrm{pD}_{2}\right)$. Statistically significant differences between groups were calculated by ANOVA followed by Newman Keuls test. $P<0.05$ was considered statistically significant.

\section{Results}

Contractile effects of NA. U46619, ET-I, vasopressin, 5$H T$ and $A T P$ in piglet pulmonary arteries

In previous experiments in piglet endothelium-denuded pulmonary arteries, $10^{-5} \mathrm{M}$ NA induced a maximally effective 
contractile response $\left(99 \pm 4 \%\right.$ of the $\mathrm{E}_{\operatorname{mas}}$ to NA), $3 \times 10^{-6} \mathrm{M}$, $10^{-7} \mathrm{M}$ and $10^{-6} \mathrm{M} U 46619$ induced a response of $56 \pm 9 \%$. $80 \pm 9 \%$ and $96 \pm 4 \%$, respectively. of the $E_{\operatorname{man}}$ to $U 46619$ and $10^{-9} \mathrm{M}$ and $3 \times 10^{-9} \mathrm{M}$ ET- 1 induced a response of $65 \pm 5 \%$ and $86 \pm 4 \%$, respectively, of the $E_{\max }$ to ET-1. The magnitude of the steady-state contractile responses induced by $10^{-4} \mathrm{M}$ methoxamine, $3 \times 10^{-8} \mathrm{M}$ or $10^{-7} \mathrm{M} U 46619$ or $10^{-9} \mathrm{M}$ ET-1 were not significantly different from those induced by $10^{-5} \mathrm{M}$ NA (Table 1). In endothelium-denuded rings NA $\left(10^{-5} \mathrm{M}\right)$. methoxamine $\left(10^{-4} \mathrm{M}\right)$, U46619 $\left(10^{-6} \mathrm{M}\right)$ and ET-1 $\left(3 \times 10^{-9} \mathrm{M}\right)$ induced contractile responses with a clearly different time-course (Figure la). NA and methoxamine induced a rapid increase in tension which reached a peak in about 1 $2 \mathrm{~min}$ and thereafter, slowly decreased to reach a lower steadystate tension at about $10 \mathrm{~min}$. This response probably reflects an initial inositol 1,4,5-triphosphate $\left(\mathrm{IP}_{3}\right)$-induced $\mathrm{Ca}^{2 *}$ release followed by a secondary component due to $\mathrm{Ca}^{2}$ entry. In contrast, U46619 and ET-1 induced a progressive monophasic contractile response which required about 20 and $40 \mathrm{~min}$, respectively, to reach a plateau. Addition of NA $10^{-5} \mathrm{M}$ on top of a steady-state contraction induced by $10^{-6} \mathrm{M}$ U 46619 (maximally effective concentration) was still able to increase tone (from $1192 \pm 190 \mathrm{mg}$ to $1595 \pm 174 \mathrm{mg}, n=7, P<0.01$ ). 5 . HT (up to $10^{-5} \mathrm{M}$ ), vasopressin (up to $10^{-6} \mathrm{M}$ ) and ATP (up to $10^{-3} \mathrm{M}$ ) produced no measurable contractile effects in resting pulmonary arteries $(n=4-6)$.

In endothelium-intact arteries the steady-state contractile response to NA was significantly smaller than in endothelium-denuded arteries, whereas endothelium removal did not significantly affect the responses to U46619 and ET-I (Figure Ib).

In endothelium-denuded arteries addition of the guanylate cyclase inhibitor methylene blue $\left(10^{-6} \mathrm{M}\right.$ and $\left.10^{-5} \mathrm{M}\right)$ on top of a steady-state contraction induced by $10^{-5} \mathrm{M}$ NA or $10^{-6} \mathrm{M}$ U46619 produced a concentration-dependent contraction (Figure Ic). This contractile response was more marked in NAthan in U46619-precontracted vessels, so that $10^{-5} \mathrm{M}$ methylene blue abolished the differences in the amplitude of the contractile responses between NA and U46619.

Vasorelaxant responses of $A C h, S N P, A N P$ and $8-B r-$ cyclic GMP on NA-, U46619-. ET-I-and methoxamineinduced contractions in piglet pulmonary arteries

As shown in Figure 2a, in endothelium-intact arteries $\mathrm{ACh}$ induced a concentration-dependent relaxant response. However, ACh induced complete relaxation in $10^{-5} \mathrm{M}$ NA-precontracted rings, while it relaxed only about $50 \%$ of the contractions induced by $10^{-6} \mathrm{M}$ U46619. Similarly, the relaxant responses induced by SNP. ANP and 8-Br-cyclic GMP were significantly less marked in endothelium-denuded arteries precontracted with U46619 than with NA (Figure 2b, c and $\mathrm{d}$ ).

To evaluate the role of the precontractile tone on SNP. induced relaxation, the effects of SNP $\left(10^{-8} \mathrm{M}-3 \times 10^{-5} \mathrm{M}\right)$ were also compared in pulmonary arteries precontracted by NA $\left(10^{-5} \mathrm{M}\right)$, U46619 $\left(3 \times 10^{-5} \mathrm{M}, 10^{-7} \mathrm{M}\right.$ and $\left.10^{-6} \mathrm{M}\right)$. ET-1 $\left(10^{-9} \mathrm{M}\right.$ and $\left.3 \times 10^{-9} \mathrm{M}\right)$ and the combination of $10^{-6}$ M U46619 plus $10^{-5}$ M NA. Parameters for the concentration-response curves are shown in Table 1 . In rings precontracted by equieffective concentrations of U46619 and NA $\left(10^{-7} \mathrm{M}\right.$ and $10^{-3} \mathrm{M}$, respectively), SNP produced complete relaxation of NA-induced contractions, while it only relaxed the contractions induced by U 46619 by $66 \%$. A similar result was observed in pulmonary arteries precontracted to lower tension levels by $3 \times 10^{-1} \mathrm{M} \cup 46619$. The relaxant effects of 8 -Br-cyclic GMP were much more marked in arteries precontracted with $10^{-5} \mathrm{M}$ NA than with $10^{-7}$ M U46619 (not shown). In rings contracted by the combination of $10^{-6} \mathrm{M} U 46619$ plus $10^{-5} \mathrm{M} \mathrm{NA}$, the relaxant response to SNP was not different from that obtained in arteries contracted by $\mathrm{U} 46619$ alone. In arteries contracted by $10^{-9} \mathrm{M}$ ET-1 (equieffective to $10^{-9} \mathrm{M}$ NA) the vasorelaxant response to SNP was similar to that observed in arteries contracted by $10^{-5} \mathrm{M} \mathrm{NA}$, whereas with contractions induced by higher concentrations of ET-1 $\left(3 \times 10^{-9} \mathrm{M}\right)$, SNP only induced a partial relaxation. Meclofenamate $\left(10^{-5} \mathrm{M}\right)$ did not modify the contractile response to $3 \times 10^{-9} \mathrm{M}$ ET-1 $(1275 \pm 159 \mathrm{mg}(n=4))$ or the relaxant response to $\mathrm{SNP} \quad\left(\mathrm{pD}_{2}=5.88 \pm 0.18\right.$ and $\mathrm{E}_{\max }=68 \pm 7 \%, P>0.05$ vs control values obtained with $3 \times 10^{-9}$ M ET-1 in Table 1).

Pulmonary arteries contracted by the selective $\alpha_{1}$-adrenoceptor agonist methoxamine $\left(10^{-4} \mathrm{M}\right)$ showed a similar relaxant response to SNP as when activated by the mixed $\alpha_{1}$ and $\alpha_{2}$ adrenoceptor agonist NA (Table 1).

\section{Vasorelaxant responses of forskolin on NA-, U46619.} and ET-1-induced contractions in piglet pulmonary arteries

Table 2 shows that the adenylate cyclase activator forskolin $\left(10^{-9} \mathrm{M}-10^{-6} \mathrm{M}\right)$ produced a similar full relaxation in pulmonary arteries contracted by either $10^{-3} \mathrm{M} \mathrm{NA}, 10^{-6} \mathrm{M}$ U46619 or $3 \times 10^{-9} \mathrm{M}$ ET- 1 . Thus, in contrast to the results obtained with the vasodilators acting through the cyclic GMP pathway, the relaxant response to forskolin was independent of the agonist employed to induce tone.

\section{Effects of SNP on NA-, U46619- and ET-1-induced contractions in piglet coronary and mesenteric arteries}

In contrast to pulmonary arteries, $\operatorname{SNP}\left(10^{-8} \mathrm{M}-3 \times 10^{-5} \mathrm{M}\right)$ produced a complete relaxation in mesenteric and coronary arteries which was independent of the agonist employed to raise tone $\left(10^{-6} \mathrm{M} \mathrm{NA}, 10^{-6} \mathrm{M}\right.$ U46619 or $\left.3 \times 10^{-9} \mathrm{M} \mathrm{ET-1}\right)$ and similar in both arteries (Table 3 ). As previously shown (Ohgushi et al., 1993). NA produced minimal contractile effects in pig coronary arteries and, therefore, the relaxant effects of SNP could not be evaluated.

Table 1 Relaxant effects of SNP in endothelium-denuded pulmonary arteries precontracted by NA, U46619. the combination of U 46619 and NA, ET-1 and methoxamine

\begin{tabular}{|c|c|c|c|c|}
\hline & $\mathbf{n}$ & Tension (mg) & $p D_{2}$ & $E_{\max }(\%)$ \\
\hline NA $\left(10^{-5} \mathrm{M}\right)$ & 13 & $654 \pm 41$ & $6.62 \pm 0.08$ & $104 \pm 2$ \\
\hline $\mathrm{U} 46619\left(3 \times 10^{-\mathrm{K}} \mathrm{M}\right)$ & 6 & $561 \pm 43$ & $5.65 \pm 0.07 *$ & $73 \pm 4 * 0$ \\
\hline $\mathrm{U} 46619\left(10^{-7} \mathrm{M}\right)$ & 12 & $720 \pm 40$ & $6.20 \pm 0.10^{*}$ & $66 \pm 7 \bullet \bullet$ \\
\hline $\mathrm{U} 46619\left(10^{-6} \mathrm{M}\right)$ & 14 & $1220 \pm 59 * *$ & $5.92 \pm 0.10^{* *}$ & $66 \pm 4 * *$ \\
\hline U46619 $\left(10^{-6} \mathrm{M}\right)+\mathrm{NA}\left(10^{-5} \mathrm{M}\right)$ & 7 & $1595 \pm 174 \cdots$ & $5.92 \pm 0.11 *$ & $75 \pm 5 * \bullet$ \\
\hline ET-1 $\left(10^{-6} \mathrm{M}\right)$ & 6 & $744 \pm 92$ & $6.52 \pm 0.08$ & $100 \pm 2$ \\
\hline ET-1 $\left(3 \times 10^{-6} \mathrm{M}\right)$ & 11 & $1015 \pm 77 * 0$ & $5.68 \pm 0.17 * *$ & $75 \pm 6 *$ \\
\hline Methoxamine $\left(10^{-4} \mathrm{M}\right)$ & 4 & $575 \pm 64$ & $6.49 \pm 0.17$ & $107 \pm 2$ \\
\hline
\end{tabular}

Tension is the pre-contraction value induced by the vasoconstrictor and $\mathrm{pD}_{2}$ and $\mathrm{E}_{\max }$ values refer to the effects of SNP. Results are means \pm s.e.means of $n$ number of experiments. ${ }^{*} P<0.05, \cdots P<0.01$, respectively, vs $10^{-5} \mathrm{M}$ NA. Data with $10^{-3} \mathrm{M} \mathrm{NA}^{-3}$ and $10^{-6} \mathrm{M}$ U46619 were calculated from Figure $2 \mathrm{~b}$. 

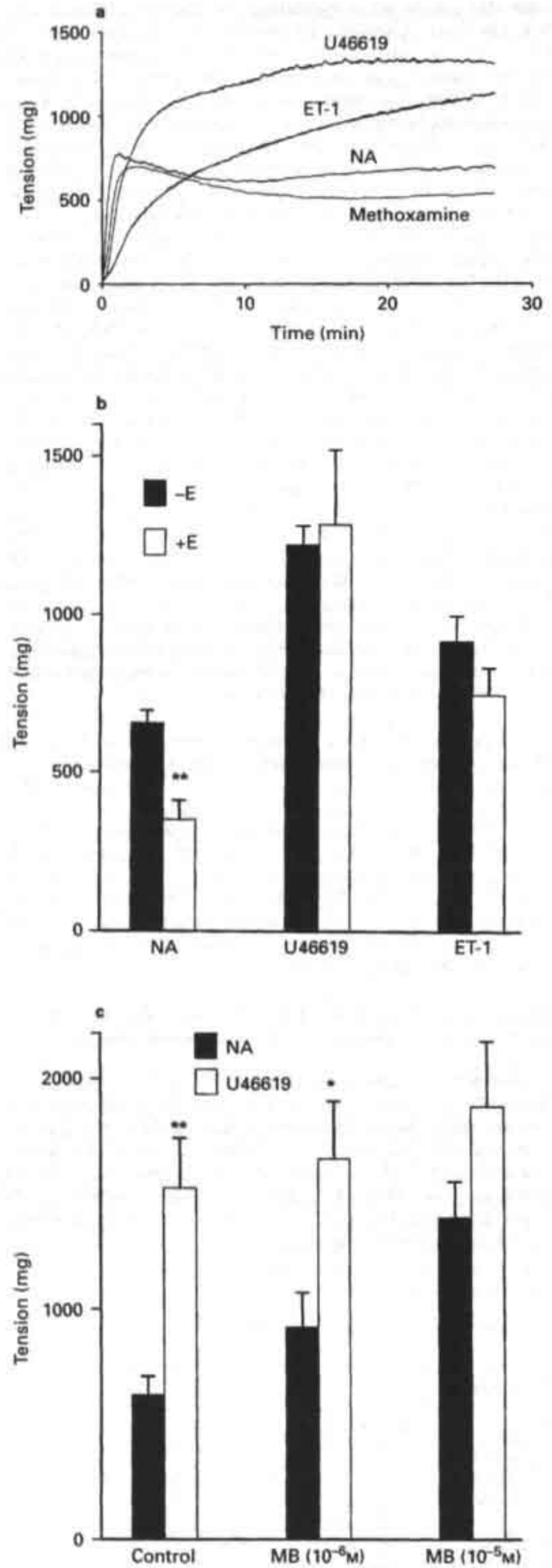

Figure 1 Time-course and role of endothelium and eyclic GMP in the contractile responses induced by NA $\left(10^{-5} \mathrm{M}\right), \mathrm{U} 46619\left(10^{-6} \mathrm{M}\right)$, ET-1 $\left(3 \times 10^{-9} \mathrm{M}\right)$ and methoxamine $\left(10^{-4} \mathrm{M}\right)$ in piglet pulmonary arteries. (a) Time-course of the contractions induced by the four
Effects of SNP on NA- and U46619-induced contractions in adult rat and 2-3 months old piglet pulmonary arteries

Endothelium-denuded rat pulmonary arteries showed no differences in their maximal responses to NA and U46619 $(351 \pm 82 \mathrm{mg}$ and $275 \pm 29 \mathrm{mg}$, respectively, $P>0.05, n=5)$. SNP $\left(10^{-10} \mathrm{M}-10^{-6} \mathrm{M}\right)$ was equally effective at relaxing the contractions induced by maximally effective concentrations of NA $\left(10^{-7} \mathrm{M}\right)$ and U46619 $\left(3 \times 10^{-6} \mathrm{M}\right)$ (Table 4).

The relaxant effects of SNP were similar in pulmonary arteries from 2-3 month old (Table 4) or 2 week old piglets (Table 1), i.e. again U46619-induced contractions were less sensitive to SNP than those induced by NA.

\section{Effects of NA, U46619 and ET-I on SNP-induced increase in cyclic GMP in pulmonary arteries}

Figure 3 shows the effects of SNP, alone or in combination with NA, U46619 and ET-1 on cyclic GMP levels in endothelium-denuded pulmonary arteries. SNP $\left(10^{-5} \mathrm{M}\right)$ increased the cyclic GMP content in resting arteries by about three fold after $3 \mathrm{~min}$. The increase in cyclic GMP levels induced by SNP was unchanged in arteries pre-contracted with NA $\left(10^{-5} \mathrm{M}\right)$, U46619 $\left(10^{-6} \mathrm{M}\right)$ or ET-1 $\left(3 \times 10^{-9} \mathrm{M}\right)$.

Effects of dipyridamole, $O D Q, K C l$, charybdotoxin, $\mathrm{K}^{+}$free solution and thapsigargin on the vasorelaxant responses to SNP in piglet pulmonary arteries

Addition of the cyclic GMP-dependent phosphodiesterase inhibitor dipyridamole $\left(3 \times 10^{-7} \mathrm{M}\right)$ relaxed NA- and U 46619 -contracted arteries by $33 \pm 4 \%$ and $9 \pm 2 \%$, respectively $(P<0.05)$, and significantly shifted the concentrationresponse curves to SNP to the left (Figure 4a). This leftward shift was similar in arteries contracted by either NA or U46619 (6.3 and 6.6 fold, respectively). However, pretreatment with dipyridamole had no effect on the maximal vasodilator response to SNP. In NA-contracted arteries, addition of $10^{-6} \mathrm{M}$ ODQ, a specific inhibitor of the soluble guanylate cyclase, raised tone by $102 \pm 47 \%$ over previous tone and inhibited the relaxant response to SNP $\left(\mathrm{pD}_{2}=5.96 \pm 0.22\right.$, $\mathrm{E}_{\max }=81 \pm 7 \%, n=6 ; P<0.05$ as compared to ODQ-untreated arteries).

In resting arteries, $80 \mathrm{mM} \mathrm{KCl}$ (replacing $\mathrm{NaCl}$ isotonically) induced a sustained contraction averaging $876 \pm 162 \mathrm{mg}$ $(n=11)$ which was relaxed by $74 \pm 3 \%$ with $10^{-6} \mathrm{M}$ nifedipine. Thereafter, a contractile response was induced by $10^{-5} \mathrm{M}$ NA (final tension $1131 \pm 107 \mathrm{mg}, n=6$ ) or $10^{-6} \mathrm{M} U 46619$ (final tension $1585 \pm 350 \mathrm{mg}, n=5$ ). As can be observed in Figure 4b, under these conditions, SNP induced a relaxant response in both NA-and U46619-contracted vessels which was slightly but significantly more potent $(P<0.05)$ than in arterial rings not treated with $\mathrm{KCl}$ plus nifedipine ( 2.8 and 3.0 fold leftward shift in NA and U46619 contracted vessels, respectively). In NA-contracted arteries, addition of the $\mathrm{Ca}^{2+}$-activated $\mathrm{K}^{+}$ channel blocking agent charybdotoxin $\left(10^{-7} \mathrm{M}\right)$ induced a weak contractile response ( $16 \pm 3 \%$ over previous tone) but did not modify the relaxant response to $\mathrm{SNP}\left(\mathrm{pD}_{2}=6.69 \pm 0.11\right.$, $\mathrm{E}_{\max }=103 \pm 3, n=4, P>0.05$ as compared to charybdotoxinuntreated arteries).

vasoconstrictors in endothelium-denuded arteries. Each trace represents the averaged recordings from 5-6 arteries. (b) Endothelialdependence of the sustained contractions induced by the NA, U46619 and ET-1. Solid columns indicate endothelium-denuded arteries (-E) and open columns endothelium-intact arteries $(+E)$. Each column represents the mean \pm s.e.mean of $6-17$ experiments. $* P<0.01$ endothelium-denuded vs endothelium-intact arteries. (c) Effects of methylene blue (MB. $10^{-6} \mathrm{M}$ and $10^{-5} \mathrm{M}$ ) on the contractions induced by NA and U46619 in endothelium-denuded arteries. Each column represents the mean \pm s.e.mean of $7-8$ arteries. $* P<0.05$ and $\because P<0.01$ NA vs U 46619 . 

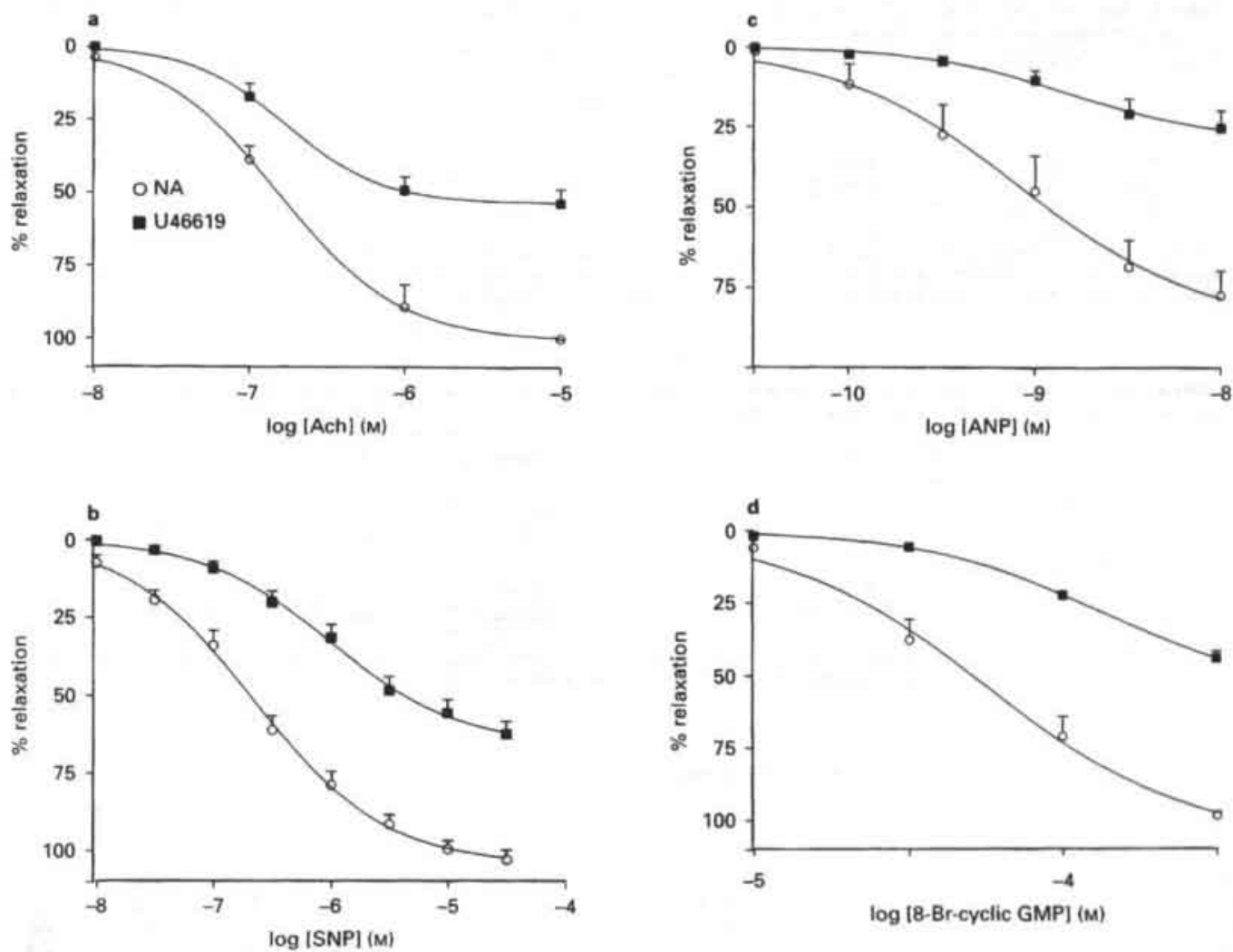

$\log [8-B r-c y c l i c$ GMP] (M)

Figure 2 Effects of stimulation of the cychic GMP pathway. Concentration-dependent relaxant effects of (a) ACh, (b) SNP, (c) ANP and (d) 8-Br-cyclic GMP in piglet pulmonary arteries precontracted with NA and U46619. The responses to ACh were studied in endothelium-intact arteries and to the other agonists in endothelium-denuded arteries. Each point represents the mean of 6-14 arteries; vertical lines show s.e.mean.

The sarcoplasmic reticulum $\mathrm{Ca}^{2+}$ ATPase inhibitor thapsigargin $\left(2 \times 10^{-6} \mathrm{M}\right)$ induced a slowly developing contractile response in resting arteries $(322 \pm 74 \mathrm{mg}, n=25)$. In the presence of thapsigargin, the contractile responses induced by $10^{-5} \mathrm{M}$ NA and $10^{-6} \mathrm{M}$ U46619 averaged $964 \pm 102 \mathrm{mg}$ $(n=12)$ and $1060 \pm 153 \mathrm{mg}(n=13)$, respectively. Figure $4 \mathrm{c}$ shows that under these conditions, the vasorelaxant response to $\mathrm{SNP}$ was strongly inhibited, thus $\mathrm{E}_{\max }$ was reduced to $60 \pm 9 \%$ and $28 \pm 4 \%$, respectively $(P<0.01)$.

Exposure of pulmonary arteries to a $K^{*}$-free solution induced a contractile response $(112 \pm 46 \mathrm{mg}, n=5)$ but did not modify the contractile response to $10^{-6} \mathrm{M}$ NA $(779 \pm 77 \mathrm{mg})$ or the relaxant effect of SNP $\left(\mathrm{pD}_{2}=6.80 \pm 0.04\right.$ and $\mathrm{E}_{\max }=105 \pm 4 \%$ ).

\section{Role of protein kinase $C$ in the impaired response to SNP in piglet pulmonary arteries precontracted by $U 46619$}

The protein kinase $\mathrm{C}$ (PKC) activator PMA $\left(3 \times 10^{-8} \mathrm{M}\right.$ and $\left.3 \times 10^{-7} \mathrm{M}\right)$ produced a contractile response which reached steady-state within $60-90 \mathrm{~min}(77 \pm 17 \mathrm{mg}, n=5$ and $498 \pm 61 \mathrm{mg}, n=10$, respectively). Figure 5a shows that in arteries contracted with $3 \times 10^{-6} \mathrm{M}$ PMA plus $10^{-5} \mathrm{M}$ NA (final tension $=618 \pm 103 \mathrm{mg}$ ), the relaxant response to SNP was significantly inhibited $\left(\mathrm{E}_{\max }=72 \pm 7 \%, n=5\right)$ as compared to NA alone $(P>0.05)$, whereas in arteries precontracted with $3 \times 10^{-7}$ M PMA alone, SNP induced only a small vasorelaxant effect $\left(E_{\max }=25 \pm 4 \%\right)$.
Table 2 Relaxant effect of forskolin $\left(10^{-9} \mathrm{M}-10^{-6} \mathrm{M}\right)$ on the contractions induced by NA, U46619 and ET-1 in piglet endothelium-denuded pulmonary arteries

$\begin{array}{lccc} & \mathrm{n} & p D_{z} & E_{\max }(\%) \\ \mathrm{NA}\left(10^{-5} \mathrm{M}\right) & 6 & 7.18 \pm 0.10 & 99 \pm 7 \\ \mathrm{U} 46619\left(10^{-6} \mathrm{M}\right) & 6 & 7.15 \pm 0.04 & 96 \pm 3 \\ \mathrm{ET}-1\left(3 \times 10^{-9} \mathrm{M}\right) & 7 & 6.97 \pm 0.14 & 100 \pm 4\end{array}$

Results are means \pm s.e.means of $n$ number of experiments. No significant differences were found between the three groups.

The effects of pretreatment for 45 min with the PKC inhibitor staurosporine $\left(10^{-1} \mathrm{M}\right.$ or $\left.10^{-7} \mathrm{M}\right)$ on the responses to SNP in arteries precontracted by $10^{-5} \mathrm{M}$ NA or $10^{-6} \mathrm{M}$ $\mathrm{U} 46619$ are shown in Figure $5 \mathrm{~b}$ and $\mathrm{c}$, respectively. This pretreatment had no effect on the contractile responses to NA (574 $\pm 98 \mathrm{mg}, n=7$, and $674 \pm 84 \mathrm{mg}, n=7$, for $10^{-3} \mathrm{M}$ and $10^{-7} \mathrm{M}$ staurosporine, respectively, $P>0.05$ vs control in Table 1). Furthermore, staurosporine did not modify the relaxant responses to SNP in arteries precontracted with NA. In contrast, $10^{-8} \mathrm{M}$ and $10^{-7} \mathrm{M}$ staurosporine decreased the contractile response to $U 46619(895 \pm 121 \mathrm{mg}, n=8$, and $852 \pm 176 \mathrm{mg}, n=6$ for $10^{-1 /} \mathrm{M}$ and $10^{-7} \mathrm{M}$ staurosporine, respectively, $P<0.01$ vs controls in Table 1) and augmented, in a concentration-dependent manner, the vasorelaxant response to 
Table 3 Relaxant effect of SNP $\left(10^{-8} \mathrm{M}-3 \times 10^{-5} \mathrm{M}\right)$ on the contractions induced by NA, U46619 and ET-1 in endotheliumdenuded mesenteric and coronary arteries

\begin{tabular}{|c|c|c|c|c|c|c|c|c|}
\hline & \multicolumn{4}{|c|}{ Mesenteric arteries } & & \multicolumn{3}{|c|}{ Coronary arteries } \\
\hline & $\mathbf{n}$ & $\begin{array}{l}\text { Tension } \\
(\mathrm{mg})\end{array}$ & $p D_{2}$ & $\begin{array}{l}E_{\operatorname{mix}} \\
(\%)\end{array}$ & n & $\begin{array}{c}\text { Tension } \\
\text { (mg) }\end{array}$ & $p D_{2}$ & $\begin{array}{l}E_{\max } \\
(\%)\end{array}$ \\
\hline NA $\left(10^{-6} \mathrm{M}\right)$ & 5 & $1480 \pm 394$ & $6.55 \pm 0.24$ & $107 \pm 3$ & 5 & - & - & - \\
\hline U46619 (10 $\left.0^{-6} \mathrm{M}\right)$ & 7 & $1640 \pm 351$ & $6.74 \pm 0.13$ & $92 \pm 4$ & 7 & $1190 \pm 145$ & $6.57 \pm 0.11$ & $96 \pm 2$ \\
\hline ET-1 $\left(3 \times 10^{-9} \mathrm{M}\right)$ & 9 & $1957 \pm 230$ & $6.42 \pm 0.10$ & $99 \pm 3$ & 6 & $1216 \pm 190$ & $6.52 \pm 0.17$ & $108 \pm 6$ \\
\hline
\end{tabular}

Tension is the pre-contraction value induced by the vasoconstrictor and $\mathrm{pD}_{2}$ and $\mathrm{E}_{\max }$ values refer to the effects of $\mathrm{SNP}$. Results are means \pm s.e.means of $n$ number of experiments. No significant differences were found between the three groups. NA produced very weak contractile effects in coronary arteries and, therefore, the effects of SNP were not studied.

Table 4 Relaxant effects of SNP on endothelium-denuded pulmonary arteries from adult rats or $2-3$ month old piglets contracted by maximally effective concentrations of NA and U46619

\begin{tabular}{|c|c|c|c|c|c|}
\hline & & $\mathbf{n}$ & Tension (mg) & $p D_{2}$ & $E_{\max }(\%)$ \\
\hline Adult rat & $\begin{array}{l}\text { NA }\left(10^{-7} \mathrm{M}\right) \\
\mathrm{U} 46619\left(3 \times 10^{-6} \mathrm{M}\right)\end{array}$ & $\begin{array}{l}5 \\
5\end{array}$ & $\begin{array}{l}351 \pm 82 \\
275 \pm 29\end{array}$ & $\begin{array}{l}7.9 \pm 0.1 \\
7.8 \pm 0.1\end{array}$ & $\begin{array}{l}101 \pm 4 \\
100 \pm 4\end{array}$ \\
\hline $2-3$ month piglets & $\begin{array}{l}\text { NA }\left(10^{-5} \mathrm{M}\right) \\
\text { U46619 }\left(10^{-6} \mathrm{M}\right)\end{array}$ & $\begin{array}{l}5 \\
7\end{array}$ & $\begin{array}{l}1081 \pm 129 \\
2034 \pm 169 * \bullet\end{array}$ & $\begin{array}{l}6.5 \pm 0.3 \\
6.1 \pm 0.1^{*}\end{array}$ & $\begin{array}{l}107 \pm 4 \\
64 \pm 6\end{array}$ \\
\hline
\end{tabular}

Tension is the pre-contraction value induced by the vasoconstrictor and $\mathrm{pD}_{2}$ and $\mathrm{E}_{\max }$ values refer to the effects of $\mathrm{SNP}$. Results are mean \pm s. e.means of $n$ number of experiments. $* P<0.05, \cdots P<0.01$, respectively, vs $10^{-5} \mathrm{M}$ NA.

SNP, increasing $(P<0.01$ vs controls in Table 1$)$ both the $\mathrm{pD}_{2}$ $\left(6.26 \pm 0.15\right.$ and $6.83 \pm 0.19$, respectively) and the $E_{\max }$ values ( $95 \pm 2 \%$ and $101 \pm 4 \%$, respectively). Thus, in the presence of $10^{-7} \mathrm{M}$ staurosporine the concentration-response curve to SNP was similar in arteries precontracted with NA and U46619. However, staurosporine $\left(10^{-8} \mathrm{M}\right)$ did not enhance the vasodilator effect of SNP when it was previously inhibited by $2 \times 10^{-6} \mathrm{M}$ thapsigargin $\left(\mathrm{pD}_{2}=5.68 \pm 0.18\right.$ and $5.49 \pm 0.10$ and $\mathrm{E}_{\max }=62 \pm 9 \%$ and $59 \pm 16 \%$ in the absence $n=13$, from Fig. ure $4 c$, and in the presence of staurosporine, $n=5$, respectively).

\section{Discussion}

In the present study we have demonstrated that piglet pulmonary arteries when activated by the thromboxane $A_{2}-$ mimetic U 46619 show abnormally low relaxant responses to either NO or cyclic GMP. This effect was specific to piglet pulmonary arteries, since it was not present in rat pulmonary arteries or in piglet mesenteric or coronary arteries. The activation of protein kinase $\mathrm{C}$ (PKC) by the phorbol ester PMA inhibited the relaxant responses to SNP whereas the inhibition of PKC by staurosporine potentiated the relaxant response to SNP in U 46619 pre-contracted arteries. The relaxant effect of SNP in piglet pulmonary arteries was inhibited by the sarcoplasmic reticulum $\mathrm{Ca}^{2+}$ ATPase inhibitor thapsigargin but not by $\mathrm{K}^{*}$. free solution, high $\mathrm{KCl}$ plus nifedipine or charybdotoxin.

\section{Role of basal cyclic GMP}

Resting pulmonary arteries have detectable basal levels of cyclic GMP which are reduced, but not abolished, when the endothelium is removed or by NO synthase inhibitors, indicating that endothelial release of NO partially accounts for the basal cyclic GMP concentration (Ignarro et al., 1987). In accordance with previous studies (Levy et al., 1995), in the piglet pulmonary artery the tonic contractile response to NA was augmented by endothelium removal. We found basal levels of cyclic GMP even in endothelium-denuded piglet pulmonary arteries, as detected by radioimmunoassay, and its inhibition by the guanylate cyclase inhibitor methylene blue augmented the contractile response induced by NA. Furthermore, dipyridamole induced a relaxant response in endothelium-denuded

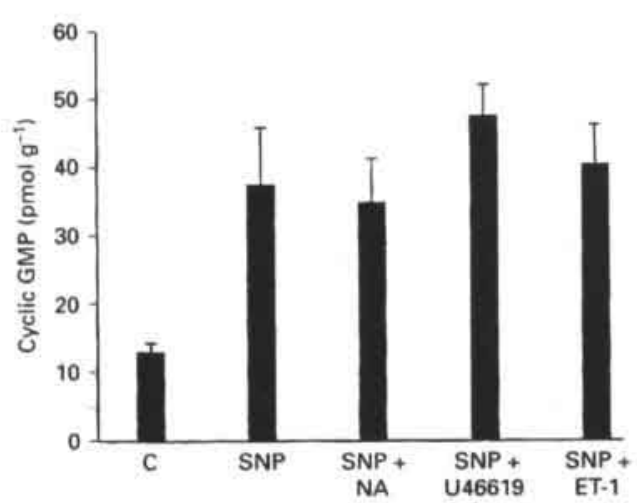

Figure 3 Effects of NA, U46619 and ET-1 on the formation of cyclic GMP stimulated by SNP, Results were obtained in endothelium-denuded arteries under control conditions $(C)$ and in the presence of $10^{-5} \mathrm{M}$ SNP alone or in combination with $10^{-5} \mathrm{M}$ NA, $10^{-6} \mathrm{M}$ U46619 or $3 \times 10^{-9} \mathrm{M}$ ET-1. Each column represents the mean \pm s.e.mean of $7-8$ experiments.

pulmonary arteries. The vasodilator response to dipyridamole in the pulmonary circulation has been attributed to an increase in cyclic GMP by specifically inhibiting its degradation by cyclic GMP-dependent (type V) phosphodiesterase and not to its inhibitory effects of the uptake of adenosine (Ziegler et al., 1995). However, this latter possibility cannot be fully excluded in our experiments. Thus, it can be concluded that basal formation of cyclic GMP modulates the contractile effects of NA and that the endothelium, by releasing NO, is partly responsible of cyclic GMP production. In contrast, the contractile responses to U46619 and ET-1 were unaffected by endothelium removal. The maximal U46619-induced tonic contractions were of higher magnitude than those induced by NA and this difference could be abolished by methylene blue, an inhibitor of soluble guanylate cyclase. From these results it seems that U46619 inhibits the synthesis or action of basal cyclic GMP in pulmonary smooth muscle cells. Alternatively, the differences 
between NA and U46619 can be explained on the basis that NA might increase cyclic GMP and induce relaxation. This has been found following the activation of endothelial $\alpha_{2}$-adrenoceptors in piglet pulmonary arteries by the non selective $\alpha$ adrenoceptor agonist phenylephrine or the selective $\alpha_{2}$-adrenoceptor agonist clonidine, but not by the selective $\alpha_{1}$-adrenoceptor agonist methoxamine (Pepke-Zaba et al., 1993).
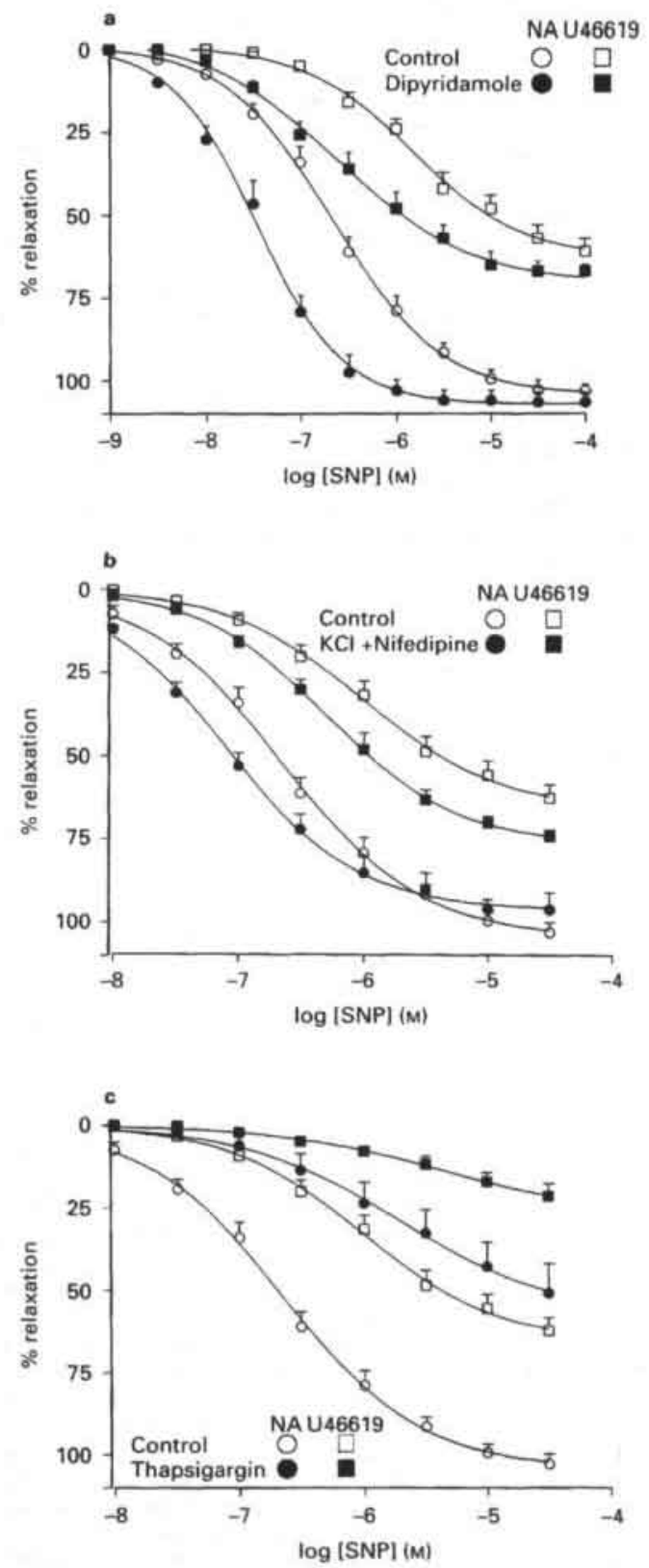

Figure 4 Effects of $3 \times 10^{-7} \mathrm{M}$ dipyridamole (a), $\mathrm{KCl} 80 \mathrm{mM}$ plus $10^{-6} \mathrm{M}$ nifedipine (b) and $2 \times 10^{-6} \mathrm{M}$ thapsigargin (c) on the responses to SNP in piglet endothelium-denuded pulmonary arteries contracted by $10^{-3} \mathrm{M} \mathrm{NA}$ and $10^{-6} \mathrm{M}$ U 46619. Each symbol represents the mean of 5-13 arteries; vertical lines show s.emean.
However, this was not the case in our study, since the experiments were performed in endothelium-denuded arteries and even in these conditions methylene blue induced a contractile
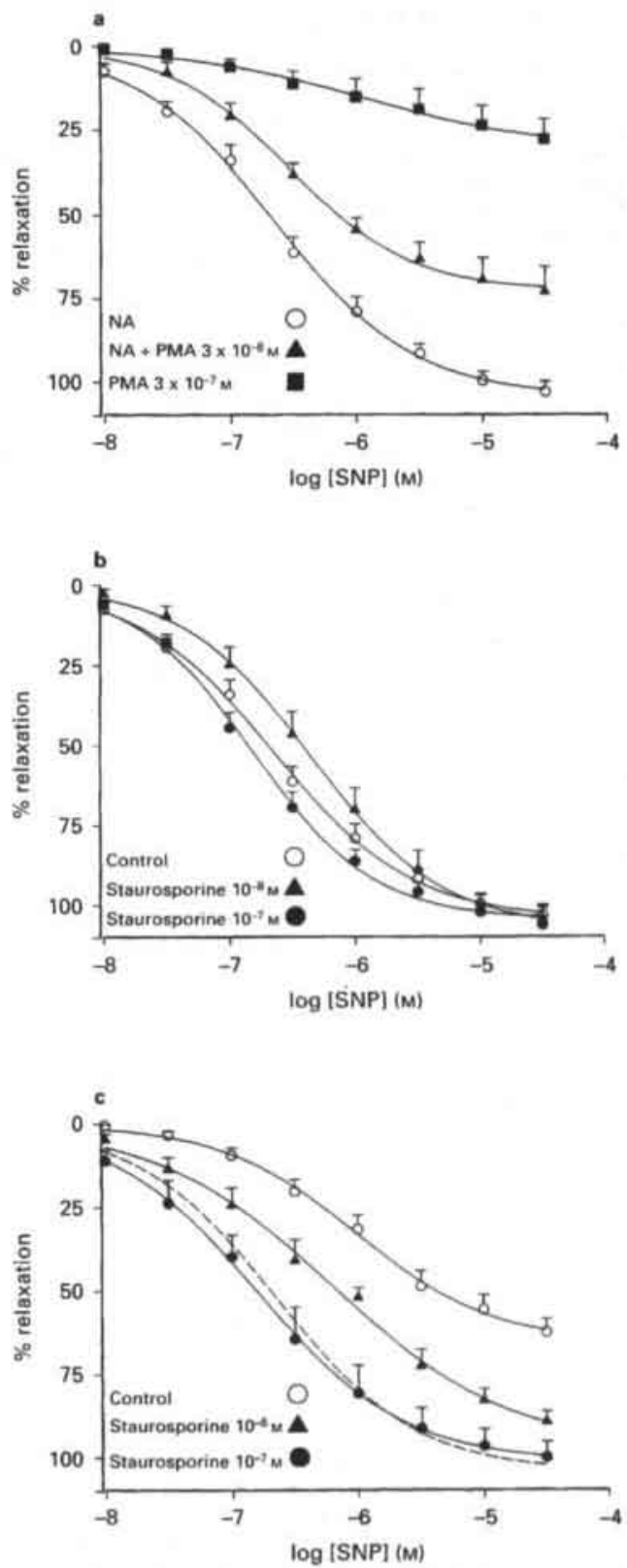

Figure 5 Role of protein kinase C pathway on U46619- and ET-1induced inhibition of the relaxant effects of SNP in endotheliumdenuded piglet pulmonary arteries. (a) The relaxant effects of SNP in arteries contracted by $10^{-5} \mathrm{M}$ NA, $3 \times 10^{-8} \mathrm{M}$ PMA plus $10^{-5} \mathrm{M}$ NA or $3 \times 10^{-7} \mathrm{M}$ PMA alone. (b) and (c) The effects of staurosporine $10^{-3} \mathrm{M}$ and $10^{-7} \mathrm{M}$ (controls are from Figure $2 \mathrm{~b}$ ) on the relaxant effects of SNP in arteries contracted by $10^{-3} \mathrm{M}$ NA (b) and $10^{-6} \mathrm{M} U 46619$ (c). In (c) the dashed line representing the fitted curve of the effects of SNP in NA-contracted arteries under control conditions (taken from (b)) is given for reference. Each symbol represents the mean of $6-10$ arteries; vertical lines show s.e.mean. 
response in arteries precontracted by NA. Furthermore, when NA was applied on top of a maximally effective U46619-induced contraction, it further contracted the artery.

\section{Effects of stimulation of cyclic GMP}

Cyclic GMP can be synthesized by the soluble and the membrane-bound isoforms of guanylate cyclase which are mainly activated by NO and ANP, respectively (Warner et al., 1994). NO can be raised by stimulating its release from endothelial cells (e.g. with ACh) or by the administration of NO donors such as SNP, Most of the effects of cyclic GMP are mediated by stimulation of the cyclic GMP-dependent protein kinase (PKG) (Warner et al., 1994: Lincoln et al., 1994), which can also be activated by membrane permeable and more stable cyclic GMP analogues such as 8-Br-cyclic GMP. In the present study, various activators of the cyclic GMP pathway (i.e., ACh, SNP, ANP and 8-Br-cyclic GMP) fully relaxed NA-contracted arteries, while only a partial relaxation was observed on the contractions induced by U46619. Likewise, expression of inducible nitric oxide synthase (iNOS) by endotoxin in these arteries depressed the contractile responses to NA but did not affect the responses to U46619 (Pérez-Vizcaino et al., 1996). Dipyridamole, an inhibitor of type $\mathrm{V}$ phosphodiesterase, produced a similar leftward shift of the concentration-response curve to SNP in NA- and U46619-contracted vessels, but was unable to enhance its maximal response, which suggests that U46619 was not increasing the degradation of cyclic GMP. Moreover, U46619 did not affect SNP-induced increase in cyclic GMP synthesis. Taken together, these results suggest that U46619 inhibits the NO/cyclic GMP pathway for smooth muscle relaxation beyond the level of cyclicGMP synthesis, probably by inhibiting the activity of PKG or the mechanisms by which PKG induces its relaxant effects. An alternative explanation for the reduced relaxant responses to $\mathrm{NO} / \mathrm{cy}$. clicGMP is that U46619 might induce a contractile response through a different signal transduction pathway from NA. This pathway could be less sensitive to inhibition by cyclic GMP. Assuming this possibility, U46619 would not actively inhibit the NO/cyclicGMP pathway but the contractions induced by U46619 would just be less sensitive to it. Because U46619 induced greater maximal contractile responses than NA, the effects of SNP were also studied (Table 1) in arteries contracted with lower concentrations of U 46619 which produced a contractile response similar to that induced by NA. Under these conditions, arteries pre-contracted by U 46619 $\left(3 \times 10^{-4} \mathrm{M}\right.$ or $\left.10^{-7} \mathrm{M}\right)$ still showed a reduced relaxant response to SNP as compared to NA. Therefore, the inhibitory action of U46619 on SNP-induced relaxation is independent of previous tone. Since the relaxant response to SNP was similar in arteries treated with U46619 alone or in combination with NA, differences in the relaxant response to SNP between NA and U46619 must be due to an U46619-induced impairment of the SNP-induced relaxation, rather than to a NA-induced potentiation of SNP-induced relaxation. A possible interference of NA with $\alpha_{2}$-adrenoceptors can be ruled out since similar results were obtained with methoxamine (selective $\alpha_{1}$-adrenoceptor agonist). Pulmonary arteries precontracted with ET-1 $\left(10^{-9} \mathrm{M}\right)$ showed similar relaxations to SNP as NA pre-contracted arteries, whereas at $3 \times 10^{-9} \mathrm{M}$ ET-1, which induced a contraction higher than $10^{-5} \mathrm{M} N A$, the relaxant response to SNP was greatly reduced, therefore, this higher tone might be responsible for the inhibitory action. However, it should be noted that $10^{-5} \mathrm{M}$ NA-induced contractions were maximal or near maximal and they could be fully inhibited by SNP, i.e. an activation of the NO/cy. clicGMP pathway can abolish vascular tone in the presence of any amount of NA. In contrast, if ET-1 concentrations were raised over a certain level, the increased vascular tone could not be fully inhibited even with a maximal activation of the NO/cyclic GMP pathway.

\section{Specificity of U46619-and ET-1-induced effects}

In order to assess the specificity of the impaired response to SNP observed in 2 week old piglet pulmonary arteries, we also studied the effects of SNP in endothelium-denuded mesenteric and coronary arteries from the same animals, pulmonary arteries from older piglets ( $2-3$ months old) and pulmonary arteries from adult rats. SNP fully relaxed mesenteric and coronary arteries precontracted by NA, U46619 or ET-1 as well as those induced by NA and $\mathrm{U} 46619$ in adult rat pulmonary arteries. However, in pulmonary arteries from 2-3 month old piglets the vasorelaxant response induced by SNP was similar to that observed in 2 week old piglets contracted by either NA or U46619 (i.e. again U46619-induced contractions were partially resistant to the relaxant effects of SNP).

The adenylate cyclase activator forskolin (Seamon \& Daly, 1986), which increases cyclic AMP levels, produced complete vasorelaxation of the contractions induced by NA, U46619 and ET-1, The mechanism by which cyclic AMP causes smooth muscle relaxation is not fully understood. While activation of the specific cyclic AMP-dependent protein kinase has been shown to be involved, more recent data suggest that cyclic AMP could also stimulate PKG and relax smooth muscle (Lincoln et al., 1990). Due to the differences in the relaxant response between cyclic AMP- and cyclic GMP-dependent vasodilators, our data might suggest that cyclic AMP- and cyclic GMP act via different pathways in these arteries. However, this requires further investigation. All these results showed that the abnormal relaxant response to the $\mathrm{NO} /$ cyclic GMP pathway is a singular feature of piglet pulmonary arteries when activated by $\mathrm{U} 46619$.

\section{Mechanism of action of the vasorelaxant effect of SNP in piglet pulmonary arteries}

SNP causes vascular smooth muscle relaxation by releasing NO which, in turn, activates guanylate cyclase and increases intracellular cyclic GMP levels (Rapoport et al., 1985; Ignarro et al., 1986; Kowaluk et al., 1992). In the present study. SNP raised intracellular cyclic GMP by about three fold and its vasorelaxant effect was potentiated by dipyridamole and inhibited by ODQ, which indicates that SNP-induced relaxation in piglet pulmonary arteries is mediated by stimulation of cyclic GMP synthesis.

Cyclic GMP and PKG may control a large number of cellular activities to regulate vascular smooth muscle tone (Lincoln et al., 1994), including inhibition of the synthesis and/or action of IP, (Hirata et al., 1990), activation of the sarcoplasmic reticulum $\mathrm{Ca}^{2+}$-ATPase (Rashatwar et al., 1987; Luo et al., 1993), activation of $\mathrm{Ca}^{2+}$-dependent $\mathrm{K}^{*}$ channels (Archer et al., 1994), inhibition of $\mathrm{Ca}^{2+}$ entry and possibly activation of the $\mathrm{Na}^{+} / \mathrm{K}^{+}$-ATPase (Rapoport et al., 1985). The role of each of these mechanisms may be different depending on the vascular bed (Ferrer et al., 1995). All these effects may lead to decreased cytosolic $\mathrm{Ca}^{2+}$ levels and $/$ or $\mathrm{Ca}^{2+}$ sensitivity of the contractile apparatus of vascular smooth muscle leading to relaxation (Lincoln et al., 1994; Warner et al., 1994). Using pharmacological tools we have investigated the role of several of these mechanisms in the piglet pulmonary artery. The role of $\mathrm{K}^{*}$ channel opening was studied in preparations exposed to high $\mathrm{KCl}$ concentrations, thus eliminating the chemical gradient for $\mathrm{K}^{*}$ efflux so that the opening of $\mathrm{K}^{*}$ channels would not result in net $\mathrm{K}^{+}$flow and hyperpolarization. Nifedipine was included in these experiments to avoid an excessive intracellular $\mathrm{Ca}^{2+}$ load induced by $\mathrm{KCl}$ depolarization. Under these conditions, the relaxant effect of SNP was not inhibited and instead a weak but significant increase was observed. suggesting that $\mathrm{K}^{*}$ channel activation is unlikely to mediate the vasodilator effects of SNP. Moreover, the specific inhibitor of large conductance $\mathrm{Ca}^{2+}$-activated $\mathrm{K}^{+}$channels charybdotoxin $\left(10^{-7} \mathrm{M}\right)$ had no effect on SNP-induced relaxation which is consistent with a lack of involvement of $\mathrm{Ca}^{2 *}$-activated $\mathrm{K}^{*}$ channels in SNP-induced relaxation. $\mathrm{Ca}^{2+}$ sequestration by the 
sarcoplasmic reticulum $\mathrm{Ca}^{2}$ - ATPase leads to decreased cytosolic $\mathrm{Ca}^{2+}$ levels and smooth muscle relaxation. Thapsigargin, a specific inhibitor of this $\mathrm{Ca}^{2+}$-ATPase (Thastrup et al. 1990), markedly suppressed SNP-induced relaxation in arteries contracted by either NA or U46619, which indicated that increased $\mathrm{Ca}^{2+}$ uptake by the sarcoplasmic reticulum is an important mechanism by which SNP decreases $\left[\mathrm{Ca}^{2+}\right]$ and induces its relaxant effects in piglet pulmonary arteries. Activation of the membrane electrogenic $\mathrm{Na}^{*} / \mathrm{K}^{*}$ ATPase leads to vascular smooth muscle hyperpolarization and relaxation, whereas its inhibition produces the opposite effects (Rapoport et al., 1985). Incubation in a $\mathrm{K}^{+}$-free solution, which inhibits the $\mathrm{Na}^{+} / \mathrm{K}^{*}$-ATPase, had no effect on SNP-induced relaxation, suggesting that an activation of this pump is not involved in its vasorelaxant effect in piglet pulmonary arteries. This is in accordance with previous results from our group (Villamor et al., 1996a), showing that the relaxant effects of $\mathrm{ACh}$ in these arteries were not modified by incubation with a $\mathrm{Mg}^{2-}$-free solution which also inhibits the activity of the pump.

\section{Possible mechanisms of reduced NO/cyclic GMP} relaxation in $U 46619$ pre-contracted arteries

We further investigated the mechanisms involved in the inhibition of the relaxant effects of SNP by U46619. Because both U46619 and ET- I inhibit several $\mathrm{K}^{-}$channels (Miyoshi et al., 1992; Scornik \& Toro, 1992) this effect might be mediating the inhibition of SNP-induced relaxation. However, as described above, $\mathrm{K}^{+}$channels do not appear to be involved in SNP. induced relaxation in pulmonary arteries. Furthermore, the inhibitory action of U46619 and ET-1 on $\mathrm{K}^{*}$ channels has been shown in porcine coronary artery myocytes (Miyoshi et al., 1992; Scornik \& Toro, 1992) which showed normal relaxation to SNP in our experiments.

G-protein linked membrane receptors for several vasoconstrictors including NA, thromboxane $\mathrm{A}_{2}\left(\mathrm{TXA}_{2}\right)$ and ET- $1\left(\alpha_{1}\right.$ adrenoceptors. TP and $\mathrm{ET}_{\mathrm{A}}$ receptors, respectively) are coupled with phospholipase C (Strader et al., 1995). Activated phospholipase C catalyzes hydrolysis of phosphoinositol 1,4,5diphosphate $\left(\mathrm{PIP}_{2}\right)$ into $\mathrm{IP}_{3}$. which releases $\mathrm{Ca}^{2-}$ from intracellular stores, and diacylglycerol, which activates PKC. In our experiments, activation of PKC by the phorbol ester PMA. alone or in combination with NA, inhibited the relaxant response to SNP, suggesting that one potential mechanism of inhibition of cyclic GMP-induced vasodilatation by U46619 might be related to the activation of PKC. This has also been shown in the rat aorta where SNP was more effective in relaxing methoxamine- than phorbol ester-induced contractions (Morrison \& Pollock, 1990). Staurosporine, a potent inhibitor of protein kinase C (Hidaka \& Kobayashi, 1992), did not modify the relaxant response to SNP in arteries precontracted by NA, but abolished the inhibition induced by U46619. Thus, these results suggest that U46619 may activate PKC and thus, inhibit the relaxant effects of cyclic GMP. Staurosporine also depressed the contractile response to U46619, indicating that inhibition of PKC might increase the sensitivity not only to stimulated cyclic GMP but also to basal cyclic GMP. ET-1 has been shown to stimulate the release of $\mathrm{TXA}_{2}$ in guinea-pig lung (De Nucci et al., 1988), so that ET-I might inhibit SNP-induced relaxation by releasing TXA . However, this was not the case in the present study, because the cyclo-oxygenase inhibitor meclofenamate did not change either the contractile effect of ET-1 or the relaxant effect of SNP.

\section{Implications of $\mathrm{TXA}_{2}, E T-1$ and impaired NO/cyclic GMP pathway in the pulmonary vascular bed}

The finding that U46619 inhibits the NO/cyclic GMP pathway in the pulmonary vasculature may help to explain why: (a) The induction of iNOS by endotoxin or Group B Streptococcus and the subsequent large increase in NO concentrations did not modify the contractile responses to $\mathrm{U} 46619$ in piglet isolated pulmonary arteries despite reducing the contractions to NA
(Villamor et al., 1996b; Pèrez-Vizcaino et al., 1996). (b) The administration of inhaled NO to piglets did not modify (10 p.p.m) (Weitzberg et al., 1993) or only slightly reduced (50 p.p.m) (Klemm et al.. 1995) the TXA -mediated early phase but inhibited the TXA $\mathrm{A}_{2}$-independent late phase of endotoxin-induced pulmonary hypertension (Weitzberg et al., 1993: Klemm et al., 1995). (c) In piglets with endotoxin-induced pulmonary hypertension, the administration of NO synthase inhibitors did not further increase pulmonary vascular resistance (Klemm et al., 1995; Weitzberg et al., 1995). (d) Inhaled NO (50 p.p.m) had no effect on the pulmonary hypertension induced by continuous i.v. administration of U46619 in dogs (Welte et al., 1995). In contrast, inhaled NO (5-80 p.p.m) inhibited U46619-induced vasoconstriction in sheep (Frostell et al., 1991). In our study, species-dependent differences were also observed, since U46619 inhibited the vasodilator effect of the NO donor SNP in piglet but not in rat pulmonary arteries.

Furthermore, our results showed that ET-I only impaired the NO/cyclic GMP induced relaxation when inducing a relatively high contraction. In addition, very high concentrations of ET-1 $\left(2 \times 10^{-\mathrm{k}} \mathrm{M}\right.$ and $\left.2 \times 10^{-7} \mathrm{M}\right)$ inhibited SNP. induced relaxation in human pulmonary arteries and veins but, in contrast to the present study, it decreased cyclic GMP synthesis (Pussard et al., 1995). To our knowledge it is not known if inhaled nitric oxide can reduce pulmonary hypertension induced by infusion of ET-1. However, the late phase of pulmonary hypertension induced by endotoxin in piglets, which has been related to increased production of ET-1 (Weitzberg et al., 1996), can be inhibited by inhaled NO (Weitzberg et al., 1993: Klemm et al., 1995). We have also recently demonstrated that iNOS induction by Group B Streptococci reduces the contractile responses to ET-1 (Villamor et al., 1996b).

Pulmonary hypertension is accompanied by an increase in pulmonary vascular resistances due to an imbalance between vasoactive mediators. Increased ET-1 and $T X A_{2}$ levels and decreased activity of $\mathrm{NO} /$ cyclic GMP are the most recognized mechanisms in the vasoconstrictor and vasodilator responses, respectively (see Introduction), It is becoming clear that no single mechanism can be responsible for the different clinical forms of pulmonary hypertension. Impairment of the NO/cyclic GMP pathway at the level of NO synthesis, activation of guanylate cyclase and/or the activity of cyclic GMP may depend on several factors, including the species, age and the factor causing the puimonary insult. Our results provide evidence for a novel mechanism of NO/cyclic GMP impairment mediated by PKC through TXA $\mathrm{A}_{2}$ receptor activation at the level of cyclic GMP activity. Inhaled NO has been shown to be effective in vasodilating the ventilated lung areas and improving gas exchange in newborn and adult patients with pulmonary hypertension (Kinsella et al., 1993; Falke, 1993; Abman \& Kinsella, 1995). However, about half of the patients do not respond to inhaled NO (Roberts et al.. 1997; Neonatal Inhaled Nitric Oxide Study Group, 1997). A possible theoretical explanation for this lack of response is an alteration of the smooth muscle responsiveness to NO (Cremona et al., 1991: Abman \& Kinsella, 1995). Because anatomical development of neonatal pig lung is similar to that of human lung and neonatal piglets have been widely used as an experimental model of pulmonary hypertension of the newborn (e.g. Gibson et al., 1987), it is tempting to speculate that an impairment of the NO/cyclic GMP pathway similar to that herein described may play a role in human nonresponders to inhaled NO. Understanding the precise mechanisms regulating the NO/cyclic GMP signalling under physiological and pathological conditions will certainly help in the therapeutic management of patients with puimonary hypertension.

In conclusion. piglet pulmonary arteries pre-contracted by the $\mathrm{TXA}_{2}$-mimetic U46619 showed reduced relaxant responses to the NO/cyclic GMP-pathway. This effect was not associated with changes in cyclic GMP content and was not observed in 
pigiet mesenteric or coronary arteries or in rat pulmonary arteries. SNP-induced relaxation in piglet pulmonary arteries was inhibited by the sarcoplasmic reticulum $\mathrm{Ca}^{2-}$-ATPase inhibitor thapsigargin (but not by inhibition of either the membrane $\mathrm{Na}^{*} / \mathrm{K}^{*}$-ATPase or $\mathrm{K}^{*}$ channels) indicating a role for $\mathrm{Ca}^{2+}$ uptake by the sarcoplasmic reticulum in these relaxant effects. The effects of U46619 on the relaxation of SNP could be abolished by inhibition of PKC, suggesting that PKC may be a part of signal transduction in the U46619-induced inhibitory effect.

The authors are grateful to C. Rivas for excellent technical assistance. This work was supported by a CICYT (SAF 96/0042) and FIS (95/0308 and 95/0318) Grants.

\section{References}

ABMAN, S.H., CHATFIELD, B., HALL. S.L. \& MCMURTRY, I.F (1990). Role of endothelium-derived releasing factor during the transition of the pulmonary circulation at birth. Am. J. Physiol., 259, H1921-H1927.

ABMAN, S.H. \& KINSELLA, J.P. (1995). Inhaled nitric oxide for persistent pulmonary hypertension of the newborn: The physiology matters! Pediatrics, 96, 1153-1155.

ARCHER, S.L., HUANG, J.M.C., HAMPL, V. NEISON, D.P., SHULTZ, P.J. \& WEIR, E.K. (1994). Nitric oxide and cyclic GMP cause vasorelaxation by activation of a charybdotoxin-sensitive $\mathbf{K}$ channel by cyclic GMP-dependent protein kinase. Proc. Natl. Acad. Sci. U.S.A., 91, 7583-7587.

BARNES, P.S. \& LIU, S.F. (1995). Regulation of pulmonary vascular tone. Pharmacol. Rev., 47, 87-131.

CODY, R.J., HASS, G.J., BINKLEY, P.F., CAPERS, Q. \& KELLEY, R. (1992). Plasma endothelin correlates with the extent of pulmonary hypertension in patients with congestive heart failure. Circulation, 85, 504-509.

CREMONA, G. DINH XUAN, A.T. \& HIGENBOTTAM, T.W. (199I). Endothelium-derived relaxing factor and the pulmonary circulation. Lung, 169, 185-202.

DE NUCC1, G., THOMAS, R., D'ORLEANS-JUSTE, P. ANTUNES, E. WALDER, C. WARNER, T \& VANE, J.R. (1988). Pressor effects of circulating endothelin are limited by its removal in the pulmonary circulation and by the release of prostacyclin and endothelium-derived relaxing factor. Proc. Natl, Acad. Sct. U.S.A., 85, $9797-9800$.

DINH-XUAN, A.T, HIGENBOTTAM, W. CLELLAND, T.W., PEPKE. ZABA, J.CREMONA, G. BUTT, A.Y., LARGE, S.R., WELLS, F.C. \& WALLWORK, J. (1991). Impairment of endothelium-dependent pulmonary-artery relaxation in chronic obstructive lung disease. N. Engl. J. Med., 324, 1539-1547

DOBYNS, E.L. WESCOTT, J.Y. KENNAUGH, J M ROS, M.N \& STENMARK. K.R. (1994). Eicosanoids decrease with successful extracorporeal membrane oxygenation therapy in neonatal pulmonary hypertension. Am. J. Respir. Crit. Care Med., 149, $873-880$

FALKE. K.J. (1993). Long term inhalation with evaluated low doses of nitric oxide for selective improvement of oxygenation in patients with adult respiratory distress syndrome. Intensive Care Med., 19, 443-449.

FERRER, M., ENCABO, A., CONDE, M.V, MARIN, J. \& BALFAGON G. (1995). Heterogeneity of endothelium-dependent mechanisms in different rabbit arteries. $J$. Vasc, Res., 32, 339-346.

FROSTELL. C., FRATACCI, M.D. WAIN, J.C., JONES, R. \& ZAPOL. W.M. (1991). Inhaled nitric oxide. A selective pulmonary vasodilator reversing hypoxic pulmonary vasoconstriction. Circulation, 83, 2038-2047.

GARCIA-SZABO, R.R., JOHNSON, A. \& MALIK, A.B. (1988). Thromboxane increases pulmonary vascular resistance and transvascular fluid and protein exchange after pulmonary microembolism. Prostaglandins, 35, 707-721.

GIAID, A. \& SALEH. D. (1995), Reduced expression of endothelial nitric oxide synthase in the lungs of patients with pulmonary hypertension. N. Engl. J. Med., 333, 214-221.

GIAID, A., YANAGISAWA, M. LANGLEBEN, D., MICHEL, R.P. LEVY, R. SHENNIB, H, KIMURA, S. MASAKI, T, DUGUID, W.P. \& STEWART, DJ. (1993). Expression of endothelin-1 in the lungs of patients with pulmonary hypertension. N. Engl. J. Med., 328, $1732-1739$

GIBSON, R.L. TRUOG, W.E. \& REDDING, G.J. (1987). Thromboxane-associated pulmonary hypertension during three types of Gram-positive bacteriemia in piglets. Pediatr. Res., 23, 553-556.

HIDAKA. H. \& KOBAYASHI. R. (1992). Pharmacology of protein kinase inhibitors: Annu. Rev. Pharmacol. Toxicol., 32, 377-397.
HIRATA, M., KOHSE, K.P., CHANG, C.H., IKEBE, T. \& MURAD, R. (1990). Mechanism of cyclic GMP inhibition of inositol phosphate formation in rat aorta segments and cultured bovine aortic smooth muscle cells. J. Biol. Chem., 265, 1268-1273.

IGNARRO, L.J. BYRNS, R.E. \& WOOD. K.S. (1987). Endotheliumdependent modulation of cyclic GMP levels and intrinsic smooth muscle tone in isolated bovine intrapulmonary artery and vein. Circ. Res., 60, 89-92.

IGNARRO, L.J., HARBISON, R.G., WOOD, K.S. \& KADOWITZ, P.J (1986). Dissimilarities between methylene blue and cyanide on relaxation and cyclic GMP formation in endothelium-intact intrapuimonary artery caused by nitrogen oxide-containing vasodilators and acetylcholine, J. Pharmacol. Exp. Ther., 236, $30-36$.

KINSELL.A, J.P., NEISH, S.R., IVY, D.D., SCHAFFER, E. \& ABMAN. S.H. (1993). Clinical responses to prolonged treatment of persistent pulmonary hypertension of the newborn with low doses of inhaled nitric oxide. J. Pediatr., 123, 103-108.

KLEMM. P.. THIEMMERMAN, C., WINKLMAIER, G., MARTORANA. P.A. \& HENNING. R. (1995). Effects of nitric oxide synthase inhibition combined with nitric oxide inhalation in a porcine model of endotoxic shock. Br. J. Pharmacol., 114, 363-368.

KOWALUK. E.A., SETH. P. \& FUNG. H.-L. (1992). Metabolic activation of sodium nitroprusside to nitric oxide in vascular smooth muscle, J. Pharmacol. Exp. Ther., 262, 916-922.

L.EVY, M. TULLOH, R.M. KOMAI, H., STUART-SMITH, K. \& HAWORTH, S.G. (1995). Maturation of the contractile response and its endothelial modulation in newborn porcine intrapulmonary arteries. Pedriatr. Res., 38, $25-29$.

LINCOLN, T.M., CORNWELI. T.L. \& TAYLOR, A.E (1990), cyclic GMP-dependent protein kinase mediates the reduction of $\mathrm{Ca}^{2+}$ by cAMP in vascular smooth muscle cells. Am. J. Physiol., 258, C399-C407

LINCOLN, T.M., KOMALAVILAS, P. \& CORNWELL, T.L. (1994). Pleiotropic regulation of vascular smooth muscle tone by cyclic GMP-dependent protein kinase, Hypertension, 23, 1141-1147.

LUO, D.-L. NAKAZAWA, M., ISHIBASHI, T. KATO, K. \& IMAI, S (1993). Putative, selective inhibitors of sarcoplasmic reticulum $\mathrm{Ca}$ * pump ATPase inhibit relaxation by nitroglycerin and atrial natriuretic factor of the rabbit aorta contracted by phenylephrine. J. Pharmacol. Exp. Ther., 265, 1187-1192.

MCQUESTON, J.A. KINSELL.A, J.P., IVY, D.D., MCMURTRY. I.F. \& ABMAN, S.H. (1995). Chronic pulmonary hypertension in utero impairs endothelium-dependent vasodilation. Am. J. Physiol., 268, H288- H294.

MIYOSHI, Y., NAKAYA, Y. WAKATSUKI, T., NAKAYA, S, FUINO K., SAITO, K. \& INOUE, I. (1992). Endothelin blocks ATP. sensitive $K^{*}$ channels and depolarizes smooth muscle cells of porcine coronary artery. Circ. Res., 70, 612-616.

MONCADA, S. PALMER, R.M J. \& HIGGS, E.A. (1991). Nitric oxide: Physiology, pathophysiology, and pharmacology. Pharmacol. Rev., 43, $109-142$.

MONTALESCOT, G. LOWENSTEIN, E., OGLETREE, M.L. GREENE, E.M. ROBINSON, D.R.. HARTL, K. \& ZAPOL. W.M. (1990). Thromboxane receptor blockade prevents pulmonary hypertension induced by heparin-protamine reactions in awake sheep. Circulation, 82, 1765-1777.

MORRISON, K.J. \& POLLOCK. D. (1990). Impairment of relaxations to acetylcholine and nitric oxide by a phorbol ester in rat isolated aorta. Br. J. Pharmacol., 101, 432-436.

NEONATAL INHALED NITRIC OXIDE STUDY GROUP. (1997). Inhaled nitric oxide in full-term and nearly full-term infants with hypoxic respiratory failure. New Engl. J. Med., 336, 597-604 
NOONAN, TC \& MALIK, A.B. (1986). Pulmonary vascular response to leukotriene $\mathrm{D}_{4}$ in unanesthetized sheep: Role of thromboxane. J. Appl, Physiol., 60, 765-769.

OHGUSHI, M., YASUE, H., KUGIYAMA, K., MUROHARA, T. \& SAKAINO, N (1993). Contraction and endothelium-dependent relaxation via alpha adrenoceptors are variable in various pig arteries. Cardiovasc, Res., 27, $779-784$.

PEPKE-ZABA, J., HIGENBOTTAM, T.W., DINH-XUAN, A.T., RID DEN, C. \& KEALEY, T. (1993). Alpha-adrenoceptor stimulation of porcine pulmonary arteries. Eur. J. Pharmacol., 235, 169-175.

PEREZ VIZCAINO, F., VILLAMOR, E., FERNANDEZ DEL POZO, B. MORO. M. \& TAMARGO. J. (1996). Lack of endotoxin-induced hyporesponsiveness to U46619 in isolated neonatal porcine pulmonary but not mesenteric arteries. J. Vasc. Res., 33, 249257.

PUSSARD, G., GASCARD, J.P., GORENNE, I., LABAT, C., NOREL, X. DULMET, E. \& BRINK, C. (1995). Endothelin-1 modulates cyclic GMP production and relaxation in human puimonary vessels. $J$. Pharmacol. Exp. Ther., 274, 969-975.

RAPOPORT, R.M., SCHWARTZ, K. \& MURAD, F. (1985). Effect of sodium-potassium pump inhibitors and membrane-depolarizing agents on sodium nitroprusside-induced relaxation and cyclic guanosine monophosphate accumulation in rat aorta. Circ. Res. 57, $164-170$.

RASHATWAR, S.S., CORNWEL1, T.L \& UNCOLN, T.M. (1987) Effects of 8-bromo-cyclic GMP on $\mathrm{Ca}^{2+}$ levels in vascular smooth muscle cells: Possible regulation of $\mathrm{Ca}^{2+}$-ATPase by cyclic GMP-dependent protein kinase. Proc. Natl. Acad. Sci. U.S.A., 84, 5685-5689.

ROBERTS, J.D., FINEMAN, J.R., MORIN III, F.C., SHAUL, P.W. RIMAR, S.. SCHREIBER, M.D., POLIN, R.A., ZWASS, M.S., ZAYEC, M.M., GROSS, I. HEYMANN. M.A. \& ZAPOL, W.M. (1997). Inhaled nitric oxide and persistent pulmonary hypertension of the newborn. New Engl, J. Med., 336, 605-610.

ROSENBERG, A.A., KENNAUGH, J., KOPPENHAFER, S.L., LOOMIS, M. \& ABMAN, S.H. (1993). Elevated immunoreactive endothelin-1 levels in infants with persistent pulmonary hypertension of the newborn. J. Pediatr., 123, $109-114$.

SCORNIK, F.S. \& TORO, L. (1992), U46619, a thromboxane $A_{2}$ agonist, inhibits $\mathrm{K}_{\mathrm{C}_{a}}$ channel activity from pig coronary artery Am. J. Physiol., 262, C708-C713.

SEAMON, K.B. \& DALY, J.W. (1986). Forskolin: Its biological and chemical properties. Adv. Cyclic Nucleotide Res., 20, 1-150.

STRADER, C.D. FONG, T.M., GRAZIANO, M.P. \& TOTA, M.R. (1995). The family of G-protein-coupled receptors. FASEB J., 9, 745754.
THASTRUP, O., CULLEN, P.J. DROBAK, B.K , HANLEY, M.R \& DAWSON. A.P. (1990). Thapsigargin, a tumor promoter, discharges intracellular $\mathrm{Ca}^{2+}$ stores by specific inhibition of the endoplasmic reticulum $\mathrm{Ca}^{2}{ }^{2}$ ATPase. Proc. Natl. Acad. Sci. U.S.A., 87, 2466-2470.

VILLAMOR, E. PEREZ-VIZCAINO, F., RUIZ, T. TAMARGO, J. \& MORO. M. (1996a). In vitro effects of magnesium sulfate in isolated intrapulmonary and mesenteric arteries of piglets. Pediatr. Res., 39, 1107-1112.

VILLAMOR, E, PEREZ-VIZCAINO, F., TAMARGo, 1 \& MORO, M (1996b). Effects of group B Streptococcus on the responses to U46619, endothelin-1 and noradrenaline in isolated puimonary and mesenteric arteries of piglets. Pediatr. Res., 40, 827-833.

WARNER, T.D., MITCHELL, J.A., SHENG, H. \& MURAD, F. (1994) Effects of cychic GMP on smooth muscle relaxation. Adv. Pharmacol., 26, 171-194.

WEITZBERG, E., HEMSEN, A., RUDEHIL.., A., MODIN, A., WANE. CEK, M. LUNDBERG, J.M. (1996). Bosentan-improved cardiopulmonary vascular performance and increased plasma levels of endothelin-1 in porcine endotoxin shock. Br. J. Pharmacol., 118, 617-626.

WEITZBERG, E., LUNDBERG, J.M \& RUDEHILL, A (1995) Inhibitory effects of diclofenac on the endotoxin shock response in relation to endothelin turnover in the pig. Acta Anaesthesiol. Scand., 39, 50-59.

WEITZBERG, E., RUDEHILL. A. \& LUNDBERG, J.M. (1993). Nitric oxide inhalation attenuates puimonary hypertension and improves gas exchange in endotoxin shock. Eur. J. Pharmacol., 233, $85-94$.

WELTE, M., ZWISSLER, B., HABLER, O., KLEEN, M. \& MESSMER, K (1995). Prostacyclin aerosol and inhaled nitric oxide fail to reverse pulmonary vasoconstriction induced by thromboxane analogue in dogs. Acta Physiol. Scand., 154, 395-405.

YOSHIBAYASHI, M., NISHIOKA, K., NAKAO, K., SITO, Y., MATSUMURA, M., UEDA, T. TEMA, S., SHIRAKAMI, G., IMURA, H. \& MIKAWA, H. (1991). Plasma endothelin concentrations in patients with puimonary hypertension associated with congenital heart disease. Circulation, 84, 2280-2285.

ZAMORA, C.A., BARON, D.A. \& HEFFNER, J.E. (1993). Thromboxane contributes to pulmonary hypertension in ischaemia-reperfusion lung injury. J. Appl. Physiol., 74, 224-229.

ZIEGLER, J.P., IVI, D.D., FOX, J.J., KINSELLA. J.P. CLARKE, W.R. \& ABMAN, S.H. (1995). Dipirydamole, a cGMP phosphodiesterase inhibitor, causes pulmonary vasodilation in the ovine fetus. $\mathrm{Am}$. J. Physiol., 269, H473-479. 

Chapter XI. Pulmonary versus systemic effects of vasodilator drugs: an in vitro study in isolated intrapulmonary and mesenteric arteries of neonatal piglets. (Eur J Pharmacol. 1996; 314:91-8). 



\title{
Pulmonary versus systemic effects of vasodilator drugs: an in vitro study in isolated intrapulmonary and mesenteric arteries of neonatal piglets
}

\author{
F. Pérez-Vizcaíno ${ }^{\text {a. }}$, E. Villamor ${ }^{\text {b }}$, M. Moro ${ }^{\text {b }}$, J. Tamargo a \\ "Department of Pharmacology, Institute of Pharmacology and Toxicology, School of Medicine, Universidad Complutense, 28040 Madrid, Spain \\ 'Disision of Neonatology, Department of Pediatrics, Hospital Universitario San Carlos. 28040 Madrid. Spain
}

Received 11 January 1996; revised 20 June 1996; accepted 9 July 1996

\begin{abstract}
The ability of several vasodilators to inhibit the responses to noradrenaline and U46619 (a thromboxane $A_{2}$ analog) in isolated pulmonary and mesenteric arteries of neonatal piglets was compared. In pulmonary arteries, acetylcholine produced endothelium-dependent relaxations $\left(\mathrm{pIC}_{30}=\right.$ about 6.8$)$ while, in mesenteric arteries, a relaxant $\left(\leq 10^{-7} \mathrm{M}\right)$ or a contractile response $\left(\geq 10^{-6} \mathrm{M}\right)$ was observed. Sodium nitroprusside produced relaxant effects in pulmonary and mesenteric arteries contracted by noradrenaline ( $\mathrm{plC} \mathrm{S}_{\mathrm{s}_{0}}=6.6$ and 6.0, respectively) and $U 46619$ ( $\mathrm{plC}_{50}=5.4$ and 6.7, respectively). ATP induced an endothelium-independent relaxation in pulmonary arteries ( $\mathrm{plC}_{50}=$ about 4 ) but in mesenteric arteries it produced weak relaxant effects. In resting mesenteric arteries, ATP induced a concentration-dependent contraction which was not observed in pulmonary arteries. Prostaglandin $E_{1}$ induced a concentration-dependent relaxation in pulmonary arteries ( $\mathrm{plC}_{50}=$ about 6 ). In mesenteric arteries, prostaglandin $\mathrm{E}_{1}$ at $<10^{-6} \mathrm{M}$ produced a contractile effect whereas, at higher concentrations, a relaxant response was observed. The $\alpha$-adrenoceptor antagonist tolazoline had no effect on arteries contracted by $U 46619$ but relaxed arteries contracted by noradrenaline being slightly more potent in mesenteric than in pulmonary arteries $\left(\mathrm{plC}_{50}=5.1\right.$ and 4.8. respectively). Nifedipine $\left(>10^{-7} \mathrm{M}\right)$ relaxed both arteries, mesenteric being more sensitive than pulmonary arteries and noradrenaline more sensitive than U46619-induced contractions. In conclusion, differences in the relaxant effects for all vasodilators were found depending on the artery, the vasoconstrictor used or both. However. ATP was the only drug which, regardless of the concentration or vasoconstrictor used, produced greater relaxant effects in pulmonary than in mesenteric anteries.
\end{abstract}

Keywords: Pulmonary artery: Prostaglandin $E_{1} ;$ ATP; Acetylcholine: Tolazoline; Nifedipine: Sodium nitroprusside

\section{Introduction}

The normal adult pulmonary circulation is a low pressure, low resistance circuit (Bames and Liu, 1995). In contrast, in the fetus, gas exchange occurs in the placenta and not in the lung and, therefore, right ventricular cardiac output is directed through the ductus arteriosus to the systemic circulation. Consequently, the fetal pulmonary vascular resistance is high and the pulmonary blood flow is low (Fineman et al., 1995). The transition from the fetal to the adult pulmonary circulation in the perinatal period is a delicate process which takes place at birth and in the following weeks (Fineman et al., 1995). Failure of the pulmonary circulation to undergo this transition results in persistent pulmonary hypertension of the newborn. Persis-

\footnotetext{
Corresponding author. Tel: (34-1) 394-1472: Fax: (34-1) 394-1470.
}

tent pulmonary hypertension of the newborn is characterized by an increased pulmonary vascular resistance resulting in right to left shunting of blood across a patent foramen ovale and/or ductus arteriosus, severe hypoxemia and acidosis (Roberts and Shaul, 1993). Various intravenous vasodilators including the $\alpha$-adrenoceptor blocker tolazoline (Stevenson et al., 1979; Ward, 1984; Gouyon and Francoise, 1992), prostaglandins $I_{2}$ and $E_{1}$ (Gouyon and Francoise, 1992), the $\mathrm{Ca}^{2+}$ channel blocker nifedipine (Simmoneau et al., 1981), $\mathrm{MgSO}_{4}$ (Abu-Osba et al., 1992). acetylcholine (Tripp et al.. 1980), the nitric oxide donor sodium nitroprusside (Benitz et al., 1985) and ATP (Fineman et al., 1990; Konduri and Woodard, 1991) have been used to reduce the increased pulmonary vascular resistance (Drummond and Lock, 1984; Kulik and Lock, 1984: Gouyon and Francoise, 1992; Roberts and Shaul. 1993). Since the magnitude of the shunt depends on the difference between pulmonary antery and aortic pressure, systemic vasodilation would increase the flow across the ductus 
reducing the blood supply to the lung and worsening the pulmonary gas exchange. Therefore, the ideal drug for the treatment of persistent pulmonary hypertension of the newbom should be a vasodilator with selectivity for pulmonary over systemic vessels (Roberts and Shaul, 1993; Drummond and Lock, 1984). Recently, the direct delivery of drugs to the lung by inhalation or endotracheal administration has been tested successfully in human newborns with nitric oxide (NO, Roberts et al., 1992; Kinsella et al., 1992) and tolazoline (Welch et al., 1995) and in animal experimental models with cGMP analogs (Lawson et al., 1995) and prostaglandin $I_{2}$ (Zobel et al., 1995) which reduce pulmonary artery pressure with minimum systemic effects. This strategy has the additional advantage that the best ventilated areas of the lung are those receiving higher concentrations of drugs and, therefore, those areas will receive higher flow allowing a higher gas exchange. However, this approach is not extensively available yet and may have other undesirable effects, particularly in chronic treatment.

The neonatal circulatory system responds quite differently to drugs than does the mature circulation but the effects of vasodilators in pulmonary neonatal vessels have been poorly investigated (Fineman et al., 1995). Therefore, the aim of the present work was to compare the ability of several vasodilators to inhibit the responses to noradrenaline and the thromboxane $A_{2}$ mimetic U46619 in the isolated pulmonary and mesenteric arteries of neonatal piglets.

\section{Materials and methods}

\subsection{Tissue preparation}

Male piglets (10-17 days of age, $4679 \pm 267 \mathrm{~g}$ ) obtained from the local abattoir were killed by exsanguination and the lungs and mesenteric beds were rapidly immersed in cold $\left(4^{\circ} \mathrm{C}\right)$ Krebs solution (composition in $\mathrm{mM}: \mathrm{NaCl}$ 118, $\mathrm{KCl}$ 4.75, $\mathrm{NaHCO}_{3} 25, \mathrm{MgSO}_{4}$ 1.2, $\mathrm{CaCl}_{2}$ 2.0, $\mathrm{KH}_{2} \mathrm{PO}_{4} 1.2$ and glucose 11) and transported immediately to the laboratory. Pulmonary and mesenteric arteries (i.d. 1-2 mm) were carefully dissected free of surrounding tissue and cut into rings of 2-3 mm of length (Pérez-Vizcaíno et al., 1994; Villamor et al., 1995). Two L-shaped stainless-steel wires were inserted into the arterial lumen and the rings were introduced in Allhin organ chambers filled with Krebs solution (gassed with $95 \% \mathrm{O}_{2}$ and $5 \% \mathrm{CO}_{2}$ at $37^{\circ} \mathrm{C}$ ). One wire was attached to the chamber and the other to an isometric force-displacement transducer coupled to a signal amplifier (model PRE 206-4; Cibertec, Madrid. Spain) and connected to a Hewlett Packard computer via an A/D interface. Contractile tension was recorded by a REGXPC computer program (Cibertec). The rings were initially stretched to a resting tension of $0.5 \mathrm{~g}$ (pulmonary rings) or $2 \mathrm{~g}$ (mesenteric rings) and allowed to equilibrate for 60-90 min. During this period, tissues were re-stretched and washed every 30 min with warm Krebs solution. In some experiments, the endothelium was removed by gently rubbing the intimal surface of the rings with a metal rod. The presence of functional endothelium was tested by addition of acetylcholine $\left(10^{-7} \mathrm{M}\right)$ in arteries pre-contracted with $3 \times 10^{-7}$ $\mathrm{M}$ noradrenaline. The ability of acetylcholine to induce relaxation of unrubbed rings was taken as an indicator of the presence of functional endothelium.

\subsection{Experimental protocol}

After equilibration, the rings were contracted with either $10^{-5} \mathrm{M}$ noradrenaline or $10^{-6} \mathrm{M} \mathrm{U} 46619$. When the contractile response to each agonist reached a stable tension, cumulative concentration-response curves to acetylcholine, ATP, prostaglandin $E_{1}$, sodium nitroprusside, nifedipine and tolazoline were carried out by cumulative addition of drugs after a steady-state relaxant response was reached after each increment. In some arteries, the effects of vasodilators were evaluated in the presence of the nitric oxide synthase inhibitor $N^{\mathrm{G}}$-nitro-L-arginine-methyl ester (L-NAME, $10^{-4} \mathrm{M}$ ) or in endothelium-denuded arteries. In another set of rings, the vasoconstrictor effects of ATP were tested in endothelium intact arteries under resting conditions.

\subsection{Drugs}

The following drugs were used: (-)-noradrenaline bitartrate, acetylcholine chloride, L-NAME, sodium nitroprusside, U46619, prostaglandin $\mathrm{E}_{1}$, ATP- $\mathrm{MgCl}_{2}$, tolazoline hydrochloride (Sigma, London, UK) and nifedipine (Bayer, Leverkusen, Germany). Drugs were dissolved in deionized distilled water (except nifedipine in absolute ethanol) and further dilutions were carried out in Krebs solution. Noradrenaline $\left(10^{-2} \mathrm{M}\right)$ was dissolved in $10^{-4}$ $\mathrm{M}$ ascorbic acid to prevent oxidation. The concentrations are expressed as final molar concentration in the tissue chamber.

\subsection{Statistical analysis}

Results are expressed as mean \pm S.E.M. of measurements in $n$ arteries. The vasoconstrictor and vasodilator responses were expressed in $\mathrm{mg}$ and as a percentage of the pre-contraction value, respectively. Individual cumulative concentration-response curves were fitted to a logistic equation. For the concentration-response of vasoconstrictors, the maximal effect $\left(E_{\max }\right)$ and the drug concentration exhibiting $50 \%$ of the $E_{\max }\left(\mathrm{pD}_{2}\right.$, expressed as negative log molar) were calculated. For vasodilators, the negative $\log$ drug concentrations producing a $50 \%$ relaxation of the control contraction ( $\mathrm{pIC}_{50}$ values) were calculated. Statistically significant differences were calculated by means of 
an unpaired Student's $t$-test. $P<0.05$ was considered statistically significant.

\section{Results}

\subsection{Effects of noradrenaline and U46619}

The parameters of the concentration-response curves to noradrenaline $\left(10^{-8}-10^{-4} \mathrm{M}\right)$ and U46619 $\left(10^{-10}-10^{-6}\right.$ $M)$ in pulmonary and mesenteric arteries are shown in Table 1. The maximal response $\left(E_{\max }\right)$ to both noradrenaline and U46619 was significantly greater in mesenteric than in pulmonary arteries $(P<0.01)$. In mesenteric arteries. noradrenaline induced greater maximal contractions than U46619 but the opposite occurred in pulmonary arteries. The $\mathrm{pD}_{2}$ values for $\mathrm{U} 46619$-induced contractions were similar in both arteries $(P>0.05)$ whereas the $\mathrm{pD}_{2}$ value to noradrenaline was greater in mesenteric than in pulmonary arteries $(P<0.05)$. The effects of vasodilators reported below were analyzed on the contractions induced by near-maximally effective concentrations of noradrenaline $\left(10^{-5} \mathrm{M}\right)$ and $\mathrm{U} 46619\left(10^{-6} \mathrm{M}\right)$.

\subsection{Vasodilator effects of acetylcholine}

Addition of acetylcholine $\left(10^{-8}-10^{-5} \mathrm{M}\right)$ resulted in a concentration-dependent relaxation in pulmonary arteries pre-contracted with noradrenaline and U46619 (Fig. 1, Table 2). The relaxant effects of acetylcholine were more pronounced in arteries pre-contracted with noradrenaline as compared to $\mathrm{U} 46619(P<0.01)$, so that acetylcholine fully relaxed arteries contracted by noradrenaline even when in arteries contracted by $\mathrm{U} 46619$ the maximal relaxation achieved was only $53 \pm 5 \%$. This relaxant effect was inhibited when the arteries were pre-treated with $10^{-4} \mathrm{M}$ L-NAME or in endothelium-denuded arteries (not shown).

In mesenteric arteries, pre-contracted with either noradrenaline or U46619 the effects of acetylcholine were biphasic (Fig. 1). At $10^{-8}$ and $10^{-7} \mathrm{M}$. it produced a relaxant response (of similar magnitude than in pulmonary arteries pre-contracted with noradrenaline). However, when the concentration of acetylcholine was increased $\left(\geq 10^{-6}\right.$ $M)$, it produced a concentration-dependent contraction in mesenteric arteries that, at $10^{-5} \mathrm{M}$, averaged $23 \pm 13$ and $64 \pm 32 \%$ over control tension in noradrenaline- and U46619-contracted vessels, respectively.

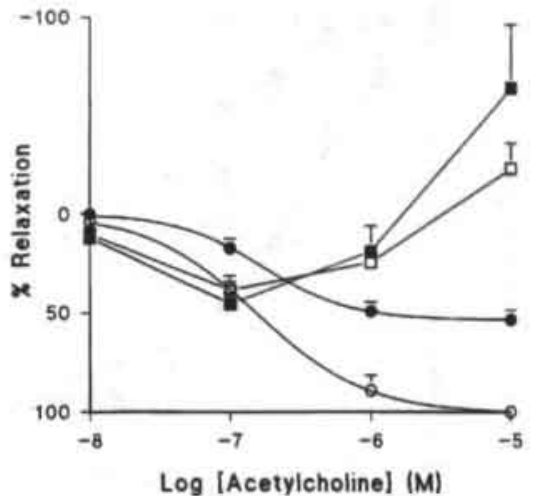

Fig. 1. Relaxant effects of cumulative addition of acetylcholine on pulmonary (circles) and mesenteric arteries (squares) pre-contracted with $10^{-5} \mathrm{M}$ noradrenaline (open symbols) or $10^{-6} \mathrm{M}$ U46619 (solid symbols) of neonatal piglets. Results are expressed as mean \pm S.E.M. of 5-10 experiments. Abscissa, \& relaxation; ordinate, log acetylcholine concentration (M).

\subsection{Vasodilator effects of sodium nitroprusside}

The relaxant effect of sodium nitroprusside $\left(10^{-8}-10^{-4}\right.$ M) was tested in endothelium-denuded arteries. Sodium nitroprusside induced a concentration-dependent relaxation in pulmonary and mesenteric arteries (Fig. 2). However, there were differences in the relaxant potency depending on the artery and the vasoconstrictor employed. Pulmonary anteries contracted by noradrenaline and mesenteric arteries contracted by U46619 were the most sensitive to sodium nitroprusside whereas pulmonary anteries contracted by U 46619 were the least (Table 2). Furthermore. sodium nitroprusside was unable to fully relax U46619-induced contractions in pulmonary arteries, so that the highest concentration tested $\left(10^{-4} \mathrm{M}\right)$ produced a maximal relaxation of $64 \pm 5 \%$

\subsection{Vasodilator effects of ATP and effects on resting tension}

ATP $\left(10^{-6}-10^{-3} \mathrm{M}\right)$ induced a concentration-dependent relaxation in pulmonary arteries contracted by either noradrenaline or U46619 $(P>0.05$ noradrenaline vs. U46619; Fig. 3). However, in mesenteric arteries contracted by noradrenaline. ATP produced only a weak relax-

Table I

Parameters $\left(\mathrm{pD}_{2}\right.$ and $\left.E_{\max }\right)$ of the concentration-response curves to noradrenaline and $U 46619$ in pulmonary and mesenteric arteries

\begin{tabular}{|c|c|c|c|c|c|c|}
\hline & \multicolumn{3}{|c|}{ Pulmonary arteries } & \multicolumn{3}{|c|}{ Mesenteric arteries } \\
\hline & $\mathrm{pD}_{2}$ & $E_{\max }(\mathrm{mg})$ & $n$ & $\mathrm{pD}_{2}$ & $E_{\max }(m g)$ & $n$ \\
\hline Noradrenaline & $6.52 \pm 0.07$ & $923 \pm 80$ & 17 & $6.07 \pm 0.11^{\circ}$ & $5273 \pm 718^{b}$ & 8 \\
\hline U46619 & $7.31 \pm 0.15^{d}$ & $1279^{\circ} \pm 145^{\circ}$ & II & $7.11 \pm 0.13$ & $2083 \pm 285=4$ & 7 \\
\hline
\end{tabular}

"and ${ }^{b} P<0.05$ and $P<0.01$ mesenteric vs, pulmonary arteries. "and ${ }^{d} P<0.05$ and $P<0.01$ noradrenaline vs. U46619, respectively. 


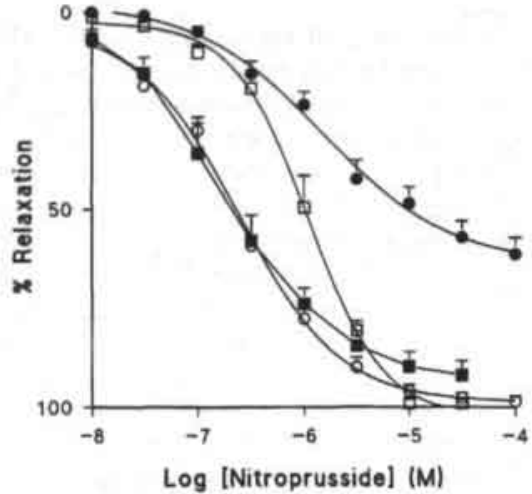

Fig. 2. Relaxant effects of cumulative addition of sodium nitroprusside on pulmonary (circles) and mesenteric arteries (squares) pre-contracted with $10^{-5} \mathrm{M}$ noradrenaline (open symbols) or $10^{-6} \mathrm{M}$ U46619 (solid symbols) of neonatal piglets. Results are expressed as mean \pm S.E.M. of 7-9 experiments. Abscissa, \% relaxation: ordinate, log nitroprusside concentration (M).

ant effect whereas, in those contracted with U46619, a biphasic effect was observed. At concentrations of $\leq 10^{-4}$ M. ATP produced a relaxant effect while, at higher concentrations, a progressive increase in contractile force was observed, so that at the highest concentration tested reached tension values similar to control values. The effects of ATP were also tested in endothelium-denuded pulmonary arteries and in rings pre-treated for 20 min with L-NAME and then contracted by U46619. In both cases, ATP produced a relaxant effect similar to that observed in control endothelium intact pulmonary arteries (not shown).

Increasing concentrations of ATP $\left(10^{-8}-10^{-3} \mathrm{M}\right)$ produced minimal or no effect in resting pulmonary arteries $(n=6$; Fig. 4). In contrast, in mesenteric arteries, ATP ( $\geq 10^{-6} \mathrm{M}$ ) produced a concentration-dependent contraction $(n=5$; Fig. 4). These contractions were fast but

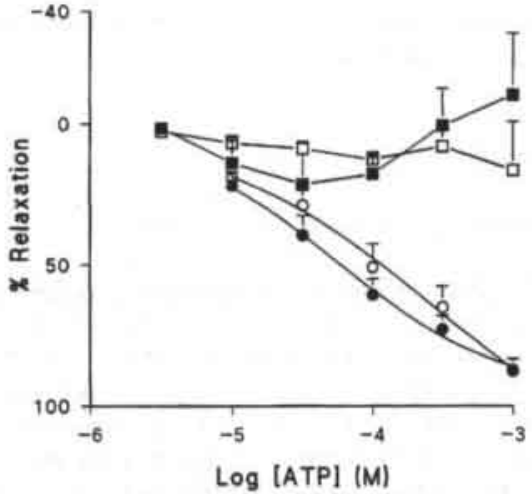

Fig. 3. Relaxant effects of cumulative addition of ATP on pulmonary (circles) and mesenteric arteries (squares) pre-contracted with $10^{-5} \mathrm{M}$ noradrenaline (open symbols) or $10^{-6} \mathrm{M} \mathrm{U} 46619$ (solid symbols) of neonatal piglets. Results are expressed as mean \pm S.E.M. of 5-7 expenments. Abscissa. \% relaxation; ordinate, log ATP concentration (M).

transient, reaching a peak in about 1-2 min and were followed by a slower decay to a lower tone.

\subsection{Vasodilator effects of prostaglandin $E_{J}$}

Addition of prostaglandin $\mathrm{E}_{1}\left(10^{-8}-10^{-5} \mathrm{M}\right)$ to pulmonary arteries resulted in a concentration-dependent relaxation (Fig. 5). The maximal relaxant effect was greater when the pulmonary arteries were contracted by noradrenaline than by $\mathrm{U} 46619(P<0.05$; Table 2$)$. In mesenteric arteries, the response to prostaglandin $\mathbf{E}_{1}$ was biphasic. At low concentrations, prostaglandin $E_{1}$ produced a contractile effect which was maximum at $10^{-7}-3 \times 10^{-7}$ $M$ while, at higher concentrations, prostaglandin $E_{1}$ produced a relaxant effect, so that, at $10^{-5} \mathrm{M}$, it produced almost full relaxation when the arteries were contracted by noradrenaline but only $41 \pm 11 \%$ when contracted by U46619.

Table 2

Parameters of the concentration-response curves to acetylcholine, sodium nitroprusside, ATP. prostaglandin $\mathrm{E}_{1}$ and tolazoline calculated from Figs. 1-3 and 5-7

\begin{tabular}{|c|c|c|c|c|c|c|c|c|c|c|c|c|}
\hline & \multicolumn{6}{|c|}{ Pulmonary anteries } & \multicolumn{6}{|c|}{ Mesenteric arteries } \\
\hline & \multicolumn{3}{|c|}{ Noradrenaline } & \multicolumn{3}{|l|}{ U46619 } & \multicolumn{3}{|c|}{ Noradrenaline } & \multicolumn{3}{|l|}{ U46619 } \\
\hline & $\mathrm{plC}_{90}$ & $\operatorname{Max}(\%)$ & $n$ & $\mathrm{plC}_{90}$ & $\operatorname{Max}(\%)$ & $n$ & $\mathrm{plC}_{90}$ & $\operatorname{Max}(\%)$ & $n$ & $\mathrm{plC}_{50}$ & $\operatorname{Max}(\%)$ & $n$ \\
\hline Acerylcholine & $6.8 \pm 0.2$ & $101 \pm 2$ & 5 & $5.9 \pm 0.4^{d}$ & $53 \pm 5^{d}$ & 5 & B.E. & B.E. & 7 & B.E. & B.E. & 8 \\
\hline Nitroprusside & $6.6 \pm 0.1$ & $100 \pm 1$ & 9 & $5.4 \pm 0.3^{d}$ & $61 \pm 4^{4}$ & 9 & $6.0 \pm 0.1^{b}$ & $106 \pm 4$ & 7 & $6.7 \pm 0.2$ b.e & $92 \pm 4$ & 7 \\
\hline ATP & $3.9 \pm 0.2$ & $87 \pm 4$ & 6 & $4.1 \pm 0.1$ & $87 \pm 4$ & 7 & N.E. & N.E. & 7 & N.E. & N.E. & 7 \\
\hline Prostaglandin $\mathrm{E}_{\mathrm{i}}$ & $6.1 \pm 0.1$ & $96 \pm 3$ & 9 & $5.7 \pm 0.2$ & $67 \pm 6^{d}$ & 10 & $5.8 \pm 0.1$ & $87 \pm 7$ & 8 & $>5$ & $41 \pm 11^{b, d}$ & 7 \\
\hline Tolazoline & $4.8 \pm 0.1$ & $91 \pm 3$ & 7 & N.E & N.E. & 7 & $5.1 \pm 0.1^{2}$ & $88 \pm 3^{2}$ & 7 & N.E. & N.E. & 5 \\
\hline Nifedipine & $5.0 \pm 0.1$ & $51 \pm 8$ & 5 & $>5$ & $15 \pm 3^{d}$ & 7 & $5.7 \pm 0.1^{\mathrm{b}}$ & $75 \pm 5=$ & 7 & $>5$ & $28 \pm 8^{d}$ & 6 \\
\hline
\end{tabular}

plC $\mathrm{s}_{50}$ is the negative logarithm of concentration which relaxed $50 \%$ and Max is the maximal relaxant effect achieved with the highest concentration of vasodilator tested.

B.E., biphasic effect; relaxation and contraction depending on drug concentration (see text and figures for details). N.E., minimum or no effect.

${ }^{4}$ and ${ }^{b} P<0.05$ and $P<0.01$ mesenteric vs. pulmonary arteries. ${ }^{d} P<0.01$ noradrenaline vs. U46619, respectively. 


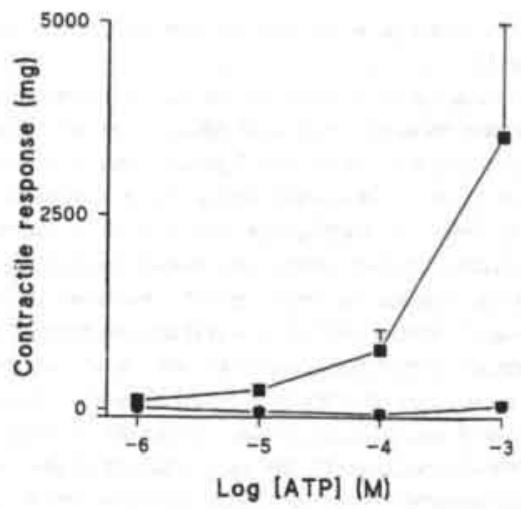

Fig. 4. Contractile effects of cumulative addition of ATP on pulmonary (circles) and mesenteric anteries (squares) on resting tension. Mesenteric arteries responded to ATP with a fast contraction reaching a peak in about $1-2 \mathrm{~min}$ and were followed by a decay in tone to a lower sustained level (peak contractile values are shown). Results are expressed as mean \pm S.E.M. of 6 experiments. Abscissa, \% relaxation; ordinate, $\log$ ATP concentration (M).

\subsection{Vasodilator effects of tolazoline}

The $\alpha$-adrenoceptor antagonist tolazoline $\left(10^{-6}-5 \times\right.$ $\left.10^{-4} \mathrm{M}\right)$ fully relaxed pulmonary or mesenteric arteries contracted by noradrenaline (Fig. 6), this effect being slightly more potent in mesenteric arteries $(P<0.05$; Table 2). However, tolazoline had no effect on arteries contracted by $\mathrm{U} 46619$.

\subsection{Vasodilator effects of nifedipine}

Fig. 7 shows that, at concentrations of $\leq 10^{-7} \mathrm{M}$. nifedipine produced no relaxant effect on pulmonary or

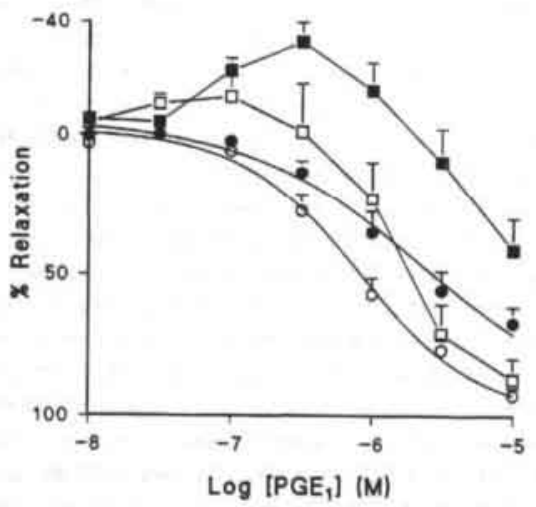

Fig. 5. Relaxant effects of cumulative addition of PGE, on pulmonary (circles) and mesenteric arteries (squares) pre-contracted with $10^{-5} \mathrm{M}$ nonadrenaline (open symbols) or $10^{-6} \mathrm{M} \mathrm{U} 46619$ (solid symbols) of neonatal piglets. Results are expressed as means \pm S.E.M. of $7-10$ experiments. Abscissa. \% relaxation: ordinate, log PGE, concentration (M).

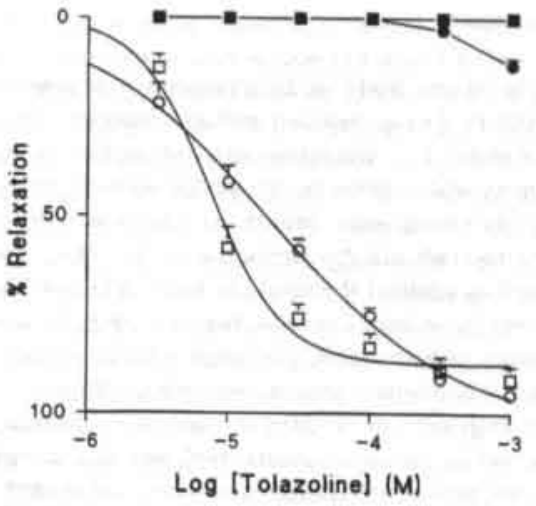

Fig. 6. Relaxant effects of cumulative addition of tolazoline on pulmonary (circles) and mesenteric arteries (squares) pre-contracted with $10^{-5} \mathrm{M}$ noradrenaline (open symbols) or $10^{-6} \mathrm{M}$ U46619 (solid symbols) of neonatal piglets. Results are expressed as mean \pm S.E.M. of $6-7$ experiments. Abscissa, \% relaxation; ordinate, log tolazoline concentra. tion (M).

mesenteric arteries. At higher concentrations, it produced a concentration-dependent relaxation in both arteries, even when the maximal relaxant effect could not be reached at the maximal concentration tested $\left(10^{-5} \mathrm{M}\right)$. Higher concentrations could not be used because the vehicle (ethanol) had significant effects at these concentrations. The relaxant responses to nifedipine were more pronounced when the arteries were contracted by noradrenaline than by U 46619 $(P<0.05)$ and in mesenteric than in pulmonary arteries $(P<0.05)$.

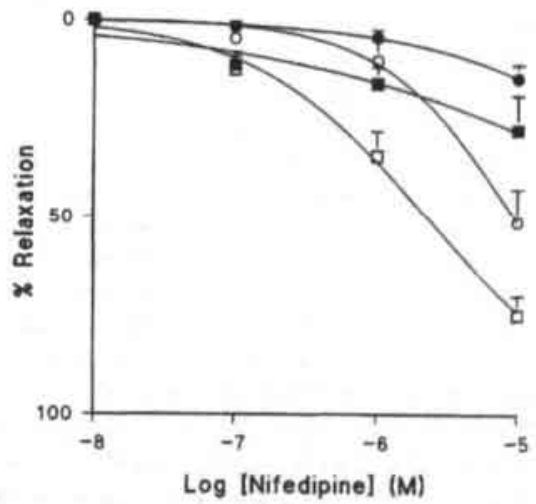

Fig. 7. Relaxant effects of cumulative addition of nifedipine on pulmonary (circles) and mesenteric arteries (squares) pre-contracted with $10^{-5} \mathrm{M}$ noradrenaline (open symbols) or $10^{-6} \mathrm{M}$ U46619 (solid symbols) of neonatal piglets. Results are expressed as mean \pm S.E.M. of 5-7 experiments. Abscissa, \% relaxation; ordinate, log nifedipine concentration (M). 


\section{Discussion}

In the present study we have compared the effects of six vasodilators (acetylcholine, sodium nitroprusside. ATP. prostaglandin $E_{1}$, tolazoline and nifedipine) in isolated pulmonary and mesenteric arteries of neonatal piglets. For any of the vasodilators studied, we have found differences in their relaxant effects depending on the artery, the agonist used to contract the artery or both. ATP was the only drug which, at any concentration and regardless of the contractile agonist used, produced relaxant effects more marked in pulmonary than in mesenteric arteries.

The responses of isolated arteries to vasodilator drugs depend on the species, vascular bed, age, sex, pre-existing tone, endothelial preservation, vasoconstrictor used to increase tone and arterial diameter among other factors. Therefore, we must rise the following methodological considerations. We have studied the effects of vasodilators under conditions of a high vascular tone, i.e. after inducing maximal or near-maximal contractions, which presumably reflect what happens in persistent pulmonary hypertension of the newborn. Noradrenaline and the thromboxane $A_{2}$ mimetic U 46619 were chosen as contractile agonists since noradrenaline is considered to be one of the most important factors regulating systemic and pulmonary vascular tone (Bülbring and Tornita, 1987; Barnes and Liu, 1995) and thromboxane $A_{2}$ has been associated with several forms of persistent pulmonary hypertension of the newborn (Dobyns et al., 1994). The same concentrations of vasoconstrictors were used in pulmonary and mesenteric arteries and, therefore, the vasodilator effects were not evaluated under equieffective concentrations of noradrenaline and U46619 for a given artery. Mesenteric arteries of a similar diameter than pulmonary arteries were chosen as representatives of systemic arteries. However, the effects of vasodilators on the whole systemic vascular resistance is the sum of the effects in all vascular beds and, thus. extrapolation of mesenteric arteries to an universal systemic artery has to be done with caution.

Acetylcholine has been reported to produce endothelium-dependent vasodilatation and both endothelium-dependent and -independent contraction (Furchgott and $\mathrm{Za}$ wadki, 1980: Altiere et al., 1986). In the present study. acetylcholine induced a concentration-dependent reiaxation in pulmonary arteries and this effect was inhibited by the nitric oxide synthesis inhibitor L-NAME indicating an acetylcholine-induced nitric oxide release from the endothelium (Furchgott and Zawadki, 1980). However, when the arteries were pre-contracted by U46619, acetylcholine was unable to induce full relaxation. In contrast, in mesenteric arteries, acetylcholine produced relaxation at concentrations of $\leq 10^{-7} \mathrm{M}$, but contraction at higher concentrations. Therefore, at high concentrations, acetylcholine showed greater relaxant effects on pulmonary than on mesenteric arteries, although its relaxant effect was signifi- cantly less marked when the arteries were pre-contracted by U46619.

The vasodilator effects of sodium nitroprusside have been attributed to the release of nitric oxide which, in turn, stimulates soluble guanylate cyclase and increases the intracellular levels of cGMP (Ignarro and Kadowitz, 1985; Feelisch, 1991). The effects of this drug were analyzed in endothelium denuded arteries to avoid interferences with endothelial release of nitric oxide. Addition of sodium nitroprusside produced full vasorelaxant effects in mesenteric arteries contracted by either U 46619 or noradrenaline and in pulmonary arteries contracted by noradrenaline but, as occurred with acetylcholine, it induced only partial relaxation in pulmonary anteries contracted by $\mathrm{U} 46619$. Thus, as recently reported (Pérez-Vizcaíno et al., 1996), activation of thromboxane $A_{2}$ receptors by $\mathrm{U} 46619$ in pulmonary arteries seems to reduce the sensitivity to nitric oxide.

ATP had no effect on resting tension but relaxed pulmonary arteries pre-contracted by noradrenaline or $\mathrm{U} 46619$. In contrast, addition of ATP ( $\left.>10^{-6} \mathrm{M}\right)$ to mesenteric arteries at resting tone induced a concentration-dependent contraction. The vasoactive effects of ATP have been attributed to the activation of membrane $\mathrm{P}_{2}$-purinoceptors. Activation of $\mathrm{P}_{2 \mathrm{x}}$-purinoceptors located on smooth muscle mediate contraction in both rat and human pulmonary arteries whereas $P_{2 y}$-purinoceptors mediating relaxation are located on the endothelium in rat and on the smooth muscle in human pulmonary arteries (Liu et al., 1989a,b). The present results show that ATP-induced relaxation in neonatal piglet pulmonary arteries are endothelium- and nitric oxide-independent. The purinoceptor subtype mediating this effect is unknown but based on the similarities of the response with human pulmonary arteries it might be tempting to speculate that it is mediated by $\mathrm{P}_{2 y}$-purinoceptors located on smooth muscle. In contrast to human pulmonary artenes (Liu et al., 1989a), ATP produced minimal contractile effect in piglet pulmonary arteries at resting tone. At present, we do not know if differences are species- or age-dependent. In pre-contracted mesenteric arteries. ATP produced both relaxant and contractile effects. A weak relaxant response was observed at low concentrations $\left(\leq 10^{-4} \mathrm{M}\right)$ where? at higher concentrations, ATP produced a weak contractile effect, so that the average tension level was not significantly different to the initial tension value. Therefore, the vasodilator effect of ATP was selective for pulmonary over mesenteric arteries regardless of the agonist used to contract the arteries.

Prostaglandin $E_{1}$ is a non-selective agonist of prostanoid $\mathrm{EP}_{1}, \mathrm{EP}_{2}$ and $\mathrm{EP}_{3}$ receptors (Coleman et al., 1994). In general. $\mathrm{EP}_{1}$ and $\mathrm{EP}_{3}$ receptor subtypes mediate contraction of smooth muscle, and $\mathrm{EP}_{2}$ receptors mediate smooth muscle relaxation. Therefore, both prostaglandin $E_{1}$-induced vasodilation and vasoconstriction have been reported (Kadowitz et al., 1976; Bergström et al., 1968; Qian 
et al., 1994). In the present study, prostaglandin $\mathrm{E}_{1}$ relaxed pulmonary arteries but this effect was significantly more pronounced when the arteries were pre-contracted by noradrenaline. In contrast, in mesenteric arteries, low concentrations of prostaglandin $\mathrm{E}_{1}$ induced a small contractile response whereas, at higher concentrations, a relaxation was observed. Therefore, prostaglandin $\mathrm{E}_{1}$ showed a weak selectivity for pulmonary over mesenteric arteries.

Tolazoline is considered a non-selective $\alpha$-adrenoceptor blocker (Ruffolo et al., 1991) that exhibits other nonadrenoceptor-mediated vasodilators effects (Drummond and Lock, 1984). In the present study, tolazoline almost fully relaxed pulmonary and mesenteric arteries pre-contracted with noradrenaline, which consistent with its $\alpha$ adrenoceptor blocking properties and this effect was slightly but significantly more potent in mesenteric than in puimonary arteries. Tolazoline, however, had no effect in pulmonary or mesenteric arteries contracted by U46619, which suggested that a direct pulmonary vasodilator effect unrelated to $\alpha$-adrenoceptor blockade was absent.

The potency of the L-type $\mathrm{Ca}^{2+}$ channel blocker nifedipine to inhibit the contractions induced by noradrenaline or other agonists is highly variable, depending on the role of $\mathrm{Ca}^{2+}$ entry through L-type $\mathrm{Ca}^{2+}$ channels in the contractile response (Cauvin et al., 1983; Godfraind et al., 1986). In the present study, only at very high concentrations of nifedipine $\left(\geq 10^{-6} \mathrm{M}\right)$ induced relaxant responses in noradrenaline- or U46619-precontracted arteries. However, at these concentrations, it is very unlikely that the vasodilator effects of nifedipine can be related to $\mathrm{Ca}^{2+}$ entry blockade. The relaxant response to nifedipine was more marked in both pulmonary or mesenteric arteries pre-contracted by noradrenaline as compared to U46619 contracted vessels. Nevertheless, mesenteric were more sensitive than pulmonary arteries to nifedipine.

Since lowering pulmonary artery pressure, while maintaining systemic vascular resistance and good cardiac output, is crucial for newborns with persistent pulmonary hypertension of the newborn, a search for selective pulmonary vasodilators has been constant in the last two decades (Roberts and Shaul, 1993). Most clinical studies in neonates suffering persistent pulmonary hypertension of the newborn, however, have been carried out in small number of patients, were not randomized, and no direct measurements of pulmonary artery pressure were made, so that arterial $\mathrm{pO}_{2}$ or clinical improvement was used to indirectly evaluate pulmonary vasodilation. Therefore, conclusions regarding drug pulmonary selectivity cannot be drawn and most data come from animal models of persistent pulmonary hypertension of the newborm. Tolazoline, the most widely used drug in the treatment of persistent pulmonary hypertension of the newborn, produced systemic hypotension in $>50 \%$ of patients (Stevenson et al., 1979; Ward, 1984; Starling et al., 1981: Gouyon and Francoise, 1992) and, therefore, it can be considered as a poor pulmonary selective drug. Similar systemic deleteri- ous effects have been reported in animal models of pulmonary hypertension after infusion of acetylcholine (Tripp et al., 1980), nifedipine (Dickstein et al., 1984) or prostaglandin $\mathrm{E}_{1}$ (Tripp et al., 1980; Starling et al., 1981). The limited use of sodium nitroprusside in persistent pulmonary hypertension of the newborn has rendered variable results (Benitz et al., 1985). The present in vitro results with tolazoline and nifedipine demonstrated that systemic arteries dilate at least as much as pulmonary arteries, supporting the poor selectivity observed in clinical studies. The results obtained with acetylcholine, prostaglandin $\mathbf{E}_{1}$ or sodium nitroprusside are difficult to interpret in terms of pulmonary vs. systemic selectivity due to the biphasic (contractile and relaxant) responses or to agonist-dependent differences. ATP has demonstrated selective pulmonary vasodilating effects in animal models of pulmonary hypertension (Konduri and Woodard, 1991; Fineman et al., 1990) and our in vitro results also provide evidence of its selective pulmonary vasodilator effect. Indeed, ATP was able to induce contractile responses in mesenteric but not in pulmonary arteries under resting conditions. Very recently, the administration of low doses of ATP in pulmonary hypertensive newborns and infants produced a decrease in pulmonary vascular resistance without effects on systemic blood pressure, suggesting that ATP may be a selective pulmonary vasodilator, although at higher doses it produced mild systemic effects (Brook et al., 1995).

In conclusion, the vasodilators studied exhibited differences in the relaxant effects depending upon the artery and/or the agonist used to contract the vessel. However, ATP was the only drug which, at all concentrations and regardless of the contracting agent used, relaxed the pulmonary artery but not the mesenteric artery.

\section{Acknowledgements}

We are grateful to C. Rivas, R. Vara and M.R. Gaítan for excellent technical assistance. This work was supported by CICYT Grant SAF $96 / 0042$ and FIS Grants $95 / 0308$ and 95/0318. M.M. is a recipient of the Asociación Española de Neonatología.

\section{References}

Abu-Osba, Y.K., O. Galal, K. Manasra and A. Rejjal, 1992. Treatment of severe persistent pulmonary bypertension of the newborn with magnesium sulfate, Arch. Dis. Child 67, 31.

Altiere, R.J., J.A. Kiritski-Roy and J.D. Catravas, 1986, Acetylcholine-induced contractions in isolated rabbit pulmonary arteries: role of thromboxane $\mathrm{A}_{2}$, J. Pharmacol. Exp. Ther. 236, 535.

Barnes, P.J. and S.F. Liu, 1995, Regulation of pulmonary vascular tone, Pharmacol. Rev, 47, 87.

Benitz. W.E. N. Malachowski, R.S, Cohen, D.K. Stevenson, R.L. Ariagno and P. Sunshine, 1985. Use of sodium nitroprusside in neonates: efficacy and safery. J. Pediatr. 106, 102. 
Bergström, S., L.A. Carison and J.R. Weeks, 1968. The prostaglandins; a family of biologically active lipids. Pharmacol. Rev, 20, 1 .

Brook, M.M., J.R. Fineman, A.M. Bolinger. A.F. Wong, M.A. Heymann and SJ. Soifer, 1995. Use of $\mathrm{ATP}-\mathrm{MgCl}_{2}$ in the evaluation and treatment of children with pulmonary hypentension secondary to congenital heart defects, Circulation 90, 1287.

Bulbring, E. and T. Tomita, 1987, Catecholamine action on smooth muscle, Pharmacol. Rev, 39, 49.

Cauvin, C., R. Loutzenhiser and C. Van Breemen, 1983, Mechanism of calcium antagonist-induced vasodilatation. Annu. Rev. Pharmacol. Toxicol. 23, 373.

Coleman. R.A., W.L. Smith and S. Narumiya, 1994, VIII. International Union of Pharmacology classification of prostanoid receptors: properties, distribution, and structure of the receptors and their subtypes. Pharmacol. Rev, 46, 205.

Dickstein, PJ., O. Trintade, R.N. Goldberg and E. Bancalari, 1984, The effect of calcium antagonists on hypoxic pulmonary hypertension in the piglet, Pediatr, Res. 18, 1262.

Dobyns, E.L. J.A. Wescot, J.M. Kennaugh, M.N. Ross and K.R. Stenmark. 1994, Eicosanoids decrease with successful extracorporeal membrane oxygenation therapy in neonatal pulmonary hypertension. Am. J. Respir. Crit. Care Med. 149, 873.

Drummond, W.E. and J.E. Lock. 1984, Neonatal 'pulmonary vasodilator' drugs, Dev. Pharmacol. Ther. 7, I.

Feelisch, M., 1991, The biochemical pathways of nitric oxide formation from nitrovasodilators: appropriate choice of exogenous NO donors and aspects of preparation and handling of aqueous solutions, $J$. Cardiovasc. Pharmacol. 17 (SuppL. 3). S25.

Fineman, J.R.. M.R. Crowley and S.J. Soifer, 1990, Selective pulmonary vasodilation with $\mathrm{ATP}-\mathrm{MgCl}_{2}$ during pulmonary hypertension in lambs, J. Appl. Physiol. 69, 1836.

Fineman, J.R., S.J. Soifer and M.A. Heyman, 1995, Regulation of pulmonary vascular tone in the perinatal period, Annu. Rev. Physiol. 57, 115.

Furchgot, R.F. and J. Zawadki, 1980, The obligatory role of endothelial cells in the relaxation of vascular smooth muscle by acetylcholine. Nature 288, 373.

Godfraind, T., R. Miller and M. Wibo, 1986. Caicium antagonism and calcium entry blockade. Pharmacol. Rev. 38, 321,

Gouyon. J.B. and M. Francoise, 1992, Vasodilators in persistent pulmonary hypertension of the newborn: a need for optimal appraisal of efficacy. Dev. Pharmacol. Ther. 19, 62.

Ignarro, L.J. and P.J. Kadowitz, 1985, The pharmacological and physiological role of cyclic GMP in vascutar smooth muscle. Annu. Rev. Pharmacol. Toxicol. 25, 171.

Kadowitz, P.J. P.D. Joiner, S. Greenberg and A.L. Hyman, 1976, Comparison of the effects of prostagiandins A, E, F and B on the canine pulmonary vascular bed, Adv, Prostagtandin Thromboxane Res. 1, 403.

Kinsella. J.P., S.R. Neish, E. Shaffer and S.H. Abman, 1992, Low-dose inhalational nitric oxide in persistent pulmonary hypertension of the newbom, Lancet $340,819$.

Konduri, G.G. and L.L. Woodard, 1991, Selective pulmonary vasodilation by low-dose infusion of adenosine triphosphate in newborn lambs, J. Pediatr. 119, 94

Kulik, T.J. and J.E. Lock, 1984, Pulmonary vasodilator therapy in persistent putmonary hypertension of the newborn, Clin, Perinatol. 11. 693.

Lawson. C.A., AJ. Smerling. Y. Naka, D. Burkhoff, M.L. Dickstein. D.M. Stern and D.J Pinsky. 1995. Selective reductions of PVR by inhalation of a cGMP analogue in a porcine model of pulmonary hypertension. Am. J. Physiol. 268. H2056.

Liu, S.F., D.G. McCormack, T.W. Evans and P.G. Barnes, 1989a, Evidence for two $\mathrm{P}_{2}$-purinoceptors subtypes in human small pulmonary arteries. Br. J. Pharmacol. 98, 1014.

Liu, S.F., D.G. McCormack, T.W. Evans and P.G. Barnes, 1989b, Characterization and distribution of $\mathrm{P}_{2}$-purinoceptor subtypes in rat puimonary vessels, J. Pharmacol. Exp. Ther. 251. 1204.

Pérez-Vizcaíno, F., B. Fernández del Pozo, F. Zaragozá and J. Tamargo. 1994, Voltage- and time-dependent inhibitory effects of rat aortic and porcine coronary artery contraction by propafenone and quinidine, $\mathrm{Br}$. J. Pharmacol. 113, 1281 .

Pérez-Vizcaíno, F., E. Villamor, B. Fernández del Pozo, M. Moro and J. Tamargo, 1996, Lack of endotoxin-induced hyporesponsiveness to U 46619 in isolated neonatal porcine pulmonary but not mesenteric anteries, J. Vasc. Res. 33, 249-257.

Qian. Y., R.L. Jones, K. Chan, A.I. Stock and J.K.S. Ho, 1994. Potent contractile actions of prostanoid $\mathrm{EP}_{3}$ receptor agonists on human isolated pulmonary antery, Br. J. Pharmacol. 113, 369.

Roberts. J.D. and P.W. Shaul, 1993, Advances in the treatment of persistent pulmonary hypertension, Pediatr. Clin. North Am, 40, 983.

Roberts, J.D., D.M. Polaner, P. Lang and W.M. Zapol, 1992, Inhaled nitric oxide in persistent puimonary hypentension of the newborn, Lancet $340,819$.

Ruffolo. R.R. Jr, A.F. Nichols, J.M. Stadel and J.P. Hieble, 1991 , Structure and function of $\alpha$-adrenoceptors, Pharmacol. Rev, 43, 475,

Simmoneau, G., P. Escourrou, P. Duroux and A. Lockhart. 1981. Inhibition of hypoxic pulmonary vasoconstriction by nifedipine, New Engl. J. Med. 304, 1583.

Starling, M.B., J.M. Neutze, R.L. Elliot and R.B. Elliot,, 1981, Comparative studies on the hemodynamic effects of prostaglandin $E_{1}$. prostacyclin and tolazoline upon elevated pulmonary vascular resistance in neonatal swine, Prostaglandin Med. 7. 349.

Stevenson, D.K., D.S. Kasting, R.A. Darnall, R.L Ariagno, J.D. Jonhson, N. Malachowski, C.L. Beets and P. Sunshine, 1979, Refractory hypoxemia associated with neonatal pulmonary disease: the use and limitations of tolazoline. J. Pediatr, 100, 458.

Tripp, M.E., W.H. Drummond, M.A. Heymann and A.M. Rudolf, 1980 , Hemodynamic effect of pulmonary arterial infusion of vasodilators in newborn lambs, Pediatr. Res. 14, 1311.

Villamor, E. F. Pérez-Vizcaíno, T. Ruiz, J.C. Leza, M. Moro and J. Tamargo, 1995, Group B Sireptococcus and E. coli LPS-induced NO-dependent hyporesponsiveness to noradrenaline in isolated intrapulmonary anteries of neonatal piglets, Br. J. Pharmacol. 115, 261.

Ward, R.M., 1984, Pharmacology of tolazoline, Clin. Perinatol. 11. 703.

Weich. J.C. J.M. Bridson and J.L. Gibbs, 1995, Endotracheal tolazoline for severe persistent pulmonary hypertension of the newborn, $\mathrm{Br}$. Heart J., 73, 99.

Zobel, F., D. Dacar, S. Rödl and I. Friehs, 1995. Inhaled nitric oxide versus inhaled prostacyclin and intravenous versus inhaled prostacyclin in acute respiratory failure with pulmonary hypertension in piglets, Pediatr. Res. 38, 198. 
Chapter XII. In vitro effects of magnesium sulfate in isolated intrapulmonary and mesenteric arteries of piglets. (Pediatr Res. 1996; 39:1107-12). 



\title{
In Vitro Effects of Magnesium Sulfate in Isolated Intrapulmonary and Mesenteric Arteries of Piglets
}

\author{
E. VILLAMOR, F. PÉREZ,VIZCAÍNO, T. RUIZ, J. TAMARGO, AND M. MORO
}

Division of Neonatology, Department of Pediatrics, Hospital Universitario San Carlos [E.V., T.R., M.M.]. and Department of Pharmacology, Institute of Pharmacology and Toxicology, School of Medicine, Universidad Complutense [F.P.-V., J.T.], 28040 Madrid, Spain

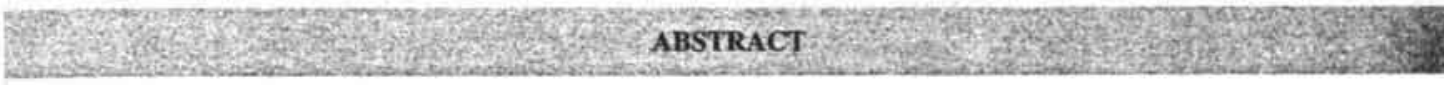

\begin{abstract}
Magnesium sulfate $\left(\mathrm{MgSO}_{4}\right)$ has been proposed to be an efficient treatment in persistent pulmonary hypertension of the newborn. We compared the ability of $\mathrm{MgSO}_{4}$ to inhibit the responses to several vasoconstrictors in isolated intrapulmonary and mesenteric arteries from 10-17-d-old piglets. $\mathrm{MgSO}_{4}(3-$ $100 \mathrm{mM}$ ) produced a slight vasodilator effect in pulmonary arteries precontracted with the thromboxane $\mathrm{A}_{2}$ mimetic $\mathrm{U} 46619$ $\left(10^{-6} \mathrm{M}\right)$, noradrenaline $\left(10^{-5} \mathrm{M}\right)$, and $\mathrm{KCl}(80 \mathrm{mM})(15.1 \pm$ $3.7 \%: 20 \pm 3.33 \% ; 10.4 \pm 0.9 \%$ at $100 \mathrm{mM} \mathrm{MgSO}_{4}$, respectively). In contrast, in mesenteric arteries $\mathrm{MgSO}_{4}$ produced a marked vasodilation $(80.4 \pm 4.0 \%, 93.1 \pm 3.46 \%$, and $87.5 \pm$ $1.93 \%$ at $100 \mathrm{mM} \mathrm{MgSO}$, respectively, $p<0.01$ versus pulmonary arteries). The vasodilator effect of $\mathrm{MgSO}_{4}$ was endothelium-independent and reversed by increasing the extracellular $\mathrm{Ca}^{2+}$ concentration. After incubation for $1 \mathrm{~h}$ of pulmonary arteries with three different $\mathrm{MgSO}_{4}$ concentrations $(0,1.2$, and $4.8 \mathrm{mM}$ ) there were no differences in the contractile responses to U46619 nor in the vasodilator effects of acetylcholine or sodium nitroprusside. Rapid removal of $\mathrm{Mg}^{2+}$ from bath medium produced a transient vasodilation which was more marked in pulmonary than in mesenteric arteries and was greatly reduced by the removal of endothelium or by the nitric oxide synthase
\end{abstract}

inhibitor L-NAME $\left(10^{-4} \mathrm{M}\right)$. We conclude that $\mathrm{MgSO}_{4}$ is a poor vasodilator of pulmonary arteries in vitro and at physiologic concentrations appears to inhibit nitric oxide release from the pulmonary endothelium. Thus, the possible beneficial clinical effects of $\mathrm{MgSO}_{4}$ in persistent pulmonary hypertension of the newborn do not seem to be related to a direct effect on pulmonary vascular smooth muscle. (Pediatr Res 39: 1107-1112, 1996)

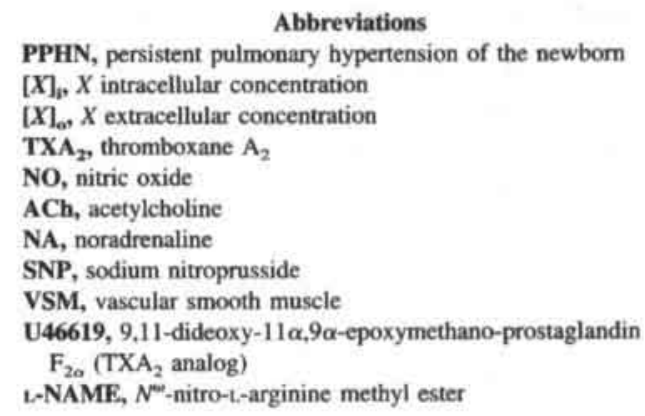

PPHN is characterized by a increased pulmonary vascular resistance resulting in right to left shunting of blood across a patent foramen ovale and/or ductus arteriosus, severe hypoxemia, and acidosis, which may produce further pulmonary vasoconstriction (1). PPHN appears as a common complication of several pulmonary and nonpulmonary diseases, including meconium aspiration syndrome, congenital diaphragmatic hernia, sepsis, and asphyxia $(1,2)$. Because the magnitude of the shunt depends on the ratio of systemic and pulmonary vascular

\footnotetext{
Received July 26, 1995; accepted November 16, 1995.

Correspondence and reprint requests: Francisco Ptrez Vizcaino, Department of Pharmacology. School of Medicine, Universidad Complutense de Madrid, 28040 Madrid.

Supported by a CICYT (92/0157) and a FIS (95/0308) Grants. EV. is a recipient of the Asociación Espahola de Pediatria/Arbora S.A. Grant for Pediatric Research.
} Spain. resistance, a selective pulmonary vasodilator would dramatically improve the treatment and outcome of PPHN. Recent studies have demonstrated that inhaled nitric oxide (NO) is a potent and selective vasodilator which causes marked improvement in many newborn infants with PPHN (3-5). However, current pharmacologic treatment of PPHN often resorts to intravenous vasodilators that are nonselective for pulmonary circulation and may sometimes exacerbate cardiovascular and intrapulmonary shunting of venous blood and cause systemic hypotension $(1,2,6)$.

Extracellular $\mathrm{Mg}^{2+}$ concentrations exert an important role in the modulation of VSM tone and reactivity $(7,8)$. Extracellular $\mathrm{Ca}^{2+}$ and $\mathrm{Mg}^{2+}$ elicit mutually antagonistic or reciprocal actions on VSM, so that $\mathrm{Mg}^{2+}$, nature's physiologic $\mathrm{Ca}^{2+}$ channel blocker (9), antagonizes $\mathrm{Ca}^{2+}$ entry into the VSM cell, 
thereby promoting vasodilation $(8,10)$. Increased $\mathrm{Mg}^{2+} \mathrm{re}-$ laxed VSM, lowered blood pressure, and attenuated VSM cell contractile responses to calcium and other vasoactive agents, whereas decreased $\mathrm{Mg}^{2+}$ caused the opposite effects $(7,8,11)$. Furthermore, $\mathrm{Mg}^{2+}$ also influences NO release (11-13) and arachidonic acid metabolism $(11,14)$, so that prostacyclin production increased when $\mathrm{Mg}^{2+}$ was elevated (15). Animal studies have shown that $\mathrm{MgSO}_{4}$ can prevent and reduce hypoxic pulmonary hypertension $(16,17)$, and two clinical reports have shown its benefit in the management of PPHN (18, 19). Thus, it was suggested that $\mathrm{MgSO}_{4}$ may exert a beneficial effect in the management of PPHN when other treatments fail, are contraindicated, or not available $(18,19)$.

Therefore, the aim of the present work was to study the vasodilator effects of $\mathrm{MgSO}_{4}$ in isolated pulmonary as compared with systemic (mesenteric) arteries of piglets. The role of $\mathrm{Mg}^{2+}$ on the vascular reactivity and endothelial regulation of $\mathrm{NO}$ in these arteries was also analyzed.

\section{METHODS}

Tissue preparation. Male piglets (10-17 d of age, $4277 \pm$ $343 \mathrm{~g}$ ) were killed by exsanguination, and the lungs and mesenteric beds were rapidly immersed in cold $\left(4^{\circ} \mathrm{C}\right) \mathrm{Krebs}$ solution (composition in mM: $\mathrm{NaCl} 118, \mathrm{KCl} 4.75, \mathrm{NaHCO}_{3}$ 25. $\mathrm{MgSO}_{4} 1.2, \mathrm{CaCl}_{2} 2.0, \mathrm{KH}_{2} \mathrm{PO}_{4} 1.2$, and glucose 11) and transported immediately to the laboratory. The pulmonary arteries (third branch) or mesenteric arteries (internal diameter 1-2 mm) were carefully dissected free of surrounding tissue and cut into rings $2-3 \mathrm{~mm}$ in length. Two L-shaped stainless steel wires were inserted into the arterial lumen, and the rings were introduced in Allhin organ chambers filled with Krebs solution (gassed with $95 \% \mathrm{O}_{2}$ and $5 \% \mathrm{CO}_{2}$ at $37^{\circ} \mathrm{C}$ ). One wire was attached to the chamber and the other to an isometric force-displacement transducer (Grass FT07) and connected to a polygraph (Grass, model 7 ) as previously described $(20,21)$. The rings were initially stretched to a resting tension of $0.5 \mathrm{~g}$ (pulmonary rings) or $2 \mathrm{~g}$ (mesenteric rings) and allowed to equilibrate for $60-90 \mathrm{~min}$. During this period tissues were restretched and washed every $30 \mathrm{~min}$ with warm Krebs solution. In some experiments the endothelium was removed by gently rubbing the intimal surface of the rings with a metal rod. The presence of functional endothelium was verified by addition of $\mathrm{ACh}\left(10^{-6} \mathrm{M}\right)$ in arteries precontracted with NA. The ability of $\mathrm{ACh}$ to induce relaxation of unrubbed rings was taken as an indicator of the presence of functional endothelium.

Experimental protocols. After equilibration, the rings were contracted with either $10^{-5} \mathrm{M} \mathrm{NA}, 10^{-6} \mathrm{M} \mathrm{U} 46619$, or $80 \mathrm{mM}$ $\mathrm{KCl}$. When the contractile response to each agonist reached a stable tension, cumulative concentration-response curves to $\mathrm{MgSO}_{4}(0.3-100 \mathrm{mM})$ were carried out by cumulative increments of $\mathrm{MgSO}_{4}$ concentration after a steady state relaxant response was reached at each increment. After the maximal

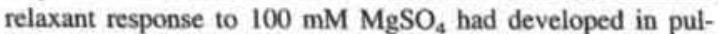
monary and mesenteric arteries precontracted with $80 \mathrm{mM}$ $\mathrm{KCl}, \mathrm{CaCl}_{2}(2-12 \mathrm{mM})$ was added to the bath medium in a cumulative fashion.
In another group of experiments, pulmonary and mesenteric artery rings were incubated for $1 \mathrm{~h}$ in Krebs solution containing $0,1.2$, or $4.8 \mathrm{mM} \mathrm{MgSO}$. After the incubation, the vasoconstrictor effects of $\mathrm{U} 46619$ were tested by cumulative increases in the concentration of U46619 $\left(10^{-10}\right.$ to $\left.10^{-6} \mathrm{M}\right)$. The vasodilator effects of $\mathrm{ACh}\left(10^{-8}\right.$ to $\left.10^{-4} \mathrm{M}\right)$ or SNP $\left(10^{-8}\right.$ to $10^{-4} \mathrm{M}$ ) were also tested in arteries precontracted with $10^{-6} \mathrm{M}$ U46619 previously incubated in $0,1.2$, or $4.8 \mathrm{mM} \mathrm{MgSO}_{4}$.

In a third group of experiments we studied the effects of acute extracellular $\mathrm{Mg}^{2+}$ removal using a protocol similar to that previously described (11). After equilibration in Krebs solution $\left(\mathrm{MgSO}_{4}\right.$ concentration $\left.1.2 \mathrm{mM}\right)$ pulmonary and mesenteric arteries were maximally precontracted with U46619 $\left(10^{-6} \mathrm{M}\right)$. When the contractile response to U46619 reached a stable tension, the bath medium was replaced by the same solution containing $\mathrm{U} 46619$ but without $\mathrm{MgSO}_{4}$. The same protocol was repeated in endothelium-denuded arteries and in the presence of the NO synthase inhibitor L-NAME $\left(10^{-4} \mathrm{M}\right)$.

Drugs. The following drugs were used: $(-)$-NA bitartrate, ACh chloride, L-NAME, SNP, U46619, and $\mathrm{MgSO}_{4} 7 \mathrm{H}_{2} \mathrm{O}$ (Sigma Chemical Co., London). Drugs were dissolved in deionized distilled water, and further dilutions were carried out in Krebs solution. NA $\left(10^{-2} \mathrm{M}\right)$ was dissolved in $0.2 \%$ ascorbic acid to prevent oxidation and then diluted in Krebs solution. The concentrations are expressed as final molar concentration in the tissue chamber.

Statistical analysis. Results are expressed as means \pm SEM of measurements in $n$ arteries. The vasoconstrictor and vasodilator responses are expressed in milligrams and as a percentage of the precontraction value, respectively. Individual cumulative concentration-response curves were fitted to a logistic equation. Statistically significant differences were calculated by means of an unpaired $t$ test. $p<0.05$ was considered statistically significant.

\section{RESULTS}

Vasodilator responses to $\mathrm{MgSO}_{4}$ and reversal by $\mathrm{Ca}^{++}$. The concentration response curves to $\mathrm{MgSO}_{4}(3-100 \mathrm{mM})$ in pulmonary and mesenteric arteries precontracted with U46619 $\left(10^{-6} \mathrm{M}\right)$, NA $\left(10^{-5} \mathrm{M}\right)$ or $\mathrm{KCl}(80 \mathrm{mM})$ are shown in Figure $1, a, b$, and $c$, respectively. In puimonary arteries, U46619, NA, and $\mathrm{KCl}$ induced a contraction averaging $1085 \pm 148 \mathrm{mg}(n=$ 6). $504 \pm 81 \mathrm{mg}(n=7)$, and $1408 \pm 83 \mathrm{mg}(n=6)$, respectively. When $\mathrm{MgSO}_{4}$ was stepwise increased from 1.2 $\mathrm{mM}$ (normal concentration in Krebs) to $100 \mathrm{mM}$, it produced a slight vasodilator effect in pulmonary arteries precontracted with $\mathrm{U} 46619, \mathrm{NA}$, and $\mathrm{KCl}$ which averaged $15.1 \pm 3.7 \%, 20.0$ $\pm 3.3 \%$, and $10.4 \pm 0.9 \%$ in the presence of $100 \mathrm{mM} \mathrm{MgSO}_{4}$, respectively. The relaxant response induced by $\mathrm{MgSO}_{4}$ on U46619-induced contraction was slightly but significantly increased when endothelium was removed (Fig. 1a). In contrast, in mesenteric arteries precontracted with U46619 (2655 \pm 525 , $n=8)$, NA ( $2315 \pm 289, n=5)$, and $\mathrm{KCl}(3158 \pm 845 \mathrm{mg}$, $n=6), \mathrm{MgSO}_{4}$ produced a much more marked relaxant effect which averaged $80.4 \pm 4.0 \%, 93.1 \pm 3.4 \%$, and $87.5 \pm 1.9 \%$ at $100 \mathrm{mM} \mathrm{MgSO}_{4}$, respectively $(p<0.01$ versus pulmonary arteries in the three groups). Furthermore, Figure $1 a$ shows that 
a

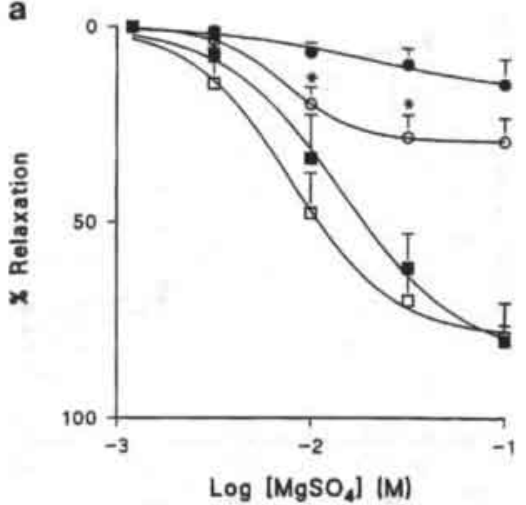

b

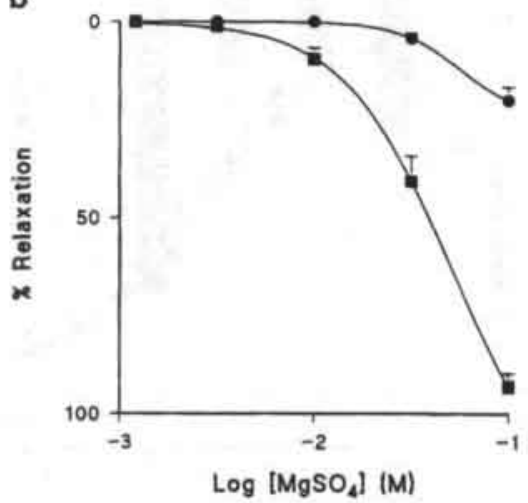

c

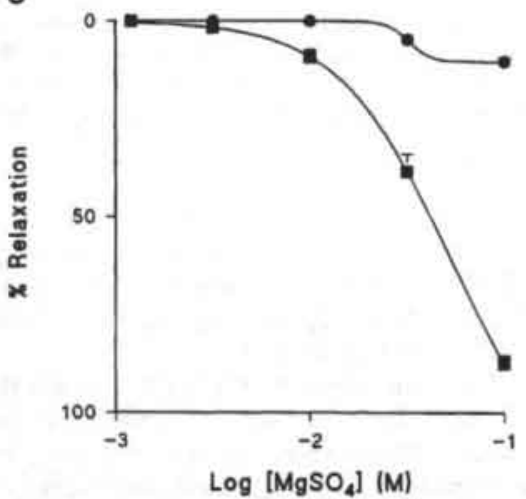

Figure 1. Concentration-response curves to $\mathrm{MgSO}_{4}(3-100 \mathrm{mM})$ in piglet endothelium intact (-. $)$ or endothelium denuded $(O, \square)$ pulmonary $(\bullet, O)$ and mesenteric arteries (․ㅛ, $\square$ ) precontracted with the TXA mimetic U46619 $\left(10^{-6} \mathrm{M}\right)(a)$, NA $\left(10^{-5} \mathrm{M}\right)(b)$, or $\mathrm{KCl}(80 \mathrm{mM})(c)$. Ordinate: relaxation (percentage of precontraction tone). Abscissa: $\log \mathrm{MgSO}_{4}$ concentration (M). Each symbol represents the mean \pm SEM of five to eight experiments.

the relaxant effects of $\mathrm{MgSO}_{4}$ on U46619-induced contractions were not significantly different in mesenteric arteries in which the endothelium was mechanically removed. No differences were observed when the concentration-response curves to
$\mathrm{MgSO}_{4}$ were carried out in pulmonary arteries previously incubated in $\mathrm{Mg}^{2+}$-free Krebs solution (data not shown).

As illustrated in Figure 2, after the maximal relaxant response to $100 \mathrm{mM} \mathrm{MgSO}_{4}$ had developed in pulmonary and mesenteric arteries precontracted with $80 \mathrm{mM} \mathrm{KCl}$, addition of $\mathrm{CaCl}_{2}(2-12 \mathrm{mM})$ to the bath medium produced a progressive reversal of the $\mathrm{MgSO}_{4}$-induced vasodilator effect. Moreover, in pulmonary arteries the precontractile response was obtained when the $\mathrm{Ca}^{2+}$ was increased over $2.5 \mathrm{mM}$, whereas in mesenteric arteries exposure to $12 \mathrm{mM} \mathrm{CaCl}_{2}$ recovered $81.6 \%$ of $\mathrm{MgSO}_{4}$-induced vasodilation.

Effects of $\mathrm{MgSO}_{4}$ on the contractile response to $\mathrm{U} 46619$ and in the vasodilator response to ACh or SNP. The incubation for $1 \mathrm{~h}$ in Krebs solution containing different $\mathrm{MgSO}_{4}$ concentrations $(0,1.2$ and $4.8 \mathrm{mM})$ did not influence the contraction-response curves to U46619 $\left(10^{-10}\right.$ to $\left.10^{-6} \mathrm{M}\right)$ both in pulmonary (Fig. 3a) and mesenteric arteries (Fig. 3b).

To determine the effects of $\mathrm{Mg}^{2+}$ on agonist-induced endothelium-dependent relaxation, the effects of cumulative addition of ACh on U46619-precontracted pulmonary arteries were studied in the presence of three concenirations of extracellular $\mathrm{Mg}^{2+}$. In pulmonary arteries contracted with U46619 $\left(10^{-6}\right.$ M), ACh produced a concentration-dependent relaxation (Fig. $4 a)$. Increasing the $\mathrm{MgSO}_{4}$ concentration $(0,1.2$, and $4.8 \mathrm{mM})$ in the bathing media tended to reduce (but not significantly) the vasorelaxant effect of $\mathrm{ACh}$. As shown in Figure $4 b$, the vasorelaxant effect of SNP was not significantly different when the arteries were incubated in 1.2 or $4.8 \mathrm{mM} \mathrm{MgSO}_{4}$.

Response of pulmonary and mesenteric arteries to rapid removal of extracellular $\mathrm{Mg}^{++}$. Rapid removal of $\mathrm{MgSO}_{4}$ from the bath medium in pulmonary and mesenteric arteries maximally precontracted with U46619 $\left(10^{-6} \mathrm{M}\right)$ produced a rapid and transient endothelium-dependent relaxation followed by a progressive spontaneous recovery of tension to previous values (Fig. 5a). This relaxant response was more marked in pulmonary than in mesenteric arteries $(p<0.01)$. In pulmo-

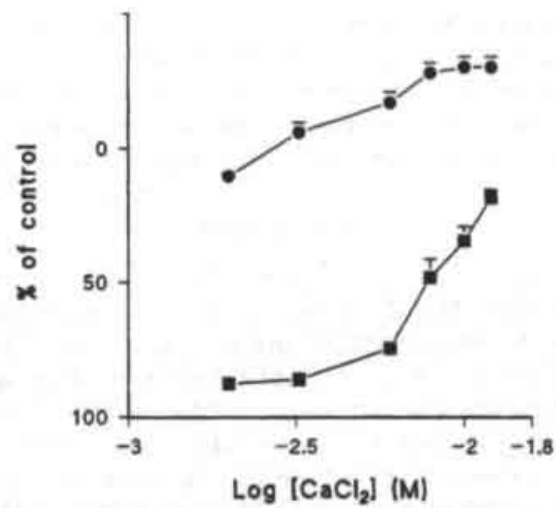

Figure 2. Reversion of the vasodilatory effect induced by $100 \mathrm{mM} \mathrm{MgSO}_{4}$ by cumulative increases of $\mathrm{CaCl}_{2}$ concentration in pulmonary $(-)$ and mesenteric arteries (-1). Both arteries were precontracted with $80 \mathrm{mM} \mathrm{KCl}$, then relaxed with $100 \mathrm{mM} \mathrm{MgSO}_{4}$, and the $\mathrm{CaCl}_{2}$ was stepwise increased from 2 to $12 \mathrm{mM}$. Ordinate: percentage of precontraction tone. Abscissa: $\log \mathrm{CaCl}_{2}$ concentration (M). Each symbol represents the mean \pm SEM of six experiments. 
a
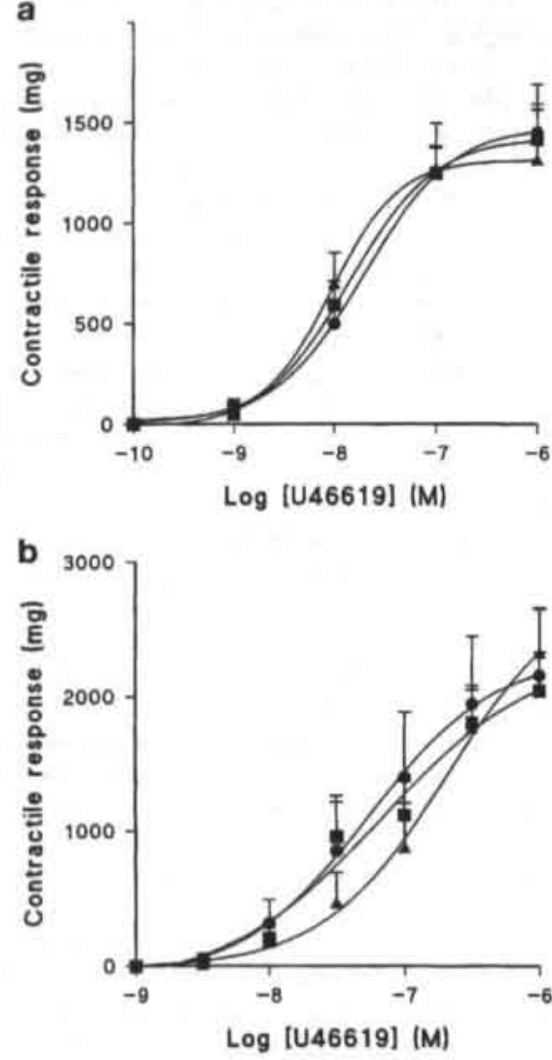

Figure 3. Concentration-response curves to the TXA2 mimetic U46619 in piglet isolated intrapulmonary $(a)$ and mesenteric arteries $(b)$ incubated in Krebs solution containing 0 (•), $1.2(\mathbf{m})$, and $4.8 \mathrm{mM}(\mathbf{\Delta}) \mathrm{MgSO}_{4}$. Ordinate: contractile response (mg). Abscissa: $\log$ U46619 concentration (M). Each symbol represents the mean \pm SEM of 7-10 experiments.

nary arteries this relaxant effect was significantly reduced to almost a similar extent in endothelium-denuded rings or in rings pretreated with the NO synthase inhibitor L-NAME $\left(10^{-4}\right.$ M) (Fig. $5 b$ ). Pretreatment of mesenteric arteries with L-NAME abolished the relaxation produced by $\mathrm{Mg}^{2+}$ removal.

\section{DISCUSSION}

The present results demonstrated that, at least in an in vitro porcine model, $\mathrm{MgSO}_{4}$ exhibited a poor pulmonary vasodilator activity. In intrapulmonary arteries (third branch) precontracted with $\mathrm{NA}, \mathrm{KCl}$, or $\mathrm{U} 46619, \mathrm{MgSO}_{4}$ produced a slight vasodilator effect as compared with the marked vasodilation produced in systemic (mesenteric) arteries of a similar diameter. Furthermore, at the normal concentration $(1.2 \mathrm{mM})$, $\mathrm{MgSO}_{4}$ inhibited the vasodilator effect of $\mathrm{NO}$, as proved by the fact that in mesenteric and pulmonary arteries precontracted by U46619 the rapid removal of $\mathrm{MgSO}_{4}$ from the bath medium produced a transient endothelium-dependent vasodilation. which was greatly reduced after removal of the endothelium or by $\mathrm{L}$-NAME. In addition, $\mathrm{MgSO}_{4}$ did not seem to play a
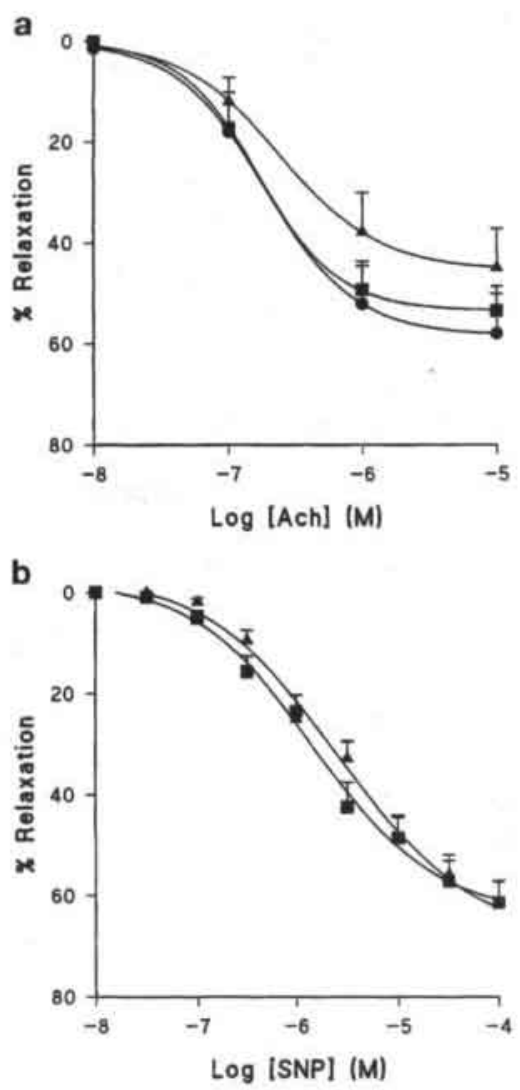

Figure 4. Concentration-response curves to $\mathrm{ACh}(a)$ and SNP $(b)$ in isolated intrapulmonary arteries incubated in Krebs solution containing 0 (-), 1.2 (…). and $4.8 \mathrm{mM}$ (A) $\mathrm{MgSO}_{4}$ and precontracted with $10^{-6} \mathrm{M}$ U46619. Abscissa: $\log \mathrm{ACh}$ or SNP concentration (M). Each symbol represents the mean \pm SEM of six to eight experiments.

marked role in the pulmonary VSM reactivity, because the vasoconstrictor effects of U46619 or the vasodilator effects of the endothelium-dependent vasodilator $\mathrm{ACh}$ or the NO donor SNP were not affected by changing the extracellular $\mathrm{Mg}^{2+}$ concentration from 0 to $4.8 \mathrm{mM}$.

$\mathrm{Mg}^{2+}$ plays an important role in VSM tone and reactivity. Therefore, $\mathrm{Mg}^{2+}$ has been used for decades as an antihypertensive agent (22). However, the use of $\mathrm{MgSO}_{4}$ in PPHN treatment remains controversial. It has been recently reported that $\mathrm{MgSO}_{4}$ produced a significant fall in mean pulmonary pressure both in an adult (16) and newborn sheep model of pulmonary hypertension induced by hypoxia (17) without adversely affecting systemic arterial pressure). After these observations, Abu-Osba et al. (18) and Tolsa et al. (19) treated 9 and 11 newborns with PPHN, respectively, with $\mathrm{MgSO}_{4}$. Even when they did not measure pulmonary arterial pressure, they observed an increase in baseline arterial oxygen tension and hemoglobin oxygen saturation, which in the absence of changes on systemic arterial pressure was attributed to a decrease in pulmonary vascular resistance and thus right to left 
a
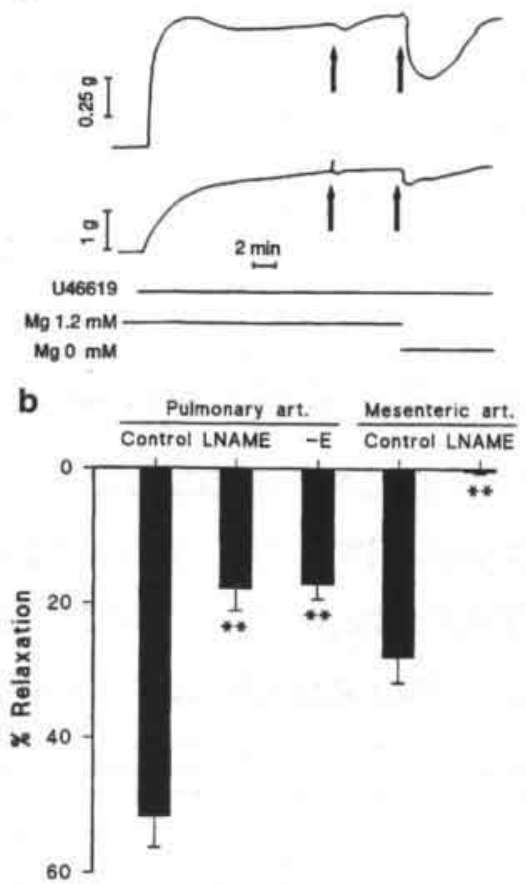

Figure 5. (a) Typical tracings of the effects of extracellular $\mathrm{Mg}^{2+}$ removal in piglet isolated intrapulmonary (upper panel) and mesenteric arteries (lower panef) precontracted with $10^{-6} \mathrm{M}$ U46619. Pulmonary and mesenteric rings were contracted by $10^{-6} \mathrm{M}$ U46619, after they reached a steady state contraction the bathing medium was changed by the same solution (Krebs solution containing $\mathrm{U} 46619$ and $1.2 \mathrm{mM} \mathrm{MgSO}$ ) as indicated by the first arrow. Note that minimal washing artifact was observed. When the medium was changed to a $\mathrm{MgSO}_{4}$-free solution (as indicated by the second arrow), a transient relaxation was observed. (b) Graph shows the influence of endothelium removal or the presence of the NO synthase inhibitor L-NAME $\left(10^{-4} \mathrm{M}\right)$ on the vasodilatory effect of extracellular $\mathrm{Mg}^{2+}$ removal. Relaxation values are expressed as a percentage of precontraction tone and are mean $\pm S E M$ of five to six experiments: ${ }^{*} p<0.01$ vs control arteries

shunt. In contrast, in newborn piglets subjected to hypoxia, the reduction in pulmonary arterial pressure and pulmonary vascular resistance produced by the infusion of $\mathrm{MgSO}_{4}$ was associated with a proportional fall in systemic and pulmonary vascular resistances, indicating that in this animal model $\mathrm{MgSO}_{4}$ was not a specific pulmonary vasodilator (2). A decrease in systemic arterial pressure and systemic vascular resistance has also been observed in newborn sheep with sepsis-mediated pulmonary hypertension treated with $\mathrm{MgSO}_{4}$ (17). In accord with these latter results, we found that $\mathrm{MgSO}_{4}$ exhibited a higher vasodilator activity in systemic than in pulmonary arteries. In fact, the pulmonary vasodilator effect was very weak. However, extrapolation of these in vitro results to the clinical situation of PPHN should be done with caution. The present experiments were performed under conditions $(\mathrm{pH}$ 7.4 and $95 \% \mathrm{O}_{2}$ ) quite different from those observed in whole animal experimental models or in patients with PPHN where both acidosis and hypoxia are present. Furthermore, our exper- iments were performed in 10-17-d-old piglets, whereas PPHN is observed during the first days after birth (1). Even when important developmental differences in pulmonary vascular reactivity have been reported during the first days of life (23). 2-3-wk-old piglet or sheep have been widely used as experimental models of PPHN (e.g. see Refs 17 and 26).

Although the mechanism of $\mathrm{Mg}^{2+}$ vascular action is not fully understood, $\mathrm{Mg}^{2+}$ deficiency-induced potentiation of VSM contraction has been attributed generally to a reciprocal increase in $\mathrm{Ca}^{2+}$ influx into VSM cells $(7,8)$. Elevated $\left[\mathrm{Mg}^{2+}\right]_{0}$ relaxes VSM, primarily by decreasing $\left[\mathrm{Ca}^{2+}\right]$ through $\mathrm{Ca}^{2+}$-channel blockade (24), so that it has been considered as nature's physiologic $\mathrm{Ca}^{2+}$-channel blocker (9). The finding that $\mathrm{MgSO}_{4}$-induced vasodilation was reversed by increasing $\left[\mathrm{Ca}^{2+}\right]_{0}$ both in pulmonary and mesenteric arteries suggests that $\mathrm{MgSO}_{4}$ may have exerted $\mathrm{Ca}^{2+}$-channel blocking activity in our experiments. However, $\mathrm{Mg}^{2+}$ is a weak $\mathrm{Ca}^{2+}$ antagonist, several orders of magnitude less potent than typical $\mathrm{Ca}^{2+}$ channel blocking agents $(8,25)$ and less potent than other multivalent cations $\left(\mathrm{La}^{3+}, \mathrm{Cd}^{2+}, \mathrm{Mn}^{2+}, \mathrm{Co}^{2+}, \mathrm{Ni}^{2+}\right)$ to inhibit $\mathrm{Ca}^{2+}$ influx stimulated by agonists (10). Moreover, the efficacy of $\mathrm{Ca}^{2+}$ channel blockers in experimental models and in patients with pulmonary hypertension has been equivocal because they also produced a marked systemic hypotension (6. 26). In fact, in our in vitro model, nifedipine was also less potent to induce vasodilation in pulmonary than in mesenteric arteries (E. Villamor and F. Pérez-Vizcaino, unpublished resuits).

The vascular effects of $\mathrm{MgSO}_{4}$ have also been related to the production and release of several arachidonic acid metabolites. Eicosanoids are present in high concentrations in infants with PPHN and decreased after resolution of their disease (27). $\mathrm{Mg}^{2+}$ increased the release of prostacyclin by endothelial cells, and cyclooxygenase inhibitors abolished the vascular effects of $\mathrm{MgSO}_{4}$ infusion (15). Furthermore, it has been proposed that high $\left[\mathrm{Mg}^{2+}\right]$ in body fluids could bind to arachidonic acid, altering the synthesis or release of vasoconstrictor eicosanoids. mainly $\mathrm{TXA}_{2}$ (14). In the present experiments, the incubation of pulmonary and mesenteric arteries with a $\left[\mathrm{MgSO}_{4}\right]$ four times greater than normal, close to the concentration which produced pulmonary vasodilation in experimental models (16. 17), did not modify the vascular response to U46619. Therefore, changes of vasodilator or vasoconstrictor eicosanoids production does not appear to be present in our experiments. However, we must consider that nonvascular sources of eicosanoids were absent in our experiments, and that eicosanoids in PPHN may not come from the endothelium (28).

$\mathrm{Mg}^{2+}$ has been implicated in the regulation of the $\mathrm{L}$ arginine-NO pathway. Inhaled NO has been shown to be a specific pulmonary vasodilator in animal models of pulmonary hypertension $(3,28)$ and in infants with PPHN $(4,5) . \mathrm{Mg}^{2+}$ withdrawal-induced vasodilation in canine coronary arteries was inhibited by both hemoglobin and dichlorobenzamil but not by nifedipine, suggesting that the major site of $\mathrm{Mg}^{2+}$ inhibition of the NO probably involves endothelial $\mathrm{Ca}^{2+}$ influx via the $\mathrm{Na}^{+} / \mathrm{Ca}^{2+}$ exchange system $(12,13)$. Furthermore, rapid removal of extracellular $\mathrm{Mg}^{2+}$ also produced a transient 
endothelium- and $\mathrm{Ca}^{2+}$-dependent vasodilation and cyclic GMP accumulation in ovine pulmonary arteries (11). We have observed a transient endothelium-dependent vasodilation upon rapid $\mathrm{MgSO}_{4}$ removal in pulmonary and mesenteric arteries that was inhibited by L-NAME, indicating that $\mathrm{Mg}^{2+}$ removal produced a transient NO release from the endothelium. Because $\mathrm{Ca}^{2+}$ is obligatory for both VSM contraction and endothelial NO formation, $\mathrm{Mg}^{2+}$ could oppose the actions of $\mathrm{Ca}^{2+}$ at both sites (11). In spite of the endothelial NO synthase activation produced by acute removal of extracellular $\mathrm{Mg}^{2+}$. NO release and activity in VSM seem to be independent of the presence of $\mathrm{MgSO}_{4}$. In fact, we found similar pulmonary vasodilator effects of $\mathrm{ACh}$ and SNP and similar vasoconstrictor effects of $\mathrm{U} 46619$ in the presence of three different $\mathrm{MgSO}_{4}$ concentrations. Thus, the antagonism of NO release by physiologic concentrations of $\mathrm{MgSO}_{4}$ seems to act only acutely. In contrast, $\mathrm{Mg}^{2+}$ appears to be required for endotheliumdependent relaxation in canine coronary arteries $(13,30)$, but not in ovine pulmonary (11) or in cat cerebral or mesenteric arteries (31). The reasons for these differences between species and different blood vessels are presently unknown.

In conclusion, the present results demonstrated that in an in vitro porcine model $\mathrm{MgSO}_{4}$ exhibits a poor pulmonary selectivity. Furthermore, acute $\mathrm{MgSO}_{4}$ removal enhanced the release and/or action of the endogenous vasodilator NO. Thus, we speculate that the beneficial clinical effects of $\mathrm{MgSO}_{4}$ in PPHN may not be related to a direct vasodilator effect on pulmonary vascular smooth muscle.

\section{REFERENCES}

1. Roberts JD, Shaul PW 1993 Advances in the treatment of persistent pulmonary hypertension of the newborn. Pediatr Clin Nonth Am 40:983-1004

2. Ryan CA, Finer NN, Barrington KJ 1994 Effects of magnesium sulphate and nitric oxide in pulmonary bypertension induced by hypoxia in newbom pielets. Arch Dis Child 71:F151-F155

3. Roberts Jr JD, Chen T, Wain J, Polaner D, Dupuy P, Zapol WM 1992 Nitric oxide gas is a selective pulmonary vasodilator in the newbom lamb during hypoxemia and acidosis. Pediatr Res 31:A1270

4. Roberts JD, Polaner DM, Lang P, Zapol WM 1992 Inhaled nitric oxide in penistent pulmonary hypenension of the newbom. Lancet 340-819-820

5. Kinsella JP. Neish SR, Shaffer E. Abman SH 1992 Low-dose inhalational nitric oxide in persistent pulmonary hypertension of the newborn. Lancet 340:819-820

6. Drummond WE, Lock JE 1984 Neonatal "pulmonary vasodilator" drugs. Dev Pharmacol Ther $7: 1-20$

7. Aluura BT, Alturs BM 1981 Magnesium ions and contraction of vaseular smooth muscles: relationship to some vascular diseases. Fed Proc 40:2672-1679

8. Altura BM, Altura BT. Carella A, Gebrewold A. Murakawa T. Nishio A 1987 $\mathrm{Mg}^{2+}-\mathrm{Ca}^{2}$ interaction in contractility of vascular smooth muscle: $\mathrm{Mg}^{2+}$ versus organic calcium channel blockers on myogenic tone and agonist-induced responsiveness of blood vessels. Can J Physiol Pharmacol 65:729-745
9. Iseri LT, French JH 1984 Magnesium: nature's physiological calcium blocker (Editorial). Am Heart J 108:188-193

10. Ruess UT, Wallnofer A. Weir S. Cauvin C 1989 Receptor-operated calciumpermeable channels in vascular smooth muscle. I Cardiovase Pharmacol 14(Suppl 6): $\$ 49-558$

11. Gold ME Buga GM, Wood KS, Byms RE, Chaudhun G, Ignarro IJ 1990 Antagonistic modulatory roles of magnesium and calcium on release of endothelium derived relaxing factor and smooth muscle tone. Cire Res 66:355-366

12. Ku DD, Ann HS 1987 Magnesium deficiency produces endothelium-dependent vasorelaxation in canine coronary arteries. J Pharmacol Exp Ther 241:961-966

13. Ku DD, Ann HS 1991 Differential effects of magnesium on basal and agonist-induced EDRF in canine coronary arteries. J Cardiovase Pharmacol 17:999-1006

14. Flink EB, Dehdia HV, Dinsmore J, Doshi HM, Banks D, Hshieh P 1992 High-dose magnesium sulfate anenuates pulmonary oxygen toxicity. Crit Care Med 20:16921698

15. Nadler IL. Goodson S. Rude RK 1987 Evidence that prostacyclin mediates the vascular action of magnesium in humans. Hypertension 9:379-383

16. Abu-Osba YK, Rhydderck D, Balansundaram S, Gatal O, Rejal A. Halees Z Duran C 1990 Reduction of hypoxia-induced pulmonary hypertension (HIPH) by $\mathrm{MgSO}_{4}$ in sheep. Pediatr Res 27:35IA

17. Anderson ME, Burnette TM, Geiser DR, Janjindarnai W 1994 Magnesium antenuates puimonary bypertension due to hypoxia and group B streptococci. I Appl Physiol $77 ; 751-756$

18. Abu-Osba YK. Galal O. Manasra K. Rejial A 1992 Treatment of severe persistent pulmonary hypentension of the newborn with magnesium sulfate. Arch Dis Child 67:31-35

19. Tolsa J.F. Coning J. Sekarski N, Payot M. Micheli J-L. Calarne A 1995 Magnesium sulphate as an alternative and safe treatment for severe persistent polmonary bypertension of the newborn. Arch Dis Child 72:F184-F187

20. Perez-Vizcaino F, Casis O, Rodriguez R, Gomez LA, Garcia Rafanell J, Tamargo J 1993 Effects of the novel potassium channel opener, UR-8225, on contractile re sponses in rat isolated smooth muscle. Br J Pharmacol 110:1165-1171

21. Villamor E. Perez-Vizcaino F. Ruiz T. Leza JC. Moro M. Tamargo J 1995 Group B Streptococcus and $E$ coll LPS-induced NO-dependent hyporesponsiveness to noradrenaline in isolated intrapulmonary aneries of neonatal piglets. $\mathrm{Br} J$ Pharmacol $115: 261-266$

22. Mclean RM 1994 Magnesium and its therapeutic uses: a review. Am J Med 96:63-76

23. Levy M, Tulloh RMR, Komai H, Stuart-Smith K. Haworth SG 1995 Maturation of the contractile response and its endothelial modulation in newborn porcine intrapulmonary anteries. Pediatr Res 38:25-29

24. D'Angelo EKG, Singer HA, Rembold CM 1992 Maynesium relaxes arterial smooth muscle by decreasing intracellular $\mathrm{Ca}^{2+}$ without changing intracellular $\mathrm{Mg}^{2+}, \mathrm{J} C \mathrm{Cl}$ Invest 89:1988-1994

25. Alborch E, Salom JB, Perales AJ, Torregrosa G, Miranda FI. Alabadi JA. Jover T 1992 Comparison of the anticonstrictor action of ditydropyridines (nimodipine and nicardipine) and $\mathrm{Mg}^{2+}$ in isolated human cerebral arteries. Eur J Pharmacol 229:83-89

26. Dickstein PJ, Trintade O. Goldberg RN, Bancalari E 1984 The effect of calcium antagonists on hypoxic pulmonary hypertension in the piglet. Pediatr Res 18:12621265

27. Dobyns El. Wescot JA. Kennaugh JM, Ross MN, Stenmark KR 1994 Eicosanoids decrease with successful extracorporeal membrane oxygenation therapy in neonatal pulmonary hypertension. Am J Respir Crit Care Med 149:873-880

28. Warner AE, Molina R, Bnin ID 1987 Uptake of bloodborne bacteria by pulmonary intravascular macrophages and coosequent inflammatory responses in sheep. Am Rev Respir Dis 136:683-693

29. Frostell C, Fratacci MD, Wain JC, Jones R, Zapol WM 1991 Inhaled nitric oxide. A selective pulmonary vasodilator reversing hypoxic pulmonary vasoconstriction. Circulation 83:2038-204?

30. Altura BT, Altura BM 1987 Endothelium-dependent relaxation in coronary arteries requires magnesium ions. Br J Pharmacol 91:449-451

31. Farago M. Dora E, Horvath 1, Szabo C, Kovach AGB 1989 Contractile and endothelium-dependent dilatory responses of cerebral and mesenteric arteries at various $\mathrm{Mg}^{2 *}$ levels. J Vase Med Biol 1:85A 
Chapter XIII. Relaxant effects of carbon monoxide compared with nitric oxide in pulmonary and systemic vessels of newborn piglets (Pediatr Res. 2000; 48:546-553). 



\title{
Relaxant Effects of Carbon Monoxide Compared with Nitric Oxide in Pulmonary and Systemic Vessels of Newborn Piglets
}

\author{
EDUARDO VILLAMOR, FRANCISCO PÉREZ-VIZCAINNO, ANGEL L. COGOLLUDO, JESÚS \\ CONDE-OVIEDO, FRANCISCO ZARAGOZÁ-ARNÁEZ, J. GUSTAVO LÓPEZ-LÓPEZ, AND \\ JUAN TAMARGO
}

Department of Pediatrics, University Hospital Maastricht, Research Institute Growth and Development, Maastricht Universiry, 6202 AZ Maastricht, The Netherlands [E.V.]; and Department of Pharmacology, Institute of Pharmacology and Toxicology (CSIC). School of Medicine, Universidad Complutense, 28040 Madrid, Spain [F.P.-V., A.LC., J.C-O., F.Z-A. J.G.L-L., J.T.]

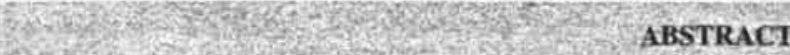

Nitric oxide (NO) has been implicated in a number of diverse physiologic processes, including regulation of vascular tone. Carbon monoxide $(\mathrm{CO})$ is another endogenously generated diatomic gas that may play an important physiologic role in vascular smooth muscle homeostasis. The purpose of this study was to compare the responses to exogenous $\mathrm{NO}$ and $\mathrm{CO}$ in isolated vessels (pulmonary arteries, pulmonary veins, and mesenteric arteries) from 12 - to 24 -h-old and 2 -wk-old piglets. Vessels precontracted with the thromboxane $\mathrm{A}_{2}$ mimetic U46619 $\left(10^{-7} \mathrm{M}\right)$ relaxed in response to $\mathrm{CO}\left(2 \times 10^{-6}\right.$ to $\left.2 \times 10^{-4} \mathrm{M}\right)$ and NO $\left(2 \times 10^{-9}\right.$ to $\left.2 \times 10^{-7} \mathrm{M}\right)$; these effects were not affected by endothelium removal but were completely abolished by the soluble guanylate cyclase inhibitor ODQ $\left(10^{-5} \mathrm{M}\right)$. In pulmonary arteries, the maximal relaxation to NO increased with postnatal age from $33 \pm 4 \%$ of the precontraction value to $56 \pm$ $5 \%$, in 12 - to 24 -h-old and 2 -week-old pigiets, respectively $(p<$ 0.01 ), but the response to $\mathrm{CO}$ decreased from $25 \pm 3 \%$ to $12 \pm$ $1 \%$, respectively $(p<0.01)$. The maximal response to $\mathrm{CO}$ was greater in pulmonary veins than in pulmonary or mesenteric arteries for both age groups $(p<0.01)$. Vasorelaxation induced by endogenous NO (stimulated by acetylcholine) was also greater in pulmonary veins when compared with pulmonary arteries and increased with postnatal age in both vessels. In contrast, no age-related differences were observed in the vasorelaxation induced by the cGMP analog 8-bromo cGMP in pulmonary arteries. When the response to NO was analyzed under three different extracellular $\mathrm{O}_{2}$ concentrations $\left(\mathrm{Po}_{2} 4.51 \pm 0.03\right.$.
$19.32 \pm 0.17$, and $86 \pm 0.62, \mathrm{kPa})$, no significant differences were found. However, in the presence of superoxide dismutase $(100 \mathrm{U} / \mathrm{mL})$. the response to $\mathrm{CO}$ remained unchanged, and the response to NO improved in pulmonary arteries from 2-week-old but not from newborn piglets. In conclusion, both $\mathrm{NO}$ and $\mathrm{CO}$ relaxed neonatal vessels through soluble guanylate cyclase activation. However, when compared with NO. CO exhibited a poor vasorelaxant activity. Pulmonary vasorelaxation induced by NO increased with postnatal age, whereas that induced by $\mathrm{CO}$ decreased. Changes in extracellular oxygen concentration did not alter the pulmonary vascular response to NO. However, the presence of superoxide dismutase improved the response to NO. indicating that oxidant activity limits the vasorelaxant response to NO but not to CO. (Pediatr Res 48: 546-553, 2000)
NO, nitric oxide
$\mathrm{CO}$, carbon monoxide
sGC, soluble guanylate cyclase
HO, heme oxygenase
SOD, superoxide dismutase
U46619, 9,11-dideoxy-1 I $\alpha, 9 \alpha$-epoxymethano-prostaglandin $\mathrm{F}_{2 \mathrm{a}}$ (thromboxane $\mathrm{A}_{2}$ analog)

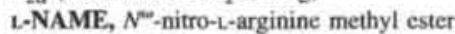
ODQ, 1 H-[1,2,4]oxadiazolo[4,3-a]quinoxalin-1-one (sGC inhibitor)

NO is known to be involved in the regulation of multiple physiologic processes, including the regulation of pulmonary

Received October 19, 1999, accepted March 5, 2000

Correspondence: E. Villamor, M.D., Department of Pediatrics, University Hospital Maastricht, P. Debyelaan 25, P. . Box 5800, 6202 AZ Maastricht, The Netherlands

Supported by SAF $99 / 0069$ and CAM 08.4/0019/1998 grants. F. Ptrez-Vizcaino and A.L Cogolludo are supported by grants from the Comunidad Autónoma de Madrid. vascular tone (1). On the other hand, another diatomic gas, $\mathrm{CO}$, traditionally considered as a toxic pollutant, poisons by binding to the iron-containing heme group found in $\mathrm{Hb}$ and other enzymes (2). Recently, evidence is accumulating that $\mathrm{CO}$ can be also a physiologic endogenous regulator $(2,3), \mathrm{CO}$ appears to mimic many of the actions of NO, including smooth muscle relaxation and inhibition of platelet aggregation (4), which are mainly mediated through the activation of SGC (5). 
$\mathrm{CO}$ is produced endogenously by two sources, i.e. enzymatic peroxidation of microsomal lipids and heme destruction catalyzed by $\mathrm{HO}(2,3)$. HOs are rate-limiting enzymes that catalyze the conversion of heme into $\mathrm{CO}$, iron, and biliverdin (3). Two distinct forms of $\mathrm{HO}$ have been characterized, including an inducible $\mathrm{HO}-1$ and a constitutively expressed $\mathrm{HO}-2$ (3). $\mathrm{HO}-2$ has been localized in several tissues, including endothelial cells and adventitial nerves of blood vessels (6). In contrast, HO- 1 is scarcely expressed under basal conditions, but it is induced widespread after several types of stressful stimuli, including hypoxia, endotoxins, and ischemia-reperfusion (7. 8). Furthermore, a protective role of $\mathrm{HO}-1$ in several inflammatory conditions has been suggested $(3,9)$.

The ability of $\mathrm{CO}$ to induce vasorelaxation has long been known (10), CO-induced vasodilation has been described in many vascular beds from several species (11-13). However, it is not a universal finding (12), and the sensitivity of the different vessels to $\mathrm{CO}$ is variable (11-13). A vasoregulatory role for endogenous $\mathrm{CO}$ produced by constitutive $\mathrm{HO}-2$ has been postulated in the maintenance of sinusoidal tone in the perfused rat liver (14) and the vascular tone of porcine distal pulmonary arteries (6). Additionally, endogenously released $\mathrm{CO}$ as a consequence of $\mathrm{HO}-1$ induction participated in the regulation of vascular contractility in rat aorta (15) and fetal lamb ductus arteriosus (16). An interaction between $\mathrm{CO}$ and NO may also significantly contribute to the fine-regulation of vascular tone $(3,17)$.

At birth, important structural and functional changes are produced in the pulmonary circulation to replace the placenta for gas exchange (18). This transformation is not limited to the first moments of extrauterine life, but it extends during the subsequent weeks or even months $(18,19)$. The mechanisms regulating birth-related changes in pulmonary circulation are incompletely understood, and numerous vasoactive factors are involved $(1,20)$. As mentioned above, a possible role for $\mathrm{CO}$ has been considered in the control of ductus arteriosus tone (16) but not in pulmonary or other vessels during the perinatal period. However, in the newborn period, the substrate for $\mathrm{CO}$ production, heme, is readily available, and increased $\mathrm{HO}$ activity, and consequently, an increased $\mathrm{CO}$ production, has been described in newborns compared with adults (21). In fact, the pulmonary excretion rate of $\mathrm{CO}$ and end-tidal breath $\mathrm{CO}$ have been proposed as methods to estimate bilirubin production (21). The possible physiologic role of this increased production of $\mathrm{CO}$ remains unknown.

Unfortunately, to the best of our knowledge, neither exogenous $\mathrm{CO}$-induced vasodilation nor the role of endogenous $\mathrm{CO}$ in vascular tone has been studied in vessels from newborn animals. We hypothesized that if $\mathrm{CO}$ plays a role in the control of neonatal vascular tone, exogenous $\mathrm{CO}$ should present the ability to relax neonatal vessels. In the present study, we have. therefore, examined the ability and the mechanisms of $\mathrm{CO}$ to induce vasorelaxation in pulmonary arteries, pulmonary veins, and mesenteric arteries from 12- to 24-h-old and 2-week-old piglets. In addition, we compared $\mathrm{CO}$ - to NO-induced vasorelaxation and studied the response under different oxygen concentrations. The effects of superoxide anions produced within the tissue in modulating the response to $\mathrm{CO}$ and $\mathrm{NO}$ were also evaluated.

\section{METHODS}

Tissue preparation. Male neonatal piglets aged 12-24 h ( $n=9)$ and $2 \mathrm{wk}(n=20)$, obtained from a local farm, were killed by exsanguination after being anesthetized with sodium pentobarbitone $(100 \mathrm{mg} / \mathrm{kg})$. These procedures were approved by the Complutense University Animal Care and Use Committee. The lungs and mesenteric beds were rapidly immersed in cold $\left(4^{\circ} \mathrm{C}\right)$ Krebs solution (composition in $\mathrm{mM}: \mathrm{NaCl} 118$, $\mathrm{KCl}$ 4.75, $\mathrm{NaHCO}_{3} 25, \mathrm{MgSO}_{4} 1.2, \mathrm{CaCl}_{2} 2.0, \mathrm{KH}_{2} \mathrm{PO}_{4} 1.2$, and glucose 11). Pulmonary arteries and veins (third branch, internal diameter, 0.5-2 mm) and mesenteric arteries (internal diameter, 1-2 mm) were carefully dissected free of surrounding tissue and cut into rings of $2-3 \mathrm{~mm}$ of length under a dissection microscope (22-24). Except as otherwise stated, the endothelium of the vessels was removed by gently rubbing the intimal surface of the rings with a metal rod, and the lack of functional endothelium was further confirmed by the failure of acetylcholine to relax vessels previously contracted by noradrenaline $\left(10^{-5} \mathrm{M}\right)$. Two L-shaped stainless-steel wires were inserted into the arterial lumen, and the rings were introduced into Allhin organ chambers filled with Krebs solution at $37^{\circ} \mathrm{C}$, gassed with $95 \% \mathrm{O}_{2} / 5 \% \mathrm{CO}_{2}$. One wire was attached to the chamber and the other to an isometric force-displacement transducer coupled to a signal amplifier (model PRE 206-4, Cibertec, Madrid) and connected to a Hewlett Packard computer via an analog to digital interface. Contractile tension was recorded by an REGXPC computer program (Cibertec, Madrid), as previously described (22-24). The rings were initially stretched to a resting tension of $0.3 \mathrm{~g}$ (pulmonary arteries of 12- to 24-h-old animals), $0.5 \mathrm{~g}$ (pulmonary arteries of 2-wk-old animals, pulmonary veins of both groups), $1 \mathrm{~g}$ (mesenteric arteries of 12- to 24-h-old animals), or $2 \mathrm{~g}$ (mesenteric arteries of 2-wk-old animals) and allowed to equilibrate for 60-90 min. During this period, tissues were restretched and washed every $30 \mathrm{~min}$ with warm Krebs solution.

Experimental protocols. After equilibration, the rings were precontracted with the thromboxane $A_{2}$ mimetic U46619 $\left(10^{-7}\right.$ M). In previous experiments, we demonstrated that this concentration produces approximately $80 \%$ of the maximal U46619-induced contraction in piglet pulmonary vessels ( 22 . 23). When the contractile response reached a stable tension, concentration-response curves to $\mathrm{CO}$ and $\mathrm{NO}$ were conducted by addition of increasing volumes of Krebs solution saturated with $\mathrm{CO}$ or NO. To prepare these solutions, two vials containing $20 \mathrm{~mL}$ of Krebs solution were initially bubbled with $\mathrm{N}_{2}$ for $10 \mathrm{~min}$ and then continuously bubbled with NO $(450 \mathrm{ppm})$ or $\mathrm{CO}$ (purity $>99 \%$ ). Continuous bubbling of the $20-\mathrm{mL}$ Krebs solution vial was started at least $5 \mathrm{~min}$ before the addition of the first dose of $\mathrm{CO}$ or $\mathrm{NO}$ and maintained during the rest of the experiment. The concentrations of $\mathrm{NO}$ and $\mathrm{CO}$ in the saturated solution were estimated from the solubility of $\mathrm{CO}$ and $\mathrm{NO}$ in water at $25^{\circ} \mathrm{C}$ and $1 \mathrm{~atm}$ of pressure $\left(9.687 \times 10^{-4} \mathrm{M}\right.$ and $1.931 \times 10^{-3} \mathrm{M}$, respectively). Actual NO concentrations of Krebs solution saturated with $450 \mathrm{ppm}$ of $\mathrm{NO}$ were measured 
using a selective NO electrode (ISO-NO), which was calibrated using the titration method (i.e. $\mathrm{NO}_{2} \mathrm{Na}$ in the presence of $\mathrm{H}_{2} \mathrm{SO}_{4}$ and $\mathrm{KI}$ ) according to the manufacturer (WPI Inc., Sarasota, FL, U.S.A.). The measured values in four independent determinations $\left(8.9 \pm 0.5 \times 10^{-7} \mathrm{M}\right)$ were in good agreement with those calculated from the solubility of NO $\left(8.6 \times 10^{-7} \mathrm{M}\right)$ considering the dilution factor $(450 \mathrm{ppm})$. The use of NO at $450 \mathrm{ppm}$ instead of pure NO has the advantage that there is no need to further dilute the saturated solution and that the half-life of NO in solution is higher at lower concentrations (25). We assumed that the loss of added $\mathrm{CO}$ or NO from the Krebs solution at the time of measuring relaxation was negligible. Because this assumption was not strictly correct, actual concentrations of $\mathrm{CO}$ or NO in the organ chamber might be somewhat lower than estimated (11).

To evaluate the role of endothelium in the vascular response to $\mathrm{CO}$ and NO, some experiments were performed in endothelium-intact pulmonary arteries. Additionally, the role of sGC stimulation in $\mathrm{CO}$ - and $\mathrm{NO}$-induced vasorelaxation was analyzed using the specific inhibitor of this enzyme, ODQ $\left(10^{-5}\right.$ M; (26). Finally, to evaluate whether superoxide anions produced within the tissue modulate the response to $\mathrm{CO}$ and $\mathrm{NO}$, some experiments were performed in the presence of the superoxide scavenger SOD $(100 \mathrm{U} / \mathrm{mL})$. Both ODQ and SOD were added after U46619-induced contractions reached steadystate and $15 \mathrm{~min}$ before the concentration-response curve to $\mathrm{CO}$ or NO.

In another group of experiments, the vascular effects of NO in pulmonary arteries were tested under different $\mathrm{O}_{2}$ conditions. For that purpose, the organ chambers were bubbled with $21 \% \mathrm{O}_{2} / 5 \% \mathrm{CO}_{2} / 74 \% \mathrm{~N}_{2}, 95 \% \mathrm{~N}_{2} / 5 \% \mathrm{CO}_{2}$, or $95 \% \mathrm{O}_{2} / 5 \%$ $\mathrm{CO}_{2}$. The $\mathrm{Po}_{2}$ values were measured by a blood gas analyzer (BGA electrolyte, Instrumentation Laboratory Inc., Lexington, MA, U.S.A.). Bubbling with the new gas mixture was started $15 \mathrm{~min}$ before the addition of U46619 and maintained for the rest of the experiment.

Additionally, concentration-response curves to acetylcholine $\left(10^{-8}\right.$ to $\left.10^{-5} \mathrm{M}\right)$ were performed in endothelium-intact vessels in the absence or in the presence of the NO synthase inhibitor L-NAME $\left(10^{-4} \mathrm{M}\right)$. In these experiments, the vessels were exposed to L-NAME for $20 \mathrm{~min}$ before the concentrationresponse curves were started. Finally, concentration-response curves to the cell membrane-permeable analog of cGMP, 8-bromo cGMP $\left(10^{-5}\right.$ to $\left.5 \times 10^{-4} \mathrm{M}\right)$, were also performed.

Drugs. The following drugs were used: acetylcholine, LNAME, U46619, SOD (from bovine erythrocytes), 8-bromocGMP (Sigma Chemical Co., Alcobendas, Spain), ODQ (Tocris Cookson Ltd, Bristol, U.K.), NO (450 ppm, Air liquid, Madrid, Spain), and CO (premier grade $>99 \%$ purity, Carburos Metálicos, Barcelona, Spain). All the solid drugs were dissolved initially in distilled deionized water (except ODQ. which was dissolved in DMSO) to prepare a $10^{-2}, 10^{-3}$, or $10^{-4} \mathrm{M}$ stock solution, and further dilutions were made in Krebs. Preparation of $\mathrm{CO}$ - and NO-saturated solutions has been explained above.

Statistical analysis. Results are expressed as means \pm SEM of measurements in $n$ arteries. In each protocol, the vessels were obtained from at least four different animals, and a maximum of two vessels per animal was studied. The contractile responses were expressed as absolute values (milligrams), and the relaxant responses as a percentage of the precontractile tone. Statistically significant differences were calculated by means of a one-way ANOVA followed by a Newman-Keuls test. The level of $p<0.05$ was considered statistically significant.

\section{RESULTS}

U46619 $\left(10^{-7} \mathrm{M}\right)$ induced sustained contractile responses in all vessels studied (Table 1). The responses were significantly greater in pulmonary veins and mesenteric arteries than in pulmonary arteries and in vessels from 2-wk-old than from 12 to 24-h-old animals.

Both CO $\left(2 \times 10^{-6}\right.$ to $\left.2 \times 10^{-4} \mathrm{M}\right)$ and NO $\left(2 \times 10^{-9}\right.$ to $\left.2 \times 10^{-7} \mathrm{M}\right)$ caused concentration-dependent relaxation of U46619-prestimulated pulmonary arteries, pulmonary veins, and mesenteric arteries from 12- to 24-h-old and 2-wk-old piglets (Figs. 1 and 2). Addition of similar volumes of Krebs solution saturated with $\mathrm{N}_{2}$ in place of $\mathrm{NO}$ or $\mathrm{CO}$ had no measurable effect on vessel tone. The vasorelaxant potency of $\mathrm{NO}$ was markedly greater than that of $\mathrm{CO}$ in all the vessels and in both age groups tested. In fact, the detectable threshold concentrations for the vasorelaxant effects of $\mathrm{CO}$ and $\mathrm{NO}$ were approximately $2 \times 10^{-5} \mathrm{M}$ and $5 \times 10^{-9} \mathrm{M}$, respectively. In addition, Figures 1 and 2 show that the relaxing effects of both $\mathrm{CO}$ and NO were completely inhibited by ODQ $\left(10^{-5} \mathrm{M}\right)$, a specific inhibitor of $\mathrm{sGC}$. Pulmonary veins from either 12 - to 24-h-old or 2-wk-old animals were the most-sensitive vessels $(p<0.05)$ to the relaxant effect of $\mathrm{CO}$ (relaxation at the maximum $\mathrm{CO}$ concentration tested was $37.4 \pm 2.4 \%$ and $33.5 \pm 4.1 \%$, respectively) compared with pulmonary ( $24.5 \pm$ $3.1 \%$ and $12 \pm 1.1 \%$, respectively) or mesenteric arteries $(7.9 \pm 1.1 \%$ and $10.1 \pm 2.4 \%$, respectively). In the $12-$ to 24-h-old piglets, NO-induced relaxation was significantly $(p<$ 0.05 ) smaller in pulmonary arteries (relaxation at the maximum NO concentration tested was $33.2 \pm 3.9 \%$ ) than in pulmonary veins $(71.8 \pm 3.6 \%)$ or mesenteric arteries $(73.1 \pm 3.0 \%)$. whereas in the 2 -wk-old piglets, NO-induced relaxation was very similar in pulmonary arteries and veins (Fig. 2). Therefore, $\mathrm{CO}$-induced vasorelaxation clearly decreased with postnatal age in pulmonary arteries (Fig. 1A), whereas no change was observed in pulmonary veins or mesenteric arteries (Fig. 1, $B$ and $C$ ). In contrast, NO-induced relaxation augmented with postnatal age in pulmonary arteries (Fig. 2A), but was only weakly modified in pulmonary veins (Fig. 2B). Because both $\mathrm{CO}$ - and $\mathrm{NO}$-induced relaxation were mediated by an activa-

Table 1. Contractile responses induced by $U 46619\left(10^{-7} \mathrm{M}\right)$ in piglet vessels

\begin{tabular}{|c|c|c|c|c|}
\hline Vessel & $n$ & $\begin{array}{c}\text { 12- to } \\
\text { 24-h-old } \\
\text { Tension (mg) }\end{array}$ & $n$ & $\begin{array}{c}\text { 2-wk-old } \\
\text { Tension (mg) }\end{array}$ \\
\hline Pulmonary artery & 60 & $471 \pm 26$ & 51 & $1163 \pm 67 \dagger$ \\
\hline Pulmonary vein & 25 & $1108 \pm 110^{\circ}$ & 20 & $2913 \pm 257 \dagger$ \\
\hline Mesenteric artery & 15 & $1059 \pm 91^{\circ}$ & 15 & $2583 \pm 298 \dagger$ \\
\hline
\end{tabular}

$* p<0.05$ vs pulmonary arteries, $+p<0.05$ vs 12 - to 24 - b-old. 

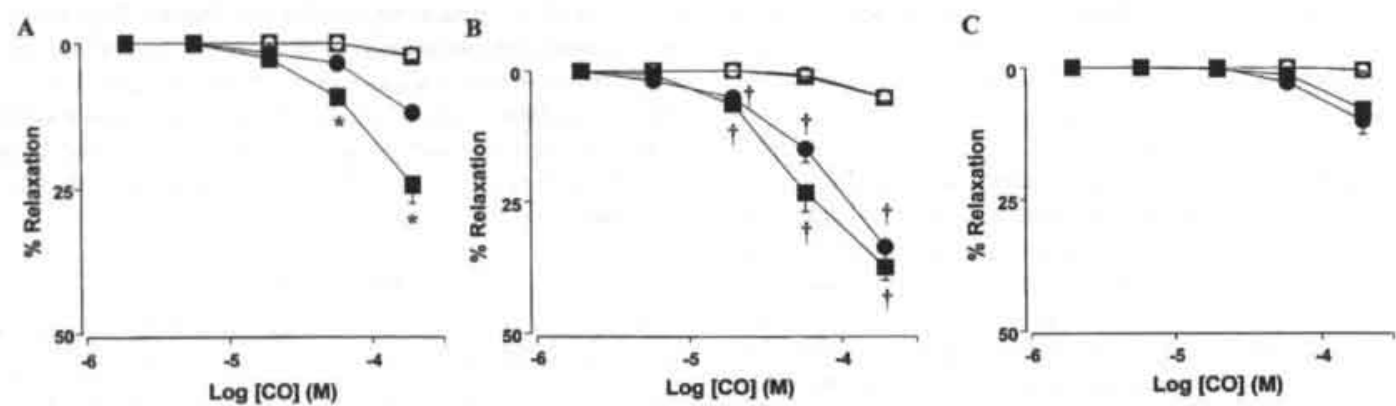

Figure 1. Concentration-dependent relaxant effects of $\mathrm{CO}$ in endothelium-denuded pulmonary arteries $(A)$, pulmonary veins $(B)$, and mesenteric arteries $(C)$ of 12- to 24-b-old (… $\square$ ) and 2-wk-old piglets $(\bullet, 0)$. Changes in tension induced by CO are expressed as percentage of the contraction induced by U46619 $\left(10^{-7}\right.$ M). The experiments were performed in the absence (solid symbols) or presence (open symbols) of the sGC inhibitor ODQ (10 ${ }^{-5} \mathrm{M}$ ), Each point represents the mean \pm SEM of $n$ arteries. Pulmonary arteries: $n=10$ (control, both groups of age), $n=6$ ( + ODQ, both groups of age). Pulmonary veins: $n=10$ (control, both groups of age), $n=6$ ( $+\mathrm{ODQ}$, both groups of age). Mesenteric arteries: $n=8$ (control, both groups of age), $n=6$ ( $+\mathrm{ODQ}$, both groups of age). " $p<$ 0.0512 - to 24 -h-old vs 2 -wk-old. $+p<0.05$ pulmonary artery vs pulmonary vein.
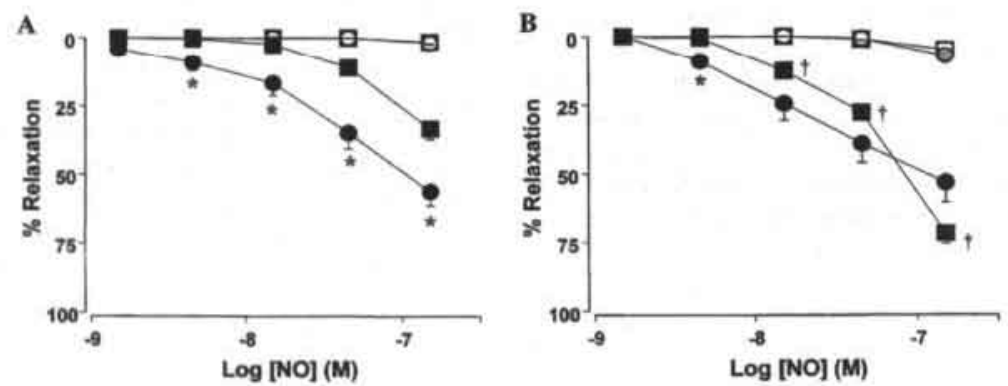

Figure 2. Concentration-dependent relaxant effects of NO in endothelium-denuded pulmonary arteries $(A)$ and puimonary veins (B) of 12-to 24-b-old (iil, $\square$ ) and 2-wk-old piglets $(\bullet, \mathrm{O})$. Changes in tension induced by $\mathrm{CO}$ are expressed as a percentage of the contraction induced by $\mathrm{U} 46619\left(10^{-7} \mathrm{M}\right)$. The experiments were performed in the absence (solid symbols) or the presence (open symbols) of the $\mathrm{SGC}$ inhibitor $\mathrm{ODQ}\left(10^{-5} \mathrm{M}\right)$. Each point represents the mean $\pm \mathrm{SEM}$ of $n$ arteries. Pulmonary arteries: $n=15$ (control, 12- to 24-h-old), $n=13$ (control, 2-wk-old), $n=6$ (+ODQ, both groups of age). Pulmonary veins: $n=10$ (control, both groups of age), $n=6$ ( $+\mathrm{ODQ}$, both groups of age). $* p<0.0512$ - to 24 -h-old $v s$-wk-old. $\nmid p<0.05$ pulmonary artery vs pulmonary vein.

tion of sGC (as indicated by the inhibitory effects of ODQ), we analyzed the relaxant effect of the cGMP analog 8-bromocGMP. However, no significant differences were observed in the relaxant effects of 8-bromo-cGMP in endothelium-denuded pulmonary anteries from 12 - to 24 -h-old and 2 -wk-old piglets (Fig. 3).

The role of endothelium in the vasodilator effects of $\mathrm{CO}$ and $\mathrm{NO}$ in pulmonary arteries from 2-wk-old piglets is shown in Figure 4 . In endothelium-intact pulmonary artery rings, both $\mathrm{CO}$ and NO induced a relaxation that was similar to that induced in endothelium-free rings.

The endothelium-dependent relaxation induced by acetylcholine $\left(10^{-8}\right.$ to $\left.10^{-5} \mathrm{M}\right)$ increased with postnatal age $(p<$ 0.05 ) and was significantly greater in endothelium-intact pulmonary veins than in pulmonary arteries for both age groups (Fig. 5). The addition of the NO synthase inhibitor L-NAME $\left(10^{-4} \mathrm{M}\right)$ increased $\mathrm{U} 46619$-induced contractions by $18 \pm 2 \%$ (pulmonary arteries of 12- to 24-h-old piglets), $32 \pm 4 \%$ (pulmonary arteries of 2-wk-old piglets, $p<0.05$ versus 12 - to 24-h-old piglets), $3.4 \pm 0.7 \%$ (pulmonary veins of 12 - to 24-h-old piglets) and $7 \pm 1 \%$ (pulmonary veins of 2 -wk-old piglets, $p<0.05$ versus 12 - to 24 -h-old piglets). The increase of the U46619-induced contraction produced by L-NAME

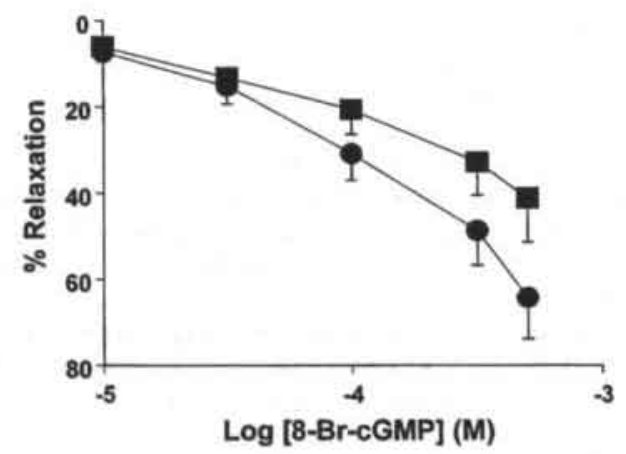

Figure 3. Concentration-dependent relaxant effects of the cGMP analog 8-bromo cGMP (8-Br-cGMP) in endothelium-denuded pulmonary arteries of 12- to 24-h-old $(n=6)$ and 2-wk-old piglets $(\bullet, n=6)$. Changes in tension induced by 8 -bromo cGMP are expressed as a percentage of the contraction induced by $\mathrm{U} 46619\left(10^{-7} \mathrm{M}\right)$. Each point represents the mean $\pm \mathrm{SEM}$ of $n$ arteries.

reached a stable value after $20 \mathrm{~min}$ of exposure. Acetylcholineinduced relaxation was strongly inhibited by L-NAME in both pulmonary arteries and veins (Fig. 5), which indicates that the 

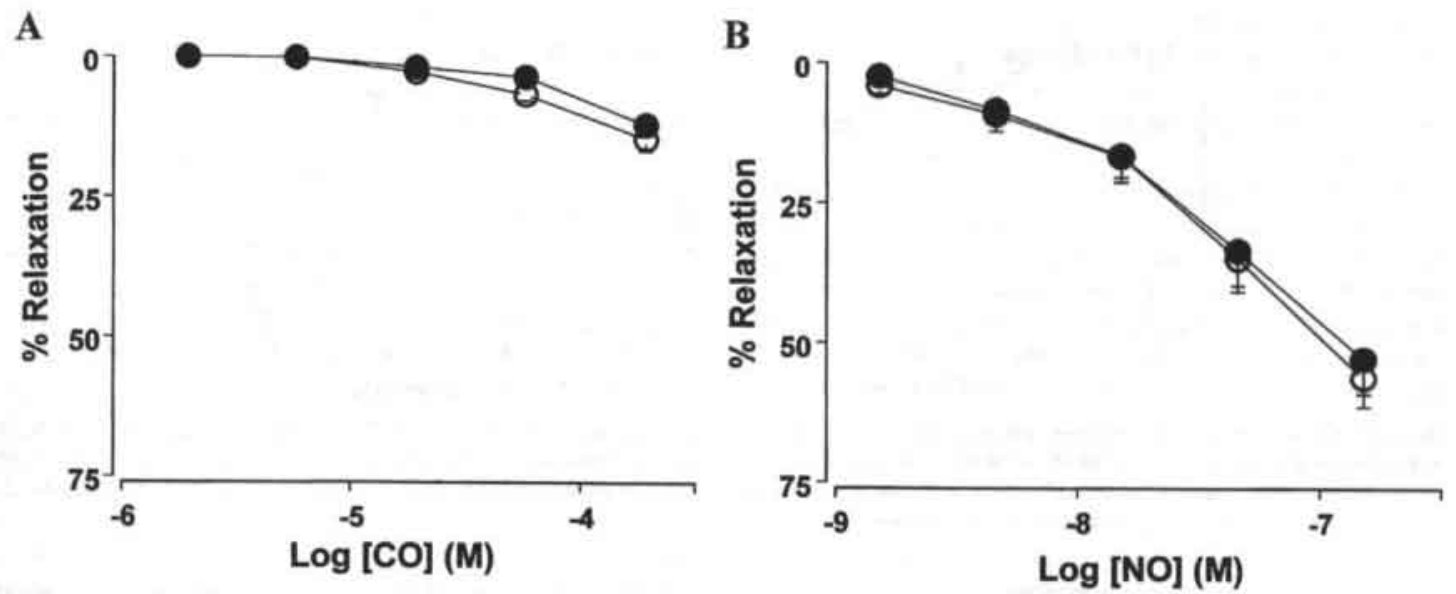

Figure 4. The effect of endothelium presence on $(A) \mathrm{CO}$ - and $(B)$ NO-induced vasorelaxation in 2-wk-old piglet pulmonary arteries. Arteries with endothelium $\left(\mathrm{O}, n=8\right.$ for both $\mathrm{CO}$ and NO experiments) and without endothelium $\left(\Theta, n=13\right.$ for both $\mathrm{CO}$ and NO experiments) were precontracted with U46619 (10 ${ }^{-7}$ M). Changes in tension induced by $\mathrm{CO}$ or NO are expressed as percentage of the contraction induced by $\mathrm{U} 46619\left(10^{-7} \mathrm{M}\right)$. Each point represents the mean \pm SEM of $n$ vessels.
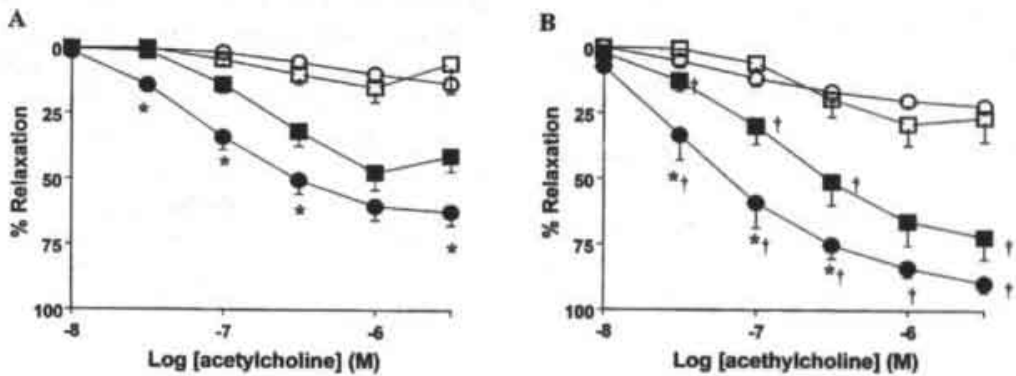

Figure 5. Concentration-dependent relaxant effects of acetylcholine in endothelium-intact pulmonary arteries $(A)$ and pulmonary veins $(B)$ of 12 - to 24 -h-old (-D) and 2-wk-old piglets $(\bullet, O)$. Changes in tension induced by acetylcholine are expressed as percentage of the contraction induced by $U 46619\left(10^{-7} \mathrm{M}\right)$. The experiments were performed in the absence (solid symbols) or the presence (open symbols) of the NO synthase inhibitor L-NAME (10 $\left.{ }^{-4} \mathrm{M}\right)$. Each point represents the mean \pm SEM of $n$ arteries. Pulmonary arteries: $n=11$ (control, 12 - to 24-h-old), $n=10$ (control, 2-wk-old), $n=6$ ( + L-NAME, both groups of age). Pulmonary veins: $n=10$ (control, 12- to 24-b-old), $n=11$ (control, 2-wk-old), $n=6\left(+\mathrm{L}\right.$-NAME, both groups of age), ${ }^{*} p<0.05$ newborn $v s 2$-wk. $\dagger p<0.05$ pulmonary antery $v s$ pulmonary vein.

endothelium-dependent relaxation is mediated mainly by the release of NO from the endothelial cells.

In endothelium-intact pulmonary arteries from 2-wk-old piglets, changing the bubbling gas mixture from $95 \% \mathrm{O}_{2}\left(\mathrm{Po}_{2}\right.$, $86 \pm 0.62 \mathrm{kPa})$ to $0 \% \mathrm{O}_{2}\left(\mathrm{Po}_{2}, 4.51 \pm 0.03 \mathrm{kPa}\right)$ or $21 \% \mathrm{O}_{2}$ $\left(\mathrm{PO}_{2}, 19.32 \pm 0.17 \mathrm{kPa}\right)$ had no significant effect on basal tone. Furthermore, these different $\mathrm{PO}_{2}$ values in the organ chamber did not affect NO-induced vasorelaxation (Fig. 6).

Addition of the superoxide scavenger SOD $(100 \mathrm{U} / \mathrm{mL})$ had no significant effect on U46619-induced contractions in endothelium-denuded pulmonary arteries. Furthermore, the vasorelaxant response to $\mathrm{CO}$ in SOD-treated arteries from 2-wk-old piglets was similar to that in untreated controls (not shown). However, the response to NO was significantly increased in pulmonary arteries from 2-wk-old (Fig. 7B) but not 12- to 24-h-old piglets (Fig. 7A).

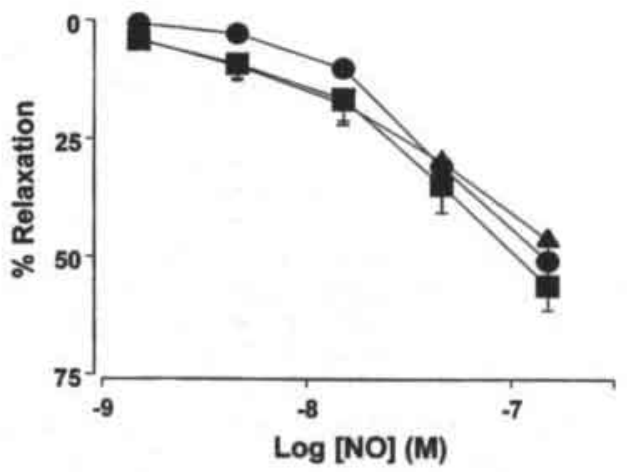

Figure 6. Effects of oxygen concentration on NO-induced vasorelaxation in 2-wk-old piglet pulmonary arteries. Organ chambers were bubbled with $0 \%$ $(\bullet, n=7), 21 \%(\mathbf{\Lambda}, n=9)$ or $95 \% \mathrm{O}_{2}(\mathbf{m}, n=13)$. Changes in tension induced by NO are expressed as percentage of the contraction induced by U $46619\left(10^{-7} \mathrm{M}\right)$. Each point represents the mean \pm SEM of $n$ arteries. 
A

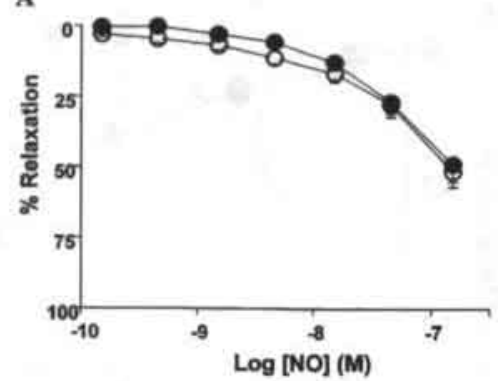

B

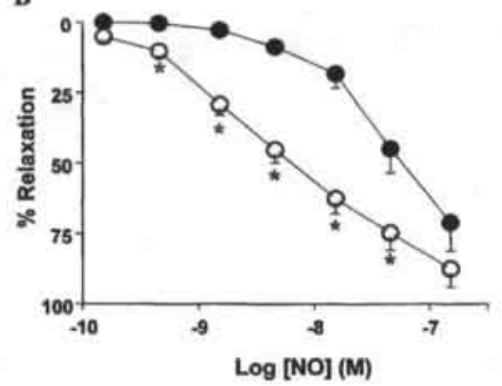

Figure 7. Effects of SOD on NO-induced vasorelaxation in 12- to 24-h-old $(A)$ and 2 -wk-old $(B)$ piglet pulmonary arteries. The experiments were performed in the absence ( $)$ or the presence $(O)$ of SOD (100 U/mL). Changes in tension induced by NO are expressed as percentage of the contraction induced by U46619 $\left(10^{-7} \mathrm{M}\right)$ Each point represents the mean $\pm \mathrm{SEM}$ of $n$ arteries. $N=15$ (control, $12-$ to 24 -h-old), $n=13$ (control, 2 -wk-old), $n=6$ ( + SOD, $12-$ to $24-\mathrm{b}$-old), $n=11(+$ SOD, 2 -wk-old). $* p<0.05$ SOD-treated arteries vs controls.

\section{DISCUSSION}

The present study demonstrated that $\mathrm{CO}$ relaxed vessels of 12- to 24-h-old and 2-wk-old piglets. Moreover, CO-induced vasorelaxation was more marked in pulmonary arteries in the first day of extrauterine life than that of 2-wk-old piglets and in pulmonary veins than in pulmonary or mesenteric arteries. Moreover, the vasorelaxant effect of $\mathrm{CO}$ was endotheliumindependent but abolished by specific inhibition of SGC. However, when compared with NO, CO was a weak vasorelaxant, the relative potency of $\mathrm{CO}$ to $\mathrm{NO}$ being approximately 1:1000. In contrast to $\mathrm{CO}$, NO- and acetylcholine-induced vasorelaxation increased with postnatal age in piglet pulmonary arteries. Changes in extracellular oxygen concentration did not affect NO-induced vasorelaxation. Finally, in 2-wk-old pulmonary arteries, SOD improved the response to NO but not to CO, whereas in 12- to 24-h-old pulmonary arteries, SOD was without effect on NO- induced vasorelaxation.

Several mechanisms have been proposed to explain the vasorelaxation induced by $\mathrm{CO}$ and $\mathrm{NO}$ (17) including not only activation of SGC (11) but also stimulation of $\mathrm{K}^{+}$channels $(17$, 27) or inhibition of the cytochrome P450 monooxygenase (28, 29). Hussain et al. (30) have shown that ODQ completely abolished relaxation of rabbit aortic rings induced by $\mathrm{CO}$. whereas only a partial attenuation of NO-induced relaxation was achieved. In contrast, we found that ODQ completely abolished $\mathrm{CO}$ - and NO-induced relaxation, indicating that sGC was responsible for the effects of both vasorelaxants in piglet neonatal vessels. Similar findings have been reported for NOinduced vasorelaxation in pulmonary arteries of newborn lambs (31). Moreover, we have previously demonstrated that the NO donor sodium nitroprusside increased cGMP levels and relaxed pulmonary arteries from 2-wk-old piglets but neither $\mathrm{K}^{+}$channels nor the membrane $\mathrm{Na}^{+} / \mathrm{K}^{+}$ATPase were involved in these effects (24). However, in the isolated lamb ductus arteriosus, $\mathrm{CO}$-induced vasorelaxation was not accompanied by a significant accumulation of cGMP (29).

$\mathrm{CO}$ produced a weak vasorelaxant effect, particularly when compared with NO. Similar results have been previously reported in several vascular beds (11). Inhaled CO in concentrations up to $1000 \mathrm{ppm}$ in adult rats and fetal lambs had no effect
$(32,33)$, whereas markedly lower concentrations of inhaled NO $(<5 \mathrm{ppm})$ are required to produce significant pulmonary vasorelaxation $(33,34)$. Differences in the activation of sGC have been proposed to explain the distinct vasorelaxant potency of $\mathrm{CO}$ and $\mathrm{NO}$ (35), i.e. enzymatic activity of sGC is increased approximately 100 - to 200 -fold by NO, but only by 4 to 5 -fold by $\mathrm{CO}(35)$. The activation of sGC by NO appears to be a complex process. First, NO binds to the heme group of the enzyme forming a hexacoordinate complex, which then converts to a pentacoordinate nitrosyl-heme (35-37). CO also forms a complex with the heme moiety of sGC, but unlike NO, only the six-coordinate complex is formed, which results in a weak activation of the enzyme (35-37). On the other hand, nanomolar concentrations of NO competitively prevent the binding of $\mathrm{CO}$ to the heme group of the SGC, thus reducing its vascular effect (37). The vasoconstrictor effect of L-NAME in our preparations indicates that NO is released from the endothelium under basal conditions. However, the presence of endothelium did not modify the relaxant effects of $\mathrm{CO}$, indicating that basal release of NO from the endothelium does not modulate the relaxant effect of $\mathrm{CO}$ in piglet pulmonary arteries.

Although blood vessels produce $\mathrm{CO}(38)$, whether this $\mathrm{CO}$ reaches a sufficient concentration to relax vascular smooth muscle remains unclear. The nonselective HO-2 inhibitor tin protoporphyrin IX has been shown to inhibit the endotheliumdependent relaxation induced by acetylcholine after inhibition of NO synthesis, suggesting an involvement of endotheliumderived $\mathrm{CO}(6)$. We found that the endothelium-dependent relaxation produced by acetylcholine was strongly reduced by the NO synthase inhibitor L-NAME, indicating that it is mainly mediated by the release of NO. This result, together with the low vasodilator potency of $\mathrm{CO}$, suggests that a possible role for $\mathrm{CO}$ as an endothelium-dependent vasodilator in neonatal pulmonary vessels would be small if any. However, this is an in vitro study, and, thus, extrapolation of the present results to in vivo vascular responses to $\mathrm{CO}$ and $\mathrm{NO}$ should be done with caution. Moreover, it is unclear whether endogenously generated $\mathrm{CO}$ has a vascular effect similar to that of exogenously applied $\mathrm{CO}$. In fact, the physiologic concentrations of $\mathrm{CO}$ and NO in the immediate vicinity of vascular smooth muscle cells 
in vivo are unknown (17). Nevertheless, studies in brain tissues (39) indicate that the concentrations of $\mathrm{CO}$ produced in vivo (1-200 $\mu \mathrm{M})$ are lower than those producing vascular relaxation in the present experiments. In contrast, these concentrations of $\mathrm{CO}$ produced significant relaxation in other vascular rings (11, 17).

Superoxide anions produced in several metabolic reactions inactivate NO, forming peroxynitrite (25). In fact, the superoxide scavenger SOD significantly increased the in vitro relaxant activity of NO (40). Moreover, the combination of high doses of inhaled $\mathrm{NO}(100 \mathrm{ppm})$ and $90 \% \mathrm{O}_{2}$ caused oxidative damage in mechanically ventilated newborn piglets, which was mitigated by the use of recombinant human SOD (41). Therefore, the use of SOD might be suggested as a way of reducing the toxicity and augmenting the response to inhaled NO, which may lead to novel clinical strategies to improve the treatment of neonatal pulmonary hypertension. Even when $\mathrm{CO}$ shares with NO some properties (i.e. activation of $\mathrm{sGC}$ and reaction with $\mathrm{Hb}$ ), $\mathrm{CO}$ is not a free radical and is not expected to react with superoxide. Accordingly, the antioxidant enzyme SOD had no effect on $\mathrm{CO}$-induced vasorelaxation but improved NO-induced vasorelaxation (but only in the 2-wk-old animals).

Fetal pulmonary arteries are exposed to a relatively hypoxic environment, and then at birth they are exposed to $21 \% \mathrm{O}_{2}$. It is well known that acetylcholine-induced endogenous production of NO is markedly influenced by the oxygen tension in the organ chamber $(42,43)$. Theoretically, extreme hyperoxia can destroy NO by an increased formation of superoxide anions. Additionally, an increased oxidative stress can produce oxidation of the heme group of sGC, resulting in loss of enzyme activity $(25,37)$. However, no differences in exogenous NOinduced vasorelaxation were observed when the organ chambers were bubbled with $0 \%, 21 \%$, or $95 \% \mathrm{O}_{2}$. This suggests that high $\mathrm{O}_{2}$ concentrations did not produce the effects mentioned above (i.e. increase in superoxide anions or oxidation of the heme group of sGC) to an extent sufficient to reduce NO-induced vasorelaxation in our experiments.

Pulmonary veins are the major site of action of a number of vasoactive factors in different animal species and at different ages $(44,45)$. In newborn piglets, we observed that the response not only to exogenous or endogenous NO but also to exogenous $\mathrm{CO}$ was greater in pulmonary veins than in pulmonary arteries. This difference was maintained in the 2 -wk-old piglets for the response to $\mathrm{CO}$ but not for NO. It has been demonstrated that basal concentrations, as well as the increase of cGMP in response to NO, were greater in pulmonary veins than in pulmonary arteries of newborn lambs (45). This could be accounted for, at least partly, by a higher activity of cGMP-specific phosphodiesterases, which produced faster hydrolysis and inactivation of cGMP in pulmonary arteries when compared with pulmonary veins (46).

In the present work, $\mathrm{CO}$-induced relaxation decreased in pulmonary arteries with postnatal age, whereas the cell membrane-permeable analog of cGMP 8-bromo-cGMP produced a similar degree of relaxation in pulmonary arteries from both groups of age. Because 8-bromo-cGMP is very resistant to being hydrolyzed by phosphodiesterases, the age-dependent changes in the effects of $\mathrm{CO}$ might be also attributed to an increase in phosphodiesterase activity during the first days of extrauterine life as described in ovine and mouse lung (47). In contrast, the vasorelaxant response to endogenous NO increased with age in piglet (48) and present results), sheep (49). and rabbit pulmonary arteries (43). We also found an agedependent increase in the vasodilator response to exogenous $\mathrm{NO}$ in piglet pulmonary arteries, suggesting that the agedependent increase to endogenous NO is not only related to increased synthesis but also to an increased action or decreased metabolism of NO. Morecroft and MacLean (43) found that SOD potentiated acetylcholine-induced relaxation in pulmonary arteries from newborn but not from adult rabbits and suggested that the age-dependent increase in the response to endogenous NO was because of an increased accumulation of superoxide in the newborn animals. In contrast, and unexpectedly, SOD did not affect NO-induced relaxation in pulmonary arteries from 12- to 24-h-old piglets but potentiated the relaxant response to NO in mesenteric arteries from these animals (not shown) and in pulmonary arteries from 2-wk-old piglets. Even when the reasons for the lack of effect of SOD in 12- to 24-h-old pulmonary arteries are unclear, several theoretical explanations can be raised: 1 ) reduced ability of exogenous SOD to penetrate cell membranes, 2) reduced endogenous superoxide production or increased endogenous antioxidant activity, and 3) differential effects of the peroxynitrites. Further studies involving the use of low-molecular-weight membranepermeant compounds that exhibit SOD-like activity (50) and SOD inhibitors are necessary to elucidate this point. Additionally, the use of SOD from a nonporcine source could have limited its effect in our experiments. However, bovine and porcine SOD have a high degree of homology in their sequences and similar kinetic variables (51) as to reasonably assume identical in vitro activity.

In conclusion, $\mathrm{CO}$ produced vasorelaxation in neonatal vessels by activation of sGC, but its vasorelaxant potency is markedly reduced compared with NO. Both $\mathrm{CO}$ - and NOinduced relaxation was greater in pulmonary veins than in pulmonary arteries. However, whereas NO-induced relaxation in pulmonary arteries was augmented with postnatal age, that induced by $\mathrm{CO}$ decreased. Changes in extracellular $\mathrm{O}_{2}$ concentration did not alter the pulmonary vascular response to NO. In contrast, the presence of SOD improved the response to NO in 2-wk-old piglets, indicating that oxidant activity limits the vasorelaxant response to NO but not to $\mathrm{CO}$. The functional significance of endogenous $\mathrm{CO}$ has not been established to date, but it might play, together with NO, a modulatory role in the regulation of vascular contractile responses. However, if the response to exogenous $\mathrm{CO}$ reflects the capacity of this gas to relax in vivo neonatal pulmonary vessels, its direct participation in the control of pulmonary vascular tone seems unlikely.

Acknowledgment. The authors thank C. Rivas for excellent technical assistance.

\section{REFERENCES}

1. Bames PJ, Liu SF 1995 Regulation of pulmonary vascular tone. Pharmacol Rev 47:87-131 
2. Marks GS, Bricn JF, Nakatsu K. McLaughlin BE 1991 Does carbon moeoxide have a physiological function? Trends Pharmacol Sci 12:185-188

3. Maines MD 1997 The beme oxygenase syatem: a regulator of secoed messenger gases. Anmu Rev Pharmacol Toxicol 37:517-554

4. Brune B, Utlrich V 1987 Inhibition of platelet aguregation by carbon monoxide is mediated by activation of guanylate cyclase. Mol Pharmacol 32:497-504

5. Kharitonov VG, Sharma VS, Pilz RB, Magde D, Koesling D 1995 Basis of guarylate cyclase activation by carbon monoxide. Proc Natl Acad Sci USA 92:2568-2571

6. Zakhary R. Gaine SP, Dinerman J. Ruat M, Flavahan NA, Sayder SH 1996 Heme oxygenase 2: endothelial and neuronal localization and rote in endothelium-dependent relaxation. Proc Natl Acad Sci USA 93:795-798

7. Okinaga S. Takahushi K, Takeda K, Yoahizawa M, Fujita H. Sasaki H, Shibahara S 1996 Regulation of human heme oxygenase-1 gene expression under thermal stress. Blood 87:5074-5084

8. Cantoni L. Rossi C, Rizzardini M, Gardina M, Ghezzi P 1991 Interleukin-I and numor necrosis factor induce hepatic beme oxygenase. Biochem J 279:891-894

9. Willis D, Moore AR. Frederick R, Willoughby DA 1996 Heme oxygenase: a novel target for the modulation of the inflammatory response. Nat Med 2:87-90

10. Duke HN, Killick EM 1952 Puimonary vasomotor responses of isolated perfused cat lungs to anoxia J Physiol (Lond) 117:303-316

11. Furchgot RF. Jothianandan D 1991 Endothelium-dependent and -independent vasodilation involving cyclic GMP: relaxation induced by nitric oxide, carbon monoxide and light. Blood Vessels 28:52-61

12. Brian Jr JE. Heistad DD, Faraci FM 1994 Effect of carbon monoxide on rabbit cerebral arteries. Stroke 25:639-643

13. Wang R. Wang Z, Wu L 1997 Carbon monoxide-induced vasoreiaxation and the underlying mechanisms. Br J Pharmacol 121:927-934

14. Sucrnatsu M, Goda N, Sano T, Kashiwagi S, Egawa T, Shinoda Y, Ishimura Y 1995 Carbon monoxide: an endogenous modulator of sinusoidal tone in the perfused rat liver. J Clin Invest $96: 2431-2437$

15. Sammut LA, Foresti R, Clark JE, Exon DJ, Vesely M, Sarathchandra P, Green CI. Motterlini R 1998 Carbon monoxide is a major coatributor to the regularion of vascular tone in aortas expressing high levels of haeme oxygenase-1. $\mathrm{Br}$ J Pharmacol 125:1437-1444

16. Coceani F, Kelsey L, Seidlitz E, Marks GS, McLaughlin BE, Vreman HI, Stevenson DK. Rabinovitch M. Ackerley C 1997 Carbon monoside formation in the ductus arteriosus in the lamb: implications for the regulation of muscle tone. $\mathrm{Br} J$ Pharmacol 120:599- 606

17. Wang $R 1998$ Resurgence of carbon monoxide: an endogenous gaseous vasorelaxing factor, Can J Physiol Pharmacol 76:1-15

18. Haworth SG. Hislop AA 1981 Adaptation of the pulmonary circulation to extrauterine life in the pig and its relevance to the human infant. Cardiovase Res 15:108-119

19. Perreault T. De Marte J 1993 Manurational changes in endothelium-derived relaxations in newbom piglet circulation. Am J Physiol 264:H302-H309

20. Ziegler JW, Ivy DD, Kinsella JP, Abman SH 1995 The role of nitric oxide. endothelin, and prostaglandins in the transition of the puimonary circulation. Clin Perinatol 22:387-403

21. Yao TC, Stevenson DK 1995 Advances in the diagnoxis and treatment of neonatal hyperbilimbinemia. Clin Perinatol 22:741-758

22. Pérez-Vizcaino F, Villamor E, Moro M. Tamargo J 1996 Lack of endotoxin-induced hyporesponsiveness to U46619 in isolated neonatal porcine pulmonary but not mesenteric arteries. I Vase Res 33:249-257

23. Villamor E. Pérez.Vizcaino F. Moro M. Tamargo J 1996 Effects of group B streptococcus on the responses to U46619, endothelin and norndrenaline in isolated intrapulmonary and mesenteric arteries of pigiets. Pediatr Res $40.827-833$

24. Perez-Vircaino F. Villarnor E, Duarte J. Tamargo J 1997 Involvement of protein kinase $C$ in reduced relaxant responses to the NO/cyclic GMP pathway in piglet pulmonary arteries contracted by the thromboxane $\mathrm{A}_{2}$-rmimetic U46619. Br J Pharmacol 121:1323-1333

25. Beckman JS. Koppenol WH 1996 Nitric oxide, superoxide, and peroxynitrite: the good, the bad, and the ugly. Am J Physiol 271:Cl424-Cl437

26. Brumer F. Schmidt K. Nielsen EB, Mayer B 1996 Novel guanylyl cyclase inhibitor potently inhibits cyclic GMP accumulation in endothelial cells and relaxation of bovine pulmonary artery. J Pharmacol Exp Ther 277:48-53

27. Bolotina VM, Najibi S, Palacino JJ, Pagano PJ, Cohen RA 1994 Nitric exide directly activates calcium-dependent potassium channels in vascular smooth muscle. Narure 368:850-853

28. Coceani F, Breen CA, Lees JG, Falek JR, Olley PM 1988 Further evidence implcating a cytochrome P-450-mediated reaction in the contractile tension of the lamb ductus arteriouss. Circ Res 62:471-477
29. Coceani F, Kelsey L, Seidlizz E 1996 Carbon monoxide-induced relaxation of the ductus arteriosus in the lamb: evidence apainst the prime role of guanylyl cyclase. Br J Pharmacol 118:1689-1696

30. Hussain AS, Marks GS, Brien JF, Nakatsa X 1997 The soluble guanylyl cyclase inhibitor $1 \mathrm{H}-[1,2,4]$ oxadiazolo(4,3-alpha)quinoxalin-1-One $(O D Q)$ inhibits relaxation of rabbit aortic rings induced by carbon monoxide, nitric oxide, and glyceryl trinitrate. Can J Physiol Pharmacol 75:1034-1037

31. Gao Y, Tolsa JF, Raj JU 1998 Heterogeneity in endothelium-denived nitric oxidemediated relaxation of different sized pulmonary arteries of newborn lambs. Pediatr Res 44:723-729

32. Cantrell JM. Tucker A 1996 Low-dose carbon monoxide does not reduce vasoconstriction in isolated rat lungs. Exp Lung Res 22:21-32

33. Grover TR, Rairigh RL, Abman SH, Kinsella JP 1999 Pulmonary vascular effects of inhaled carbon monoxide on the ovine transitional circulation. Pediatr Res 45:303A(abstr)

34. Rich GF, Roos CM. Anderson SM. Urich DC. Daugherty MO, Johns RA 1993 Inhaled nitric oxide: dose response and the effocts of blood in the isolated rat lung. J Appl Physiol 75:1278-1284

35. Deinum G, Stone IR. Babcock GT, Marletta MA 1996 Binding of nitric oxide and carton monoxide to soluble guanylate cyclase as observed with resonance Raman spectroscopy. Biochemistry 35:1540-1547

36. Stone JR, Marletta MA 1994 Soluble guanylate cyclase from bovine lung: activation with nitric oxide and carbon monoxide and spectral characterization of the ferrous and ferric states. Biochemistry 33:5636-5640

37. Hobbs AJ 1997 Soluble guanylate cyclase: the forgotten sibling. Trends Pharmacol Sci 18:484-491

38. Ginudemar L, Johansson MB. Ekelund M, Hogestan ED 1995 Haem oxygenase activity in blood vessel homogenates as measured by carbon monoxide production. Acta Physiol Scand 153:203-204

39. Nathanson JA, Scavone C, Scanion C, McKee M 1995 The cellular $\mathrm{Na}^{*}$ pump as a site of action for carbon monoxide and glutamate: a mechanism for long-term modulation of cellular activity. Neuron 14:781-794

40. Rubanyi GM, Vanboutte PM 1986 Superoxide anions and hyperoxia inactivate endothelium-derived relaxing factor. Am J Physiol 250:H822-H827

41. Robbins CG, Horowitz S, Merrit TA, Kheiter A. Tiemey J, Narula P, Davis JM 199? Recombinant human superoxide dismutase reduces lung injury caused by inhaied aitrie oxide and byperoxia. Am J Phyxiol 272:1903-1907

42. Furchgort RF, Zawadzki JV 1980 The obligatory role of endothelial cells in the relaxation of anterial smooth muscle by acetylcholine. Nature 288:373-376

43. Morecroft L. Maclean MR 1998 Developenental changes in endothelium-dependent vasodilation and the influence of superoxide anions in perinatal mabit pulmonary anteries, Br J Pharmacol 125:1585-1593

44. Raj JU, Hillyard R. Kaapa P. Gropper M. Anderson I 1990 Pulmonary arterial and venous constriction during hypoxia in 3- to 5-wk-old and adult ferrets. J Appl Physiol 69:2183-2189

45. Gao Y. Zhou H. Raj JU 1995 Endothelium-derived nitric oxide plays a larger role in pulmonary veins than in arteries of newborn lambs. Circ Res 76:559-56s

46. Okogbule-Wonodi AC, Ibe BO, Yue BW, Hsu S. Raj JU 1998 Phosphodiesterase activity in intrapulmonatry arteries and veins of perinatal lambs. Mol Genet Metab 65:229-237

47. Hanson KA, Burns F, Rybalkin SD, Miller JW, Beavo J, Clarke WR 1998 Devel. opmental changes in lung cGMP phosphodiesterase-5 activity, protein, and message. Am J Respir Crit Care Med 158:279-288

48. Liu SF, Hislop AA, Haworth SG. Barnes PJ 1992 Developmental changes in endothelium-dependent pulmonary vasodilatation in pigs. Br J Pharmacol 106:324330

49. Steinhom RH. Morin 3d FC, Gugino SF, Giese EC, Russell JA 1993 Developmental differences in endothelium-dependent responses in isolated ovine pulmonary anteries and veins. Am J Physiol 264:H2162-H2167

50. MacKenzie A. Martin W 1998 Loss of endothelium-derived nitric oxide in rabbit acrta by oxidant stress: restoration by superoxide distnutase mimeties. Br 3 Pharmacol 124:719-728

51. Desideri A, Falconi M. Polticelli F, Bolognesi M, Djinovic K, Rotilio G 1992 Evolutionary conservativeness of electric field in the Cu. $\mathrm{Zn}$ superoxide dismutase active site: evidence for coordinated mutation of charged amino acid residues. J Mol Biol 223:337-342 


\section{PART III}

\section{Chapter XIV. General discussion, summary, and future perspectives.}

During the perinatal period, the pulmonary circulation undergoes important structural and functional changes to allow the sudden transition from gas exchange by the placenta to gas exchange by the lungs (1-5). These changes lead to a fall in pulmonary vascular resistance (PVR), with pulmonary blood flow increasing roughly ten-fold and pulmonary arterial pressure falling to one-half systemic values within hours. Failure of the pulmonary circulation to undergo this transition results in persistent pulmonary hypertension of the newborn (PPHN). PPHN is a clinical syndrome of various neonatal cardiopulmonary disorders, which are characterized by sustained elevation of pulmonary vascular resistance after birth, leading to right-to-left shunting of blood across the ductus arteriosus or foramen ovale and severe hypoxemia $(6,7)$.

This thesis is a compilation of work that addresses several unknown aspects of the pathophysiology and treatment of PPHN. Because PPHN is not an homogeneous entity, but a clinical syndrome occurring in a heterogeneous group of diseases with a wide diversity of etiologies (7), its study is severely limited by the experimental approach that is selected (8). In the present thesis, we used an experimental model of PPHN induced by chronic compression of the ductus arteriosus (chapter V), and studies of vascular contractility in isolated intrapulmonary arteries and veins, compared to systemic vessels (chapters VI to XIII).

Experimental models used to study PPHN can be characterized as based on acute perinatal insults, or on chronic intrauterine insults (8). The acute models of PPHN have the advantage of mimicking relevant clinical situations, such as hypoxic stress during labor and delivery $(9,10)$, sepsis $(11,12)$, or aspiration of meconium $(13,14)$. On the other hand, only the chronic models are characterized by suprasystemic pressures in the pulmonary vasculature and the associated right-to-left shunting of blood $(8,15)$. In addition, pulmonary hypertension in the acute models is based on the alteration of the equilibrium between vasoactive factors, but only the chronic models allow the study of a structurally remodeled 
pulmonary vascular bed $(8,16)$. For that reason, chronic models of PPHN have been particularly suited to study alterations in gene expression (8). Chronic intrauterine hypoxia $(17,18)$, ductal constriction or ligation $(19,20)$, and chronic NO synthase inhibition (21) are three examples of adverse intrauterine environment that are widely used to experimentally reproduce PPHN. However, only the model of ductal compression or ligation consistently mimics not only the hemodynamic, but also the morphological pulmonary vascular findings of infants with PPHN $(8,16)$.

Contractility studies in isolated vascular rings have become an invaluable tool for the study of pharmacology, physiology and pathophysiology and very relevant pieces of knowledge of these disciplines have been obtained using this model $(22,23)$. However, it is, undoubtedly, an approach that is subjected to important limitations. Blood vessels are very sensitive to local changes in intraluminal pressure and flow $(24,25)$, and both stimuli, which play an important role to determine vascular tone, are absent in isolated vascular rings. In addition, important segmental differences in vascular contractility are present in the pulmonary circulation $(26,27)$. Therefore, information obtained in large or small conduit pulmonary arteries should be cautiously extrapolated to resistance vessels. Another important point in this experimental approach is the level of oxygenation that is achieved. The use of $95 \%$ oxygen to bubble organ chambers is a standard method in pharmacological studies. In fact, many previous works have studied fetal and neonatal pulmonary vessels using that oxygen concentration $(26,28-30)$. Recently, caution has been claimed to this fact due to the substantial lower oxygen environment in which pulmonary arteries are exposed under physiological conditions (31). An extremely high oxygen tension $(86 \pm 0.62 \mathrm{kPa})$ is produced when the organ chamber is bubbled with $95 \%$ oxygen. Parallelism between this oxygen tension in vitro and in vivo is, however, not completely suitable due to the absence in the organ chamber of hemoglobin (i.e. the fundamental factor for oxygen transportation in vivo). Therefore, in vitro oxygen content is only dependent on the oxygen in solution that is expressed by the partial pressure of oxygen (32). Interestingly, it has been demonstrated that high oxygen tensions markedly influenced endothelium-dependent relaxation in foetal but not in neonatal rabbit pulmonary arteries (31). In fact, in the present thesis we describe (chapter 
XIII) that bubbling the organ chamber with $95 \%, 21 \%$ or $0 \%$ oxygen had no influence on the pulmonary vascular response to NO.

In spite of the limitations of the experimental approaches, we believe that this thesis collects some original contributions to the understanding of PPHN pathophysiology and treatment. In chapter $\mathbf{V}$ we demonstrated that chronic intrauterine pulmonary hypertension caused by ductus compression decreased eNOS mRNA, protein content, and activity in the late gestation ovine fetus. These findings support previous studies that demonstrated preferential impairment of endothelium-dependent pulmonary vasodilation in this experimental model of PPHN $(33,34)$. Because NO modulates both vascular tone -as a vasodilator- and vascular smooth muscle growth -as an antiproliferative factor- diminished eNOS expression may contribute to both the functional and structural abnormalities that are characteristic of the pulmonary vasculature in PPHN.

Chapter VI is focused on the pulmonary vascular response to hypoxia. Oxygen tension is a determinant regulator of pulmonary vascular tone through the presence of hypoxic pulmonary vasoconstriction (HPV), a rather unique response specific for the pulmonary vascular bed by which circulating blood is diverted to better ventilated alveoli, optimizing the ventilation/perfusion matching (35). During the fetal life, HPV is responsible, at least partially, for maintaining high pulmonary vascular resistance. Reduction of this HPV, by elevation of arterial $\mathrm{pO}_{2}$, has been suggested as a mechanism to produce the pulmonary vasodilation that occurs at birth $(5,36-38)$. In addition, chronic intrauterine hypoxia, acute hypoxia at birth, and sustained hypoxia in the neonatal period are mechanisms involved in the development of PPHN $(8,39)$.

In isolated piglet (Landrace-Largewhite strain) pulmonary arteries we observed that hypoxia produced a transient contractile response due to inhibition of basal EDNO production. Other endothelial factors, such as eicosanoids, were not involved in this contractile response. However, we observed a similar response to hypoxia in pulmonary arteries, pulmonary veins, coronary arteries, and mesenteric arteries whereas HPV is unique 
to the pulmonary vascular bed. Therefore, we suggest that correlation between the response to hypoxia in isolated pulmonary arteries and HPV should be avoided.

Sepsis is one of the most important factors involved in the etiology of PPHN (40). In chapters VII, VIII, and IX, we studied sepsis-induced changes in pulmonary and systemic vascular contractility. We analyzed the effects of incubation of piglet pulmonary and mesenteric arteries with heat-inactivated group B Streptococcus (GBS) and Escherichia coli lipopolysaccharide (LPS) on the vascular responses to several vasoconstrictor agonists. GBS, a gram-positive bacterium, and E. coli, a gram-negative bacterium, are among the most common causal agents of neonatal sepsis (41). We observed that prolonged incubation with the bacterial products reduced the contractile responses to noradrenaline in neonatal porcine pulmonary arteries. This hyporesponsiveness was potentiated by the substrate for NO synthesis L-arginine, while the NOS inhibitor L-NAME completely reversed it, indicating that overproduction of NO was responsible for this effect. Dexamethasone, which inhibits the induction of iNOS, and cycloheximide, an inhibitor of protein synthesis, when coincubated with GBS or LPS, completely reversed the reduced response to noradrenaline. Moreover, GBS and LPS induced a marked increase in iNOS activity in lung tissue, which was abolished by dexamethasone. All these results indicated that GBS and LPS-induced pulmonary vascular hyporesponsiveness to noradrenaline was due to an enhanced formation of NO via iNOS induction that required de novo synthesis of the enzyme in the pulmonary vasculature. We tested also the effects on systemic vascular contractility of incubation with GBS or LPS. We observed that GBS and LPS reduced the vascular responsiveness to noradrenaline in piglet mesenteric arteries and this effect was reversed by the presence of the NOS inhibitor L-NAME. These data suggest a role for iNOS induction in the systemic vascular dysfunction associated with sepsis, produced not only by gram-negative, but also by gram positive bacteria.

Pulmonary hypertension is the single most reliable circulatory disturbance noted in every laboratory model of neonatal sepsis (40). However, we described lung induction of iNOS and decreased responses to pressor agents in pulmonary arteries after incubation with two common neonatal pathogens. In an attempt to explain this apparent contradiction, we 
studied the pulmonary vascular response to the thromboxane $A_{2}$ analog U46619, after incubation with LPS or GBS. Thromboxane $A_{2}$ has been shown to be the vasoconstrictor responsible for sepsis-induced pulmonary hypertension, at least during the early phases of the process $(11,40)$. We observed that LPS- or GBS-incubated pulmonary arteries did not show reduced responsiveness to U46619. In contrast, similar incubation, in mesenteric arteries, produced a marked reduction in U46619-induced contraction that was reversed by NOS inhibition. This absence of pulmonary hyporesponsiveness to U46619 may contribute to the persistence of pulmonary hypertension in sepsis, despite iNOS induction in the lung.

In an attempt to explain the differences in the vasoconstriction induced by thromboxane $A_{2}$ (i.e. by U46619) and noradrenaline when iNOS was induced in pulmonary arteries, chapter $\mathbf{X}$ is focussed on the study of the interactions of these agents with the NO/cyclic GMP pathway, as well as the mechanisms involved in NO/cyclic GMP-induced relaxation. We observed that various activators of the cyclic GMP pathway (i.e., ACh, SNP, ANP and 8-Br-cyclic GMP) fully relaxed noradrenaline-contracted arteries, while only a partial relaxation was observed on the contractions induced by U46616. This effect was specific for piglet pulmonary arteries, since it was not present in rat pulmonary arteries or in piglet mesenteric or coronary arteries. Moreover, U466619 was not affecting the rise in cyclic GMP induced by SNP, nor increasing the degradation of cyclic GMP by phosphodiesterases. Our results suggest that U46619 inhibits the NO/cyclic GMP pathway for smooth muscle relaxation beyond the level of cyclic GMP synthesis.

We have studied several mechanisms proposed to explain cyclic GMP-induced vascular relaxation. Our results indicate that neither activation of $\mathrm{Ca}^{2+}$-activated $\mathrm{K}^{+}$channels, nor activation of the membrane $\mathrm{Na}^{+} / \mathrm{K}^{+}$-ATPase were responsible for this relaxation in piglet pulmonary arteries. However, inhibition of the sarcoplasmic reticulum $\mathrm{Ca}^{2+}$-ATPase by thapsigargin, markedly suppressed the relaxation induced by the NO donor SNP in arteries contracted by either noradrenaline or U46619. This finding suggests that increased $\mathrm{Ca}^{2+}$ uptake by the sarcoplasmic reticulum is an important mechanism by which cyclic GMP decreases cytosolic $\mathrm{Ca}^{2+}$, and induces its relaxant effects in piglet pulmonary arteries. 
In addition, we further investigated the mechanisms involved in the inhibition of the relaxant effects of SNP by U46619. We observed that the activation of protein kinase C (PKC) by the phorbol ester PMA inhibited the relaxant responses to SNP. Conversely, inhibition of PKC by staurosporine potentiated the relaxant response to SNP in U46619 precontracted arteries. These results provide evidence for a novel mechanism of NO/cyclic GMP impairment mediated by PKC through $\mathrm{TXA}_{2}$ receptor activation at the level of the cyclic GMP activity. Further experiments, involving the use of more specific inhibitors of PKC, are needed to confirm the presence of this mechanism.

Since lowering pulmonary artery pressure, while maintaining systemic vascular resistance and good cardiac output, is crucial for newborns with PPHN, the ideal drug for their treatment should be a vasodilator with selectivity for pulmonary over systemic vessels $(41,42)$. Search for this 'selective' pulmonary vasodilator has been constant in the last two decades. In chapter XI we have compared the relaxant effects of six putative selective pulmonary vasodilators (acetylcholine, sodium nitroprusside, ATP, PGE 1 , tolazoline, and nifedipine) in isolated piglet pulmonary and mesenteric arteries. We have found differences in their relaxant effects depending on the artery, the agonist used to contract the vessel (i.e. noradrenaline or U46619) or both. ATP was the only drug, which, at any concentration and regardless of the contractile agonist used, produced relaxant effects more marked in pulmonary than in mesenteric arteries. Moreover, results with tolazoline and nifedipine demonstrated that systemic arteries dilate at least as much as pulmonary arteries, supporting the poor selectivity observed in clinical studies.

In chapter XII we analyzed the in vitro relaxant effects of magnesium sulfate $\left(\mathrm{MgSO}_{4}\right)$, another drug proposed as an alternative and safe treatment for PPHN $(44,45)$. We observed that in intrapulmonary arteries precontracted with noradrenaline, $\mathrm{KCl}$ or U46619, $\mathrm{MgSO}_{4}$ produced a weak vasorelaxant effect as compared with the marked vasorelaxation induced in systemic (mesenteric) arteries of a similar diameter. Furthermore, at physiological concentrations, $\mathrm{MgSO}_{4}$ inhibited the vasorelaxant effect of $\mathrm{NO}$, as proved by the fact that in mesenteric and pulmonary arteries precontracted by $\mathrm{U} 46619$ the rapid removal of $\mathrm{MgSO}_{4}$ 
from the bath medium produced a transient endothelium-dependent relaxation, which was greatly reduced after removal of the endothelium or by the NOS inhibitor L-NAME. In addition, $\mathrm{MgSO}_{4}$ did not seem to play a marked role in the pulmonary vascular smooth muscle reactivity, since the vasoconstrictor effects of U46619 or the relaxant effects of the endothelium-dependent vasodilator ACh or the NO donor SNP were not affected by changing the extracellular $\mathrm{Mg}^{2+}$ concentration. In view of our results, we conclude that $\mathrm{MgSO}_{4}$ exhibits a poor pulmonary selectivity in vitro, and we speculate that the beneficial clinical effects of $\mathrm{MgSO}_{4}$ in PPHN may not be related to a direct vasodilator effect on pulmonary vascular smooth muscle.

The remarkable basic scientific discovery that the simple gas molecule NO was endogenously released by endothelial cells, producing paracrine vasodilatory effects in the adjacent vascular smooth muscle, enormously boosted the search for a specific treatment for PPHN (46). Administered by inhalation, characterized by a short half-life and the absence of measurable systemic effects, the use of inhaled NO as an adjunct to conventional PPHN therapy is presently, widespread (47). In chapter XIII we compared the vasorelaxant effects of NO with another diatomic gas, carbon monoxide (CO), which appears to mimic many of the actions of NO including smooth muscle relaxation (48). The possible role of endogenously produced $\mathrm{CO}$ in the control of pulmonary vascular tone during the perinatal period remains unknown. We analyzed the mechanisms involved in NO- and $\mathrm{CO}$-induced relaxation, as well as the age-dependent changes, and the influence of oxygen on NO and $\mathrm{CO}$ vascular actions. In addition, we evaluated the effects of superoxide anions produced within the tissue in modulating the response to $\mathrm{NO}$ and $\mathrm{CO}$. We observed that both $\mathrm{NO}$ and $\mathrm{CO}$ relaxed neonatal vessels through soluble guanylate cyclase activation. However, when compared with NO, CO exhibited a 1000-fold lower vasorelaxant activity. The maximal response to $\mathrm{NO}$ and $\mathrm{CO}$ was greater in pulmonary veins than in pulmonary arteries. In addition, pulmonary vasorelaxation induced by NO increased with postnatal age, whereas that induced by $\mathrm{CO}$ decreased, suggesting a different mechanism of soluble guanylate cyclase activation. Changes in extracellular oxygen concentration did not alter the pulmonary vascular response to NO. However, the presence of superoxide dismutase improved the 
response to NO indicating that oxidant activity limits the vasodilator response to NO but not to $\mathrm{CO}$. We concluded that if the response to exogenous $\mathrm{CO}$ reflects the capacity of this gas to relax in vivo neonatal pulmonary vessels, it seems unlikely its direct participation in the control of pulmonary vascular tone.

\section{FUTURE PERSPECTIVES}

Our understanding of the molecular and cellular changes in the pulmonary circulation during fetal life, the normal adaptation to extrauterine life, and early postnatal development is still deficient to identify the early crucial factors, which instigate the cascade of abnormal structural and functional changes that manifest themselves clinically as PPHN (39). Blood vessels in the lung undergo profound structural remodeling as pulmonary hypertension develops. Changes include cellular hypertrophy, hyperplasia, and increased deposition of structural matrix proteins such as collagen and elastin in the vessel wall (49). The identification of a number of defined growth factors, observations in genetically manipulated mice, and the recognition of the importance of cell-cell interactions have greatly expanded our understanding of the regulation of vascularization under physiological and pathological conditions. The paracrine actions of a variety of polypeptide growth factors, including platelet-derived growth factor, vascular endothelial growth factor, transforming growth factor-beta, and the angiopoietins, appear to be orchestrated in a complex sequence of steps that lead to the development of the vascular system (50-53). Some of these factors stimulate increases in a variety of immediate-early genes (54). Thus, communication between the forming vasculature and the tissue parenchyma, as well as interactions among cells of the vascular wall, influence vascular development and growth (49). Elucidation of the signaling pathways which are activated under adverse perinatal environment may help to develop new strategies to treat PPHN, to avoid complications of present therapies, and ultimately to develop new therapies aimed at preventing the early cellular and molecular changes prompted by pulmonary hypertensive stimuli. 
Understanding the precise mechanisms regulating the NO/cyclic GMP signaling under physiological and pathological conditions, and the interactions between cyclic GMPinduced relaxation and the action of vasoconstrictors, will certainly help in the therapeutic management of patients with PPHN. Vasoconstriction results from increased $\mathrm{Ca}^{2+}$. calmodulin dependent myosin light chain kinase activation, but also from $\mathrm{Ca}^{2+}$-independent mechanisms (often referred as $\mathrm{Ca}^{2+}$-sensitization). The latter may involve inhibition of myosin light chain phosphatase, actin-linked regulatory mechanisms, or availability of calmodulin (55). Conversely, vasodilation may result from a reduction in intracellular $\mathrm{Ca}^{2+}$ concentration or from $\mathrm{Ca}^{2+}$-independent effects. Therefore, it is expected that the sensitivity to a given vasodilator depends on the mechanism by which agonists induce their contractile response, e.g. a $\mathrm{Ca}^{2+}$-dependent contractile response should be preferentially relaxed by vasodilators lowering $\mathrm{Ca}^{2+} \cdot \mathrm{Ca}^{2+}$-independent mechanisms of vasodilation have been reported following the activation of the cyclic nucleotide dependent protein kinases $(55,56)$. In addition, vasoconstrictors involved in the pathophysiology of PPHN, such as thromboxane $\mathrm{A}_{2}$ and endothelin-1, induce part of their activity, in pulmonary arteries, through an increase in $\mathrm{Ca}^{2+}$ sensitivity $(57,58)$. Further studies are necessary to understand the interactions, at the level of $\mathrm{Ca}^{2+}$-dependent and -independent transduction mechanisms, between the vasoconstrictors and vasorelaxants pathways involved in the pathophysiology of PPHN.

In addition, vascular maturation involves important shifts in the mechanisms mediating vascular smooth muscle pharmacomechanical coupling. Thus, in ovine cerebral arteries, normal development involves a reduction in the $\mathrm{Ca}^{2+}$ sensitizing effects of agonists, with parallel increases in the agonist-induced intracellular $\mathrm{Ca}^{2+}$ release $(59,60)$. Until the present moment, studies of pulmonary arteries focused on developmental changes in $\mathrm{Ca}^{2+}$ sensitivity have not been performed. Such studies might explain why vascular reactivity varies with age. Moreover, from a pathophysiologic perspective a hypothetical failure to shift from the increased $\mathrm{Ca}^{2+}$ sensitivity typical of immature arteries, might lead to vascular hyperreactivity in the neonatal or adult life. 
Randomized controlled trials have demonstrated that inhaled NO is an effective treatment for PPHN, by improving oxygenation and reducing the need for extracorporeal membrane oxygenation therapy (47). However, approximately $40-50 \%$ of the infants assigned to NO in these trials failed to respond. Several mechanisms may explain variability in responsiveness to inhaled NO therapy. However, responders did not appear to differ clinically from non-responders. Further studies are necessary to elucidate the potential mechanisms underlying poor responses to inhaled NO and to identify the groups of patients that may receive the maximal benefits from this therapy. Additionally, pharmacological augmentation of inhaled NO responsiveness may also constitute an attractive field for future research. Further studies searching for more selective phosphodiesterases inhibitors, evaluating the effectiveness of augmentation of soluble guanylate cyclase cofactors, or analyzing the effects of antioxidant agents may lead to novel clinical strategies to improve the treatment of $\mathrm{PPHN}$, and to reduce the potential toxicity of inhaled NO.

Recent epidemiological studies have suggested that perinatal factors may be linked with the development of adult disease (61). Thus, adverse environmental events occurring prenatally or early in life are currently receiving progressive attention as predictors of disease in later stages of life (61). During the last years, the chances of survival from PPHN have increased greatly. Recently, it has been reported that young adults that had PPHN showed exaggerated pulmonary vasoconstriction at high altitude, despite having normal pulmonary artery pressure at low altitude (62). In addition, perinatal exposure to hypoxia in the rat, which induces transient pulmonary hypertension, predisposes to augmented pulmonary vasoconstrictor responses to hypoxia $(63,64)$, and increases severity of pulmonary hypertension after later exposure to hypoxia or monocrotaline $(65,66)$. These data suggest that brief hypoxic exposure during a critical period of lung growth may alter the course of normal pulmonary development, and leaves persistent changes in lung structure and/or function that cause an exaggerated response to adverse stimuli later in life. Therefore, early hypoxic exposition on patients with PPHN might influence the susceptibility of pulmonary vasculature to future adverse stimuli. Consequently, it may be worth to pay attention to those infants who suffered from hypoxia during the perinatal period, critical for lung development, because they may be at risk to develop adult pulmonary 
hypertension. Further studies are needed to determine the possible alterations of pulmonary vascular function and/or structure in adult animals subjected to perinatal insults, to understand the mechanisms by which these stimuli may adversely affect pulmonary vessels, and to clarify the links between perinatal adverse environment and altered vasoreactivity.

\section{References}

1 Cassin S, Dawes GS, Mott JC, Ross BB, Strang LB. Vascular resistance of the foetal and newly ventilated lung of the lamb. J. Physiol. 1964; 171:61-79.

2 Rudolph AM, Heymann MA. The fetal circulation. Annu Rev Med. 1968; 19:195-206.

3 Walter AM. Circulatory transition at birth and the control of neonatal circulation. In Hanson MA, Spencer JAD, Rodeck CH (Eds.): fetus and neonate physiology and clinical applications, Volume 1, The Circulation. Cambridge University Press, 1993, pp 160-196.

4 Fineman JR, Soifer SJ, Heymann MA. The role of pulmonary vascular endothelium in perinatal pulmonary circulatory regulation. Semin Perinatol. 1991; 15:58-62.

5 Teitel DF, Iwamoto HS, Rudolph AM. Changes in the pulmonary circulation during birth-related events. Pediatr Res. 1990; 27:372-8.

6 Levin DL, Heymann MA, Kitterman JA, Gregory GA, Phibbs RH, Rudolph AM. Persistent pulmonary hypertension of the newborn. J. Pediatr 1976; 89:626-633.

7 Kinsella JP, Abman SH. Recent developments in the pathophysiology and treatment of persistent pulmonary hypertension of the newborn. J Pediatr 1995; 126:853-64.

8 Steinhorn RH, Morin FC $3^{\text {rd }}$, Fineman JR. Models of persistent pulmonary hypertension of the newborn (PPHN) and the role of cyclic guanosine monophosphate (GMP) in pulmonary vasorelaxation. Semin Perinatol. 1997; 21:393-408

9 Green RS, Leffler CW. Hypoxia stimulates prostacyclin synthesis by neonatal lungs. Pediatr Res. 1984; 18:832-5.

10 Roberts JD Jr, Chen TY, Kawai N, Wain J, Dupuy P, Shimouchi A, Bloch K, Polaner D, Zapol WM. Inhaled nitric oxide reverses pulmonary vasoconstriction in the hypoxic and acidotic newbom lamb. Circ Res. 1993; 72:246-54.

11 Tarpey MN, Graybar GB, Lyrene RK, Godoy G, Oliver J, Gray BM, Philips JB 3d. Thromboxane synthesis inhibition reverses group B Streptococcus-induced pulmonary hypertension. Crit Care Med. 1987; 15:6447.

12 Covert RF, Schreiber MD. Three different strains of heat-killed group B beta-hemolytic streptococcus cause different pulmonary and systemic hemodynamic responses in conscious neonatal lambs. Pediatr Res 1993; 33:373-9.

13 Cuesta EG, Diaz FJ, Renedo AA, Ruanova BF, de Heredia y Goya, Sanchez LF, Valls i Soler A. Transient response to inhaled nitric oxide in meconium aspiration in newborn lambs. Pediatr Res. 1998; 43:198-202. 
14 Soukka H, Viinikka L, Kaapa P. Involvement of thromboxane A2 and prostacyclin in the early pulmonary hypertension after porcine meconium aspiration. Pediatr Res. 1998; 44:838-42.

15 Shaul PW, Yuhanna IS, German Z, Chen Z, Steinhorn RH, Morin FC $3^{\text {rd }}$. Pulmonary endothelial NO synthase gene expression is decreased in fetal lambs with pulmonary hypertension. Am J Physiol. 1997; 272:L1005-12.

16 Abman SH. Abnormal vasoreactivity in the pathophysiology of persistent pulmonary hypertension of the newborn. Pediatr Rev (Online). 1999; 20:e103-9.

17 Murphy JD, Aronovitz MJ, Reid LM. Effects of chronic in utero hypoxia on the pulmonary vasculature of the newborm guinea pig. Pediatr Res. 1986; 20:292-5.

18 Geggel RL, Aronovitz MJ, Reid LM. Effects of chronic in utero hypoxemia on rat neonatal pulmonary arterial structure. J Pediatr. 1986; 108:756-9.

19 Abman SH, Shanley PF, Accurso FJ. Failure of postnatal adaptation of the pulmonary circulation after chronic intrauterine pulmonary hypertension in fetal lambs. J. Clin. Invest. 1989; 83:1849-1858.

20 Morin FC 3d. Ligating the ductus arteriosus before birth causes persistent pulmonary hypertension in the newborn lamb. Pediatr Res. 1989; 25:245-50.

21 Fineman JR, Wong J, Morin III FC, Wild LM, Soifer SJ. Chronic nitric oxide inhibition in utero produces persistent pulmonary hypertension in newborn lambs. J. Clin. Invest. 1994; 93:2675-2683.

22 Furchgott RF, Zawadzki JV. The obligatory role of endothelial cells in the relaxation of arterial smooth muscle by acetylcholine. Nature (Lond.) 1980; 288:373-376.

23 Moncada S, Higgs EA, Vane JR. Human arterial and venous tissues generate prostacyclin (prostaglandin X), a potent inhibitor of platelet aggregation. Lancet. 1977; 1:18-20.

24 Ngai AC, Winn HR. Modulation of cerebral arteriolar diameter by intraluminal flow and pressure. Circ Res. 1995; 77:832-40.

25 Cockell AP, Poston L. Flow-mediated vasodilatation is enhanced in normal pregnancy but reduced in preeclampsia. Hypertension. 1997; 30:247-51.

26 Gao Y, Tolsa JF, Raj JU. Heterogeneity in endothelium-derived nitric oxide-mediated relaxation of different sized pulmonary arteries of newborn lambs. Pediatr Res. 1998; 44:723-9.

27 Zellers TM, Vanhoutte PM. Heterogeneity of endothelium-dependent and independent responses among large and small porcine pulmonary arteries. Pulm Pharmacol. 1989; 2:201-8.

28 Levy M, Tulloh RM, Komai H, Stuart-Smith K, Haworth SG. Maturation of the contractile response and its endothelial modulation in newborn porcine intrapulmonary arteries. Pediatr Res 1995; 38:25-9.

29 Boels PJ, Gao B, Deutsch J, Haworth SG. ATP-dependent K+ channel activation in isolated normal and hypertensive newborn and adult porcine pulmonary vessels. Pediatr Res 1997; 42:317-26.

30 Gao Y, Zhou H, Tolsa JF, Shen H, Raj JU. Antenatal betamethasone therapy augments isoproterenol and prostaglandin E2-mediated relaxation of preterm ovine pulmonary veins. Pediatr Res 1997; 42:545-9. 
31 Morecroft I, MacLean MR 1998 Developmental changes in endothelium-dependent vasodilation and the influence of superoxide anions in perinatal rabbit pulmonary arteries. Br J Pharmacol 125:1585-1593.

32 van der Hoeven M. Venous oxygen saturation and oxygen transport in the newborn period. An experimental and clinical study. Maastricht Universitaire Pers, Maastricht, 1999, pp 21-38.

33 McQueston JA, Kinsella JP, Ivy DD, McMurtry IF, Abman SH. Chronic pulmonary hypertension in utero impairs endothelium-dependent vasodilation. Am. J. Physiol. 1995; 268:H288-H294.

34 Steinhom RH, Russell JA, Morin FC. Disruption of cGMP production in pulmonary arteries isolated from fetal lambs with pulmonary hypertension. Am. J. Physiol. 1995; 268:H1483-H1489.

35 Barnes PJ, Liu SF. Regulation of pulmonary vascular tone. Pharmacol Rev 1995; 47:87-131.

36 McQueston JA, Cornfield DN, McMurtry IF, Abman SH. Effects of oxygen and exogenous L-arginine on EDRF activity in fetal pulmonary circulation. Am J Physiol 1993; 264:H865-H871.

37 Tiktinsky MH, Morin FC. Increasing oxygen tension dilates fetal pulmonary circulation via endotheliumderived relaxing factor. Am J Physiol 1993; 265:H376-H380.

38 Cornfield DN, Chatfield BA, McQueston JA, McMurtry IF, Abman SH. Effects of birth-related stimuli on L-arginine-dependent pulmonary vasodilation in the ovine fetus. Am J Physiol 1992; 262:H1474-H1481.

39 Haworth SG. The pathophysiology of persistent pulmonary hypertension of the newborn. Semin Neonatol $1997 ; 2: 13-23$.

40 Meadow W, Rudinsky B. Inflammatory mediators and neonatal sepsis. Rarely has so little been known by so many about so much. Clin Perinatol. 1995; 22:519-36.

41 Stoll BJ, Gordon T, Korones SB, Shankaran S, Tyson JE, Bauer CR, Fanaroff AA, Lemons JA, Donovan EF, Oh W, Stevenson DK, Ehrenkranz RA, Papile LA, Verter J, Wright LL Early-onset sepsis in very low birth weight neonates: a report from the National Institute of Child Health and Human Development Neonatal Research Network. J Pediatr. 1996; 129:72-80.

42 Drummond WE, Lock J. Neonatal "pulmonary vasodilator" drugs. Dev. Pharmacol. Ther. 1984; 7:1-20.

43 Roberts JD, Shaul PW. Advances in the treatment of persistent pulmonary hypertension, Pediatr. Clin. North Am. 1993; 40:983-995.

44 Abu-Osba YK, Galal O, Manasra K, Rejjal A. Treatment of severe persistent pulmonary hypertension of the newborn with magnesium sulfate. Arch. Dis. Child. 1992; 67:31-35.

45 Tolsa JF, Cotting J, Sekarski N, Payot M, Micheli J, Calame A. Magnesium sulphate as an alternative and safe treatment for severe persistent pulmonary hypertension of the newborn. Arch Dis Child Fetal Neonatal Ed. 1995; 72:F184-7.

46 Truog WE. Inhaled nitric oxide: a tenth anniversary observation. Pediatrics. 1998; 101:696-7.

47 Finer NN, Barrington KJ. Nitric oxide for respiratory failure in infants bom at or near term (Cochrane Review). In: The Cochrane Library, Issue 1, 2000. Oxford: Update Software.

48 Wang $\mathrm{R}$, Wang $\mathrm{Z}$, Wu $\mathrm{L}$. Carbon monoxide-induced vasorelaxation and the underlying mechanisms. $\mathrm{Br} \mathrm{J}$ Pharmacol 1997; 121:927-934. 
49 Durmowicz AG, Stenmark KR. Mechanisms of structural remodeling in chronic pulmonary hypertension. Pediatr Rev. 1999; 20:e91-e102.

S0 Beck L Jr, D'Amore PA. Vascular development: cellular and molecular regulation. FASEB J. 1997; 11:365-73.

51 Mandriota SJ, Pepper MS. Regulation of angiopoietin-2 mRNA levels in bovine microvascular endothelial cells by cytokines and hypoxia. Circ Res. 1998; 83:852-9.

52 Colen KL, Crisera CA, Rose MI, Connelly PR, Longaker MT, Gittes GK. Vascular development in the mouse embryonic pancreas and lung. J Pediatr Surg. 1999; 34:781-5.

53 Shehata SM, Sharma HS, van der Staak FH, van de Kaa-Hulsbergen C, Mooi WJ, Tibboel D.Remodeling of pulmonary arteries in human congenital diaphragmatic hernia with or without extracorporeal membrane oxygenation. J Pediatr Surg. 2000; 35:208-15.

54 Rothman A, Wolner B, Button D, Taylor P. Immediate-early gene expression in response to hypertrophic and proliferative stimuli in pulmonary arterial smooth muscle cells. J Biol Chem. 1994; 269:6399-404.

55 Karaki H, Ozaki H, Hori M, Mitsui-Saito M, Amano K, Harada K, Miyamoto S, Nakazawa H, Won KJ, Sato K. Calcium movements, distribution, and functions in smooth muscle. Pharmacol Rev. 1997; 49:157. 230

56 Lee MR, Li L, Kitazawa T. Cyclic GMP causes Ca2+ desensitization in vascular smooth muscle by activating the myosin light chain phosphatase. J Biol Chem. 1997; 272:5063-8.

57 Evans AM, Cobban HJ, Nixon GF. ET(A) receptors are the primary mediators of myofilament calcium sensitization induced by ET-1 in rat pulmonary artery smooth muscle: a tyrosine kinase independent pathway. Br J Pharmacol. 1999;127:153-60.

58 Himpens B, Kitazawa T, Somlyo AP. Agonist-dependent modulation of Ca2+ sensitivity in rabbit pulmonary artery smooth muscle. Pflugers Arch. 1990; 417:21-8.

59 Akopov SE, Zhang L, Pearce WJ. Regulation of $\mathrm{Ca} 2+$ sensitization by $\mathrm{PKC}$ and rho proteins in ovine cerebral arteries: effects of artery size and age. Am J Physiol. 1998; 275:H930-939.

60 Akopov SE, Zhang L, Pearce WJ. Maturation alters the contractile role of calcium in ovine basilar arteries. Pediatr Res. 1998; 44:154-60.

61 Osmond C, Barker DJ. Fetal, Infant, and Childhood Growth Are Predictors of Coronary Heart Disease, Diabetes, and Hypertension in Adult Men and Women. Environ Health Perspect. 2000;108 Suppl 3:545553.

62 Sartori C, Allemann Y, Trueb L, Delabays A, Nicod P, Scherrer U. Augmented vasoreactivity in adult life associated with perinatal vascular insult. Lancet. 1999; 353:2205-7.

63 Hampl V, Herget J. Perinatal hypoxia increases hypoxic pulmonary vasoconstriction in adult rats recovering from chronic exposure to hypoxia. Am Rev Respir Dis. 1990; 142:619-24.

64 Hakim TS, Mortola JP. Pulmonary vascular resistance in adult rats exposed to hypoxia in the neonatal period. Can J Physiol Pharmacol. 1990; 68:419-24. 
65 Tang JR, Le Cras TD, Morris KG Jr, Abman SH. Brief perinatal hypoxia increases severity of pulmonary hypertension after reexposure to hypoxia in infant rats. Am J Physiol Lung Cell Mol Physiol. 2000; 278:L356-64.

66 Caslin A, Heath D, Smith P. Influence of hypobaric hypoxia in infancy on the subsequent development of vasoconstrictive pulmonary vascular disease in the Wistar albino rat. J Pathol. 1991; 163:133-41. 


\section{Samenvatting}

Om de plotselinge overgang van gasuitwisseling via de placenta naar gasuitwisseling via de longen te bewerkstelligen moeten er tijdens de perinatale periode belangrijke structurele en functionele veranderingen plaatsvinden in de longcirculatie. Deze veranderingen resulteren in een ongeveer 10-voudige toename van bloeddoorstroming omdat er een belangrijke afname van de weerstand in de longvaten ontstaat. Als deze aanpassing in vaatweerstand niet optreedt spreken we van een persisterende pulmonale hypertensie van de neonaat (PPHN). PPHN is een klinisch syndroom dat optreedt bij verschillende cardiopulmonaire afwijkingen die gekenmerkt worden door een blijvende hoge vaatweerstand in de longvaten na de geboorte. Dit resulteert in een rechts-links shunt van bloed over de Ductus Arteriosus of het Foramen Ovale en zal leiden tot ernstige hypoxie.

Omdat het klinisch beeld van PPHN een uiting is van het uitblijven van de postnatale adaptatie in de longcirculatie is het begrijpen van de basale functie en structurele ontwikkeling van de longcirculatie in utero van belang om meer inzicht te krijgen in het klinisch beeld van PPHN en in de behandeling ervan. Vanuit deze achtergrond worden in dit proefschrift enkele aspecten van de pathofysiologie en behandeling van PPHN beschreven. In de hoofdstukken II, III en IV wordt een overzicht van de huidige stand van zaken gegeven en in de hoofdstukken V tot XII worden eigen onderzoeksgegevens gepresenteerd. Omdat PPHN geen duidelijk omschreven ziektebeeld is, maar een klinisch syndroom dat op kan treden bij een diverse groep van afwijkingen met diverse oorzaken is het onderzoek beperkt vanwege het gekozen experimentele model. In het voorliggend onderzoek is gekozen voor een model waarbij is uitgegaan van PPHN veroorzaakt door chronische compressie van de Ductus Arteriosus (hoofdstuk V) en door het bestuderen van de vaatreactiviteit in geïsoleerde longvaten te vergelijken met de vaatreactiviteit in geïsoleerde vaten van de lichaamscirculatie (hoofdstukken VI tot XII).

In hoofdstuk $\mathbf{V}$ wordt bij foetale lammeren aangetoond dat chronische pulmonale hypertensie veroorzaakt door ductus compressie laat in de zwangerschap kan leiden tot een 
afname in productie van eNOS mRNA, eNOS hoeveelheid en eNOS activiteit. Deze bevinding is een bevestiging van eerdere studies die aantoonden dat er in dit experimentele model van PPHN sprake was van een afname van pulmonale vasodilatatie.

In hoofdstuk VI wordt de reactie van de pulmonale vaten op hypoxie beschreven. We hebben bij longvaten van pasgeboren biggen aan kunnen tonen dat hypoxie aanleiding geeft tot een passagère contractie, veroorzaakt door een blokkade van endotheel afhankelijke NO productie. Andere endotheel-factoren, zoals b.v. eicosanoieden, waren in dit proces niet betrokken. Echter, een zelfde reactie op hypoxie als in de longarteriën kon ook worden aangetoond in de longvenen, de coronair-arteriën en in de mesenteriaal arteriën ofschoon normaliter alleen de longarteriën met vasoconstrictie reageren op hypoxie. Daarom adviseren we om voorzichtig te zijn met het leggen van verbanden tussen het optreden van een hypoxische pulmonaire vasoconstrictie en de beschreven reactie op hypoxie bij geïsoleerde longarteriën.

Sepsis is een van de belangrijkste factoren die betrokken zijn bij het ontstaan van PPHN. Door sepsis geïnduceerde veranderingen in contractilitiet van longvaten en van vaten in de systeemcirculatie wordt beschreven in de hoofdstukken VII, VIII, en IX. We bestudeerden de vasculaire respons van long- en mesenteriaal arteriën van biggen op enkele vasoconstrictore agonisten door deze vaten te incuberen met geïnactiveerde groep B Streptococcus agalactiae (GBS) en Escherichia Coli lipopolysaccharide (LPS). GBS en

E. Coli zijn de meest voorkomende verwekkers van sepsis bij pasgeborenen. In deze proefopstelling konden we aantonen dat er in alle vaten sprake was van een verminderde contractile respons op noradrenaline. Dit effect werd nog versterkt door toevoeging van L-arginine (het substraat voor NO synthese), terwijl L-NAME (een NOS-remmer) een tegengesteld effect had. Dit toont aan dat een overproductie van NO verantwoordelijk was voor de verminderde contractile respons. Bovendien toonden we aan dat GBS en LPS een duidelijke toename van iNOS activiteit in de long teweegbrachten. Deze bevindingen wijzen er op dat door GBS en LPS geïnduceerde hyporeactiviteit op noradrenaline veroorzaakt wordt door een toegenomen productie van NO via iNOS inductie. 
Pulmonaire hypertensie is de meest uitgesproken circulatoire afwijking die gevonden wordt in iedere proefopzet uitgaande van een sepsis. In ons model vonden wij echter dat als longarteriën geïncubeerd werden met voor pasgeborenen frequent voorkomende pathogenen dat er dan sprake was van een inductie van iNOS en een afgenomen vaatrespons op vasoconstrictieve stoffen. Om een verklaring te vinden voor deze tegenstrijdige bevinding bestudeerden we de respons van longvaten op toevoeging van de thromboxane $A_{2}$ analoog U46619, ook weer na incubatie met GBS en LPS. Van thromboxane $A_{2}$ is aangetoond dat het verantwoordelijk is voor de vasoconstrictieve respons bij door een sepsis geïnduceerde pulmonaire hypertensie, althans zeker tijdens de eerste fase van het proces. Wij vonden dat met GBS of met LPS geïncubeerde longarteriën geen verminderde reactie vertoonden op U46619. In mesenteriale vaten daarentegen vonden we wel een duidelijk verminderde reactie op door U46619 geïinduceerde vaatconstrictie die weer kon worden opgeheven door NOS remming. Het ontbreken van deze verminderde gevoeligheid van longarteriën op U46619 bij een sepsis zou kunnen bijdragen tot het persisteren van pulmonaire hypertensie, zulks ondanks iNOS inductie in de long.

Om het verschil te kunnen verklaren in vasoconstrictie door thromboxane $\mathrm{A}_{2}$ (d.w.z. door U46619) en door noradrenaline bestudeerden we, zoals beschreven in hoofdstuk $\mathbf{X}$, de interacties tussen deze twee stoffen en de NO/cyclisch GMP weg. Hierbij komen ook de mechanismen ter sprake die betrokken zijn bij de door NO/cyclisch GMP geïnduceerde relaxatie. Wij vonden dat diverse stoffen van de cyclisch GMP weg in staat waren om door noradrenaline gecontraheerde arteriën volledig te relaxeren, terwijl dit veel minder het geval was als de arteriën gecontraheerd waren middels U46619. Dit effect was specifiek voor pulmonale longarteriën bij biggen en kon niet worden aangetoond in longarteriën van de rat of bij andere arteriën van biggen. Bovendien had U46619 geen effect op een door Nanitroprusside geïnduceerde cyclisch CMP stijging, of op een door phospho-di-esterase geïnduceerde afbraak van cyclisch GMP. Onze bevindingen wijzen in de richting dat U46619 in staat is om de NO/cyclisch GMP weg tot gladde spier relaxatie meer te remmen dan dat er compensatie via cyclisch GMP aanmaak is. 
Omdat het doen dalen van de pulmonale vaatweerstand en het tegelijkertijd handhaven van de systeemdruk van essentieel belang is bij de behandeling van pasgeborenen met PPHN, moet het ideale medicament een stof zijn die een selectieve vasodilatatie in de longvaten geeft. Dit zoeken naar een ideaal medicament is al sinds enkele decennia een doel op zich zelf. In hoofdstuk XI beschrijven we een vergelijkend onderzoek naar de relaxerende eigenschappen van een 6-tal mogelijk selectief vasodilatatoire stoffen (acetylcholine, Nanitroprusside, ATP, PGE1, tolazoline en nifedipine) op long- en mesenteriale arteriën bij biggen. Afhankelijk van de onderzochte arterie of van de vooraf gebruikte vasoconstrictor (noradrenaline of U46619), of van beiden, vonden we duidelijke verschillen in relaxerend vermogen van deze stoffen. ATP was het enige medicament dat onafhankelijk van de gebruikte concentratie in alle gevallen een sterker relaxerend effect op longarteriën dan op mesenteriaal arteriën had. Zoals al bekend uit klinisch onderzoek waren met name tolazoline en nifedipine niet selectief in relaxerend effect op arteriën van verschillende orgaansystemen.

Van magnesiumsulfaat $\left(\mathrm{MgSO}_{4}\right)$ wordt gesuggereerd dat het mogelijk een goed en veilig alternatief medicament voor vaatrelaxatie zou zijn. In hoofdstuk XII beschrijven we in vitro experimenten om het relaxerend effect van $\mathrm{MgSO}_{4}$ te meten. We vonden dat $\mathrm{MgSO}_{4}$ een sterker relaxerend effect heeft op systeem arterien dan op pulmonaal arteriën en dat het in fysiologische concentraties zelfs het relaxerend effect van $\mathrm{NO}$ remt. $\mathrm{MgSO}_{4}$ lijkt geen belangrijke rol te spelen in de reactive processen die betrokken zijn in de gladde spieren van de longvaten. Immers, veranderingen in extracellulaire $\mathrm{Mg}^{2+}$ concentraties hebben geen invloed op vasoconstrictieve effecten van U46619 of op de relaxerende effecten van acetylcholine of Na-nitroprusside. Gezien deze bevindingen menen we te mogen concluderen dat $\mathrm{MgSO}_{4}$ in vitro geen specifiek relaxerend effect op de longarteriën heeft en suggereren we dat het mogelijk klinisch effect op een ander mechanisme berust.

De opzienbarende ontdekking dat het door endotheelcellen geproduceerde simpele molecuul NO verantwoordelijk is voor vaatverwijding heeft geleid tot veel onderzoek naar een mogelijk specifieke behandeling van PPHN. Als NO wordt toegevoegd aan de inademingslucht zijn er door de zeer korte halfwaarde-tijd geen effecten op de 
systeemcirculatie en wordt deze therapie thans veelvuldig toegepast bij de behandeling van PPHN. Een ander gas, koolstof monoxide (CO) heeft een vergelijkbaar effect als NO. In hoofdstuk XIII beschrijven we een studie die de vasorelaxerende effecten van NO vergelijkt met die van CO. We vonden dat bij beide gassen het relaxerend effect ontstaat via activatie van guanylaat cyclase in de vaatwand. Echter, het vasorelaxerend effect van $\mathrm{CO}$ is slechts een fractie (minder dan 1000-voud) vergeleken met dat van NO. Bovendien nam het relaxerend effect van NO toe met de postnatale leeftijd, terwijl dat van $\mathrm{CO}$ afnam. Dit suggereert dat de weg waarlangs de guanylaat cyclase activatie verloopt voor beide gassen een andere is.

Veranderingen in de $\mathrm{pO}_{2}$ hadden geen invloed op het relaxerend effect van NO. Maar dit effect werd wel versterkt onder invloed van superoxide dismutase, terwijl de effectiviteit van $\mathrm{CO}$ niet beïnvloed werd door activiteit van oxidanten. Hieruit mogen we concluderen dat als deze reacties op $\mathrm{CO}$ een afspiegeling zijn van het relaxerend vermogen in vivo, dat het dan onwaarschijnlijk is dat $\mathrm{CO}$ een directe rol speelt in de regulatie van de pulmonale vaattonus. 


\section{Acknowledgements}

The present thesis is the result of many years of work. Therefore, numerous people participated not only in the research work, but also in my formation as Pediatrician and Neonatologist. I would like to manifest my gratitude to all of them

To my "promotores" Carlos Blanco and Juan Tamargo for his support, advice and for giving me the opportunity to present this thesis.

To my "co-promotor" Paco Pérez Vizcaino for his patience, knowledge and dedication.

To Manuel Moro for his teaching, support and inspiration.

To Steven H. Abman for the opportunity and the example he gave me.

To all the colleagues, co-workers and even friends that I was so lucky to meet at:

Departamento de Farmacología e Instituto de Farmacología y Toxicología.

Universidad Complutense de Madrid: Pedro Lorenzo, Eva Delpón, Carmen Valenzuela, Nesi Pérez (esta vez puse bien el apellido), Buensu Fernández del Pozo, Angel Luis Cogolludo, Manuel Ibarra, Juan Carlos Leza, Cristina Rivas ...

Hospital Universitario San Carlos: Jose Luis Ruibal, Teresa Ruiz, Elena Piñero, Amparo Almenar, Angela Sánchez-Algaba, Miguel Guitart, Fernando Rivilla, Luis M. Antón Rodrigálvarez, Gloria Bueno, Fernando Donoso, María Elena Borja... y todos aquellos que con sus enseñanzas y ejemplos contribuyeron a mi formación como pediatra. 
University of Colorado Health Sciences Center: John Kinsella, Jacinto Hernández, Dunbar Ivy, Tom Parker, Tim Le Cras, Marilee Horan, John Fox, James Ziegler, Henry Galan...

Sanatorio San Francisco de Asís y Clínica Belén: todos los compañeros con los que compartí la ilusión de ser neonatólogo y todas las enfermeras y auxiliares que contribuyeron a ello.

Centros de Salud Martín de Vargas y Villa de Vallecas: todos los médicos, enfermeras, auxiliares y administrativos con los que compartí mi tiempo de Atención Primaria.

Ik dank mijn collegae neonatologen Wiel Maertzdorf, Mark van der Hoeven, Pieter Degraeuwe, Danilo Gavilanes en Twan Mulder voor hun ontvangst, hulp, onderricht, steun en vriendelijke sfeer. Ik dank ook de kinderartsen, arts-assistenten, verpleegkundingen en secretaressen van de Neonatologie en de Kindergeneeskunde op het Academisch Ziekenhuis Maastricht en de medewerkers van de Farmacologie afdeling op de Universiteit Maastricht voor hun ontvangst en geduld. 


\section{Curriculum vitae}

Eduardo Villamor Zambrano.

Born in 1965 in Córdoba (Spain).

Education, training and positions held

Bachelor in Medicine Universidad Complutense. Madrid

1983-89.

Resident in Pediatrics Hospital Universitario San Carlos. Madrid. 1990-93.

Doctorate in Medicine Universidad Complutense. Madrid 1992-94.

Research Fellow

Instituto de Farmacologia y Toxicología. 1994, Universidad. Complutense. Madrid. Sept 95- Jun 98

Neonatologist

Hospital San Francisco de Asís and 1994 , Clínica Belén. Madrid Sept 95- Jun 98

Research Scholar

Department of Pediatrics, University of Colorado Health Sciences Jan 95-Aug 95 Center. Denver, Colorado, U.S.A.

Pediatrician

Centros de Salud Villa de Vallecas and Martín de Vargas. Instituto Nacional de Salud. Madrid.

Sept 95- Jun 98

Neonatologist

Department of Pediatrics.

Jul 98-

Academisch Ziekenhuis Maastricht. 


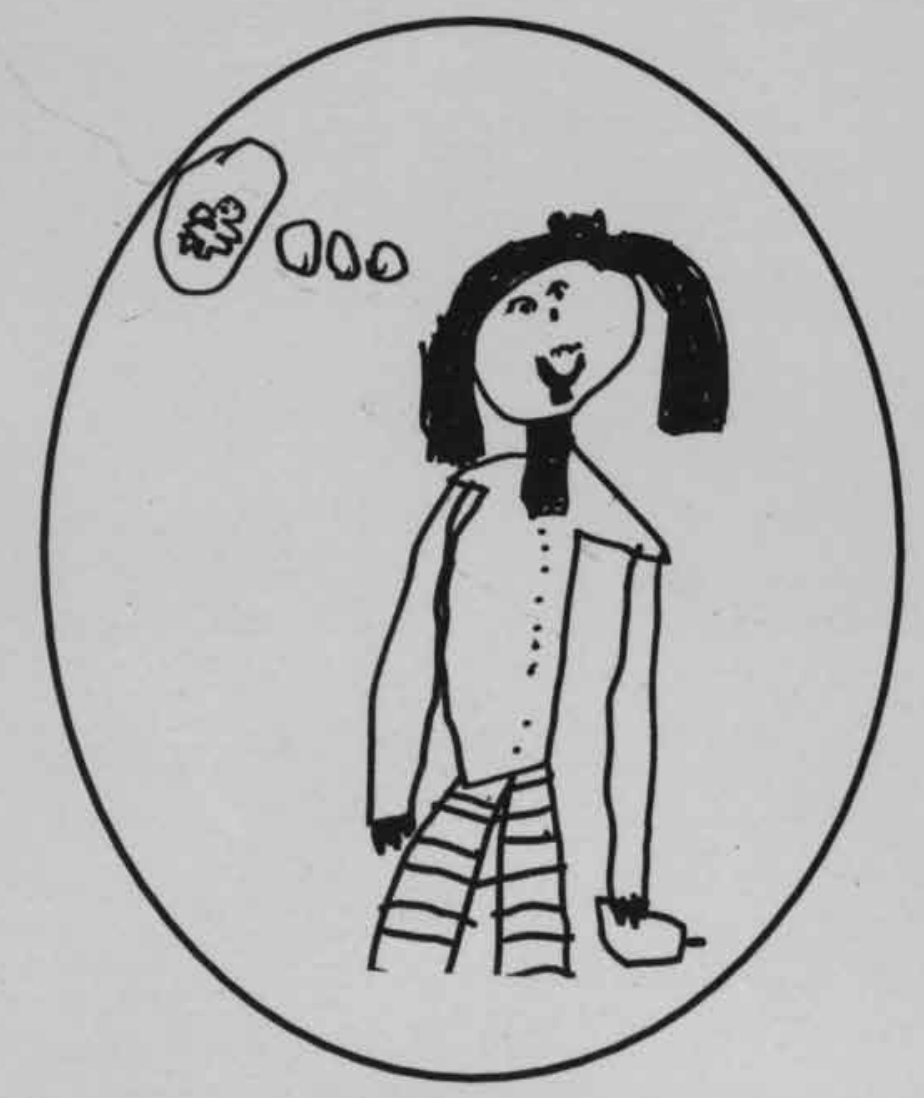

$$
\text { SERVETUS }
$$

